A Study of Production/Injection Data from Slim Holes and Large-Diameter Wells at the Okuaizu Geothermal Field, Tohoku, Japan

Sabodh K. Garg Jim Combs

June 2002

Idaho National Engineering and Environmental Laboratory Bechtel BWXT Idaho, LLC 


\section{Disclaimer}

This report was prepared as an account of work sponsored by an agency of the U.S. Government. Neither the U.S. Government nor any agency thereof, nor any of their employees, makes any warranty, express or implied, or assumes any legal liability or responsibility for the accuracy, completeness, or usefulness of any information herein, or represents that its use would not infringe privately owned rights. References herein to any specific commercial product, process or service by trade name, trademark, manufacturer, or otherwise, does not necessarily constitute or imply its endorsement, recommendations, or favoring by the U.S. Government or any agency thereof. The view and opinions of authors expressed herein do not necessarily state or reflect those of the U.S. Government or any agency thereof. 


\title{
A Study of Production/Injection Data from Slim Holes and Large-Diameter Wells at the Okuaizu Geothermal Field, Tohoku, Japan
}

\author{
Sabodh K. Garg \\ Jim Combs
}

June 2002

SAIC

Prepared for the

U.S. Department of Energy

Assistant Secretary for Energy Efficiency and Renewable Energy

Office of Geothermal Technologies

Under DOE Idaho Operations Office

Contract DE-AC07-99ID13727 


\section{ACKNOWLEDGEMENT}

This report was prepared by Science Applications International Corporation (SAIC) under Contract No. 1070 to Bechtel BWXT LLC at the Idaho National Engineering and Environmental Laboratory (INEEL). SAIC wishes to express our sincere appreciation to the Okuaizu Geothermal Company, Ltd., Tokyo, Japan, for their kind cooperation in making their proprietary data for the Okuaizu Geothermal Field available for the present study. 


\begin{abstract}
Discharge from the Okuaizu boreholes is accompanied by in situ boiling. Analysis of cold-water injection and discharge data from the Okuaizu boreholes indicates that the two-phase productivity index is about an order of magnitude smaller than the injectivity index. The latter conclusion is in agreement with analyses of similar data from Oguni, Sumikawa, and Kirishima geothermal fields. A wellbore simulator was used to examine the effect of borehole diameter on the discharge capacity of geothermal boreholes with two-phase feedzones. Based on these analyses, it appears that it should be possible to deduce the discharge characteristics of largediameter wells using test data from slim holes with two-phase feeds.
\end{abstract}




\section{Contents}

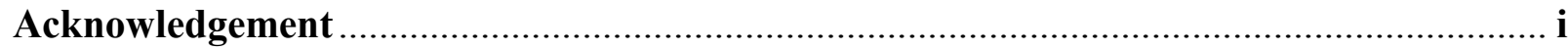

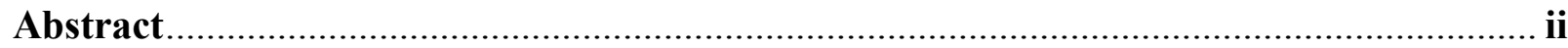

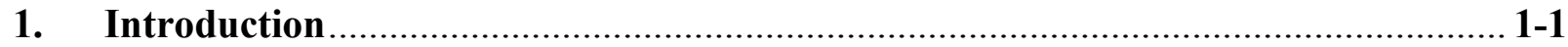

2. An Overview of the Okuaizu Geothermal Field..................................................... 2-1

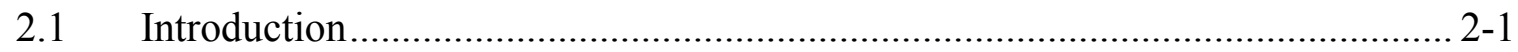

2.2 Geological Setting and Subsurface Stratigraphic Sequence ................................ 2-2

2.3 Reservoir Characteristics and Permeability .................................................... 2-3

$2.4 \quad$ Reservoir Fluid State............................................................................... 2-7

2.4.1 Reservoir Pressures ......................................................................... 2-7

2.4.2 Reservoir and Fluid Inclusion Temperatures ........................................ 2-7

2.4.3 Fluid Origin, Salinity, and Gas Content........................................... 2-10

3. Analysis of Downhole Data ............................................................................................. 3-1

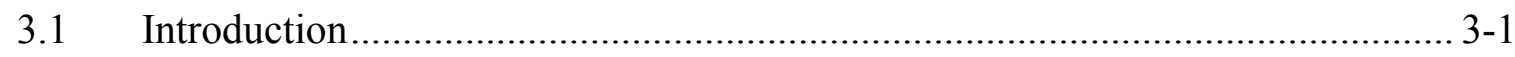

3.2 Feedzone Locations, Pressures and Temperatures …………………………..... 3-1

3.2.1 Boreholes Drilled By Government Agencies ……............................. 3-1

Slim Hole T-1 …….................................................................. 3-1

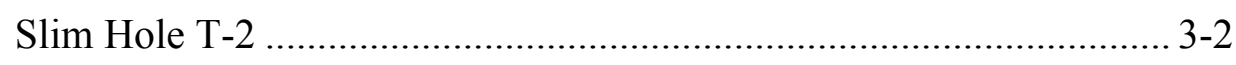

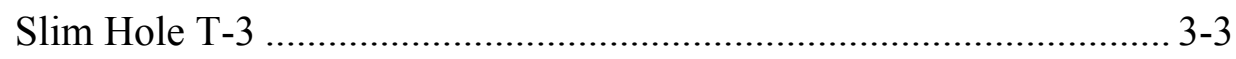

Slim Hole T-4 .................................................................. 3-4

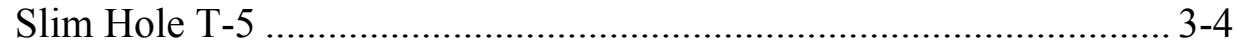

Slim Hole T-6 .......................................................................... 3-5

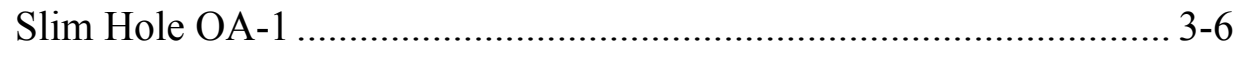

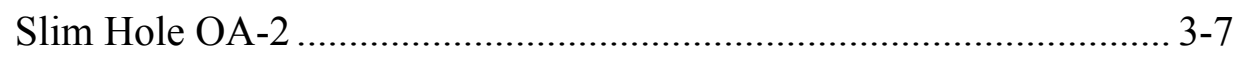

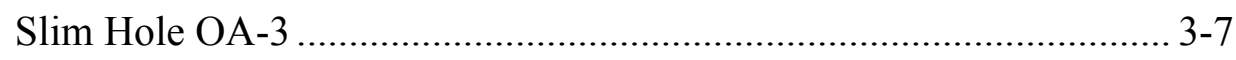

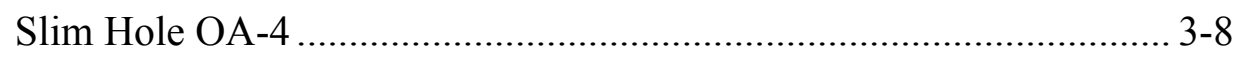

Slim Hole OA-5 ………........................................................ 3-10

Slim Hole OA-6

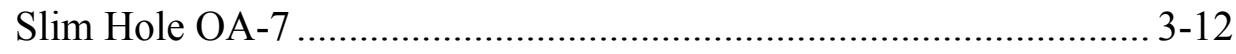


3.1.2 Boreholes Drilled by Okuaizu Geothermal Co., Ltd.................... 3-13

Slim Hole N-1t ................................................................... 3-13

Slim Hole N-2t ..................................................................... 3-14

Slim Hole $\mathrm{N}-3 \mathrm{t}$...................................................................... 3-15

Slim Hole N-4r...................................................................... 3-16

Slim Hole N-5t ......................................................................... 3-17

Production Well N-6T ............................................................. 3-18

Exploration Well N-7T ......................................................... 3-20

Exploration Well N-8T ....................................................... 3-21

Exploration Well N-9T ......................................................... 3-21

Production Well N-10T................................................................... 3-21

Production Well N-11T................................................................ 3-23

Slim Hole N-12t ............................................................... 3-25

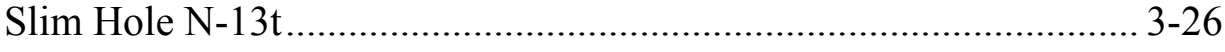

Production Well N-14T............................................................. 3-27

Production Well N-15T............................................................. 3-29

Production Well N-16T................................................................. 3-31

Production Well N-17T..................................................................... 3-32

Slim Hole N-18t ......................................................................... 3-34

Injection Well N-19R............................................................ 3-35

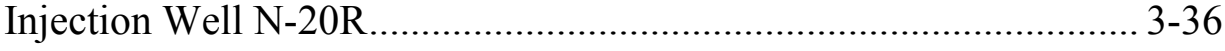

Production Well N-21T............................................................. 3-37

Production Well N-22T.................................................................. 3-38

Production Well N-23P............................................................ 3-40

Production Well N-24P................................................................... 3-41

Production Well N-25P.................................................................. 3-41

Production Well N-26P............................................................ 3-42

Production Well N-27P........................................................... 3-44

Production Well N-28P........................................................... 3-44

Injection Well N-29R........................................................... 3-46

Production Well N-30P............................................................ 3-47

Production Well N-31P................................................................. 3-48

3.3 Reservoir Pressures and Temperatures .................................................. 3-50

4. Injection and Discharge Tests ................................................................................... 4-1

4.1 Injectivity and Productivity Indices ........................................................... 4-1 


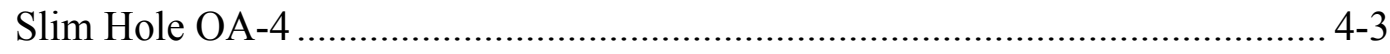

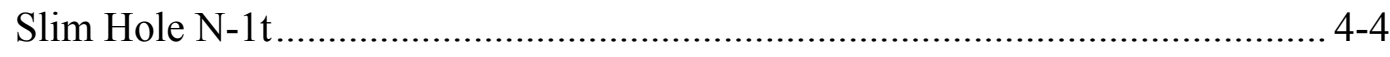

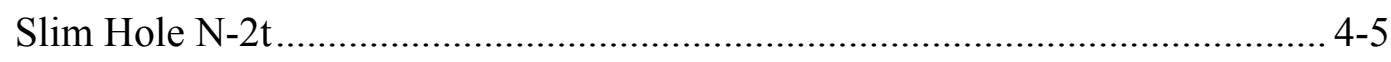

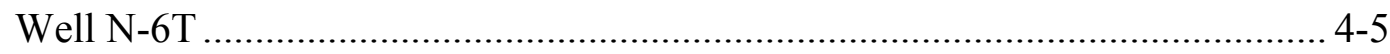

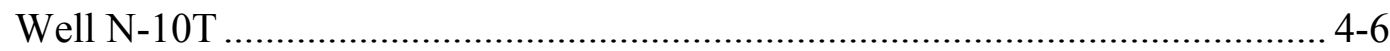

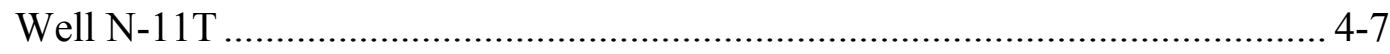

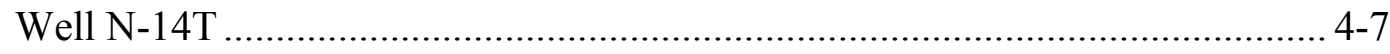

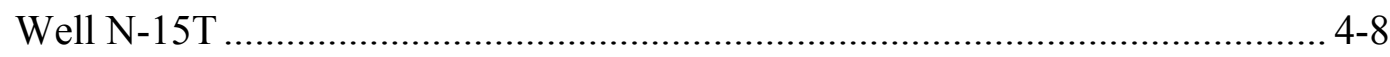

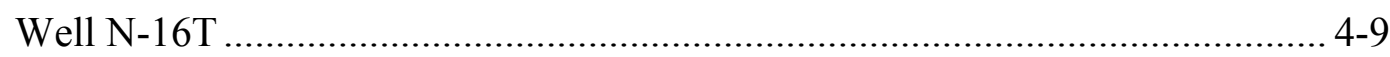

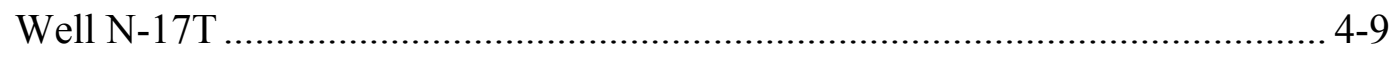

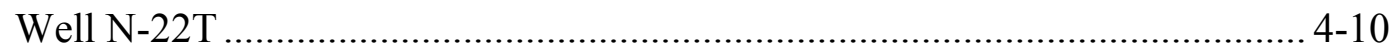

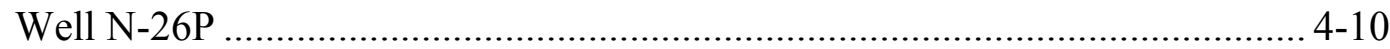

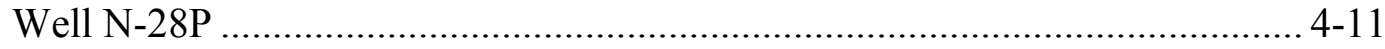

4.2 Relationship between Injectivity and Two-Phase Productivity Indices ............. 4-3

5. Discharge Capacity and Borehole Diameter ....................................................................... 5-1

$5.1 \quad$ Discharge Tests ....................................................................................... 5-1

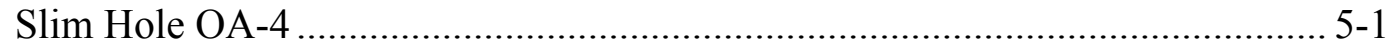

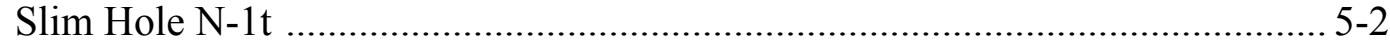

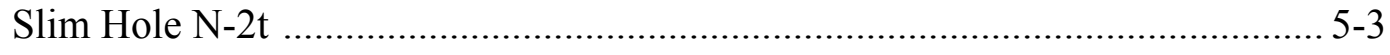

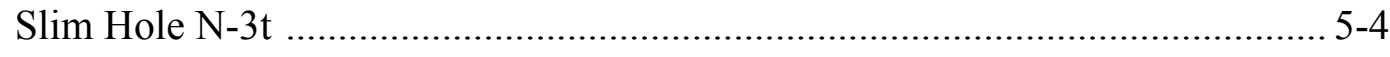

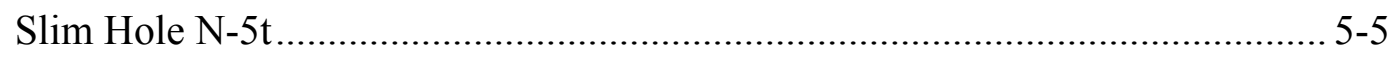

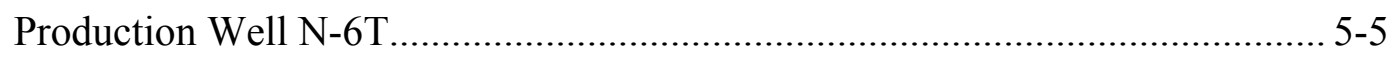

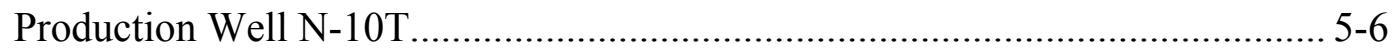

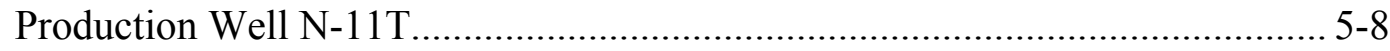

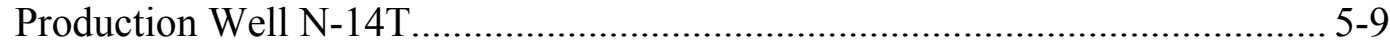

Production Well N-15T........................................................................... 5-10

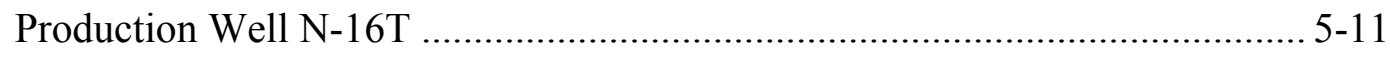

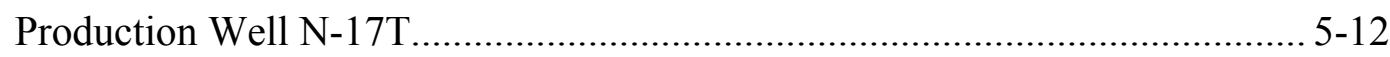

Production Well N-21T................................................................. 5-12

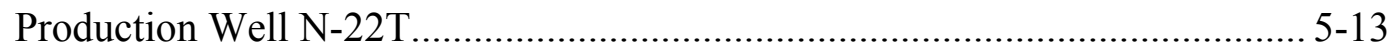

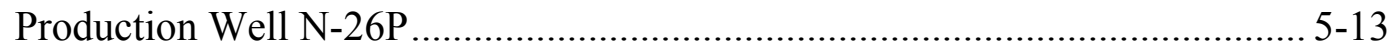

Production Well N-28P......................................................................... 5-14

5.2 Stable Discharge Rate and Wellhead Enthalpy ............................................... 5-15 
5.3 Mathematical Modeling of Fluid Flow in Boreholes with Two-Phase

Feedzones

Production Well N-6T ........................................................................... 5-19

Production Well N-10T …................................................................ 5-20

Production Well N-11T ............................................................................. 5-21

Production Well N-14T ......................................................................... 5-22

Production Well N-15T ....................................................................... 5-24

Production Well N-16T ............................................................................. 5-25

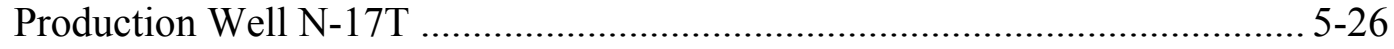

Production Well N-22T.......................................................................... 5-27

Production Well N-26P.......................................................................... 5-29

Production Well N-28P....................................................................... 5-30

5.4 Borehole Diameter and Discharge Capacity of Two-Phase Wells ................... 5-31

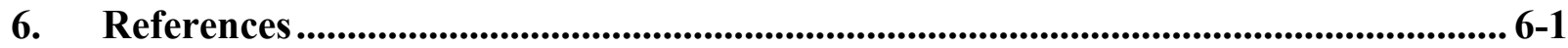
Appendices

A: Drilling and Completion Data for Okuaizu Boreholes............................................... A-1

B: Discharge Rate and Enthalpy Data for Okuaizu Boreholes .........................................B-1 


\section{FIGURES}

Figure

Page

2.1 Location map of the Okuaizu Geothermal Area in Northern Honshu, Japan (adapted from Field trip guide of NEDO International Geothermal Symposium on May 13, 1997 at Sendai, Japan)

2.2 Map showing surface geology of the Sunagohara Formation, major fault zones, and location of several exploration and production boreholes

2.3 Regional stratigraphic column for the Okuaizu Geothermal Area with the geological formation abbreviation symbols as in Figure 2.5 (adapted from Mizugaki, 2000, and Seki, 2000).....

2.4 A topographic map of the Okuaizu borefield, showing surface features the major fault zones, and the borehole wellhead locations and downhole traces (adapted from Mizugaki, 2000, and Seki, 2000).

2.5 Geological cross section along line A-A' in Figure 2.2 with isotherms, major fault zones, and geothermal well traces.

3.1 Temperature surveys in slim hole T-1

3.2 Pressures computed from water level and temperature data in slim hole T-1 ............ 3-2

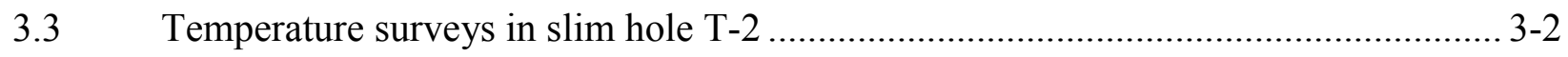

3.4 Pressures computed from water level and temperature data in slim hole T-2 2.......... 3-3

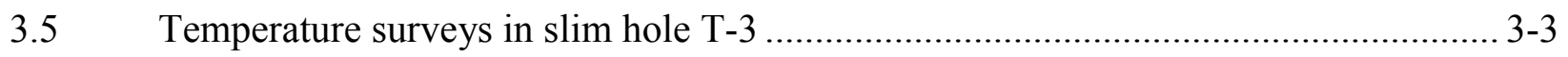

3.6 Pressures computed from water level and temperature data in slim hole T-3 ........... 3-3

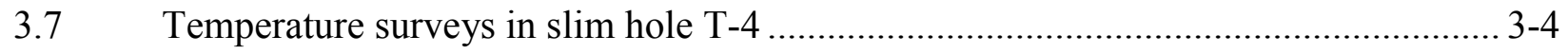

3.8 Pressures computed from water level and temperature data in slim hole T-4 ........... 3-4

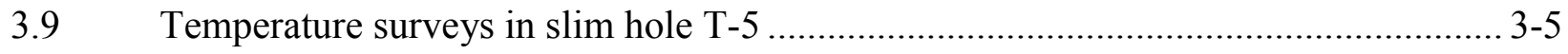

3.10 Pressures computed from water level and temperature data in slim hole T-5 ........... 3-5

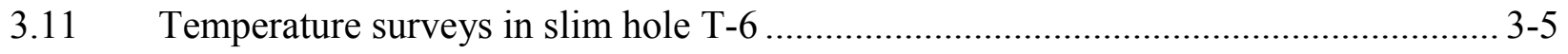

3.12 Pressures computed from water level and temperature data in slim hole T-6 ........... 3-6

3.13 Selected temperature surveys in slim hole OA-1 .......................................... 3-6 
Figure

3.14 Pressures computed from water level and temperature data in slim hole OA-1 ........... 3-6

Selected temperature surveys in slim hole OA-2 .............................................. 3-7

3.16 Pressures computed from water level and temperature data in slim hole OA-2 ........... 3-7

Selected temperature surveys in slim hole OA-3 ............................................ 3-8

3.18 Pressures computed from water level and temperature data in slim hole OA-3 ........... 3-8

S.19 Selected heatup surveys in slim hole OA-4 ....................................................... 3-9

3.20 Temperature surveys taken before, during, and after an injection test performed on slim hole OA-4 in August 1983 ......................................................... 3-9

3.21 Temperature surveys taken during a discharge test performed on slim hole

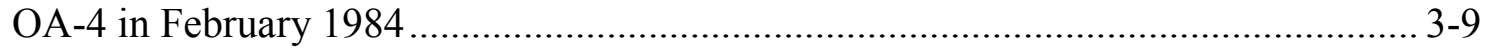

3.22 Pressure surveys taken during a discharge test performed on slim hole

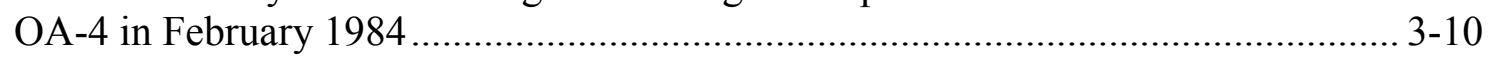

3.23 Pressures computed from water level and temperature data in slim hole OA-4 .......... 3-10

Selected temperature surveys in slim hole OA-5 ........................................ 3-10

3.25 Pressures computed from water level and temperature data in slim hole OA-5 .......... 3-11

S.26 Selected temperature surveys in slim hole OA-6......................................... 3-11

3.27 Pressures computed from water level and temperature data in slim hole OA-6 on November 12, 1983 ...................................................................... 3-11

S.28 Selected temperature surveys in slim hole OA-7 ........................................ 3-12

3.29 Pressures computed from water level and temperature data in slim hole OA-7 ...........3.12

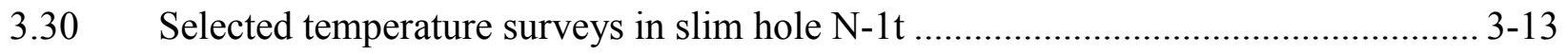

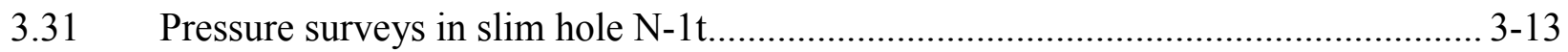

3.32 Pressures computed from water level and temperature data on

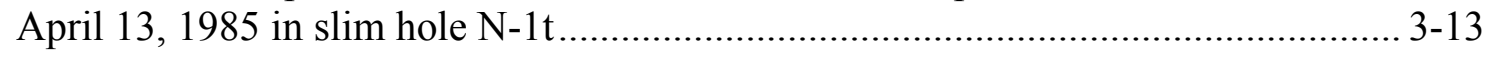

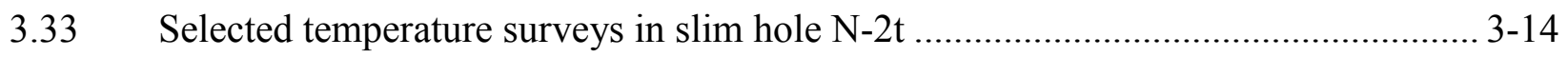

Pressure surveys in slim hole N-2t......................................................... 3-14 
3.35 Pressures computed from water level and temperature data taken on November 23, 1984 in slim hole N-2t .......................................................... 3-15

3.36 Selected temperature surveys in slim hole N-3t ............................................... 3-15

3.37 A pressure survey taken in slim hole N-3t on November 16, 1985 ...................... 3-16

3.38 Pressures computed from water level and temperature data in slim hole N-3t ........... 3-16

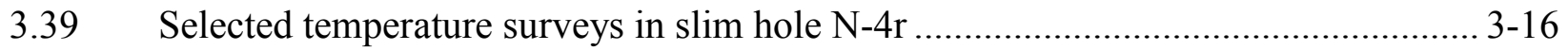

3.40 Pressures computed from water level and temperature data in slim hole

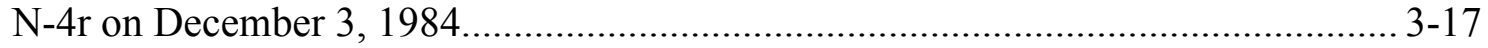

3.41 Selected temperature surveys in slim hole N-5t .......................................... 3-17

3.42 Pressures computed from water level and temperature data in slim hole N-5t ............. 3-18

3.43 Selected temperature surveys taken during 1985-1987 in production well N-6T .......... 3-18

P.44 Pressure surveys taken during 1985-1987 in well N-6T...................................... 3-19

3.45 Temperature surveys taken during a discharge test on production well N-6T in February 1988

3.46 Pressure surveys taken during a discharge test on production well N-6T in February 1988

3.47 Spinner surveys taken during a discharge test of production well N-6T in February 1988

3.48 Available temperature surveys in exploration well N-7T ................................. 3-20

3.49 Pressures computed from water level and temperature data taken in exploration well N-7T on March 16, 1987

3.50 Temperature survey taken in exploration well N-8T on October 2, $1985 \ldots \ldots \ldots \ldots \ldots . . . .31$

3.51 Temperature surveys in exploration well N-9T …............................................. 3-21

3.52 Selected temperature surveys in production well N-10T ................................... 3-22

3.53 A spinner survey taken during an injection test on September 24, 1986 in production well $\mathrm{N}-10 \mathrm{~T}$....

3.54 A spinner survey taken during a discharge test on September 10, 1988 in production well $\mathrm{N}-10 \mathrm{~T}$.... 
Figure $\quad$ Page

Selected pressure surveys in production well N-10T …....................................... 3-23

3.56 Pressures computed from water level and temperature data in production

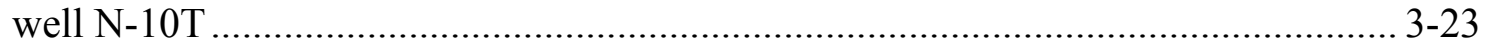

Selected heatup surveys in production well N-11T .......................................... 3-24

3.58 Temperature surveys taken before, during, and after discharge test (March

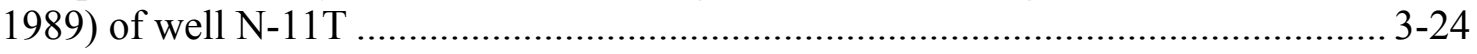

3.59 Pressure surveys in production well N-11T .................................................. 3-24

3.60 Spinner surveys taken during a discharge test of production well N-11T in

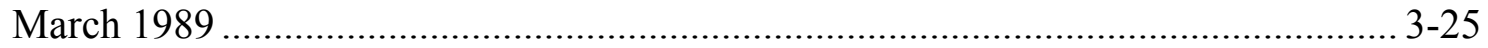

3.61 Pressures computed from water level and temperature data in production

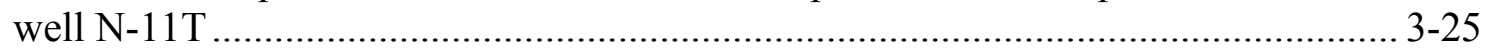

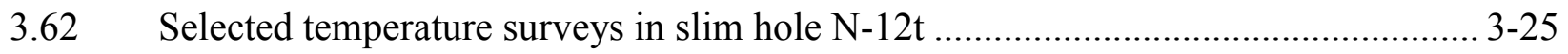

3.63 A pressure survey recorded in slim hole N-12t on August 18, 1988 .................... 3-26

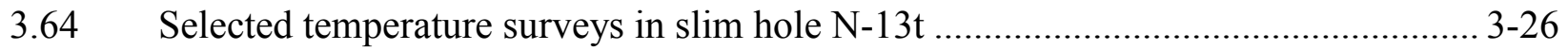

3.65 Pressures computed from water level and temperature data in slim hole N-13t .......... 3-27

S.66 Selected heatup surveys in production well N-14T ......................................... 3-27

3.67 Spinner surveys taken during a discharge test of production well N-14T in March 1988 ......................................................................................... 3-28

3.68 Selected temperature surveys in production well N-14T ................................... 3-28

3.69 Selected pressure surveys in production well N-14T ...................................... 3-28

3.70 Pressures computed from water level and temperature data in production

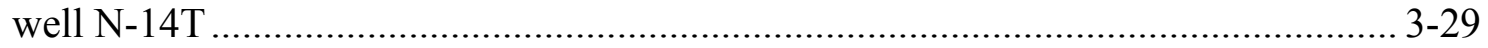

3.71 Selected heatup surveys in production well N-15T ....................................... 3-29

3.72 Spinner surveys recorded during a discharge test of production well N-15T in March 1988

3.73 Selected temperature surveys taken during a discharge test on production well N-15T in March 1988 $3-30$

S.74 Selected pressure surveys in well N-15T ................................................... 3-30 
3.75 Pressures computed from water level and temperature data in production well N-15T

3.76 Selected heatup surveys in production well N-16T

3.77 Spinner surveys taken during a discharge test of production well N-16T in March 1989

3.78 Temperature surveys taken during a discharge test on production well N-16T in March 1989

3.79 Pressure surveys in production well N-16T

3.80 Pressures computed from water level and temperature data in production well N-16T

3.81 Selected heatup surveys in production well N-17T

3.82 Spinner surveys taken during a discharge test of production well N-17T in March 1989

3.83 Selected temperature surveys in production well N-17T.

P.84 Pressure surveys in production well N-17T ............................................... 3-34

3.85 Pressures computed from water level and temperature data in production well N-17T

3.86 Selected temperature surveys in slim hole N-18t

3.87 Pressures computed from water level and temperature data in slim hole N-18t

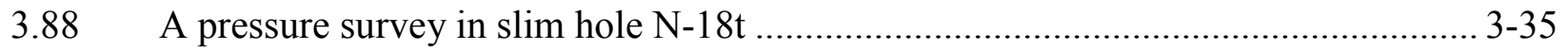

3.89 Selected temperature surveys in injection well N-19R ................................... 3-36

3.90 Pressures computed from water level and temperature data in injection well N-19R

3.91 Selected temperature surveys in injection well N-20R

3.92 Pressures computed from water level and temperature data in injection well N-20R.

3.93 Selected temperature surveys in production well N-21T. 
Figure $\quad$ Page

3.94 Pressures computed from water level and temperature data in production

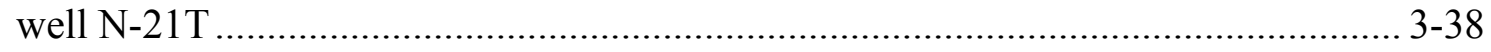

3.95 A pressure survey taken during an injection test on November 29, 1991 in

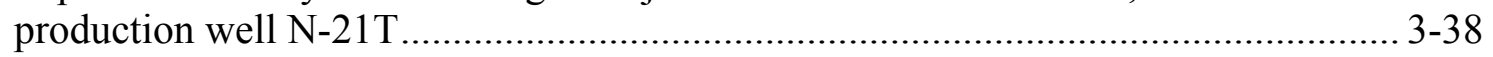

S.96 Selected temperature surveys in production well N-22T .................................... 3-39

P.97 Pressure surveys in production well N-22T .................................................. 3-39

3.98 Pressures computed from water level and temperature data in production

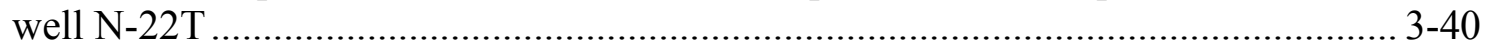

3.99 Selected temperature surveys in production well N-23P ................................. 3-40

3.100 Pressures computed from water level and temperature data in production well N-23P ....................................................................................... $3-41$

3.101 Selected temperature surveys in production well N-24P .................................. 3-41

3.102 Selected temperature surveys in production well N-25P .................................. 3-42

3.103 Selected temperature surveys in production well N-26P .................................. 3-43

3.104 Spinner surveys taken during a discharge test of production well N-26P in July 1993.

3.105 Pressure surveys taken during a discharge test on production well N-26P in July 1993.

3.106 Pressures computed from water level and temperature data in production well N-26P assuming local atmospheric pressure at water level

3.107 Selected temperature surveys in production well N-27P ................................... 3-44

3.108 Pressures computed from water level and temperature data in production well N-27P

3.109 Selected temperature surveys in production well N-28P .................................. 3-45

3.110 Spinner surveys taken during a discharge test of well N-28P in November 1993 ........... 3-45

3.111 Temperature surveys taken during a discharge test of production well $\mathrm{N}-28 \mathrm{P}$ in November 1993

3.112 Pressure surveys taken during a discharge test of production well N-28P in November 1993 
3.113 Pressures computed from water level and temperature data in production well N-28P

3.114 Selected temperature surveys in injection well N-29R $3-46$

3.115 Pressures computed from water level and temperature data in injection well N-29R

3.116 Selected temperature surveys in production well N-30P

3.117 Pressures computed from water level and temperature data in production well N-30P

3.118 Temperature surveys in production well N-31P $3-48$

3.119 A detailed view of temperature profile recorded while injecting cold water in production well N-31P on September 13, 1997.

3.120 Detailed views of temperature profiles recorded while injecting cold water in production well N-31P on September 14, 1997, and October 3, 1997.

3.121 A spinner survey taken while injecting cold water in production well N-31P on September 14, 1997

3.122 Pressure surveys in production well N-31P

3.123 Correlation of feedzone pressure versus feedzone elevation for Okuaizu boreholes

4.1 Injectivity Test 1 for slim hole OA-4 performed on November 13, 1982

4.2 Injectivity Test 2 for slim hole OA-4 performed from August 26, 1983 to September 2,1983

4.3 Injectivity Test 2 for slim hole OA-4 performed from August 26, 1983 to September 2, 1983

4.4 A multi-rate injectivity test of slim hole N-1t performed on April 14, 1985

4.5 A multi-rate injectivity test of production well N-6T performed on December 8, 1985

4.6 A multi-rate injectivity test of production well N-10T performed on September 24 and 26, 1986.

4.7 A multi-rate injectivity test of production well $\mathrm{N}-11 \mathrm{~T}$ performed on October 12, 1986 
Figure

4.8 A multi-rate injectivity test of production well $\mathrm{N}-14 \mathrm{~T}$ performed on

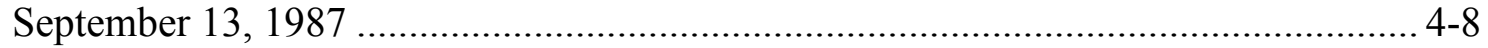

4.9 A multi-rate injectivity test of production well $\mathrm{N}-16 \mathrm{~T}$ performed on July 27,1987

4.10 A multi-rate injectivity test of production well $\mathrm{N}-17 \mathrm{~T}$ performed on October 15, 1987

4.11 A multi-rate injectivity test of production well $\mathrm{N}-22 \mathrm{~T}$ performed on November 19, 1989

4.12 A multi-rate injectivity test of production well $\mathrm{N}-26 \mathrm{P}$ performed on June 17, 1993

4.13 A multi-rate injectivity test of production well $\mathrm{N}-28 \mathrm{P}$ performed on May 31, 1993

4.14 Injectivity index (II) versus two-phase productivity index (PI) for Okuaizu, Kirishima, Sumikawa, and Oguni boreholes

5.1 Wellhead pressure, discharge rate, and wellhead enthalpy measurements taken during the discharge test of slim hole OA-4 from January 10, 1984 to February 11, 1984

5.2 Characteristic output data recorded for slim hole OA-4 on January 22-23, 1984, and February 7-10, 1984

5.3 Characteristic output data recorded for slim hole N-1t from June 7, 1985 to June 14, 1985

5.4 Wellhead pressure, discharge rate, and wellhead enthalpy measurements taken during the preliminary discharge test of slim hole $\mathrm{N}-2 \mathrm{t}$ from August 18, 1985 to November 15, 1985 ....

5.5 Wellhead pressure, discharge rate, and wellhead enthalpy measurements taken during a discharge test of slim hole N-2t from January 12, 1988 to March 28, 1988

5.6 Characteristic output data recorded for slim hole N-3t during discharge tests in January and February 1986.

5.7 Stable discharge rate and wellhead enthalpy versus wellhead pressure data recorded from slim hole N-5t during a discharge test from November 27, 1984 to December 16, 1984. 
Figure

Page

5.8 Wellhead pressure, discharge rate, and wellhead enthalpy measurements taken during the first long-term discharge test of well N-6T from December 8, 1986 to April 5, 1987.

5.9 Wellhead pressure, discharge rate, and wellhead enthalpy measurements taken during the second long-term discharge test of well N-6T from December 9, 1987 to March 28, 1988.

5.10 Wellhead pressure, discharge rate, and wellhead enthalpy measurements taken during the third long-term discharge test of well N-6T from November 17, 1989 to March 3, 1990

5.11 Wellhead pressure, discharge rate, and wellhead enthalpy measurements taken during the first long-term discharge test of well $\mathrm{N}-10 \mathrm{~T}$ from September 7, 1987 to October 7, 1987

5.12 Wellhead pressure, discharge rate, and wellhead enthalpy measurements taken during the second long-term discharge test of well N-10T from December 15, 1987 to March 27, 1988.

5.13 Wellhead pressure, discharge rate, and wellhead enthalpy measurements taken during the third long-term discharge test of well N-10T from August 23, 1988 to October 8, 1988 .....

5.14 Wellhead pressure, discharge rate, and wellhead enthalpy measurements taken during the fourth long-term discharge test of well N-10T from November 26, 1989 to March 3, 1990.

5.15 Wellhead pressure, discharge rate, and wellhead enthalpy measurements taken during the first long-term discharge test of well $\mathrm{N}-11 \mathrm{~T}$ from December 2, 1988 to March 20, 1989.

5.16 Wellhead pressure, discharge rate, and wellhead enthalpy measurements taken during the first long-term discharge test of well $\mathrm{N}-14 \mathrm{~T}$ from October 8, 1987 to November 6, 1987.

5.17 Wellhead pressure, discharge rate, and wellhead enthalpy measurements taken during the second long-term discharge test of well N-14T from December 12, 1987 to March 29, 1988.

5.18 Wellhead pressure, discharge rate, and wellhead enthalpy measurements taken during the third long-term discharge test of well N-14T from November 28, 1989 to March 1, 1990 
Figure $\quad$ Page

5.19 Wellhead pressure, discharge rate, and wellhead enthalpy measurements taken during the first long-term discharge test of well N-15T from November 7, 1987 to March 26, 1988

5.20 Wellhead pressure, discharge rate, and wellhead enthalpy measurements taken during the second long-term discharge test of well N-15T from November 15, 1989 to March 1, 1990

5.21 Wellhead pressure, discharge rate, and wellhead enthalpy measurements taken during the first long-term discharge test of well N-16T from December 1, 1988 to March 19, 1989

5.22 Wellhead pressure, discharge rate, and wellhead enthalpy measurements taken during the first long-term discharge test of well N-17T from December 4, 1988 to March 21, 1989

5.23 Wellhead pressure, discharge rate, and wellhead enthalpy measurements taken during a discharge test of well N-21T from November 24, 1989 to March 2, 1990

5.24 Wellhead pressure, discharge rate, and wellhead enthalpy measurements taken during a discharge test of well N-22T from December 1, 1989 to February 27, 1990

5.25 Wellhead pressure, discharge rate, and wellhead enthalpy measurements taken during a discharge test of well N-26P from June 26, 1993 to July 25, 1993.

5.26 Wellhead pressure, discharge rate, and wellhead enthalpy measurements taken during a discharge test of well N-28P from October 26, 1993 to November 28, 1993

5.27 Pressure profile recorded in discharging well N-6T on February 26, 1988............. 5-20

5.28 Pressure profile recorded in discharging well N-10T on September 10, 1988.......... 5-21

5.29 Pressure profile recorded in discharging well N-11T on March 11, 1989............... 5-22

5.30 Pressure profile recorded in discharging well N-14T on February 21, 1988............ 5-24

5.31 Pressure profile recorded in discharging well N-15T on March 2, 1988................. 5-25

5.32 Pressure profile recorded in discharging well N-16T on March 17, 1989............... 5-26

5.33 Pressure profile recorded in discharging well N-17T on March 14, 1989............... 5-27

5.34 Pressure profile recorded in discharging well N-22T on February 26, 1990_........... 5-28

5.35 Pressure profile recorded in discharging well N-26P on July 22, 1993.................. 5-30

5.36 Pressure profile recorded in discharging well N-28P on November 25, $1993 \ldots \ldots \ldots . . .5-31$ 


\section{TABLES}

Table

Page

3.1 Stable feedzone pressures and temperatures for Okuaizu boreholes ......................... 3-52

4.1 Productivity indices for Okuaizu boreholes .............................................................. 4-2

4.2 Injectivity indices for selected Okuaizu boreholes ..................................................... 4-3

4.3 Productivity and Injectivity indices for Oguni, Sumikawa, Kirishima, and Okuaizu boreholes with two-phase feedzones......................................................... 4-13

5.1 Measured stable (or quasi-stable) discharge rates and enthalpies for Okuaizu boreholes ............................................................................................ 5-16 


\section{INTRODUCTION}

During the exploration phase of a geothermal prospect, both wireline-cored and rotarydrilled slim holes offer an attractive alternative to large-diameter production well drilling for preliminary assessment of the geothermal reservoir, owing both to the lower cost and reduced environmental impacts. The U.S. Department of Energy ("DOE") Geothermal Program through Sandia National Laboratories ("Sandia") initiated in 1992 a research effort to demonstrate that slim holes can be used (1) to provide reliable geothermal reservoir parameter estimates comparable to those obtained from large-diameter wells, and (2) to predict the discharge behavior of largediameter wells (Combs and Dunn, 1992). The DOE/Sandia slim hole research program has consisted of two primary elements, examination, and analysis of slim hole and large-diameter well data from Japanese geothermal fields and drilling and testing of slim holes in a few geothermal fields in the western United States.

Dr. Sabodh Garg of SAIC (formerly Maxwell Technologies, Inc./S-Cubed) and Dr. Jim Combs of Geo Hills Associates (collectively SAIC) have analyzed borehole data under contract to Sandia (from 1992 to 1999) as part of the DOE/Sandia effort to demonstrate the merits of slimhole drilling for geothermal exploration and reservoir assessment. Production and injection data from several hundred slim holes and large-diameter wells at five geothermal fields (Oguni, Japan; Sumikawa, Japan; Takigami, Japan; Kirishima, Japan; and Steamboat Hills, U.S.A.) have been examined by scientists at SAIC. These borehole data were analyzed in order to establish relationships (1) between injectivity and productivity indices, (2) between productivity/injectivity index and borehole diameter, and (3) between discharge capacity of slim holes and large-diameter wells. Based on the analysis of these borehole data sets, which had included a total of 147 boreholes, including 65 slim holes and 82 large-diameter wells, Garg and Combs (1997) have documented that the productivity and injectivity indices for boreholes (i.e., both slim holes and large-diameter wells) with liquid feedzones are essentially equal. Therefore, the productivity index (or, more importantly, the injectivity index in the absence of discharge data) from a slim hole in a naturally fractured geothermal reservoir with liquid feedzones can be used to compute the flow resistance of reservoir rocks to liquid production and predict the deliverability of geothermal fluids from a large-diameter geothermal production well. Thus, in moderate- to high-temperature geothermal reservoirs (e.g., in the United States, the East Mesa, Steamboat Hills, Cove Fort, and Coso Geothermal Fields) with liquid feeds, slimhole data can be used to predict the production and injection characteristics of large-diameter wells.

Currently available data and analyses are, however, insufficient to predict the discharge characteristics of large-diameter wells with two-phase feeds based on slimhole data. Because of relative permeability effects in two-phase flow, the productivity index (with in situ boiling) is likely to be much smaller than the injectivity index. Additional studies are required to understand relationships (1) between injectivity index and two-phase productivity index, (2) between borehole diameter and two-phase productivity index, 
and (3) between well completion (i.e., diameter) and the discharge capacity of boreholes with two-phase feedzones. Data from high-temperature geothermal fields spanning a wide range of transmissivities are needed for these latter studies.

Based on published literature, the Okuaizu Geothermal Field in the Fukushima prefecture, Tohoku, northern Honshu, Japan, appeared to be a reasonable candidate to provide the information necessary to examine the possible relationship between well test data from slim holes and large-diameter wells with two-phase feedzones. Preliminary examination of the borehole information suggests that the above conclusion was correct in that the maximum reservoir temperatures are greater than $340^{\circ} \mathrm{C}$ and there was production induced boiling in most of the boreholes. Multiple data sets on several of the wells indicate that the steam-water ratio increases during production suggesting that these boreholes are completed in two-phase feedzones. It was hoped that the Okuaizu reservoir data would provide evidence that the conclusions for boreholes with liquid feedzones will also be valid for boreholes with two-phase feedzones.

With DOE/Sandia funding, Garg and Combs traveled to Japan in August 1997 and July 1998 to meet with the technical staff of Okuaizu Geothermal Co., Ltd. (OAG) which is primarily owned by Mitsui Mining \& Smelting Co., Ltd. (MMS), to continue the data gathering efforts associated with analyzing Japanese borehole data. Data were obtained from forty-four (44) boreholes drilled in the Okuaizu Geothermal Field. Because of programmatic reasons, this effort was temporarily discontinued in the years 1999 and 2000. During 2001 and 2002, DOE funded the continuation of this analysis of Okuaizu borehole data through a contract to SAIC from Bechtel BWXT.
MMS began a geological survey in the Yanaizu Nishiyama area in 1956 and purchased land for the mining of perlite (Kanazawa and Yoshitome, 1996). Thereafter, the company obtained data regarding the geology and geothermal features of the area. Based on the geothermal data obtained in the early 1970s from some reconnaissance surveys conducted by MMS and the Geological Survey of Japan, an initial model of the geological and geothermal structure was proposed. During the period 1977 through 1983 as a part of Project Sunshine, the New Energy and Industrial Technology Development Organization (NEDO) drilled six (6) shallow slim holes ranging in total depth from 300 to 600 meters and seven (7) deep slim holes with total depths of 1,000 to 1,500 meters. Two of the deep slim holes were discharged. These boreholes indicated the existence of a commercial geothermal reservoir. Therefore, MMS and its subsidiary, $\mathrm{OAG}$, decided to establish the areal extent and quality of the geothermal reservoir in the Okuaizu area.

During 1984 to 1990 , OAG drilled, and tested on multiple occasions, eight (8) slim holes (4 were discharged) and seventeen (17) largediameter wells (12 were discharged) with total depths of 650 to 2,700 meters. Finally, in 1992, OAG drilled 4 additional large-diameter wells of which 3 were production wells. As of 1998, several of the $21 \mathrm{slim}$ holes are being utilized as observation wells and of the 21 large-diameter wells drilled, 7 are used as production wells and 3 are injection wells for the Yanaizu Nishiyama Geothermal Power Station of Tohoku Electric Power Co., Ltd. The 65 MW power plant has been in commercial operation since May 25, 1995 and is the largest single unit geothermal power plant in Japan. Soon after the power plant started generating electricity, another two production wells (N-30P in late 1995 and N$31 \mathrm{P}$ in 1997) were drilled by OAG. 
In the present report, we examine data from twenty-one (21) slim holes and twenty-three (23) large-diameter wells at the Okuaizu Geothermal Field. A brief overview of the Okuaizu Geothermal Field is presented in Section 2. The available drilling information (circulation loss, well completion and geologic data) and downhole pressure, temperature, spinner and water level surveys are presented and analyzed in Section 3 to determine feedzone locations, pressures and temperatures for the forty-four (44) boreholes drilled to date at the Okuaizu Geothermal Field. The feedzone pressures (and temperatures) for individual boreholes are then synthesized to determine the fluid state in the reservoir. Thereafter, estimates of injectivity and productivity indices are presented in Section 4. Relationships between the productivity and injectivity indices of slim holes and of large-diameter wells with liquid feedzones and two-phase feedzones are also investigated in Section 4. Characteristic discharge data and variation of maximum discharge rate with borehole diameter are discussed in Section 5. Mathematical modeling of fluid flow in boreholes with twophase feedzones from the Okuaizu Geothermal Field is also presented in Section 5. Finally, in Section 5, the conclusions and recommendations for geothermal reservoir evaluation using discharge and injection data from slim holes with two-phase feedzones are presented. 


\section{AN OVERVIEW OF THE OKUAIZU GEOTHERMAL FIELD}

\subsection{Introduction}

Mitsui Mining \& Smelting Co., Ltd. (MMS) carried out an initial reconnaissance survey in 1974 with the purpose of investigating the geothermal potential of the Yanaizu Nishiyama area (Kanazawa and Yoshitome, 1996) located in the western part of Fukushima Prefecture, northern Honshu, Japan (see Figure 2.1). In 1976 and 1977, the Geological Survey of Japan conducted surveys of surface alteration zones, heat discharge, an electrical sounding and drilled a slim hole with a total depth of 603 meters. As a result, a model of geological and geothermal structure was proposed and the New Energy and Industrial Technology Development Organization (NEDO) decided to sponsor the "Geothermal Development Promotion Survey Program - Okuaizu Area” from 1982 to 1990.

Geothermal investigations since 1974 by MMS, OAG, and governmental researchers in the vicinity of the Okuaizu Geothermal Field have included geological, geophysical, and geochemical studies (e.g., Nitta, et al., 1988; Nonokuchi, 1988; Takenouchi, 1988; Seki, 1991; Mizugaki, 2000; Seki, 2000; Toshiyuki, et al., 2000). Surface geothermal manifestations include solfataras, hot springs ranging in temperature from $40^{\circ} \mathrm{C}$ to $90^{\circ} \mathrm{C}$, $\mathrm{H}_{2} \mathrm{~S}$ and $\mathrm{CO}_{2}$ discharges, hydrothermal alteration, and abandoned sulfur and clay mines. The hot springs include the Nishiyama spa, the Arayu spa, and the Kaminoyu spa. Under NEDO sponsorship, geochemical exploration, electromagnetic exploration (AFMT method), and electric prospecting (SP method) surveys were performed over an area of 70 square kilometers.
Based on geothermal exploration surveys in the Yanaizu Nishiyama area, NEDO initiated in 1982 and 1983 a heat flow survey, which consisted of six (6) slim holes drilled to depths of 400 meters. These heat flow holes led to the additional drilling of seven (7) slim holes to depths of $1,000 \mathrm{~m}$ to $1,500 \mathrm{~m}$. As a result of the NEDO sponsored geothermal exploration, a high temperature zone of more than $200^{\circ} \mathrm{C}$ was confirmed in the southern section of the Nishiyama Spa (Nonokuchi, 1988). This high temperature zone appeared to be restricted by a NW-SE fault passing through the Nishiyama Spa. The hot water appeared to be primarily situated along the fractures in the dacites and tuffs of the Miocene Takizawagawa formation at depths ranging from $1,080 \mathrm{~m}$ to $1,270 \mathrm{~m}$.

Utilizing the results of the NEDO sponsored geothermal exploration; OAG initiated a geothermal development project focused on the most prospective area of 24.5 square kilometers. OAG conducted additional geological, geochemical, and geophysical surveys and drilled an additional 29 exploration, production and injection boreholes (8 slim holes and 21 large-diameter wells). A 3-dimensional numerical simulation of the Okuaizu geothermal reservoir was conducted for OAG by GeothermEx (1987), resulting in the conclusion that a fuel source for electrical production of more than $50 \mathrm{MW}$ could be maintained for a long term without pressure support from injection.

Based on the geothermal exploration surveys, well drilling program, and the 3-dimensional numerical simulation of the geothermal reservoir, Tohoku Electric Power Co., Ltd. 
and OAG decided that the Okuaizu Geothermal Field could provide the long-term fuel source for a 65 MW power plant. Construction work on the power plant began in June 1993, and on May 25, 1995, the Yanaizu Nishiyama power station started commercial operation.

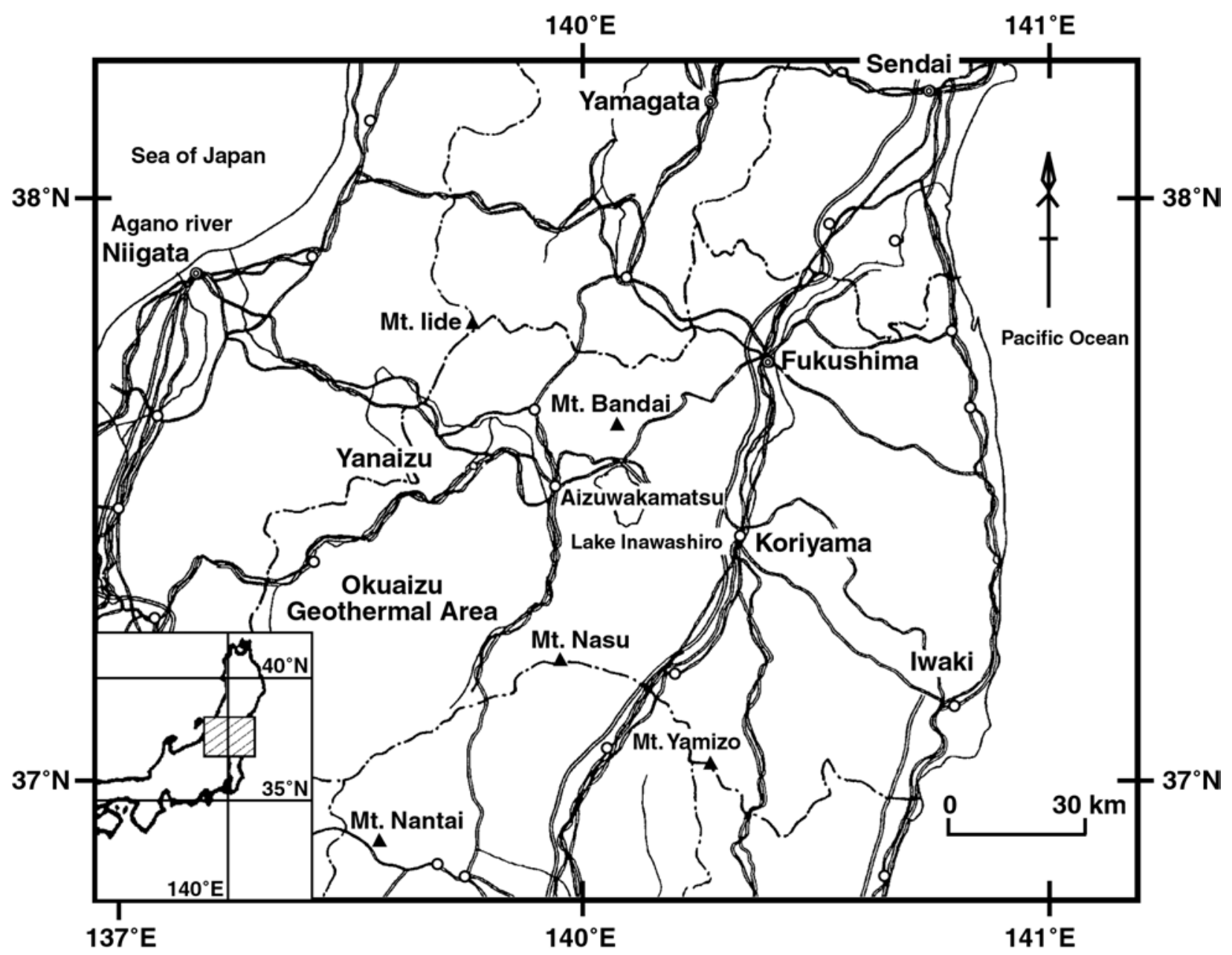

Figure 2.1. Location map of the Okuaizu Geothermal area in Northern Honshu, Japan (adapted from field trip guide of NEDO International Geothermal Symposium on May 13, 1997 at Sendai, Japan).

\subsection{Geological Setting and Subsurface Stratigraphic Sequence}

The Okuaizu Geothermal Field is located approximately $35 \mathrm{~km}$ southwest of the active volcano Mt. Bandai. The field is characterized by rhyolitic volcanism of about $0.3 \mathrm{Ma}$ to 0.2 $\mathrm{Ma}$ that formed the nearby Sunagohara volcano. The geology of the Yanaizu Nishiyama area consists primarily of pyroclastic rocks of Miocene age and lake sediments and rhyolite lava of Pleistocene age. An argillic alteration zone composed mainly of smectite is spread over an area of about $4 \mathrm{~km}^{2}$ around the Nishiyama hot springs. Acidic alteration resulting in kaolinite is also apparent.

The Sunagohara formation, which is composed of rhyolite lava domes and tuffaceous lacustrine sediments, is present at shallow depths throughout the Okuaizu geothermal area (see Figure 2.2). The 
maximum depth to the base of the lake sediments is $\sim 350 \mathrm{~m}$ and the maximum measured temperature in the Sunagohara formation is about $120^{\circ} \mathrm{C}$.

Pyroclastic flows from the Numazawa volcano, which is located about $10 \mathrm{~km}$ to the west and was active about 5,000 years ago, covers essentially all of the northern part of the Okuaizu geothermal area.

In order of increasing depth (see Figure 2.3), the regional stratigraphic column in the Okuaizu geothermal area is the following (adapted from Seki, 1991 and 2000; Mizugaki, 2000):

Numazawa Pyroclastics: Holocene $(0.005$ $\mathrm{Ma})$, Dacitic pyroclastic flow, tuff and scoria.

Sunagohara Formation: Pleistocene (0.2$0.9 \mathrm{Ma})$, Glassy and perlitic rhyolite, lucustrine sediments consisting of tuffaceous sandstone, siltstone and conglomerate, thickness of $>150 \mathrm{~m}$.

Tertiary Rocks: Tertiary $(2.0 \quad-\sim 60 \mathrm{Ma})$, consists of the following eight separate formations that have been identified, with some having been age dated.

Fujitoge Formation: Late Pliocene ( 4.0 Ma), Dacitic pumice tuff with some intercalations of sandstone and mudstone, thickness of $\sim 300 \mathrm{~m}$.

Iriyamazawa Formation: Late Miocene $(\sim 7$ $\mathrm{Ma}$ ), voluminous intracaldera ash-flow tuffs and lake sediments, and characterized by a discontinuous half-ring of post-caldera lava domes.

Urushikubo Formation: Middle Miocene $(>10 \mathrm{Ma})$, Sandstone, siltstone, mudstone, conglomerate, tuff breccia, pumice tuff, basaltic pyroclastics, and rhyolite lava, thickness of 200 to $600 \mathrm{~m}$.
Ogino Formation: Middle Miocene (15-16 $\mathrm{Ma})$, Green tuffs, rhyolitic pyroclastics and lava, thickness 200 to $300 \mathrm{~m}$.

Myojingatake Formation: Middle Miocene (15-16 Ma), Andesitic and basalitic pyroclastics, thickness of 100 to $150 \mathrm{~m}$.

Miyashita Formation: Middle Miocene (15$16 \mathrm{Ma})$, Mudstone that has undergone extensive hydrothermal alteration and appears to act as a caprock, thickness of 100 to $150 \mathrm{~m}$.

Takizawagawa Formation: Early Miocene (16-18 Ma), Green tuffs, green colored volcanic rocks, rhyolitic pyroclastics and lava, thickness of 1000 to $1300 \mathrm{~m}$.

Ohizawa Formation: Early Miocene (17-20 $\mathrm{Ma}$, Green tuffs, conglomerate, sandstone and rhyolite, thickness of 500 to $600 \mathrm{~m}$.

Basement Rocks: Pre-Tertiary (>65.0 Ma), Basement has not been identified on the surface in the Yanaizu Nishiyama area nor has it been encountered in the drilling cores. Nevertheless, the basement is believed to be granitic rocks because granite fragments occur in Neogene tuffs obtained from the bottom of some of the boreholes and granite outcrops 20 $\mathrm{km}$ north and northwest of the Okuaizu Geothermal Field.

\subsection{Reservoir Characteristics and Permeability}

Originally, the Okuaizu geothermal reservoir was thought to be a porous media type reservoir in the Sunagohara formation (Kanazawa and Yoshitome, 1996), which consists of lake sediments distributed essentially in a circular shape. It was assumed that there was a hydrothermal reservoir of hot water in the Sunagohara formation with high permeability, and that anomalous geothermal 


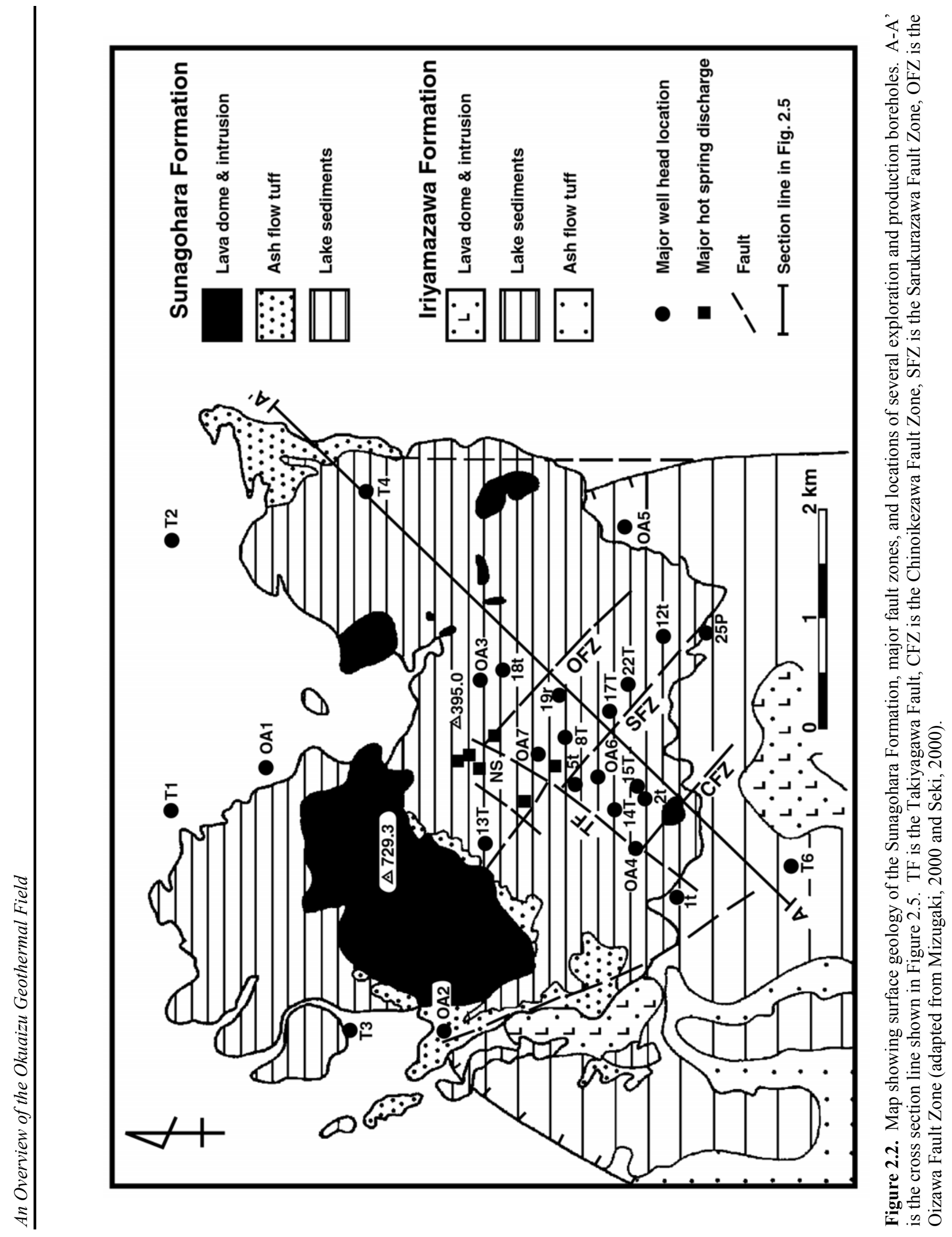




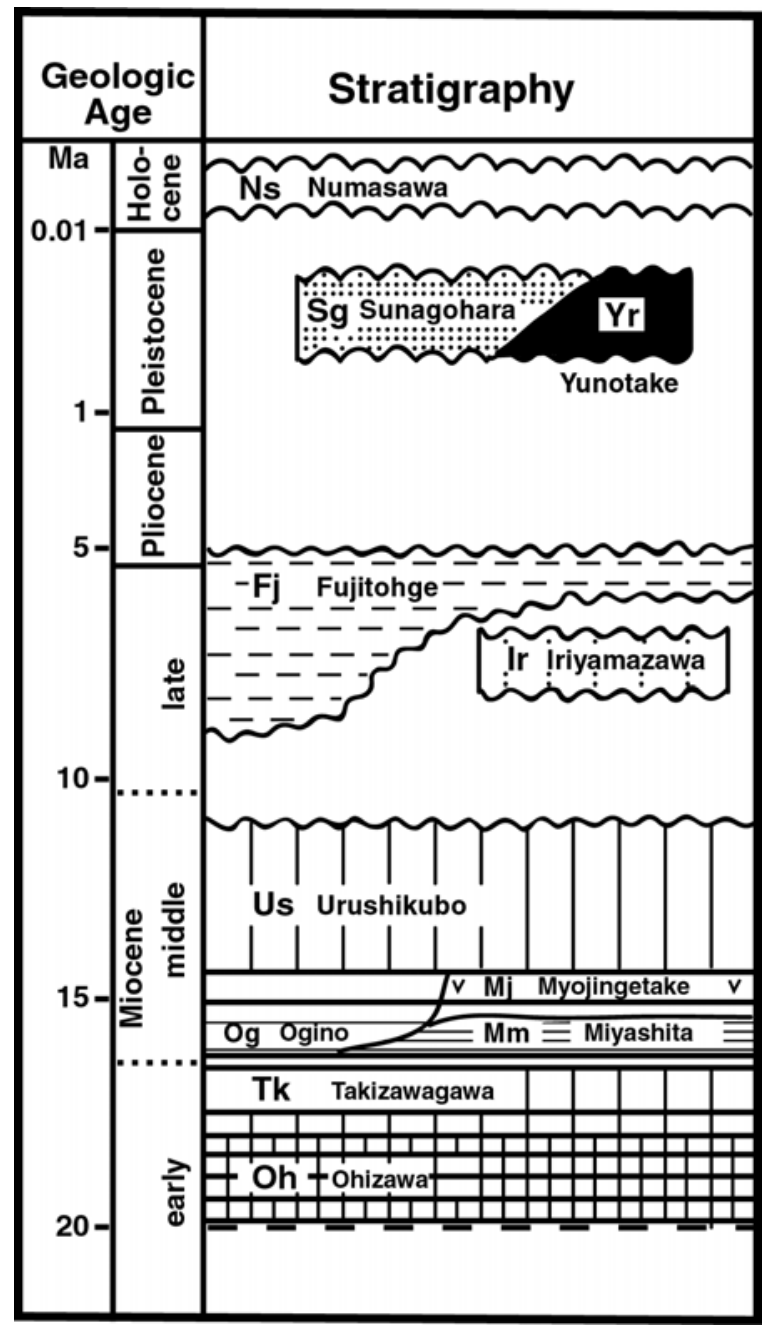

Figure 2.3. Regional stratigraphic column for the Okuaizu Geothermal Area with the geological formation abbreviations and symbols as in Figure 2.5 (adapted from Mizugaki, 2000 and Seki, 2000).

fluids are circulated by convection from the Takizawagawa formation through the invervening low permeability Miyashita mudstone member.

However, after obtaining a significant amount of geological, well testing, and drilling data from the slim holes and large-diameter wells at Okuaizu, it was determined that the geothermal reservoir is of the fracture type, controlled by the Chinoikezawa and Sarukurazawa faults which appear on the ground surface running linearly in a NW direction. The Okuaizu borefield is shown in Figure 2.4. The distribution of feedzones (see Section 3) indicates that the reservoirs are of the vertical fracture type, which exists along the Chinoikezawa and Sarukurazawa fault zones.

A conceptual model of the geothermal fluid flow based on the temperature data indicates that high temperature geothermal fluid flows up along the Chinoikezawa fault in a direction from southwest to northwest, and then changes into a northeasterly direction along the Takiyagawa fault zone at shallow depths. In other words, geothermal fluid rises along the deeper portion of the Chinoikezawa, and probably the Sarukurazawa, fault zones, both of which are steeply dipping NE. The zone of argillic alteration and the Miyashita mudstone member act as aquitards. Consequently, the high temperature geothermal fluid, which is ascending below the low permeability Miyashita mudstone does not easily discharge to shallow levels.

A portion of the convecting geothermal fluid discharges along the Takiyagawa fault, which strikes NE and dips steeply SE. This fault intersects the Chinoikezawa and Sarukurazawa fault zones at their NW ends. The outflow rises to the NE along the Takiyagawa fault and mixes with cold ground water near the surface. A cold influx zone exists along the Oizawa fault zone near the intersection of the two fault systems. The Nishiyama hot springs are discharges of these mixed fluids (Seki, 1991).

The Okuaizu geothermal reservoir thus appears to be controlled by the Miyashita mudstone as an impermeable formation and two fault systems, that is, the Chinoikezawa and Sarukurazawa fault zones which function as pathways for hydrothermal fluids from greater depths (Mizugaki, 2000). Tosha, et al. (2000) observed a positive self-potential (SP) anomaly over high temperature zones, the amplitude of which exceeded $100 \mathrm{mV}$ before 


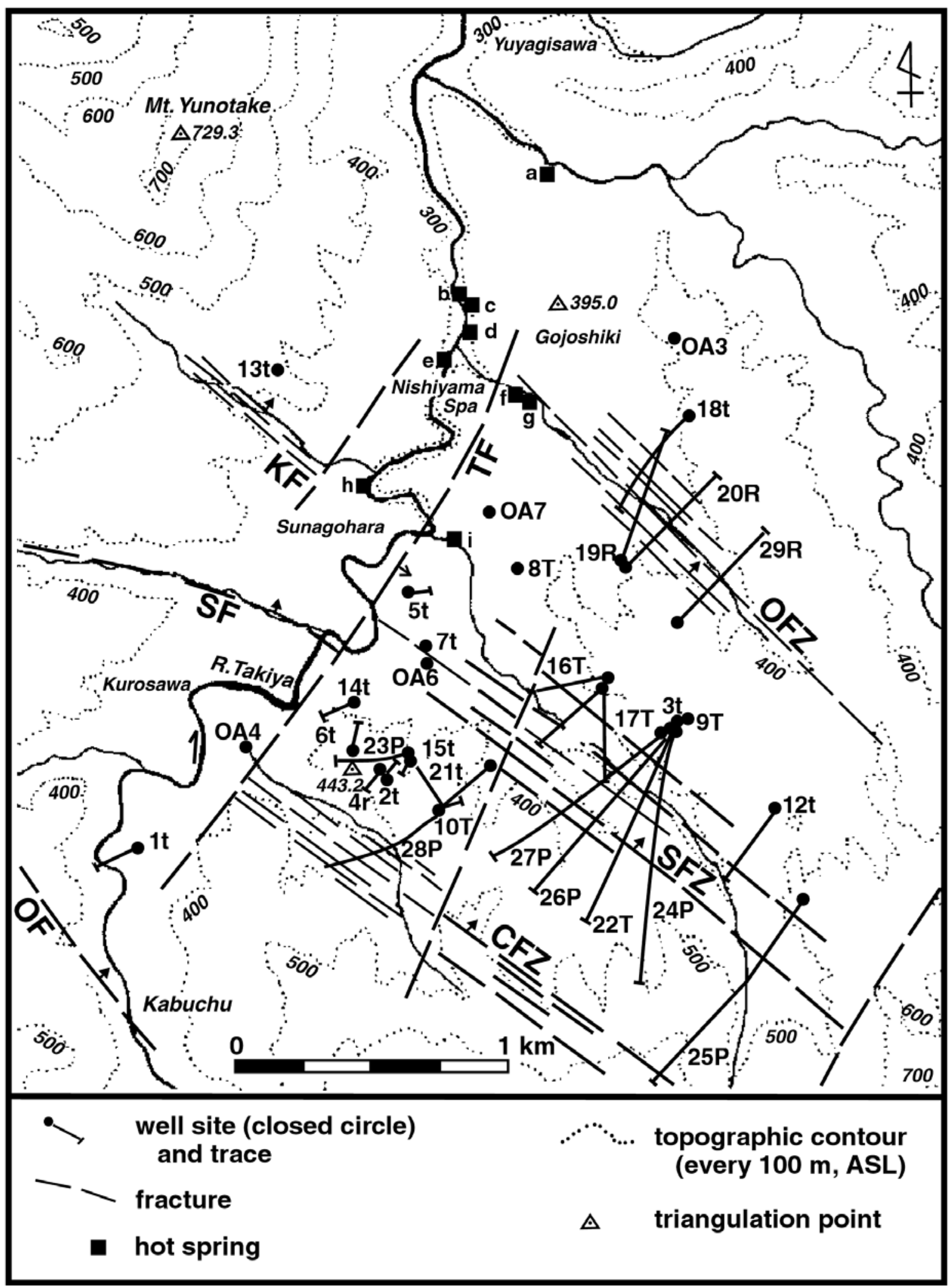

Figure 2.4. A topographic map of the Okuaizu borefield, showing major fault zones, and borehole locations and downhole traces (adapted from Mizugaki, 2000 and Seki, 2000). 
the commencement of geothermal fluid production. After the geothermal power plant commenced operations in May 1995, the positive SP anomaly disappeared on the profile in 1996, possibly owing to the development of the downward geothermal flow into the reservoir. Further surveys were carried out between May and September after a 2-month shutin of all the production wells in 1998. The positive SP anomaly was again observed on the profile in May, but decreased with time after the re-start of fluid production. Fumaroles discharging carbon dioxide and hydrogen sulfide are also observed along the Chinoikezawa and Sarukurazawa faults.

The permeability of the Takizawagawa Formation in the production zones of the Okuaizu geothermal reservoir is quite low. Injection, falloff and buildup tests were conducted on slim hole OA-4 (Ishido, 1985). $\mathrm{He}$ interpreted the pressure transient data using conventional type-curve and graphical analysis. Assuming that the viscosity of the hot reservoir fluid is appropriate to use for the injection data, Ishido (1985) obtained a kh value of 0.1 darcy-meter from the injection and falloff data. An estimate of the formation $\mathrm{kh}$ product for the buildup data is 0.2 darcymeter which is of the same order of magnitude as the value estimated from the injection/falloff data.

\subsection{Reservoir Fluid State}

\subsubsection{Reservoir Pressures}

In most of the Okuaizu boreholes, repetitive surveys of downhole temperature and standing water level were carried out for at least several days after cold-water injection was terminated. These heatup surveys permit the estimation of reservoir pressure and temperature. Feedzone pressures for the Okuaizu boreholes determined in this study are listed in Table 3.1 and a plot of feedzone pressure versus elevation is presented in Figure 3.123. For a geothermal reservoir system with moderate to good horizontal and vertical permeabilities, feedzone pressures should principally depend upon feedzone elevation as demonstrated in the detailed analysis of the feedzone pressures presented in Section 3.2.

The vertical pressure gradient for the Okuaizu geothermal area is $8.297 \mathrm{kPa} / \mathrm{m}$ which corresponds to a hydrostatic gradient at about $215^{\circ} \mathrm{C}$. Since the reservoir temperatures in the southern part of the field, i.e., in the production area, exceed $215^{\circ} \mathrm{C}$, it is likely that fluid upflow is occurring in the area. The preproduction pressures and temperatures at Okuaizu are such that the reservoir fluid is single-phase liquid at feedzone depths. However, the formation permeability in the Okuaizu geothermal reservoir is low and discharge from Okuaizu boreholes is usually accompanied by in situ boiling.

For example, during the first simultaneous production test of five production wells $(\mathrm{N}-2 \mathrm{t}$, $\mathrm{N}-6 \mathrm{~T}, \mathrm{~N}-10 \mathrm{~T}, \mathrm{~N}-14 \mathrm{~T}$ and N-15T, from December 1987 to March 1988), all five wells showed a significant amount of excess enthalpy, up to $600 \mathrm{~kJ} / \mathrm{kg}$. This development of excess enthalpy is derived from excess steam inflow produced from in situ boiling caused by the discharge-induced pressure drop. The total discharge enthalpy of the wells gradually increased with time during the test (see Section 5), which indicates extension of boiling around the wells into the reservoir.

\subsubsection{Reservoir and Fluid Inclusion Temperatures}

Hot springs, including some high-temperature springs (up to $93^{\circ} \mathrm{C}$ ), are distributed in the Yanaizu Nishiyama area. More than 15 hot springs that discharge near-neutral $\mathrm{pH}$ dilute NaCl-type water with a total flow of $>270$ $1 / \mathrm{min}$, are found in the northern part of the 
geothermal system. They cover an area about $500 \mathrm{~m}$ by $2,000 \mathrm{~m}$ and are collectively called the Nishiyama spa (see Figure 2.4). An extensive hydrothermally altered zone developed in an area of $4.4 \mathrm{~km}^{2}$ around the Nishiyama spa.

At the Okuaizu Geothermal Field, subsurface temperatures are highest in the south and southwest, and decline to the north and to the east. The highest temperature $\left(341^{\circ} \mathrm{C}\right)$ was measured at Okuaizu in borehole $\mathrm{N}-22 \mathrm{~T}$ at $\sim 2,600 \mathrm{mTVD}(\sim 2,150 \mathrm{mASL})$ in the southern part of the field. Temperatures in excess of $300^{\circ} \mathrm{C}$ have been observed in several boreholes (see Table 3.1) intersecting the production zones located along the NW-SE trending Chinoikezawa and Sarukurazawa fault zones. The heat source for the Okuaizu Geothermal Field probably exists under the SE extension of the Chinoikezawa fault zone. Furthermore, the heat source is most likely a cooling silicic igneous body, perhaps the Numazawa volcano that is located about $10 \mathrm{~km}$ west of the Okuaizu reservoir and was active about 5,000 years ago.

The thermal structure of the Okuaizu geothermal reservoir may be constructed from thermal profiles based on temperatures measured at least 120 hours after drilling, the time allowed for thermal conditions to stabilize (see Section 3). The thermal structure of the Okuaizu geothermal reservoir is primarily controlled by the fault and fracture systems. Faults and fault zones in the Okuaizu geothermal area are classified as N-S, NWSE, and NE-SW systems. The major feedzones in the Okuaizu Geothermal Field are distributed between the depths of $500 \mathrm{~m}$ and 1,700 $\mathrm{m}$ below sea level (see Section 3). The feedzone temperatures are between $250^{\circ} \mathrm{C}$ and $320^{\circ} \mathrm{C}$ and the center of the high temperature zone is located along the Chinoikezawa fault zone.
In the deeper part of the system, the zone of thermal upwelling is located along the Chinoikezawa fault zone, and isotherms open towards the SE (see Figure 2.5) At shallower levels, the highest temperature isotherms are located between the Chinoikezawa and the Sarukurazawa fault zone. Still closer to the surface, the axis of thermal maxima changes direction to parallel the Takiyagawa fault zone, trending NE-SW. A zone of argillic alteration at shallow levels appears to act as a barrier to upflow.

Samples for a fluid inclusion study were collected from the drill cores of OA-6, OA-7, $\mathrm{N}-1 \mathrm{t}, \mathrm{N}-2 \mathrm{t}, \mathrm{N}-3 \mathrm{t}, \mathrm{N}-5 \mathrm{t}, \mathrm{N}-12 \mathrm{t}, \mathrm{N}-13 \mathrm{t}$ and N18t (Takenouchi, 1988). These boreholes were selected along SW-NE and SE-NW sections in order to characterize the vertical and lateral change of homogenization temperature in comparison with the measured borehole temperatures. The fluid inclusions are all twophase gas and liquid inclusions and no $\mathrm{CO}_{2}-$ bearing or halite-bearing fluid inclusions were observed. The fluid inclusion data indicate that the geothermal activity at the Okuaizu geothermal area has not changed appreciably since the deposition of the vein-filling minerals (Takenouchi, 1988). The homogenization temperatures of fluid inclusions correspond fairly well to the measured downhole temperatures both laterally and vertically. In the central part of the Okuaizu Geothermal Field, borehole and fluid inclusion temperatures range up to approximately $300^{\circ} \mathrm{C}$ at about $1,000 \mathrm{~m}$ below sea level, but in the peripheral zone of the Okuaizu geothermal reservoir, the maximum value is only $150^{\circ} \mathrm{C}$, especially in the western block of the Takizawagawa fault zone. 


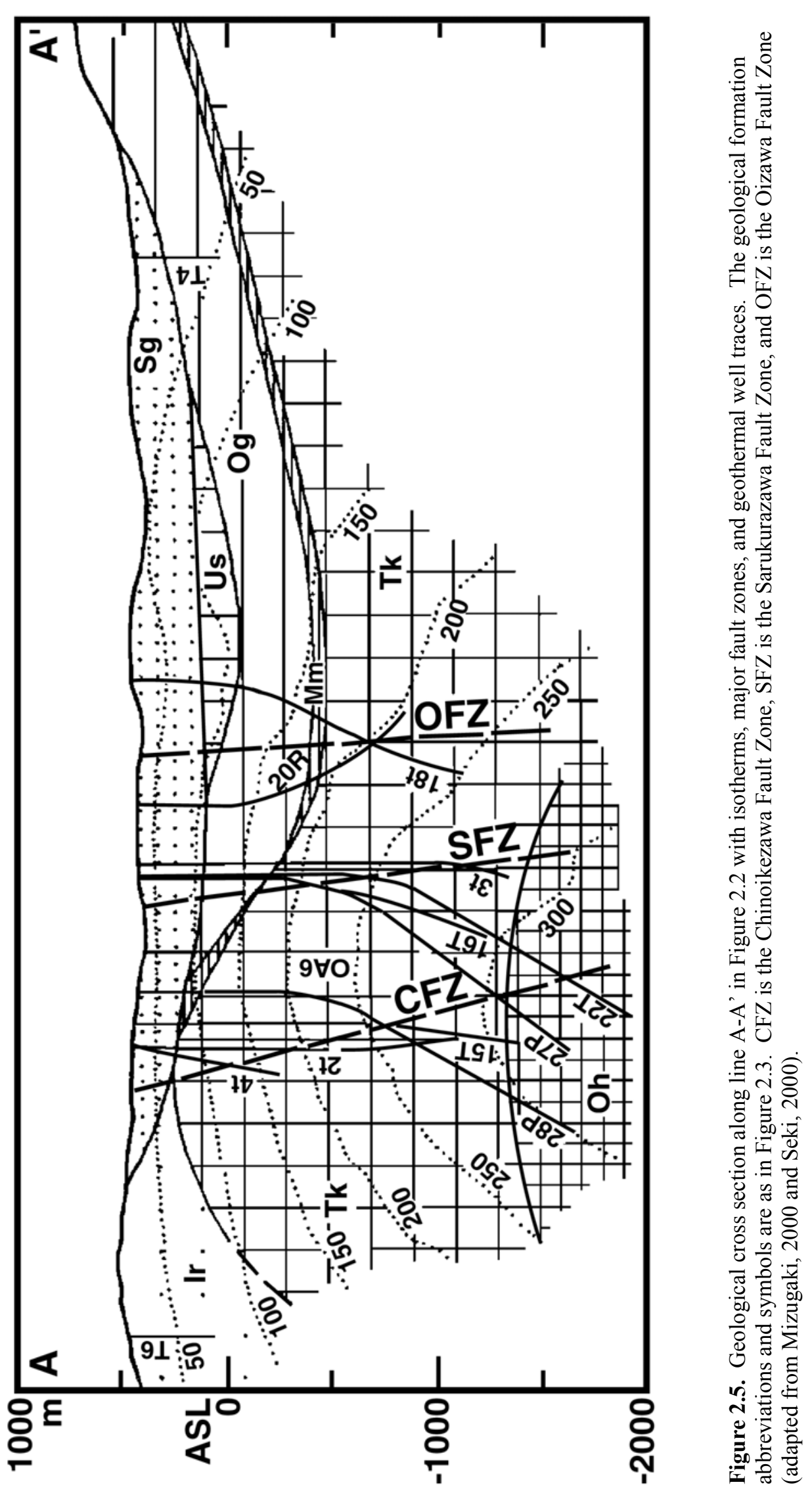




\subsubsection{Fluid Origin, Salinity, and Gas Content}

One characteristic phenomenon of the Okuaizu geothermal reservoir is the high gas content in well discharges (Seki, 1991). The concentrations of non-condensable gases (NCG) in steam separated at about $6.5 \mathrm{~kg} / \mathrm{cm}^{2}$ range from $2 \%$ to $10 \%$ by volume. Most of the NCG is $\mathrm{CO}_{2}$ (95 to $99 \%$ ) with the balance being $\mathrm{H}_{2} \mathrm{~S}(0.1$ to $4 \%)$ and residual gases. The non-condensable gas content of the Okuaizu geothermal reservoir is greater than that at other Japanese geothermal reservoirs. However, the amount of non-condenaible gas generally tends to decrease with continued steam production.

The separated hot water has the highest salinity of geothermal systems in Japan except for Fushime, which is a seawater dominated geothermal system (Seki, 1991). The dominant anion in the Okuaizu reservoir fluids is $\mathrm{Cl}^{-}(5,300$ to $22,000 \mathrm{mg} / \mathrm{kg})$ and major cations are $\mathrm{Na}^{+}(2,700$ to $10,600 \mathrm{mg} / \mathrm{kg})$ with lesser amounts of $\mathrm{K}^{+}$(180 to $2,550 \mathrm{mg} / \mathrm{kg}$ ). The silica concentration is also quite high (440 to $1,010 \mathrm{mg} / \mathrm{kg}$ ), reflecting the high reservoir temperatures in excess of $300^{\circ} \mathrm{C}$. Hot water from most boreholes has a $\mathrm{pH}$ from 6 to 7 , whereas hot water from some wells is acidic. The ratios of $\mathrm{B} / \mathrm{Cl}$ and $\mathrm{Br} / \mathrm{Cl}$ show no evidence of a present-day seawater component in the geothermal fluids (Seki, 2000).

Sato and coworkers (2000) plotted deuterium isotope values relative to oxygen-18 isotope $\left({ }^{18} \mathrm{O}\right)$ values for brine samples from the Okuaizu geothermal reservoir. There is a positive ${ }^{18} \mathrm{O}$ shift relative to isotopic values for the local meteoric water, indicating that the rock/water ratio is fairly high and/or the geothermal system is relatively mature.

The reservoir fluid at Okuaizu has a high temperature (greater than $300^{\circ} \mathrm{C}$ ), and is estimated to have a salinity of about $2 \mathrm{wt} \%$ and a large gas component (about $1 \mathrm{wt} \% \mathrm{CO}_{2}$ and $250 \mathrm{mg} / \mathrm{kg} \mathrm{H}_{2} \mathrm{~S}$ ). The relative $\mathrm{He}$, Ar and $\mathrm{N}_{2}$ contents of gases from geothermal borehole discharges are close to the composition of volcanic arc magmatic gas, indicating that the Okuaizu geothermal reservoir has a relatively large contribution of magmatic gas (Seki, 2000).

High salinity and gas contents suggest a significant magmatic component of the geothermal fluids in the Okuaizu geothermal reservoir. Isotopic characteristics of the discharged fluids (Seki, 1991) also support this hypothesis. Mizugaki (2000) has pointed out that the Okuaizu Geothermal Field is located $10 \mathrm{~km}$ east of the Numazawa caldera, and about $50 \mathrm{~km}$ behind the volcanic front of the northeast Japan arc, which is associated with the westward subduction of the Pacific Plate along the Japan Trench. 


\section{Section 3}

\section{ANALYSIS OF DOWNHOLE DATA}

\subsection{Introduction}

The New Energy and Industrial Technology Development Organization (NEDO) initiated the well drilling and testing program in the Okuaizu area with the drilling of 13 slim holes (T-1 to T-6 and OA-1 to OA-7) in 1982 and 1983. During the period extending from 1984 to 1992, the Okuaizu Geothermal Co., Ltd. drilled an additional 29 exploration, production and injection boreholes (8 slim holes and 21 large-diameter wells). Since the start of the 65 MW Yanaizu Nishiyama Geothermal Power Plant on May 25, 1995, another two production wells $(\mathrm{N}-30 \mathrm{P}$ and N31P) have been drilled.

In this section, we present the analysis of the available drilling (circulation loss, well completion, and geologic data) and downhole PTS (pressure, temperature, spinner and water level) surveys to obtain feedzone pressures, and temperatures for the forty-four (44) boreholes (21 slim holes and 23 largediameter wells) drilled at Okuaizu. The essential well completion and drilling data, required in the interpretations, are presented in Appendix A.

At the Okuaizu Geothermal Field, only a few downhole pressure surveys were made in shutin boreholes. Therefore, the water level and temperature data are used to determine the feedzone pressures in the shut-in boreholes. Most of the available downhole pressure surveys were made with Kuster tools. Since these Kuster gauges were not recalibrated in the field, the accuracy of downhole pressure measurements may not be all that good.

Approximately half of the Okuaizu boreholes were directionally drilled. Because of borehole deviation, the measured depths along the borehole (MD) need to be corrected to obtain true vertical depths (TVD) from the surface. Depths are also sometimes given in terms of elevation (meters) above sea level. Thus, $800 \mathrm{mASL}$ denotes an elevation of 800 meters above sea level. Casing, liner and borehole dimensions are generally given in $\mathrm{mm}$.

\subsection{Feedzone Locations, Pressures, and Temperatures}

\subsubsection{Boreholes Drilled by Governmental Agencies}

\section{Slim Hole T-1}

Slim hole T-1 is located approximately $3 \mathrm{~km}$ north of the main Okuaizu borefield. Heatup surveys for T-1 (Figure 3.1) exhibit a persistent temperature depression at about 190 mTVD. While drilling, circulation losses were encountered nearby at 178-188 mTVD and at 194 mTVD. Thus, it is likely that the principal fluid entry for T-1 is located at 190 mTVD (93 $\mathrm{mASL})$. The maximum temperature in $\mathrm{T}-1$ occurs towards bottomhole. After 30 days of shut-in (Figure 3.1), the temperature at bottomhole had recovered to $\sim 56^{\circ} \mathrm{C}$. By comparison, the temperature at the feedpoint does not exceed $45^{\circ} \mathrm{C}$.

Pressures computed from water level and temperature data are shown in Figure 3.2. The pressure at $190 \mathrm{mTVD}$ (93 mASL) is estimated to be 19.0 bars.

No injection or discharge test data are available for slim hole T-1. 


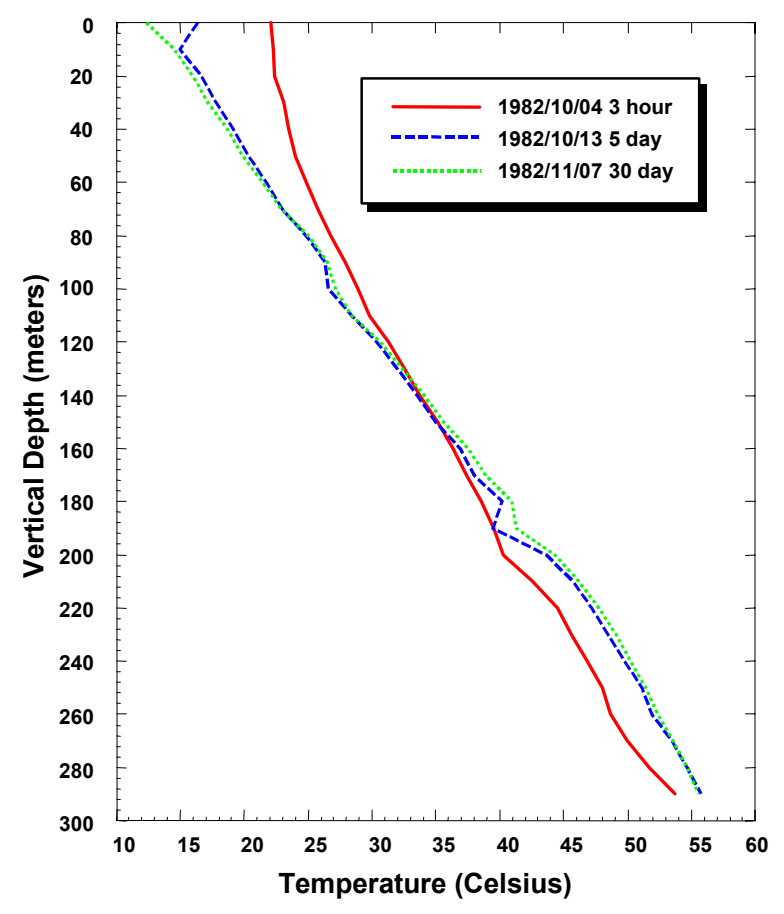

Figure 3.1. Temperature surveys in slim hole $\mathrm{T}-1$.

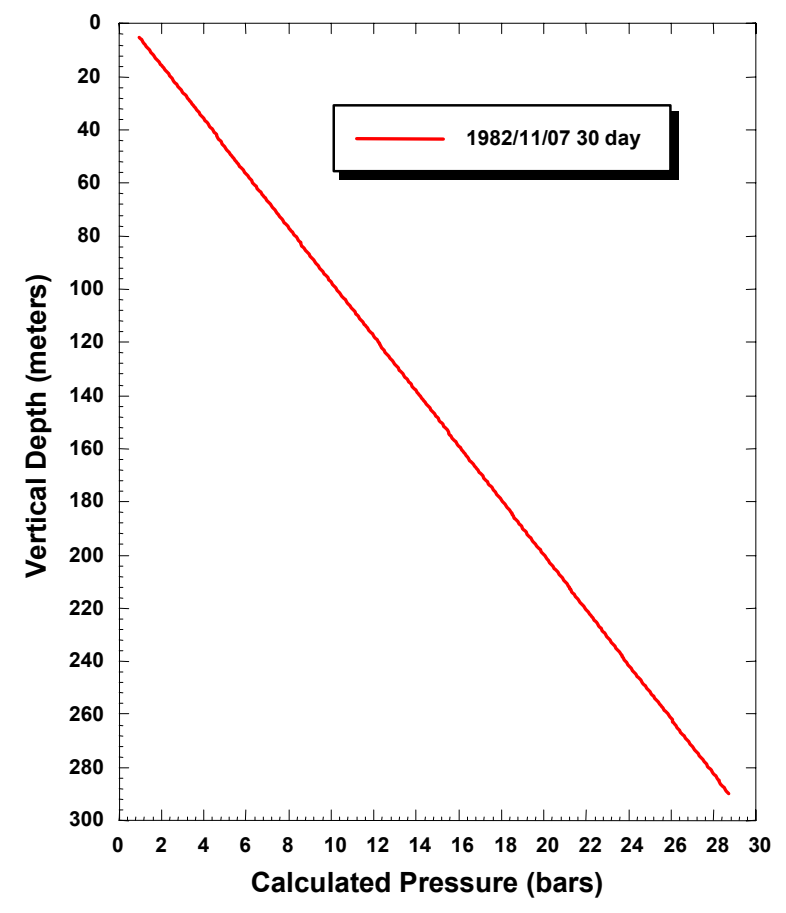

Figure 3.2. Pressures computed from water level and temperature data in slim hole T-1.

\section{Slim Hole T-2}

Slim hole T-2 is located about $3 \mathrm{~km}$ north and $1 \mathrm{~km}$ east of the main Okuaizu borefield. Heatup surveys (Figure 3.3) for T-2 display a depressed temperature zone at 400 mTVD. Since a total circulation loss zone occurred nearby at 399 mTVD, it is reasonable to assume that the major fluid entry for T-2 is situated at about $400 \mathrm{mTVD}$ (83 mASL). After 24 days of shut-in, a temperature of $\sim 56^{\circ} \mathrm{C}$ was recorded at bottom hole on November 20, 1982 (Figure 3.3). The stable feedzone temperature is estimated to be $\sim 47^{\circ} \mathrm{C}$.

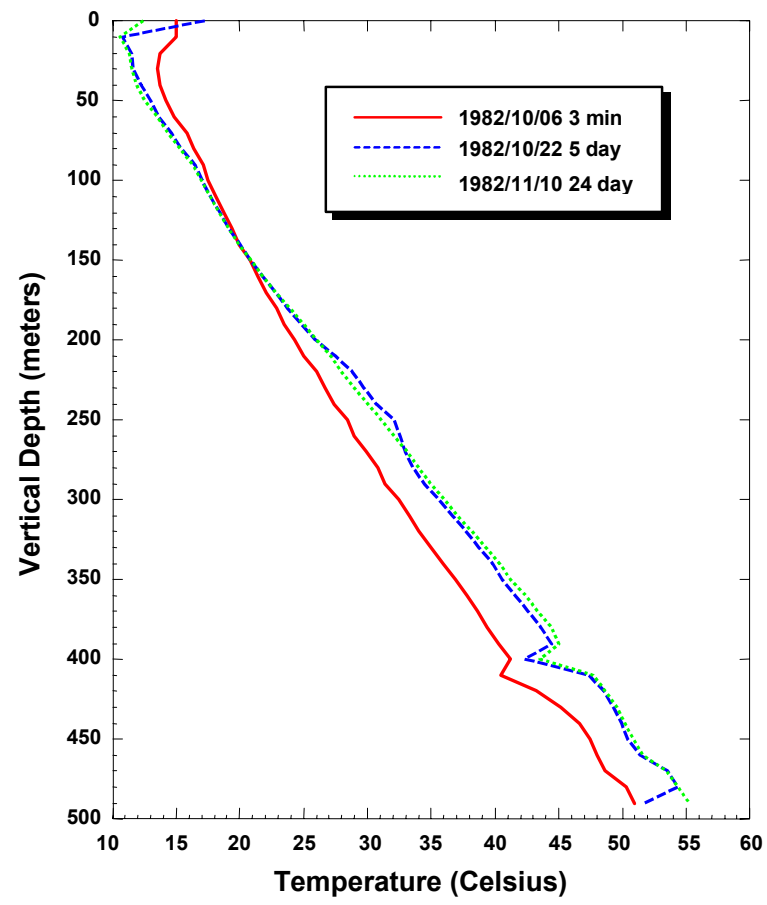

Figure 3.3. Temperature surveys in slim hole $\mathrm{T}-2$.

Pressures computed from water level and temperature data are plotted in Figure 3.4. The pressure at $400 \mathrm{mTVD}$ ( $83 \mathrm{mASL})$ is about 39.5 bars.

No injection or discharge test data are available for slim hole T-2. 


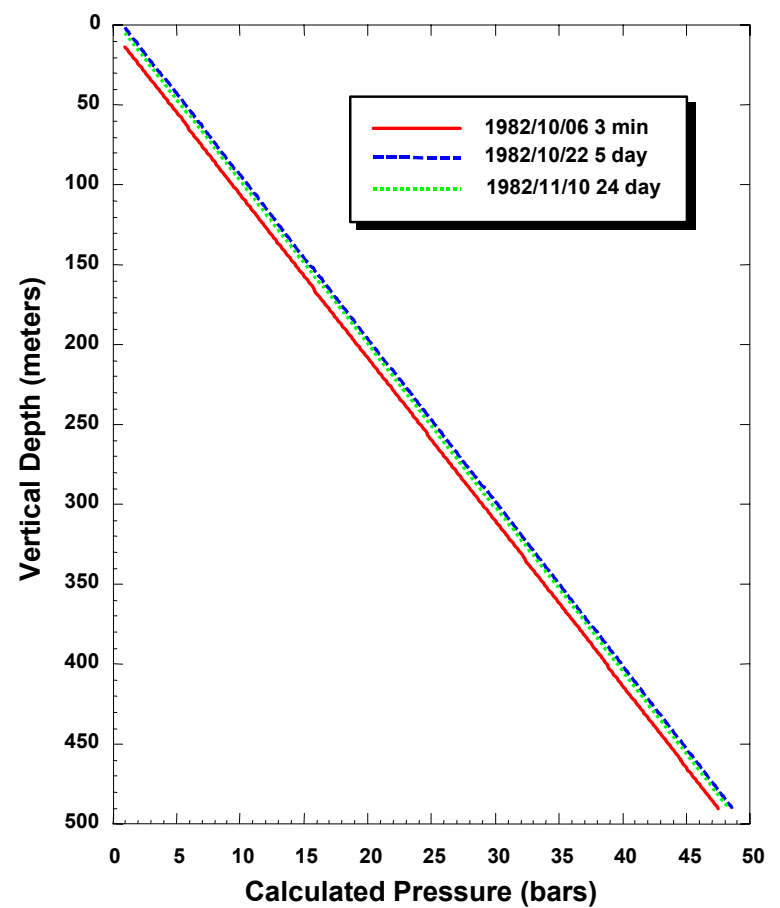

Figure 3.4. Pressures computed from water level and temperature data in slim hole T-2.

\section{Slim Hole T-3}

The wellhead for slim hole T-3 is located approximately $1.5 \mathrm{~km}$ north and $1.5 \mathrm{~km}$ west of the main Okuaizu borefield. Heatup surveys (Figure 3.5) for T-3 provide no clear indication of a permeable horizon. Since a circulation loss was encountered at 339-340 mTVD, it is assumed that the principal fluid entry for T-3 is located at 340 mTVD (40 mASL). The maximum temperature occurs towards bottomhole. After 53 days of shut-in, a temperature of $47^{\circ} \mathrm{C}$ was recorded at bottomhole on November 8, 1982. The feedzone temperature does not exceed $44^{\circ} \mathrm{C}$.

Pressures computed from water level and temperature data are exhibited in Figure 3.6. The pressure at $340 \mathrm{mTVD}$ (40 mASL) is $\sim 28.5$ bars.

No injection or discharge test data are available for slim hole T-3.

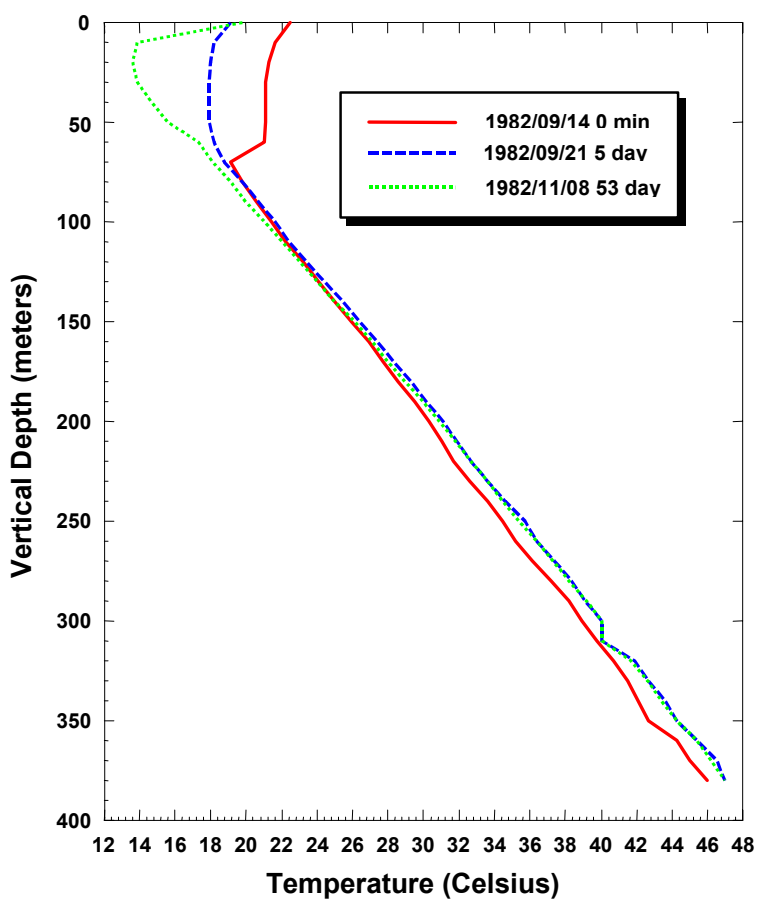

Figure 3.5. Temperature surveys in slim hole T-3.

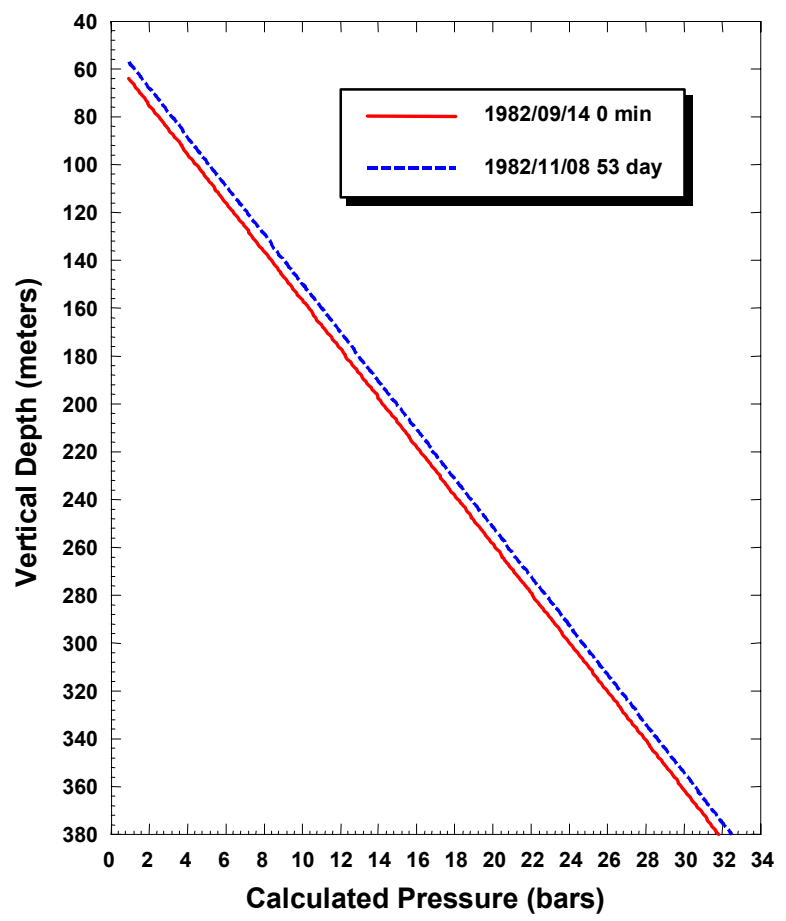

Figure 3.6. Pressures computed from water level and temperature data in slim hole T-3. 


\section{Slim Hole T-4}

Slim hole T-4 was drilled from a location about $1 \mathrm{~km}$ east and $1 \mathrm{~km}$ north of the main Okuaizu borefield. Heatup surveys (Profiles taken on November 8 and December 3, 1982, Figure 3.7) exhibit a conductive temperature profile and provide no indication of a permeable horizon. No circulation losses were encountered in the uncased part (below $150 \mathrm{~m}$ depth) of the hole. A conductive temperature profile indicates poor formation permeability. The maximum temperature occurs at the bottom of the hole. After 30 days of shut-in, a temperature of $\sim 50^{\circ} \mathrm{C}$ was recorded at 450 mTVD (7 mASL) on December 3, 1982.

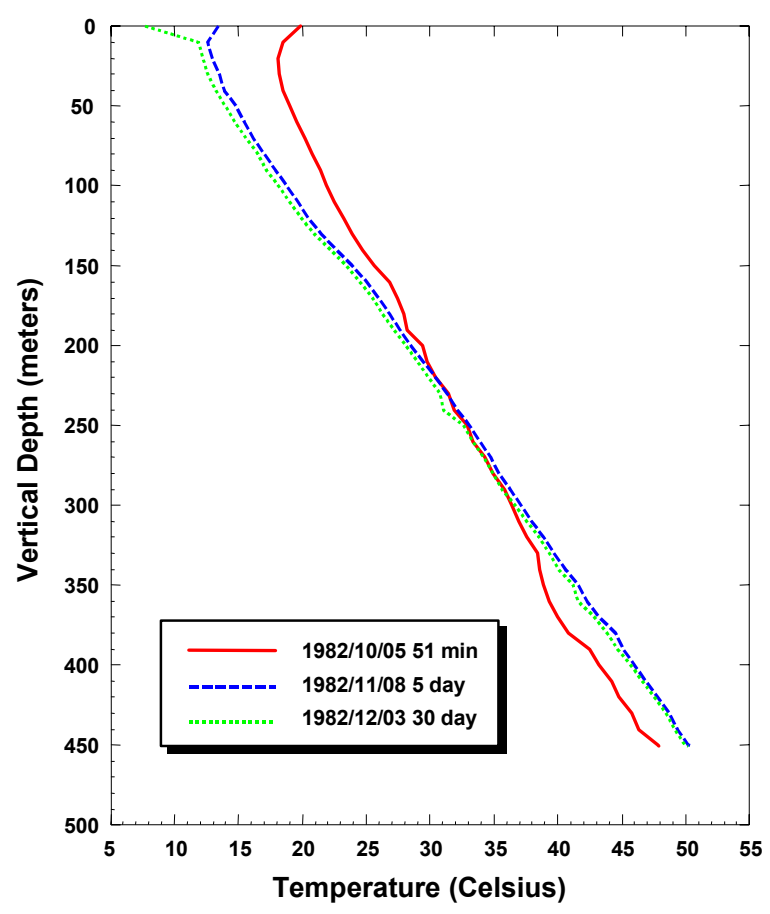

Figure 3.7. Temperature surveys in slim hole T-4.

Pressures computed from water level and temperature data are shown in Figure 3.8. The pressure at $450 \mathrm{mTVD}$ ( $7 \mathrm{mASL}$ ) is $\sim 44.4$ bars.

No injection or discharge test data are available for slim hole T-4.

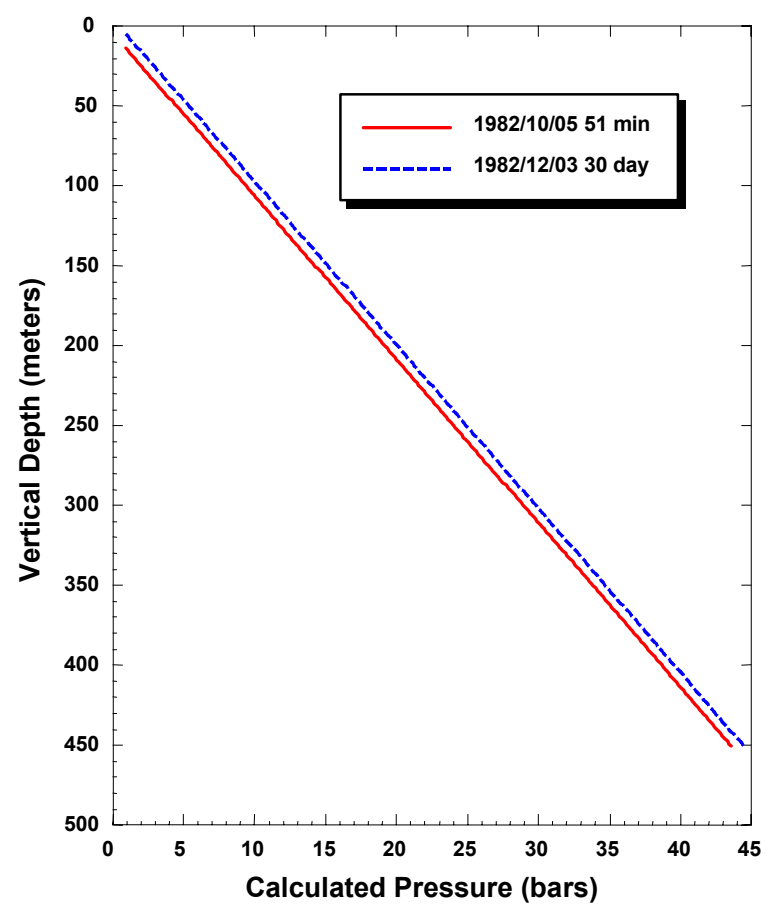

Figure 3.8. Pressures computed from water level and temperature data in slim hole T-4.

\section{Slim Hole T-5}

The wellhead for slim hole T-5 is located within the main Okuaizu borefield. Heatup surveys for T-5 (Figure 3.9) show several changes in the depth interval from $\sim 380$ mTVD to $420 \mathrm{mTVD}$. While drilling T-5, several circulation loss zones were encountered over the depth interval 380-424 mTVD. It is therefore reasonable to assume that the principal fluid entry for T-5 is at 400 mTVD (i.e., the middle of the permeable zone). The maximum temperature occurs towards the bottom of the hole. A temperature of $\sim 109^{\circ} \mathrm{C}$ was recorded at the bottomhole on December 20, 1982 after the borehole had been shut-in for 5 days. Somewhat surprisingly, the temperatures recorded after 30 days of shut-in are lower than those observed on December 20, 1982 (Figure 3.9). The stable feedzone temperature is estimated to be $\sim 105^{\circ} \mathrm{C}$. 


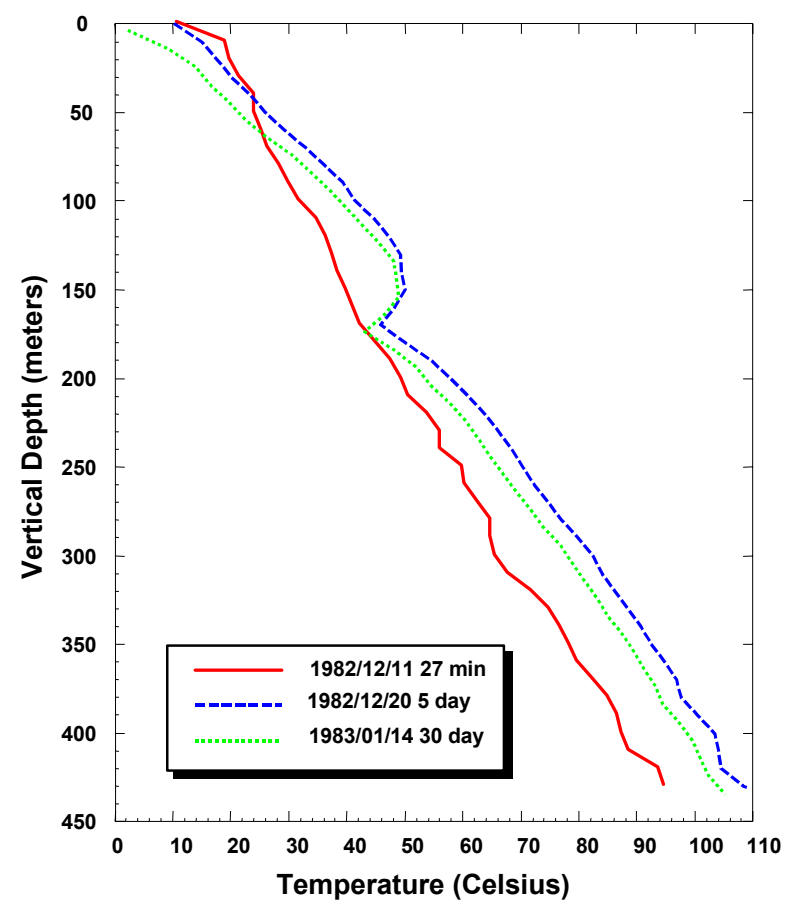

Figure 3.9. Temperature surveys in slim hole $T-5$.

Pressures computed from water level and temperature data are displayed in Figure 3.10. The pressure at $400 \mathrm{mTVD}$ (26 mASL) is $\sim 38.3$ bars.

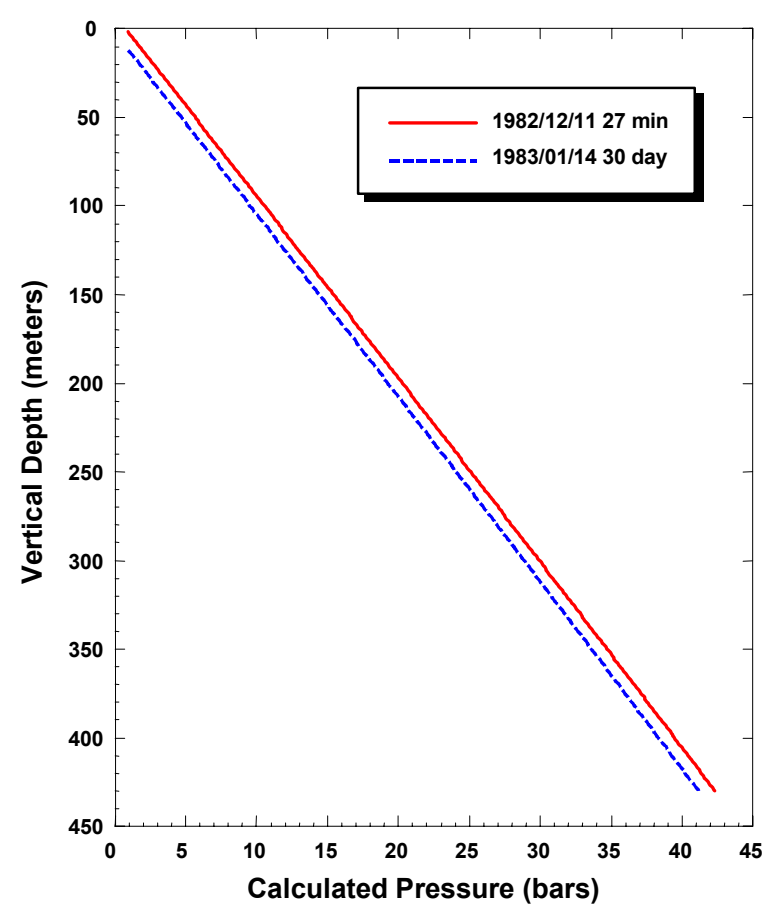

Figure 3.10. Pressures computed from water level and temperature data in slim hole T-5.
No injection or discharge test data are available for slim hole T-5.

\section{Slim Hole T-6}

The wellhead for slim hole T-6 is located about $200 \mathrm{~m}$ to the southwest of the Okuaizu borefield. Heatup surveys (Figure 3.11) exhibit a sharp change in temperature gradient at 350 mTVD. Since a total circulation loss zone was encountered nearby at $347 \mathrm{mTVD}$, it is reasonable to conclude that the principal fluid entry for T-6 is located at 350 mTVD (39 $\mathrm{mASL})$. The maximum temperature occurs towards bottomhole. After the borehole had been shut-in for 30 days, a temperature of $60^{\circ}$ $\mathrm{C}$ was recorded at bottomhole on December 1, 1982 (Figure 3.11). By comparison, the temperature at $350 \mathrm{mTVD}$ is $\sim 59^{\circ} \mathrm{C}$.

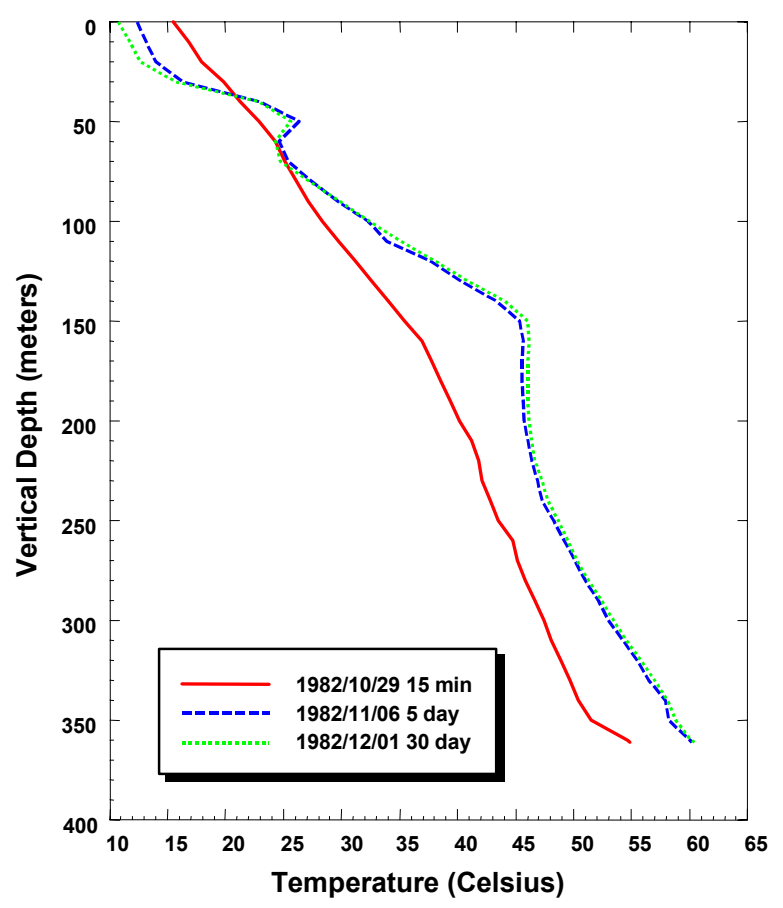

Figure 3.11. Temperature surveys in slim hole T-6.

Pressures computed from water level and temperature data are plotted in Figure 3.12. The pressure at $350 \mathrm{mTVD}(39 \mathrm{mASL})$ is $\sim 31.5$ bars. 


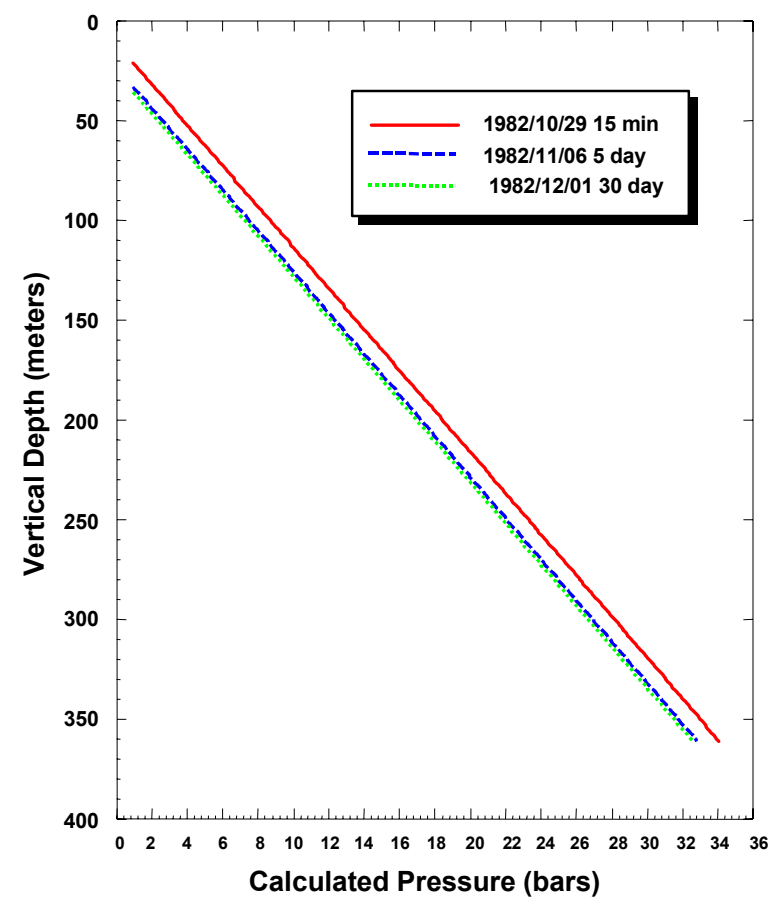

Figure 3.12. Pressures computed from water level and temperature data in slim hole T-6.

No injection or discharge test data are available for slim hole T-6.

\section{Slim Hole OA-1}

Slim hole OA-1 was drilled from a location about $2 \mathrm{~km}$ north of the Okuaizu borefield. Heatup surveys for OA-1 (Figure 3.13) exhibit a conductive temperature profile indicating poor formation permeability. Significantly, no circulation losses were reported below a depth of 196 mTVD.

In the absence of other data, it is assumed that the principal fluid entry for OA-1 is located at 900 mTVD (i.e. the middle of the slotted interval from $791 \mathrm{mTVD}$ to $998 \mathrm{mTVD})$. The maximum temperature occurs towards bottomhole. After 5 days of shut-in, a temperature of $\sim 136^{\circ} \mathrm{C}$ was measured at bottomhole on October 31, 1982.

Pressures computed from water level and temperature data are shown in Figure 3.14. Since the water level did not stabilize during the 5-day observation period, it is not possible to compute the stable feedzone pressure. The pressure at $900 \mathrm{mTVD}(-580 \mathrm{mASL})$ does not exceed 83.8 bars.

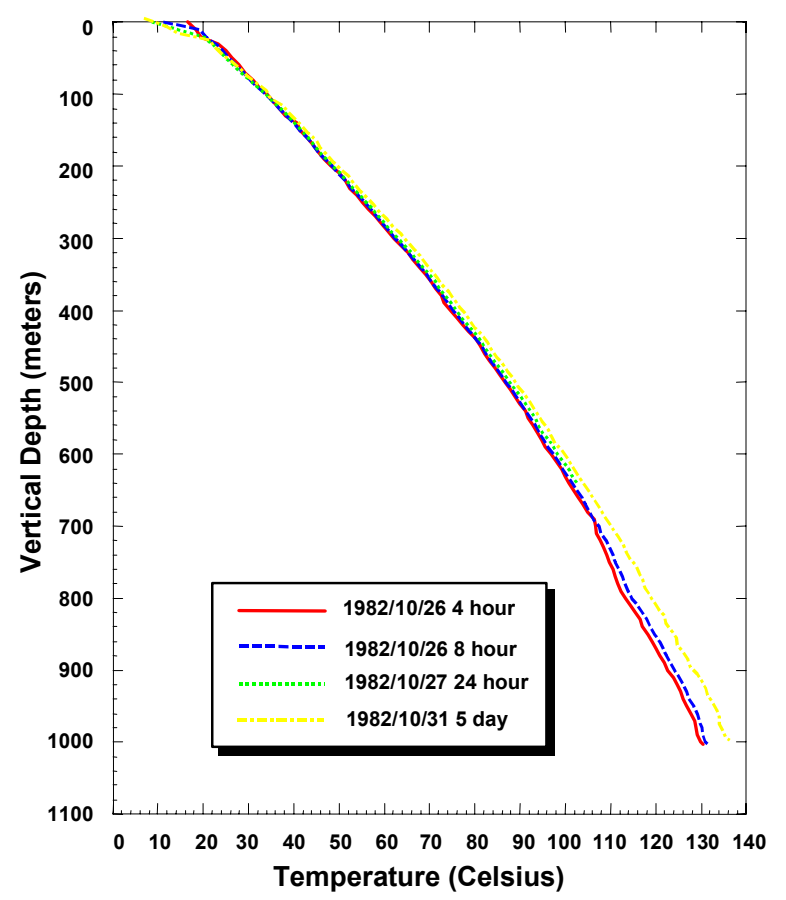

Figure 3.13. Selected temperature surveys in slim hole OA-1.

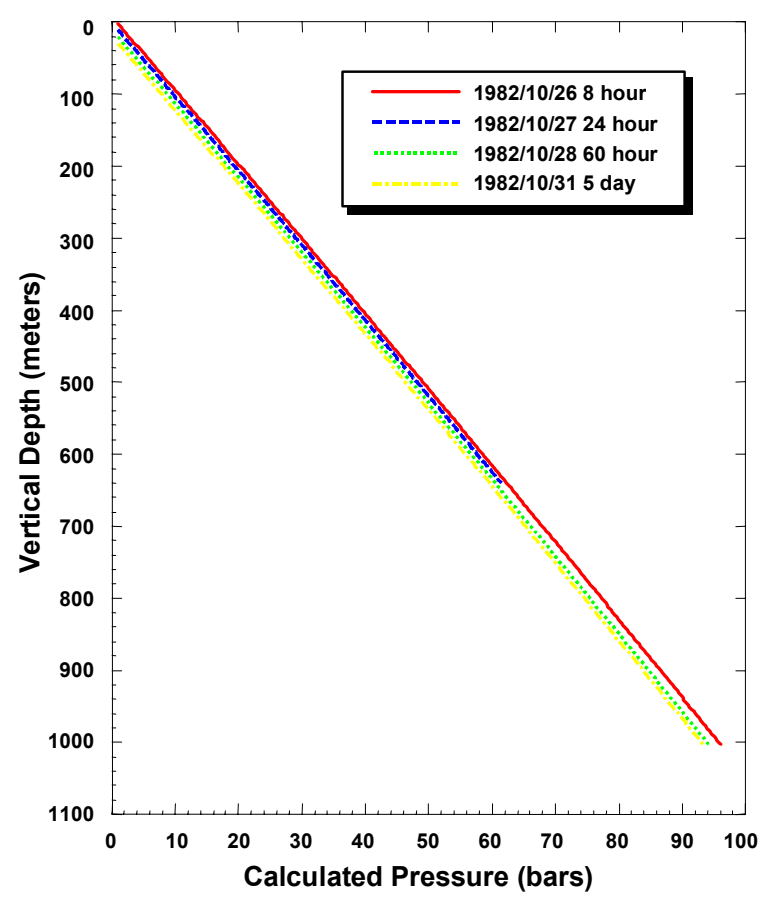

Figure 3.14. Pressures computed from water level and temperature data in slim hole OA-1. 
No useful injection or discharge test data are available for slim hole OA-1.

\section{Slim Hole OA-2}

The wellhead for slim hole OA-2 is located about $1.5 \mathrm{~km}$ west and $400 \mathrm{~m}$ north of the Okuaizu borefield. Heatup surveys for OA-2 (Figure 3.15) generally show a conductive temperature profile indicating little or no formation permeability. While drilling OA-2, a few minor circulation loss zones were recorded over the slotted section (748-950 mTVD) of the well. In the absence of a definitive indication of a permeable horizon, it is assumed that the major feedzone for OA-2 is located at $850 \mathrm{mTVD}$ (i.e. the middle of the slotted interval). The maximum temperature occurs towards the bottom of the hole. After 5 days of shut-in, a temperature of $\sim 103^{\circ} \mathrm{C}$ was recorded at 1003 mTVD on February 8, 1983. The temperature at $850 \mathrm{~m}$ is somewhat lower $\left(\sim 90^{\circ} \mathrm{C}\right)$.

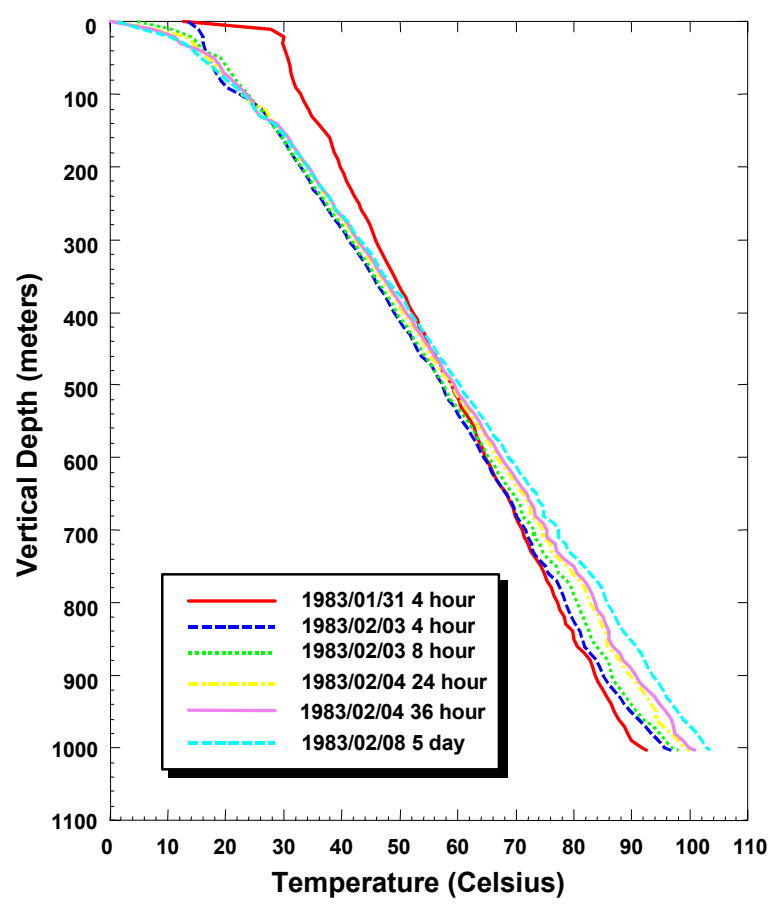

Figure 3.15. Selected temperature surveys in slim hole OA-2.
Pressures computed from water level and temperature data are plotted in Figure 3.16. The pressure at $850 \mathrm{mTVD}(-378 \mathrm{mASL})$ is 69.8 bars.

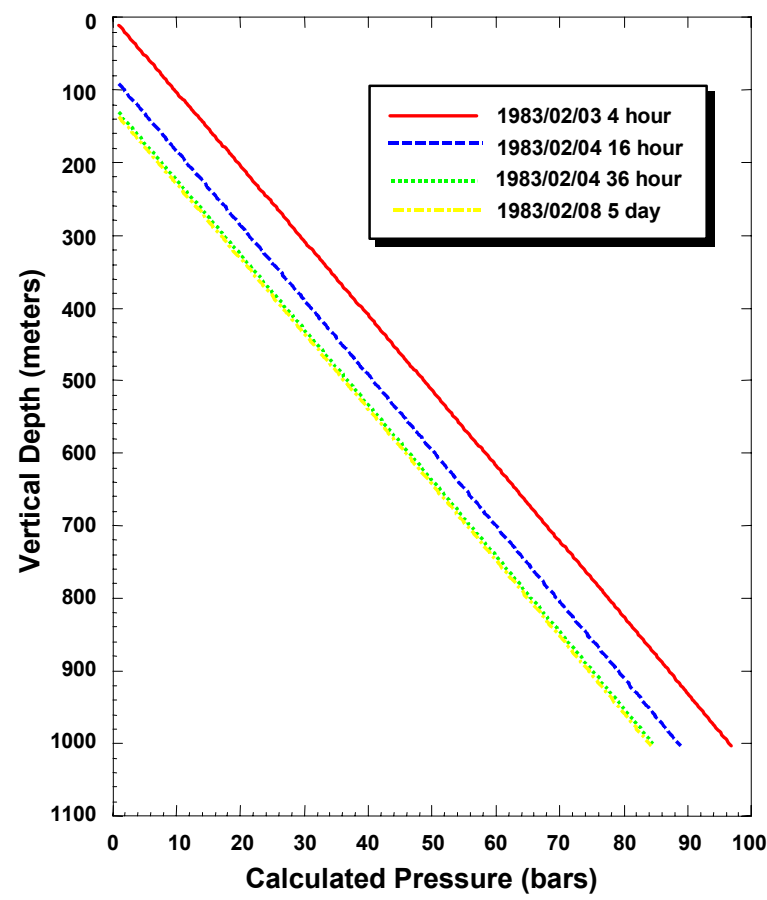

Figure 3.16. Pressures computed from water level and temperature data in slim hole OA-2.

No useful injection or discharge test data are available for slim hole OA-2.

\section{Slim Hole OA-3}

Slim hole OA-3 was drilled from a location at the northern edge of the Okuaizu borefield. A heatup survey (Figure 3.17) taken shortly after circulating cold water on February 5, 1983 exhibits breaks in temperature gradient at $\sim 1240 \mathrm{mTVD}$ and at 1400 mTVD. While drilling OA-3, circulation losses were observed nearby both of these horizons at 1232 mTVD and at 1400 mTVD. The isothermal zone between $1240 \mathrm{mTVD}$ and 1400 mTVD implies crossflow in the slim hole. Apparently, water enters the wellbore at $1240 \mathrm{mTVD}$, flows down the borehole, and is 
injected back into the formation at 1400 mTVD. Existence of permeable horizons at 1240 mTVD and 1400 mTVD is also implied by the persistence of depressed temperatures at these depths (Figure 3.17, see e.g. Profile taken on February 10, 1983). The maximum temperature occurs towards the bottom of the well. After 5 days of shut-in, a temperature of $\sim 156^{\circ} \mathrm{C}$ was recorded at bottom hole on February 10, 1983. The temperature at 1400 mTVD is lower by $3^{\circ} \mathrm{C}$ or $4^{\circ} \mathrm{C}$.

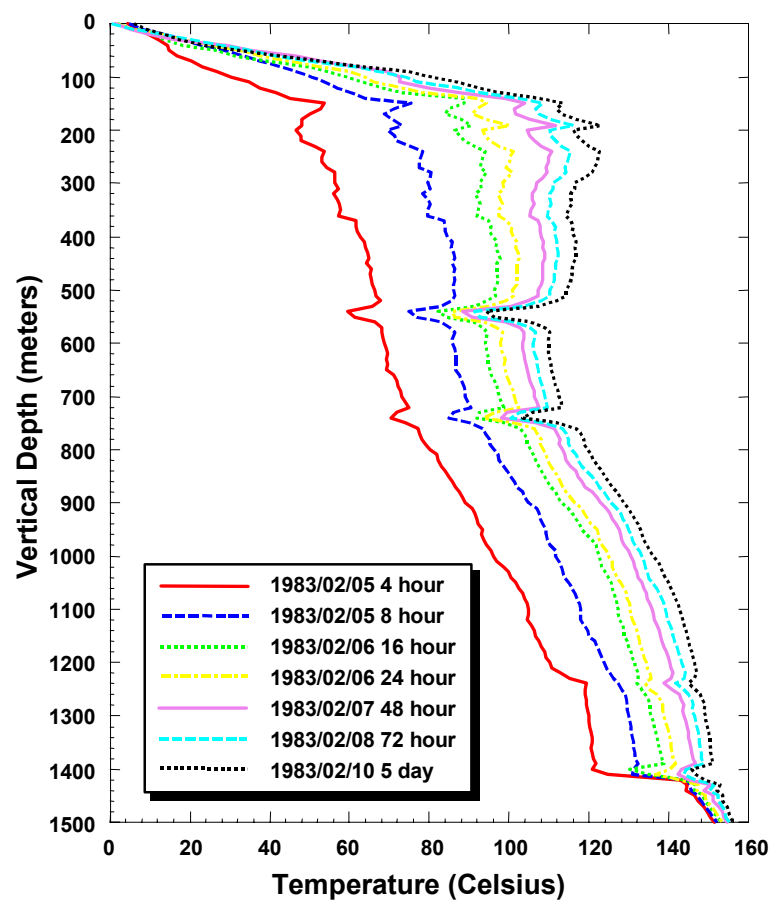

Figure 3.17. Selected temperature surveys in slim hole OA-3.

Pressures computed from water level and temperature data are shown in Figure 3.18. The pressure at $1320 \mathrm{mTVD}$ (-928.5 mASL), i.e., at the middle of the permeable zones at 1240 mTVD and 1400 mTVD, is $\sim 111.4$ bars.

No useful injection or discharge test data are available for slim hole OA-3.

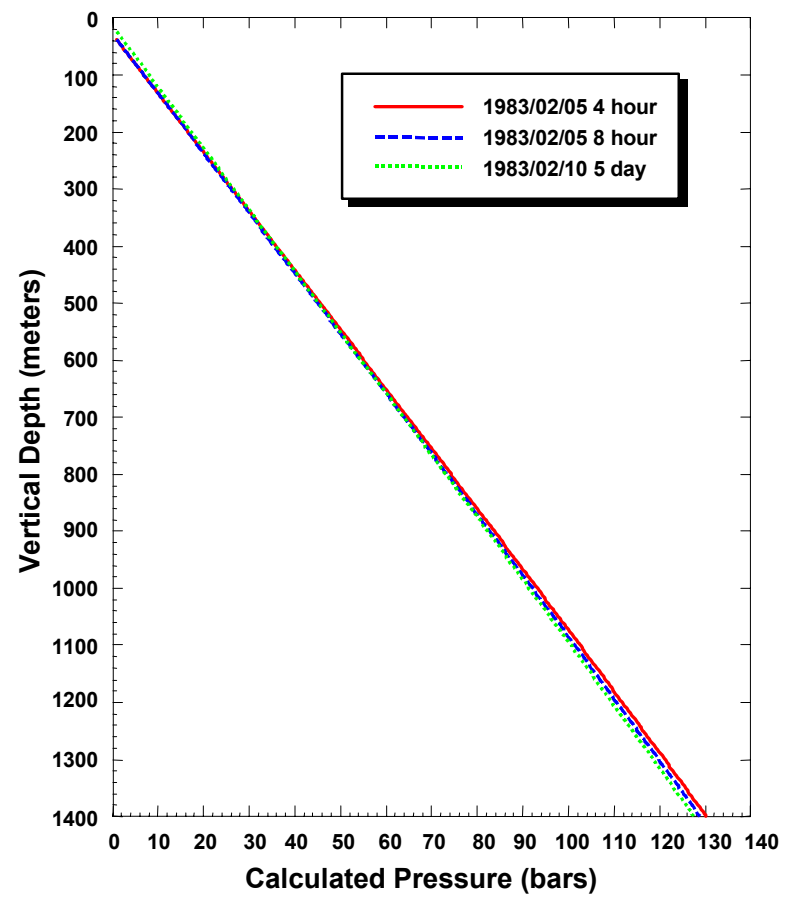

Figure 3.18. Pressure computed from water level and temperature data in slim hole OA-3.

\section{Slim Hole OA-4}

The wellhead for slim hole OA-4 is located at the western edge of the Okuaizu borefield. Heatup surveys for OA-4 show persistent depressed temperatures at 1190 mTVD and at 1270 mTVD (Figure 3.19). While drilling OA-4, circulation losses were encountered at 1194-1195 mTVD and at 1263 mTVD. Temperature surveys taken during an injection test performed in August 1983 (Figure 3.20) exhibit no evidence of fluid loss at 1190 mTVD, and it appears that almost all of the injected fluid leaves the wellbore at about 1260-1270 mTVD. The injection data imply that the principal fluid entry for OA-4 is located at 1270 mTVD (-925.5 mASL). After the borehole had been shut-in for more than 9 months, a temperature survey was recorded on August 26, 1983 (Figures 3.19 and 3.20). Unfortunately, the latter temperature survey extends to a depth of only 1200 mTVD. The stable temperature at $1200 \mathrm{mTVD}$, as indicated by the temperature survey taken on August 26, 1983, is around $261^{\circ} \mathrm{C}$. In all 
likelihood, the stable temperature at 1270 mTVD is somewhat higher than $261^{\circ} \mathrm{C}$.

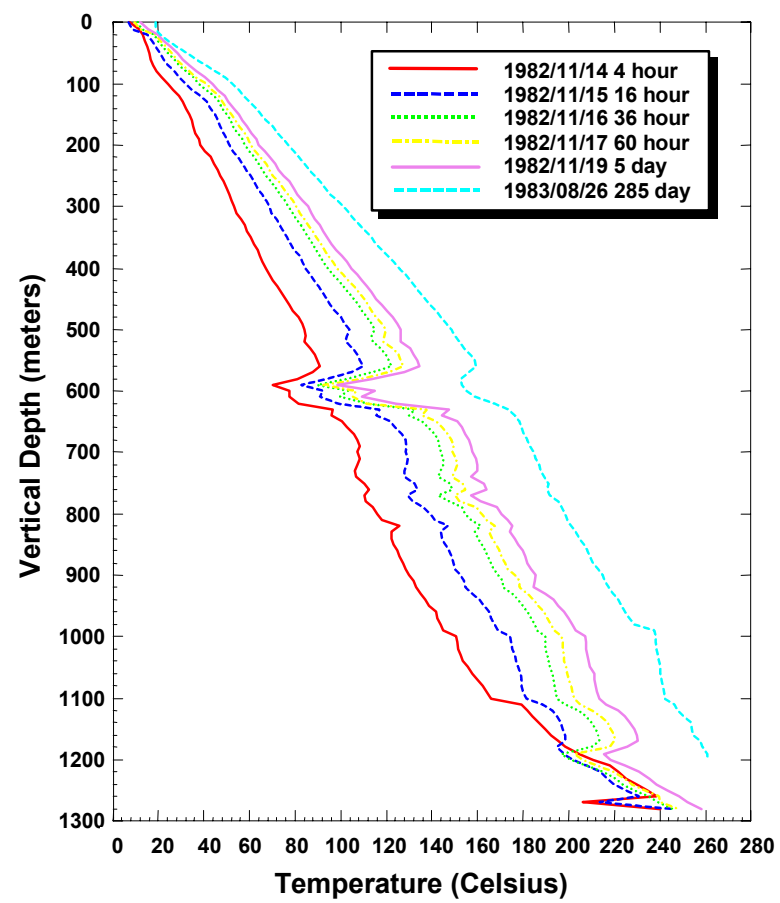

Figure 3.19. Selected heatup surveys in slim hole OA-4.

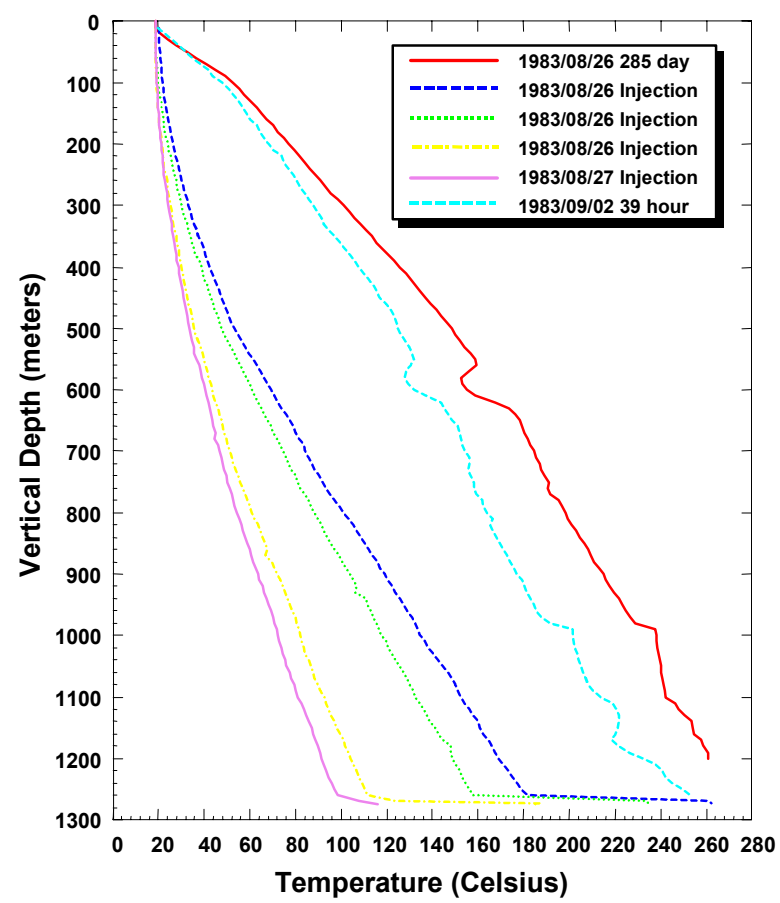

Figure 3.20. Temperature surveys taken before, during, and after an injection test performed on slim hole OA-4 in August 1983.
Temperature and pressure surveys recorded during a discharge test in February 1984 are shown in Figures 3.21 and 3.22, respectively. The temperatures recorded during the discharge test at 1270 mTVD are lower than the stable feedzone temperature. Also, the measured pressures are close to the saturation pressures for water at the local temperature. It is, therefore, likely that the discharge from OA-4 is accompanied by in situ boiling. The single shut-in pressure survey, taken on February 13, 1984, extends to a depth of less than $1000 \mathrm{~m}$, and cannot be used to estimate the stable feedzone pressure.

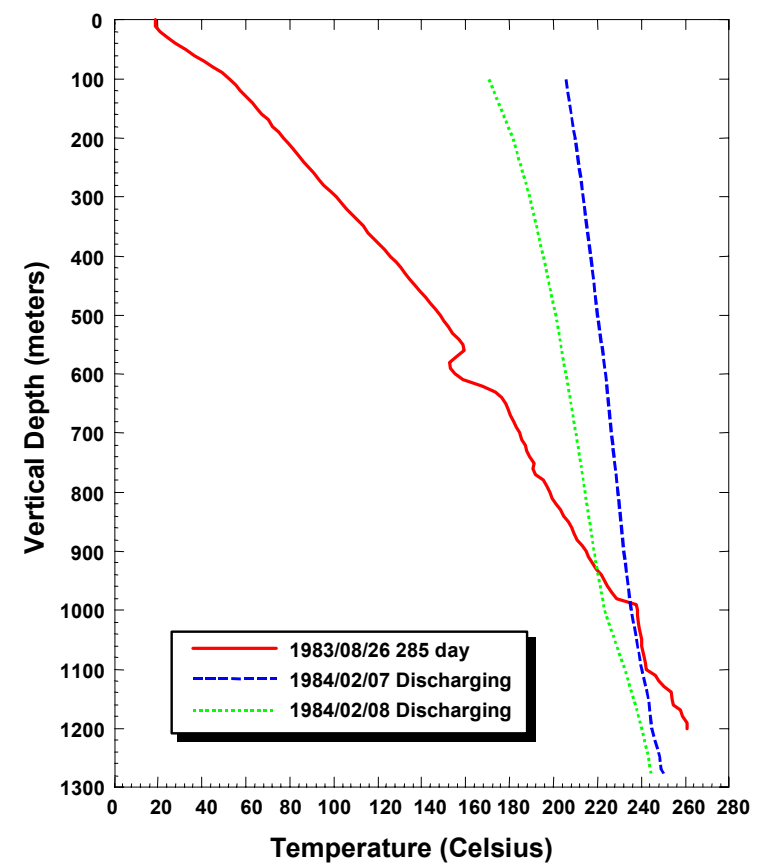

Figure 3.21. Temperature surveys taken during a discharge test performed on slim hole OA-4 in February 1984.

Pressures computed from water level and temperature data in slim hole OA-4 are displayed in Figure 3.23. The pressure at 1270 mTVD (-925.5 mASL) is $\sim 115.0$ bars. The latter pressure value is consistent with that (113.6 bars at $1250 \mathrm{mTVD}$ ) recorded by a downhole gauge on September 2, 1983 after the well had been shut-in for 36 hours. Both injection and discharge test data are available for slim hole OA-4. 


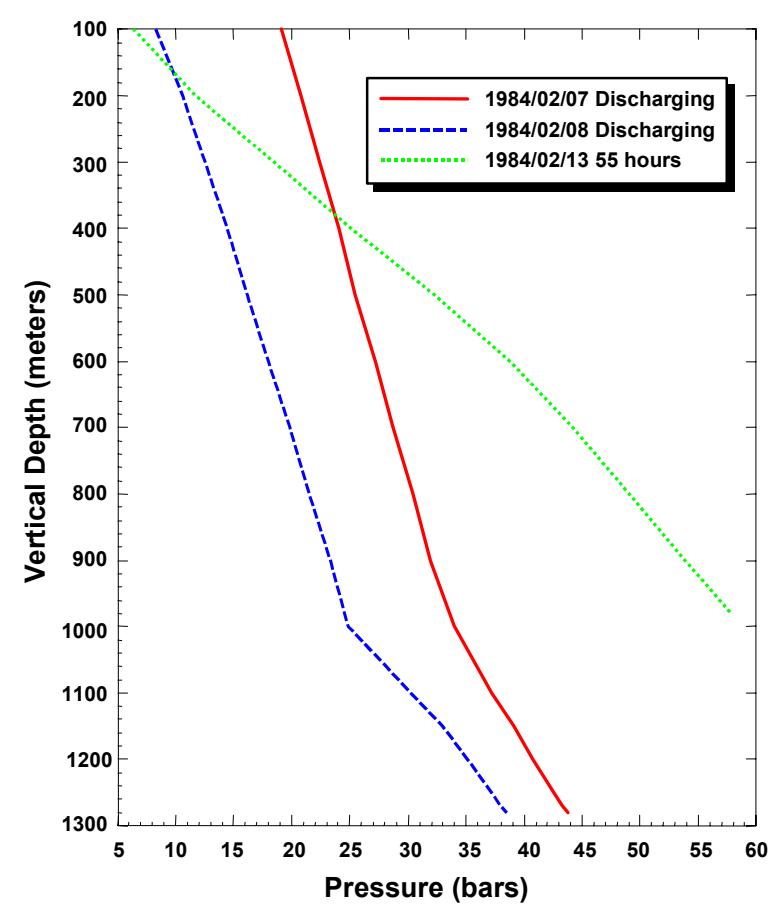

Figure 3.22. Pressure surveys taken during a discharge test performed on slim hole OA-4 in February 1984.

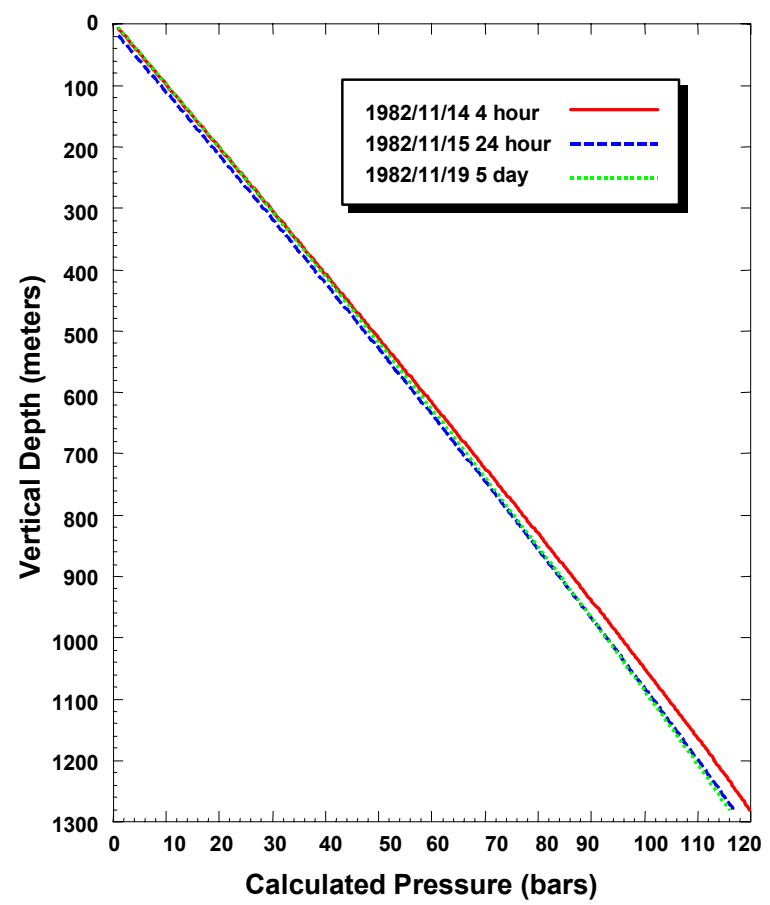

Figure 3.23. Pressures computed from water level and temperature data in slim hole OA-4.

\section{Slim Hole OA-5}

The wellhead for slim hole OA-5 is located about $800 \mathrm{~m}$ to the east of the Okuaizu borefield. Heatup surveys (Figure 3.24) for OA-5 show a generally conductive profile indicating poor formation permeability. Small changes in temperature gradient are present at $\sim 710 \mathrm{mTVD}$ and at $\sim 830$ mTVD. While drilling OA-5, minor circulation losses were observed at $735 \mathrm{~m}, 778 \mathrm{~m}$, and $791 \mathrm{~m}$. In the absence of other data, it is assumed that the major feedzone for OA-5 is located at the midpoint (770 mTVD) of the permeable horizons at $710 \mathrm{mTVD}$ and $830 \mathrm{mTVD}$. The maximum temperature occurs towards bottomhole, and was recorded as $120^{\circ} \mathrm{C}$ after 5 days of shut-in on December 10, 1982. By contrast, the temperature at $770 \mathrm{mTVD}$ is significantly lower $\left(\sim 93^{\circ} \mathrm{C}\right)$.

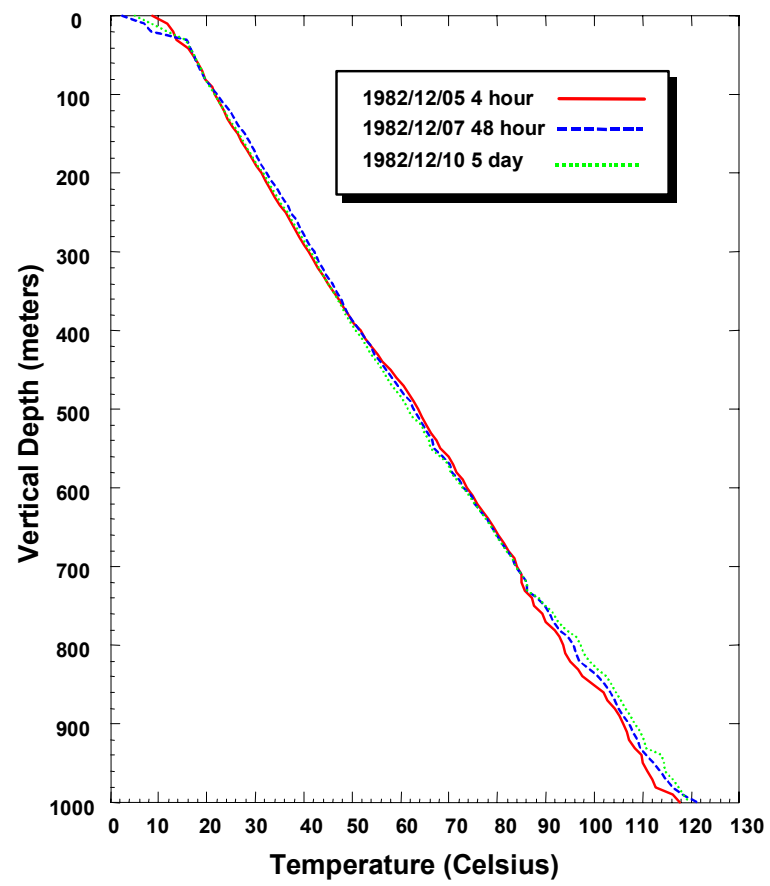

Figure 3.24. Selected temperature surveys in slim hole OA-5.

Pressures computed from water level and temperature data are plotted in Figure 3.25. The pressure at $770 \mathrm{mTVD}(-378 \mathrm{mASL})$ is about 72.9 bars. 
No useful injection or discharge test data are available for slim hole OA-5.

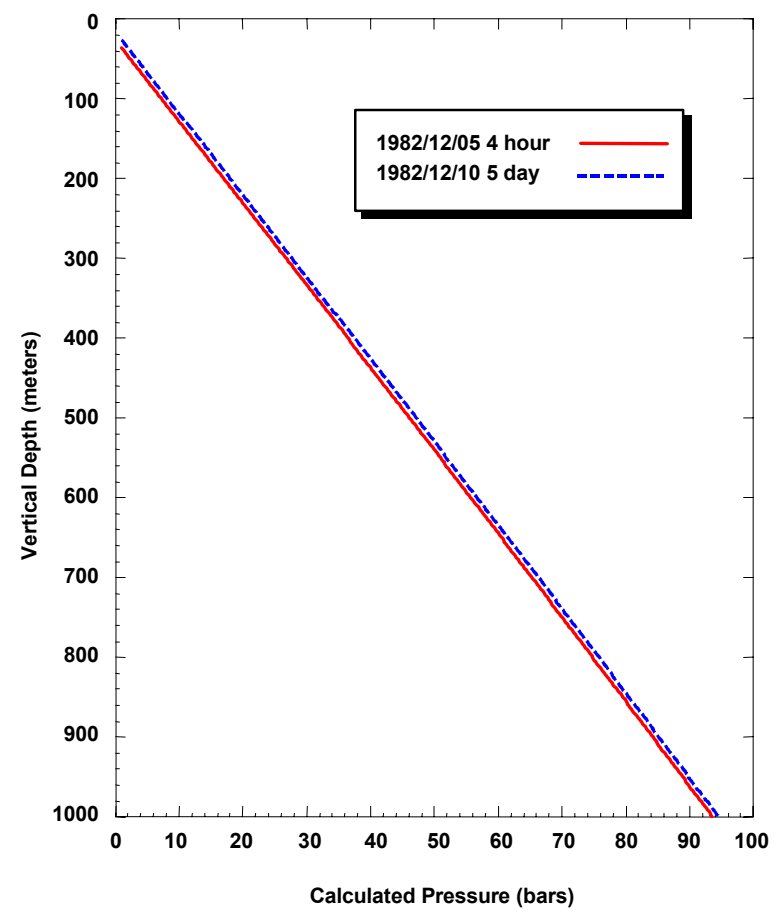

Figure 3.25. Pressures computed from water level and temperature data in slim hole AO-5.

\section{Slim Hole OA-6}

Slim hole OA-6 was drilled from a location within the Okuaizu borefield. None of the available temperature surveys for OA-6 extends below a depth of 1156 mTVD. The available heatup surveys for OA-6 (Figure 3.26) exhibit a conductive temperature profile, and provide no indication of permeability. Since a circulation loss zone was encountered at 1084-1091 mTVD, it is tentatively assumed that the feedzone for OA-6 is located at 1090 mTVD (-714.5 mASL). After the slim hole was shut-in for 5 days, a temperature of $\sim 256^{\circ}$ $\mathrm{C}$ was recorded at 1090 mTVD on November 12, 1983. Although no downhole temperature data are available below 1156 mTVD, a NEDO report quotes a stable temperature of $286^{\circ} \mathrm{C}$ at the bottom of the hole (1500 mTVD).

During the 5-day observation period, the water level did not fall below the wellhead.
Pressures computed from temperature data recorded on November 12, 1983 are plotted in Figure 3.27. The pressure at 1090 mTVD ($714.5 \mathrm{mASL}$ ) is about 96.6 bars.

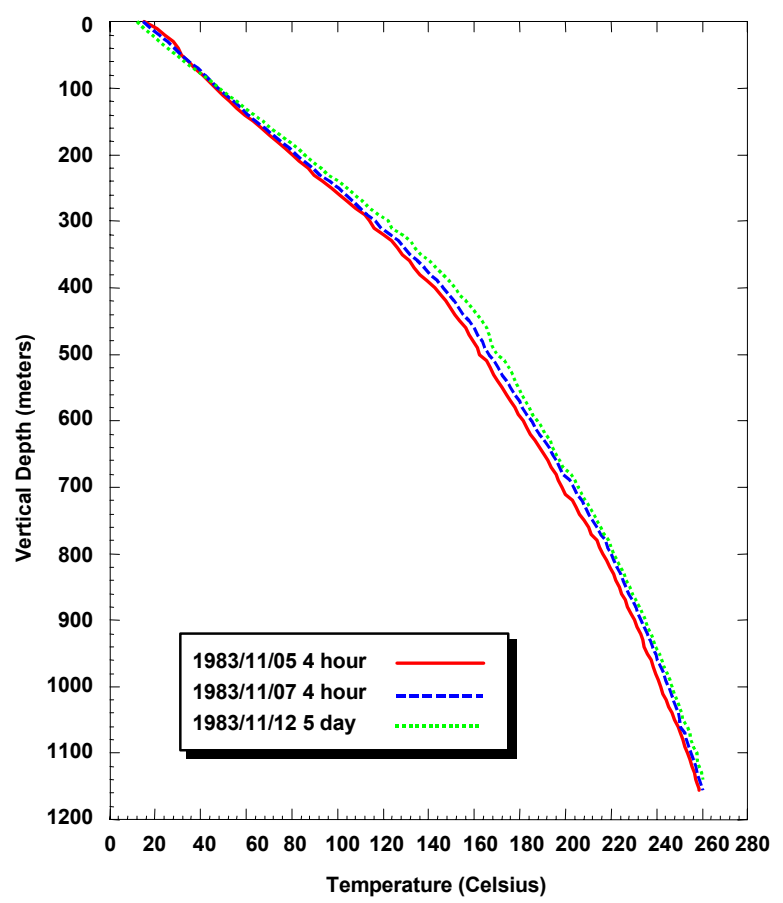

Figure 3.26. Selected temperature surveys in slim hole OA-6.

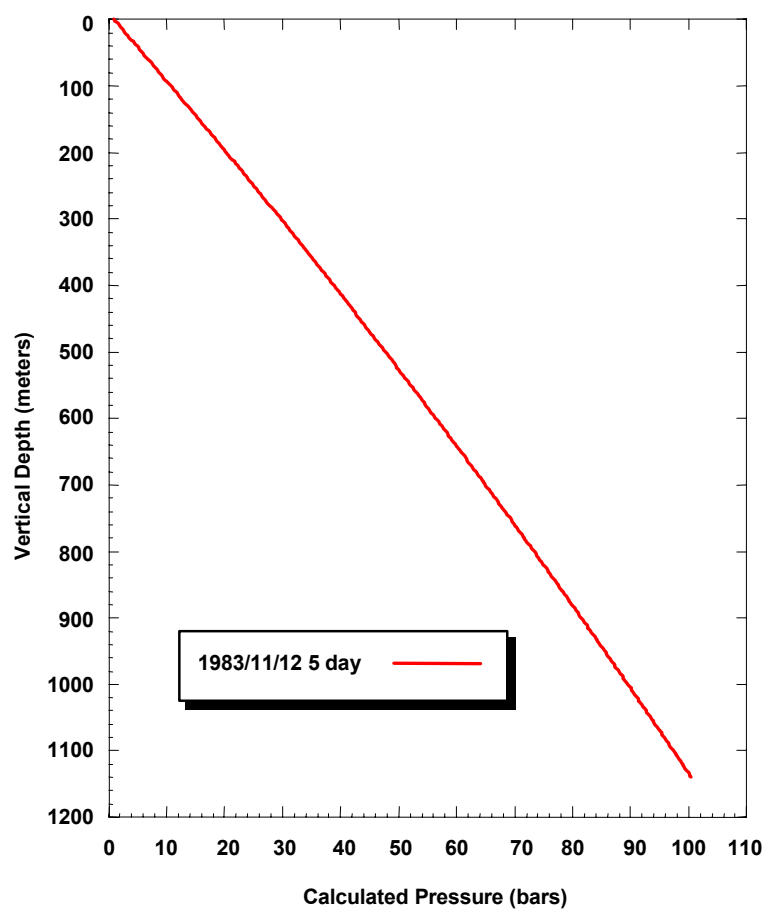

Figure 3.27. Pressures computed from water level and temperature data in slim hole OA-6 on November 12, 1983. 
After numerous swabbing attempts, OA-6 was discharged for about 4 days from November 22, 1983 to November 26, 1983. The average discharge rate was only $\sim 1.2$ tons/hour. Apparently, the discharge from OA-6 was accompanied by in situ boiling. Clearly, OA-6 has little or no permeability.

No useful injection or discharge test data are available for slim hole OA-6.

\section{Slim Hole OA-7}

Slim hole OA-7 was drilled from a location in the northwest part of the Okuaizu borefield. A temperature survey taken on November 16, 1983 (Figure 3.28) displays a discontinuity in temperature gradient at $\sim 710$ mTVD. This discontinuity identifies the major feedzone for

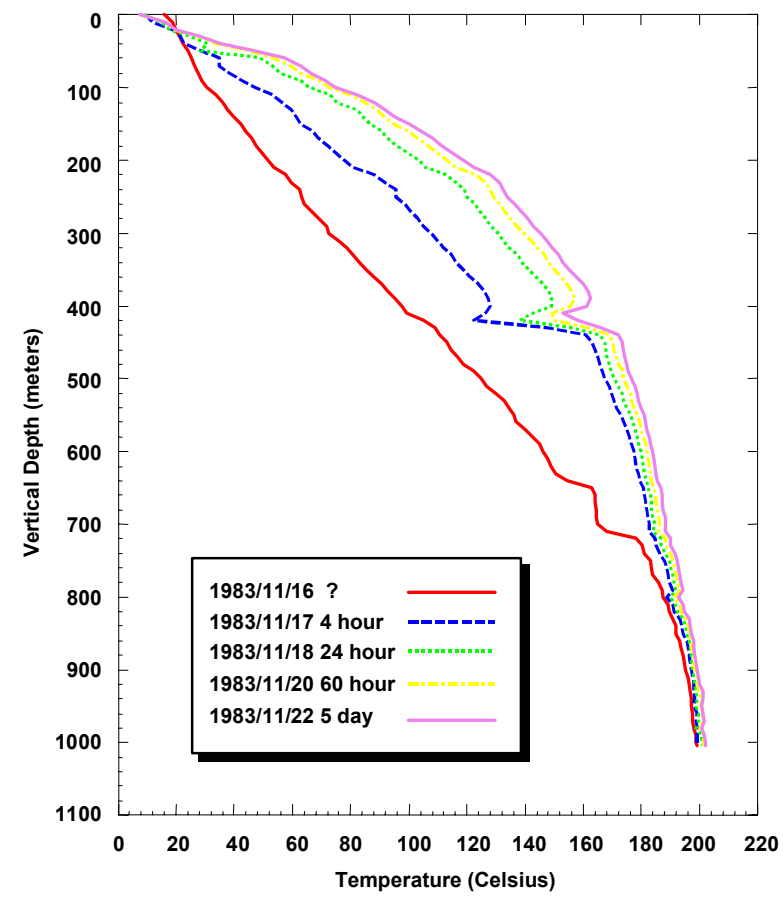

Figure 3.28. Selected temperature surveys in slim hole $\mathrm{OA}-7$.
OA-7. Other temperature surveys (Figure 3.28) show persistent temperature depression at 710 mTVD, 800 mTVD, and 980 mTVD. It is likely that some permeability is also present at 800 mTVD and 980 mTVD. The maximum temperature occurs towards bottomhole, and was recorded as $\sim 202^{\circ} \mathrm{C}$ on November 22, 1983 (Shut-in time $=5$ days). By comparison with the temperature at the bottomhole, the temperature at $710 \mathrm{mTVD}$ is lower by about $10^{\circ} \mathrm{C}$.

Pressures computed from water level and temperature data are shown in Figure 3.29. The pressure at $710 \mathrm{mTVD}(-347 \mathrm{mASL})$ is $\sim 60.6$ bars.

No useful injection or discharge test data are available for slim hole OA-7.

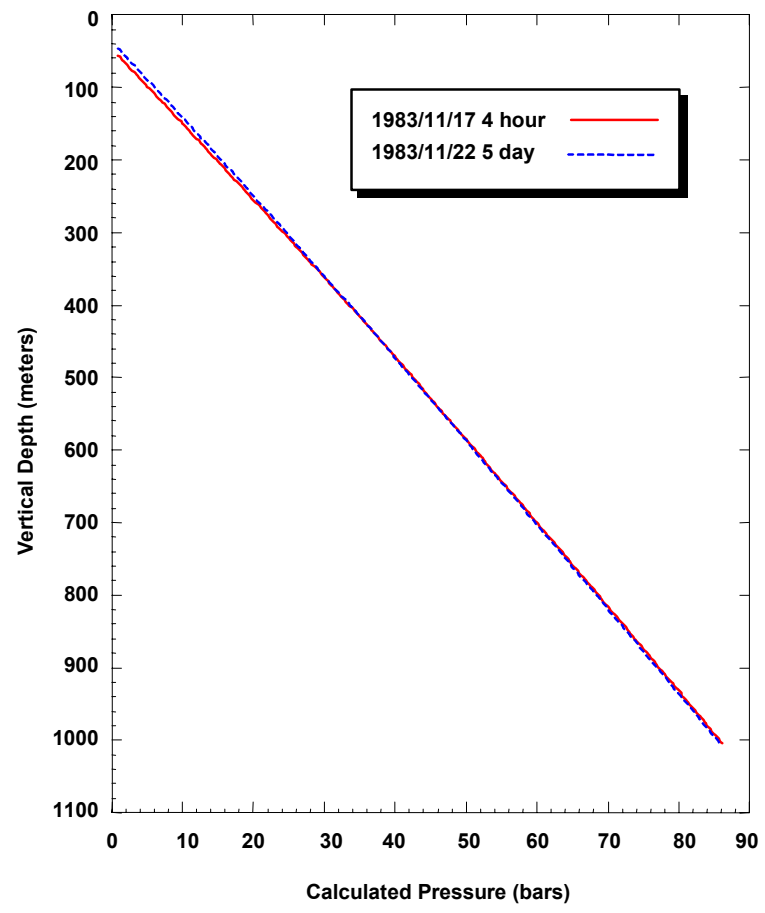

Figure 3.29. Pressures computed from water level and temperature data in slim hole OA-7. 


\subsubsection{Boreholes Drilled by Okuaizu Geothermal Co., Ltd.}

\section{Slim Hole N-1t}

Slim hole N-1t is located along the western edge of the main Okuaizu borefield. Heatup surveys taken in April 1985 (Figure 3.30) show a persistent cold zone centered at $\sim 1700$ mTVD. Temperature (Figure 3.30) and pressure (Figure 3.31) surveys taken during a discharge test in June 1985 are consistent with a liquid feedzone at $\sim 1700$ mTVD $(\sim 1706$ $\mathrm{mMD})$. The stable feedzone temperature as indicated by temperature surveys taken during the discharge test is $\sim 220^{\circ} \mathrm{C}$. The maximum temperature occurs towards bottomhole. A temperature of $\sim 254^{\circ} \mathrm{C}$ was recorded at bottomhole on April 13, 1985 after the borehole had been shut-in for 5 days.

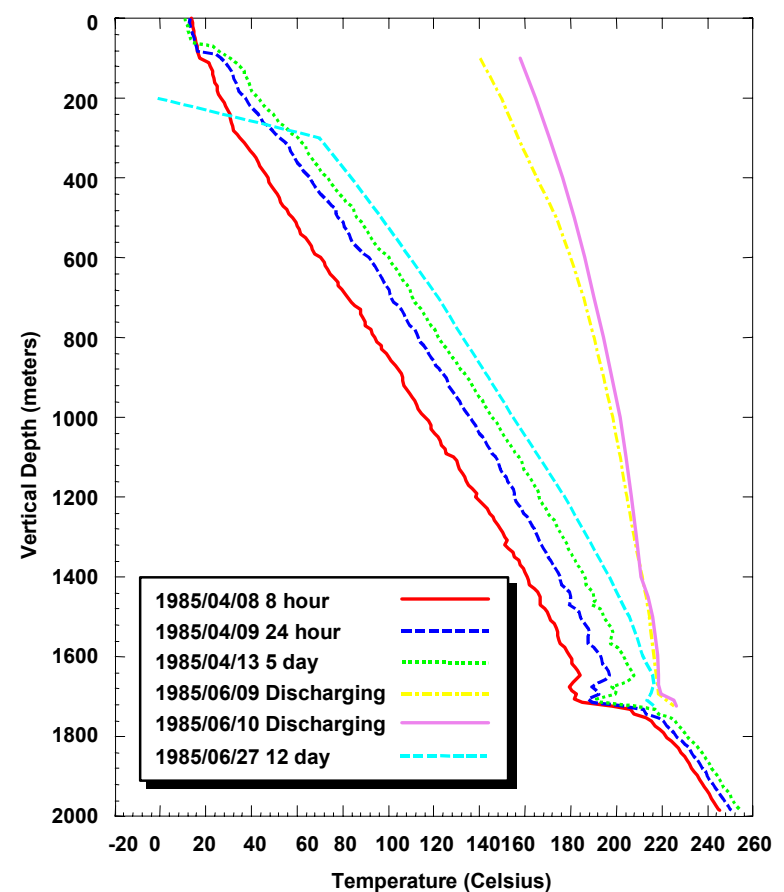

Figure 3.30. Selected temperature surveys in slim hole N-1t.

Pressures computed from water level and temperature data taken on April 13, 1985 are plotted in Figure 3.32. The pressure at 1700 mTVD (-1324.5 mASL) is computed to be $\sim 149.8$ bars. The latter pressure value is virtually identical with that (149.5 bars) recorded in the shut-in slim hole on June 27, 1985 (Figure 3.31). Both injection and discharge test data are available for slim hole N-1t.

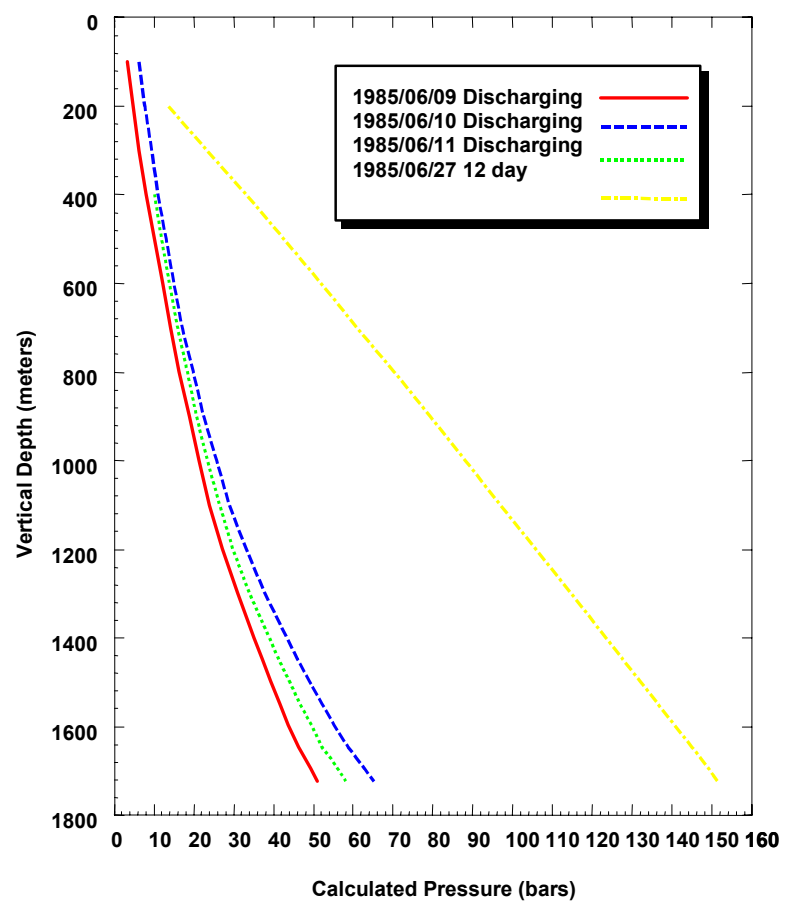

Figure 3.31. Pressure surveys in slim hole N-1t.

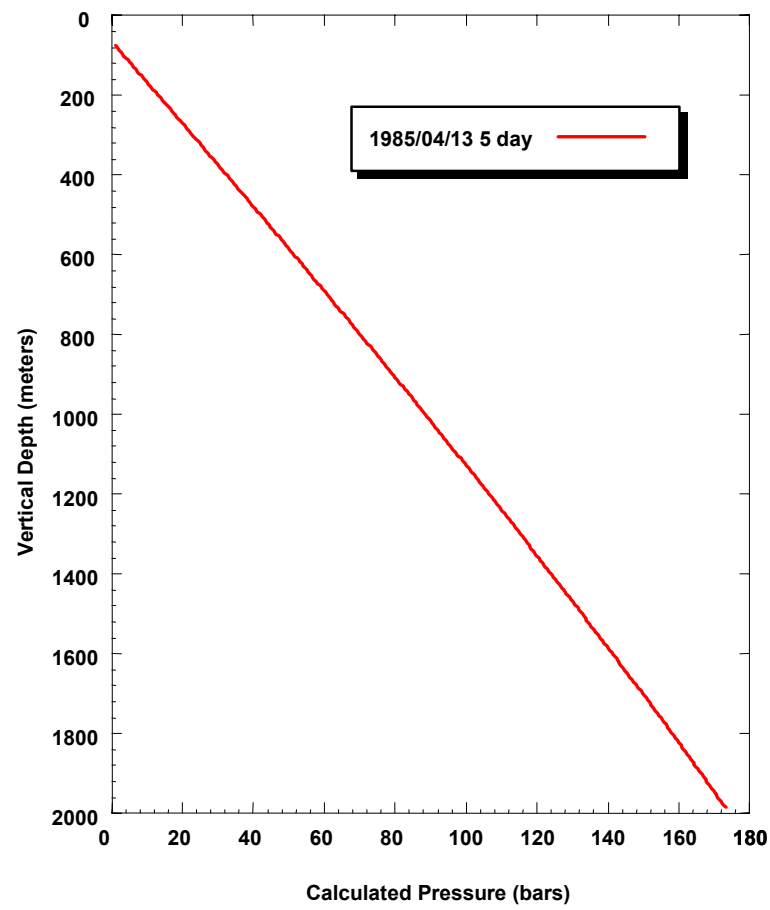

Figure 3.32. Pressures computed from water level and temperature data on April 13, 1985 in slim hole N-1t. 


\section{Slim Hole N-2t}

Slim hole N-2t is located within the Okuaizu borefield. Heatup surveys taken in November 1984 (Figure 3.33) indicate extremely rapid temperature recovery in the depth interval 1230-1290 mTVD. Since a total circulation loss zone was encountered at $\sim 1230$ mTVD, it is reasonable to assume that the principal feedzone for $\mathrm{N}-2 \mathrm{t}$ is located in the depth interval 1230-1290 mTVD. Temperature surveys (Figure 3.33) also indicate rapid temperature recovery at $\sim 1120 \mathrm{mTVD}$ and at $\sim 1460$ mTVD. Additional permeable zones may be present at these depths. Temperature (Figure 3.33) and pressure (Figure 3.34) surveys taken during a discharge test in November 1985 are consistent with a liquid feedzone at 1230-1290 mTVD. The feedzone temperature is about $300^{\circ} \mathrm{C}$. The maximum temperature occurs towards bottomhole, and is $\sim 305^{\circ} \mathrm{C}$.
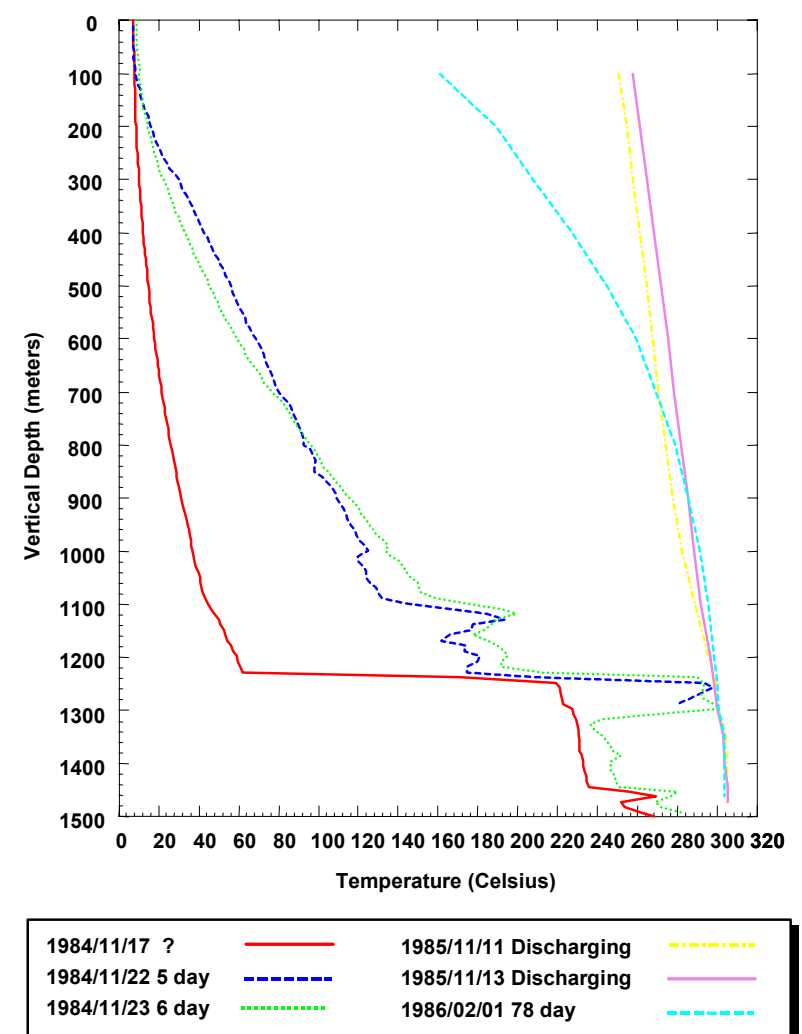

Figure 3.33. Selected temperature surveys in slim hole N-2t.

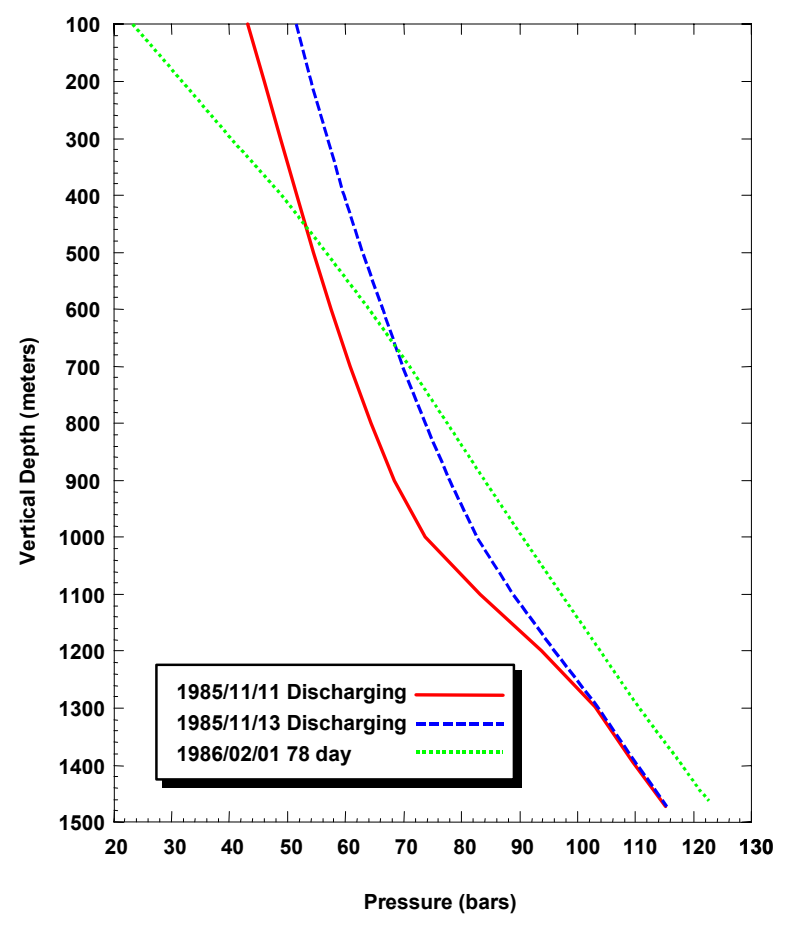

Figure 3.34. Pressure surveys in slim hole N-2t.

The downhole pressure and temperature surveys during the November 1985 discharge test were taken at relatively low flow rates and high wellhead pressures. These pressure and temperature data provide no evidence of in situ boiling. There are, however, indications that during the November 1985 test, discharge at high rates was accompanied by in situ boiling. During a field-wide discharge test performed from December 9, 1987 to March 29, 1988, slim hole N-2t was flowed from January 12, 1988 to March 28, 1988. Somewhat surprisingly, slim hole $\mathrm{N}-2 \mathrm{t}$ discharged mostly steam. It appears that the liquid fraction of the discharge from the Okuaizu wells declined significantly from December 1987 to March 1988.

Pressures computed from water level and temperature data taken on November 23, 1984 are displayed in Figure 3.35. The pressure at 1260 mTVD (-836 mASL) is 107.9 bars. The latter pressure value is virtually the same as that (108.0 bars) obtained during a downhole pressure survey run on February 1, 1986 (Figure 3.34). Both injection and discharge test data are available for slim hole $\mathrm{N}-2 \mathrm{t}$. 


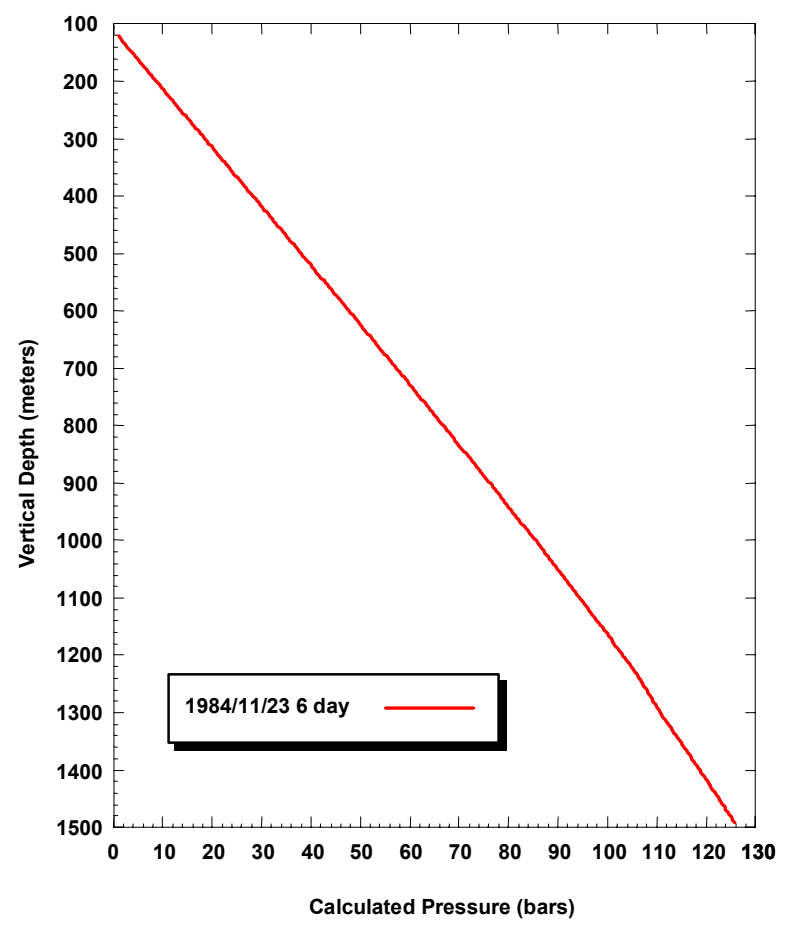

Figure 3.35. Pressures computed from water level and temperature data taken on November 23, 1984 in slim hole N-2t.

\section{Slim Hole N-3t}

Slim hole N-3t is located in the eastern part of the Okuaizu borefield. Heatup surveys taken in January 1985 (Figure 3.36) show a relatively fast temperature recovery in the depth interval from $\sim 1780$ mTVD to $\sim 1830$ mTVD. The temperature survey of November 16, 1985 was taken after the borehole had been shut-in for more than 10 months. The profile exhibits an essentially isothermal zone from $\sim 1790$ mTVD to $\sim 1830$ mTVD. While drilling N-3t, partial circulation losses were recorded at $1812 \mathrm{mTVD}$ and $1816 \mathrm{mTVD}$. A total circulation loss occurred at 1833 mTVD. Based on the temperature and circulation loss data, it is reasonable to assume that the principal feedzone for $\mathrm{N}-3 \mathrm{t}$ is located at $\sim 1810$ mTVD. The feedzone temperature is $\sim 277^{\circ} \mathrm{C}$. Heatup surveys (Figure 3.36) also exhibit a temperature depression at $\sim 1415 \mathrm{mTVD}$, and, therefore, indicate the presence of a minor permeable zone at this depth.

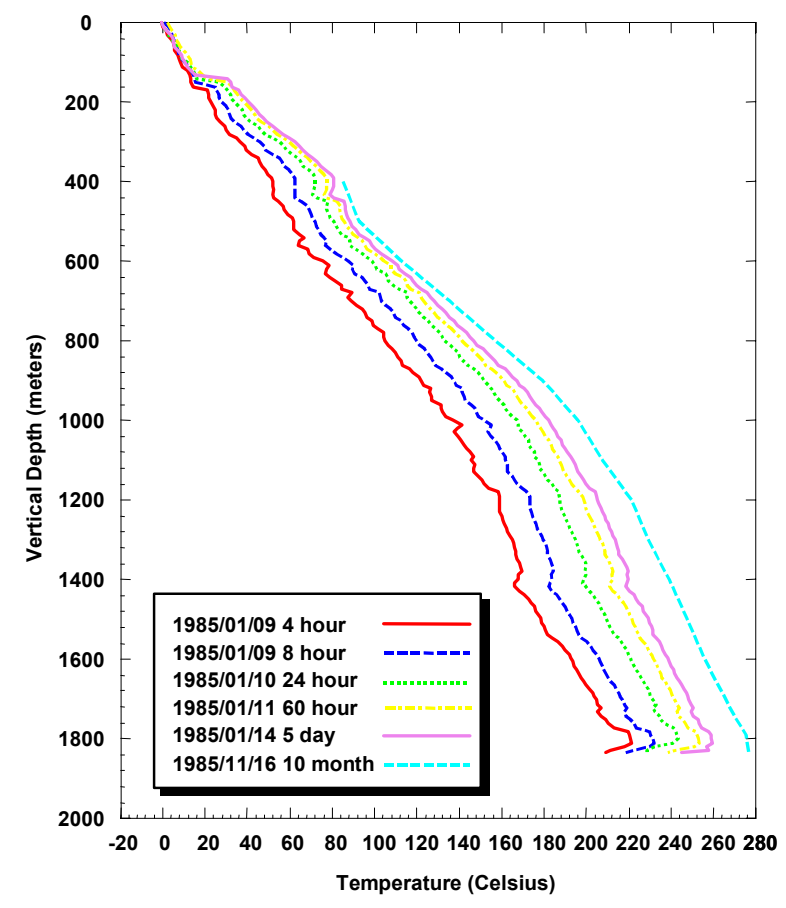

Figure 3.36. Selected temperature surveys in slim hole $\mathrm{N}-3 \mathrm{t}$.

A pressure survey recorded in the shut-in well on November 16, 1985 is shown in Figure 3.37 ; the pressure at 1810 mTVD $(-1361$ mASL) is $\sim 145.4$ bars. The latter pressure value is lower by about 2.6 bars from that (148.0 bars) estimated from water level and temperature data (Figure 3.38).

Slim hole N-3t was discharged twice in early 1986; however, no downhole pressure or temperature measurements were made in the discharging slim hole. The available discharge data cannot be used to compute the productivity index for $\mathrm{N}-3 \mathrm{t}$. 


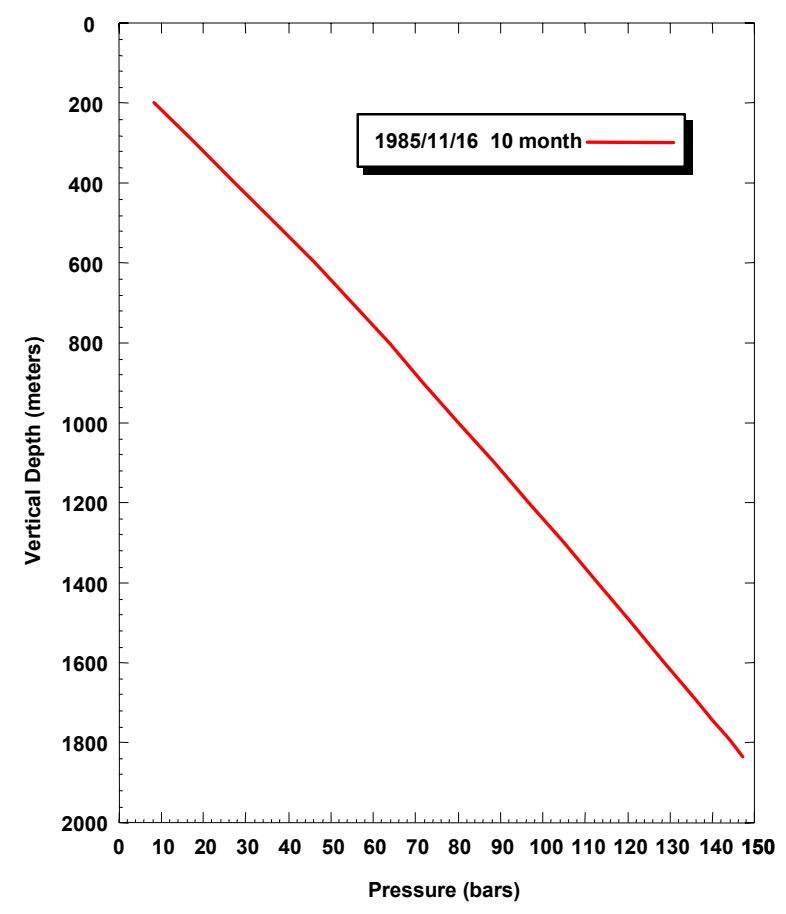

Figure 3.37. A pressure survey taken in slim hole N-3t on November 16, 1985.

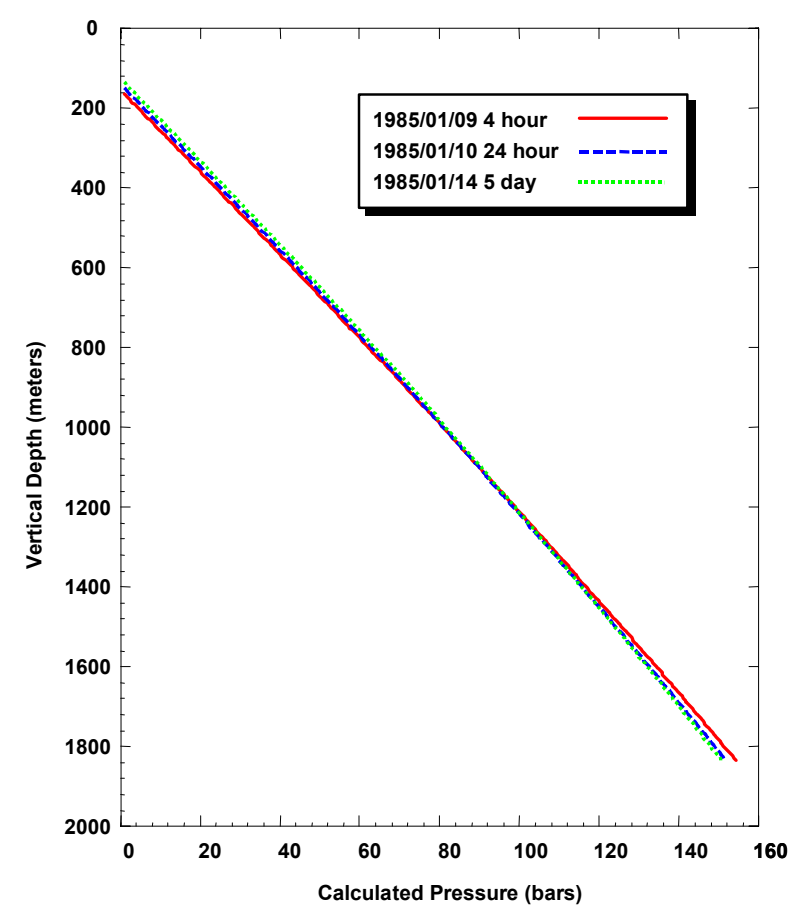

Figure 3.38. Pressures computed from water level and temperature data in slim hole N-3t.

\section{Slim Hole $\mathrm{N}-4 \mathrm{r}$}

Slim hole N-4r was drilled from a location close to the wellhead for slim hole N-2t. Temperature surveys taken during an injection test on December 3, 1984 indicate that almost all of the injected fluid enters the formation between 160 mTVD and 360 mTVD. The temperature profiles below 360 mTVD (Figure 3.39) are conductive indicating little or no permeability. While drilling N-4r, partial circulation losses were encountered at 178 mMD, $191 \mathrm{mMD}$, and 496-499 mMD, and a total circulation loss occurred at $350 \mathrm{mMD}$. It is therefore reasonable to conclude that the principal feedzone for $\mathrm{N}-4 \mathrm{r}$ is located at 260 (+/- 100) mTVD. Since only a single short time (4 hours) shut-in temperature survey is available, it is not possible to estimate the stable feedzone temperature. A maximum temperature of $\sim 165^{\circ} \mathrm{C}$ was recorded at bottom hole ( 700 mTVD) on December 3, 1984. The latter temperature value may be compared to that $\left(\sim 269^{\circ} \mathrm{C}\right)$ recorded in slim hole N-2t at 700 mTVD on February 1, 1986 (shut-in time: 78 days).

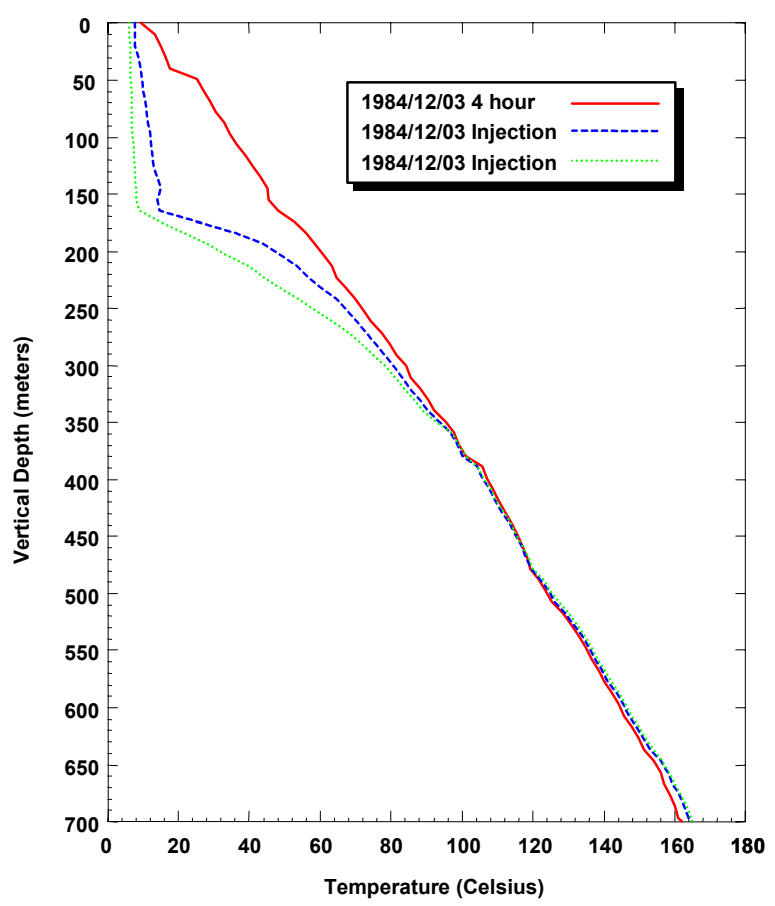

Figure 3.39. Selected temperature surveys in slim hole N-4r. 
Pressures computed from short shut-in time temperature and water level data taken on December 3, 1984 are plotted in Figure 3.40. The pressure at $260 \mathrm{mTVD}$ (164 mASL) is $\sim 22.3$ bars.

No useful injection or discharge test data are available for slim hole N-4r.

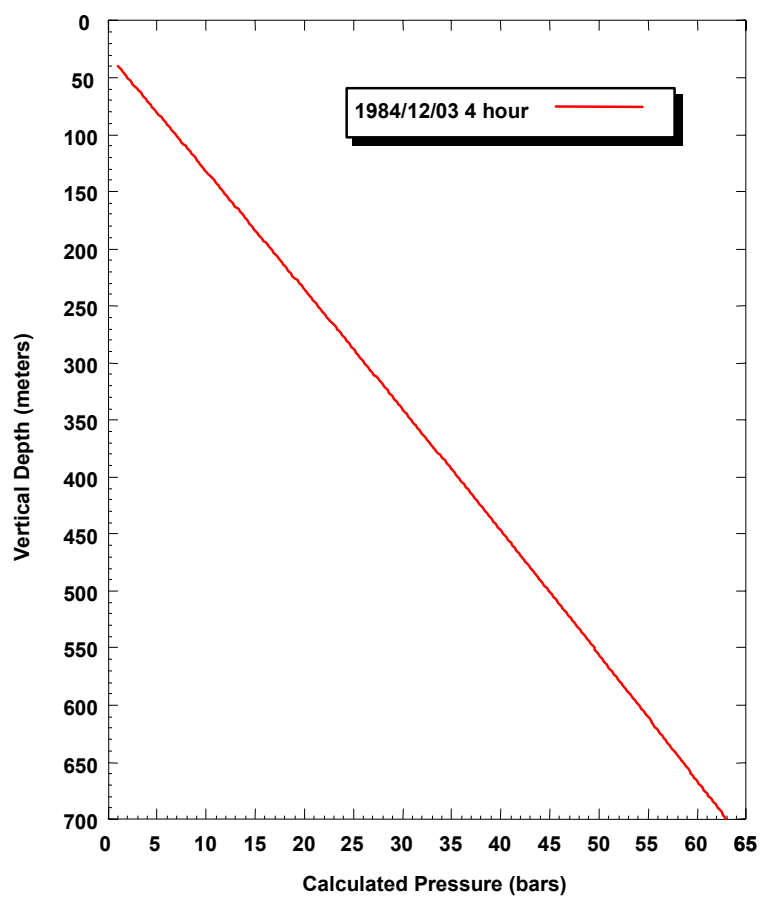

Figure 3.40. Pressures computed from water level and temperature data taken in slim hole N-4r on December 3, 1984.

\section{Slim Hole N-5t}

Slim hole N-5t was drilled from a location about $240 \mathrm{~m}$ north and $75 \mathrm{~m}$ west of the wellhead for slim hole OA-6. All the heatup surveys for N-5t (Figure 3.41) display persistent cold zones at $1100 \mathrm{mTVD}$ and towards bottomhole ( $\sim 790$ mTVD). Since the zone at 1100 mTVD lies behind a blank liner, it is assumed that the principal fluid entry for $\mathrm{N}-5 \mathrm{t}$ is at $\sim 1700 \mathrm{mTVD}(-1343 \mathrm{mASL})$. A temperature of $\sim 265^{\circ} \mathrm{C}$ was recorded at 1690 mTVD on October 26, 1984 after the borehole had been shut-in for only 5 days. By comparison with the measured temperature at 1690 mTVD, it is likely that the stable feedzone temperature is at least $270^{\circ} \mathrm{C}$.

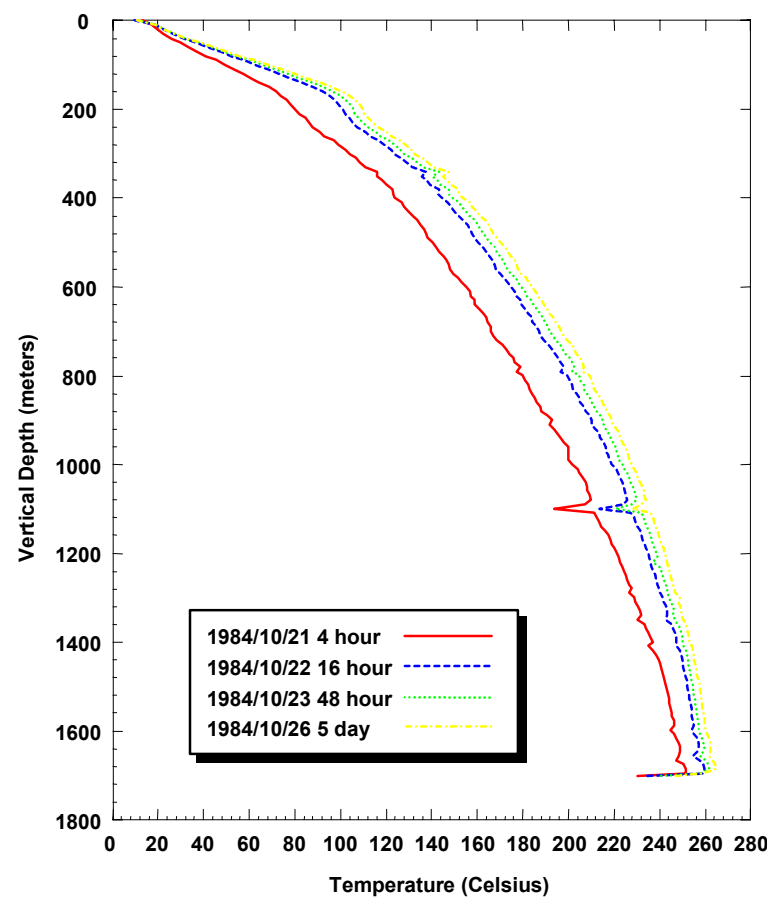

Figure 3.41. Selected temperature surveys in slim hole N-5t.

A discharge test was performed from November 27, 1984 to December 16, 1984. The average discharge rate and enthalpy were $\sim 5.2$ tons/hour and $1205 \mathrm{~kJ} / \mathrm{kg}$, respectively. The discharge enthalpy $(1205 \mathrm{~kJ} / \mathrm{kg})$ corresponds to a saturation temperature of $\sim 274^{\circ} \mathrm{C}$ for pure liquid water. The lack of downhole pressure and temperature measurements makes it difficult to determine if discharge from N-5t was accompanied by in situ boiling.

Pressures computed from water level and temperature data are displayed in Figure 3.42. The pressure at $1700 \mathrm{mTVD}(-1343.0 \mathrm{mASL})$ is about 145.0 bars. 


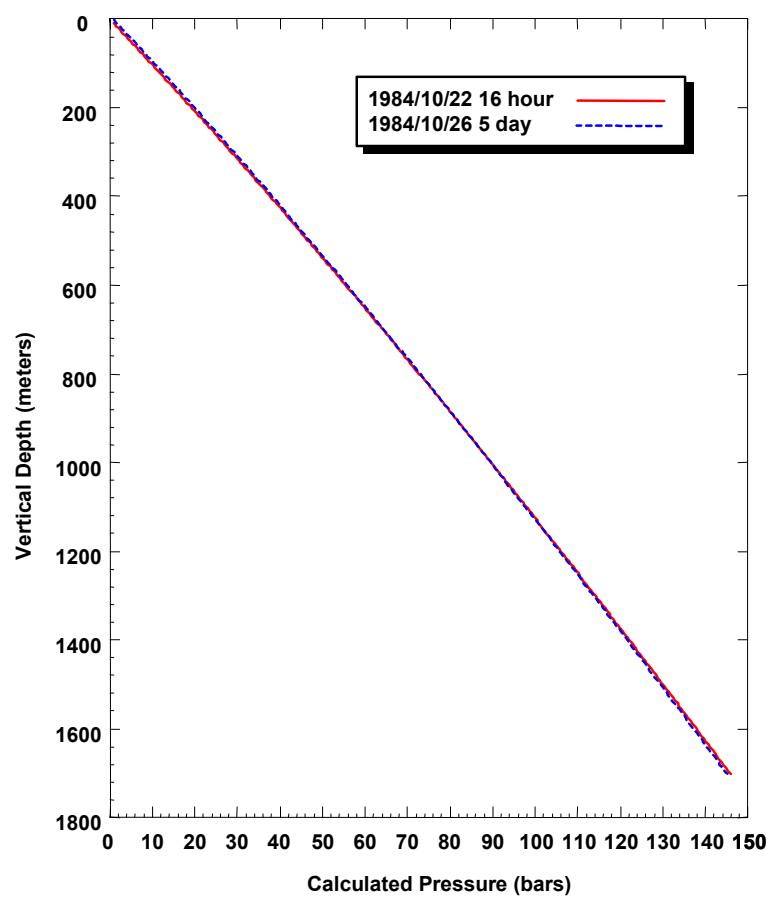

Figure 3.42. Pressures computed from water level and temperature data in slim hole N-5t.

\section{Production Well N-6T}

Temperature surveys taken shortly after cold water injection in December 1985 (Figure 3.43) show sharp changes in temperature gradient at about $920 \mathrm{mTVD}, 1140 \mathrm{mTVD}$, 1180 mTVD, 1390 mTVD, and 1590 mTVD. It is likely that some permeability is present at or near all of these depths. After preliminary discharge tests in October and November 1986, well N-6T was discharged for about 4 months from December 8, 1986 to April 5, 1987. Temperature (Figure 3.43) and pressure (Figure 3.44) taken in December 1986 indicate liquid conditions in the borehole below a depth of $\sim 900$ mTVD. These temperature surveys indicate the influx of liquid water (temperature $\sim 283^{\circ}$ C) at 1550 mTVD. Additional fluid entries are present at 13401390 mTVD and at 1150-1200 mTVD. Temperature surveys in the discharging well provide no clear evidence of a fluid entry at $\sim 920$ mTVD. The presence of essentially isothermal zones over the depth interval 1200$1350 \mathrm{mTVD}$ and above $1150 \mathrm{mTVD}$ (Figure
3.43) implies that the major permeable intervals in N-6T are located at 1340-1390 mTVD and 1150-1200 mTVD. The temperature survey of September 28, 1987 was taken after the well had been shut-in (after the 1986-87 discharge test) for almost 6 months, and exhibits a temperature inversion over the depth interval from 1400 mTVD to $1550 \mathrm{mTVD}$. This temperature inversion is, however, absent from the temperature survey recorded on March 11, 1996 (Figure 3.45). The maximum temperature occurs towards the bottom of the well, and was recorded as $\sim 305^{\circ}$ C on March 11, 1996 at 1625 mTVD.

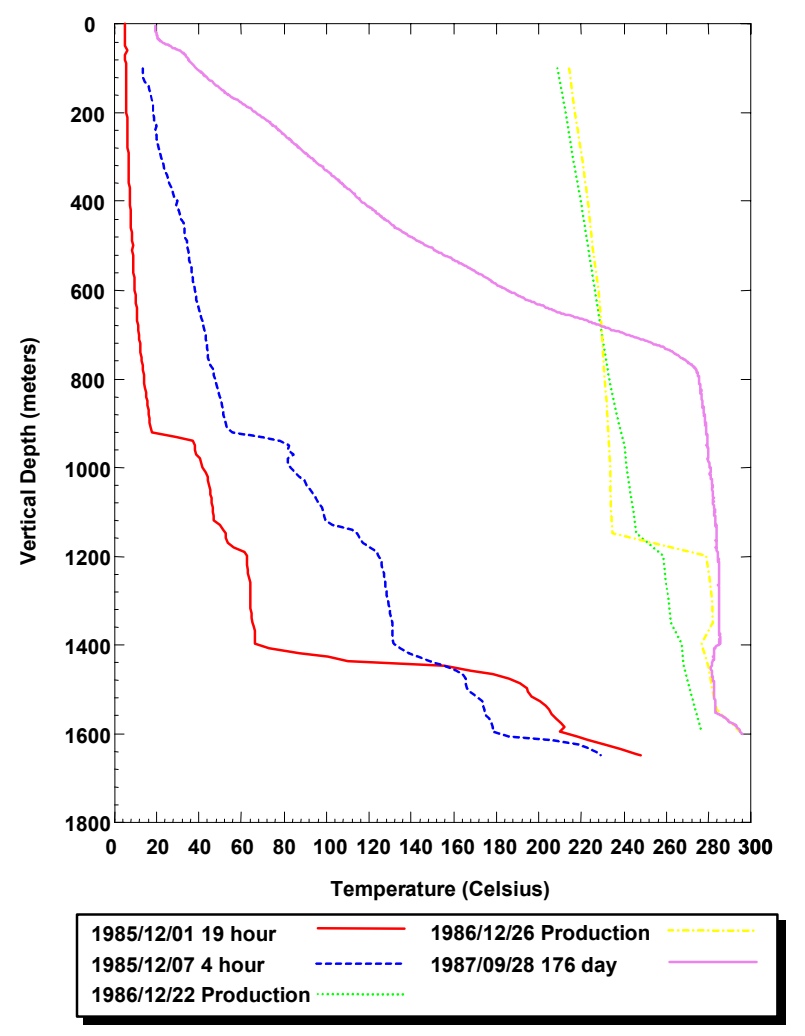

Figure 3.43. Selected temperature surveys taken during 1985-1987 in production well N-6T.

During the field-wide discharge test in the winter of 1987-1988, N-6T was produced from December 9, 1987 to March 28, 1988. Like other Okuaizu wells, the discharge from $\mathrm{N}-6 \mathrm{~T}$ tended to dry out, and the discharge enthalpy increased from $\sim 1530 \quad \mathrm{~kJ} / \mathrm{kg}$ (December 16, 1987) to $2290 \mathrm{~kJ} / \mathrm{kg}$ (March 
26, 1988). Temperature, pressure and spinner surveys taken during February 1988 are displayed in Figures 3.45-3.47. It appears that two-phase conditions are present at least above 1400 mTVD (Figure 3.46) and possibly deeper. The spinner surveys (Figure 3.47) indicate fluid entries at 1390 mTVD, 1190 mTVD, 990 mTVD, and 910 mTVD.

Two shut-in pressure surveys (Figure 3.44) indicate essentially the same $(118.5+/-0.3$ bars) pressure at $1390 \mathrm{mTVD}$ (- $962.5 \mathrm{mASL})$.

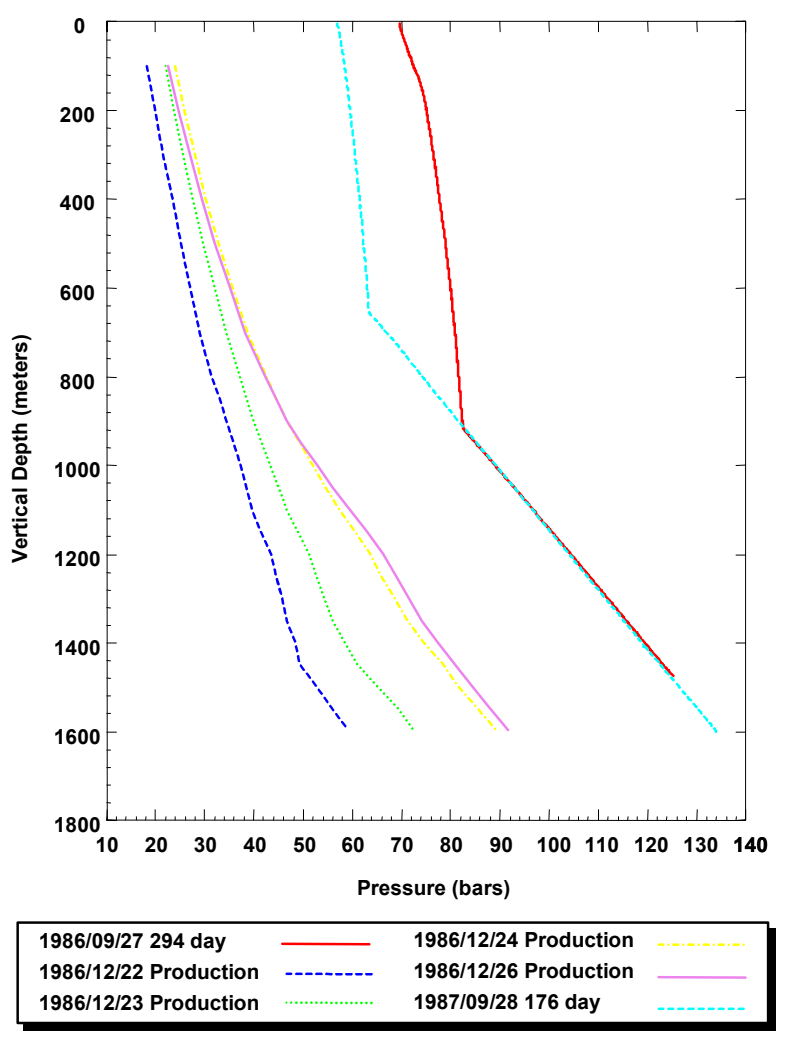

Figure 3.44. Pressure surveys taken during 1985-1987 in well N-6T.

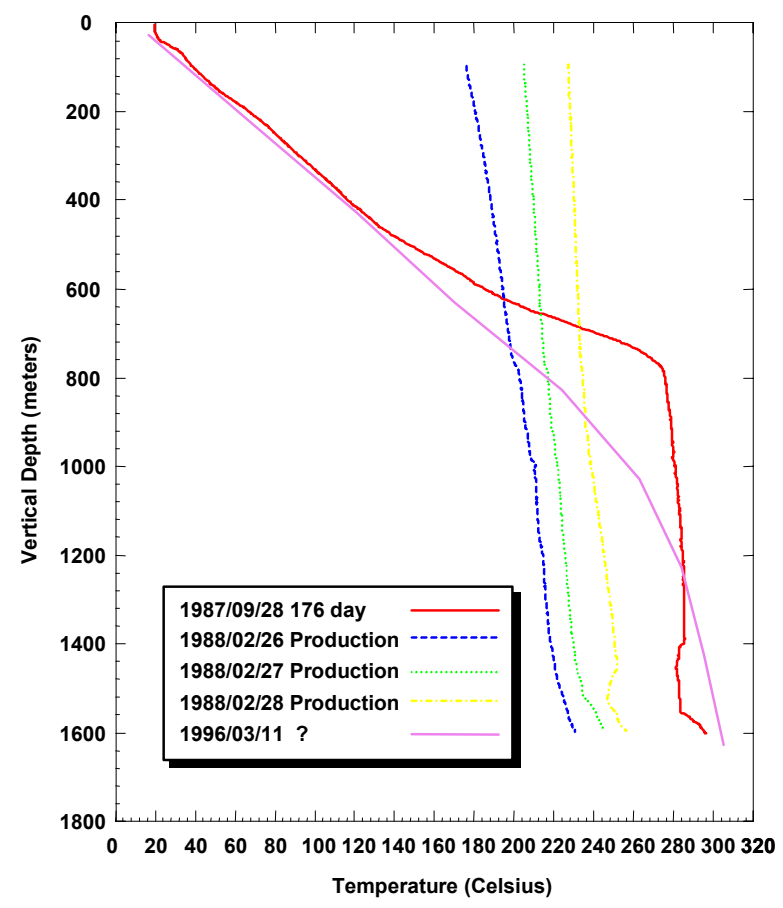

Figure 3.45. Temperature surveys taken during a discharge test on production well N-6T in February 1988.

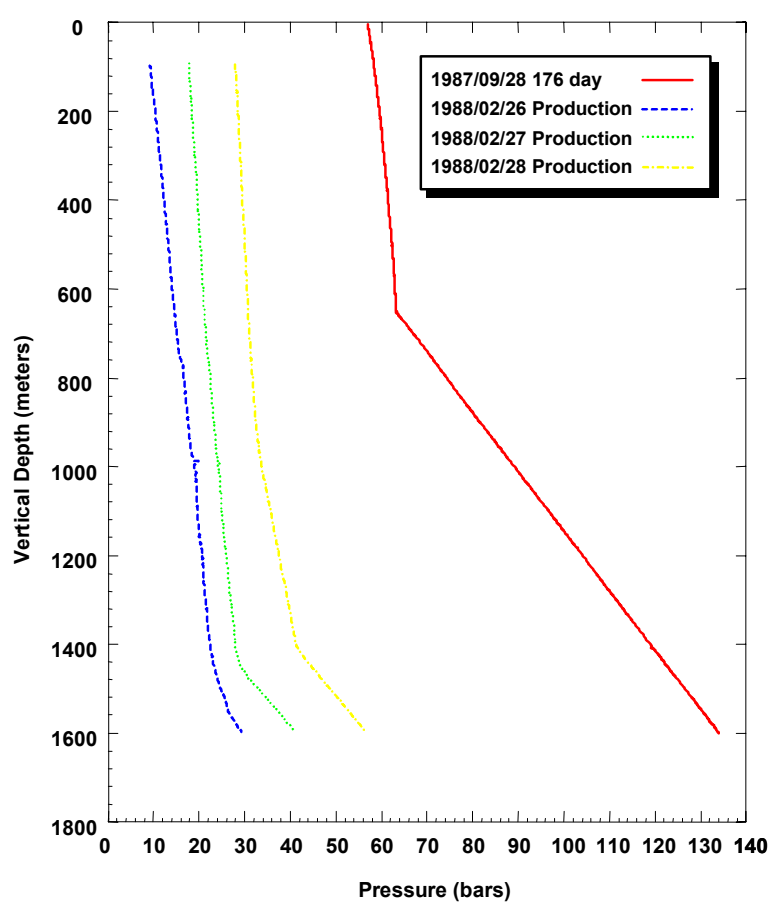

Figure 3.46. Pressure surveys taken during a discharge test on production well N-6T in February 1988. 


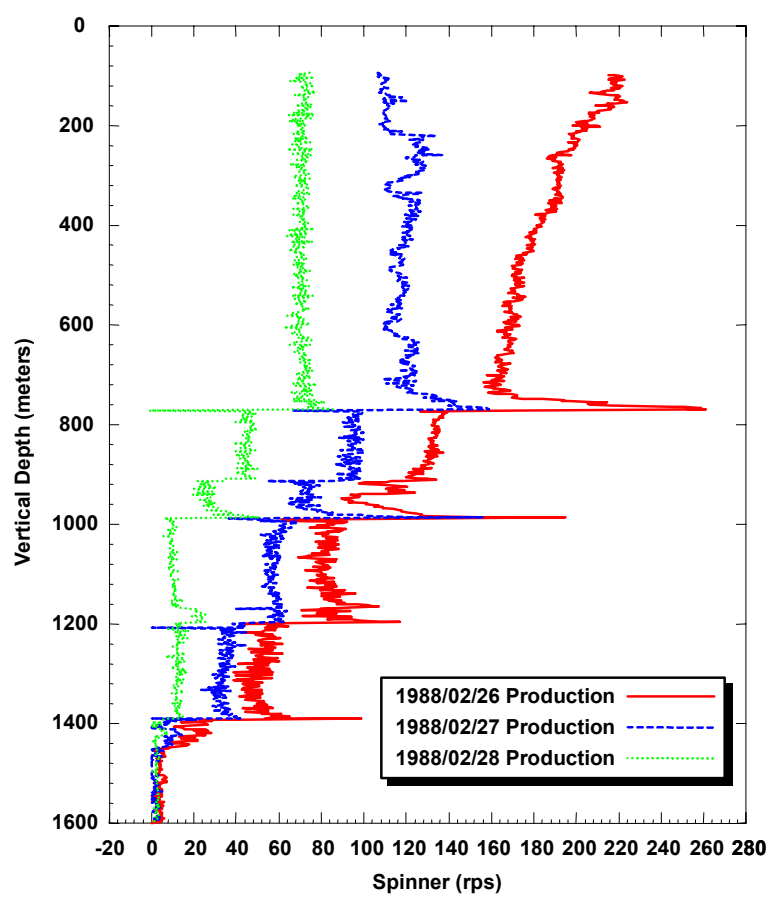

Figure 3.47. Spinner surveys taken during a discharge test on production well N-6T in February 1988.

\section{Exploration Well N-7T}

Exploration well N-7T was drilled from a location near the wellhead for slim hole OA-6. Available temperature surveys for $\mathrm{N}-7 \mathrm{~T}$ are exhibited in Figure 3.48. The temperature survey of June 30, 1985 was taken shortly after well completion and provides no clear indication of formation permeability. The only other available temperature survey extends to a depth of only 411 meters. A temperature depression in the latter temperature profile at about 280 mTVD may be indicative of permeability at this depth since a circulation loss was reported nearby at 303 mTVD. Available data are insufficient for estimating the stable feedzone temperature.

Pressures computed from water level and temperature data recorded on March 16, 1987 are plotted in Figure 3.49. The pressure at 280 mTVD (96.5 mASL) is about 23.1 bars.
No useful injection or discharge test data are available for exploration well N-7T.

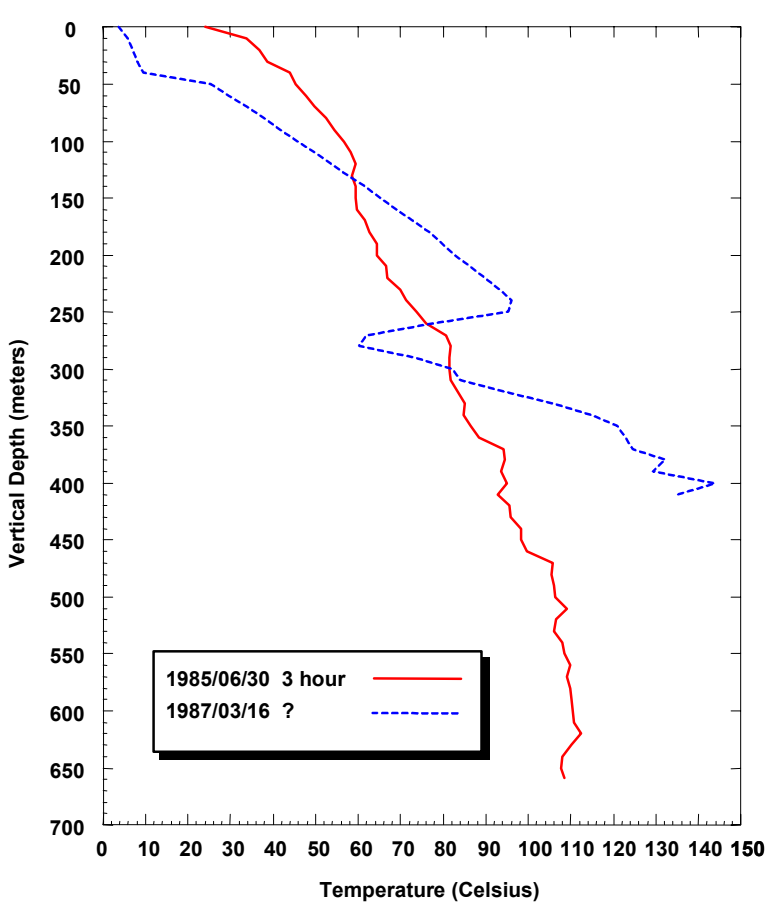

Figure 3.48. Available temperature surveys in exploration well N-7T.

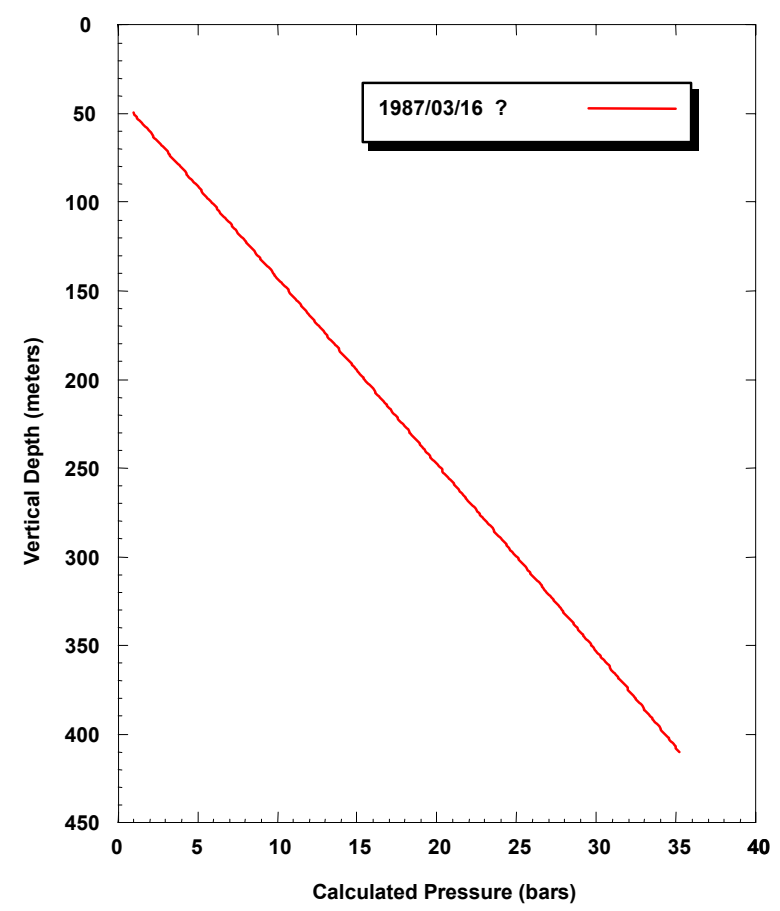

Figure 3.49. Pressures computed from water level and temperature data taken in exploration well N-7T on March 16, 1987. 


\section{Exploration Well N-8T}

The single available temperature survey in well N-8T (Figure 3.50) was taken just after well completion. Somewhat faster heatup at $\sim 570$ mTVD and at 590 mTVD may indicate permeability at these depths. Absence of other temperature data makes it impossible to precisely locate the feedzone for N-8T.

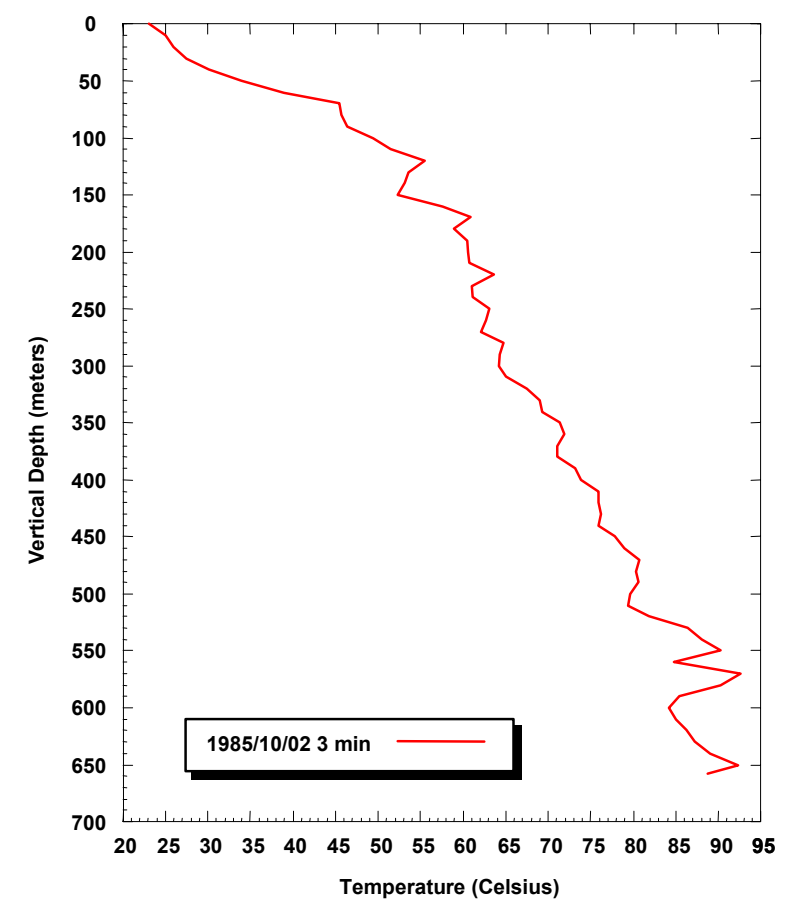

Figure 3.50. A temperature survey taken in exploration well N-8T on October 2, 1985.

No water level or pressure data are available for exploration well N-8T.

No useful injection or discharge test data were taken in exploration well N-8T.

\section{Exploration Well N-9T}

Exploration well N-9T was drilled from a location close to the wellhead for slim hole N3t. Only a single temperature survey (Figure 3.51) extends below the casing shoe at 300 mTVD. The temperature survey of August 5, 1985 was presumably taken just after cold water injection. The presence of a cold zone at $\sim 450$ mTVD and a sharp change in temperature gradient at $\sim 650$ mTVD indicate the permeable horizons for N-9T.

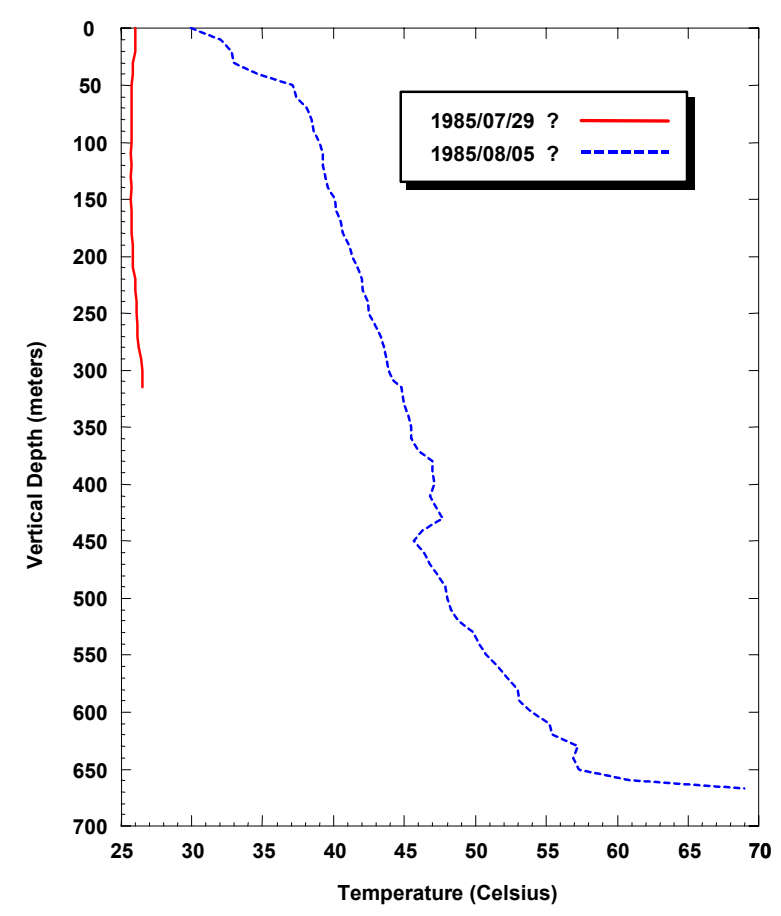

Figure 3.51. Temperature surveys in exploration well N-9T.

No pressure or appropriate water level data are available for exploration well N-9T.

Furthermore, no useful injection or discharge test data exist for N-9T.

\section{Production Well N-10T}

During an injection test on September 24, 1986, a PTS survey was run in production well N-10T. The temperature survey (Figure 3.52) shows changes in temperature gradient at about $950 \mathrm{mTVD}, 1350 \mathrm{mTVD}$ and 1500 mTVD. Because of the slotted/blank liner present in the well, it is somewhat difficult to interpret the spinner survey (Figure 3.53). The spinner survey indicates that most of the injected fluid is lost in the depth interval from $\sim 1480$ mTVD to $\sim 1640$ mTVD. 


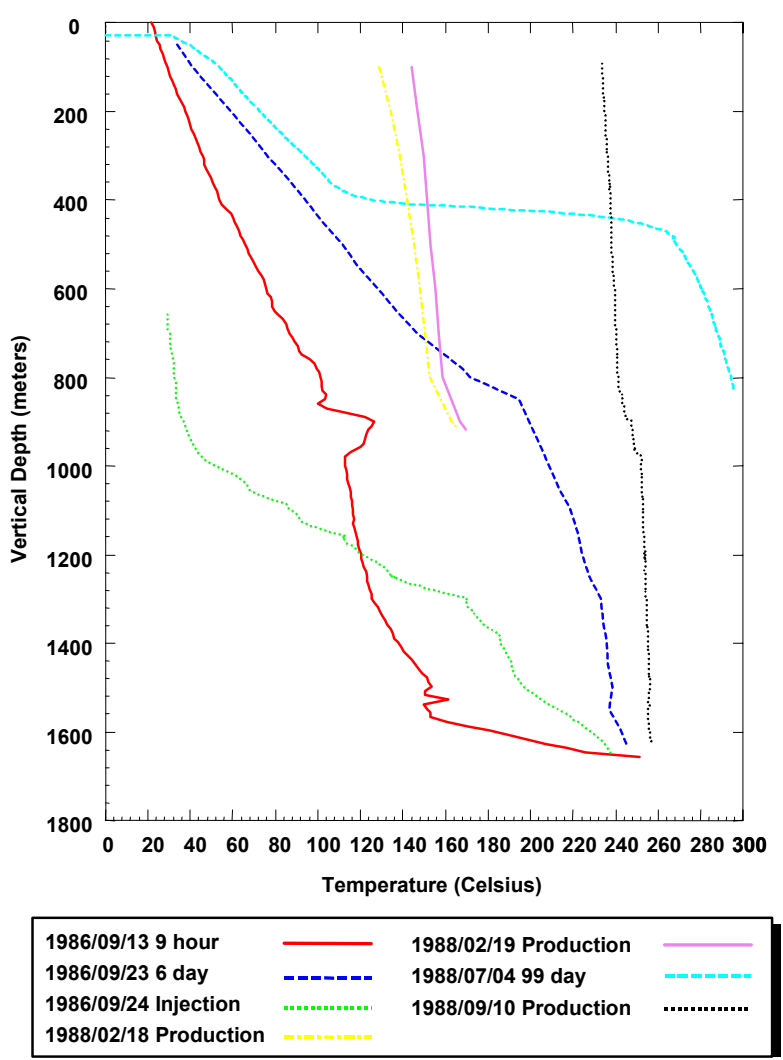

Figure 3.52. Selected temperature surveys in production well N-10T.

A PTS survey was obtained during a discharge test on September 10, 1988. The temperature (Figure 3.52) and pressure (Figure 3.55) profiles indicate the presence of two-phase (mostly steam) fluid in the wellbore. The existence of an essentially isothermal profile from $1500 \mathrm{mTVD}$ to $980 \mathrm{mTVD}$ is consistent with one or more fluid entries at or below 1500 mTVD. The spinner survey (Figure 3.54) indicates the existence of fluid entries at 1540 mTVD and 1620 mTVD. The temperature survey also implies the entry of cold fluid over the depth interval $\sim 840$ mTVD to $\sim 980 \mathrm{mTVD}$.

The fluid entry at $1540 \mathrm{mTVD}$ is also confirmed by the existence of a cold zone at this depth in the heatup survey taken on September 23, 1986 (Figure 3.52). The temperature survey of September 13, 1986 was taken shortly after well completion. A cold zone at $\sim 900$ mTVD and a sharp change in temperature gradient at $\sim 1560$ mTVD (Figure 3.52) imply permeable horizons.

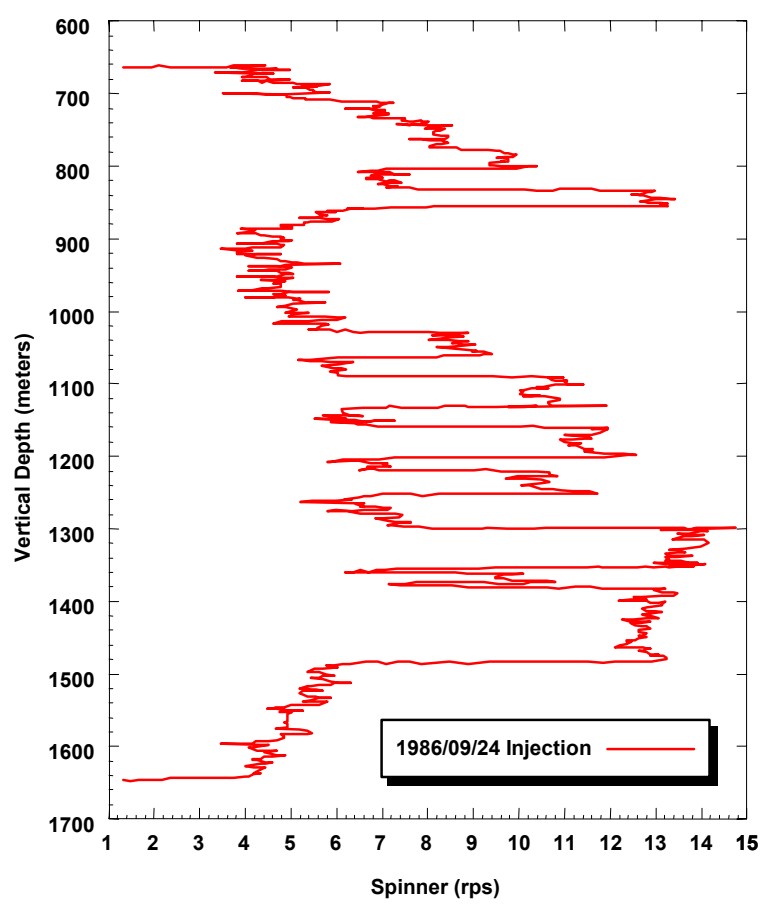

Figure 3.53. A spinner survey taken during an injection test on September 24, 1986 in production well N-10T.

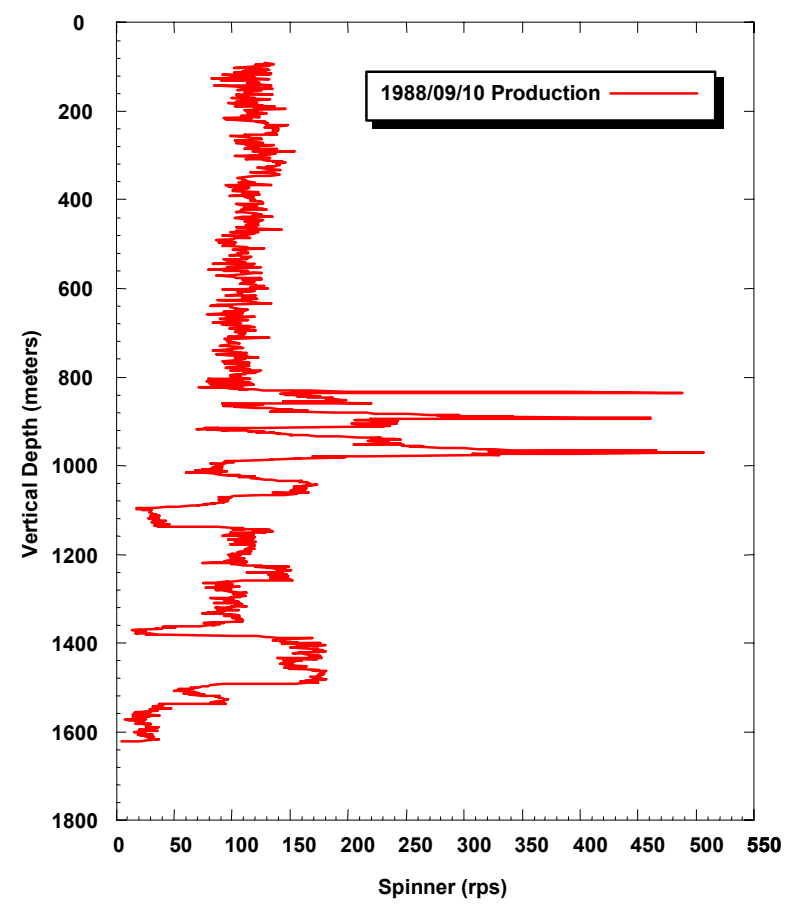

Figure 3.54. A spinner survey taken during a discharge test on September 10, 1988 in production well N-10T. 


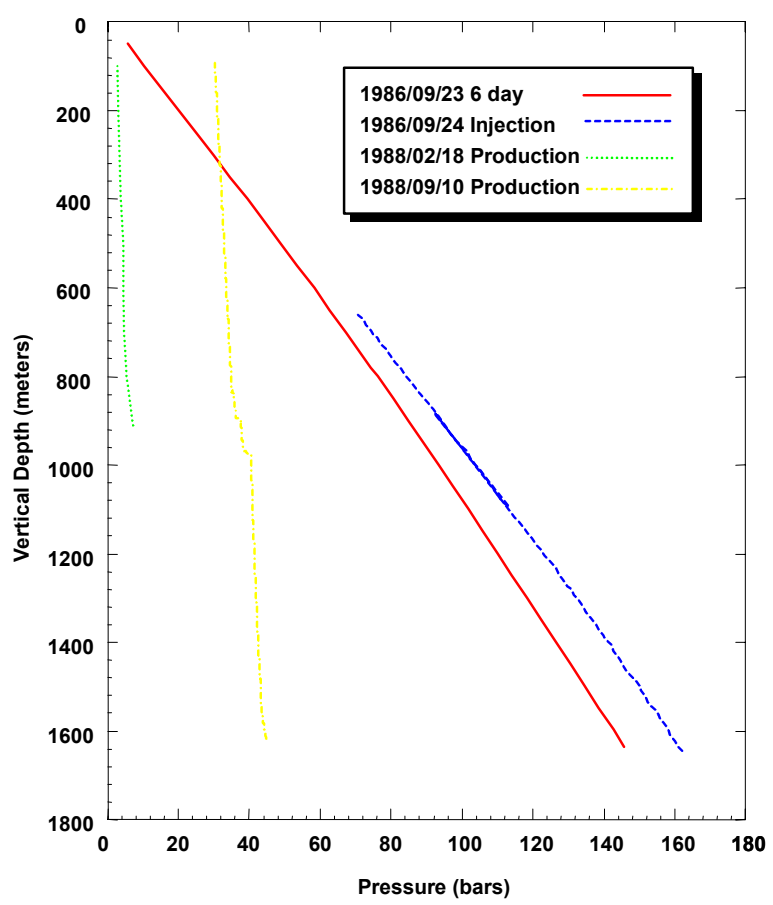

Figure 3.55. Selected pressure surveys in production well N-10T.

In keeping with the above discussion, it is assumed that the principal feedzone for N-10T is located at $1540 \mathrm{mTVD}(-1114.5 \mathrm{mASL})$. The absence of long-term shut-in temperature data makes it difficult to estimate the stable feedzone temperature. By comparison with the measured temperature on July 4, 1988 at 800 mTVD (Figure 3.52), the feedzone temperature must be at least $300^{\circ} \mathrm{C}$.

Pressures measured from water level and temperature data obtained on September 13, 1986 (shut-in time $\sim 9$ hours) are plotted in Figure 3.56. The pressure at $1540 \mathrm{mTVD}$ (-1114.5 mASL) is $\sim 141.3$ bars. The latter pressure value is about 3 bars higher than that (138.0 bars) recorded by a downhole gauge on September 23, 1986 (shut-in time $\sim 6$ days, Figure 3.55). The pressure survey of July 4, 1988 was taken after the well was shut-in for about 3 months. Unfortunately, this pressure survey extends to only about 820 mTVD. The July 1988 pressure survey indicates that the well develops a gas cap when shut-in. An extrapolation of July 1988 pressure data gives a feedzone pressure of $\sim 129$ bars. Clearly, the stable feedzone pressure for $\mathrm{N}-10 \mathrm{~T}$ is somewhat uncertain.

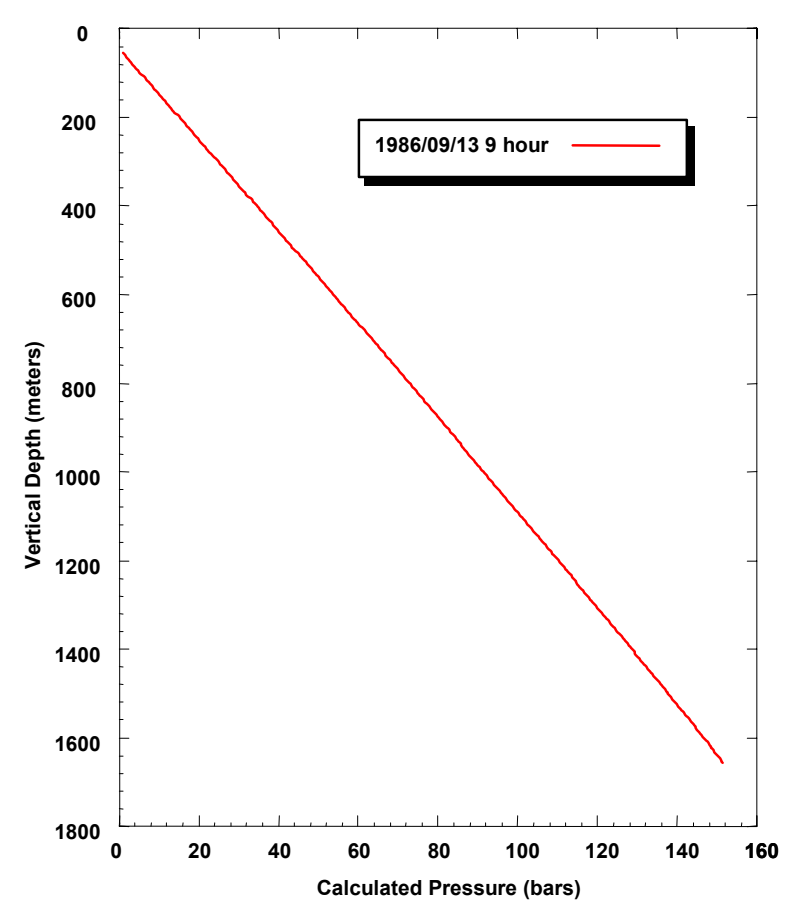

Figure 3.56. Pressures computed from water level and temperature data in production well N-10T.

\section{Production Well N-11T}

A heatup survey taken on September 30, 1986 (Figure 3.57), just after cold water injection in production well $\mathrm{N}-11 \mathrm{~T}$, shows changes in temperature gradient at $1150 \mathrm{mTVD}, 1310$ mTVD and 1490 mTVD. The sharp change in temperature gradient at $1490 \mathrm{mTVD}$ is present in all of the heatup surveys plotted in Figure 3.57. During an extended discharge test lasting from December 2, 1988 to March 20, 1989, N-11T discharged a mixture of water and steam with wellhead enthalpies ranging from $1085 \mathrm{~kJ} / \mathrm{kg}$ to $1663 \mathrm{~kJ} / \mathrm{kg}$. The wellhead enthalpies were even higher (1301-1813 $\mathrm{kJ} / \mathrm{kg}$ ) in a subsequent discharge test (November 20, 1989 to March 2, 1990). Temperature, pressure and spinner surveys taken in the discharging well in March 1989 are displayed in Figures 3.58-3.60. The latter temperature and pressure data (Figures 3.58 and 3.59) indicate the presence of boiling 
conditions along the entire length of the borehole. The relatively small pressure gradient in the discharging well implies that the continuous flowing phase is steam. Clearly, discharge from N-11T is accompanied by in situ boiling. Because of the presence of the slotted liner in the borehole, the spinner surveys (Figure 3.60) are somewhat difficult to interpret. In any case, the spinner surveys indicate fluid entries at $\sim 1560 \mathrm{mTVD}, \sim 1430 \mathrm{mTVD}$, and $\sim 1150$ mTVD. Additional fluid entries are probably present in the depth interval from 1150 mTVD to $1430 \mathrm{mTVD}$.

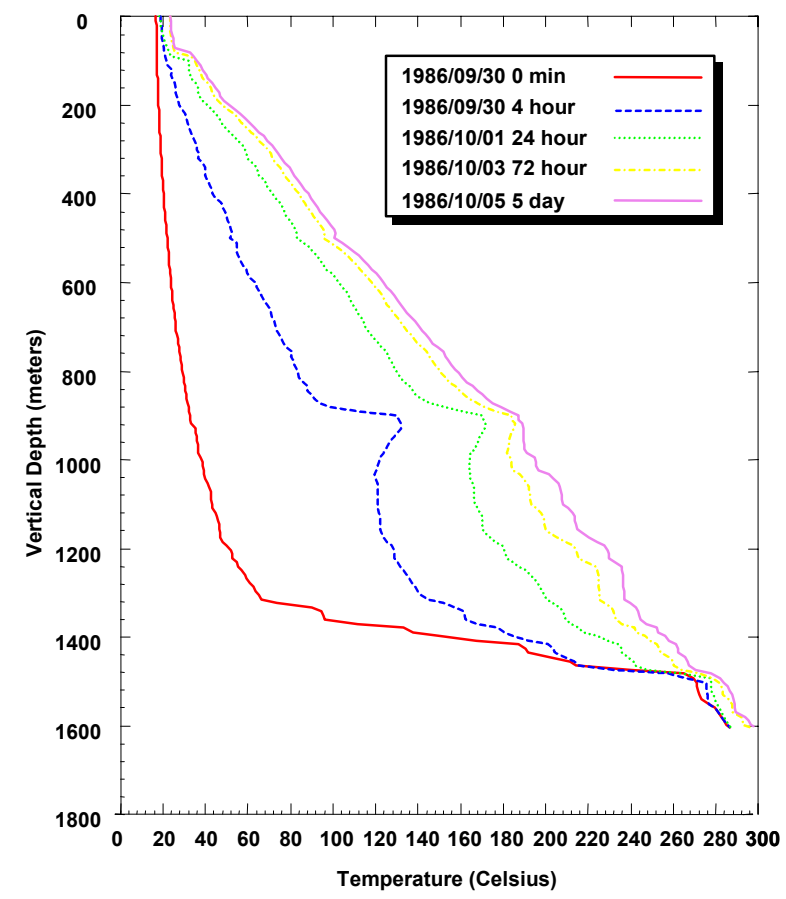

Figure 3.57. Selected heatup surveys in production well N-11T.

The temperature survey of November 27, 1991 was presumably taken after the well had been shut-in for several months. The maximum temperature in $\mathrm{N}-11 \mathrm{~T}$ occurs towards the bottom of the well, and is $\sim 283^{\circ}$ C. A weak temperature inversion centered at $\sim 1410$ mTVD is also present in the temperature survey of November 27, 1991 (Figure 3.58). If real, the inversion implies that well N-11T is located in an outflow zone of the Okuaizu Geothermal Field.

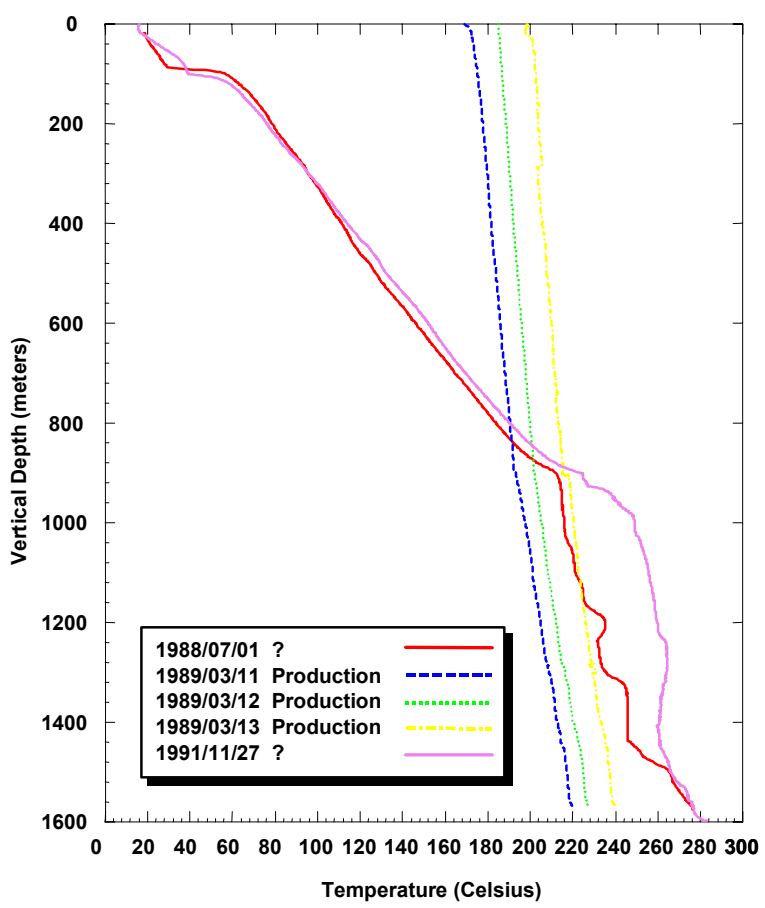

Figure 3.58. Temperature surveys taken before, during, and after a discharge test (March 1989) of well $\mathrm{N}-11 \mathrm{~T}$.

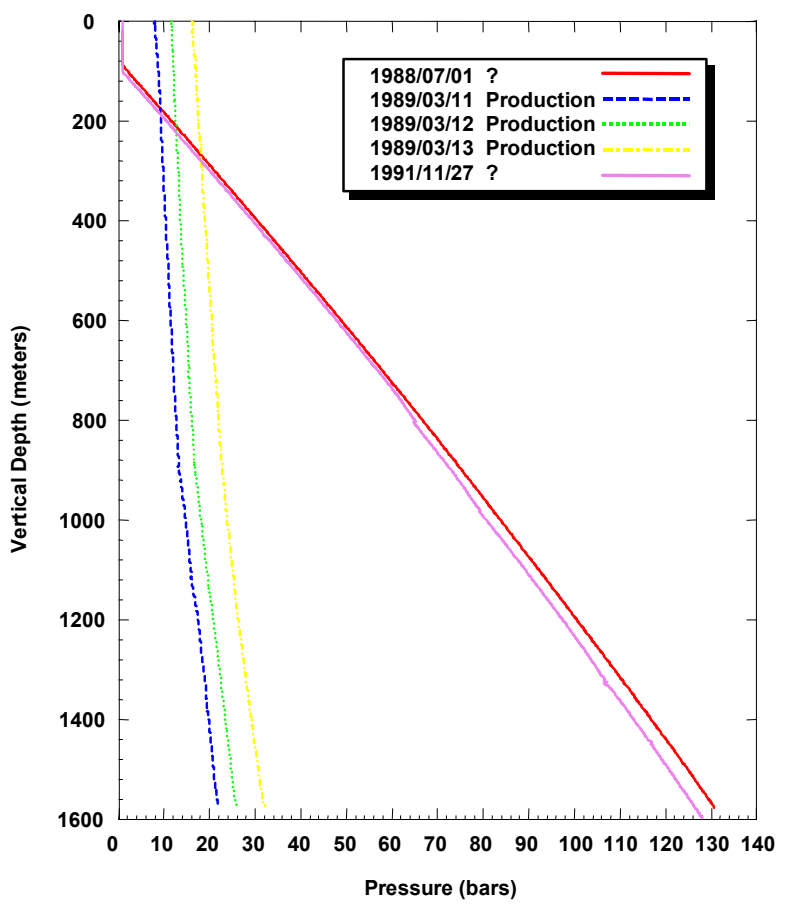

Figure 3.59. Pressure surveys in production well N-11T. 


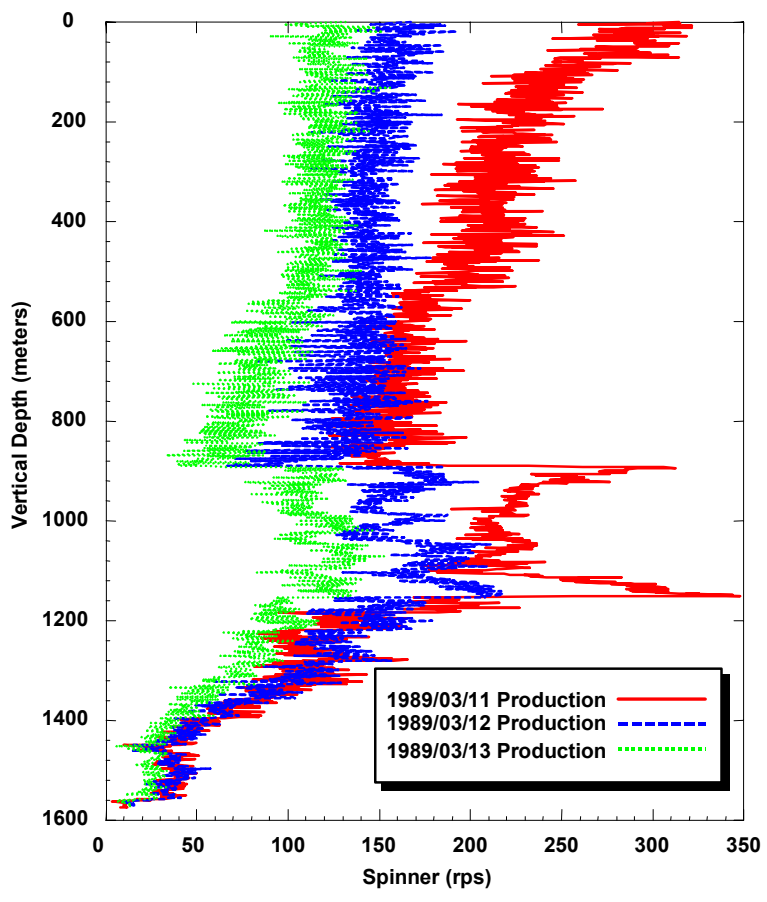

Figure 3.60. Spinner surveys taken during a discharge test of production well N-11T in March 1989.

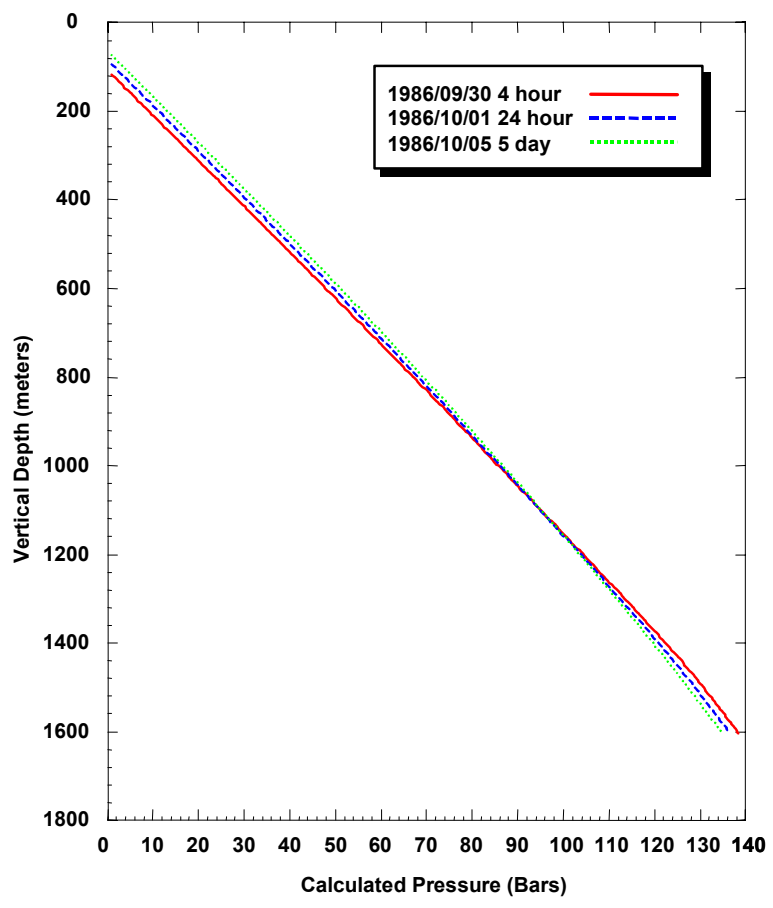

Figure 3.61. Pressures computed from water level and temperature data in production well N-11T.

Pressures computed from water level and temperature data are displayed in Figure 3.61.
The pressure at $1150 \mathrm{mTVD}(-735.5 \mathrm{mASL})$ is 299.4 bars. The latter pressure value is significantly higher than that (96.5 bars) recorded by a downhole gauge on July 1, 1988 (Figure 3.59). Apparently, by November 1991, the pressure at $1150 \mathrm{mTVD}$ had declined to $\sim 93.4$ bars (Figure 3.59).

\section{Slim Hole N-12t}

Slim hole N-12t was drilled from a location along the eastern edge of the Okuaizu borefield. A heatup survey (Figure 3.62) recorded shortly after cold water injection on January 27, 1987 exhibits a cold zone at 9401020 mTVD. Minor permeable zones at 1395 mTVD and $1510 \mathrm{mTVD}$ are indicated by changes in temperature gradient at these depths (Figure 3.62). Temperature survey of August 18, 1988 was taken after the slim hole was shut-in for several months. The conductive temperature profile implies poor permeability. The maximum temperature occurs towards bottomhole and is $\sim 236^{\circ} \mathrm{C}$.

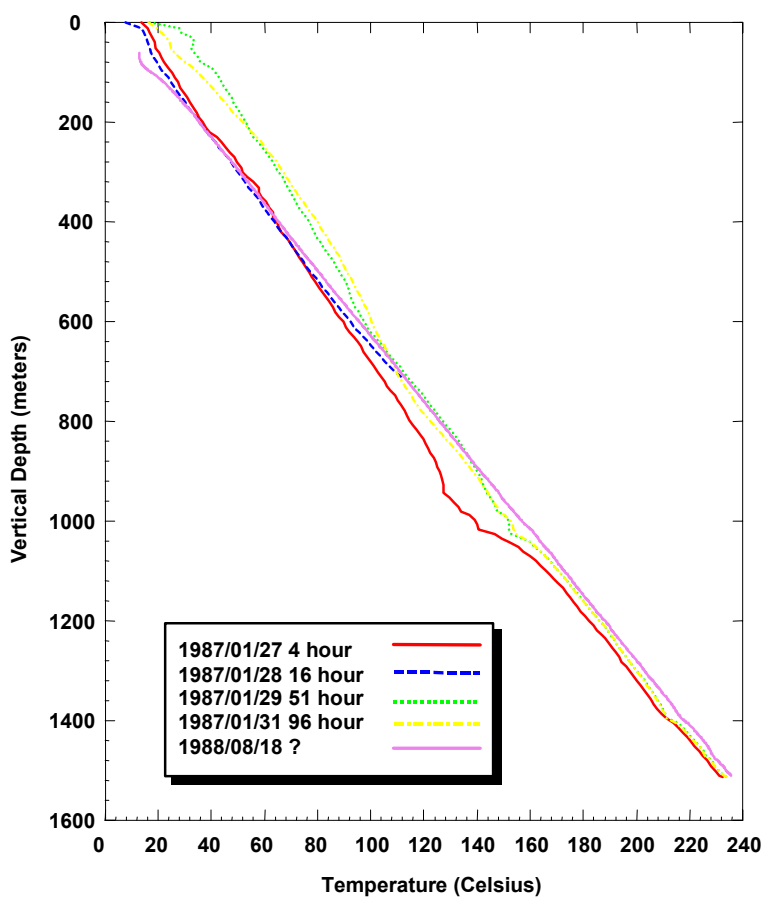

Figure 3.62. Selected temperature surveys in slim hole N-12t. 
A pressure survey recorded in the shut-in borehole on August 18, 1988 (Figure 3.63) shows a gas column in the borehole above $\sim 1010$ mTVD. It appears that some upflow is taking place in the shut-in borehole. The liquid fraction of the upflow leaves the wellbore at $\sim 1010 \mathrm{mTVD}$, and the gas rises above 1010 MTVD to form a gas column. The gas column cannot extend below the upper feedzone at $1010 \mathrm{mTVD}$ since gas will be injected into the permeable zone at this depth. The pressure at 1010 mTVD (-520.5 mASL) is $\sim 96.2$ bars. Because of internal flow in the borehole, the latter value may not represent the stable pressure at 1010 mTVD.

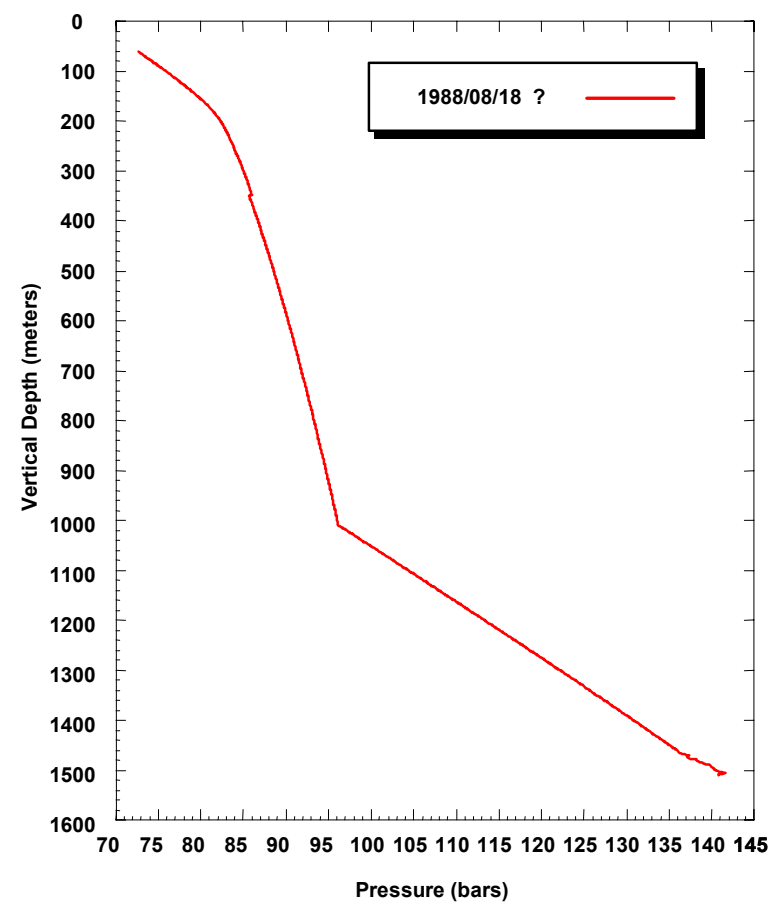

Figure 3.63. A pressure survey recorded in slim hole N-12t on August 18, 1988.

\section{Slim Hole N-13t}

The wellhead for slim hole $\mathrm{N}-13 \mathrm{t}$ is located along the northern edge of the Okuaizu borefield. Temperature survey (Figure 3.64), taken during an injection test on December 21, 1986, shows the entry of hot water at $\sim 1100$ mTVD. The hot water mixes with the injected cold water, travels down the borehole and enters the formation at 1310 mTVD. The entries at 1100 mTVD and 1310 mTVD are confirmed by thermal features (change in temperature gradient at $1100 \mathrm{mTVD}$, and a cold zone at $1310 \mathrm{mTVD}$ ) in the various heatup surveys shown in Figure 3.64. The presence of an isothermal zone from $\sim 1110$ mTVD to $\sim 1300$ mTVD implies crossflow (downflow) in the shut-in well. The maximum temperature occurs towards the bottom of the borehole, and was recorded as $\sim 176^{\circ} \mathrm{C}$ on December 26, 1986 after the borehole had been shut-in for 5 days.

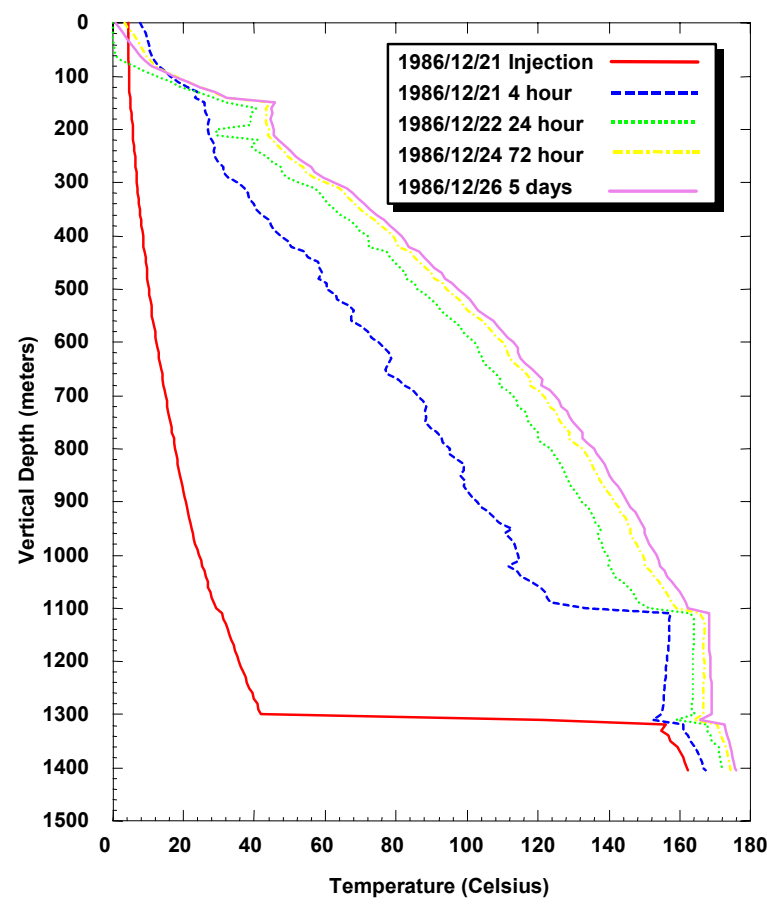

Figure 3.64. Selected temperature surveys in slim hole N-13t.

A single water level measurement is available for slim hole N-13t. Pressures computed from water level and temperature data recorded on December 14, 1986 (shut-in time: 4 hours) are plotted in Figure 3.65. The pressure at 1200 mTVD (-782 mASL) - the mid point of the two fluid entries - is about 96.8 bars. Because of the brief shut-in time, the latter value may not represent the stable feedzone pressure for $\mathrm{N}-13 \mathrm{t}$.

No useful injection or discharge test data are available for slim hole N-13t. 


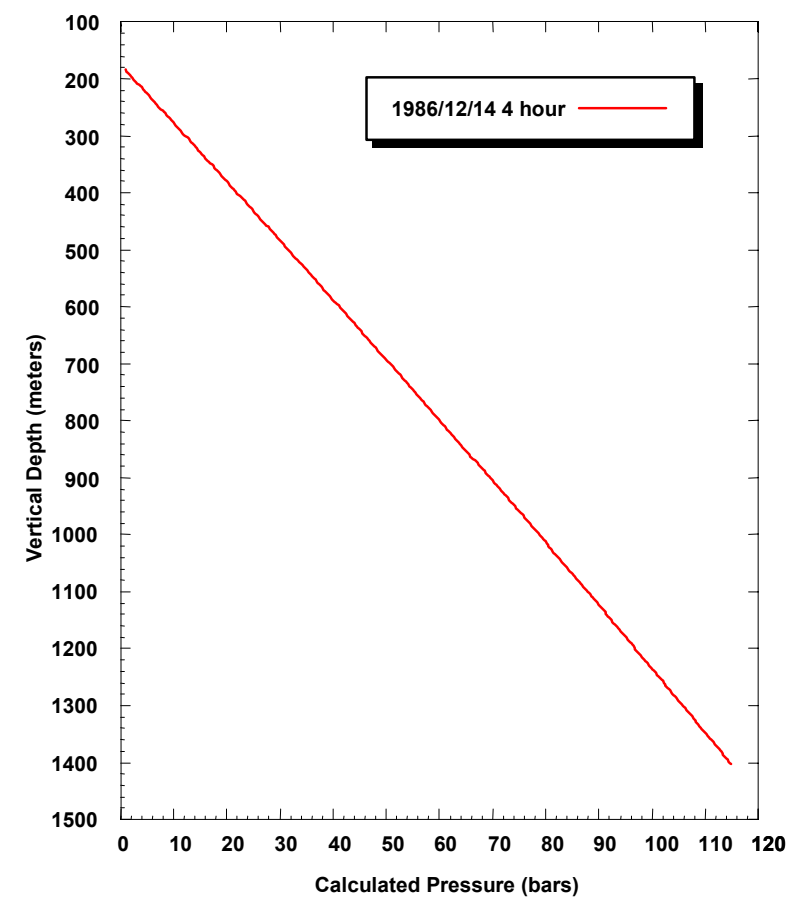

Figure 3.65. Pressures computed from water level and temperature data in slim hole N-13t.

\section{Production Well N-14T}

Heatup survey of September 11, 1987 (Figure 3.66) was taken shortly after cold water injection in production well N-14T, and exhibits breaks in temperature gradient at $\sim 1130 \mathrm{mTVD}$ and $\sim 1470 \mathrm{mTVD}$. It appears that hot water enters the well at 1130 mTVD, mixes with the injected cold water and moves down the borehole, and finally leaves the formation at $1470 \mathrm{mTVD}$. The permeable zones at 1130 mTVD and 1470 mTVD are confirmed by thermal features in later heatup surveys (Figure 3.66). A change in temperature gradient at $\sim 850 \mathrm{mTVD}$ in the temperature survey of September 11, 1987 implies the existence of another permeable horizon at this depth. Downhole spinner surveys run during a discharge test in March 1988 (Figure 3.67) indicate that the bulk of the fluid enters the well at 1130 mTVD. The spinner surveys provide no clear evidence of fluid influx at 1470 mTVD and 850 mTVD. It is therefore reasonable to conclude that the principal feedzone for $\mathrm{N}-14 \mathrm{~T}$ is located at 1130 mTVD (-738 mASL). The temperature survey of November 25, 1991 was presumably recorded after the well had been shut-in for several months, and shows that the maximum temperature $\left(\sim 288^{\circ} \mathrm{C}\right)$ occurs towards the bottom of the well. The feedzone temperature is about $265^{\circ} \mathrm{C}$.

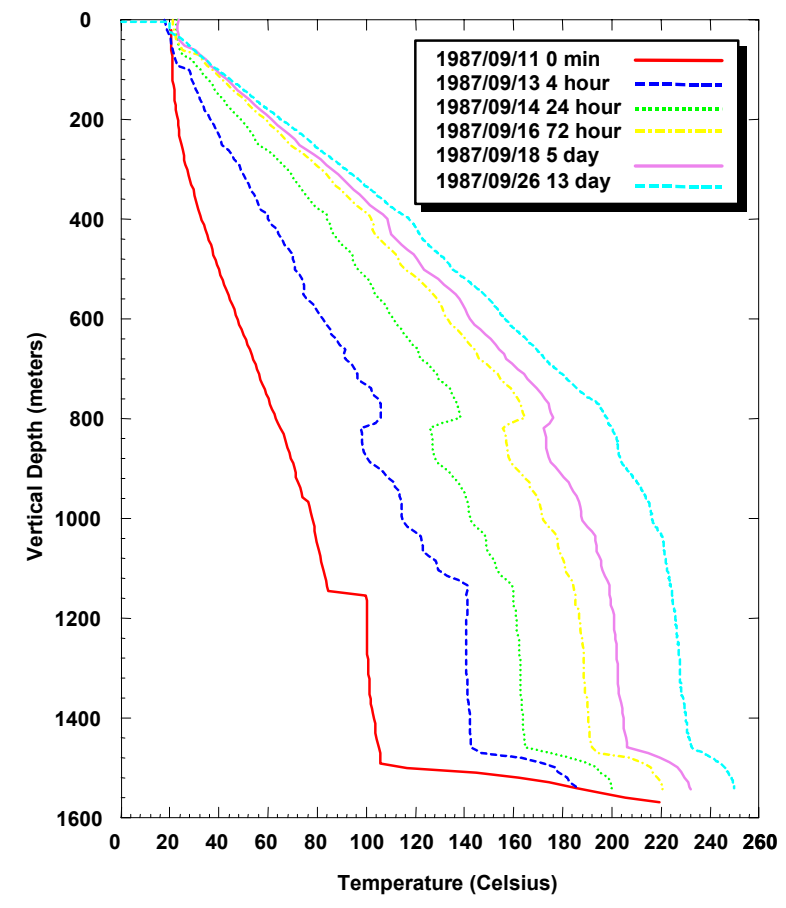

Figure 3.66. Selected heatup surveys in production well N-14T.

During three (3) separate discharge tests (October 8, 1987 - November 6, 1987, December 12, 1987 - March 29, 1988, and November 28, 1989 - March 1, 1990), N-14T discharged a mixture of water and steam with wellhead enthalpies ranging from $1250 \mathrm{~kJ} / \mathrm{kg}$ to $2620 \mathrm{~kJ} / \mathrm{kg}$. Downhole pressure (Figure 3.69) and temperature (Figure 3.68) surveys taken in the discharging well in March 1988 show the presence of boiling conditions in the well at the feedzone depth. Both the wellhead enthalpy and downhole pressure/temperature data imply that discharge from N-14T is accompanied by in situ boiling. 


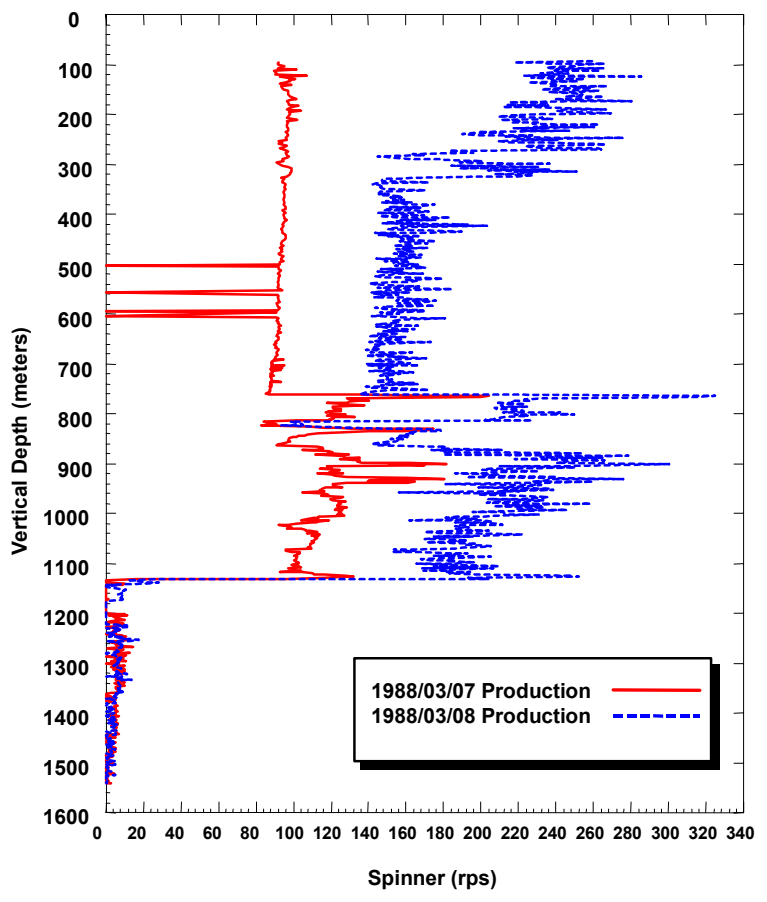

Figure 3.67. Spinner surveys taken during a discharge test of production well N-14T in March 1988.

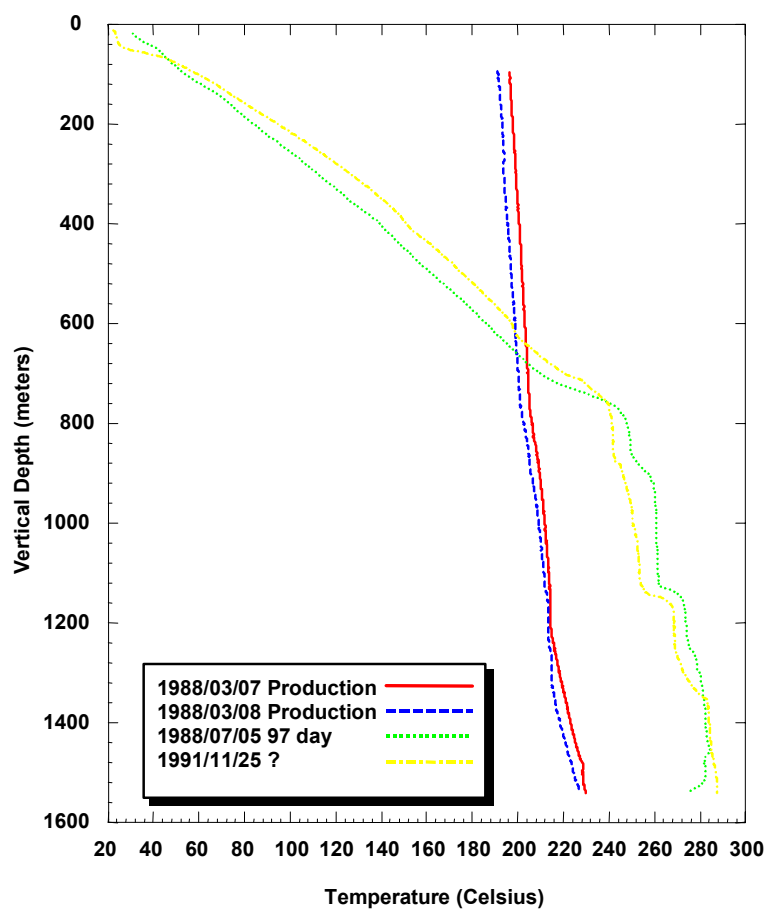

Figure 3.68. Selected temperature surveys in production well N-14T.
Pressures computed from water level and temperature data are plotted in Figure 3.70. The pressure at $1130 \mathrm{mTVD}(-738 \mathrm{mASL})$ is $\sim 99.5$ bars. The latter pressure value is not too different from that (100.5 bars) recorded by a downhole gauge on September 26, 1987 (Figure 3.69). Later pressure surveys in the shut-in well show considerably lower pressures (76.0 bars on July 5, 1988, and 84.1 bars on November 25, 1991). Apparently, the feedzone pressure recovers rather slowly after a discharge test.

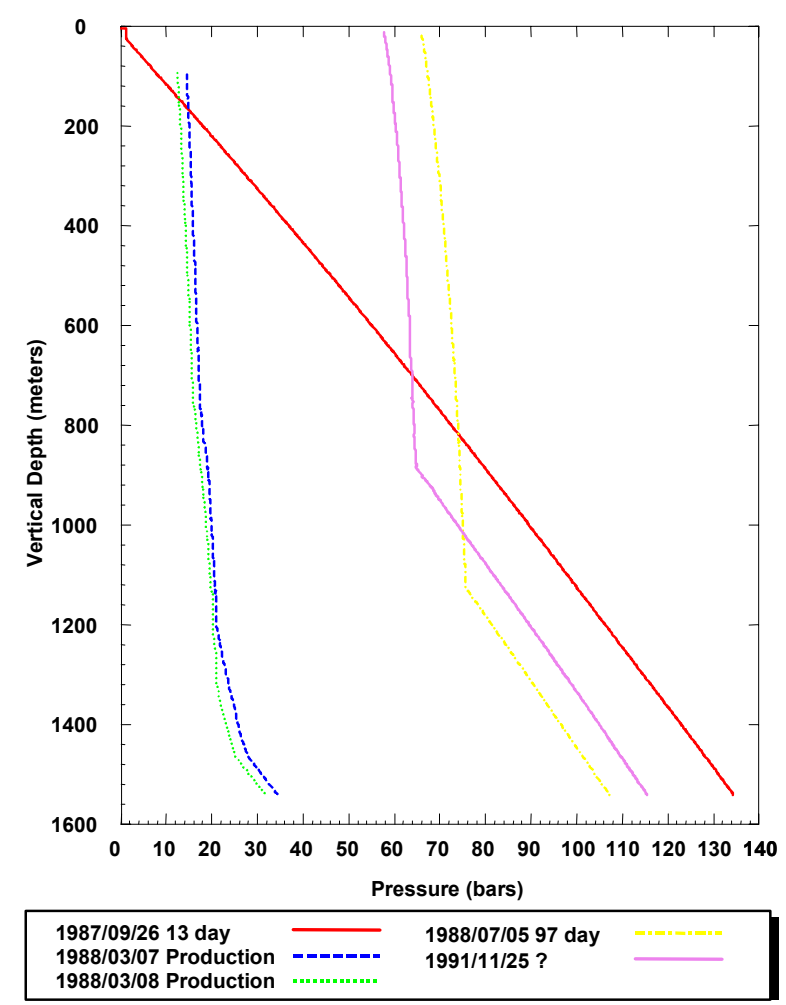

Figure 3.69. Selected pressure surveys in production well N-14T. 


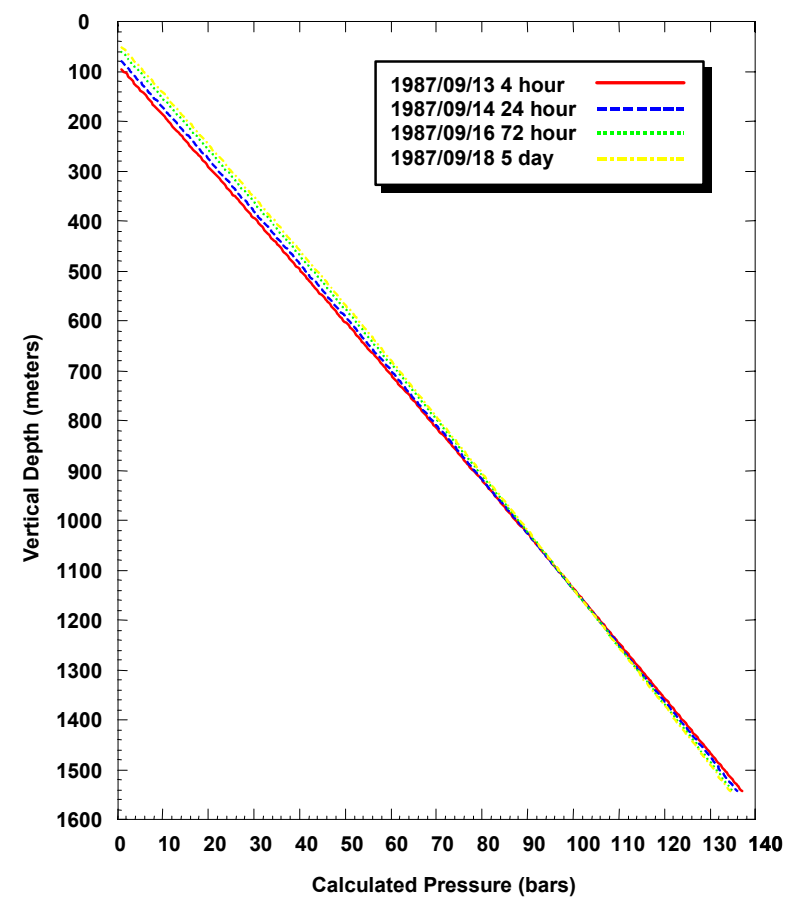

Figure 3.70. Pressures computed from water level and temperature data in production well N-14T.

\section{Production Well N-15T}

Heatup survey of September 11, 1987 (Figure 3.71), taken shortly after cold water injection, exhibits a sharp break in temperature gradient at $\sim 1215$ mTVD and a cold zone at 1790-1830 mTVD. In later temperature surveys (Figure 3.71), the permeable zone at 1215 mTVD heats up rapidly. The cold zone at 1790-1830 mTVD also appears to persist for at least several days. A more or less isothermal interval is present from 1265 mTVD to 1705 mTVD. An isothermal zone implies the existence of some permeability at both of its end points. Spinner surveys taken during a discharge test of well N-15T (Figure 3.72) indicate the presence of major fluid entries at 1150 mTVD, 1645 mTVD and 1790 mTVD. Because of the presence of slotted liner in the borehole, spinner surveys are less useful in confirming the existence of other fluid entries. The temperature survey of November 26, 1991 (Figure 3.71) was taken after the well had been shut-in for several months, and indicates that the maximum temperature $\left(\sim 300^{\circ} \mathrm{C}\right)$ occurs at the bottom of the well. The stable temperature at the deepest fluid entry at $1790 \mathrm{mTVD}$ is $\sim 298^{\circ} \mathrm{C}$.

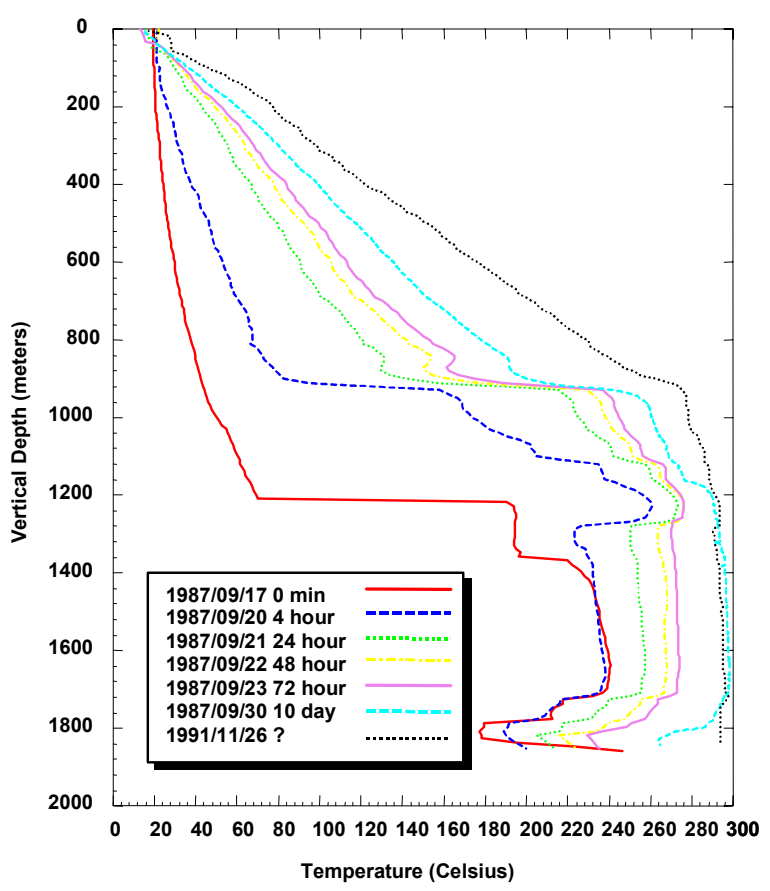

Figure 3.71. Selected heatup surveys in production well N-15T.

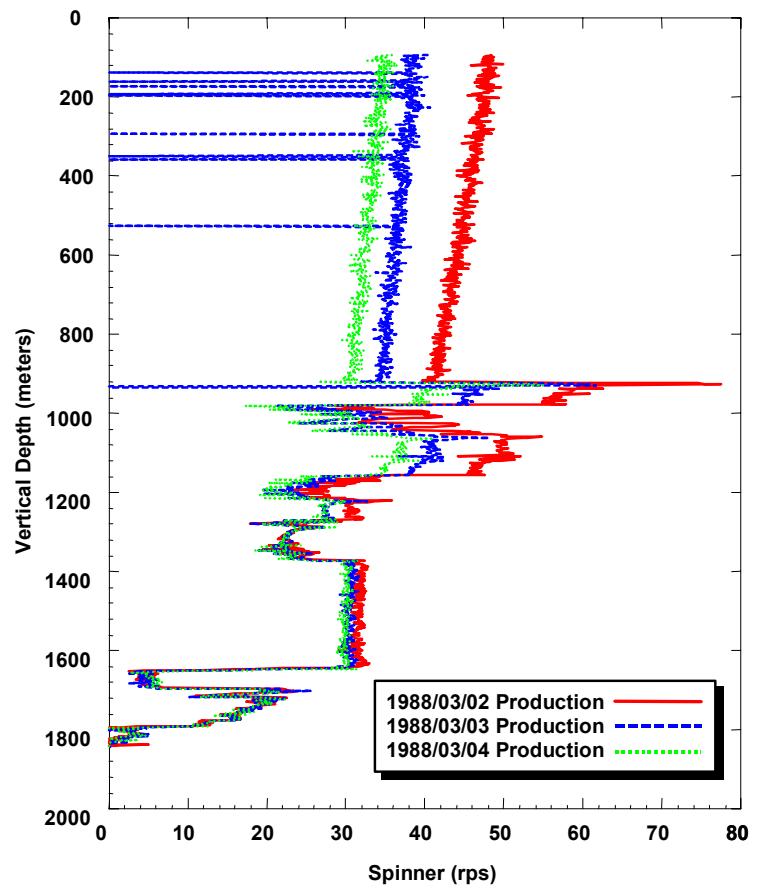

Figure 3.72. Spinner surveys recorded during a discharge test of production well N-15T in March 1988. 
After an initial discharge test (November 7, 1987 - December 8, 1987), well N-15T was discharged during two long-term field wide discharge tests (December 9, 1987 - March 26, 1988 and November 15, 1989 -March 1, 1990). During these three discharge tests, N$15 \mathrm{~T}$ produced a mixture of water and steam with wellhead enthalpies ranging from $\sim 1400$ $\mathrm{kJ} / \mathrm{kg}$ to $\sim 2700 \mathrm{~kJ} / \mathrm{kg}$. Temperature (Figure 3.73) and pressure (Figure 3.74) surveys in the flowing well show the presence of two-phase conditions along the entire length of the borehole. The relatively small value of the pressure gradient implies that steam is the continuous phase. There is little doubt that discharge from N-15T induces in situ boiling.

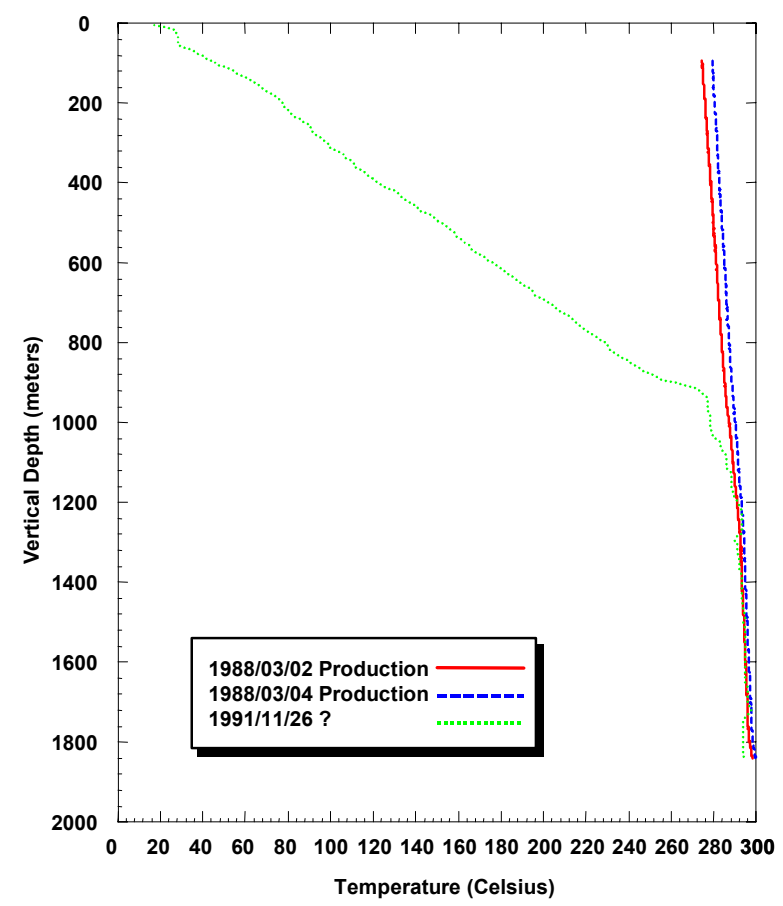

Figure 3.73. Selected temperature surveys taken during a discharge test of production well N-15T in March 1988.

Pressures computed from water level and temperature data are displayed in Figure 3.75. The pressure at $1150 \mathrm{mTVD}$ (-749.6 mASL) is about 102.6 bars. The latter pressure value is virtually the same as that (103.3 bars) recorded by a downhole gauge on September 30, 1987 (Figure 3.74). Pressure surveys taken on July 8, 1988 and November 26, 1991 do, however, indicate lower pressure values (86.9 and 84.8 bars) at 1150 mTVD.

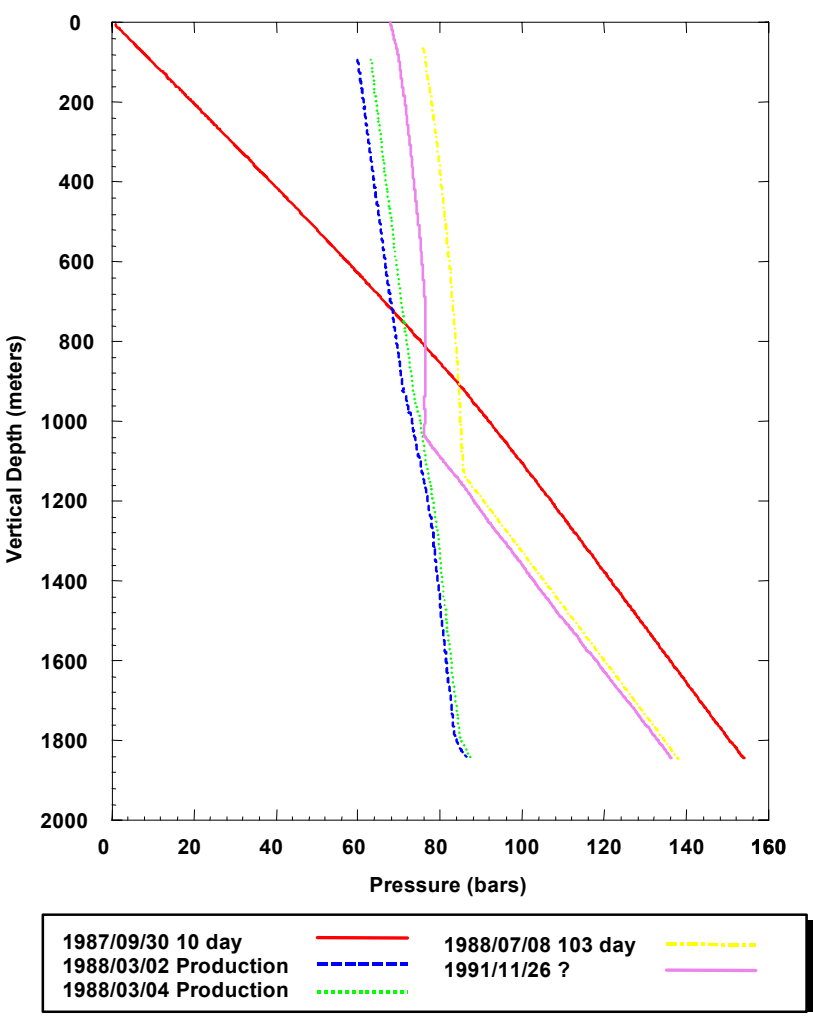

Figure 3.74. Selected pressure surveys in well N-15T.

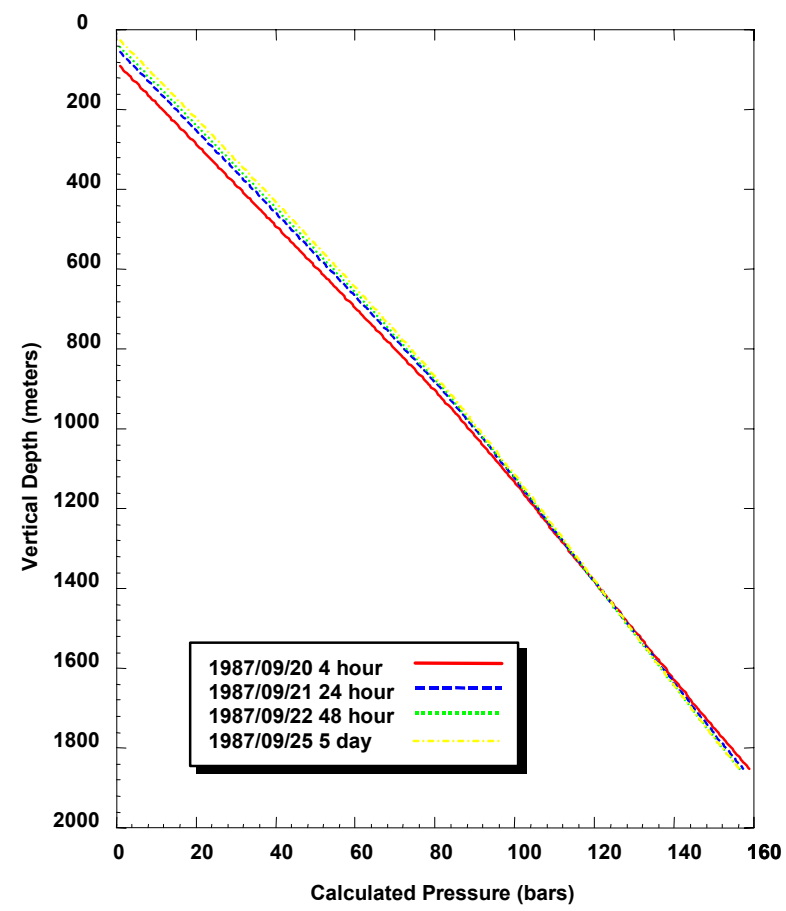

Figure 3.75. Pressures computed from water level and temperature data in production well N-15T. 


\section{Production Well N-16T}

Temperature survey of July 11, 1987 (Figure 3.76), taken while injecting cold water, indicates that most of the injected water is lost over the depth interval 1580-1660 mTVD. Short time heatup survey of July 18, 1987 (Figure 3.76) exhibits cold zones centered at $\sim 1250 \mathrm{mTVD}, \sim 1350 \mathrm{mTVD}$, and $\sim 1620$ mTVD. Changes in temperature gradient at $1250 \mathrm{mTVD}, 1350 \mathrm{mTVD}, 1580 \mathrm{mTVD}$, and $1640 \mathrm{mTVD}$ are seen in later heatup surveys (Figure 3.76). Spinner surveys taken during a discharge test in March 1989 (Figure 3.77) indicate the presence of fluid entries at about $1620 \mathrm{mTVD}, 1600 \mathrm{mTVD}, 1550 \mathrm{mTVD}$, and $1260 \mathrm{mTVD}$. The temperature survey of November 28, 1991 (Figure 3.76) was taken after the well was shut-in for several months. The latter temperature survey shows a cold zone at $1650(+/-30)$ mTVD. The maximum temperature in well N-16T occurs towards the bottom of the well and is about $280^{\circ} \mathrm{C}$. The stable temperature at the deepest fluid entry (1620 mTVD) is around $268^{\circ} \mathrm{C}$.

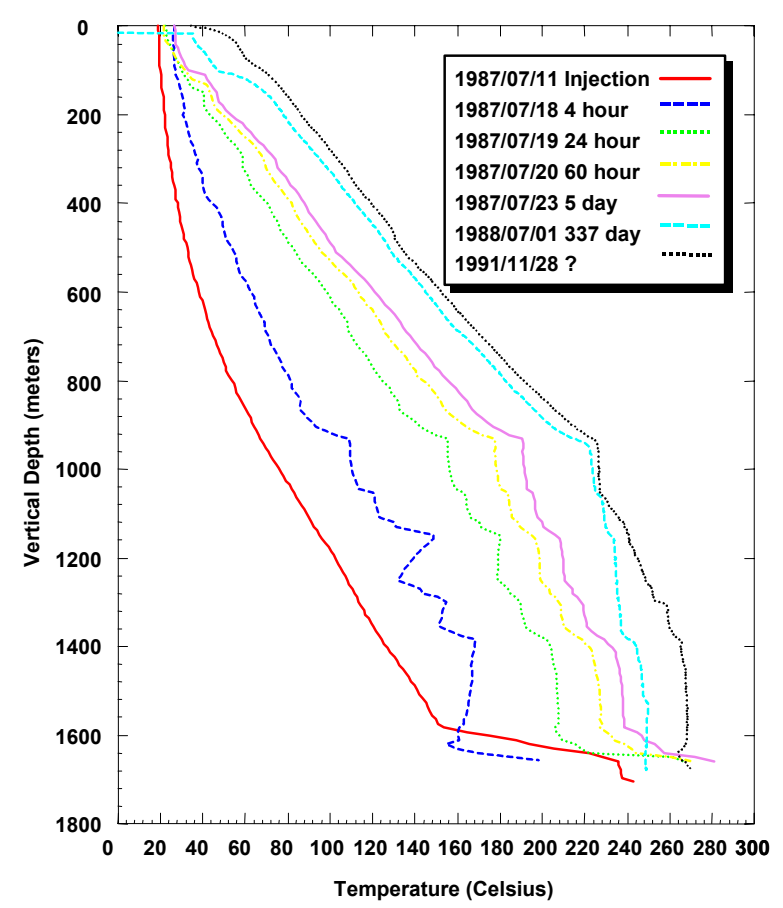

Figure 3.76. Selected heatup surveys in production well N-16T.

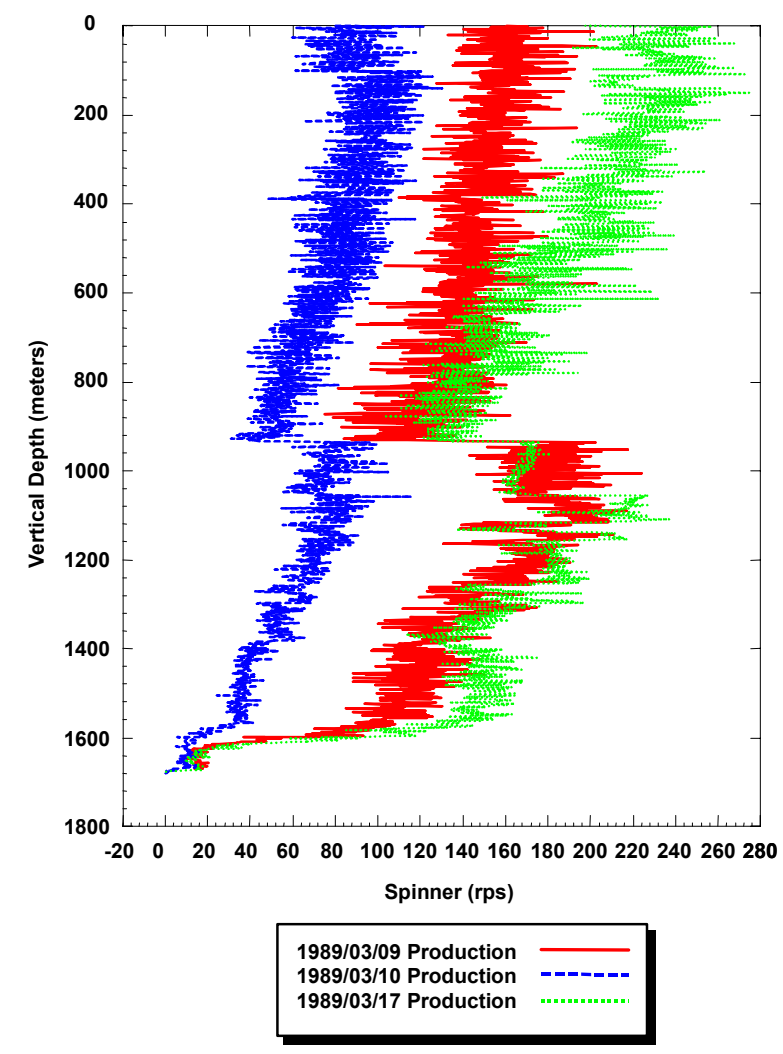

Figure 3.77. Spinner surveys taken during a discharge test of production well N-16T in March 1989.

Production well N-16T was discharged for extended periods during field-wide discharge tests conducted in 1988-89 and 1989-90. During the 1988-89 test (December 1, 1988 to March 19, 1989), the wellhead enthalpies ranged from $1100 \mathrm{~kJ} / \mathrm{kg}$ to $1500 \mathrm{~kJ} / \mathrm{kg}$. Available data indicate that the wellhead enthalpies during the 1989-90 test were significantly higher. Temperature (Figure 3.78) and pressure (Figure 3.79) surveys taken in the discharging well in March 1989 imply the existence of two-phase conditions in the wellbore. Clearly, production from N-16T is accompanied by in situ boiling.

Pressures computed from water level and temperature data are plotted in Figure 3.80. The pressures at $1260 \mathrm{mTVD}(-845.5 \mathrm{mASL})$ and $1620 \mathrm{mTVD}(-1205.5 \mathrm{mASL})$ are 105.7 bars and 135.1 bars, respectively. The latter pressure values are not too different from those (104.0 bars and 133.5 bars) recorded by 
a downhole gauge on July 1, 1988. The pressure survey taken on November 28, 1991 gave somewhat lower (102.2 bars and 130.2 bars) pressure values.

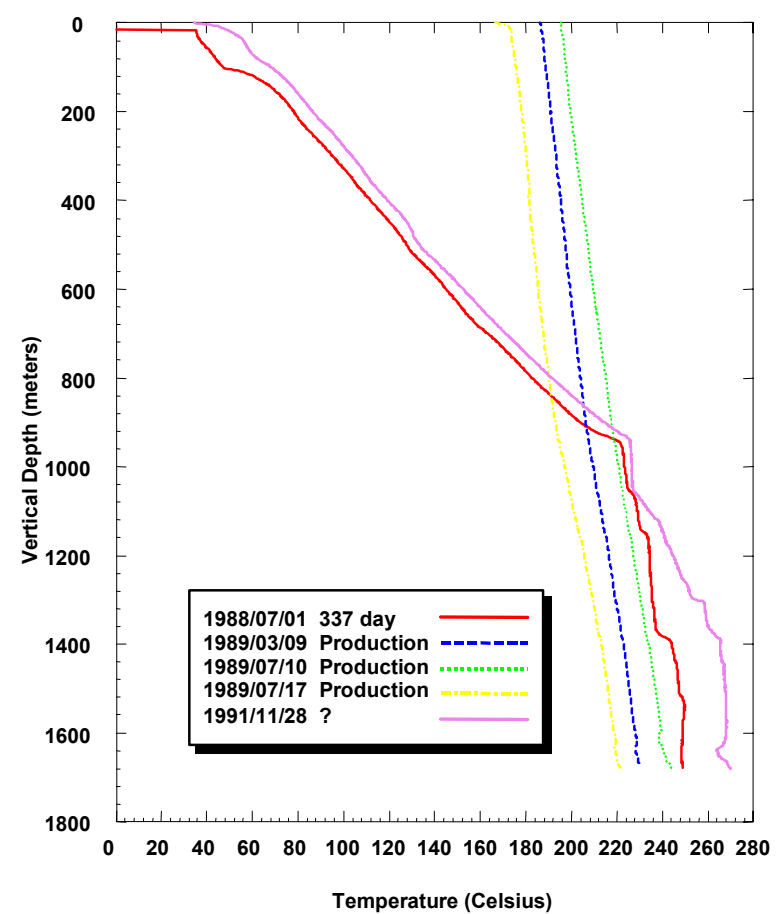

Figure 3.78. Temperature surveys taken during a discharge test of production well N-16T in March 1989.

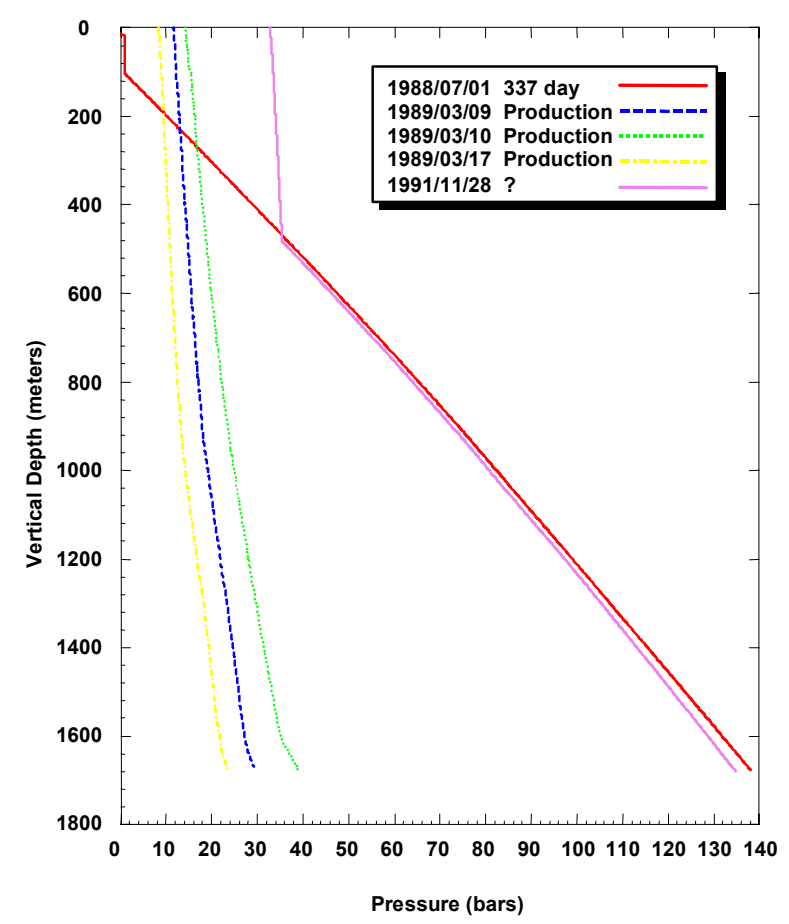

Figure 3.79. Pressure surveys in production well N-16T.

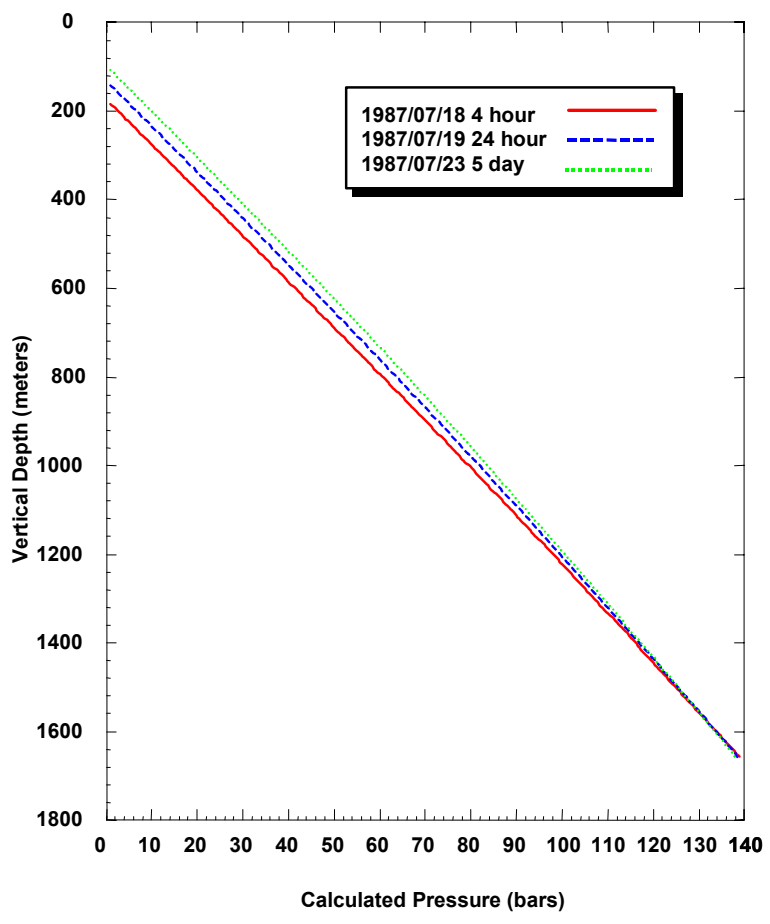

Figure 3.80. Pressures computed from water level and temperature data in production well N-16T.

\section{Production Well N-17T}

A temperature survey taken during an injection test on September 30, 1987 (Figure 3.81) implies that the injected fluid enters the formation at $910 \mathrm{mTVD}$ and at 1520 mTVD. While drilling N-17T, total circulation losses were encountered nearby (at 918 mTVD and $1510 \mathrm{mTVD}$ ) both of the latter depths. The existence of a permeable zone at $1520 \mathrm{mTVD}$ is confirmed by the presence of a cold zone at this depth in several heatup surveys (Figure 3.81). Spinner surveys performed during a discharge test in March 1989 (Figure 3.82) indicate fluid influx at $1520 \mathrm{mTVD}$ and at $\sim 940 \mathrm{mTVD}$. Because of the scatter in the spinner data, the location of the upper entry is not exact. Temperature surveys in the discharging well (Figure 3.83) show changes in temperature gradient at $\sim 935$ mTVD and at $\sim 850 \mathrm{mTVD}$, and thus imply the existence of a fluid entry in the depth interval 850-935 mTVD. The maximum temperature in $\mathrm{N}-17 \mathrm{~T}$ occurs towards the bottom of the well, and is $\sim 285^{\circ} \mathrm{C}$. The stable 
temperature at the lower fluid entry (1520 mTVD) is $\sim 279^{\circ} \mathrm{C}$.

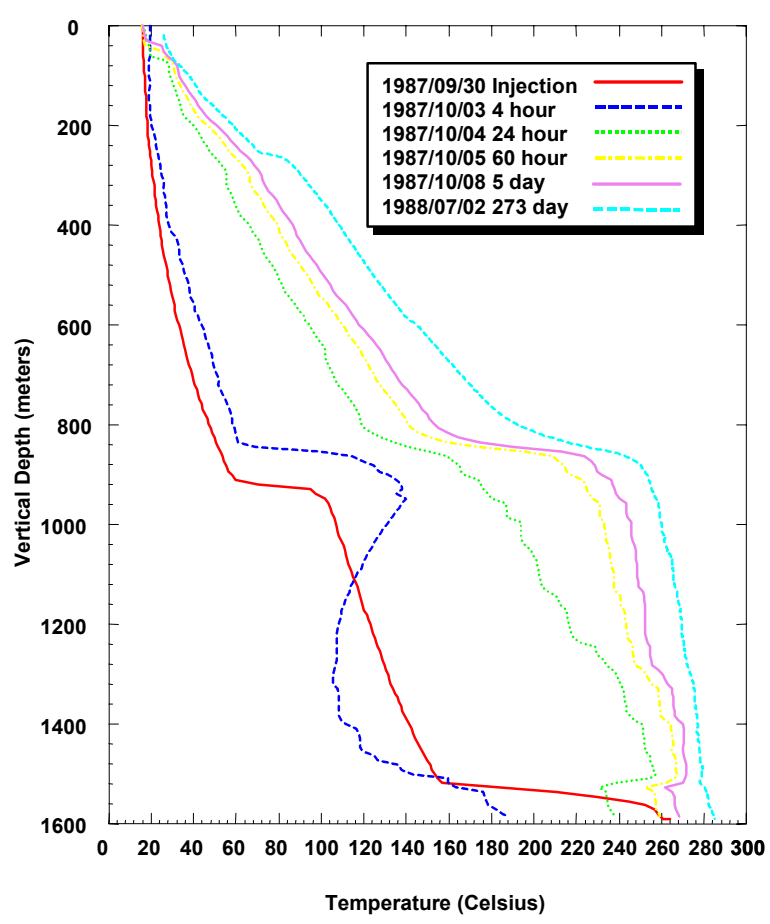

Figure 3.81. Selected heatup surveys in production well N-17T.

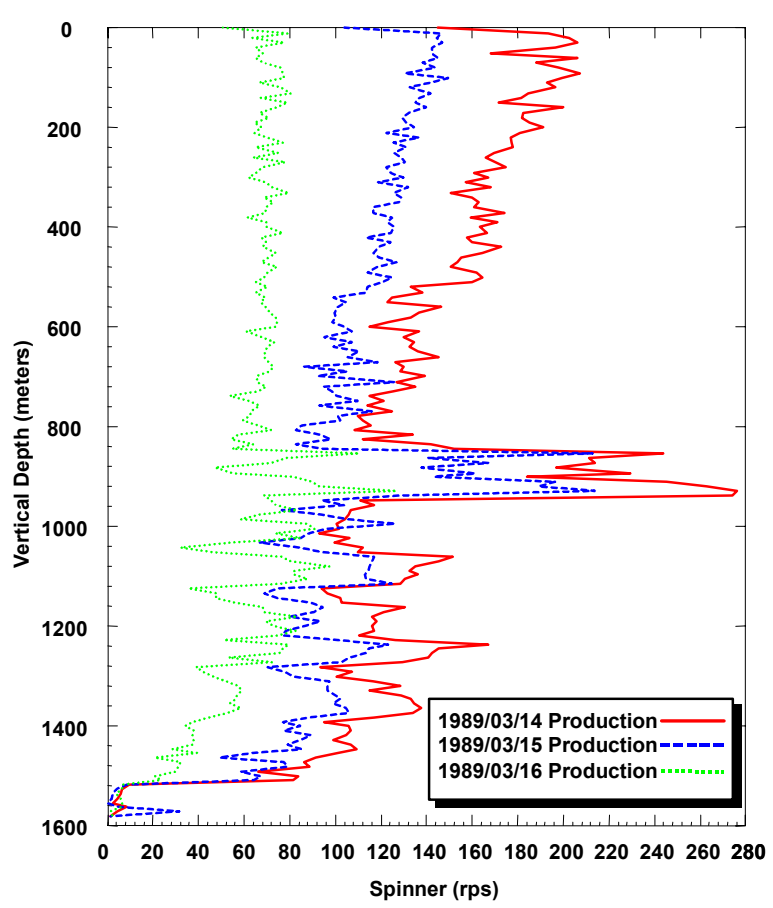

Figure 3.82. Spinner surveys taken during a discharge test of production well N-17T in March 1989.
Discharge tests of N-17T were performed in 1988-89 (December 4, 1988 - March 21, 1989) and 1989-1990 (November 22, 1989 March 2, 1990). The well discharged a mixture of water and steam with wellhead enthalpies ranging from $\sim 1340 \mathrm{~kJ} / \mathrm{kg}$ to $\sim 1830$ $\mathrm{kJ} / \mathrm{kg}$. Temperature (Figure 3.83) and pressure (Figure 3.84) surveys in the discharging well show the presence of two-phase conditions along the entire length of the borehole. Clearly, discharge from N-17T is accompanied by in situ boiling.

Pressures computed from water level and temperature data are plotted in Figure 3.85. The pressure at $910 \mathrm{mTVD}(-495.5 \mathrm{mASL})$ is $\sim 82.6$ bars, and the pressure at 1520 mTVD $(-1105.5 \mathrm{mASL})$ is $\sim 130.3$ bars. The latter pressure values are significantly higher than those (79.3 bars and 125.2 bars) measured by a downhole gauge on July 2, 1988. Still lower pressure values (74.4 bars and 123.4 bars) were recorded during a pressure survey made on November 28, 1991.

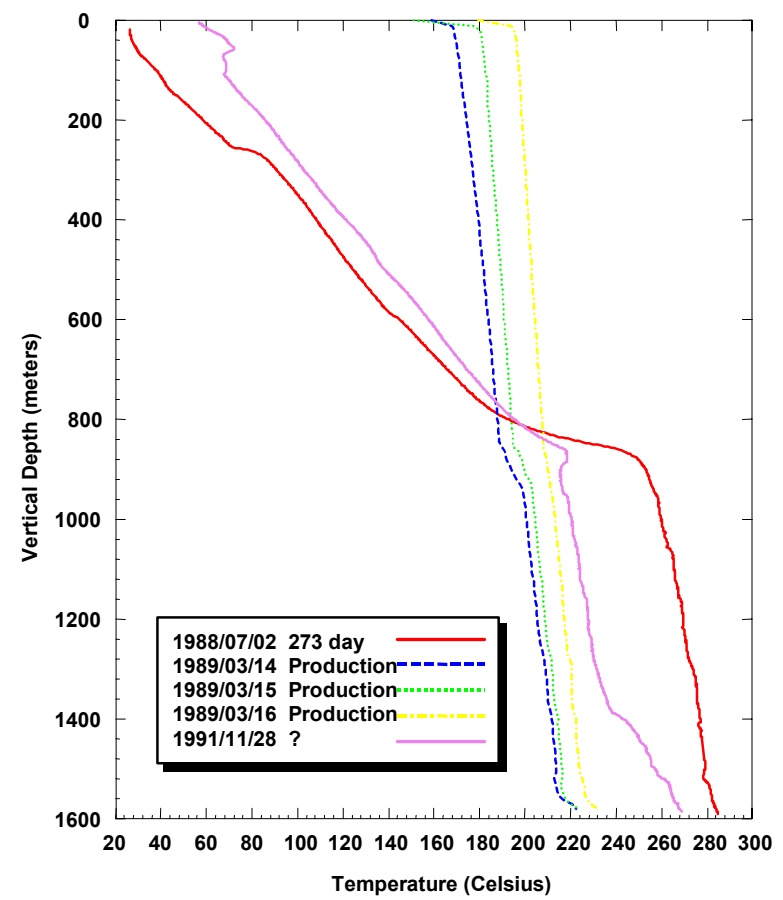

Figure 3.83. Selected temperature surveys in production well $\mathrm{N}-17 \mathrm{~T}$. 


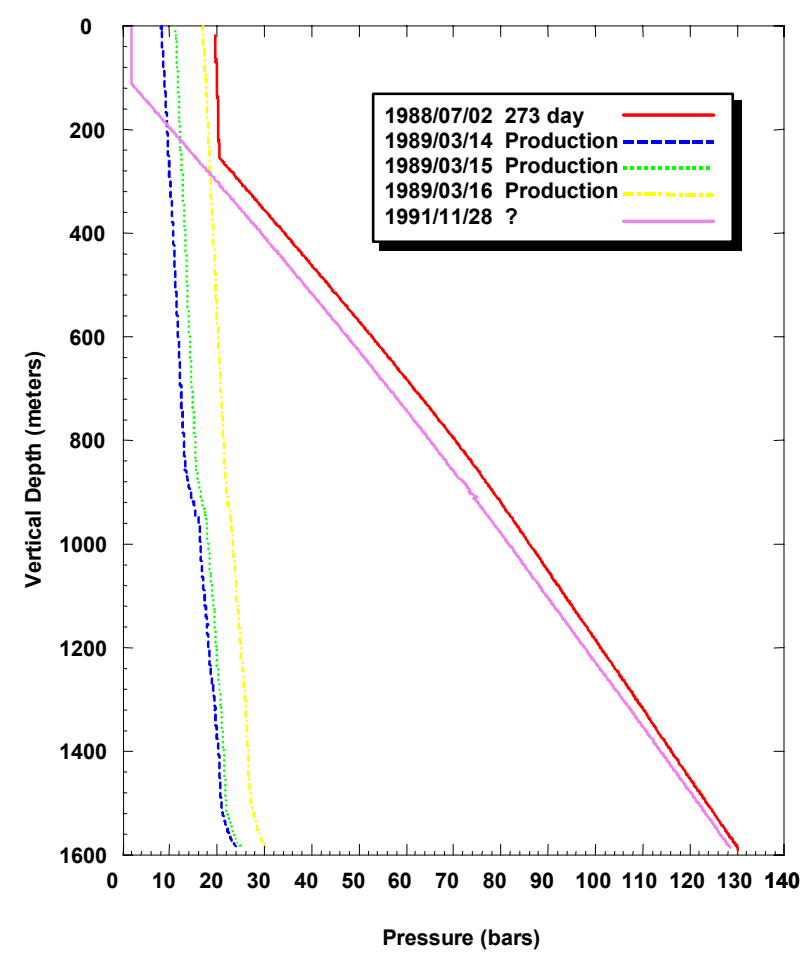

Figure 3.84. Pressure surveys in production well N-17T.

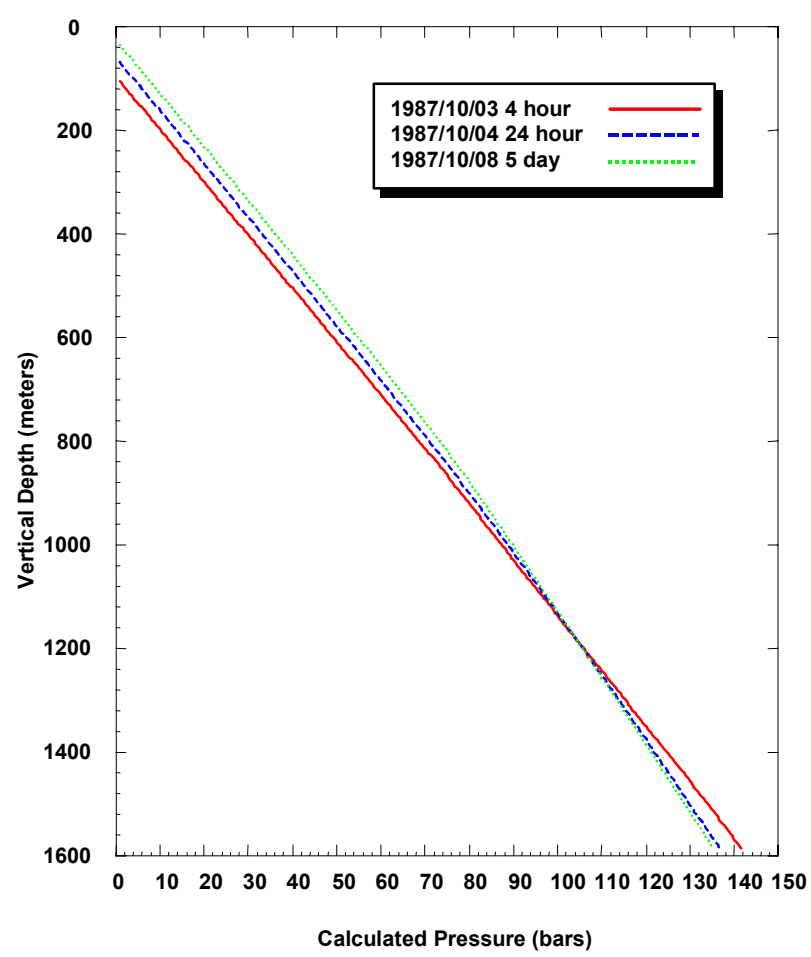

Figure 3.85. Pressures computed from water level and temperature data in production well N-17T.

\section{Slim Hole N-18t}

Slim hole N-18t was drilled from a location in the northeastern part of the Okuaizu borefield. A temperature survey taken while injecting cold water on February 7, 1988 (Figure 3.86) exhibits a cold zone and a change in temperature gradient at $\sim 1040 \mathrm{mTVD}$. Other temperature surveys show the cold zone at a slightly greater depth ( 1050 mTVD). While drilling $\mathrm{N}-18 \mathrm{t}$, a complete loss of circulation occurred nearby at $\sim 1033$ mTVD. Several temperature surveys (Figure 3.86) also exhibit a change in temperature gradient at $\sim 1180$ mTVD; it appears that very little, if any, of the injected fluid is lost below the latter depth. In the absence of more definitive data, it is reasonable to assume that the principal feedzone for $\mathrm{N}-18 \mathrm{t}$ is located at $\sim 1110$ mTVD (i.e., at the mid point of the entries at 1040 mTVD and 1180 mTVD).

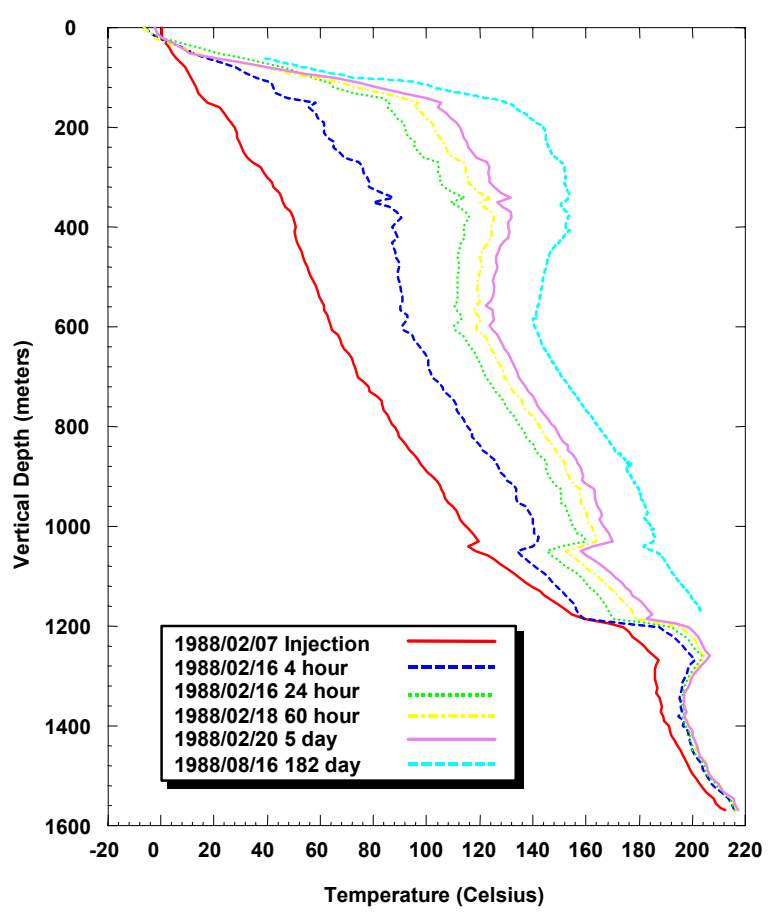

Figure 3.86. Selected temperature surveys in slim hole $\mathrm{N}-18 \mathrm{t}$.

All of the available temperature surveys (Figure 3.86) show a temperature inversion below $\sim 1260$ mTVD. If real, the temperature 
inversion suggests that $\mathrm{N}-18 \mathrm{t}$ is located in an outflow zone of the Okuaizu Geothermal Field. The maximum temperature occurs towards the bottom of the borehole, and was recorded as $\sim 218^{\circ} \mathrm{C}$ on February 20, 1988 after the borehole had been shut-in for only 5 days.

Pressures computed from water level and temperature data are plotted in Figure 3.87. The pressure at $1110 \mathrm{mTVD}(-697.3 \mathrm{mASL})$ is $\sim 91.3$ bars. The latter pressure value is in exact agreement with that recorded by a downhole gauge on August 16, 1988 (Figure 3.88).

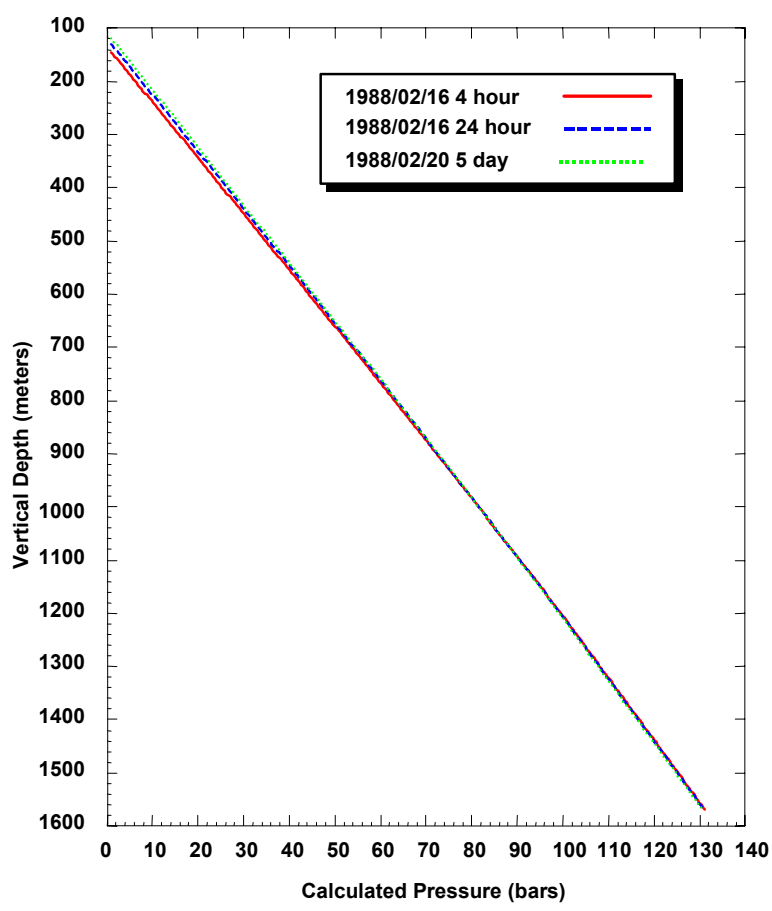

Figure 3.87. Pressures computed from water level and temperature data in slim hole N-18t.

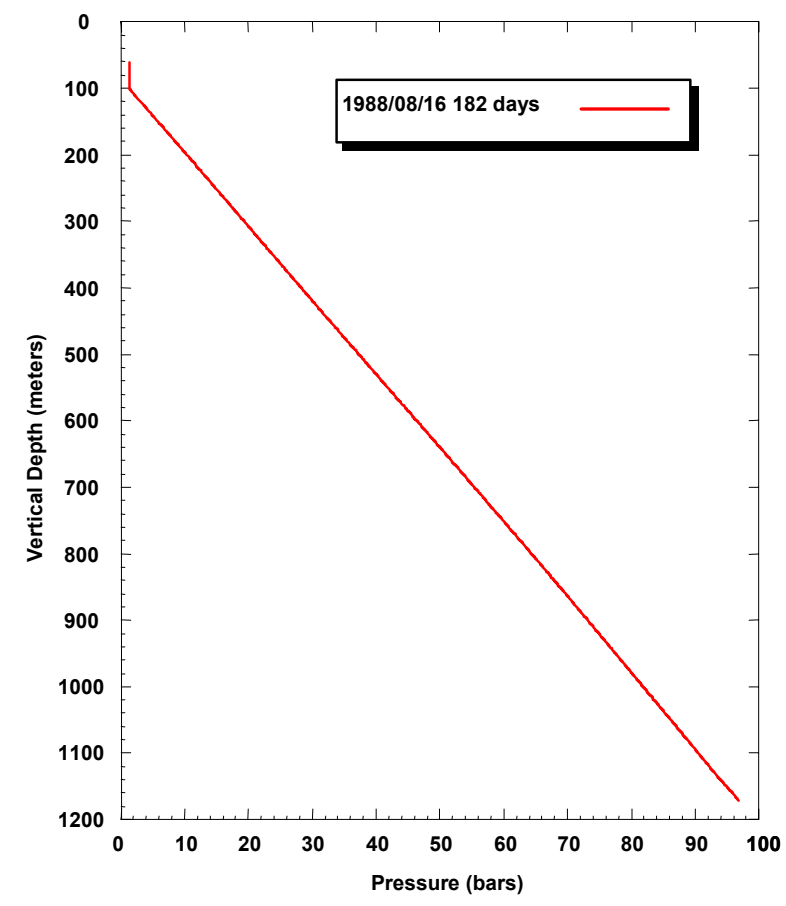

Figure 3.88. A pressure survey in slim hole N-18t.

No useful injection or discharge test data are available for slim hole $\mathrm{N}-18 \mathrm{t}$.

\section{Injection Well N-19R}

The temperature survey of September 17, 1988 (Figure 3.89) was taken while injecting cold water into injection well N-19R, and indicates fluid entries (?) at $\sim 860 \mathrm{mTVD}, 950$ mTVD, 1000 mTVD, and 1100 mTVD. Apparently hot water enters the well at the latter depths, mixes with the cold injected water, moves down the borehole, and finally enters the formation at 1350 mTVD. The heatup surveys display a more or less isothermal zone between $\sim 1010$ mTVD and $\sim 1350 \mathrm{mTVD}$, and confirm the presence of permeable horizons at or near both of the latter depths. In the absence of other data, it is assumed that the principal feedzone for N-19R is located at $\sim 1110$ mTVD (i.e., at the midpoint between the entries at 860 mTVD and $1350 \mathrm{mTVD})$. After 5 days of shut-in, a temperature of $\sim 173^{\circ} \mathrm{C}$ was recorded at 1350 mTVD on September 22, 1988. 


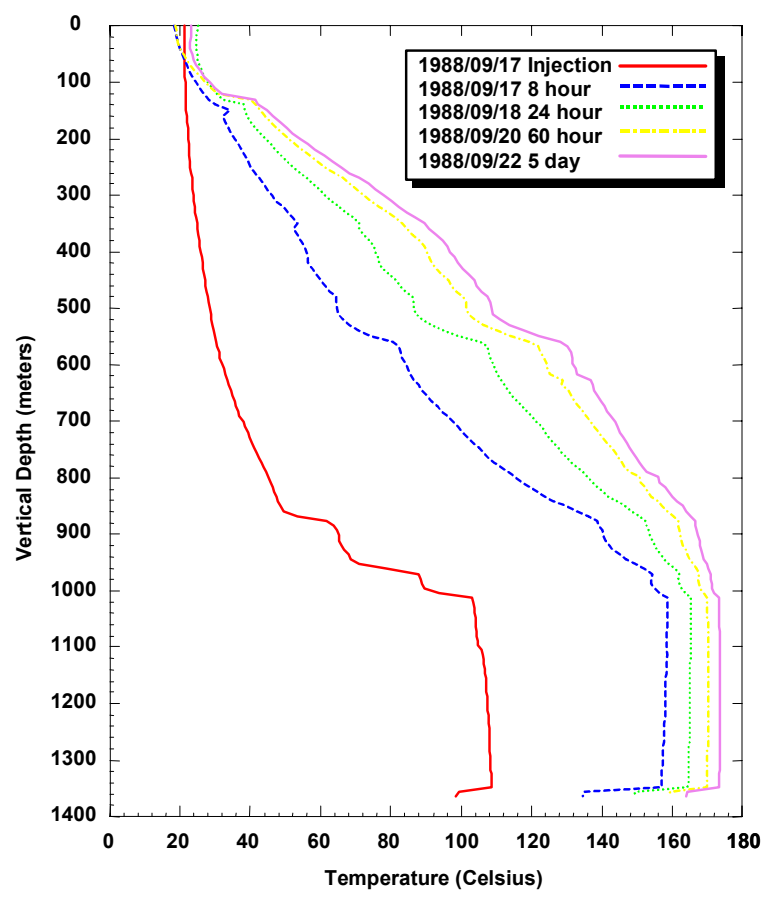

Figure 3.89. Selected temperature surveys in injection well N-19R.

Pressures computed from water level and temperature data are displayed in Figure 3.90. The pressure at $1110 \mathrm{mTVD}(-708.8 \mathrm{mASL})$ is $\sim 92.0$ bars.

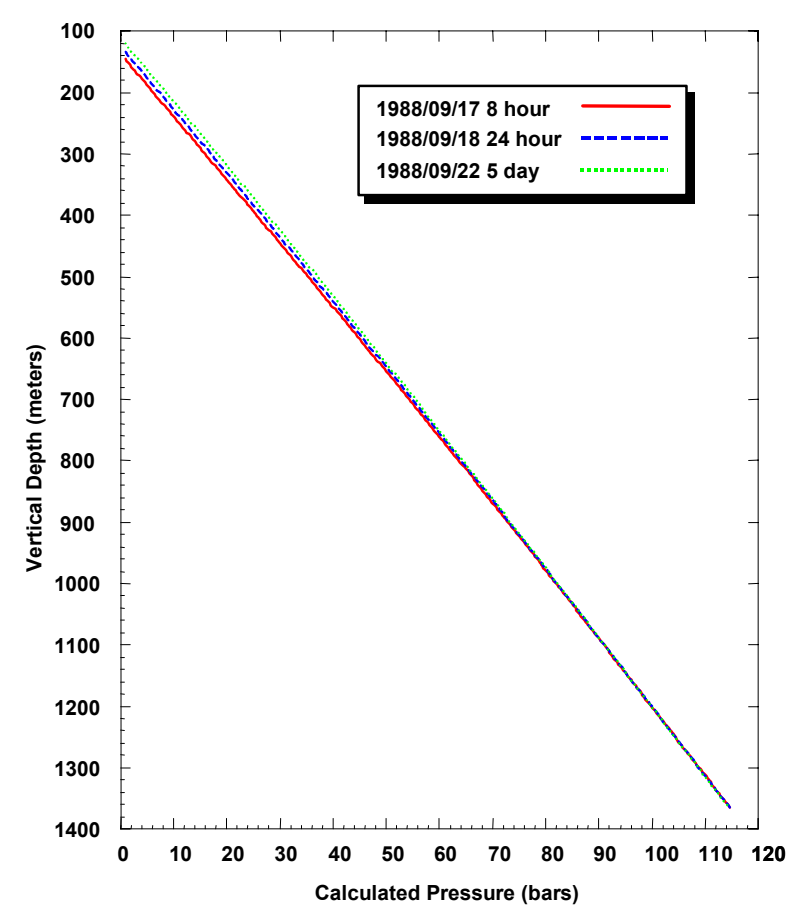

Figure 3.90. Pressures computed from water level and temperature data in injection well N-19R.
No useful injection or discharge test data are available for injection well N-19R.

\section{Injection Well $\mathrm{N}-20 R$}

A temperature survey taken during an injection test on November 19, 1988 (Figure 3.91) indicates the influx of hot water at $\sim 1030-1050$ mTVD. The hot water mixes with the cold injected water, moves down the borehole, and eventually enters the formation at $\sim 1250$ mTVD. While drilling N-20R, a total loss of circulation occurred at 1034 mTVD. An isothermal temperature zone extending from $\sim 1050$ mTVD to $\sim 1250$ mTVD can be discerned in all of the heatup surveys shown in Figure 3.91. An isothermal section implies the presence of permeable intervals at both its end points. In the absence of other data, it is assumed that the principal feedzone for N-20R is located at 1140 mTVD (i.e., the midpoint of the fluid entries at $1030 \mathrm{mTVD}$ and 1250 mTVD). The maximum temperature occurs towards the bottom of the well, and was recorded as $\sim 167^{\circ} \mathrm{C}$ on November 24, 1988 after the well had been shut-in for 5 days.

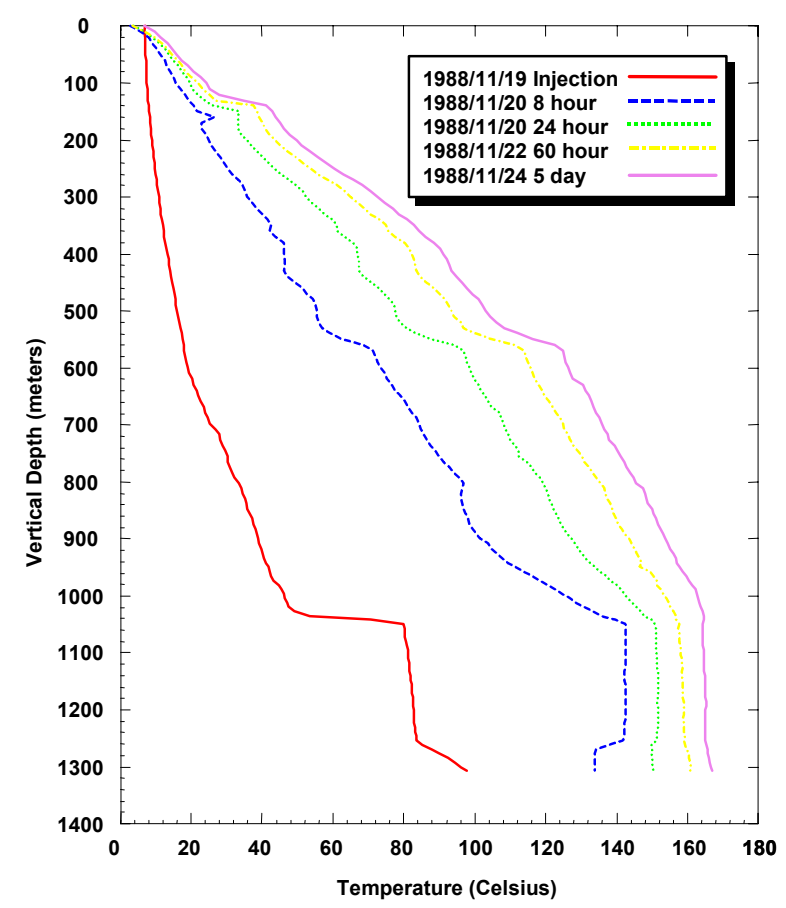

Figure 3.91. Selected temperature surveys in injection well N-20R. 
Pressures computed from water level and temperature data are displayed in Figure 3.92. The pressure at $1140 \mathrm{mTVD}(-738.8 \mathrm{mASL})$ is about 94.4 bars.

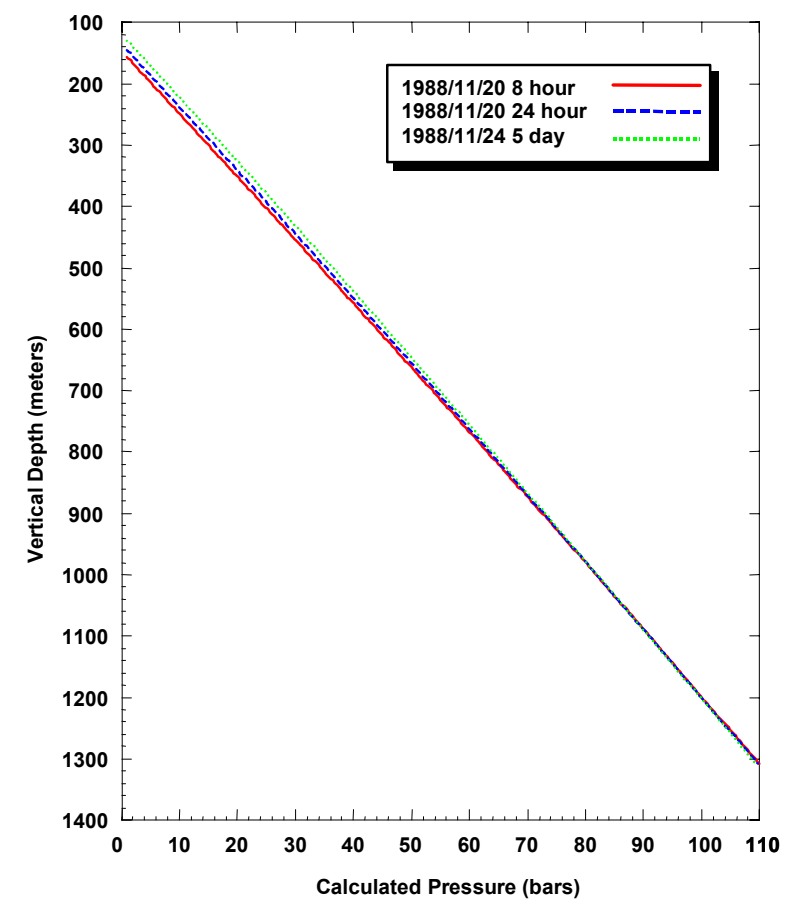

Figure 3.92. Pressures computed from water level and temperature data in injection well N-20R.

No useful injection or discharge test data are available for injection well N-20R.

\section{Production Well N-21T}

A temperature survey taken during an injection test on August 13, 1989 (Figure 3.93) exhibits gradient changes at $\sim 960$ mTVD, 1350 mTVD(?), and 1500 mTVD. Heatup surveys (Figure 3.93) exhibit more rapid heating at $970 \mathrm{mTVD}$ and $1290 \mathrm{mTVD}$. Two more or less isothermal zones (970-1300 mTVD, and 1310-1490 mTVD) can be discerned in the temperature survey taken after the well had been shut-in for about 5 days (Figure 3.93). The temperature survey of November 29, 1991, recorded while injecting cold water, extends to a depth of only 977 mTVD. A sharp increase in temperature at
960 mTVD (Figure 3.93) indicates the inflow of hot fluid (temperature $>277^{\circ} \mathrm{C}$ ) at this depth. The available temperature surveys thus indicate fluid entries at $\sim 960$ mTVD, 1300 mTVD, and $\sim 1500$ mTVD. The temperature survey taken during the 1989 injection test can be construed to indicate that the major feedzone for $\mathrm{N}-21 \mathrm{~T}$ is located at $\sim 1300$ mTVD. The presence of one or more minor fluid entries at or below $1850 \mathrm{mTVD}$ is also indicated by the heatup surveys. The maximum temperature occurs towards the bottom of the well. After 5 days of shut-in, a temperature of $\sim 309^{\circ} \mathrm{C}$ was recorded at the well bottom on August 18, 1989.

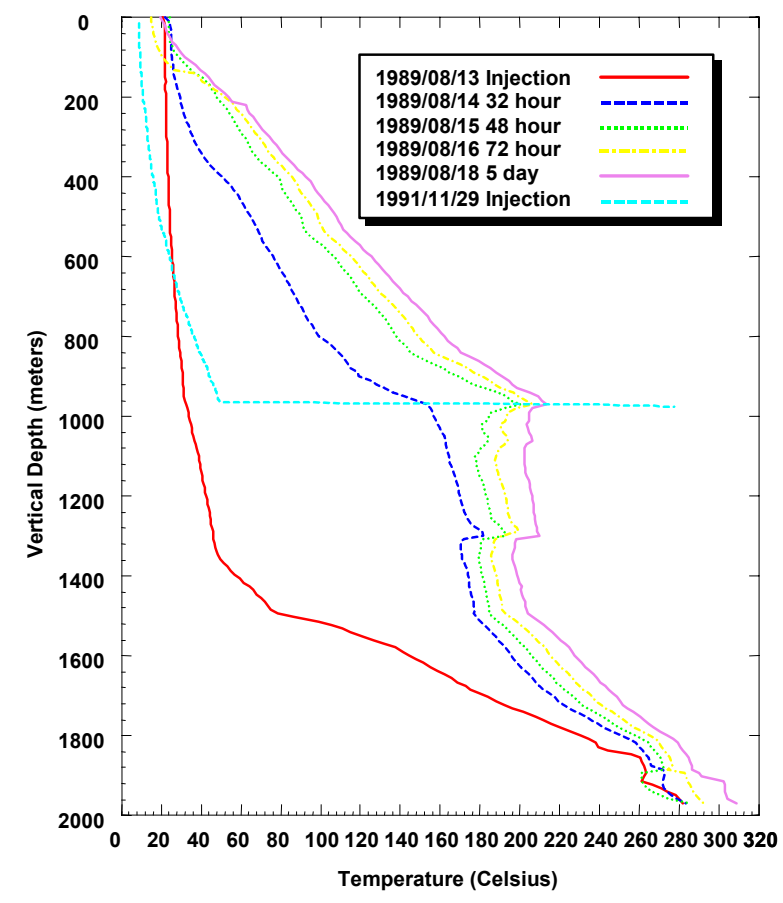

Figure 3.93. Selected temperature surveys in production well N-21T.

Production well N-21T was discharged for 99 days from November 24, 1989 to March 2, 1990. During a characteristic test performed on January 23, 1990, the wellhead enthalpies ranged from $1940 \mathrm{~kJ} / \mathrm{kg}$ to $2030 \mathrm{~kJ} / \mathrm{kg}$. Unfortunately, no downhole PTS surveys were taken in the discharging well. The enthalpy data indicate that production from N$21 \mathrm{~T}$ is accompanied by in situ boiling. 
Pressures computed from water level and temperature data are plotted in Figure 3.94. The pressure at $1300 \mathrm{mTVD}(-899.6 \mathrm{mASL})$ is $\sim 106.8$ bars, and the pressure at $960 \mathrm{mTVD}$ (-559.6 mASL) is $\sim 77.5$ bars. The stable pressure ( 77.5 bars) at $960 \mathrm{mTVD}$ is about 5 bars greater than that (72.2 bars) recorded by the PTS survey taken during the injection test on November 29, 1991. The November 1991 pressure data are thus consistent with the influx of hot fluid at 960 mTVD (see above).

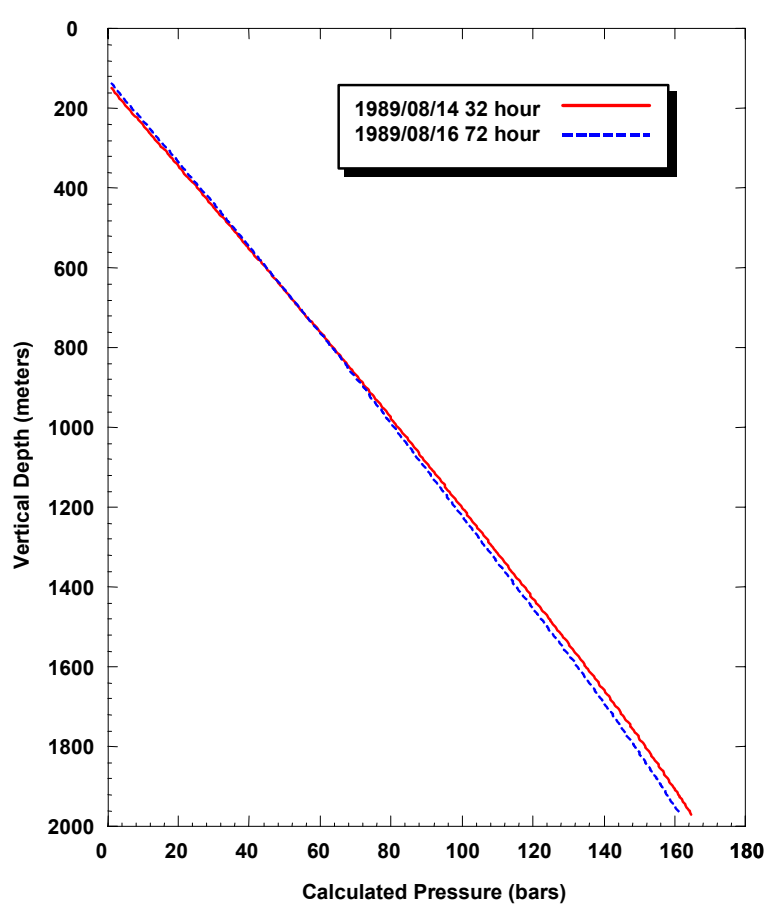

Figure 3.94. Pressures computed from water level and temperature data in production well N-21T.

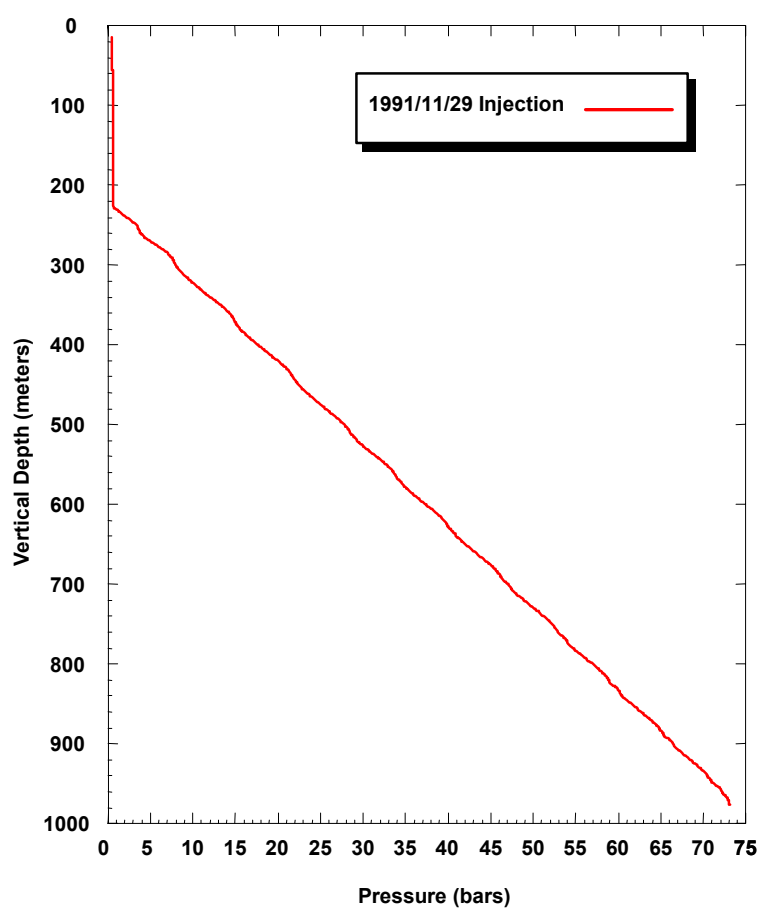

Figure 3.95. A pressure survey taken during an injection test on November 29, 1991 in production well N-21T.

\section{Production Well N-22T}

A temperature survey taken during an injection test on November 19, 1989 (Figure 3.96) exhibits breaks in temperature gradient at $\sim 1550$ mTVD and 2395 mTVD. While drilling $\mathrm{N}-22 \mathrm{~T}$, large circulation losses were encountered near both of the latter depths. Heatup surveys taken in November 1989 (Figure 3.96) also show a break in temperature gradient at $\sim 2140 \mathrm{mTVD}$, and thus imply the existence of a permeable zone at this depth. Temperature/pressure/spinner surveys taken during a discharge test in February 1990 extend to a depth of only $\sim 1530$ mTVD, and are therefore not helpful in deciding as to which of three entries (1550 mTVD, 2140 mTVD, 2395 mTVD) constitutes the principal feedzone for N-22T. Some of the highest temperatures at Okuaizu have been encountered in production well N-22T. After only 9 days of shut-in, a temperature of $\sim 341^{\circ}$ $\mathrm{C}$ was recorded at the bottom of the well on November 28, 1989. 

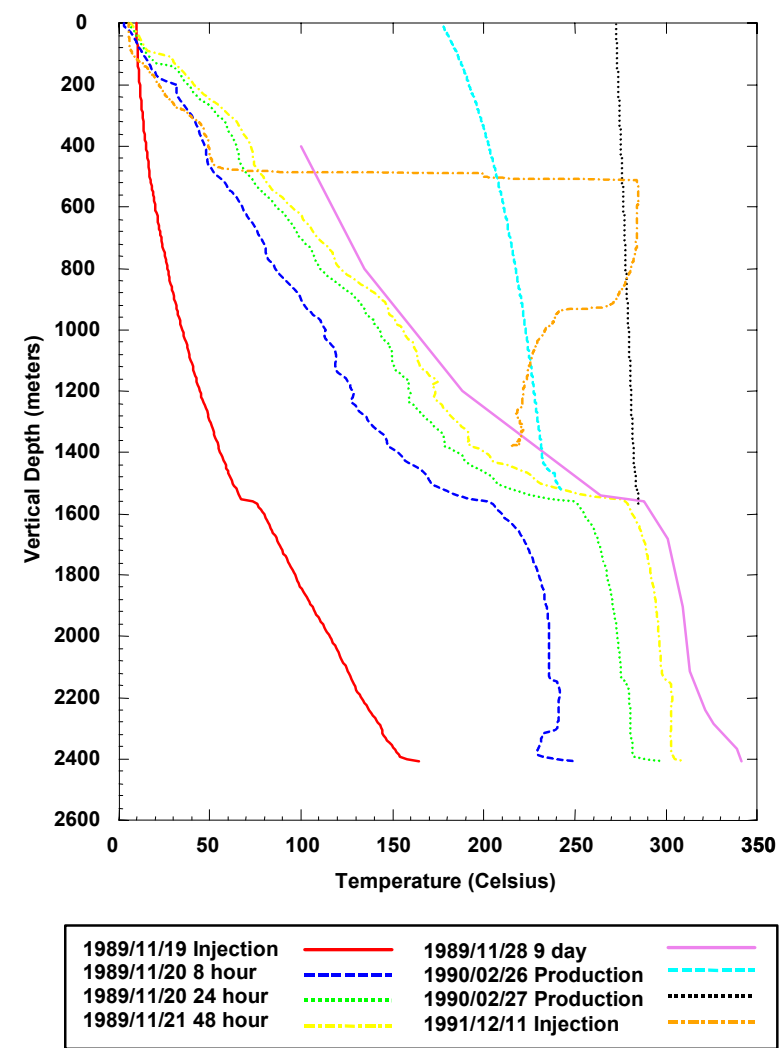

Figure 3.96. Selected temperature surveys in production well N-22T.

Temperature (Figure 3.96) and pressure (Figure 3.97) surveys recorded during an injection test on December 11, 1991 exhibit interesting features. The temperature survey shows a sharp rise in temperature at $\sim 470-480$ mTVD, and an isothermal zone (temperature $\sim 284^{\circ} \mathrm{C}$ ) from $510 \mathrm{mTVD}$ to $720 \mathrm{mTVD}$. The pressure gradient is very small ( $\sim 0.005 \mathrm{bars} / \mathrm{m})$ over the depth interval 510 mTVD to 860 mTVD. It is likely that hot fluid (steam or gas?) enters the well at 720-930 mTVD, flows up the wellbore, mixes with the injected cold fluid, and leaves the well at $\sim 470-480$ mTVD. In any event, it appears that by December 11, 1991, production well N-22T had developed several casing breaks.

A discharge test of $\mathrm{N}-22 \mathrm{~T}$ was performed from December 1, 1989 to February 27, 1990. The wellhead enthalpies ranged from $\sim 2120$ $\mathrm{kJ} / \mathrm{kg}$ to $\sim 2380 \mathrm{~kJ} / \mathrm{kg}$. The temperature (Figure 3.96) and pressure (Figure 3.97) surveys in the discharging well indicate the existence of twophase conditions over the entire logged interval (i.e., above $\sim 1530 \mathrm{mTVD}$ ). It is thus likely that discharge from N-22T induces in situ boiling.

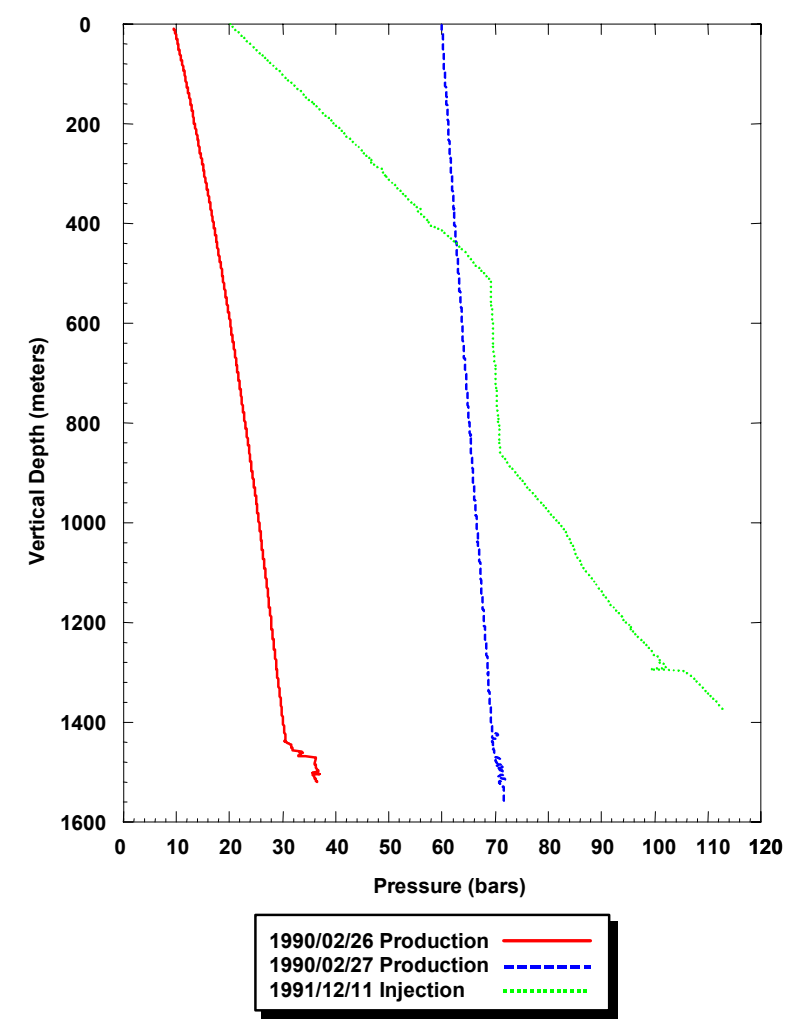

Figure 3.97. Pressure surveys in production well N-22T.

Pressures computed from water level and temperature data are plotted in Figure 3.98. The stable pressures at $1550 \mathrm{mTVD}(-1106.1 \mathrm{mASL})$ and 2395 mTVD (-1951.1 mASL) are estimated to be 133.7 bars and 194.9 bars, respectively. Pressure profiles (Figure 3.98) form a pivot around 2000 mTVD (-1556.1 mASL). The pressure at $2000 \mathrm{mTVD}$ is $\sim 166.5$ bars. 


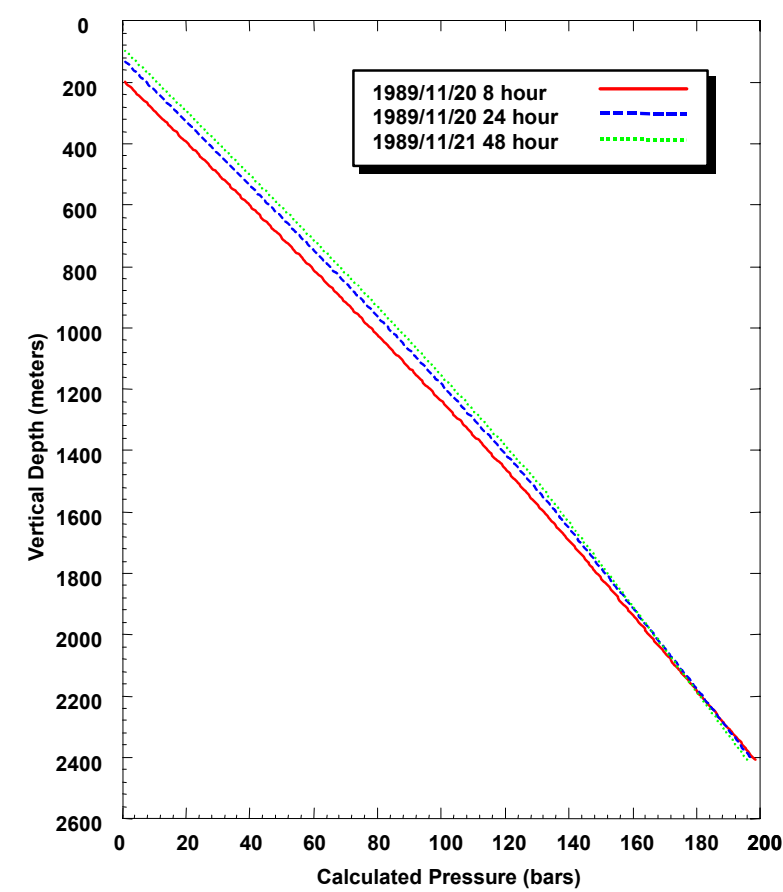

Figure 3.98. Pressures computed from water level and temperature data in production well N-22T.

\section{Production Well N-23P}

Temperature survey of August 5, 1990 (Figure 3.99) taken during a cold water injection test indicates hot fluid influx at $\sim 950$ mTVD and $\sim 1290$ mTVD. While drilling N23P, total circulation loss zones were encountered near both of the latter depths. The inflowing hot fluid mixes with the injected cold water, travels down the borehole, and then leaves the wellbore at or below a depth of $\sim 1460$ mTVD. The feedzone at 1460 mTVD is indicated by a change in temperature gradient (Figure 3.99) at this depth. Heatup surveys taken in August 1990 (Figure 3.99) show a cold zone over the depth interval 1600-1770 mTVD. Apparently, this latter zone accepted some cold water during injection. In the absence of other data, it is assumed that the major feedzone for N-23P is located at $\sim 1360$ mTVD (i.e., the middle of the permeable zones at $950 \mathrm{mTVD}$ and 1770 mTVD). The maximum temperature occurs towards the bottom of the well. After only 5 days of shut-in, a temperature of $320^{\circ} \mathrm{C}$ was recorded on August 10, 1990 at 1700 mTVD.

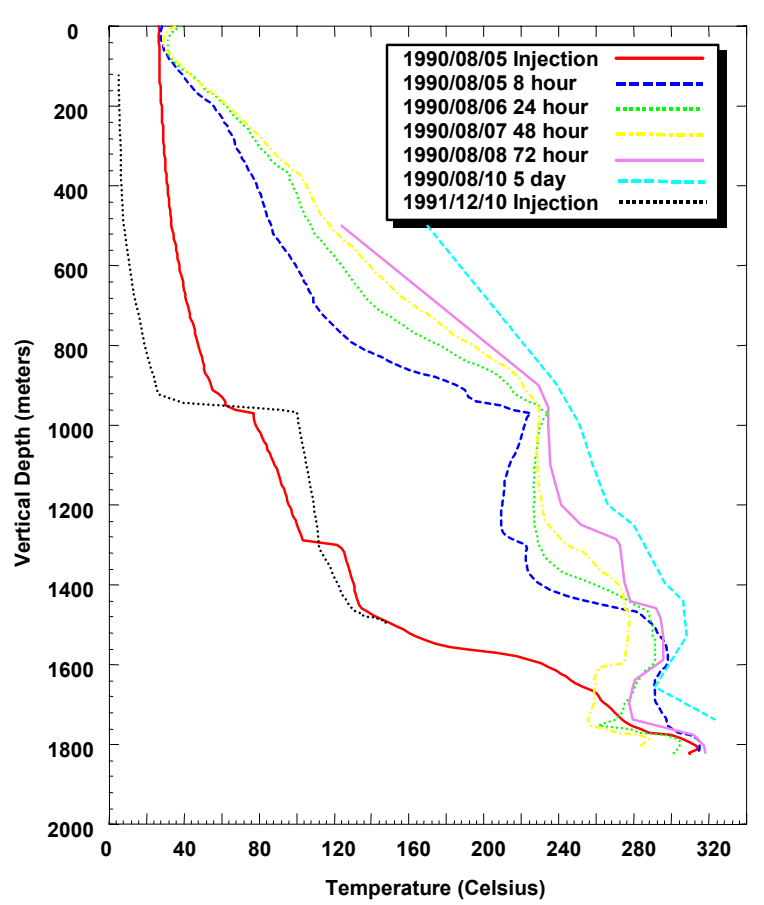

Figure 3.99. Selected temperature surveys in production well N-23P.

Well N-23P was discharged for about one month from October 1, 1990 to November 3, 1990. Towards the end of the test, the wellhead enthalpy exceeded $2100 \mathrm{~kJ} / \mathrm{kg}$. It is therefore likely that discharge from N-23P is accompanied by in situ boiling. Apparently, no downhole pressure/temperature/spinner surveys were recorded in the discharging well.

Pressures computed from water level and temperature data are plotted in Figure 3.100. The pressure at $1360 \mathrm{mTVD}$ (-959.5 mASL) is estimated to be $\sim 111.0$ bars. 


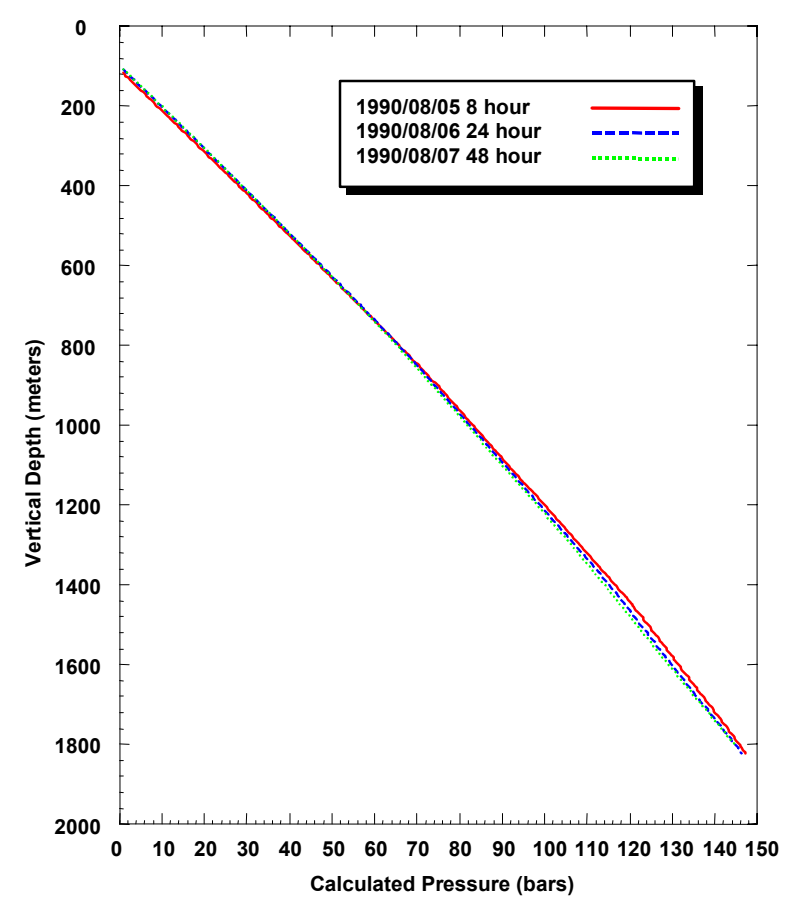

Figure 3.100. Pressures computed from water level and temperature data in production well N-23P.

\section{Production Well N-24P}

A temperature survey recorded (Figure 3.101) while injecting cold water on September 10, 1990 exhibits a sharp change in temperature gradient at $\sim 2120 \mathrm{mTVD}$. All the available heatup surveys (Figure 3.101) show a persistent cold zone centered at $\sim 2120$ mTVD. While drilling N-24P, a large circulation loss was recorded at the latter depth. Thus, both the temperature and drilling data imply that the principal feedzone for $\mathrm{N}-24 \mathrm{P}$ is located at 2120 mTVD. All the temperature surveys in Figure 3.101 exhibit a spike in temperature at 780 mTVD where a circulation loss zone was encountered during drilling. Apparently, flow behind casing is occurring at the latter depth. The maximum temperature in $\mathrm{N}-24 \mathrm{P}$ occurs towards the bottom of the well. A temperature of $\sim 319^{\circ} \mathrm{C}$ was recorded at the well bottom on September 15, 1990 after the well had been shut-in for only 5 days.

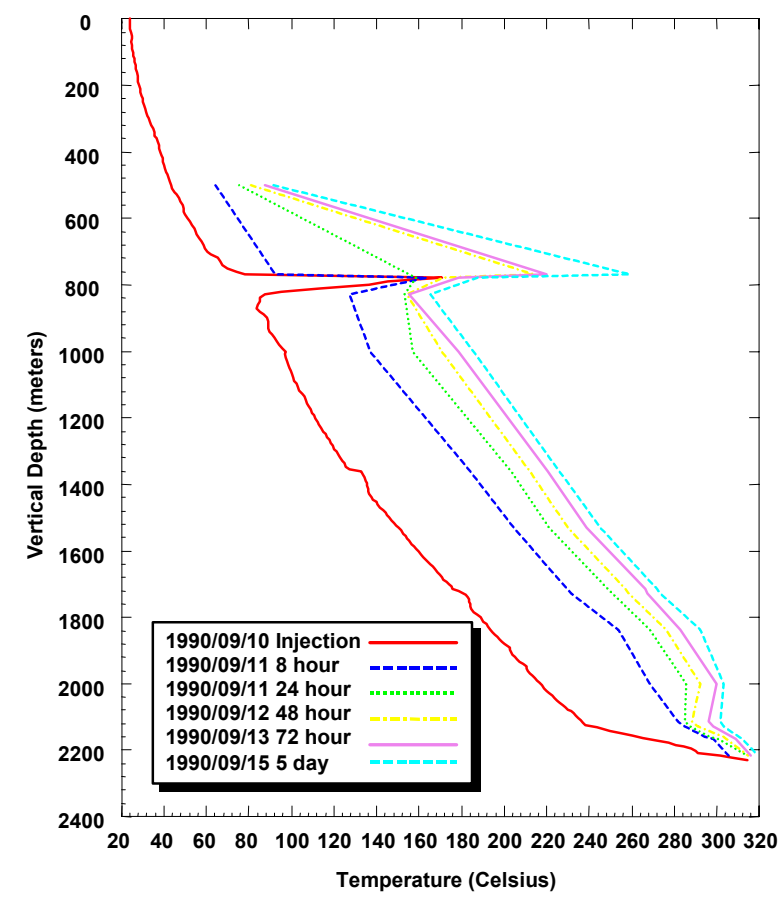

Figure 3.101. Selected temperature surveys in production well N-24P.

The well was discharged for about one month from October 2, 1990 to November 2, 1990. Towards the end of the test, the discharge enthalpies were in excess of $2400 \mathrm{~kJ} / \mathrm{kg}$. It appears that no downhole PTS surveys were recorded in the discharging well. However, the wellhead enthalpy implies that discharge from N-24P induces in situ boiling.

No water level or downhole pressure surveys are available for $\mathrm{N}-24 \mathrm{P}$. Consequently, it is not possible to estimate the stable feedzone pressure.

\section{Production Well N-25P}

A temperature survey in production well N$25 \mathrm{P}$ recorded during an injection test on January 20, 1991 (Figure 3.102) exhibits a sharp change in temperature gradient at $\sim 1550$ mTVD, and indicates that the injected fluid enters the formation at or below this depth. Since a circulation loss was encountered nearby, it is reasonable to conclude that the major fluid entry for $\mathrm{N}-25 \mathrm{P}$ is located at $\sim 1550$ mTVD. Heatup surveys (Figure 3.102) 
show a persistent cold zone at 1830 mTVD. This zone probably accepted some cold water during the injection test. Some additional permeability may also be present at or below 2300 mTVD where several circulation loss zones were recorded while drilling N-25P. Unforunately, none of the available temperature surveys extend below a depth of $\sim 2300$ mTVD. The maximum temperature in $\mathrm{N}-25 \mathrm{P}$ occurs towards the bottom of the logged interval. A temperature of $\sim 270^{\circ} \mathrm{C}$ was recorded at 2270 mTVD on January 25, 1991 (shut-in time $\sim 5$ days).

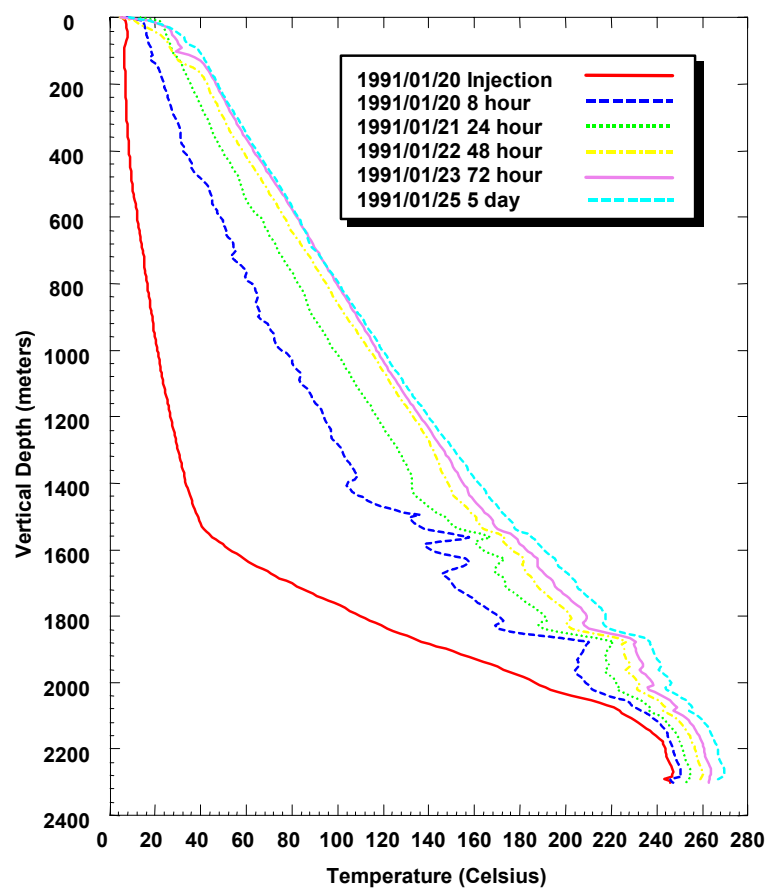

Figure 3.102. Selected temperature surveys in production well N-25P.

During a characteristic discharge test performed on May 30-31, 1991, the maximum discharge rate and enthalpy were $\sim 50 \mathrm{t} / \mathrm{h}$ and $\sim 1800 \mathrm{~kJ} / \mathrm{kg}$, respectively. A second characteristic discharge test was conducted from October 8 to October 10, 1991. The maximum discharge rate and enthalpy during the latter test were $\sim 68 \mathrm{t} / \mathrm{h}$ and $\sim 1340 \mathrm{~kJ} / \mathrm{kg}$. It appears that no downhole pressuretemperature-spinner surveys were run in the discharging well; however, the wellhead enthalpy data imply that discharge from $\mathrm{N}-$ 25P induces in situ boiling.

Production well N-25P develops a positive wellhead pressure in a shut-in condition. It appears that the available water level data were estimated from the temperature profiles, and are of little use for estimating the stable feedzone pressure.

\section{Production Well N-26P}

Heatup surveys taken in June 1993 (Figure 3.103) exhibit a persistent cold zone below $\sim 1890$ mTVD. It is likely that this zone accepted cold injected water. While drilling $\mathrm{N}-26 \mathrm{P}$, a total circulation loss zone was encountered at 1890 mTVD. It is therefore reasonable to assume that the principal feedzone for N-26P is located at about 1890 mTVD. The latter conclusion is consistent with spinner surveys (Figure 3.104) recorded during a discharge test of N-26P in July 1993. Heatup surveys (June 18 and 19, 1993; Figure 3.103) exhibit changes in temperature gradient at $1300 \mathrm{mTVD}, 1520 \mathrm{mTVD}$ and 1720 mTVD. It is likely that some permeability is also present at these depths. Temperature (Figure 3.103) and Spinner (Figure 3.104) surveys in the discharging well also indicate fluid influx at $\sim 1265$ mTVD. After five days of shut-in, a temperature of $\sim 280^{\circ} \mathrm{C}$ was recorded towards the bottom of the well on June 23, 1993. Very likely, the stable feedzone temperature is somewhat higher.

Production well N-26P was discharged for about one month from June 26, 1993 to July 25,1993 . The wellhead discharge enthalpies were reported to be as high as $2600 \mathrm{~kJ} / \mathrm{kg}$. Pressure (Figure 3.105) and temperature (Figure 3.103) surveys in the discharging well show the existence of two-phase conditions over the entire length of the logged interval (0-1895 mTVD). There is little question that discharge from N-26P induces in situ boiling. 


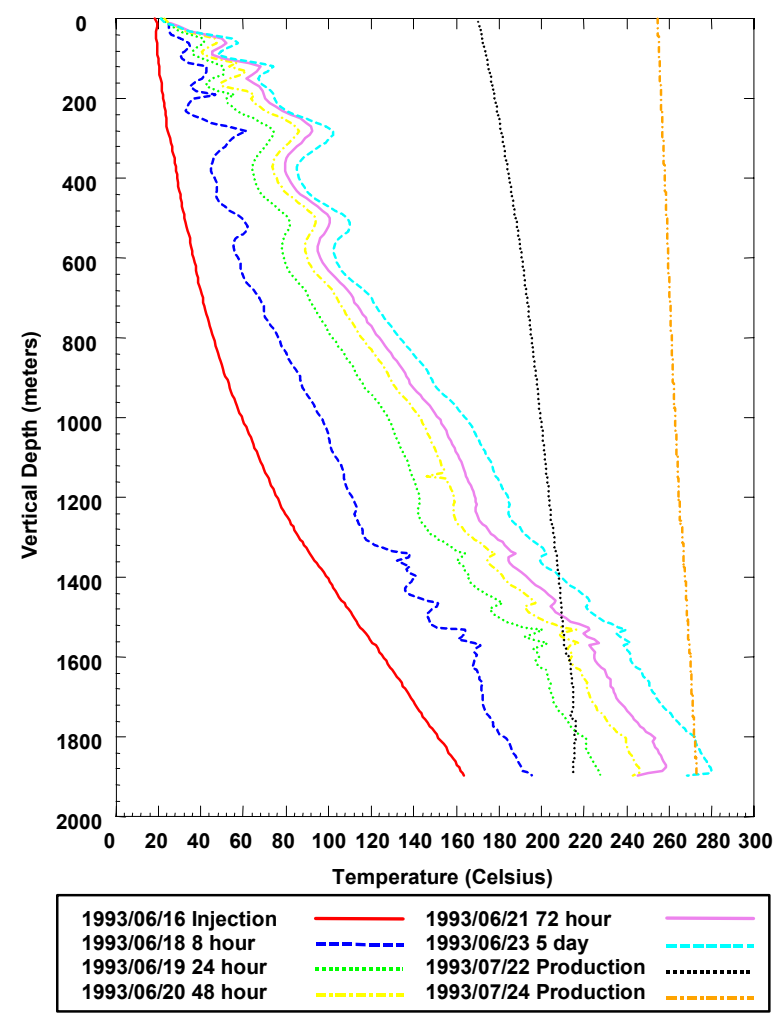

Figure 3.103. Selected temperature surveys in production well $\mathrm{N}-26 \mathrm{P}$.

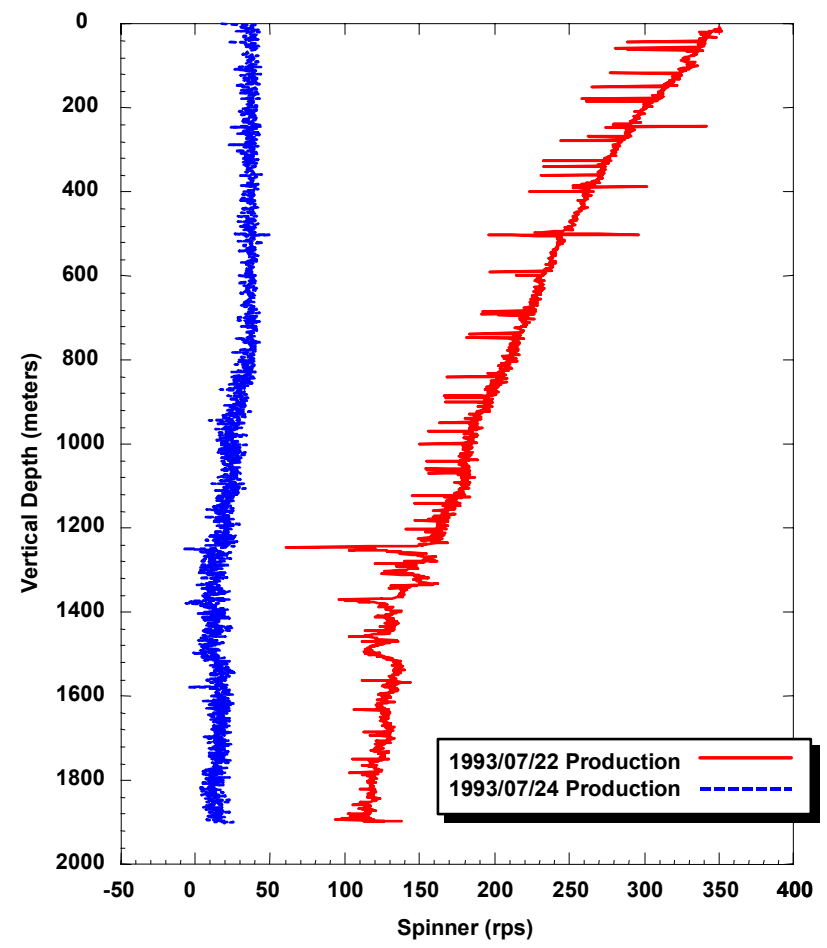

Figure 3.104. Spinner surveys taken during a discharge test of production well N-26P in July 1993.

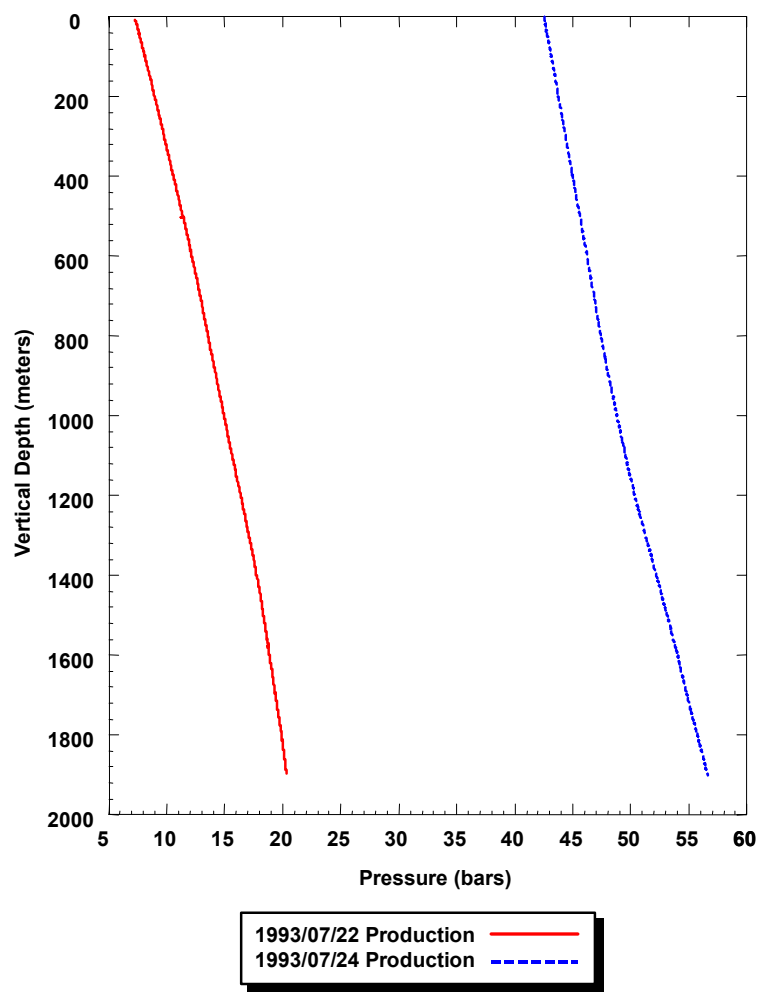

Figure 3.105. Pressure surveys taken during a discharge test of production well N-26P in July 1993.

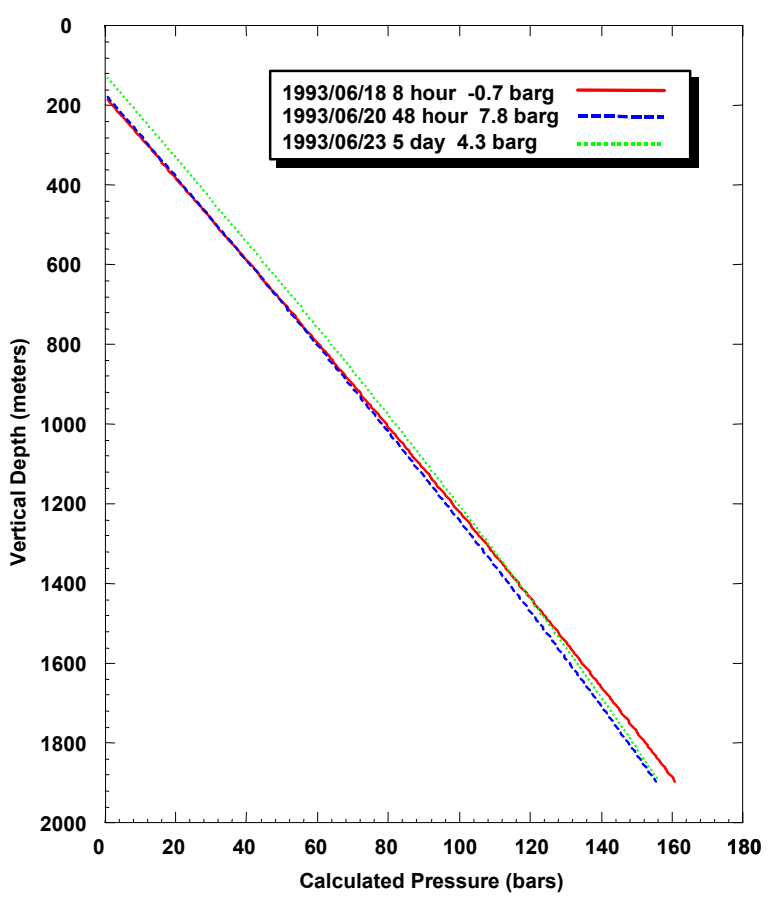

Figure 3.106. Pressures computed from water level and temperature data in production well N-26P assuming local atmospheric pressure at water level. The well head pressure (shown in the parentheses) should be added to the calculated values to obtain the true pressures. 
Apparently, N-26P develops positive wellhead pressures on shut-in. Pressures computed from wellhead pressure, water level and temperature data are plotted in Figure 3.106. The pressure at $1890 \mathrm{mTVD}(-1446.1 \mathrm{mASL})$ is estimated to be about 160 bars.

\section{Production Well N-27P}

The temperature survey of November 22, 1993 (Figure 3.107) was taken while injecting cold water at a low rate. The survey provides no clear indication of a permeable horizon in the borehole. All the available heatup surveys (Figure 3.107) exhibit faster temperature recovery at $\sim 1660 \mathrm{mTVD}$ and at $\sim 1860$ mTVD. In the absence of other data, it is assumed that the principal feedzone for N-27P is located at $\sim 1760$ mTVD (i.e., the middle of the permeable zones at 1660 and $1860 \mathrm{mTVD}$ ). After the well had been shut-in for only five days, a temperature of $\sim 271^{\circ} \mathrm{C}$ was recorded at 1870 mTVD on November 28, 1993.

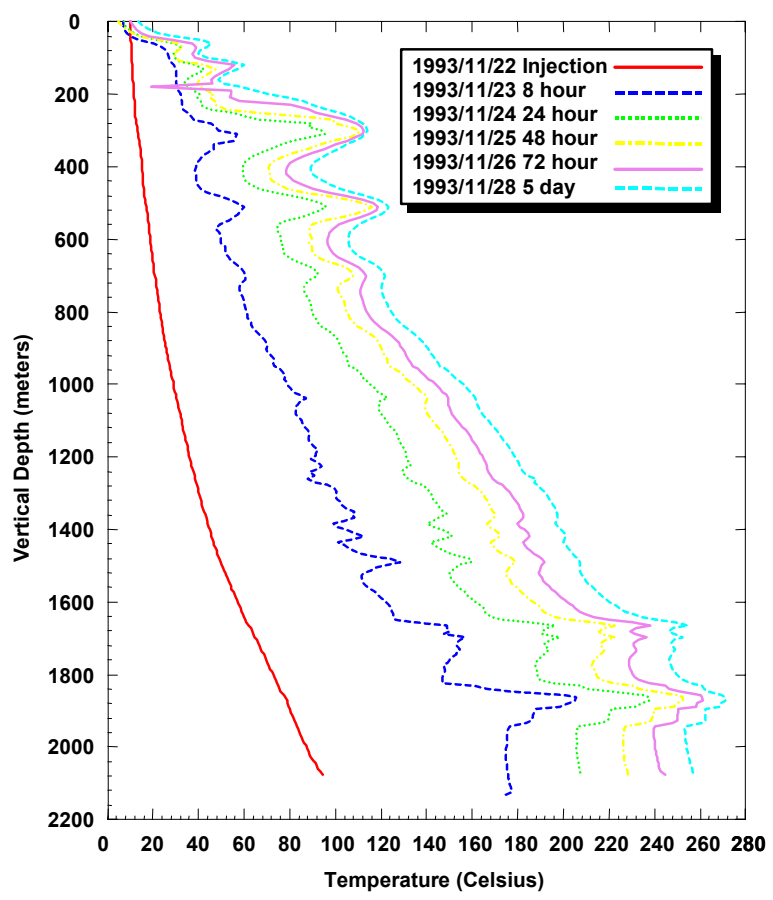

Figure 3.107. Selected temperature surveys in production well N-27P.
Pressures computed from water level and temperature data are plotted in Figure 3.108. The pressure at $1760 \mathrm{mTVD}(-1316.1 \mathrm{mASL})$ is about 138.8 bars.

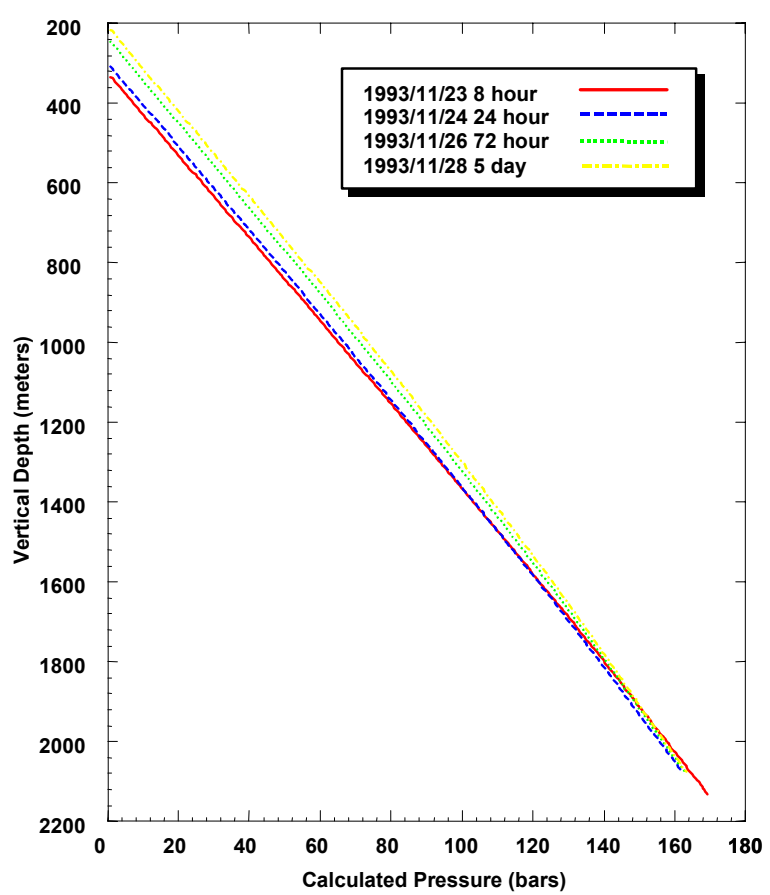

Figure 3.108. Pressures computed from water level and temperature data in production well N-27P.

No useful injection or discharge test data are available for production well N-27P.

\section{Production Well N-28P}

A temperature survey obtained in production well N-28P during an injection test on September 24, 1993 (Figure 3.109) exhibits a sharp change in temperature gradient at 1745 mTVD and 1760 mTVD; apparently, most of the injected fluid leaves the wellbore in the depth interval 1745-1760 mTVD. The heatup surveys (Figure 3.109) show a persistent cold zone centered at $\sim 1785$ mTVD. While drilling $\mathrm{N}-28 \mathrm{P}$, total loss of circulation occurred at $1762 \mathrm{mTVD}$ and 1773 mTVD. Spinner surveys (Figure 3.110) recorded during a discharge test in November 1993 indicate fluid entries at 1760-1780 mTVD and at 
$\sim 1400$ mTVD. The available data thus imply that the major feedzone for N-26P is located at $\sim 1760$ mTVD. After five days of shut-in, a maximum temperature of $\sim 309^{\circ} \mathrm{C}$ was recorded at $\sim 1615 \mathrm{mTVD}$ on October 5, 1993. It is likely that the feedzone (at 1760 mTVD) temperature is at least $310^{\circ} \mathrm{C}$.

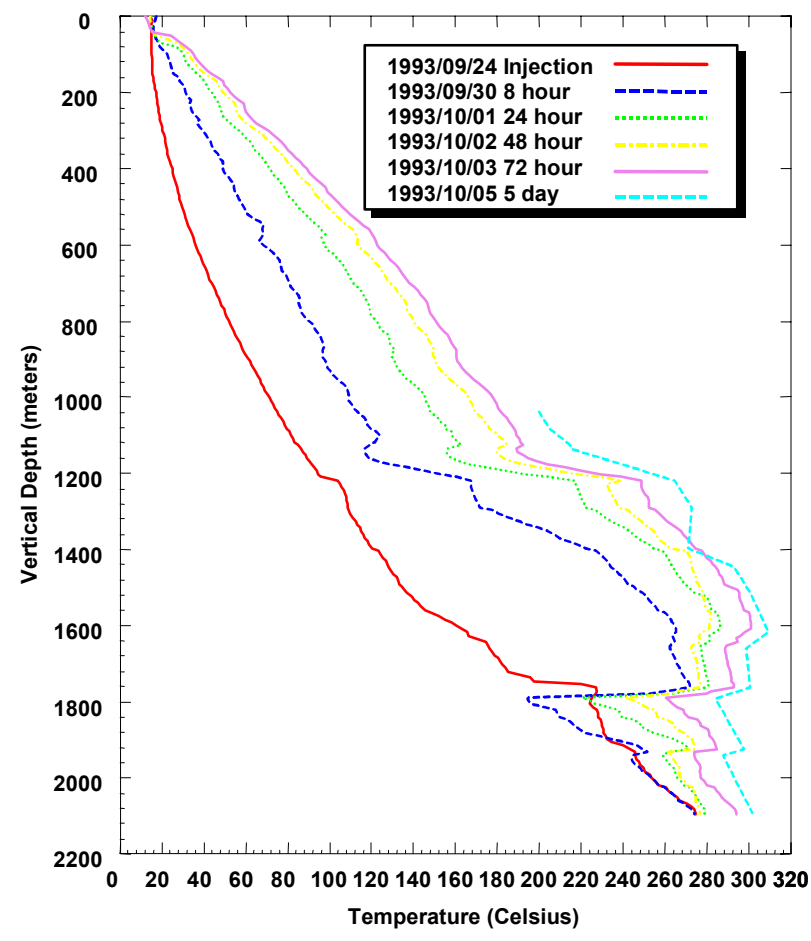

Figure 3.109. Selected temperature surveys in production well N-28P.

Production well N-28P was discharged for about a month from October 26, 1993 to November 28, 1993. The wellhead enthalpies ranged up to $\sim 2540 \mathrm{~kJ} / \mathrm{kg}$. Temperature and pressure surveys (Figures 3.111 and 3.112) taken during the discharge test indicate twophase conditions at the feedzone depth. Thus, it is almost certain that production from N-28P is accompanied by in situ boiling.

Pressures computed from water level and temperature data are plotted in Figure 3.113. The pressure at $1760 \mathrm{mTVD}(-1370 \mathrm{mASL})$ is $\sim 151.7$ bars.

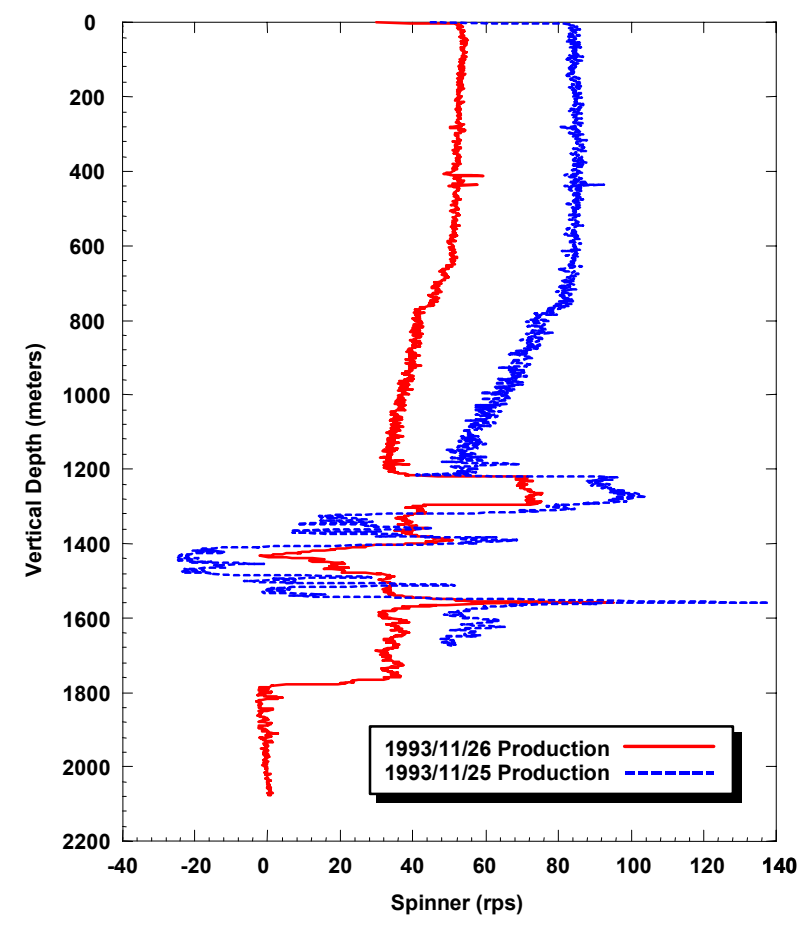

Figure 3.110. Spinner surveys taken during a discharge test of well N-28P in November 1993.

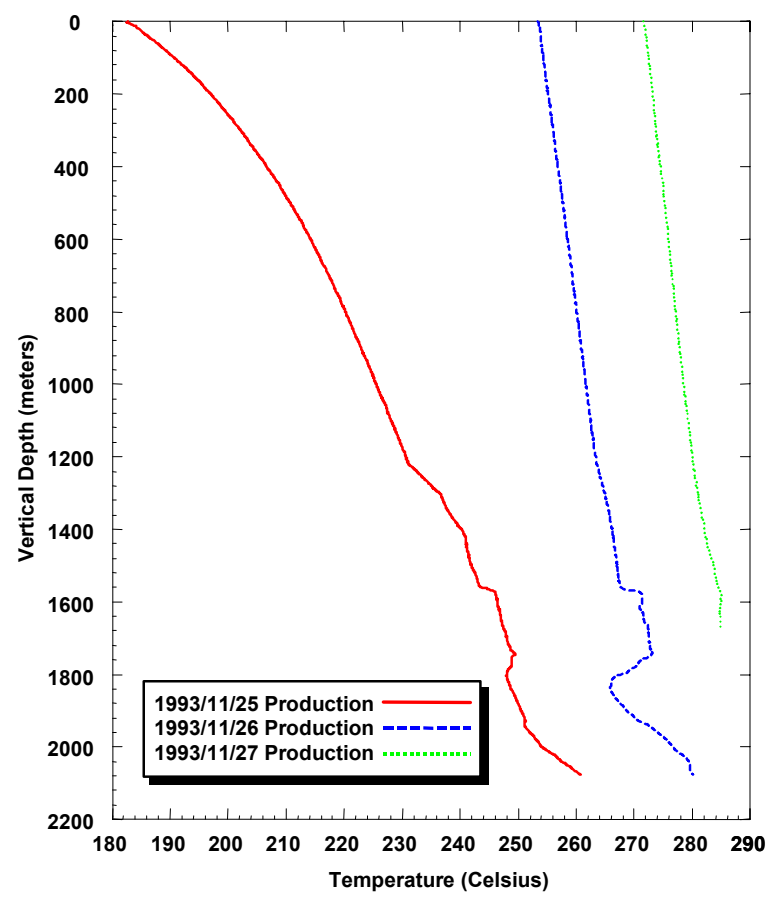

Figure 3.111. Temperature surveys taken during a discharge test of production well N-28P in November 1993. 


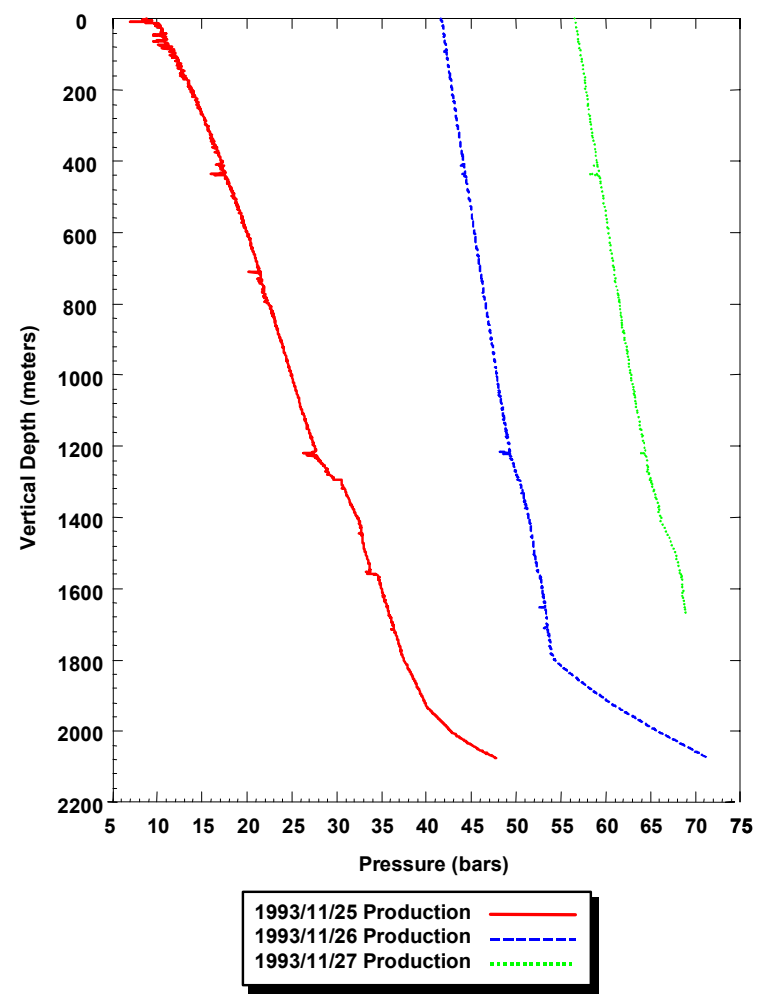

Figure 3.112. Pressure surveys taken during a discharge test of production well N-28P in November 1993.

\section{Injection Well $\mathrm{N}-29 R$}

Temperature profile of July 16, 1993, obtained about eight hours after cold water injection, exhibits sharp changes in temperature gradient at $\sim 1060$ mTVD and $\sim 1120$ mTVD, and implies that most of the injected fluid is lost in this depth interval. While drilling N-29R, circulation losses occurred at $\sim 1078$ mTVD and $\sim 1114$ mTVD. All the available heatup surveys (Figure 3.114) indicate a persistent cold zone centered at $1210 \mathrm{mTVD}$, and indicate the presence of some permeability at this depth as well. In the absence of other data, it is assumed that the major feedzone for $\mathrm{N}$ $29 \mathrm{R}$ is located at $\sim 1120 \mathrm{mTVD}$. The maximum temperature in N-29R occurs towards the bottom of the borehole. After only five days of shut-in, a temperature of $\sim 181^{\circ} \mathrm{C}$ was recorded on July 21, 1991 at the well bottom.

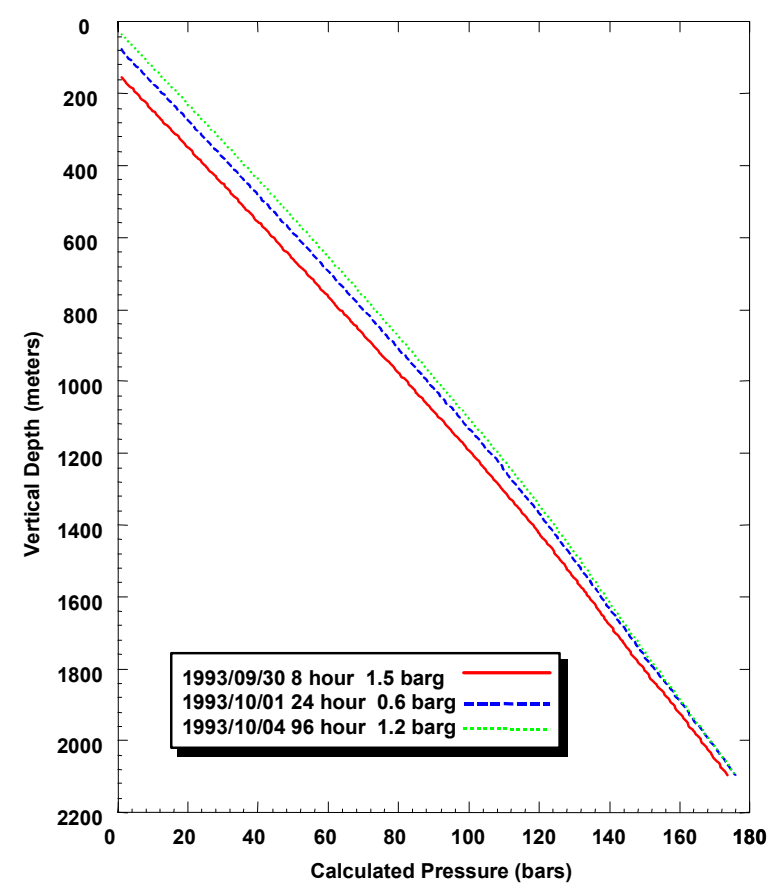

Figure 3.113. Pressures computed from water level and temperature data in production well $\mathrm{N}-28 \mathrm{P}$.

Pressures computed from water level and temperature data are plotted in Figure 3.115. The pressure at $1120 \mathrm{mTVD}(-685 \mathrm{mASL})$ is about 90.0 bars.

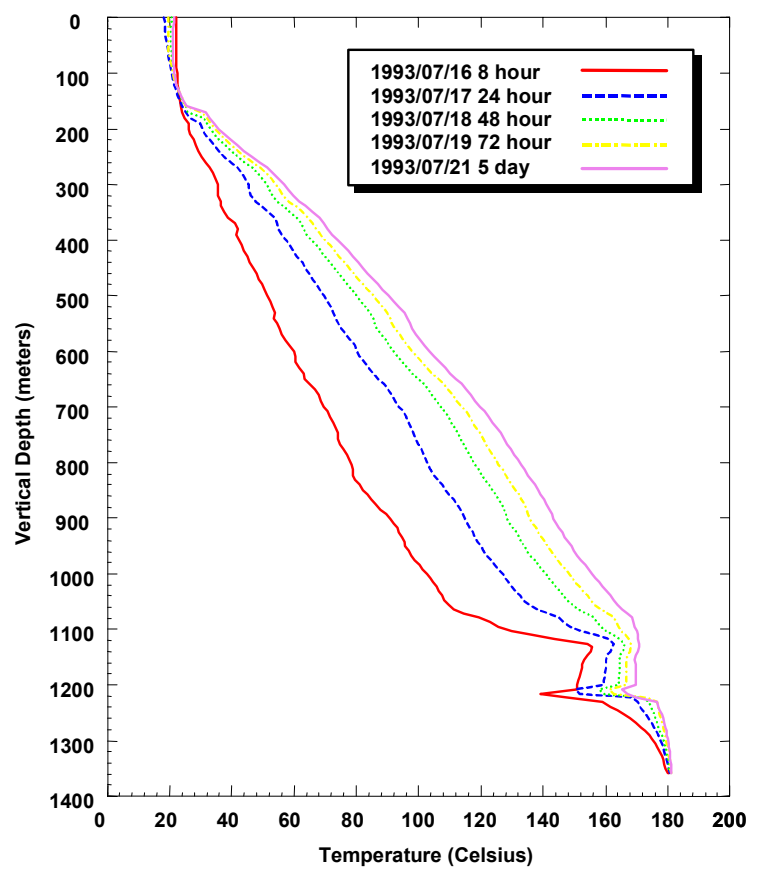

Figure 3.114. Selected temperature surveys in injection well N-29R. 
No useful discharge or injection test data are available for injection well N-29R.

\section{Production Well N-30P}

A temperature survey (Figure 3.116), taken while injecting cold water, indicates the influx of hot water in the depth interval 1475-1490 mTVD. The inflowing hot water mixes with the injected cold water, moves down the borehole, and finally leaves the wellbore at $2320 \mathrm{mTVD}$ and $2380 \mathrm{mTVD}$. The permeable zones at 2320 mTVD and 2380 mTVD are implied by changes in temperature gradient at these depths (Figure 3.116). While drilling N$30 \mathrm{P}$, large circulation losses were observed at $\sim 2311$ mTVD and 2382 mTVD. In the absence of other data, it is therefore assumed that the principal fluid entry for $\mathrm{N}-30 \mathrm{P}$ is located at 2350 mTVD (i.e., the middle of the permeable zones at $2320 \mathrm{mTVD}$ and 2380 mTVD). Unfortunately, only one short shut-in time ( $\sim 8$ hours) temperature profile extends to a depth below 2290 mTVD. By comparison with the temperature recorded on November 22, 1998 (shut-in time $\sim 8$ hours), the stable bottomhole temperature is estimated to be over $300^{\circ} \mathrm{C}$.

Pressures computed from water level and temperature data are plotted in Figure 3.117. The pressure at $2350 \mathrm{mTVD}$ (-1914.4 mASL) is estimated to be $\sim 174$ bars.

No useful injection or discharge test data are available for N-30P.

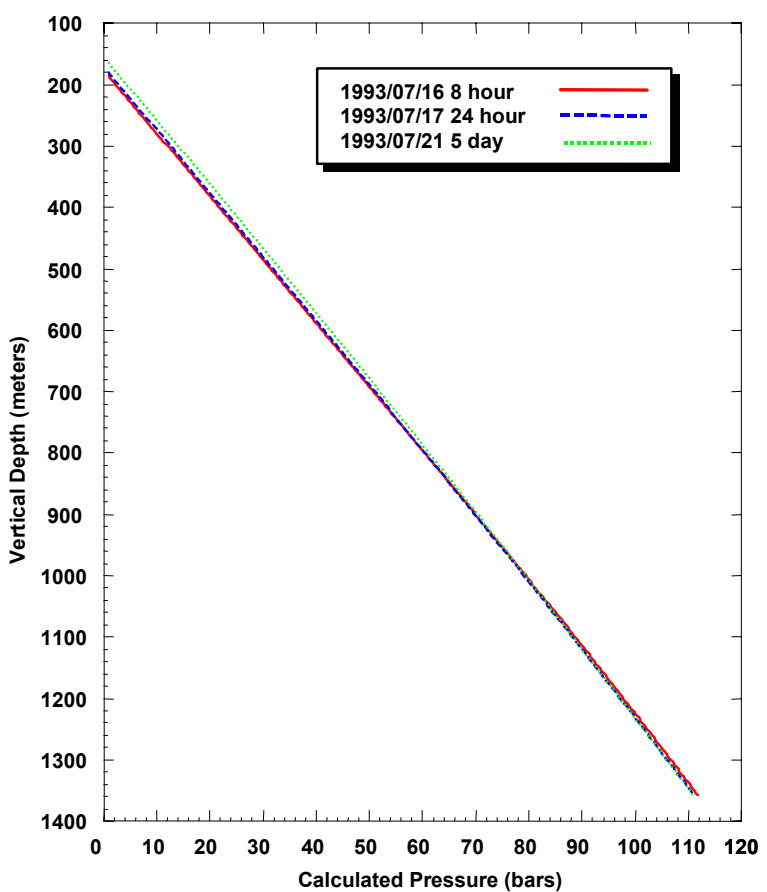

Figure 3.115. Pressures computed from water level and temperature data in injection well N-29R.

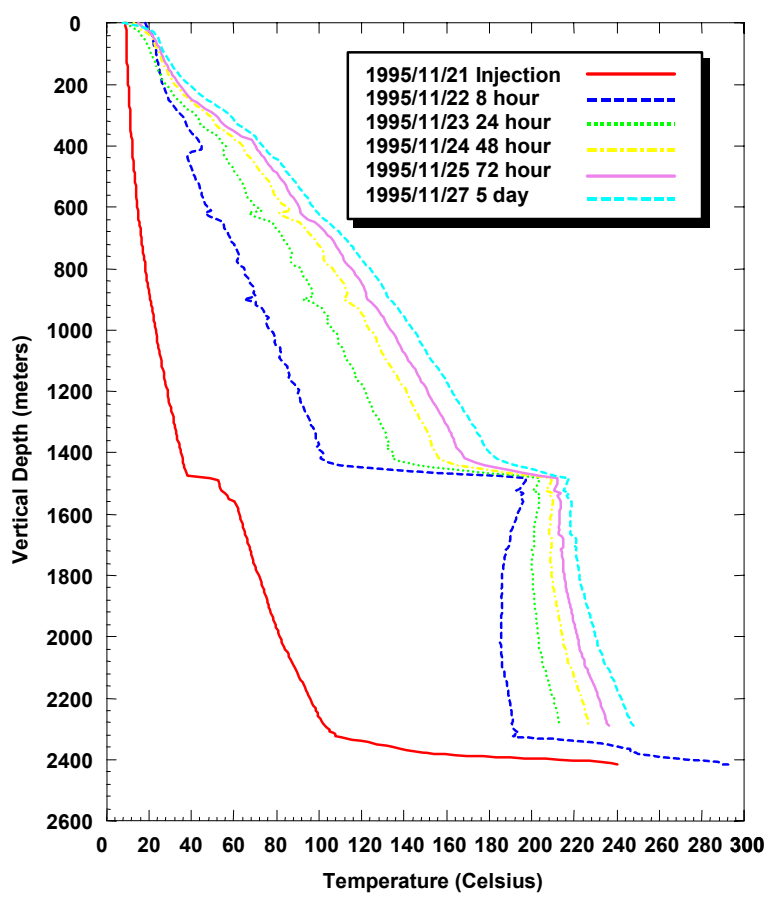

Figure 3.116. Selected temperature surveys in production well N-30P. 


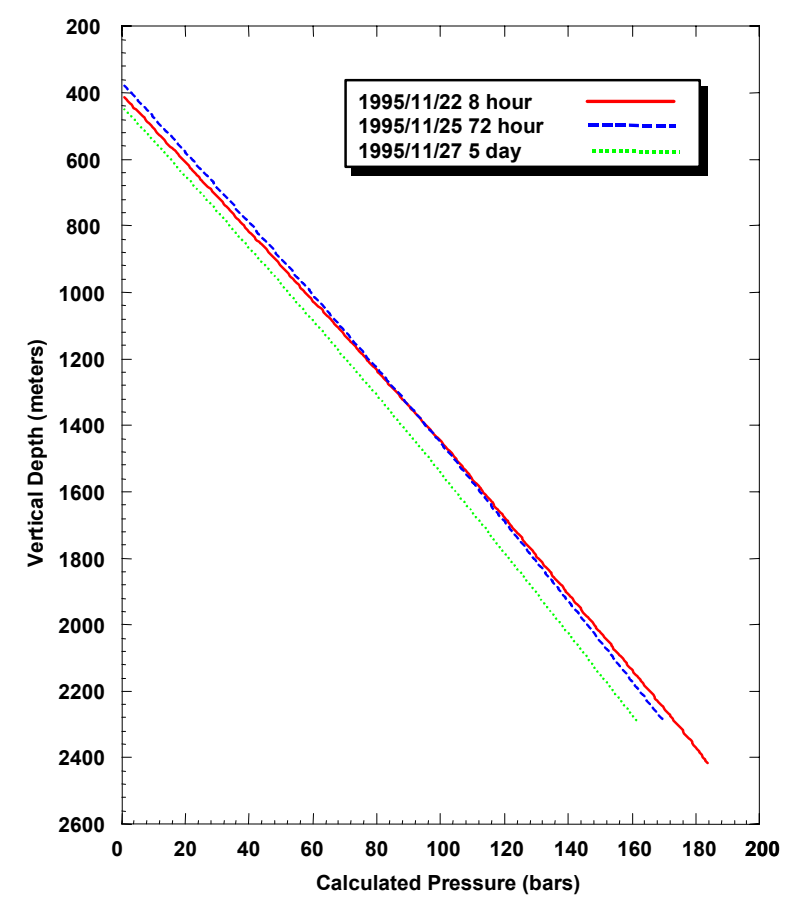

Figure 3.117. Pressures computed from water level and temperature data in production well N-30P.

\section{Production Well N-31P}

All the available temperature surveys (Figure 3.118) in production well N-31P were taken while injecting cold water. Temperature survey of September 13, 1997 (Figures 3.118 and 3.119) indicates hot water influx at $\sim 1420$ mTVD and $1490 \mathrm{mTVD}$, and fluid loss to the formation at $\sim 1530 \mathrm{mTVD}$. This temperature survey extends to a depth of only $\sim 1563$ mTVD. Below 1530 mTVD, the temperature increases rapidly, and a temperature of $303^{\circ} \mathrm{C}$ was recorded at $1563 \mathrm{mTVD}$. The temperature survey of September 13, 1997 implies that none of the injected fluid flows past a depth of $\sim 1530$ mTVD.

Temperature survey taken on September 14, 1997 indicates a rather different behavior than that implied by the earlier temperature survey. While permeable zones at $1420 \mathrm{mTVD}$ and 1490 mTVD can still be discerned, the more or less uniform temperature gradient in the depth interval 1425-2098 mTVD (Figures 3.118 and 3.120), implies that most of the injected fluid leaves the wellbore around the bottom ( 2098 mTVD) of the logged interval. The latter interpretation is consistent with the spinner survey (Figure 3.121) run concurrently with the temperature survey of September 14, 1997. Because of the presence of the blank and slotted liner in the wellbore, it is difficult to extract additional information from the spinner log.

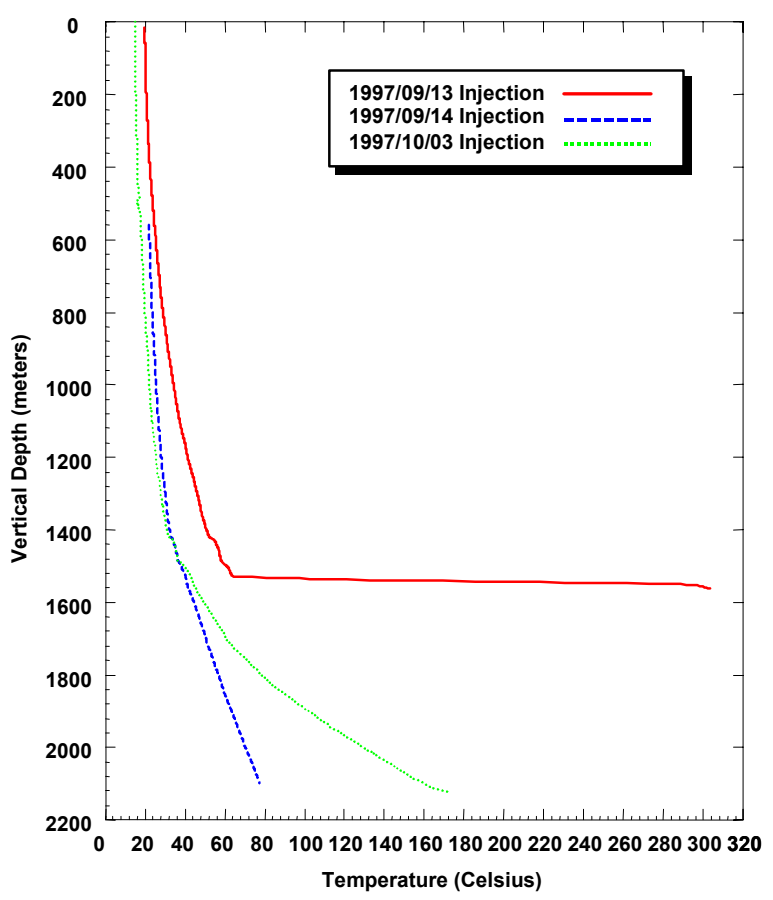

Figure 3.118. Temperature surveys in production well $\mathrm{N}-31 \mathrm{P}$.

The pressure surveys run concurrently with the temperature logs on September 13 and 14, 1997 are displayed in Figure 3.122. Somewhat surprisingly, the pressures in the wellbore were higher on September 13 than on September 14. Injection rate on September 14 (1700 1/min) was much higher than that $(500 \mathrm{l} / \mathrm{min})$ on September 13. In the absence of additional information such as the static pressure distribution in the borehole, it is not possible to use the pressure data of Figure 3.122 to obtain the injectivity index for N-31P.

Production well N-31P was put on production and connected to line P-1 on October 28, 1997. After the initial transient (lasting a few hours), the well discharge was estimated to 
consist of only steam. The discharge rate on October 28, 1997 was $~ 99$ tons/hour. It is unlikely that the latter value represents the stable discharge rate for N-31P. After a shutin (duration: ?), well N-31P was again put on production on May 21, 1998. Within a couple of months, the steam discharge rate declined from over 100 tons/hour (May 21, 1998) to less than 50 tons/hour.

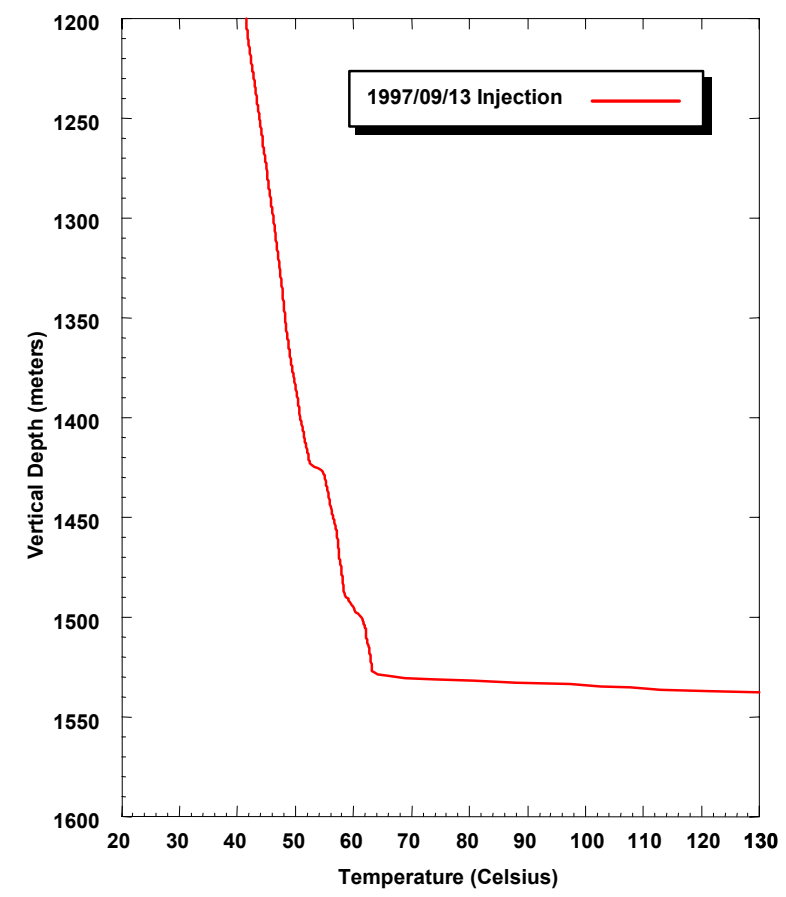

Figure 3.119. A detailed view of temperature profile recorded while injecting cold water in production well N-31P on September 13, 1997.

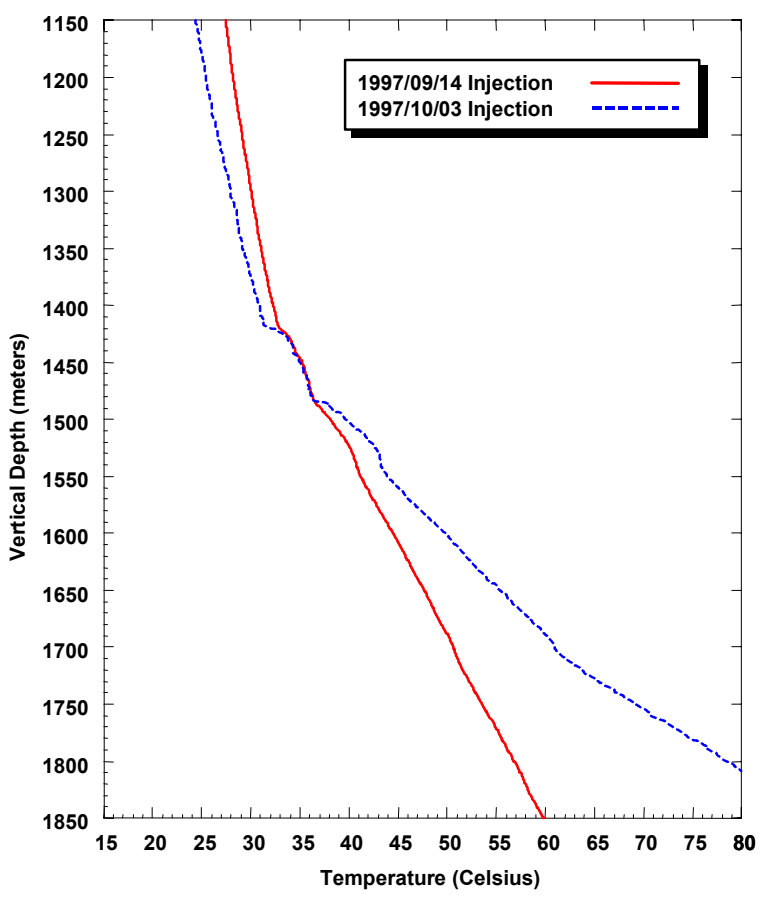

Figure 3.120. Detailed views of temperature profiles recorded while injecting cold water in production well N-31P on September 14, 1997 and October 3, 1997.

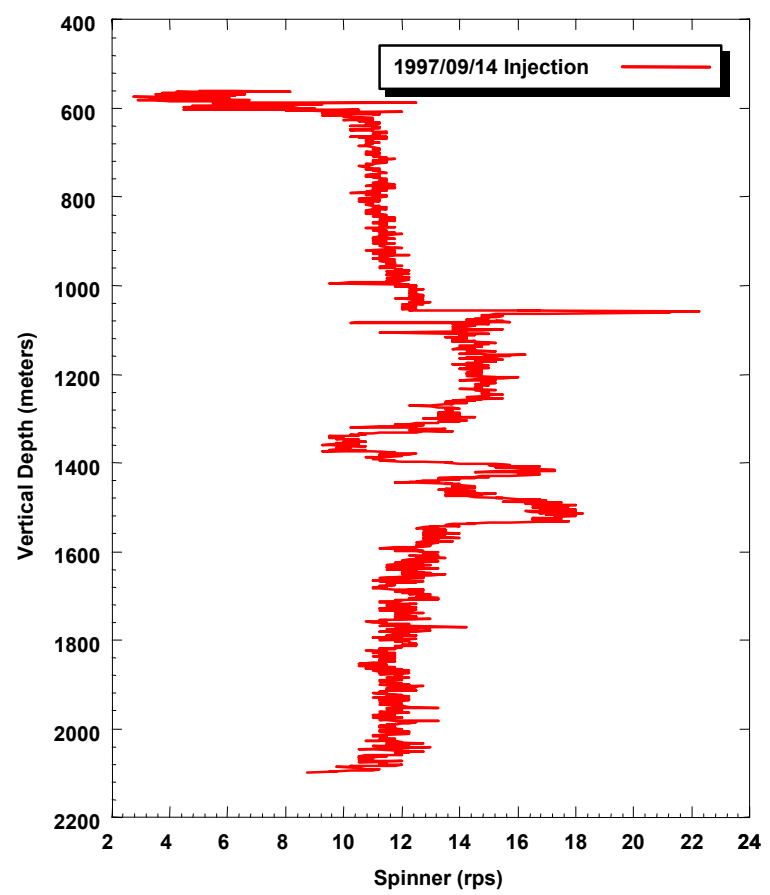

Figure 3.121. A spinner survey taken while injecting cold water in production well N-31P on September 14, 1997. 


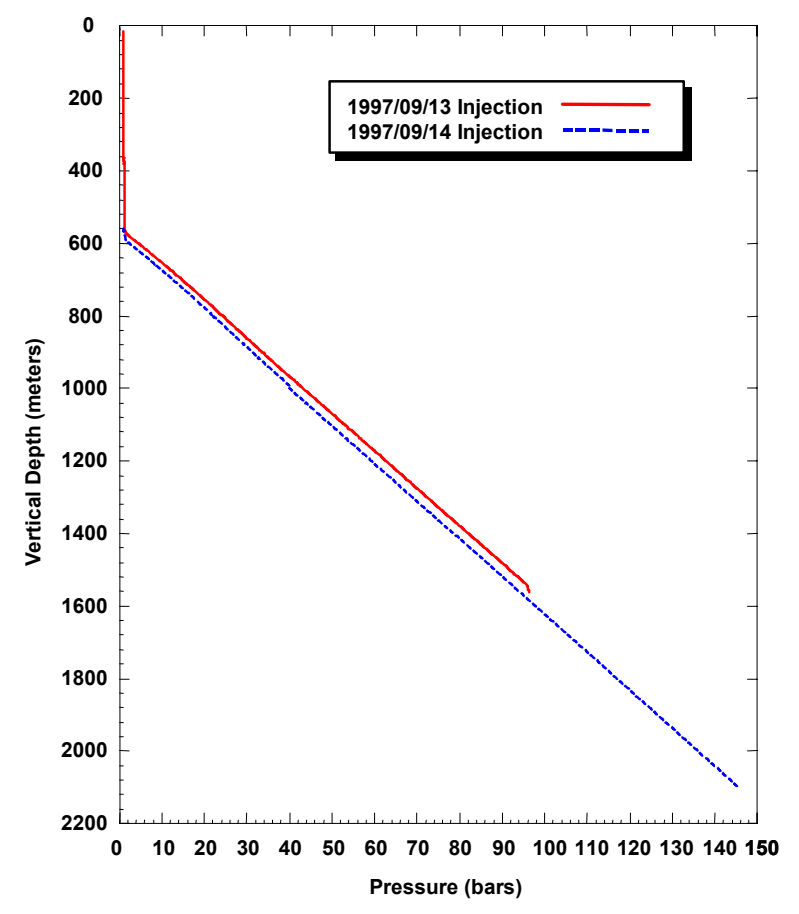

Figure 3.122. Pressure surveys in production well N-31P.

\subsection{Reservoir Pressures and Temperatures}

In this subsection, we will synthesize the results of Section 3.1 to deduce the natural state (i.e., pre-production) pressure distribution in the Okuaizu area. The feedzone pressures and temperatures for the Okuaizu boreholes are listed in Table 3.1. A plot of feedzone pressure versus feedzone elevation is displayed in Figure 3.123.

For a geothermal reservoir system with good horizontal and vertical permeabilities, feedzone pressures should principally depend upon feedzone elevation, i.e.,

$\mathrm{P}=\mathrm{P}_{0}+\alpha \mathrm{Z}$

Here $\mathrm{P}_{0}$ and $\alpha$ are empirically determined constants and $\mathrm{Z}$ is the feedzone elevation. A preliminary examination of the pressure data listed in Table 3.1 revealed that pressure data for seven boreholes (T-1 to T-4, N-10T, N$12 \mathrm{t}$, and N-30P) do not lie on the trend line for other boreholes. Slim holes T-1, T-2, T-3 and
T-4 are located outside the main Okuaizu borefield, and it is likely that these boreholes are not in good communication with the permeable aquifer(s) intersected by other Okuaizu boreholes. As remarked in Section 3.1 , the feedzone pressures for N-10T and N$12 \mathrm{t}$ are uncertain. Production well N-30P was drilled after the start of the Yanaizu Nishiyama Power Plant, and apparently the reservoir pressures in the vicinity of $\mathrm{N}-30 \mathrm{P}$ had declined by several bars at the time downhole surveys were obtained in N-30P. Excluding the pressure data from these seven (7) boreholes, a least-squares procedure was employed to fit the pressure data for the Okuaizu boreholes. The results of the leastsquares fit are

$\mathrm{P}($ bars $)=35.884-0.08297 \mathrm{Z}$

Root-mean-square error $=3.27$ bars .

The mathematical fit (Figure 3.123) closely agrees with the data used to derive it.

The vertical pressure gradient for the Okuaizu area is $8.297 \mathrm{kPa} / \mathrm{m}$ and corresponds to a hydrostatic gradient at about $215^{\circ} \mathrm{C}$. Since the reservoir temperatures in the southern part of the field (i.e. in the production area) exceed $215^{\circ} \mathrm{C}$, it is likely that fluid upflow is taking place in the area. The nominal piezometric surface (i.e., 1-atmosphere surface) is $\sim 420$ mASL which is close to the average elevation for the local ground surface.

The stable feedzone temperatures, where available, for Okuaizu boreholes are listed in Table 3.1. The highest temperature $\left(341^{\circ} \mathrm{C}\right)$ was recorded in borehole $\mathrm{N}-22 \mathrm{~T}$ at a depth of $\sim 2600 \mathrm{mTVD}$ ( -2150 mASL). Temperatures in excess of $300^{\circ} \mathrm{C}$ have been observed in several boreholes intersecting the production zones located along the NW-SE trending Chinoikezawa and Sarukurasawa faults. Apparently, temperatures decline markedly towards the northeast. Injection wells are 
drilled to intersect the NW-SE trending Oizawa fault zone which is located about 2 $\mathrm{km}$ to the north of the Chinoikezwa fault zone. The temperature data suggest that the hot fluid source for the Okuaizu Geothermal field is located in the western part of the Chinoikezawa fault zone (i.e., in the vicinity of the bottom hole for well N-22T).

The pre-production pressures and temperatures at Okuaizu are such that the reservoir fluid is single-phase liquid at feedzone depth. The formation permeability in the Okuaizu area is low, and discharge from Okuaizu boreholes is usually accompanied by in situ boiling. Prior to December 1987,
Okuaizu boreholes (OA-4, N-1t, N-2t, N-3t, N-5t, N-6T, N-10T, N-14T and N-15T) were discharged one at a time. From December 1987 to March 1988, a field-wide discharge test was conducted and five boreholes $(\mathrm{N}-2 \mathrm{t}$, $\mathrm{N}-6 \mathrm{~T}, \mathrm{~N}-10 \mathrm{~T}, \mathrm{~N}-14 \mathrm{~T}$ and N-15T) were produced simultaneously. During the latter test, the discharge tended to quickly dry out. As an example, the wellhead discharge enthalpy for N-6T increased from $\sim 1530 \mathrm{~kJ} / \mathrm{kg}$ on December 16, 1987 to $\sim 2290 \mathrm{~kJ} / \mathrm{kg}$ on March 26, 1988. Since the initiation of the Yanaizu Nishiyama Power Plant, the progressive drying of the discharge steam from the production wells has continued.

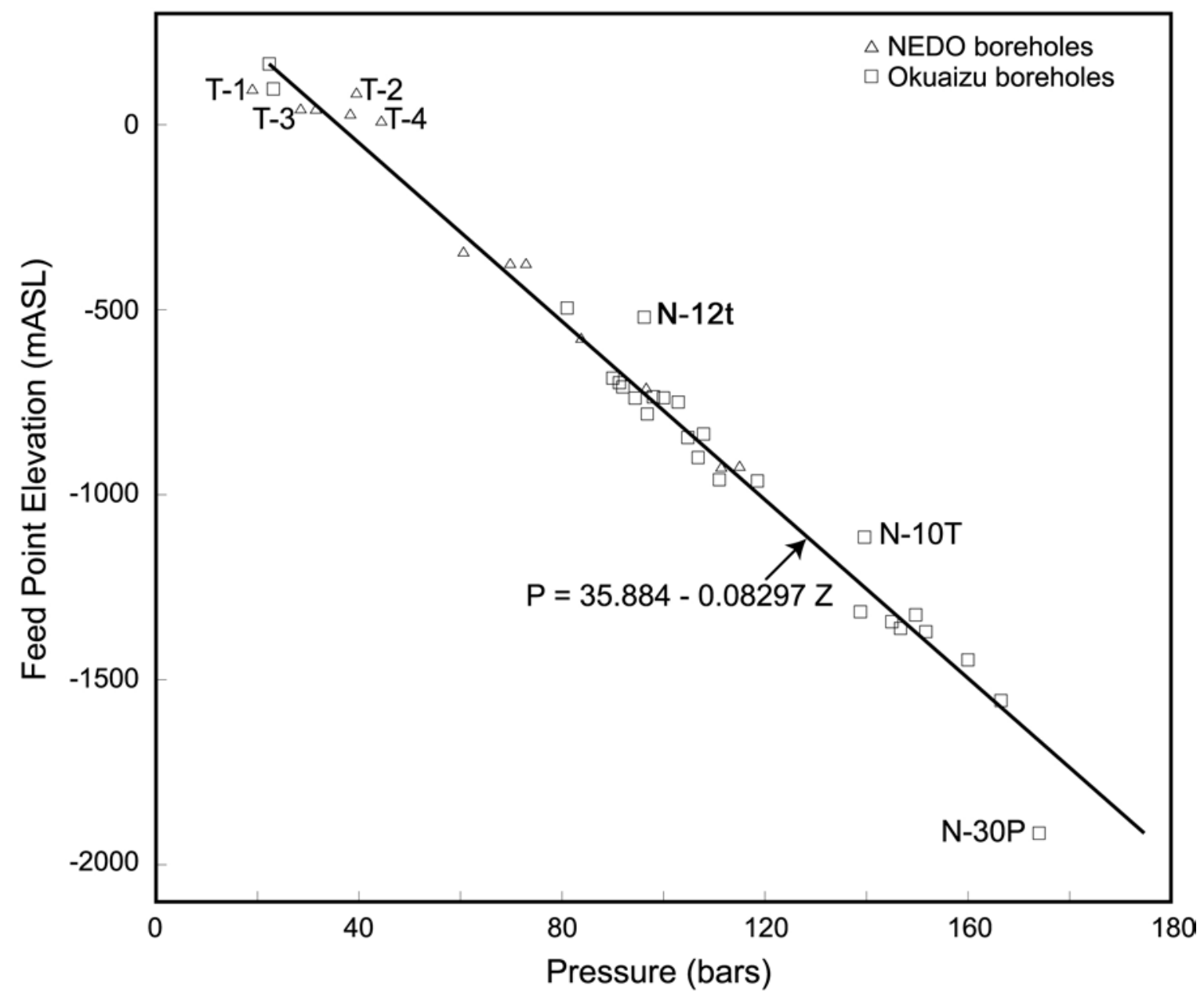

Figure 3.123. Correlation of feedzone pressure versus feedzone elevation for Okuaizu boreholes. Feedzone pressures for T-1, T-2, T-3, T-4, N-10T, N-12t and N-30P were not included in the mathematical fit. 
Table 3.1. Stable feedzone pressures and temperatures for Okuaizu boreholes. The feedzone depth is with respect to the wellhead. The feedzone coordinates are in the local coordinate system with origin at the Mukaiyama triangulation point (Latitude $37^{\circ} 25^{\prime} 59.795^{\prime \prime} \mathrm{N}$; Longitude $139^{\circ} 41^{\prime} 39.409^{\prime \prime} \mathrm{E}$ ). The following abbreviations are used in the table: $\mathrm{T}=$ temperature, $\mathrm{P}=$ pressure, $\mathrm{b} . \mathrm{h} .=$ bottom hole, $\mathrm{mTVD}=$ meters true vertical depth, $\mathrm{mASL}=$ meters above sea level.

\begin{tabular}{|c|c|c|c|c|c|c|c|}
\hline $\begin{array}{l}\text { Well } \\
\text { Name }\end{array}$ & $\begin{array}{l}\text { Feedpt } \\
\text { Depth } \\
\text { (mTVD) }\end{array}$ & $\begin{array}{l}\text { Feedpt. } \\
\text { Elev. } \\
\text { (mASL) }\end{array}$ & $\begin{array}{l}\text { Press. } \\
\text { (bars) }\end{array}$ & $\begin{array}{l}\text { Temp. } \\
\text { (deg C) }\end{array}$ & $\begin{array}{l}\text { Co-ordin } \\
\text { North } \\
(\mathrm{km})\end{array}$ & $\begin{array}{l}\text { hates } \\
\text { East } \\
(\mathrm{km})\end{array}$ & Remarks \\
\hline $\mathrm{T}-1$ & 190. & 93. & 19.0 & 45 . & 4.235 & -0.036 & $\mathrm{~T}$ at 30 days \\
\hline $\mathrm{T}-2$ & 400 & 83. & 39.5 & 47 & 4.285 & 2.494 & $\mathrm{~T}$ at 24 days \\
\hline $\mathrm{T}-3$ & 340. & 40. & 28.5 & 44. & 2.886 & -1.862 & $\mathrm{~T}$ at 53 days \\
\hline$T-4$ & 450. & 7 . & 44.4 & 50 & 2.505 & 2.904 & $\mathrm{~T}$ at 30 days \\
\hline$T-5$ & 400 & 26. & 38.3 & 105. & 0.341 & 0.988 & $\mathrm{~T}$ at 30 days \\
\hline $\mathrm{T}-6$ & 350. & 39. & 31.5 & 59. & $-1 \cdot 325$ & -0.550 & T at 30 days \\
\hline$O A-1$ & 900. & -580 & 83.8 & 136. & 3.470 & 0.329 & T at b.h. (5 days) \\
\hline $\mathrm{OA}-2$ & 850. & -378 & 69.8 & 90. & 1.857 & -2.049 & $\mathrm{~T}$ at 5 days \\
\hline$O A-3$ & 1320 & -928.5 & 111.4 & 156. & 1.555 & 1.163 & T at b.h. (5 days) \\
\hline $\mathrm{OA}-4$ & 1270 . & -925.5 & 115.0 & 261. & 0.056 & -0.392 & $\mathrm{~T}$ at $1200 \mathrm{mTVD}(9 \mathrm{mo})$. \\
\hline$O A-5$ & 770 & -378 & 72.9 & 93. & 0.160 & 2.501 & $\mathrm{~T}$ at 5 days \\
\hline$O A-6$ & 1090. & -714.5 & 96.6 & 256. & 0.418 & 0.285 & $\mathrm{~T}$ at 5 days \\
\hline $\mathrm{OA}-7$ & 710 & -347 & 60.6 & 202 . & 0.931 & 0.513 & T at b.h. (5 days) \\
\hline$N-1 t$ & 1700 . & -1324.5 & 149.7 & 220 & -0.362 & -0.904 & T from disch. profile \\
\hline$N-2 t$ & 1260 . & -836 & 107.9 & 300 & -0.004 & 0.145 & T from disch. profile \\
\hline$N-3 t$ & 1810 . & -1361. & 146.7 & 277 . & 0.108 & 1.152 & T at 10 months \\
\hline$N-4 r$ & 260 & 164 & 22.3 & - & -0.072 & 0.059 & $\mathrm{P}$ from $\mathrm{T}$ at 4 hours \\
\hline$N-5 t$ & 1700 . & -1343 & 145.0 & 270. & 0.663 & 0.260 & Minimum feedzone temp. \\
\hline $\mathrm{N}-6 \mathrm{~T}$ & 1390. & -962.5 & 118.5 & 305 . & 0.092 & 0.005 & $\mathrm{~T}$ at $1625 \mathrm{mTVD}$ (>6 mo. \\
\hline $\mathrm{N}-7 \mathrm{~T}$ & 280 & 96.5 & 23.1 & - & 0.442 & 0.277 & \\
\hline $\mathrm{N}-10 \mathrm{~T}$ & 1540. & -1114.5 & 139.6 & 300 & 0.136 & 0.384 & Minimum feedzone temp. \\
\hline $\mathrm{N}-11 \mathrm{~T}$ & 1150 . & -735.5 & 98.0 & 283. & 0.202 & 0.783 & $\mathrm{~T}$ at b.h. ( 1650 mTVD $)$ \\
\hline$N-12 t$ & 1010 . & -520.5 & 96.2 & 236. & -0.308 & 1.471 & T at b.h. (1574 mTVD) \\
\hline$N-13 t$ & 1200 . & -782 & 96.8 & - & 1.441 & -0.294 & $\mathrm{P}$ from $\mathrm{T}$ at 4 hours \\
\hline$N-14 T$ & 1130 . & -738 & 100 & 265 . & 0.182 & -0.064 & \\
\hline $\mathrm{N}-15 \mathrm{~T}$ & 1150 . & -749.6 & 102.9 & 300. & -0.001 & 0.201 & $\mathrm{~T}$ at b.h. ( 1860 mTVD $)$ \\
\hline $\mathrm{N}-16 \mathrm{~T}$ & 1260 . & -845.5 & 104.8 & 280. & 0.274 & 0.733 & T at b.h. ( 1750 mTVD $)$ \\
\hline $\mathrm{N}-17 \mathrm{~T}$ & 910 & -495.5 & 81.0 & 285 . & 0.235 & 0.901 & T at b.h. ( 1660 mTVD $)$ \\
\hline$N-18 t$ & 1110 . & -697.3 & 91.3 & 218 . & 1.067 & 1.065 & $\mathrm{~T}$ at b.h. (5 days) \\
\hline$N-19 R$ & 1110 . & -708.8 & 92.0 & 173. & 1.038 & 1.119 & T at 1350 mTVD (5 days) \\
\hline$N-20 R$ & 1140. & -738.8 & 94.4 & 167. & 0.952 & 1.257 & T at b.h. (5 days) \\
\hline $\mathrm{N}-21 \mathrm{~T}$ & 1300. & -899.6 & 106.8 & 309. & 0.024 & 0.256 & T at 2000 mTVD (5 days) \\
\hline $\mathrm{N}-22 \mathrm{~T}$ & 2000 . & -1556.1 & 166.5 & 341. & -.290 & 0.956 & T at 2600 mTVD (9 days) \\
\hline$N-23 P$ & 1360 . & -959.5 & 111.0 & 320. & 0.043 & 0.197 & T at 1700 mTVD (5 days) \\
\hline$N-26 P$ & 1890 . & -1446.1 & 160 & 280 & -0.443 & 0.628 & $\mathrm{~T}$ at $2200 \mathrm{mTVD}$ (5 days) \\
\hline$N-27 P$ & 1760. & -1316.1 & 138.8 & 271. & -0.222 & 0.651 & T at 1870 mTVD (5 days) \\
\hline$N-28 P$ & 1760. & -1370 & 151.7 & 309. & -0.311 & 0.062 & T at 1615 mTVD (5 days) \\
\hline$N-29 R$ & 1120 . & -685 & 90.0 & 181. & 0.723 & 1.380 & $\mathrm{~T}$ at b.h. (5 days) \\
\hline $\mathrm{N}-30 \mathrm{P}$ & 2350 . & -1914.4 & 174. & - & -0.179 & 0.853 & \\
\hline
\end{tabular}




\section{INJECTION AND DISCHARGE TESTS}

Prior to the startup of the Yanaizu Nishiyama Geothermal Power Plant on May 25, 1995, a total of five (5) slim holes and fourteen (14) large-diameter wells were discharged at one time or another. All five slim holes (OA-4, N-1t, $\mathrm{N}-2 \mathrm{t}, \mathrm{N}-3 \mathrm{t}, \mathrm{N}-5 \mathrm{t}$ ) and one large diameter well (N-6T) were discharged one at a time during the years 1984-1987. A field-wide discharge test involving five boreholes (N-2t, N-6T, N-10T, $\mathrm{N}-14 \mathrm{~T}, \mathrm{~N}-15 \mathrm{~T}$ ) was performed from December 1987 to March 1988. It appears that with a single exception (i.e., slim hole OA-4), discharge from the Okuaizu boreholes before the field-wide discharge test did not induce in situ boiling. A distinct qualitative change occurred during the 1987-1988 field-wide discharge test. The discharge stream tended to dry out and the discharge enthalpy increased substantially. Apparently, discharge from the various Okuaizu boreholes during and after the 1987-1988 fieldwide discharge test is accompanied by in situ boiling. As part of the discharge tests, characteristic output curves (i.e., mass and enthalpy versus wellhead pressure) were also obtained; these data are discussed in Section 5.

Downhole pressure surveys were run during the discharge tests of three (3) slim holes and ten (10) large-diameter wells. The pressure data can be used to calculate the productivity index, PI.

$$
\mathrm{PI}=\mathrm{M} /\left(\mathrm{P}_{\mathrm{ns}}-\mathrm{P}_{\mathrm{fp}}\right)
$$

Here $\mathrm{P}_{\mathrm{ns}}$ is the stable feedzone pressure as estimated from the shut-in temperature, water level, and pressure data (Section 3), and $\mathrm{P}_{\mathrm{fp}}$ denotes the measured feedzone pressure in the discharging well. The productivity indices for the Okuaizu boreholes are discussed in Section 4.1, and a summary is presented in Table 4.1.

Brief injection tests (test duration: 0.5 hours -3 hours) are usually carried out at Okuaizu after the drilling and completion of a borehole. A typical injection test at Okuaizu consists of injecting cold water into a borehole at several different rates and simultaneously monitoring the wellhead pressure. With two exceptions (OA-4, N-10T), no downhole pressure surveys were run during the injection tests. Thus, for most of the injection tests, the pressure gauge was located hundreds of meters above the feedzone depth. Because of wellbore cooling due to the injection of cold water and the change in the water level in the well, the pressure change at the wellhead will underestimate the change in pressure at the feedzone depth. It is therefore likely that the use of wellhead pressure data will tend to overestimate the injectivity index. Because of the paucity of downhole pressure data, it was decided to use the wellhead pressure data to compute the injectivity index for the boreholes for which estimates of productivity index are available (see Table 4.1). The injectivity index (II) is defined as follows:

$$
\mathrm{II}=\mathrm{M} /\left(\mathrm{P}_{\text {flowing }}-\mathrm{P}_{\text {static }}\right)
$$

where $\mathrm{M}$ is the injection rate (single rate test), $\mathrm{P}_{\text {flowing }}$ is the flowing pressure at the gauge depth during cold water injection, and $\mathrm{P}_{\text {static }}$ is the shut-in pressure at the gauge depth. For multirate injection tests, Equation (4.2) can be rewritten as follows:

$$
\mathrm{II}=\Delta \mathrm{M} / \Delta \mathrm{P}
$$

where $\Delta \mathrm{M} / \Delta \mathrm{P}$ is the slope of the straight-line fit to the multi-step injection rate versus injection pressure (at gauge depth) data.

The determination of injectivity indices for selected Okuaizu boreholes is described in Section 4.1. The injectivity data are summarized in Table 4.2. 
Table 4.1. Productivity indices for Okuaizu boreholes.

\begin{tabular}{|c|c|c|c|c|c|c|c|}
\hline $\begin{array}{c}\text { Borehole } \\
\text { Name }\end{array}$ & $\begin{array}{l}\text { Open Hole } \\
\text { Diameter } \\
\text { (mm) }\end{array}$ & $\begin{array}{c}\text { Feedzone } \\
\text { or Gauge } \\
\text { Depth } \\
\text { (mTVD) }\end{array}$ & Test Date & $\begin{array}{c}\text { Discharge } \\
\text { Rate } \\
(\mathrm{kg} / \mathrm{s})\end{array}$ & $\begin{array}{c}\text { Static } \\
\text { Pressure } \\
\text { (bars) }\end{array}$ & $\begin{array}{c}\text { Flowing } \\
\text { Pressure } \\
\text { (bars) }\end{array}$ & $\begin{array}{l}\text { Productivity } \\
\text { (kg/s-bar) }\end{array}$ \\
\hline OA-4 & 79. & 1270 & $\begin{array}{l}02-07-84 \\
02-08-84\end{array}$ & $\begin{array}{l}2.53 \\
2.78\end{array}$ & 115.0 & $\begin{array}{l}43.2 \\
37.9\end{array}$ & $\begin{array}{l}0.035 \\
0.036\end{array}$ \\
\hline $\mathrm{N}-1 \mathrm{t}$ & 101. & 1700. & $\begin{array}{l}06-09-85 \\
06-10-85 \\
06-11-85\end{array}$ & $\begin{array}{l}7.53 \\
4.81 \\
6.42 \\
\end{array}$ & 149.7 & $\begin{array}{l}49.6 \\
63.2 \\
56.4 \\
\end{array}$ & $\begin{array}{l}0.075^{*} \\
0.056^{*} \\
0.069^{*}\end{array}$ \\
\hline $\mathrm{N}-2 \mathrm{t}$ & 101. & 1260. & $\begin{array}{l}11-11-85 \\
11-13-85\end{array}$ & $\begin{array}{l}11.47 \\
6.72\end{array}$ & 107.9 & $\begin{array}{l}99.5 \\
100.5\end{array}$ & $\begin{array}{l}1.37 * \\
0.91 *\end{array}$ \\
\hline $\mathrm{N}-6 \mathrm{~T}$ & 216. & 1390. & $\begin{array}{l}12-22-86 \\
12-23-86 \\
12-24-86 \\
12-26-86 \\
02-26-88 \\
02-27-88 \\
02-28-88\end{array}$ & $\begin{array}{l}52.4 \\
45.1 \\
35.0 \\
34.2 \\
\\
17.2 \\
15.1 \\
9.6\end{array}$ & 118.5 & $\begin{array}{l}48.1 \\
58.1 \\
74.0 \\
76.8 \\
\\
22.5 \\
27.9 \\
41.1\end{array}$ & $\begin{array}{l}0.74 \\
0.75 \\
0.79 * \\
0.82 * \\
0.18 \\
0.17 \\
0.12\end{array}$ \\
\hline $\mathrm{N}-10 \mathrm{~T}$ & 216. & 1540. & $09-10-88$ & 15.4 & 128.4 & 43.3 & 0.18 \\
\hline $\mathrm{N}-11 \mathrm{~T}$ & 216. & 1150. & $\begin{array}{l}03-11-89 \\
03-12-89 \\
03-13-89\end{array}$ & $\begin{array}{l}18.4 \\
16.0 \\
13.3\end{array}$ & 98.0 & $\begin{array}{l}16.5 \\
20.0 \\
25.6\end{array}$ & $\begin{array}{l}0.23 \\
0.21 \\
0.18\end{array}$ \\
\hline $\mathrm{N}-14 \mathrm{~T}$ & 216. & 1130. & $\begin{array}{l}02-21-88 \\
02-22-88 \\
03-06-88 \\
03-07-88 \\
03-08-88\end{array}$ & $\begin{array}{l}12.03 \\
5.67 \\
11.97 \\
9.75 \\
10.94\end{array}$ & 100.0 & $\begin{array}{l}18.4 \\
20.9 \\
18.5 \\
20.8 \\
19.9\end{array}$ & $\begin{array}{l}0.15 \\
0.07 \\
0.15 \\
0.12 \\
0.14\end{array}$ \\
\hline $\mathrm{N}-15 \mathrm{~T}$ & 216. & 1150. & $\begin{array}{l}03-02-88 \\
03-03-88 \\
03-04-88\end{array}$ & $\begin{array}{l}3647.2 .2 \\
32.6\end{array}$ & 102.9 & $\begin{array}{l}76.0 \\
76.9 \\
77.4\end{array}$ & $\begin{array}{l}1.76 \\
1.39 \\
1.28\end{array}$ \\
\hline $\mathrm{N}-16 \mathrm{~T}$ & 216. & 1260. & $\begin{array}{l}03-09-89 \\
03-10-89 \\
03-17-89\end{array}$ & $\begin{array}{l}15.50 \\
11.61 \\
18.14\end{array}$ & 104.8 & $\begin{array}{l}22.8 \\
29.0 \\
17.6\end{array}$ & $\begin{array}{l}0.19 \\
0.15 \\
0.21\end{array}$ \\
\hline $\mathrm{N}-17 \mathrm{~T}$ & 216. & 910. & $\begin{array}{l}03-14-89 \\
03-15-89 \\
03-16-89\end{array}$ & $\begin{array}{l}17.6 \\
16.4 \\
11.0\end{array}$ & 81.0 & $\begin{array}{l}14.7 \\
16.6 \\
22.2\end{array}$ & $\begin{array}{l}0.27 \\
0.25 \\
0.19\end{array}$ \\
\hline $\mathrm{N}-22 \mathrm{~T}$ & 216. & 1550. & $\begin{array}{l}02-26-90 \\
02-27-90\end{array}$ & $\begin{array}{l}30.75 \\
17.53\end{array}$ & 133.7 & $\begin{array}{l}38.8 \\
71.6\end{array}$ & $\begin{array}{l}0.32 \\
0.28\end{array}$ \\
\hline $\mathrm{N}-26 \mathrm{P}$ & 216. & 1890. & $\begin{array}{l}07-22-93 \\
07-24-93\end{array}$ & $\begin{array}{l}18.6 \\
9.4\end{array}$ & 160.0 & $\begin{array}{l}20.3 \\
56.5\end{array}$ & $\begin{array}{l}0.13 \\
0.09\end{array}$ \\
\hline $\mathrm{N}-28 \mathrm{P}$ & 216. & 1760. & $\begin{array}{l}11-25-93 \\
11-26-93 \\
11-27-93\end{array}$ & $\begin{array}{l}24.7 \\
16.8 \\
9.9\end{array}$ & 151.7 & $\begin{array}{l}37.0 \\
53.8 \\
69.2 * *\end{array}$ & $\begin{array}{l}0.22 \\
0.17 \\
0.12\end{array}$ \\
\hline
\end{tabular}

* Single-phase (liquid) feedzone

**Extrapolated. 
Table 4.2. Injectivity indices for selected Okuaizu boreholes (see text).

\begin{tabular}{|c|c|c|c|c|c|}
\hline $\begin{array}{c}\text { Borehole } \\
\text { Name }\end{array}$ & $\begin{array}{c}\text { Open Hole } \\
\text { Diameter (mm) }\end{array}$ & $\begin{array}{c}\text { Feedzone } \\
\text { Depth (mTVD) }\end{array}$ & Test Date & $\begin{array}{c}\text { Pressure Gauge } \\
\text { Depth (mTVD) }\end{array}$ & $\begin{array}{c}\text { Injectivity } \\
\text { Index (kg/s-bar) }\end{array}$ \\
\hline OA-4 & 79.0 & 1270. & $11-13-82$ & 0. & 0.36 \\
& & & $08-26-83$ & 0. & 0.28 \\
& & & $09-02-83$ & 1250. & 0.29 \\
\hline N-1t & 101.0 & 1700. & $04-14-85$ & 0. & 0.45 \\
\hline N-6t & 216.0 & 1390. & $12-08-85$ & 0. & 3.71 \\
\hline N-10T & 216.0 & 1540. & $09-24-86$ & & 1.79 \\
& & & $09-26-86$ & 0. & 0.86 \\
\hline N-11T & 216.0 & 1150. & $10-12-86$ & 0. & 2.53 \\
\hline N-14T & 216.0 & 1130. & $09-13-87$ & 0. & 3.04 \\
\hline N-16T & 216.0 & 1260. & $07-27-87$ & 0. & 6.73 \\
\hline N-17T & 216.0 & 910. & $10-15-87$ & 0. & 3.95 \\
\hline N-22T & 216.0 & 1550. & $11-19-89$ & 0. & 3.29 \\
\hline N-26P & 216.0 & 1890. & $06-17-93$ & 0. & 2.93 \\
\hline N-28P & 216.0 & 1760. & $05-31-93$ & 0. & 7.45 \\
\hline
\end{tabular}

\subsection{Injectivity and Productivity Indices}

Injection rates for Okuaizu boreholes are usually given as volume injection rates $\left(\mathrm{m}^{3} / \mathrm{s}\right.$ or liters/min). For present purposes, it suffices to assume that the density of cold injected water is $1000 \mathrm{~kg} / \mathrm{m}^{3}$. Therefore, a volume flow rate of 1 liter/s equals a mass injection rate of $1 \mathrm{~kg} / \mathrm{s}$.

\section{Slim Hole OA-4}

A brief multi-rate injection test (test duration: 75 minutes) was performed on November 13, 1982 with the pressure gauge located at the wellhead. The pressure and injection test data are displayed in Figure 4.1, and the corresponding injectivity index is $0.36 \mathrm{~kg} / \mathrm{s}-$ bar. A second multi-rate injection test was performed from August 26, 1983 to September 2, 1983. The injection time at the various rates ranged from a low of $\sim 8$ hours to a high of 24 hours. During the second injection test, pressures were measured both at the wellhead and at $1250 \mathrm{mTVD}$. The pressure and injection rate data are plotted in Figures
4.2 and 4.3. The injectivity indices obtained from the wellhead and downhole pressure data are $0.28 \mathrm{~kg} / \mathrm{s}-\mathrm{bar}$ and $0.29 \mathrm{~kg} / \mathrm{s}-\mathrm{bar}$, respectively.

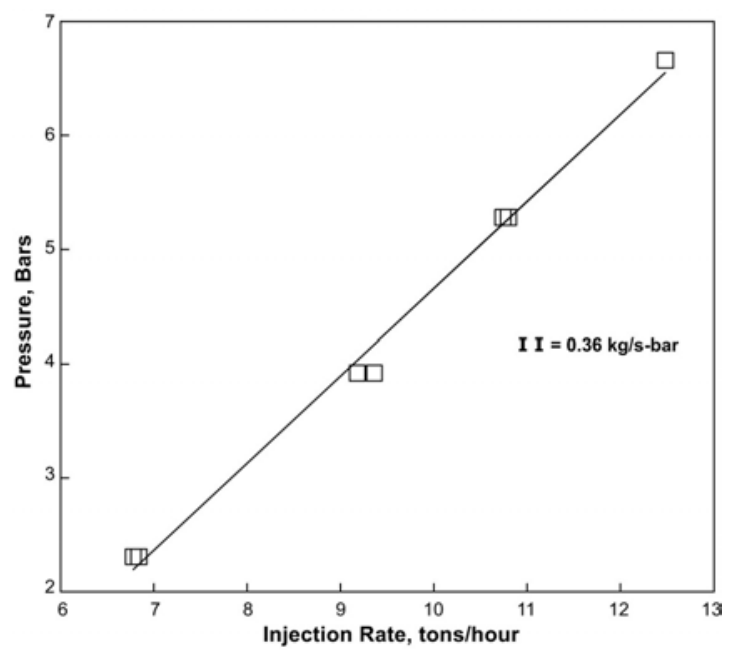

Figure 4.1. Injectivity Test 1 for slim hole OA-4 performed on November 13, 1982. The pressures were measured at the wellhead. 


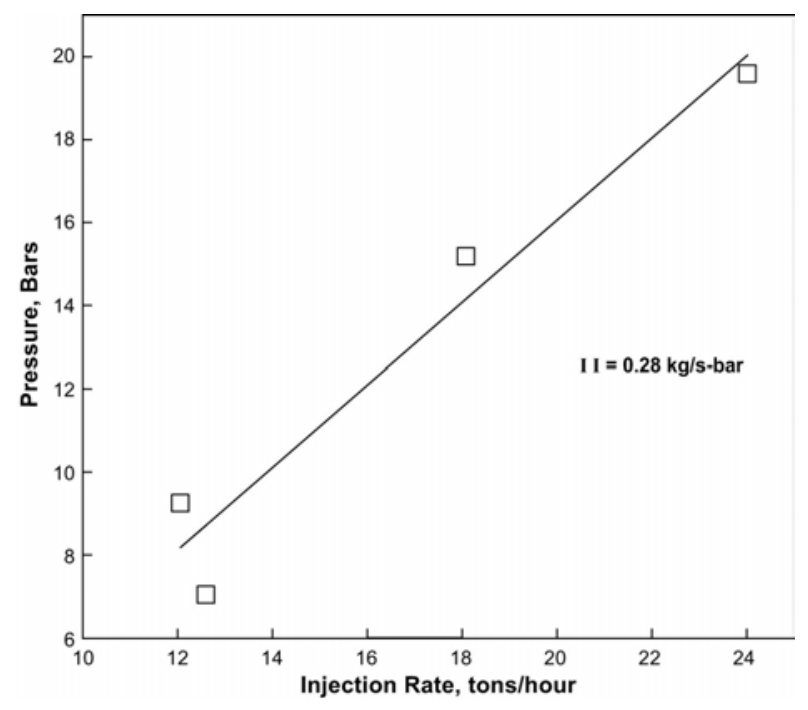

Figure 4.2. Injectivity Test 2 for slim hole OA-4 performed from August 26, 1983 to September 2, 1983. The pressures were measured at the wellhead (this figure) and at $1240 \mathrm{mTVD}$ (Figure 4.3).

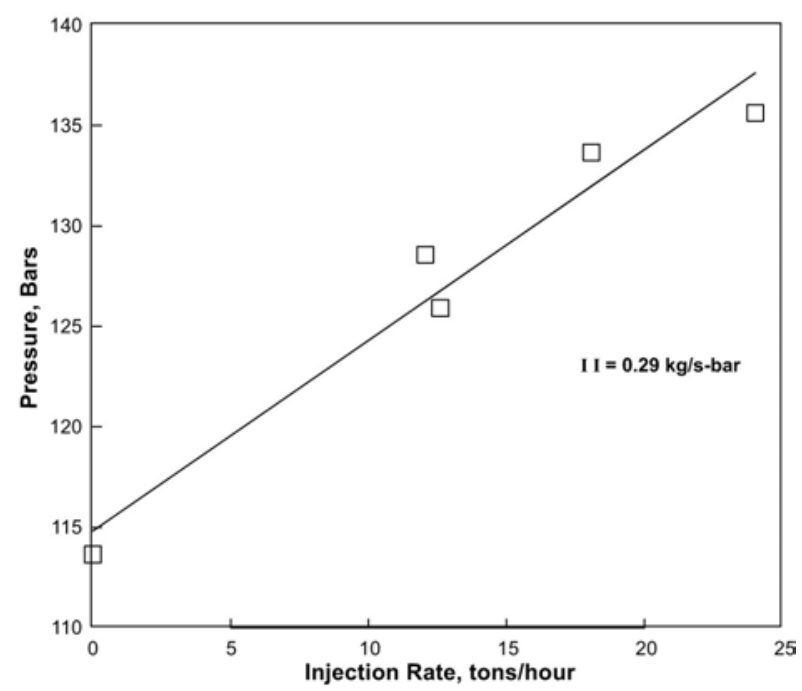

Figure 4.3. Injectivity Test 2 for slim hole OA-4 performed from August 26, 1983 to September 2, 1983. The pressures were measured at the wellhead (Figure 4.2) and at $1250 \mathrm{mTVD}$ (this figure).

During a discharge test of slim hole OA-4 in early 1984 (January 10 - February 11), two downhole pressure/temperature surveys were run on February 7, 1984 and February 8, 1984. The discharge rate and flowing pressure at the feedzone depth on February 7, 1984 were 9.1 tons/hour and 43.2 bars, respectively. The corresponding values on February 8, 1984 were 10.0 tons/hour and 37.9 bars. The stable feedzone pressure (Section 3) is 115.0 bars. As discussed earlier in Section 3, discharge from OA-4 is accompanied by in situ boiling. Using the measured discharge rates and flowing pressures, the following estimates for the productivity index are obtained:

February 7, 1984: PI = 9.1/ 3.6(115.0-43.2)

$$
=0.035 \mathrm{~kg} / \mathrm{s}-\mathrm{bar}
$$

February 8, 1984: PI $=10.0 / 3.6(115.0-37.9)$

$$
=0.036 \mathrm{~kg} / \mathrm{s}-\text { bar. }
$$

\section{Slim Hole N-1t}

A brief multi-rate injection test (test duration: 110 minutes) of slim hole N-1t was performed on April 14, 1985. The pressures were recorded at the wellhead. The wellhead pressure and injection rate data are exhibited in Figure 4.4, and the corresponding injectivity index is $0.45 \mathrm{~kg} / \mathrm{s}-\mathrm{bar}$.

A discharge test of slim hole $\mathrm{N}-1 \mathrm{t}$ was performed from May 28, 1985 to June 14, 1985. As discussed in Section 3, slim hole $\mathrm{N}-1 \mathrm{t}$ produces from a single-phase liquid feedzone at $\sim 1700$ mTVD. The stable feedzone temperature and pressure are $220{ }^{\circ} \mathrm{C}$ and 149.7 bars, respectively. During the discharge test, three (3) downhole pressure/temperature surveys were run on June 9 (discharge rate $=7.53 \mathrm{~kg} / \mathrm{s}$ ), June 10 (discharge rate $=4.81 \mathrm{~kg} / \mathrm{s}$ ), and June 11, 1985 (discharge rate $=6.42 \mathrm{~kg} / \mathrm{s}$ ). Apparently, the well was discharged at $4.81 \mathrm{~kg} / \mathrm{s}$ for only a few hours on June 10, and the feedzone flowing pressure may not have stabilized. Using the measured values for the feedzone flowing pressure, the following estimates are obtained for the productivity index:

June 9, 1985: PI = 7.53 / (149.7 - 49.6)

$$
=0.075 \mathrm{~kg} / \mathrm{s}-\mathrm{bar}
$$

June 10, 1985: PI = 4.81/(149.7-63.2)

$$
=0.056 \mathrm{~kg} / \mathrm{s}-\mathrm{bar}
$$


June 11, 1985: PI = $6.42 /(149.7-56.4)$ $=0.069 \mathrm{~kg} / \mathrm{s}-\mathrm{bar}$.

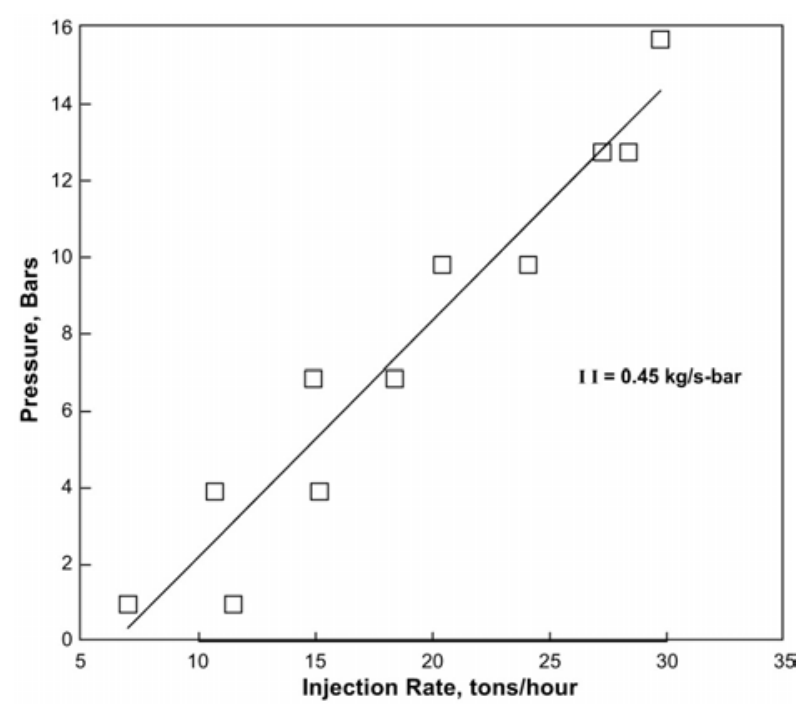

Figure 4.4. A multi-rate injectivity test of slim hole $\mathrm{N}-1 \mathrm{t}$ performed on April 14, 1985. The pressure gauge was set at the wellhead.

\section{Slim Hole N-2t}

A brief injection test of slim hole $\mathrm{N}-2 \mathrm{t}$ (test duration: 70 minutes) was carried out on November 18, 1984. The pressure gauge was located at the wellhead. Unfortunately, no pressure change could be observed at the wellhead since injection was carried out at zero(0) wellhead pressure. Therefore, the available data are not useful for estimating the injectivity index for $\mathrm{N}-2 \mathrm{t}$.

A preliminary discharge test of $\mathrm{N}-2 \mathrm{t}$ was performed from August 18, 1985 to November 14, 1985. Towards the end of the discharge test, two downhole pressure/temperature surveys were carried out on November 11 (discharge rate $=11.47 \mathrm{~kg} / \mathrm{s}$ ) and November 13 (discharge rate $=6.72 \mathrm{~kg} / \mathrm{s}$ ). Unfortunately, these pressure/temperature surveys were performed by drastically lowering the discharge rate for a few hours. It is doubtful that the feedzone conditions had time to stabilize at these flow rates. Although discharge from slim hole $\mathrm{N}-2 \mathrm{t}$ is known to be accompanied by in situ boiling, it appears that single-phase liquid conditions prevailed at the feedzone depth at the time the downhole surveys were recorded. Using a stable feedzone (1260 mTVD) pressure of 107.9 bars and measured flowing pressures of 99.5 bars on November 11 and 100.5 bars on November 13 , the productivity index is estimated to be:

November 11, 1985: PI $=11.47 /(107.9$ - 99.5)

$$
=1.37 \mathrm{~kg} / \mathrm{s}-\mathrm{bar}
$$

November 13, 1985: PI $=6.72 /(107.9-100.5)$

$$
=0.91 \mathrm{~kg} / \mathrm{s}-\mathrm{bar} \text {. }
$$

\section{Well N-6T}

A brief multi-rate injection test (test duration: 34 minutes) of well N-6T was performed on December 8, 1985. The pressure gauge was set at the wellhead. The wellhead pressure and injection rate data (for $\mathrm{t}>2$ minutes) are shown in Figure 4.5. The corresponding injectivity index is $3.71 \mathrm{~kg} / \mathrm{s}-\mathrm{bar}$.

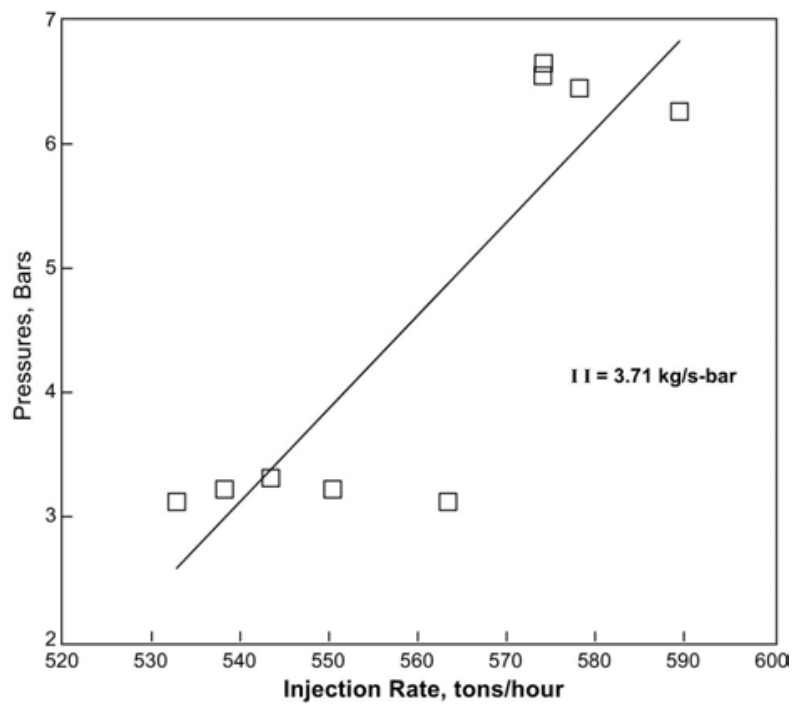

Figure 4.5. A multi-rate injectivity test of production well N-6T performed on December 8, 1985. The pressure gauge was set at the wellhead.

After two preliminary discharge tests in October and November 1986, well N-6T was discharged for about 4 months from December 
8, 1986 to April 5, 1987. During the discharge test, four (4) downhole pressure/temperature surveys were run on December 22 (discharge rate: $52.4 \mathrm{~kg} / \mathrm{s}$ ), December 23 (discharge rate: $45.1 \mathrm{~kg} / \mathrm{s}$ ), December 24 (discharge rate: 35.0 $\mathrm{kg} / \mathrm{s}$ ) and December 26, 1986 (discharge rate: $34.2 \mathrm{~kg} / \mathrm{s}$ ). It appears that single-phase liquid conditions prevailed at the feedzone depth (1390 mTVD) on December 24 and December 26, 1986. The stable feedzone pressure (see Section 3) is 118.5 bars. Using the measured flowing pressures at the feedzone depth, the productivity index for N-6T is computed to be:

December 22, 1986: PI $=52.4 /(118.5-48.1)$ $=0.74 \mathrm{~kg} / \mathrm{s}-\mathrm{bar}$

December 23, 1986: PI $=45.1 /(118.5-58.1)$ $=0.75 \mathrm{~kg} / \mathrm{s}-\mathrm{bar}$

December 24, 1986: PI $=35.0 /(118.5-74.0)$ $=0.79 \mathrm{~kg} / \mathrm{s}-\mathrm{bar}$

December 26, 1986: PI = 34.2/(118.5-76.8) $=0.82 \mathrm{~kg} / \mathrm{s}-$ bar.

As part of a field-wide discharge test, well N6T was discharged for about 3.5 months from December 9, 1987 to March 28, 1988. Like other Okuaizu wells, the discharge from N-6T tended to dry out during the 1987-1988 discharge test. Three (3) pressure/temperature/ spinner surveys were run in the discharging well on February 26 (discharge rate: 17.2 $\mathrm{kg} / \mathrm{s}$ ), February 27 (discharge rate: $15.1 \mathrm{~kg} / \mathrm{s}$ ), and February 28, 1988 (discharge rate: 9.6 $\mathrm{kg} / \mathrm{s}$ ). These downhole surveys clearly indicate the presence of boiling conditions at the feedzone depth. Based on the measured flowing feedzone pressures in February 1988, the productivity index for N-6T becomes:

$$
\begin{aligned}
\text { February 26, 1988: PI } & =17.2 /(118.5-22.5) \\
& =0.18 \mathrm{~kg} / \mathrm{s}-\mathrm{bar}
\end{aligned}
$$

February 27, 1988: PI $=15.1 /(118.5-27.9)$

$$
=0.17 \mathrm{~kg} / \mathrm{s}-\mathrm{bar}
$$

February 28, 1988: PI = $9.6 /(118.5-41.1)$

$$
=0.12 \mathrm{~kg} / \mathrm{s}-\text { bar. }
$$

It is significant that the productivity indices calculated from the February 1988 data are only about $20 \%$ of those obtained from the December 1986 data. Clearly, the onset of in situ boiling is responsible for this drastic reduction in the productivity indices.

\section{Well N-10T}

A multi-rate injection test of well N-10T was performed on September 24 and 26, 1986 with the pressure gauge set at the wellhead. The injection rate and pressure data are exhibited in Figure 4.6, and the corresponding injectivity index is $1.79 \mathrm{~kg} / \mathrm{s}-\mathrm{bar}$. During cold water injection on September 26, 1986 (injection rate: $21.0 \mathrm{~kg} / \mathrm{s}$ ), a downhole pressure/temperature survey was run. Using a stable feedzone (1540 mTVD) pressure of 128.4 bars (computed from the pressure fit in Section 3.2) and a flowing feedzone pressure of 152.9 bars, the injectivity index becomes:

$$
\mathrm{II}=21.0 /(152.9-128.4)=0.86 \mathrm{~kg} / \mathrm{s}-\text { bar } .
$$

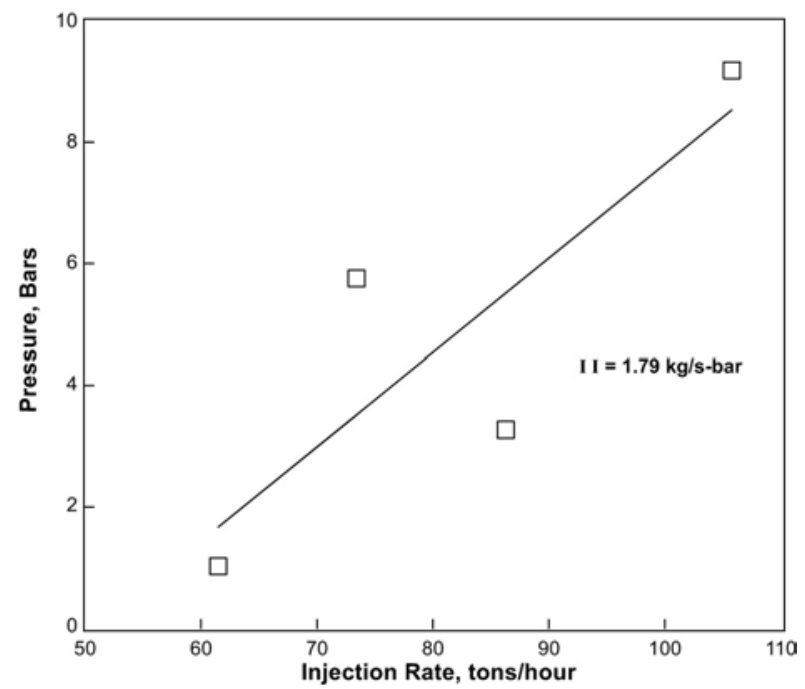

Figure 4.6. A multi-rate injectivity test of production well N-10T performed on September 24 and 26, 1986. The pressure gauge was set at the wellhead. 
During the 1987-88 field-wide discharge test, three (3) downhole pressure/temperature/ spinner surveys were run in the discharging well. Unfortunately, all of these surveys extend to a depth of only $920 \mathrm{mMD}$, and are, therefore, unsuitable for computing the productivity index. In a subsequent discharge test, a PTS survey was run in the discharging well on September 10, 1988 (discharge rate: $15.4 \mathrm{~kg} / \mathrm{s}$ ). The measured pressures and temperatures on September 10, 1988 indicate the presence of two-phase conditions at the feedzone depth. With a flowing feedzone pressure of 43.3 bars, the productivity index is computed to be:

$$
\mathrm{PI}=15.4 /(128.4-43.3)=0.18 \mathrm{~kg} / \mathrm{s}-\mathrm{bar} .
$$

\section{Well N-11T}

An injectivity test of production well N-11T was performed on October 12, 1986 with the pressure gauge set at the wellhead. After an initial transient lasting about 30 minutes, the wellhead pressure was maintained at about 8.15 bars from $\mathrm{t}=30.5$ minutes to $\mathrm{t}=93.0$ minutes while the injection rate declined from $\sim 193$ tons/hour to $\sim 161$ tons/hour. Between $\mathrm{t}=93.0$ minutes and $\mathrm{t}=116.5$ minutes (end of the injection test), the pressure was kept at $\sim 10.5$ bars. Towards the end of the injection test, the injection rate was $\sim 182$ tons/hour. The injection rate and pressure data at $\mathrm{t}=62.5$, 93.0, and 116.5 minutes are displayed in Figure 4.7. The corresponding injectivity index is $2.53 \mathrm{~kg} / \mathrm{s}-\mathrm{bar}$.

As part of a multi-well discharge test, well N-11T was discharged from December 2, 1988 to March 20, 1989. Pressure/ temperature/spinner (PTS) surveys were run in the discharging well on March 11 (discharge rate: $18.4 \mathrm{~kg} / \mathrm{s}$ ), March 12 (discharge rate: $16.0 \mathrm{~kg} / \mathrm{s}$ ), and March 13, 1989 (discharge rate: $13.3 \mathrm{~kg} / \mathrm{s}$ ). It appears that in each case, the discharge rate was maintained at a particular rate for only a few hours. Therefore, it is unlikely that downhole conditions were stable at the time the PTS surveys were run. Assuming a stable feedzone (1150 mTVD) pressure of 98.0 bars and using the measured flowing pressures, the productivity index is computed as follows:

March 11, 1989, PI = $18.4 /(98.0-16.5)$

$$
=0.23 \mathrm{~kg} / \mathrm{s}-\mathrm{bar}
$$

March 12, 1989, PI = 16.0/ $(98.0-20.0)$

$$
=0.21 \mathrm{~kg} / \mathrm{s}-\mathrm{bar}
$$

March 13, 1989, PI = 13.3 / $(98.0-25.6)$

$$
=0.18 \mathrm{~kg} / \mathrm{s}-\mathrm{bar} \text {. }
$$

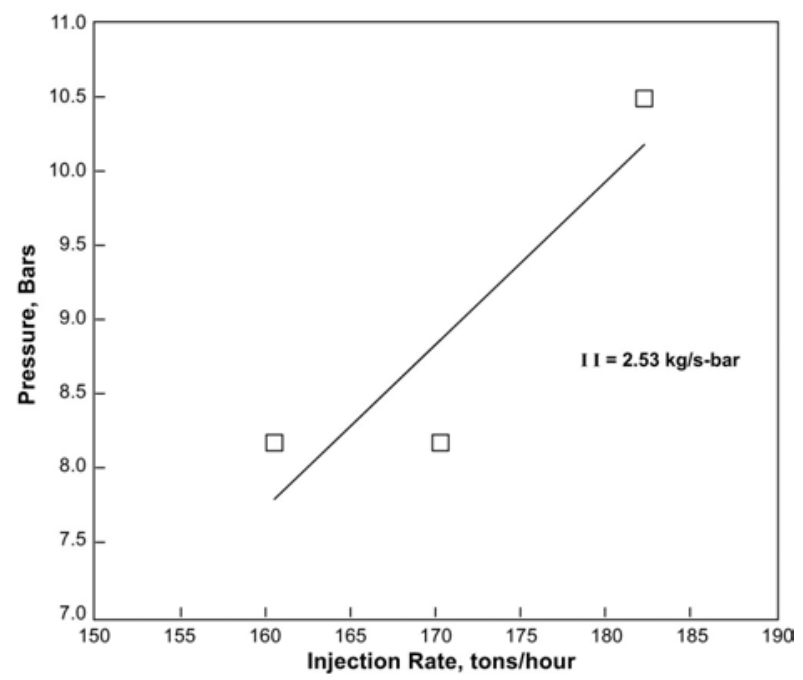

Figure 4.7. A multi-rate injectivity test of production well N-11T performed on October 12, 1986. The pressure gauge was set at the wellhead.

\section{Well N-14T}

A brief multi-rate injection test (test duration: 140 minutes) of production well N-14T was performed on September 13, 1987 with the pressure gauge set at the wellhead. The injection rate and pressure data are displayed in Figure 4.8. The corresponding injectivity index is $3.04 \mathrm{~kg} / \mathrm{s}-\mathrm{bar}$.

As part of a field-wide discharge test, well N14T was discharged from December 12, 1987 to March 29, 1988. Production from N-14T 
was accompanied by in situ boiling. Two pressure/temperature (PT) and three pressure/temperature/spinner (PTS) surveys were run in the flowing well on February 21 (discharge rate: $12.03 \mathrm{~kg} / \mathrm{s}$ ), February 22 (discharge rate: $5.67 \mathrm{~kg} / \mathrm{s}$ ), March 6 (discharge rate: $11.97 \mathrm{~kg} / \mathrm{s}$ ), March 7 (discharge rate: $9.75 \mathrm{~kg} / \mathrm{s}$ ) and March 8, 1988 (discharge rate: $10.94 \mathrm{~kg} / \mathrm{s})$. With a stable feedzone (1130 mTVD) pressure of 100.0 bars and using the measured flowing feedzone pressures, the productivity index becomes:

February 21, 1988: PI = $12.03 /(100.0-18.4)$

$$
=0.15 \mathrm{~kg} / \mathrm{s}-\mathrm{bar}
$$

February 22, 1988: PI = $5.67 /(100.0-20.9)$

$$
=0.07 \mathrm{~kg} / \mathrm{s}-\mathrm{bar}
$$

March 6, 1988: PI = 11.97 / $(100.0-18.5)$

$$
=0.15 \mathrm{~kg} / \mathrm{s}-\mathrm{bar}
$$

March 7, 1988: PI $=9.75 /(100.0-20.8)$

$$
=0.12 \mathrm{~kg} / \mathrm{s}-\mathrm{bar}
$$

March 8, 1988: PI $=10.94 /(100.0-19.9)$

$$
=0.14 \mathrm{~kg} / \mathrm{s}-\mathrm{bar} \text {. }
$$

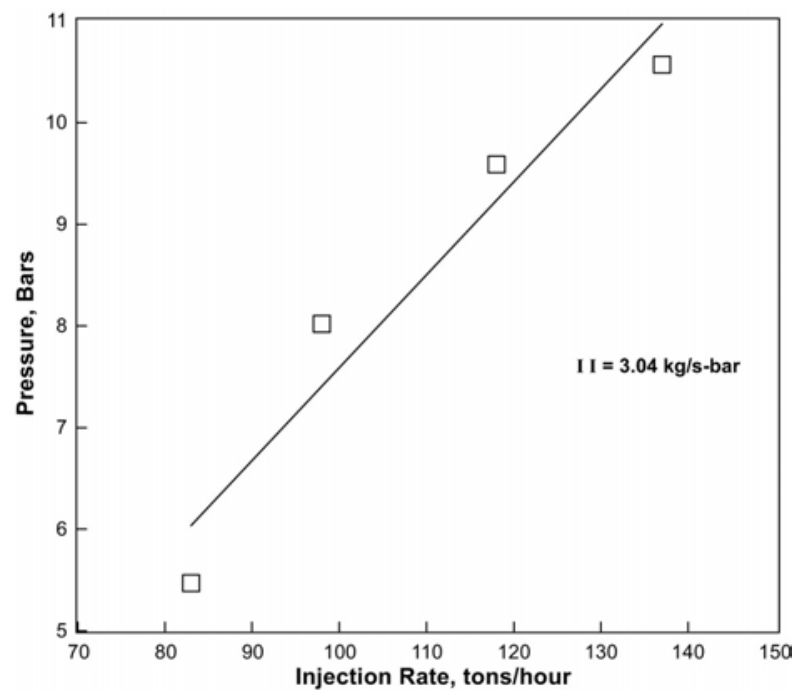

Figure 4.8. A multi-rate injectivity test of production well N-14T performed on September 13, 1987. The pressure gauge was set at the wellhead.
The large variability in the computed productivity indices for N-14T is most likely due to insufficient time being allowed for downhole conditions to stabilize after a change in the discharge rate. Because of the extremely high compressibility of two-phase (water/steam) mixtures, it can take a long time (days?) for the feedzone pressure to stabilize.

\section{Well N-15T}

A brief injection test (test duration: 60 minutes) of production well N-15T was performed on September 19, 1987 with the pressure gauge set at the wellhead. For the most part, injection occurred at negative wellhead pressures (gauge), and the data cannot be used to compute an injectivity index for N-15T.

As part of a field-wide discharge test, N-15T was discharged for about 3.5 months from December 9, 1987 to March 26, 1988. Discharge from N-15T was accompanied by in situ boiling. Three pressure/temperature/ spinner surveys were run in the discharging well on March 2 (discharge rate: $47.2 \mathrm{~kg} / \mathrm{s}$ ), March 3 (discharge rate: $36.2 \mathrm{~kg} / \mathrm{s}$ ), and March 4, 1988 (discharge rate: $32.6 \mathrm{~kg} / \mathrm{s}$ ). The stable feedzone (1150 mTVD) pressure is 102.9 bars (Section 3). Using the measured flowing feedzone pressures, the productivity index for $\mathrm{N}-15 \mathrm{~T}$ is computed to be:

March 2, 1988: PI = 47.2 / $(102.9-76.0)$

$$
=1.76 \mathrm{~kg} / \mathrm{s}-\mathrm{bar}
$$

March 3, 1988: PI = 36.2 / (102.9-76.9)

$$
=1.39 \mathrm{~kg} / \mathrm{s}-\mathrm{bar}
$$

March 4, 1988: PI = 32.6 / (102.9- 77.4)

$$
=1.28 \mathrm{~kg} / \mathrm{s}-\mathrm{bar} \text {. }
$$

Production well N-15T has productivity indices which are significantly greater than the average Okuaizu production well. 


\section{Well N-16T}

A five (5) rate injectivity test of well N-16T was performed on July 27, 1987 with the pressure gauge set at the wellhead. Step 5 of the injection test involved decreasing the wellhead pressure from $\sim 10.4$ bars to $\sim 8.4$ bars. Paradoxically, the decrease in the wellhead pressure was accompanied by an increase in the injection rate. The pressure and injection rate data from the first four (4) steps are displayed in Figure 4.9. The corresponding injectivity index is $6.73 \mathrm{~kg} / \mathrm{s}-\mathrm{bar}$.

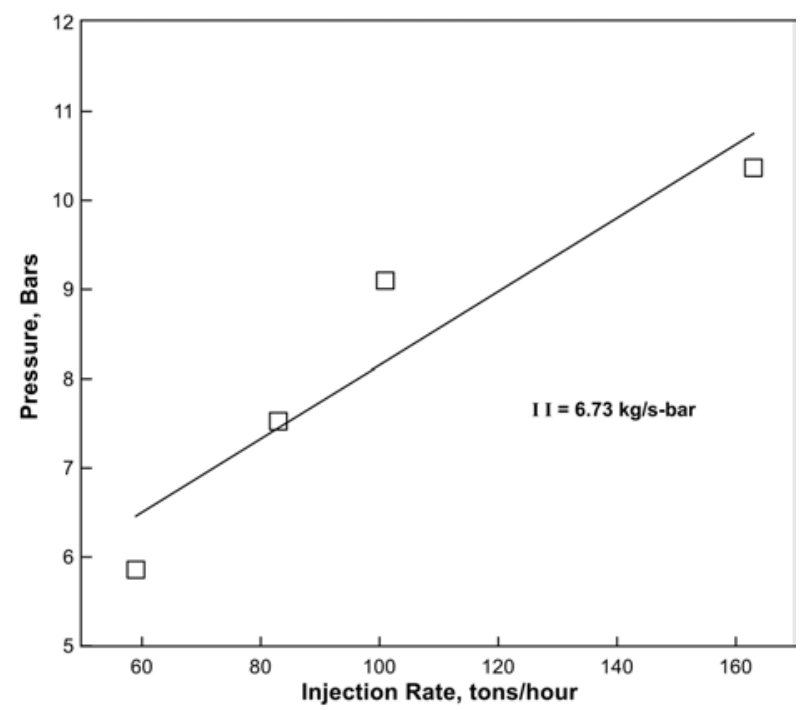

Figure 4.9. A multi-rate injectivity test of production well N-16T performed on July 27, 1987. The pressure gauge was set at the wellhead.

As part of a multi-well discharge test, well N16T was discharged for about 3.5 months from December 1, 1988 to March 19, 1989. Production from N-16T was accompanied by in situ boiling (Section 3). Three (3) downhole pressure/temperature/spinner (PTS) surveys were run in the flowing well on March 9 (discharge rate: $15.50 \mathrm{~kg} / \mathrm{s}$ ), March 10 (discharge rate: $11.61 \mathrm{~kg} / \mathrm{s}$ ), and March 17, 1989 (discharge rate: $18.14 \mathrm{~kg} / \mathrm{s}$ ). The stable feedzone (1260 mTVD) pressure is 104.8 bars (Section 3). Using the measured flowing feedzone pressures, the productivity index for $\mathrm{N}-16 \mathrm{~T}$ is computed to be:

March 9, 1989: PI $=15.50 /(104.8-22.8)$

$$
=0.19 \mathrm{~kg} / \mathrm{s}-\mathrm{bar}
$$

March 10, 1989: PI = $11.61 /(104.8-29.0)$

$$
=0.15 \mathrm{~kg} / \mathrm{s}-\mathrm{bar}
$$

March 17, 1989: PI = 18.14 / (104.8-17.6)

$$
=0.21 \mathrm{~kg} / \mathrm{s}-\mathrm{bar} \text {. }
$$

\section{Well N-17T}

A multi-rate (6 pressure steps) brief injection test (test duration: 2 hours) of well N-17T was performed on October 15, 1987. During the first two pressure steps, the injection rate kept on declining; these data are therefore unsuitable for computing the injectivity index. The pressure and injection rate data from the last four pressure steps are plotted in Figure 4.10. The corresponding injectivity index is $3.95 \mathrm{~kg} / \mathrm{s}-\mathrm{bar}$.

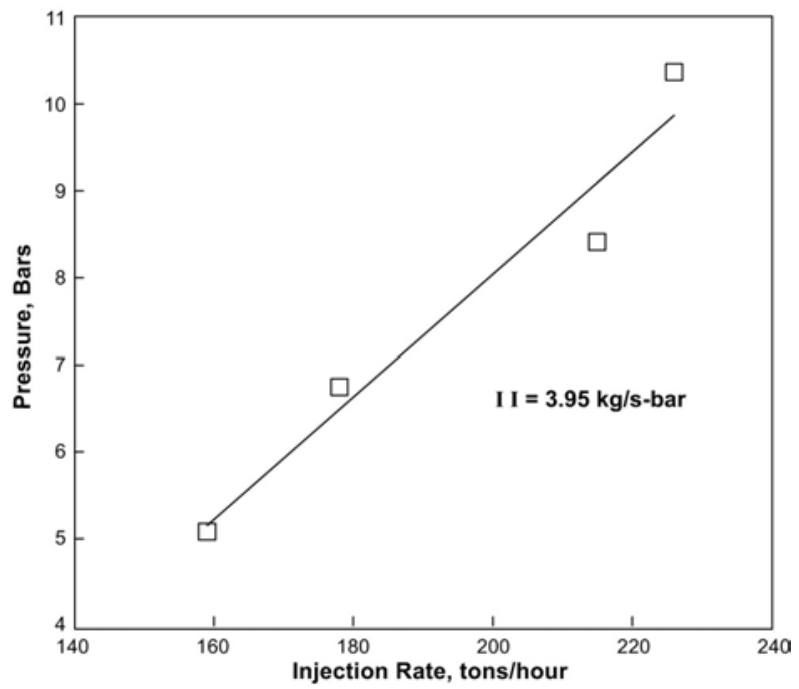

Figure 4.10. A multi-rate injectivity test of production well N-17T performed on October 15, 1987. The pressure gauge was set at the wellhead.

Production well N-17T was discharged for about 3.5 months from December 4, 1988 to March 21, 1989. A total of three (3) pressure/temperature/spinner (PTS) surveys were run in the discharging well on March 14 (discharge rate: $17.6 \mathrm{~kg} / \mathrm{s}$ ), March 15 (discharge rate: $16.4 \mathrm{~kg} / \mathrm{s}$ ) and March 16, 1989 (discharge rate: $11.0 \mathrm{~kg} / \mathrm{s}$ ). The stable feedzone (910 mTVD) pressure is 81.0 bars 
(Section 3). The PTS surveys imply that discharge from N-17T was accompanied by in situ boiling. Using the measured flowing feedzone pressures, the productivity index for $\mathrm{N}-17 \mathrm{~T}$ is estimated to be:

March 14, 1989: PI $=17.6 /(81.0-14.7)$

$$
=0.27 \mathrm{~kg} / \mathrm{s}-\mathrm{bar}
$$

March 15, 1989: PI = $16.4 /(81.0-16.6)$

$$
=0.25 \mathrm{~kg} / \mathrm{s}-\mathrm{bar}
$$

March 16, 1989: PI $=11.0 /(81.0-22.2)$

$$
=0.19 \mathrm{~kg} / \mathrm{s}-\mathrm{bar} \text {. }
$$

\section{Well N-22T}

A brief multi-rate injection test (test duration: 103 minutes) was performed on November 19, 1989 with the pressure gauge set at the wellhead. The injection rate and pressure data are plotted in Figure 4.11. The corresponding injectivity index is $3.29 \mathrm{~kg} / \mathrm{s}-\mathrm{bar}$.

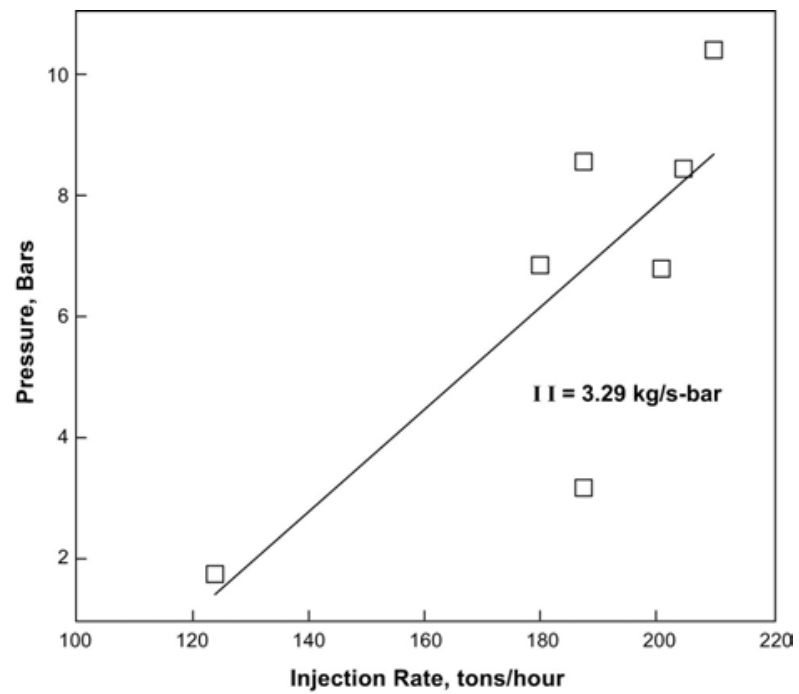

Figure 4.11. A multi-rate injectivity test of production well N-22T performed on November 19, 1989. The pressure gauge was set at the wellhead.

As part of a field-wide discharge test, well N22T was discharged for about 3 months from December 1, 1989 to February 27, 1990. Two pressure/temperature/spinner surveys were run in the discharging well on February 26 (discharge rate: $30.75 \mathrm{~kg} / \mathrm{s}$ ) and February 27, 1990 (discharge rate: $17.53 \mathrm{~kg} / \mathrm{s}$ ). Unfortunately, the PTS surveys could not be run below the shallowest major entry at 1550 mTVD. Assuming a stable feedzone (1550 mTVD) pressure of 133.7 bars and using the measured flowing pressures, the productivity index for $\mathrm{N}-22 \mathrm{~T}$ is computed to be:

February 26, 1990: PI = 30.75 / (133.7 - 38.8)

$$
=0.32 \mathrm{~kg} / \mathrm{s}-\mathrm{bar}
$$

February 27, 1990: PI = $17.53 /(133.7-71.6)$

$$
=0.28 \mathrm{~kg} / \mathrm{s}-\text { bar. }
$$

\section{Well N-26P}

A brief multi-rate injection test (test duration: 2 hours 45 minutes) was performed on June 17, 1993 with the pressure gauge set at the wellhead. The injection rate and pressure data are plotted in Figure 4.12. The corresponding injectivity index is $2.93 \mathrm{~kg} / \mathrm{s}-\mathrm{bar}$.

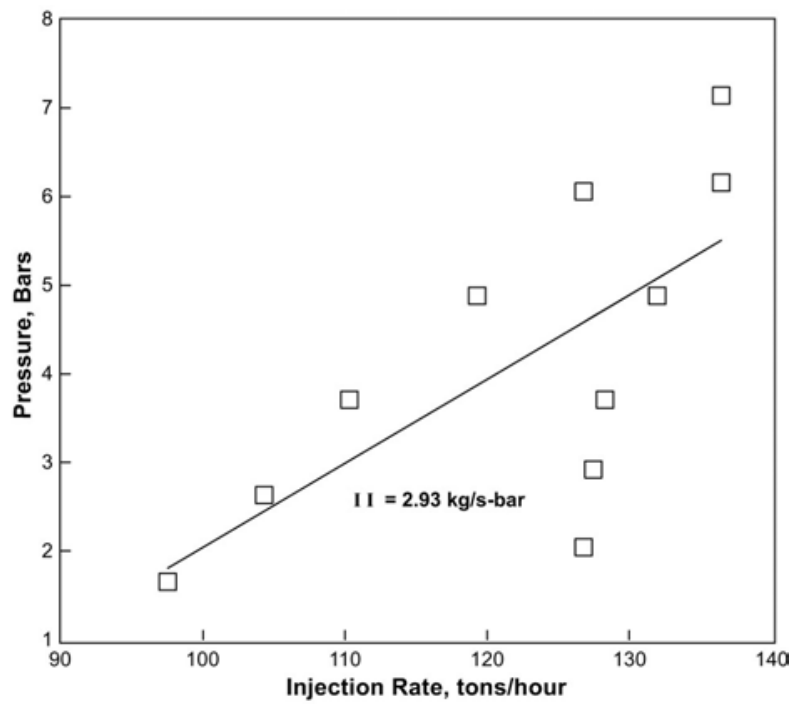

Figure 4.12. A multi-rate injectivity test of production well N-26P performed on June 17, 1993. The pressure gauge was set at the wellhead.

Production well N-26P was discharged for about a month from June 26 to July 25, 1993. Three pressure/temperature/spinner (PTS) surveys were run in the discharging well on 
July 22 (discharge rate: $18.6 \mathrm{~kg} / \mathrm{s}$ ), July 23 (discharge rate: $14.6 \mathrm{~kg} / \mathrm{s}$ ), and July 24, 1993 (discharge rate: $9.4 \mathrm{~kg} / \mathrm{s}$ ). The major feedzone for $\mathrm{N}-26 \mathrm{P}$ is located at about $1890 \mathrm{mTVD}$, and the stable feedzone pressure is 160 bars (Section 3). For some unknown reason, the PTS survey of July 23, 1993 extended to a depth of only $\sim 875$ mTVD, and these data are unsuitable for calculating the productivity index. Using the measured flowing feedzone pressures on July 22 and July 24, 1993, the productivity index is computed to be:

$$
\begin{aligned}
\text { July 22, 1993: PI } & =18.6 /(160.0-20.3) \\
& =0.13 \mathrm{~kg} / \mathrm{s}-\mathrm{bar}
\end{aligned}
$$

July 24, 1993: PI $=9.4$ / $(160.0-56.5)$

$$
=0.09 \mathrm{~kg} / \mathrm{s}-\mathrm{bar} \text {. }
$$

\section{Well N-28P}

A brief multi-rate injection test (test duration: 58 minutes) of production well N-28P was performed on May 31, 1993 with the pressure gauge set at the wellhead. The injection rate and pressure data are displayed in Figure 4.13. The corresponding injectivity index is $7.45 \mathrm{~kg} / \mathrm{s}-\mathrm{bar}$.

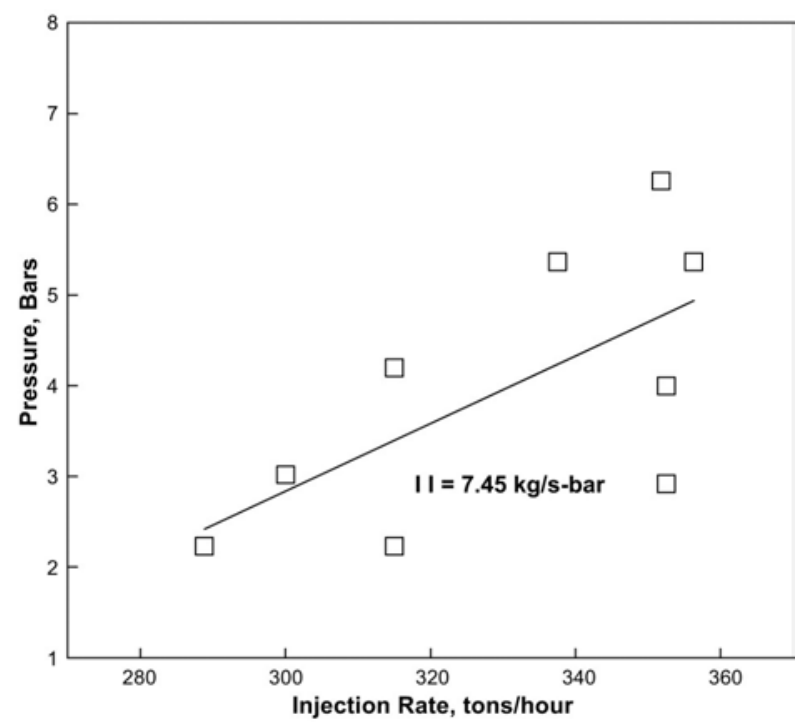

Figure 4.13. A multi-rate injectivity test of production well N-28P performed on May 31, 1993. The pressure gauge was set at the wellhead.
Production well N-28P was discharged for about one month from October 26, 1993 to November 28, 1993. Three pressure/ temperature/spinner (PTS) surveys were run in the discharging well on November 25 (discharge rate: $24.7 \mathrm{~kg} / \mathrm{s}$ ), November 26 (discharge rate: $16.8 \mathrm{~kg} / \mathrm{s}$ ), and November 27 , 1993 (discharge rate: $9.9 \mathrm{~kg} / \mathrm{s}$ ). The stable feedzone (1760 mTVD) pressure is $\sim 151.7$ bars (Section 3). Using the measured flowing feedzone pressures, the productivity index for $\mathrm{N}-28 \mathrm{P}$ is computed to be:

November 25, 1993: PI $=24.7 /(151.7-37.0)$

$$
=0.22 \mathrm{~kg} / \mathrm{s}-\mathrm{bar}
$$

November 26, 1993: PI $=16.8 /(151.7-53.8)$

$$
=0.17 \mathrm{~kg} / \mathrm{s}-\mathrm{bar}
$$

November 27, 1993: PI $=9.9 /(151.7-69.2)$

$$
=0.12 \mathrm{~kg} / \mathrm{s}-\mathrm{bar} \text {. }
$$

\subsection{Relationship between Injectivity and Two-Phase Productivity Indices}

Discharge capacity of a geothermal borehole is determined by pressure losses associated with flow (1) in the reservoir rocks, and (2) in the wellbore. Given mass flow rate and feedzone pressure and flowing enthalpy, equations governing mass and energy transport in the wellbore may be integrated to obtain wellhead parameters such as pressure and discharge enthalpy. Two-phase fluid flow in a geothermal borehole is not amenable to strict analytical treatment, and it is necessary to use empirical correlations for flowing steam quality, friction factor and heat losses in order to obtain a tractable set of governing equations. Although utilization of different correlations does not usually give identical results, the available correlations are adequate for computing a first approximation to the pressure losses in the wellbore.

Ignoring pressure transient effects, the pressure losses in the reservoir rocks can be 
computed using a productivity index. Prediction of the mass output of a largediameter well requires, among other things, a relationship between the productivity index and borehole diameter. Because of the increased importance of frictional and heat losses in small-diameter boreholes, it is often impractical to discharge slim holes. There is, however, no problem in performing injection tests and computing the injectivity index. Therefore, if a relationship can be established between injectivity and productivity indices, then it should be possible to use injection tests on slim hole to estimate the probable discharge rate of large-diameter wells.

Based on theoretical considerations, Pritchett (1993) and Hadgu, et al. (1994) have suggested that the productivity (or injectivity) index should exhibit only a weak dependence on borehole diameter. The single-phase (liquid) productivity and injectivity index data for Sumikawa, Takigami, and Kirishima boreholes do not display a systematic correlation with borehole diameter (Garg et al, 1998). However, the injectivity and productivity indices for Oguni boreholes display a strong dependence on borehole diameter. Garg et al. (1995) hypothesized that core drilling at Oguni resulted in enhanced formation plugging and consequent reduction in borehole productivity/injectivity. Since core drilling did not result in any impairment of borehole injectivity/productivity at other geothermal fields (i.e. Sumikawa, Takigami, Kirishima), it is unlikely that enhanced formation plugging in boreholes drilled with coring rigs is a pervasive phenomenon.

At Okuaizu, most injection tests were conducted with the pressure gauge set at the wellhead. As remarked earlier, injectivity indices computed from wellhead pressure gauges provide a gross overestimate of the injection capacity of a geothermal borehole. For Okuaizu boreholes OA-4 and N-10T, injection tests were performed with both wellhead and downhole pressure gauges. In the case of slim hole OA-4, both the wellhead and downhole pressure data gave similar values for the injectivity index. The injectivity index calculated from downhole pressure data for production well N-10T is less than $50 \%$ of that obtained from the wellhead data (see Table 4.2). During a discharge test in December 1986, production well N-6T discharged from a liquid feedzone with a productivity index of about $0.78 \mathrm{~kg} / \mathrm{s}-\mathrm{bar}$ (Table 4.1). Garg and Combs (1997) have shown that the single-phase (liquid) productivity and injectivity indices are more or less equal. Thus, it is reasonable to assume that the injectivity index for $\mathrm{N}-6 \mathrm{~T}$ is $\sim 0.78$ $\mathrm{kg} / \mathrm{s}-$ bar. The latter value is about $20 \%$ of that inferred from wellhead data (Table 4.1). The available data from Okuaizu boreholes OA-4, $\mathrm{N}-6 \mathrm{~T}$ and $\mathrm{N}-10 \mathrm{~T}$ suggest that the injectivity indices obtained from wellhead pressure data do not provide a reliable estimate of the actual injectivity index for the borehole. To determine the injectivity index, it is essential to perform injection tests with the pressure gauge located at or close to the major feedzone for the borehole.

Injectivity indices (based on downhole pressure data) are available for one slim hole (OA-4) and one large-diameter well (N-10T). Also, estimates of single-phase (liquid) productivity index for two slim holes $(\mathrm{N}-1 \mathrm{t}$, $\mathrm{N}-2 \mathrm{t})$ and one large-diameter well $(\mathrm{N}-6 \mathrm{~T})$ are given in Table 4.2. Slim holes OA-4 and N-1t are located to the west of the main Okuaizu borefield. The injectivity/productivity indices for $\mathrm{N}-2 \mathrm{t}, \mathrm{N}-6 \mathrm{~T}$ and $\mathrm{N}-10 \mathrm{~T}$ are similar. The injectivity index for OA-4 is about a third of the injectivity index for N-10T. The productivity index for slim hole $\mathrm{N}-1 \mathrm{t}$ is, however, only $10 \%$ of that for production well N-6T. Disregarding slim hole N-1t, which in any event lies outside the main Okuaizu borefield, it may be concluded that the injectivity/productivity indices for 
Okuaizu boreholes do not display a significant correlation with borehole diameter.

Discharge from most of the Okuaizu boreholes is accompanied by in situ boiling. Productivity indices listed in Table 4.1 were obtained from downhole pressure/temperature/ spinner (PTS) surveys run in discharging boreholes. In many cases, the PTS surveys were taken by reducing the discharge rate. Apparently, no attempt was made to ensure that the feedzone pressure had sufficient time to recover prior to performing the PTS survey. Inadequate time for pressure recovery is most likely responsible for the apparent decrease in the two-phase productivity index with a reduction in the discharge rate (see Table 4.1). Because of the very large compressibility of the two-phase water/steam system, it takes a relatively long time (days?) for the feedzone pressures to equilibrate after a change in the discharge rate. It is likely that the two-phase productivity indices corresponding to lowest discharge rates (Table 4.2) are in substantial error, and should not be used to compute the average productivity index for a borehole.
Both injectivity and two-phase productivity indices are available for two Okuaizu boreholes (OA-4 and N-10T). In addition, both single-phase and two-phase productivity indices are available for large-diameter well N-6T. Productivity/injectivity indices for these three boreholes along with similar data from other Japanese geothermal fields are given in Table 4.3, and are plotted in Figure 4.14. It is apparent from Table 4.3 that the productivity index for a borehole with in situ boiling is much smaller than the injectivity index. Because of relative permeability effects, the flow resistance of reservoir rocks is much greater for two-phase flow than for singlephase liquid transport. Based on the ten (10) data points listed in Table 4.3, the injectivity index on average is about 9 times larger than the two-phase productivity index. In view of the sparseness of the available data set, no great significance should be attached to the exact numerical value for the ratio of the injectivity and two-phase productivity indices. Additional studies and data from a range of geothermal fields are needed to draw firm conclusions regarding the relationship between the injectivity and two-phase productivity index.

Table 4.3. Productivity and injectivity indices for Oguni, Sumikawa, Kirishima, and Okuaizu boreholes with two-phase feedzones.

\begin{tabular}{|l|l|c|c|c|c|}
\hline $\begin{array}{c}\text { Geothermal } \\
\text { Field }\end{array}$ & Borehole & $\begin{array}{c}\text { Final } \\
\text { Diameter } \\
(\mathbf{m m})\end{array}$ & $\begin{array}{c}\text { Productivity } \\
\text { Index (PI) } \\
\mathbf{( k g / s - b a r )}\end{array}$ & $\begin{array}{c}\text { Injectivity } \\
\text { Index (II) } \\
\text { (kg/s-bar) }\end{array}$ & II / PI \\
\hline Oguni & GH-15 & 216 & 0.25 & 1.75 & 7 \\
\hline Sumikawa & S-2(i) & 101 & 0.03 & 0.76 & 25 \\
\hline Sumikawa & S-4 & 159 & 0.94 & 1.4 & 1 \\
\hline Sumikawa & SA-1 & 216 & 0.16 & 1.5 & 9 \\
\hline Sumikawa & SA-4 & 216 & 0.11 & 0.94 & 9 \\
\hline Kirishima & KE1-1 & 78 & 0.05 & 0.16 & 23 \\
\hline Kirishima & KE1-6 & 98 & 0.05 & 1.15 & 7 \\
\hline Okuaizu & OA-4 & 79 & 0.04 & 0.29 & 4 \\
\hline Okuaizu & N-6T & 216 & 0.18 & $0.78^{*}$ & 5 \\
\hline
\end{tabular}




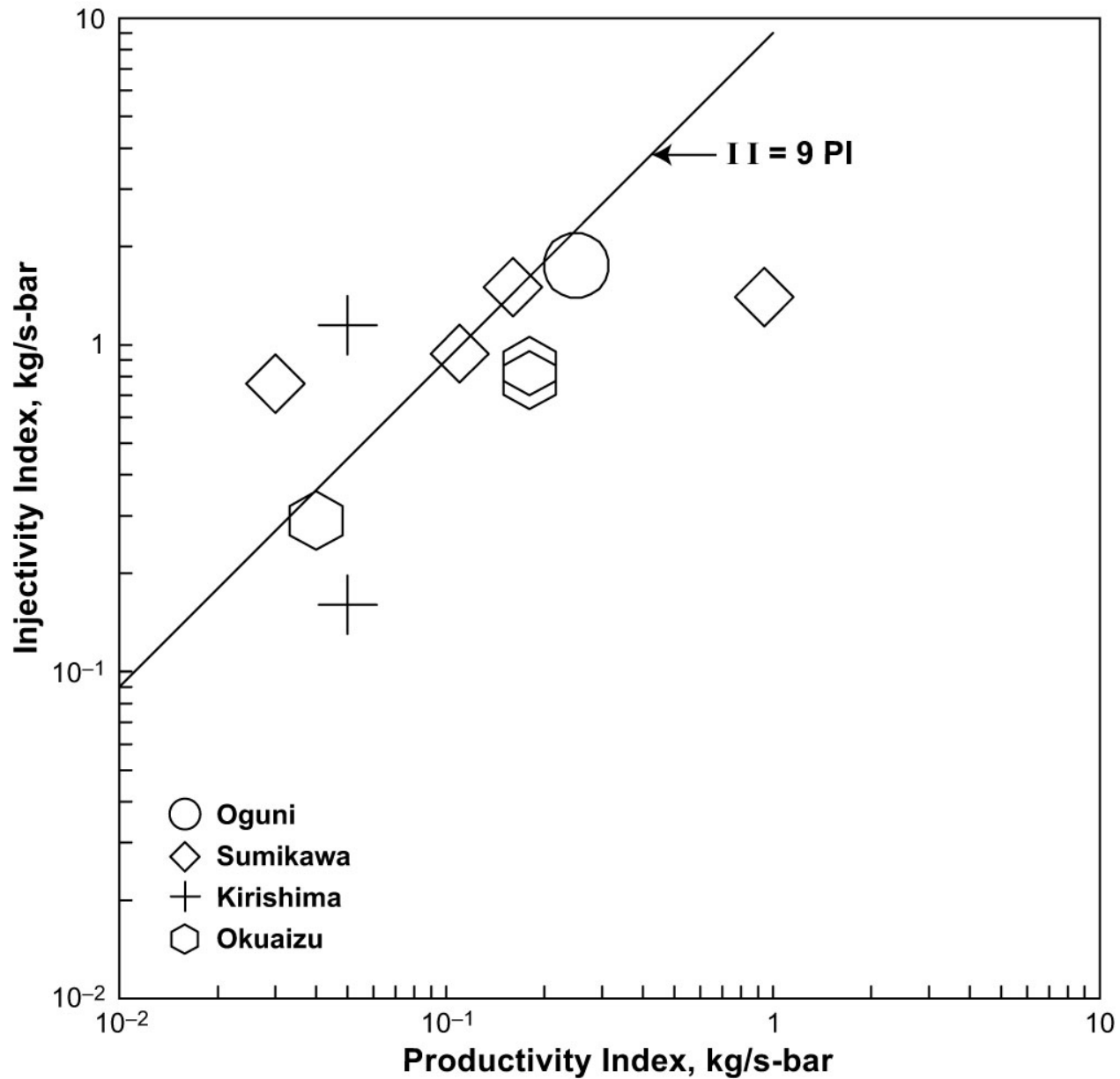

Figure 4.14. Injectivity index (II) versus two-phase productivity index (PI) for Okuaizu, Kirishima, Sumikawa, and Oguni boreholes. 


\section{DISCHARGE CAPACITY AND BOREHOLE DIAMETER}

\subsection{Discharge Tests}

Okuaizu Geothermal Company, Ltd. has provided discharge test data for a total of five (5) slim holes (OA-4, N-1t, N-2t, N-3t, N-5t) and eleven (11) large-diameter wells (N-6T, N-10T, N-11T, N-14T, N-15T, N-16T, N-17T, $\mathrm{N}-21 \mathrm{~T}, \mathrm{~N}-22 \mathrm{~T}, \mathrm{~N}-26 \mathrm{P}, \mathrm{N}-28 \mathrm{P})$. Although large-diameter wells N-18T, N-23P, N-24P and $\mathrm{N}-25 \mathrm{P}$ were also discharged, no useful discharge data are available for these wells. All the five slim holes (OA-4, N-1t, N-2t, N$3 \mathrm{t}, \mathrm{N}-5 \mathrm{t}$ ) and four large diameter wells (N-6T, $\mathrm{N}-10 \mathrm{~T}, \mathrm{~N}-14 \mathrm{~T}$ and $\mathrm{N}-15 \mathrm{~T}$ ) were discharged one at a time during the years 1984-1987. A field-wide discharge test involving five boreholes (N-2t, N-6T, N-10T, N-14T, N15T) was performed from December 1987 to March 1988. It appears that with a single exception (OA-4), Okuaizu boreholes prior to the 1987-1988 field-wide test discharged either from liquid feedzones or produced a moderate amount of excess steam. A qualitative change occurred during the 19871988 field-wide discharge test. The discharge stream tended to dry out and the discharge enthalpy increased substantially. Apparently, discharge from the various Okuaizu boreholes during and after the 1987-1988 field-wide discharge test is accompanied by extensive in situ boiling. As part of the discharge tests, characteristic output curves (i.e. mass and enthalpy versus wellhead pressure) were also obtained. In addition, downhole pressure/ temperature/spinner or pressure/temperature surveys have been carried out under discharge conditions (see Sections 3 and 4 for details) in three (3) slim holes (OA-4, N-1t, N-2t) and ten (10) large-diameter wells (N-6T, N-10T, N-11T, N-14T, N-15T, N-16T, N-17T, N-22T,
$\mathrm{N}-26 \mathrm{P})$. The discharge test data for the various Okuaizu boreholes are more fully described in the following paragraphs.

\section{Slim Hole OA-4}

Slim hole OA-4 was discharged for about a month from January 10, 1984 to February 11, 1984. For most of this period, the well was discharged at a more or less constant wellhead pressure $(1.25 \quad+/-0.1$ bars $)$ Two characteristic tests were performed from January 22 to January 23, 1984 and from February 7 to February 10, 1984 by adjusting the wellhead pressure. Two downhole pressure/temperature surveys were run in the discharging well on February 7 and February 8, 1984 .

During discharge at constant wellhead pressure (see Figure 5.1 and Table B.1), the discharge rate declined from over 15 tons/hour on January 12 to about 8 tons/hour on February 1, 1984. During the same period, wellhead enthalpy increased from $\sim 1600 \mathrm{~kJ} / \mathrm{kg}$ to $\sim 2300 \mathrm{~kJ} / \mathrm{kg}$. As remarked in Section 4 , discharge from OA-4 is accompanied by in situ boiling.

Characteristic output (i.e. discharge rate and wellhead enthalpy versus wellhead pressure) curves recorded on January 22-23, 1984 and February 7-10, 1984 are displayed in Figure 5.2 (see also Table B.2). Comparison of these data with measurements made at constant wellhead pressure (Figure 5.1) indicates that stable discharge conditions were not attained at any time during the characteristic output measurements. Because of the very high compressibility of water/steam mixtures, it 
can take many days (or even weeks) for the discharge conditions to stabilize. Apparently, insufficient time was allowed between wellhead valve setting changes for the discharge rate and wellhead enthalpy to attain stable values.
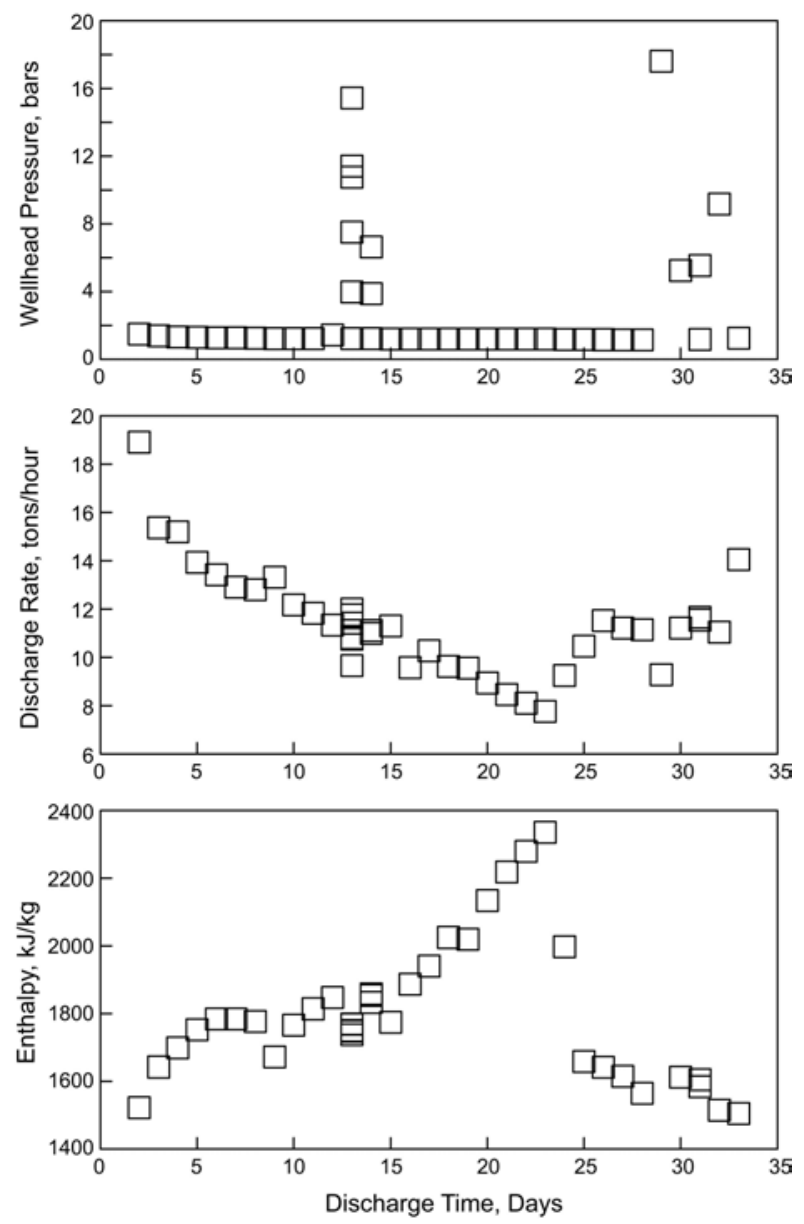

Figure 5.1. Wellhead pressure, discharge rate, and wellhead enthalpy measurements taken during the discharge test of slim hole OA-4 from January 10, 1984 to February 11, 1984.

The maximum discharge rate as measured during the characteristic output tests is about 11.5 tons/hour. As discussed above, the latter value was recorded under transient conditions and does not represent a stable or quasi-stable measurement. The stable discharge rate in all likelihood is less than 8 tons/hour.
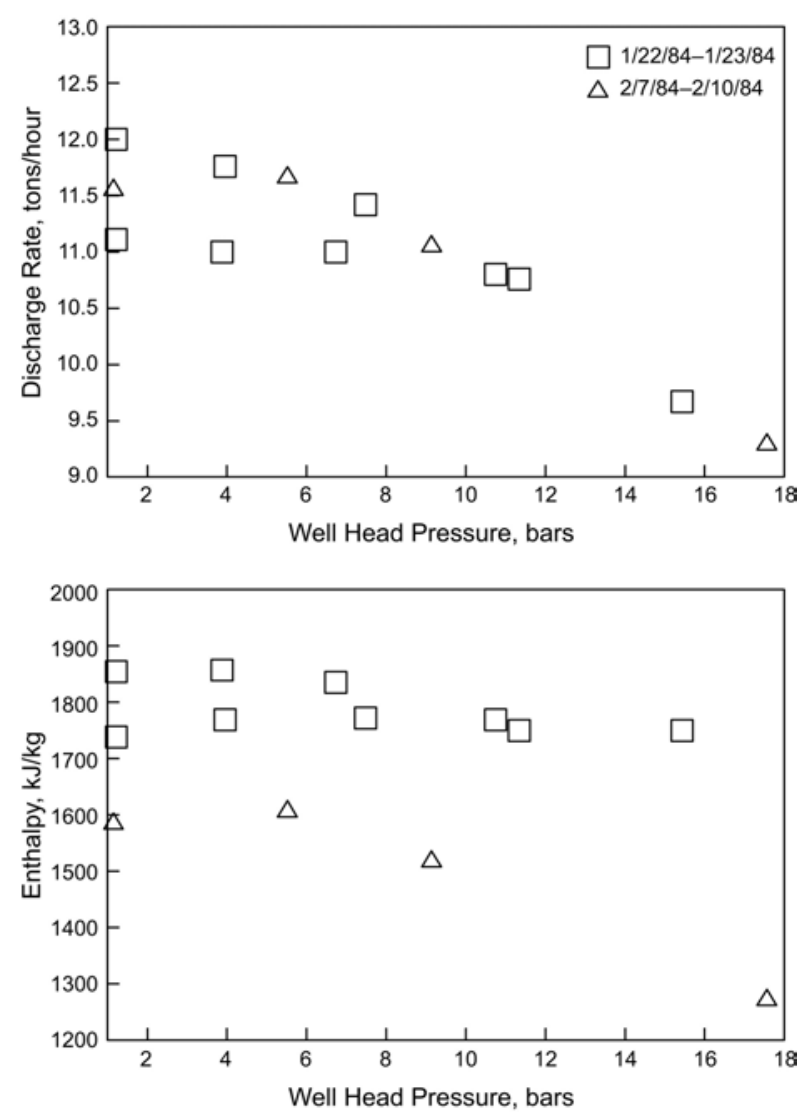

Figure 5.2. Characteristic output (i.e. mass and enthalpy versus wellhead pressure) data recorded for slim hole OA-4 on January 22-23, 1984, and February 7-10, 1984.

\section{Slim Hole N-1t}

Slim hole N-1t was discharged from May 28, 1985 to June 14, 1985. During the latter discharge test, N-1t produced from a singlephase feedzone at 1700 mTVD. The stable feedzone temperature is $\sim 220{ }^{\circ} \mathrm{C}$. Characteristic output measurements taken from June 7, 1985 to June 14, 1985, are displayed in Figure 5.3. The maximum discharge rate and enthalpy (Figure 5.3 and Table B.3) are $\sim 28$ tons/hour and $\sim 910 \mathrm{~kJ} / \mathrm{kg}$, respectively. The maximum discharge enthalpy value of $910 \mathrm{~kJ} / \mathrm{kg}$ corresponds to the enthalpy of saturated liquid water at $\sim 213{ }^{\circ} \mathrm{C}$. 

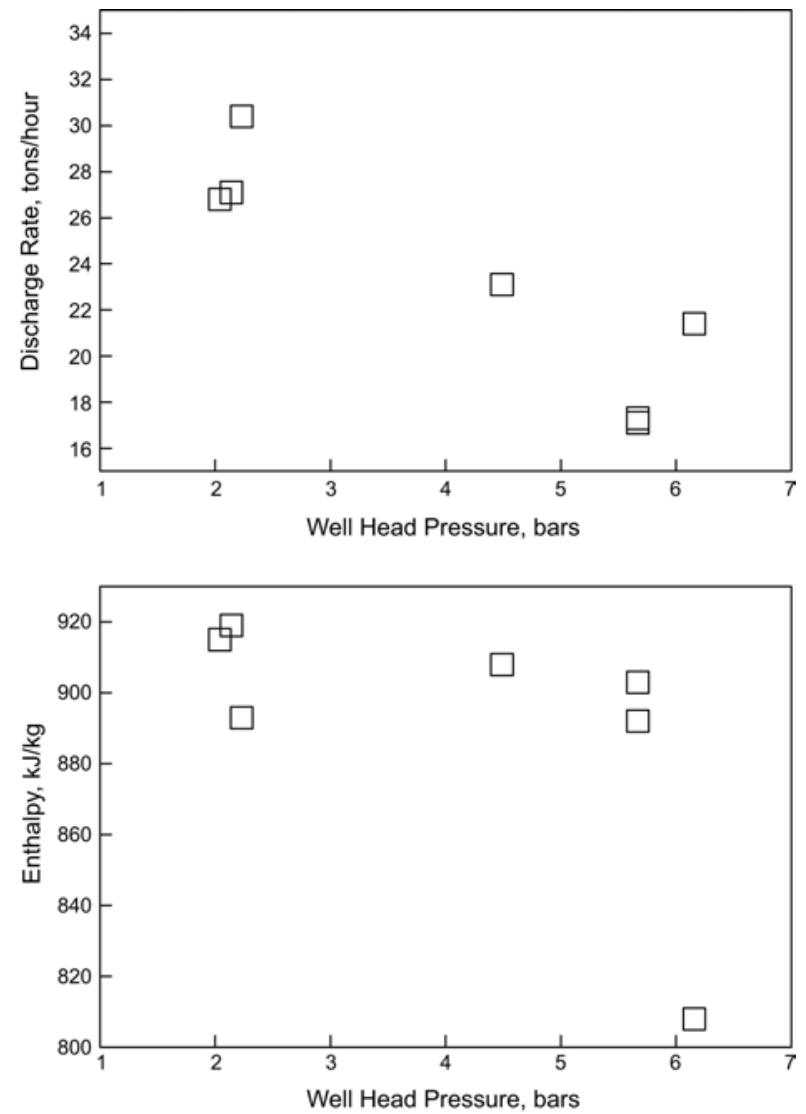

Figure 5.3. Characteristic output (i.e. mass and enthalpy versus wellhead pressure) data recorded for slim hole N-1t from June 7, 1985 to June 14, 1985.

\section{Slim Hole N-2t}

The principal feedzone for $\mathrm{N}-2 \mathrm{t}$ is located at a depth of 1260 mTVD. The stable feedzone temperature is $\sim 300{ }^{\circ} \mathrm{C}$. A preliminary discharge test of $\mathrm{N}-2 \mathrm{t}$ was performed from August 18, 1985 to November 15, 1985. During most of this period, the borehole was discharged at a more or less constant ( 7 to 9 bars) wellhead pressure, and the discharge rate declined from an initial value of $\sim 82$ tons/hour to a final quasi-stable value of $\sim 58$ tons/hour (Figure 5.4 and Table B.4). The wellhead enthalpies ranged from $\sim 1300 \mathrm{~kJ} / \mathrm{kg}$ to $\sim 1440$ $\mathrm{kJ} / \mathrm{kg}$, and correspond to saturated liquid water temperatures of $292{ }^{\circ} \mathrm{C}-316{ }^{\circ} \mathrm{C}$. The wellhead enthalpy data thus imply some in situ boiling and a small amount of steam production. Towards the end of the preliminary discharge test, two downhole pressure/temperature surveys were run by drastically lowering the discharge rate. As remarked in Section 4, single-phase liquid conditions prevailed at the feedzone depth at the time these pressure/temperature surveys were run.
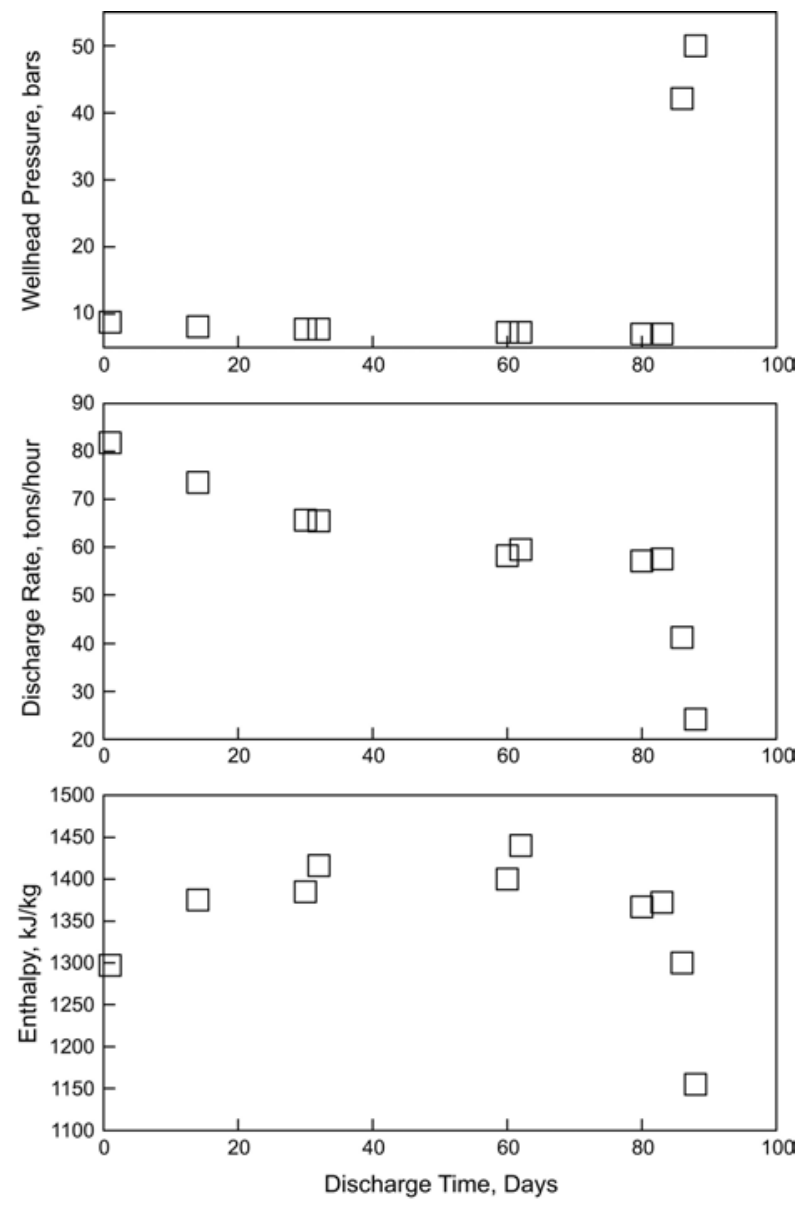

Figure 5.4. Wellhead pressure, discharge rate, and wellhead enthalpy measurements taken during the preliminary discharge test of slim hole $\mathrm{N}-2 \mathrm{t}$ from August 18, 1985 to November 15, 1985.

As part of a field-wide discharge test, slim hole N-2t was discharged from January 12, 1988 to March 28, 1988. During this test, N-2t discharged mostly steam. After an initial transient period, the discharge rate and wellhead enthalpy stabilized at $\sim 13$ tons/hour and $\sim 2630 \mathrm{~kJ} / \mathrm{kg}$, respectively (see Figure 5.5 
and Table B.5). It appears that a fundamental change occurred in the discharge behavior of Okuaizu boreholes in 1987-1988. Prior to 1987, the Okuaizu boreholes were discharged one at a time. From December 1987 to March 1988, the first field-wide discharge test was performed with the simultaneous discharge of boreholes N-2t, N-6T, N-10T, N-14 T and N15T. Wells N-6T, N-10T, N-14T and N-15T were put on discharge between December 9, 1987 and December 15, 1987. Slim hole N-2t was added to the list on January 12, 1988. The discharge from all the five (5) boreholes tended to dry out during the 1987-1988 fieldwide discharge test.
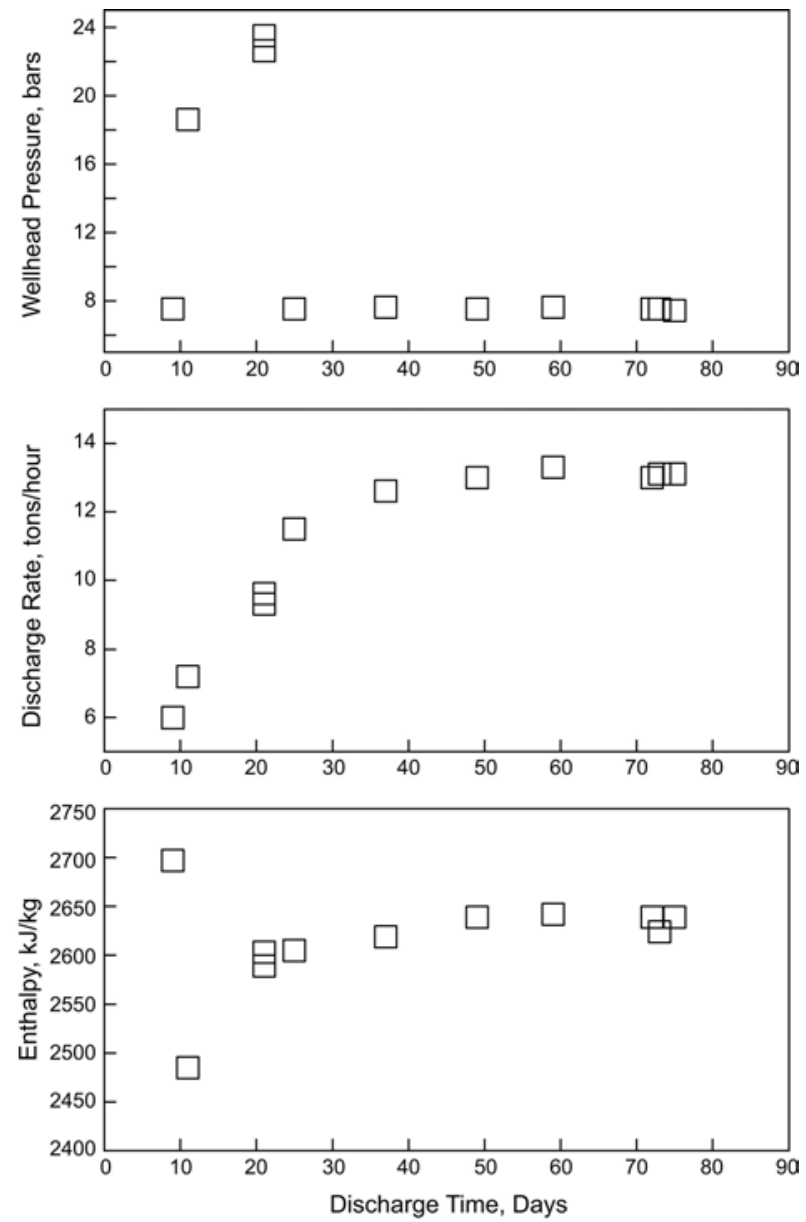

Figure 5.5. Wellhead pressure, discharge rate, and wellhead enthalpy measurements taken during a discharge test of slim hole N-2t from January 12, 1988 to March 28, 1988.

\section{Slim Hole N-3t}

Slim hole N-3t was discharged from January 10, 1986 to January 18, 1986 and from February 21, 1986 to March 5, 1986. The principal feedzone for $\mathrm{N}-3 \mathrm{t}$ is located at $\sim 1810$ mTVD. The stable feedzone temperature is $\sim 277^{\circ} \mathrm{C}$. Only two measurements of discharge rate and wellhead enthalpy are available for N-3t (Figure 5.6 and Table B.6). The available enthalpy data are consistent with a liquid entry and indicate little or no boiling in situ. Based on the two data points, the discharge rate is 40 $(+/-4)$ tons/hour.
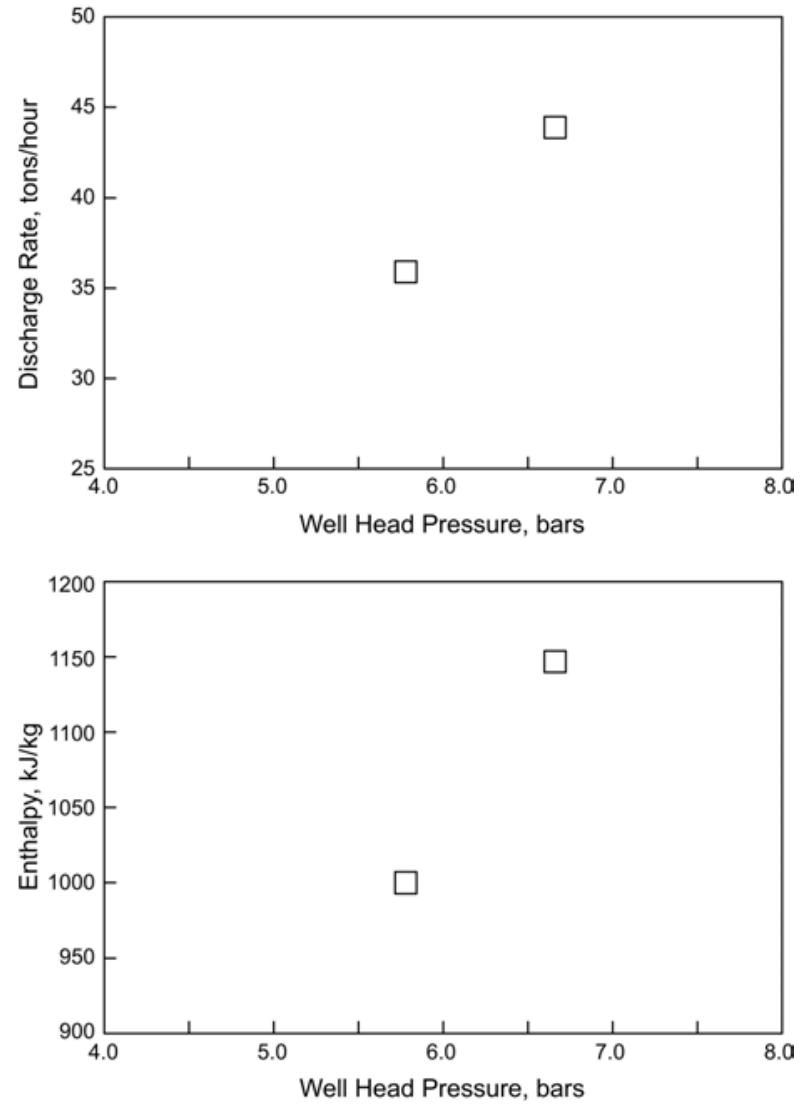

Figure 5.6. Characteristic output (i.e. mass and enthalpy versus wellhead pressure) data recorded for slim hole N-3t during discharge tests in January and February 1986. 


\section{Slim Hole N-5t}

A discharge test of slim hole $\mathrm{N}-5 \mathrm{t}$ was performed from November 27, 1984 to December 16, 1984. The stable discharge rate and enthalpy were $\sim 5$ tons/hour and 1200 $\mathrm{kJ} / \mathrm{kg}$, respectively (Figure 5.7 and Table B.7). The discharge enthalpy corresponds to a saturation temperature of $\sim 273{ }^{\circ} \mathrm{C}$ for pure liquid water. The stable feedzone (1700 mTVD) temperature is estimated to be $\sim 270$ ${ }^{\circ} \mathrm{C}$. It is therefore possible that discharge from $\mathrm{N}-5 \mathrm{t}$ was accompanied by some in situ boiling.
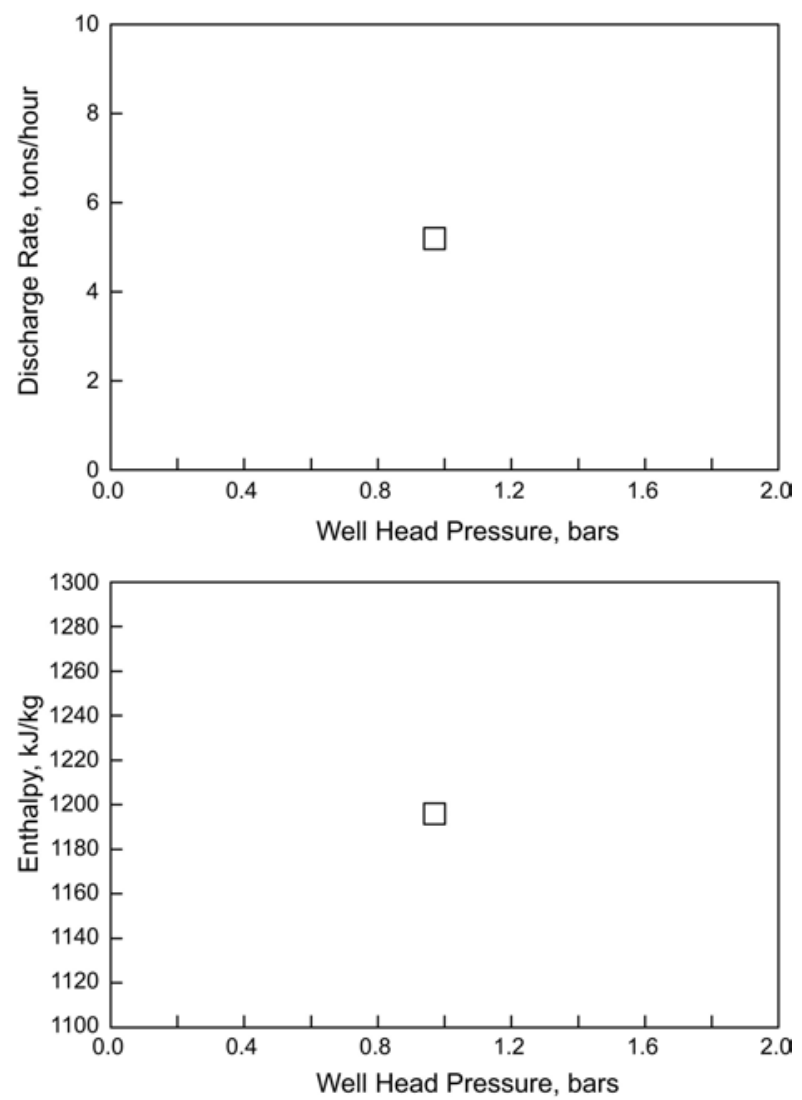

Figure 5.7. Stable discharge rate and wellhead enthalpy versus wellhead pressure data recorded for slim hole $\mathrm{N}-5 \mathrm{t}$ during a discharge test from November 27, 1984 to December 16, 1984.

\section{Production Well N-6T}

After two preliminary discharge tests (October 15-20, 1986 and November 14-19, 1986), large-diameter well N-6T was discharged for about four months from December 8, 1986 to April 5, 1987. During the latter discharge test, the discharge from N-6T progressively dried out. The discharge rate decreased from $\sim 200$ tons/hour on December 18, 1986 to $\sim 76$ tons/hour on April 5, 1987. Over the same time, wellhead enthalpy increased from $\sim 1300 \mathrm{~kJ} / \mathrm{kg}$ to $\sim 1650 \mathrm{~kJ} / \mathrm{kg}$ (Figure 5.8 and Table B.8).
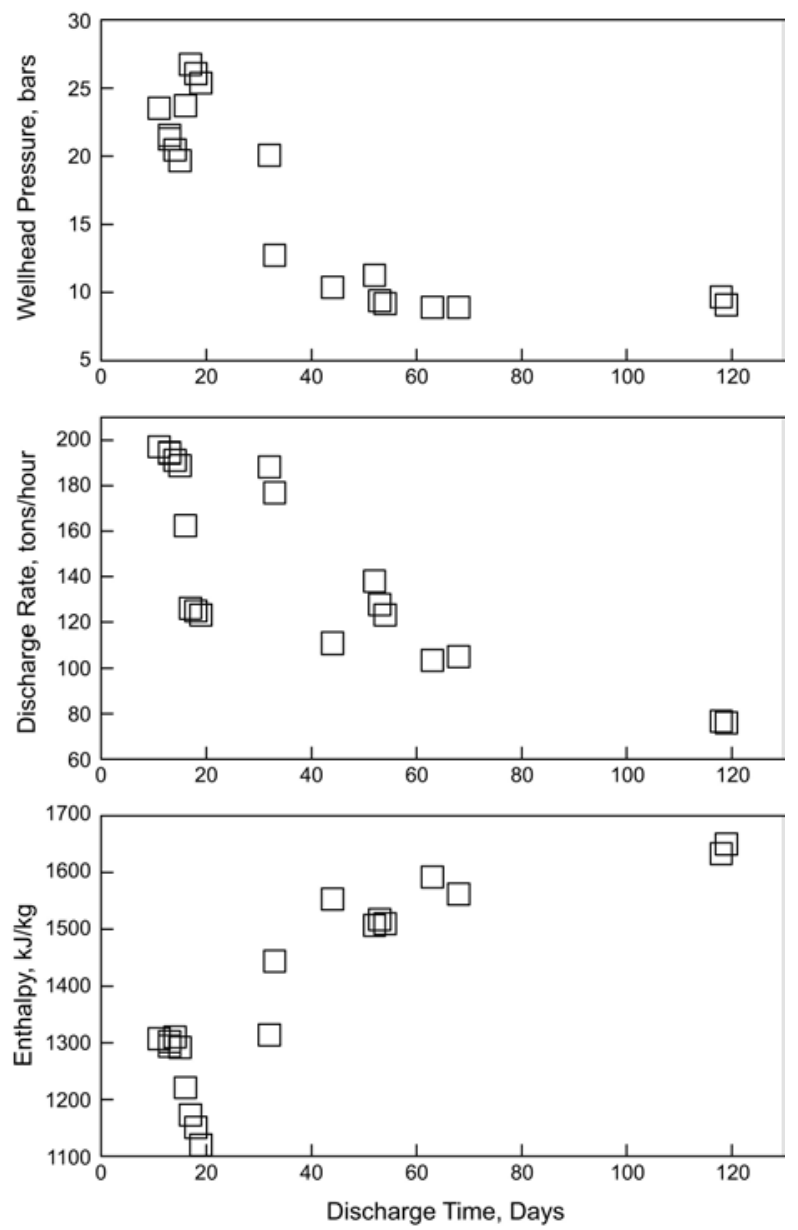

Figure 5.8. Wellhead pressure, discharge rate, and wellhead enthalpy measurements taken during the first long-term discharge test of well N-6T from December 8, 1986 to April 5, 1987.

Additional long-term discharge tests of N-6T were performed from December 9, 1987 to March 28, 1988 and from November 17, 1989 to March 3, 1990. During the 1987-1988 test, the discharge rate declined from $\sim 81$ tons/hour to $\sim 56$ tons/hour while the enthalpy increased 
from $\sim 1540 \mathrm{~kJ} / \mathrm{kg}$ to $\sim 2290 \mathrm{~kJ} / \mathrm{kg}$ (Figure 5.9 and Table B.9). Further decreases in discharge rate (from 64 tons/hour to $\sim 44$ tons/hour) and increases in wellhead enthalpy (from $\sim 2050$ $\mathrm{kJ} / \mathrm{kg}$ to $\sim 2560 \mathrm{~kJ} / \mathrm{kg}$ ) were observed during the 1989-1990 test (Figure 5.10 and Table B.10).
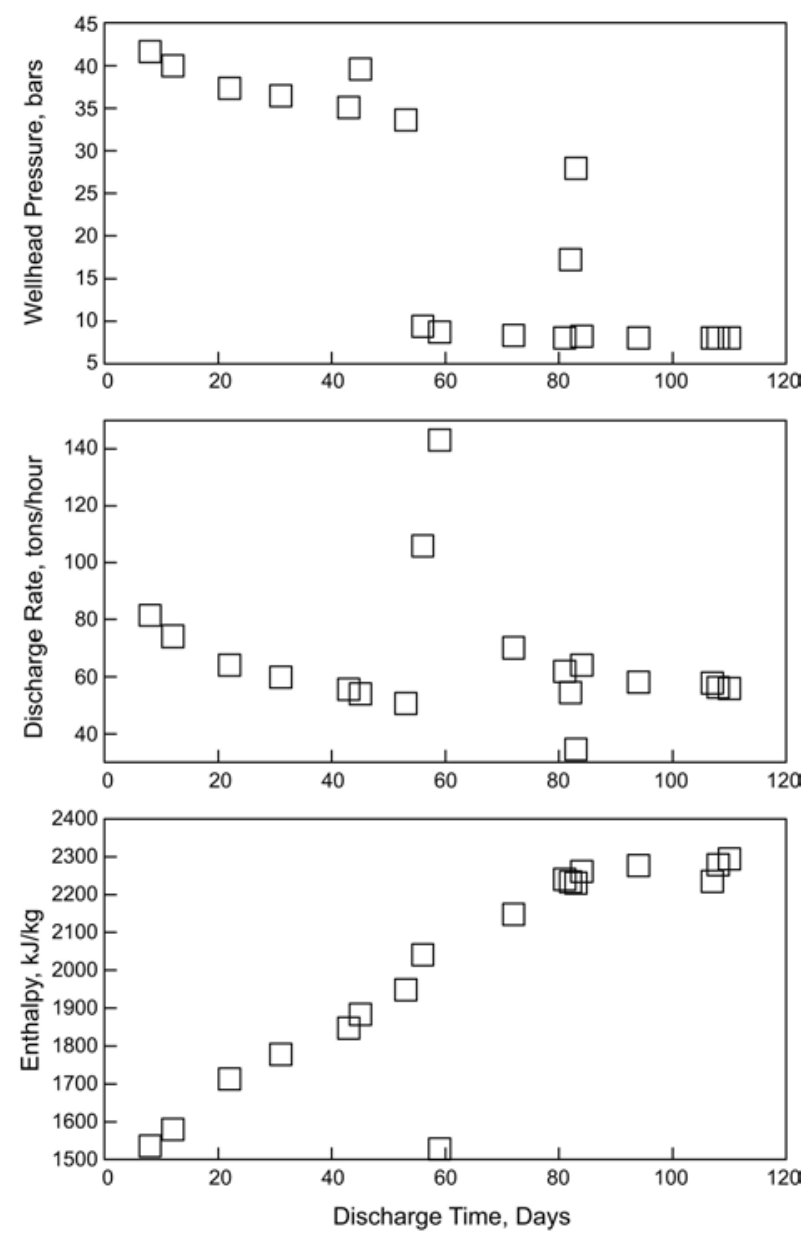

Figure 5.9. Wellhead pressure, discharge rate, and wellhead enthalpy measurements taken during the second long-term discharge test of well N-6T from December 9, 1987 to March 28, 1988.

The changes in the discharge behavior of N$6 \mathrm{~T}$ with time are similar to those for other Okuaizu production wells. The discharge rate declines rapidly with time, and the flow stream dries out. Given the rapid changes in the discharge behavior, it is impossible to construct meaningful characteristic discharge curves for the Okuaizu boreholes. Instead, the quasi-steady discharge rate attained towards the end of a particular discharge test will be used to characterize the discharge behavior.
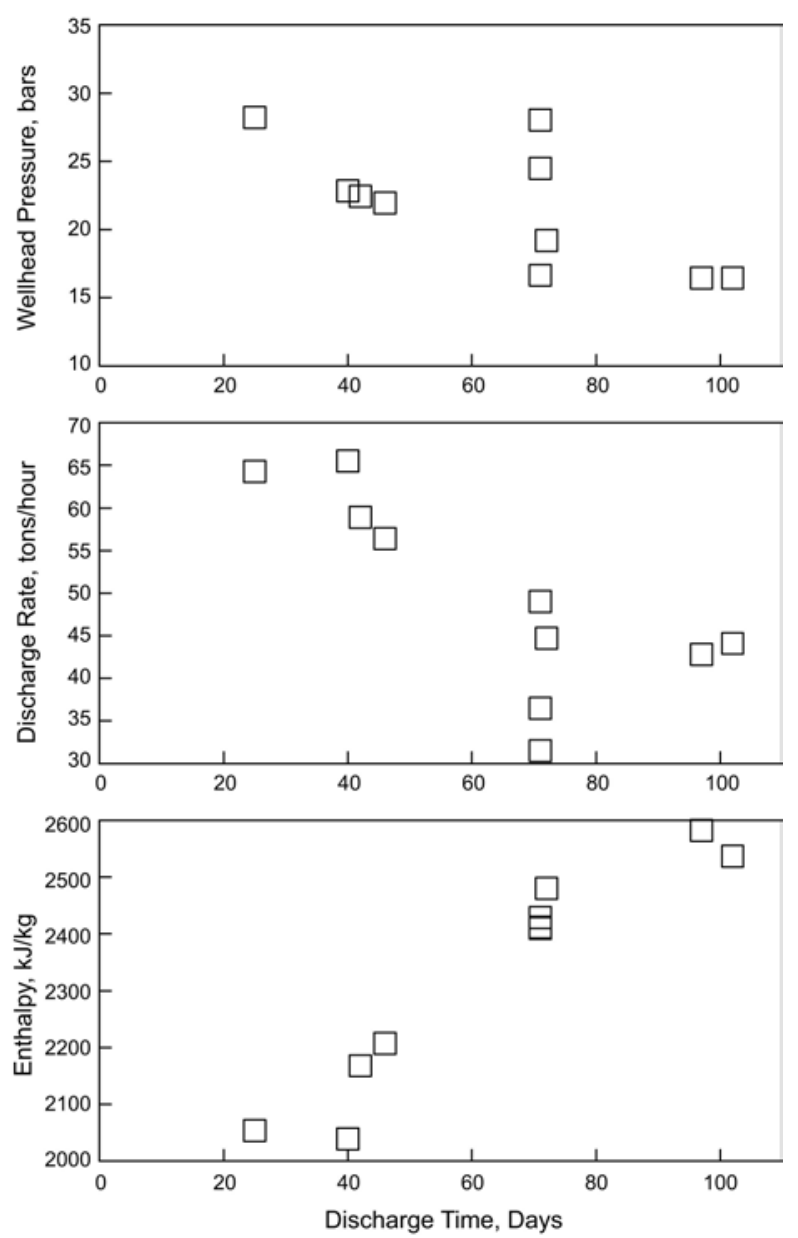

Figure 5.10. Wellhead pressure, discharge rate, and wellhead enthalpy measurements taken during the third long-term discharge test of well N-6T from November 17, 1989 to March 3, 1990.

\section{Production Well N-10T}

The first long-term discharge test of well N10T was performed from September 7, 1987 to October 7, 1987. During the month long discharge test, the wellhead enthalpy increased from $\sim 1770 \mathrm{~kJ} / \mathrm{kg}$ to $\sim 2010 \mathrm{~kJ} / \mathrm{kg}$, and the mass discharge rate went down from over 160 tons/hour to $\sim 73$ tons/hour (Figure 5.11 and Table B.11). The second discharge test of N-10T was carried out from December 
15, 1987 to March 27, 1988. Anomalous discharge rate and enthalpy data from February 15, 1988 to February 24, 1988 (Figure 5.12 and Table B.12) are most likely associated with the adjustments to well settings made to carry out PTS surveys. The well was shut-in on February 25, 1988, and then put back on discharge on March 17, 1988. The discharge rate did not have sufficient time to stabilize before the termination of the discharge test on March 27, 1988. In any event, it appears that the wellhead enthalpy during the second discharge test did not increase appreciably compared to its value at the end of the first discharge test.
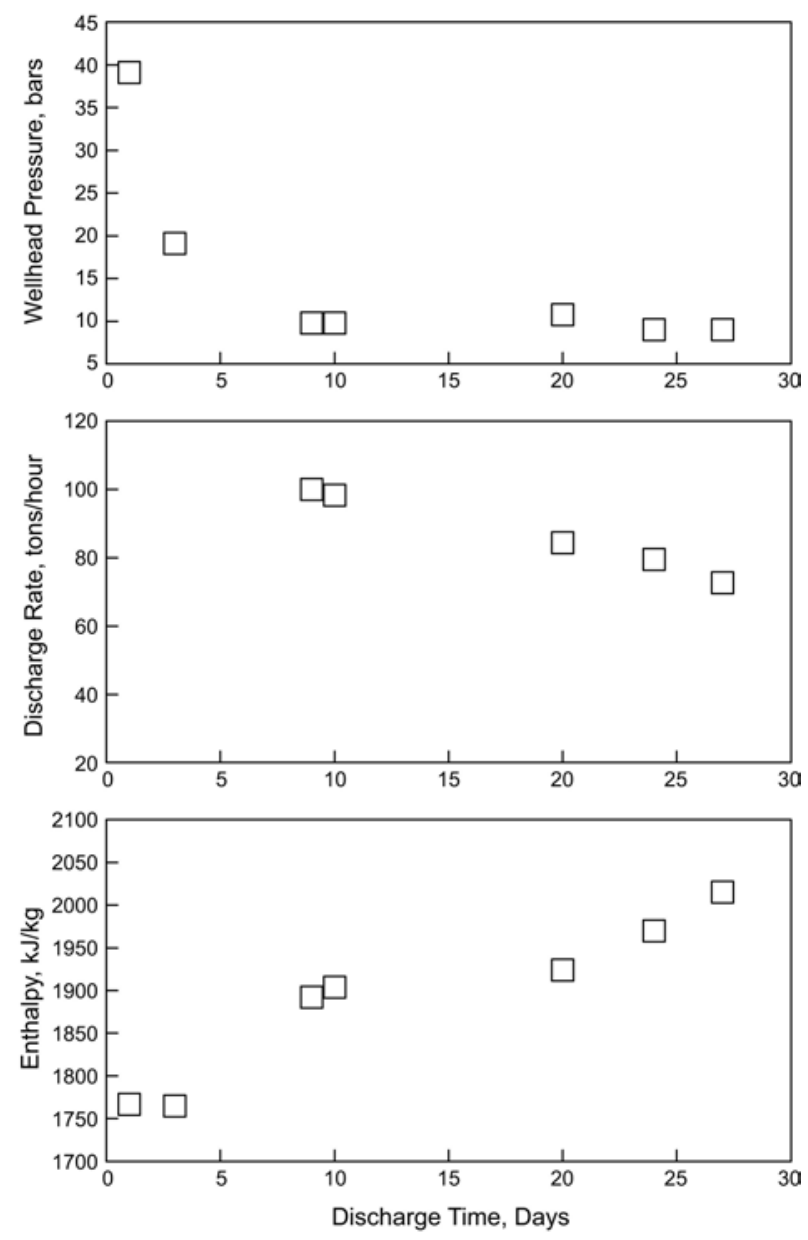

Figure 5.11. Wellhead pressure, discharge rate, and wellhead enthalpy measurements taken during the first long-term discharge test of well N-10T from September 7, 1987 to October 7, 1987.
During the third discharge test (August 23, 1988 to October 8, 1988), the wellhead enthalpy varied between $\sim 1950 \mathrm{~kJ} / \mathrm{kg}$ and $\sim 2140 \mathrm{~kJ} / \mathrm{kg}$. The mass discharge rate however declined from $\sim 69$ tons/hour on August 29 to $\sim 36$ tons/hour on September 27, 1988 (Figure 5.13 and Table B.13). Except for an anomalous value on January 24, 1990, the wellhead enthalpy showed little variation $(2110-2170 \mathrm{~kJ} / \mathrm{kg})$ during the fourth discharge test performed from November 26, 1989 to March 3, 1990 (Figure 5.14 and Table B.14). The stable mass discharge rate during the fourth test, as reported in late February 1990, was about 39 tons/hour.
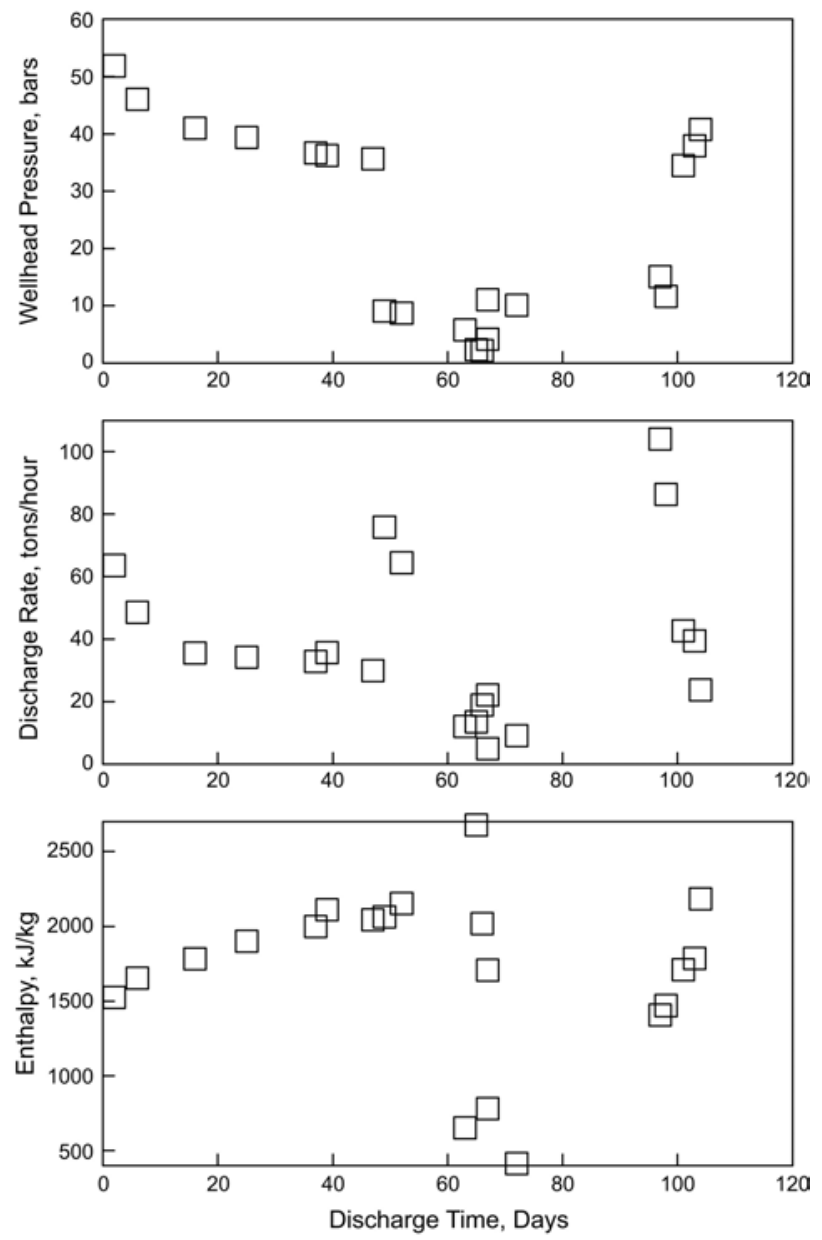

Figure 5.12. Wellhead pressure, discharge rate, and wellhead enthalpy measurements taken during the second long-term discharge test of well N-10T from December 15, 1987 to March 27, 1988. 

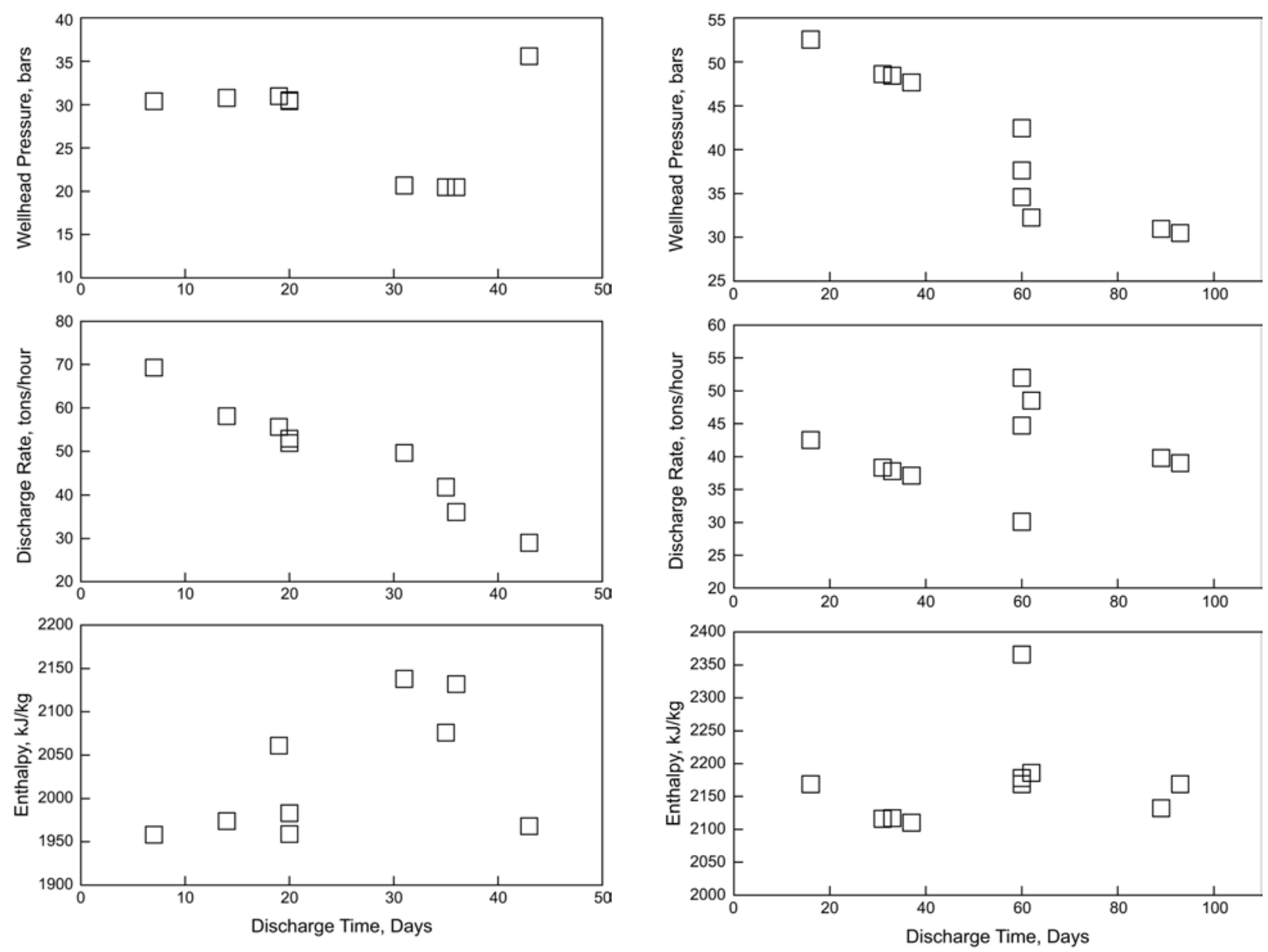

Figure 5.13. Wellhead pressure, discharge rate, and wellhead enthalpy measurements taken during the third long-term discharge test of well N-10T from August 23, 1988 to October 8, 1988.

\section{Production Well N-11T}

Two long-term discharge tests of well N-11T were performed from December 2, 1988 to March 20, 1989 and from November 20, 1989 to March 2, 1990. During the second discharge test (November 1989 - March 1990), the discharge streams from wells N$11 \mathrm{~T}, \mathrm{~N}-16 \mathrm{~T}$ and N-17T were directed to a common separator, and only the combined mass discharge and enthalpy data for the three wells are reported. Consequently, the discharge data from the second test cannot be used to determine the discharge capacity of N-

Figure 5.14. Wellhead pressure, discharge rate, and wellhead enthalpy measurements taken during the fourth long-term discharge test of well N-10T from November 26, 1989 to March 3, 1990.

11T (or for that matter N-16T or N-17T), and will not be further considered here.

The discharge rate and enthalpy measurements from March 11, 1989 to March 13, 1989 (Figure 5.15 and Table B.15) were affected by the transient conditions in the wellbore associated with the PTS surveys. Ignoring the latter data, it is observed that the mass discharge rate during the first discharge test declined from over 110 tons/hour on December 4, 1988 to $\sim 67$ tons/hour on March 17, 1989 while the wellhead enthalpy increased from $\sim 1090 \mathrm{~kJ} / \mathrm{kg}$ to $\sim 1650 \mathrm{~kJ} / \mathrm{kg}$. 

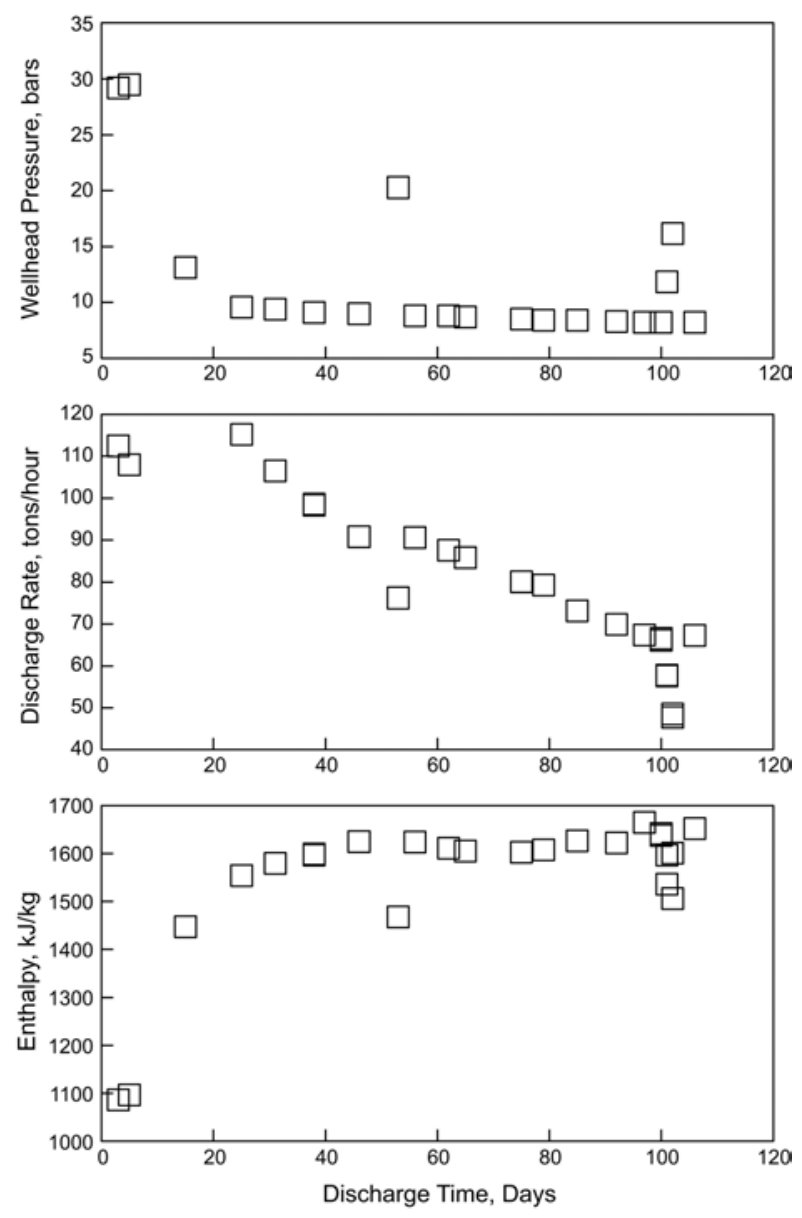

Figure 5.15. Wellhead pressure, discharge rate, and wellhead enthalpy measurements taken during the first long-term discharge test of well $\mathrm{N}-11 \mathrm{~T}$ from December 2, 1988 to March 20, 1989.

\section{Production Well N-14T}

The first long-term discharge test of well N14T was carried out from October 8, 1987 to November 6, 1987. During the month long discharge test, the discharge rate decreased from $\sim 165$ tons/hour to $\sim 105$ tons/hour, and the wellhead enthalpy increased from $\sim 1250$ $\mathrm{kJ} / \mathrm{kg}$ to $\sim 1620 \mathrm{~kJ} / \mathrm{kg}$ (Figure 5.16 and Table B.16). A second discharge test was performed from December 12, 1987 to March 29, 1988. Ignoring the transient conditions associated with the downhole PTS surveys on February 21-22, 1988 and March 6-8, 1988, it is observed that the discharge rate stabilized at about 45 tons/hour in March 1988. The wellhead enthalpy in March 1988 was about $2350(+/-150) \mathrm{kJ} / \mathrm{kg}$ (Figure 5.17 and Table B.17). The third long-term discharge test was undertaken from November 28, 1989 to March 1, 1990. The discharge rate and wellhead enthalpy in late February 1990 (Figure 5.18 and Table B.18) were $\sim 44$ tons/hour and $\sim 2440 \mathrm{~kJ} / \mathrm{kg}$, respectively. The latter values for discharge rate and wellhead enthalpy are similar to those obtained during the second discharge test.
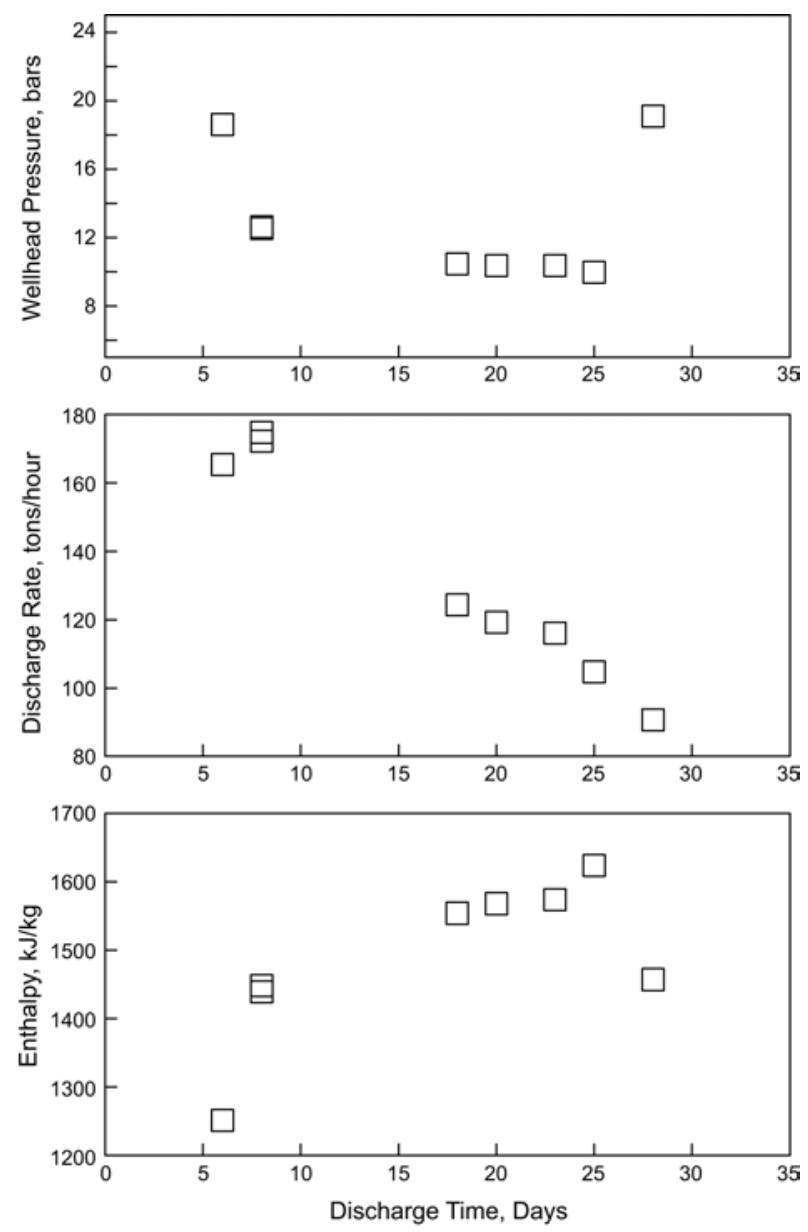

Figure 5.16. Wellhead pressure, discharge rate, and wellhead enthalpy measurements taken during the first long-term discharge test of well N-14T from October 8, 1987 to November 6, 1987. 

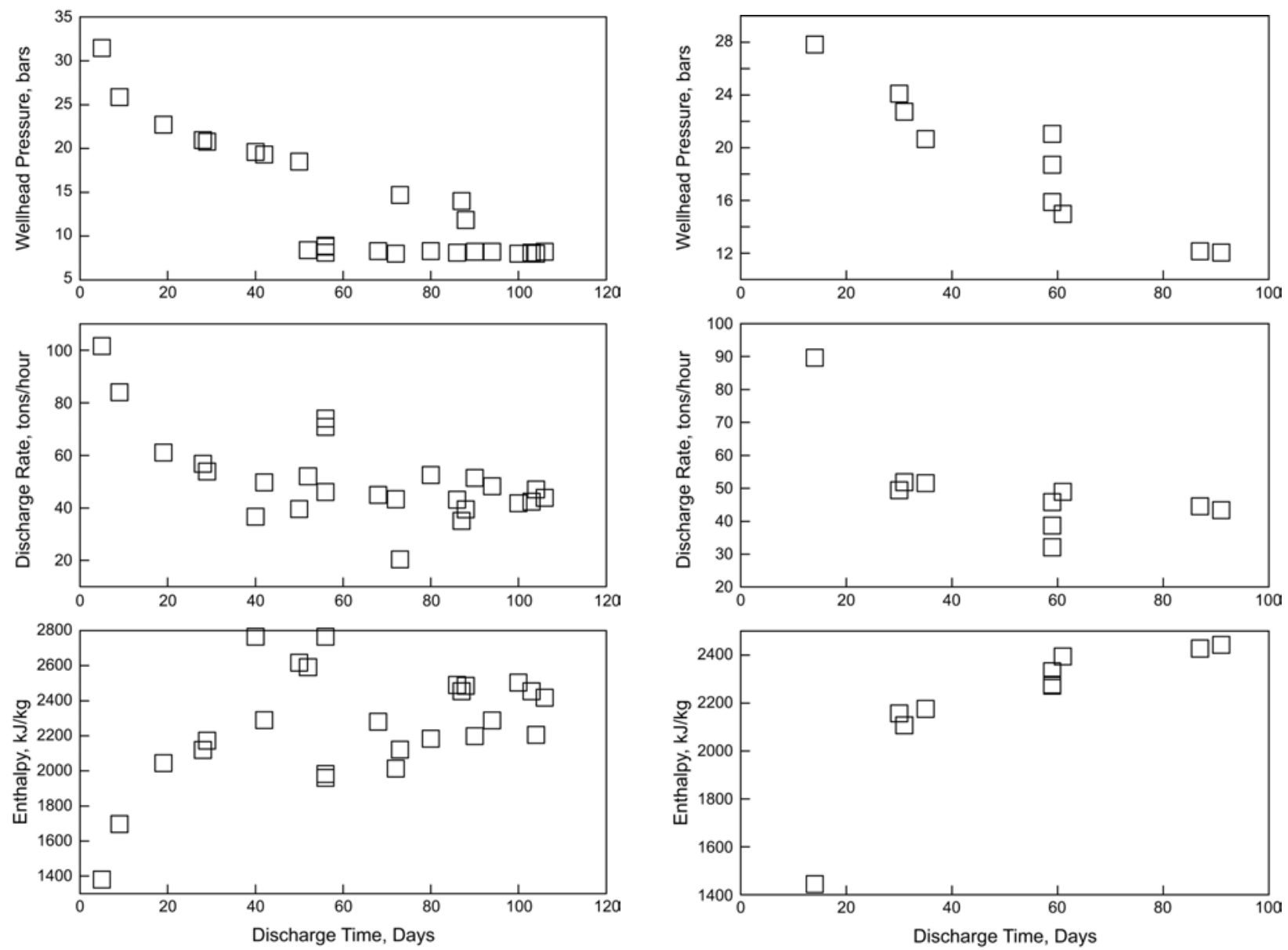

Figure 5.17. Wellhead pressure, discharge rate, and wellhead enthalpy measurements taken during the second long-term discharge test of well N-14T from December 12, 1987 to March 29, 1988.

Figure 5.18. Wellhead pressure, discharge rate, and wellhead enthalpy measurements taken during the third long-term discharge test of well N-14T from November 28, 1989 to March 1, 1990.

\section{Production Well N-15T}

Large-diameter well N-15T is by far the most productive well at Okuaizu. The productivity index for $\mathrm{N}-15 \mathrm{~T}$ is almost an order of magnitude higher than that for other Okuaizu wells (Section 4). Two long-term discharge tests of N-15T were performed from November 7, 1987 to March 26, 1988 and from November 15, 1989 to March 1, 1990. During the first discharge test, the discharge rate stabilized at $\sim 170$ tons/hour with a wellhead enthalpy of $\sim 1950 \mathrm{~kJ} / \mathrm{kg}$ (Figure 5.19 and Table B.19). The discharge rate towards the end of the second test was about 155 tons/hour with a wellhead enthalpy of

$\sim 2690 \mathrm{~kJ} / \mathrm{kg}$ (Figure 5.20 and Table B.20). Even though well N-15T was not discharged during the 1988-1989 test (December 1988March 1989), it appears that its discharge behavior (particularly wellhead enthalpy) was significantly affected by the 1988-1989 discharge test. 

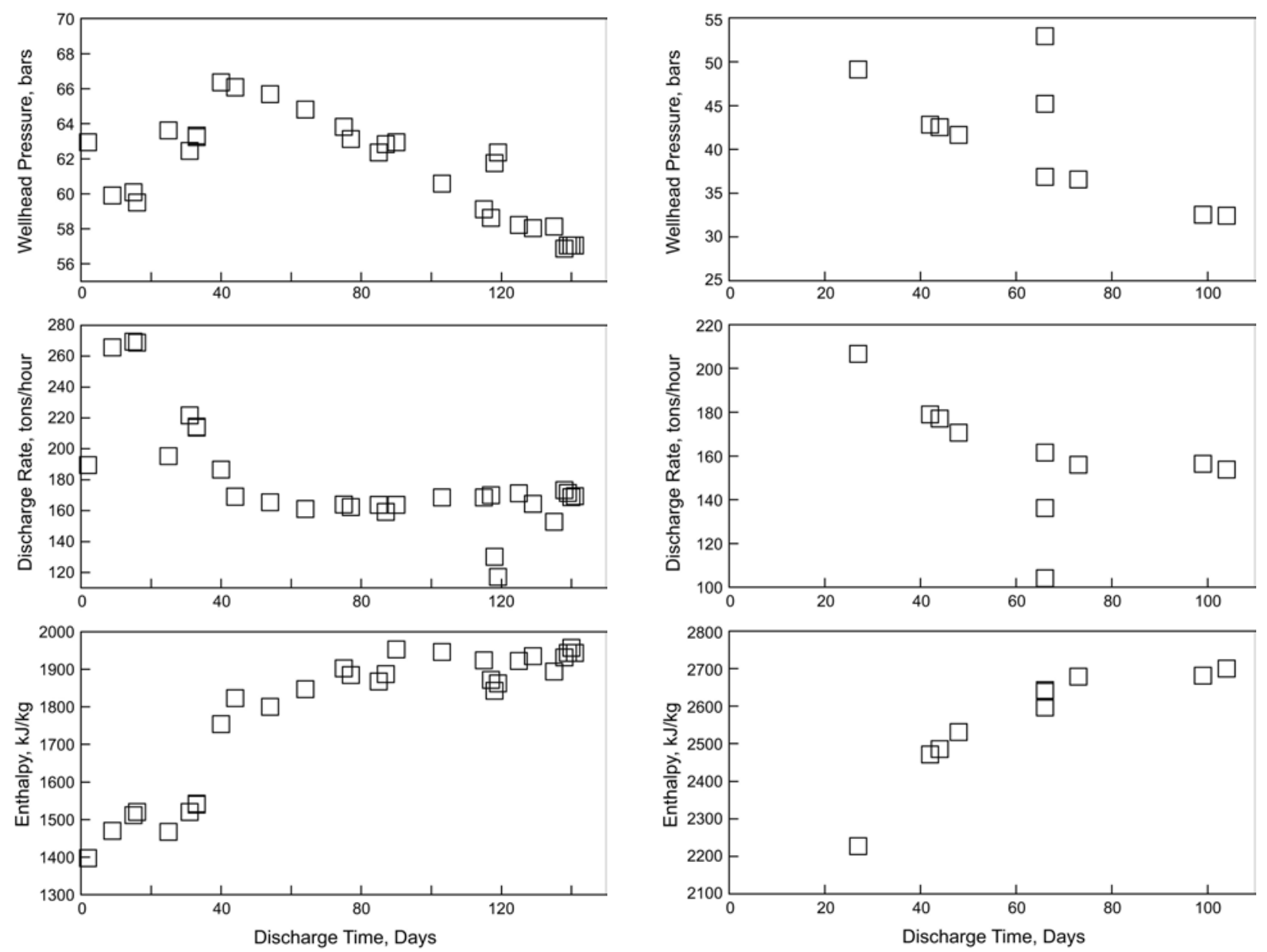

Figure 5.19. Wellhead pressure, discharge rate, and wellhead enthalpy measurements taken during the first long-term discharge test of well N-15T from November 7, 1987 to March 26, 1988.

Figure 5.20. Wellhead pressure, discharge rate, and wellhead enthalpy measurements taken during the second long-term discharge test of well N-15T from November 15, 1989 to March 1, 1990.

\section{Production Well N-16T}

Two long-term discharge tests of well N-16T were performed from December 1, 1988 to March 19, 1989 and from November 21, 1989 to March 2, 1990. As discussed earlier (see production well $\mathrm{N}-11 \mathrm{~T}$ ), the discharge data from the second test are not useful for defining the discharge characteristics of $\mathrm{N}$ 16T. Ignoring the transients in the discharge rate associated with the PTS surveys, the discharge rate during the first long term test appears to have stabilized at $\sim 65$ tons/hour

with a wellhead enthalpy of $\sim 1475 \mathrm{~kJ} / \mathrm{kg}$ (Figure 5.21 and Table B.21). 


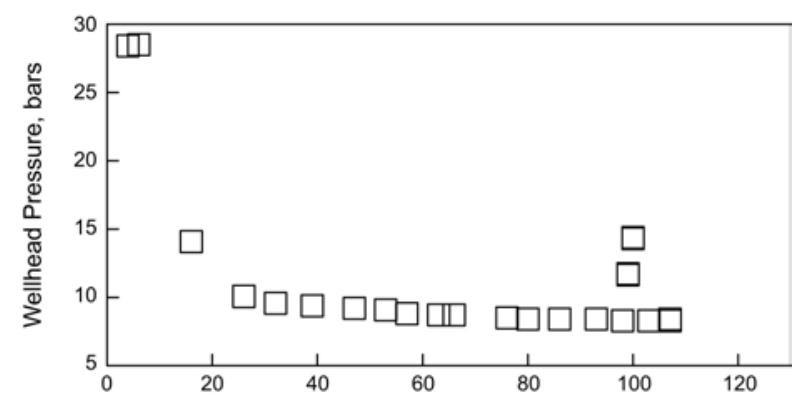

wellhead enthalpy of $\sim 1850 \mathrm{~kJ} / \mathrm{kg}$ (Figure 5.22 and Table B.22).
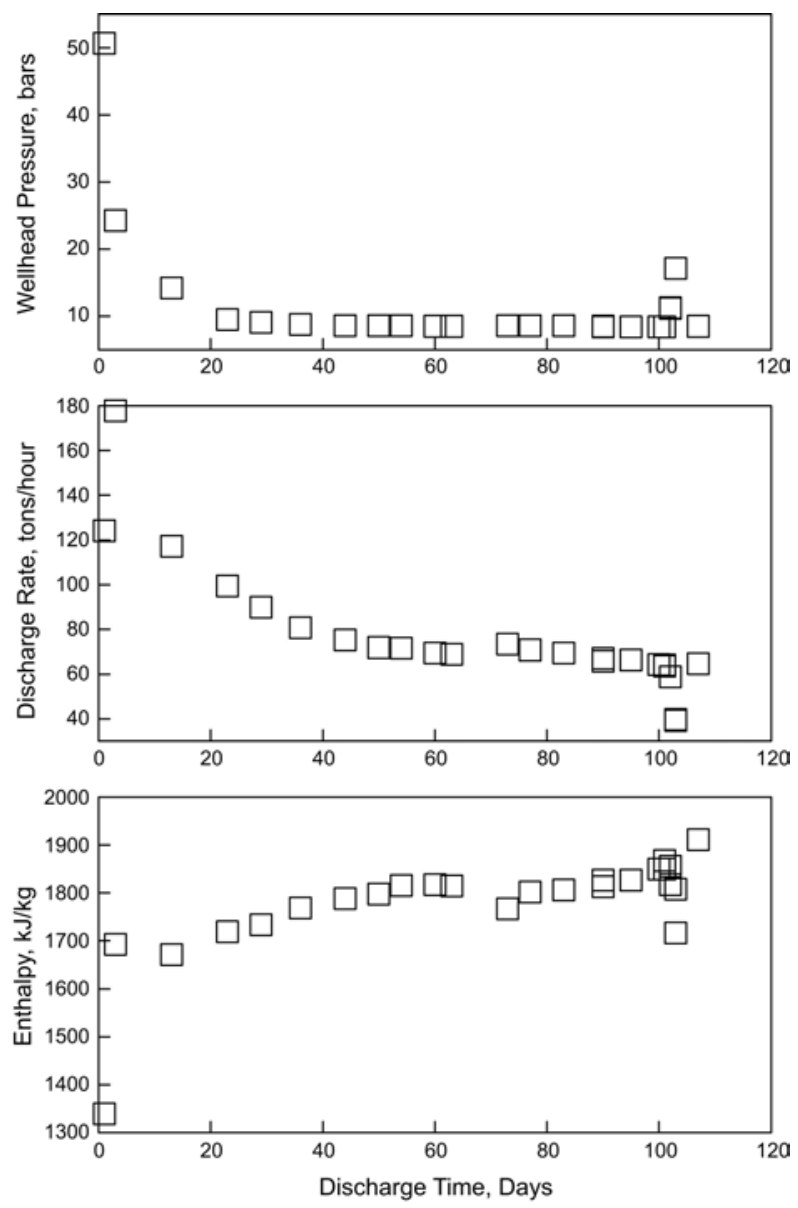

Figure 5.22. Wellhead pressure, discharge rate, and wellhead enthalpy measurements taken during the first discharge test of well N-17T from December 4, 1988 to March 21, 1989.

Two long-term discharge tests of well N-17T were carried out from December 4, 1988 to March 21, 1989 and from November 22, 1989 to March 2, 1990. Like wells N-11T and N16T, data from the second discharge test cannot be used to characterize the discharge behavior of N-17T. The discharge data from March 14, 1989 to March 16, 1989 were affected by transient wellbore phenomena associated with the downhole PTS surveys. Excluding the latter data, the discharge rate towards the end of the 1988-1989 test appears to have stabilized at about 64 tons/hour with a

\section{Production Well N-21T}

A long-term discharge test of well N-21T was performed from November 24, 1989 to March 2,1990 . Towards the end of the discharge test, the discharge rate was $\sim 69$ tons/hour with a wellhead enthalpy of $\sim 2140 \mathrm{~kJ} / \mathrm{kg}$ (Figure 5.23 and Table B.23). 

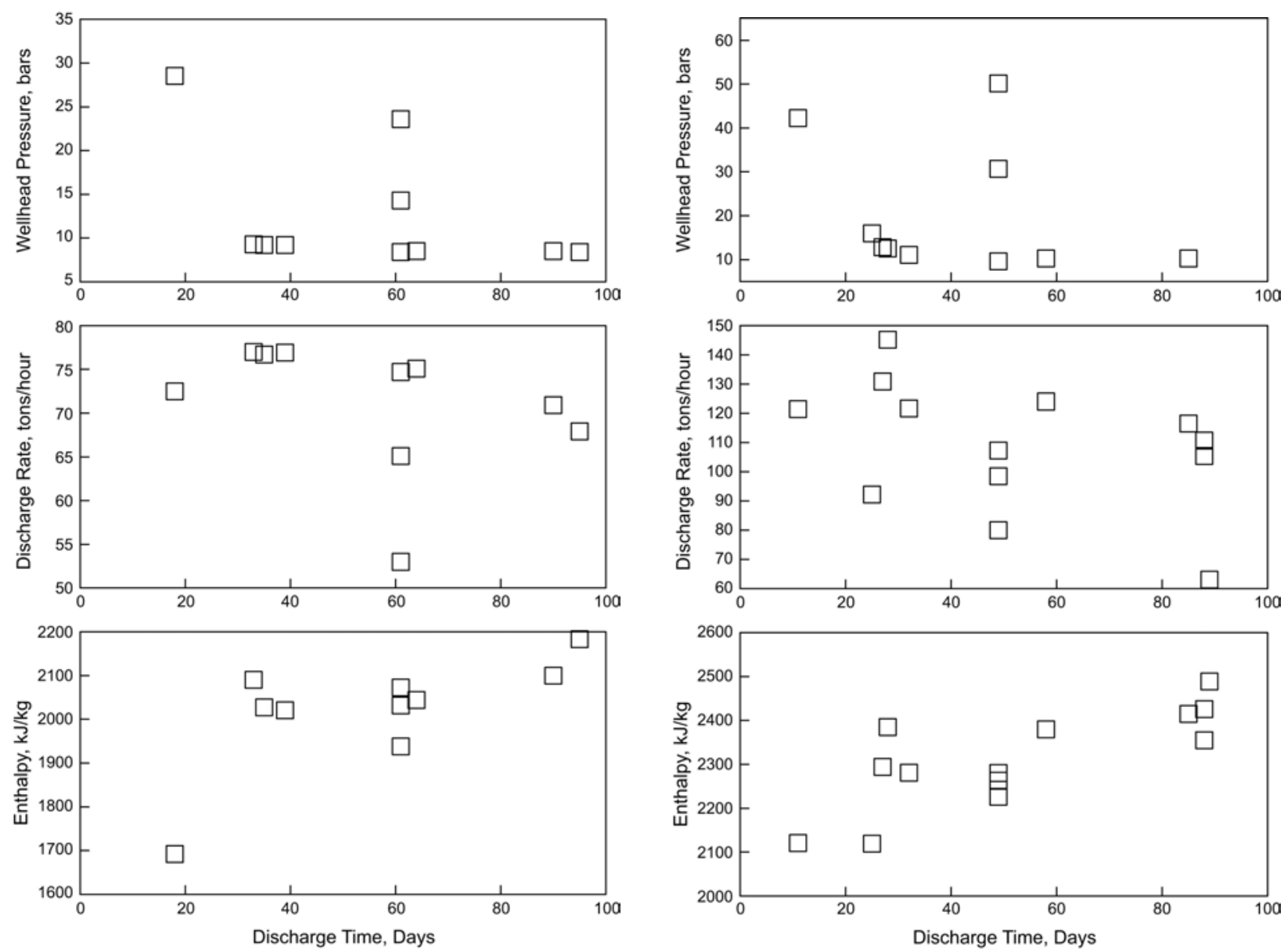

Figure 5.23. Wellhead pressure, discharge rate, and wellhead enthalpy measurements taken during a discharge test of well N-21T from November 24, 1989 to March 2, 1990.

\section{Production Well N-22T}

\section{Production Well N-26P}

A long-term discharge test of well N-22T was carried out from December 1, 1989 to February 27, 1990 (Figure 5.24 and Table B.24). Wellhead settings were apparently changed to carry out a characteristic discharge test on January 18, 1990 and downhole PTS surveys on February 26-27, 1990. The discharge rate measurements on the latter dates are affected by transient wellbore phenomena. Using the measurements made on January 27, 1990 and February 23, 1990 (Table B.24), the quasi-stable discharge rate is estimated to be $\sim 120$ tons/hour with a wellhead enthalpy of $\sim 2400 \mathrm{~kJ} / \mathrm{kg}$.

Production well N-26P was discharged for about one month from June 26, 1993 to July 25, 1993. Three downhole PTS surveys were run from July 22, 1993 to July 24, 1993. Prior to these PTS surveys, the discharge rate and wellhead enthalpy were $\sim 67$ tons/hour and $\sim 2560 \mathrm{~kJ} / \mathrm{kg}$, respectively (Figure 5.25 and Table B.25). 

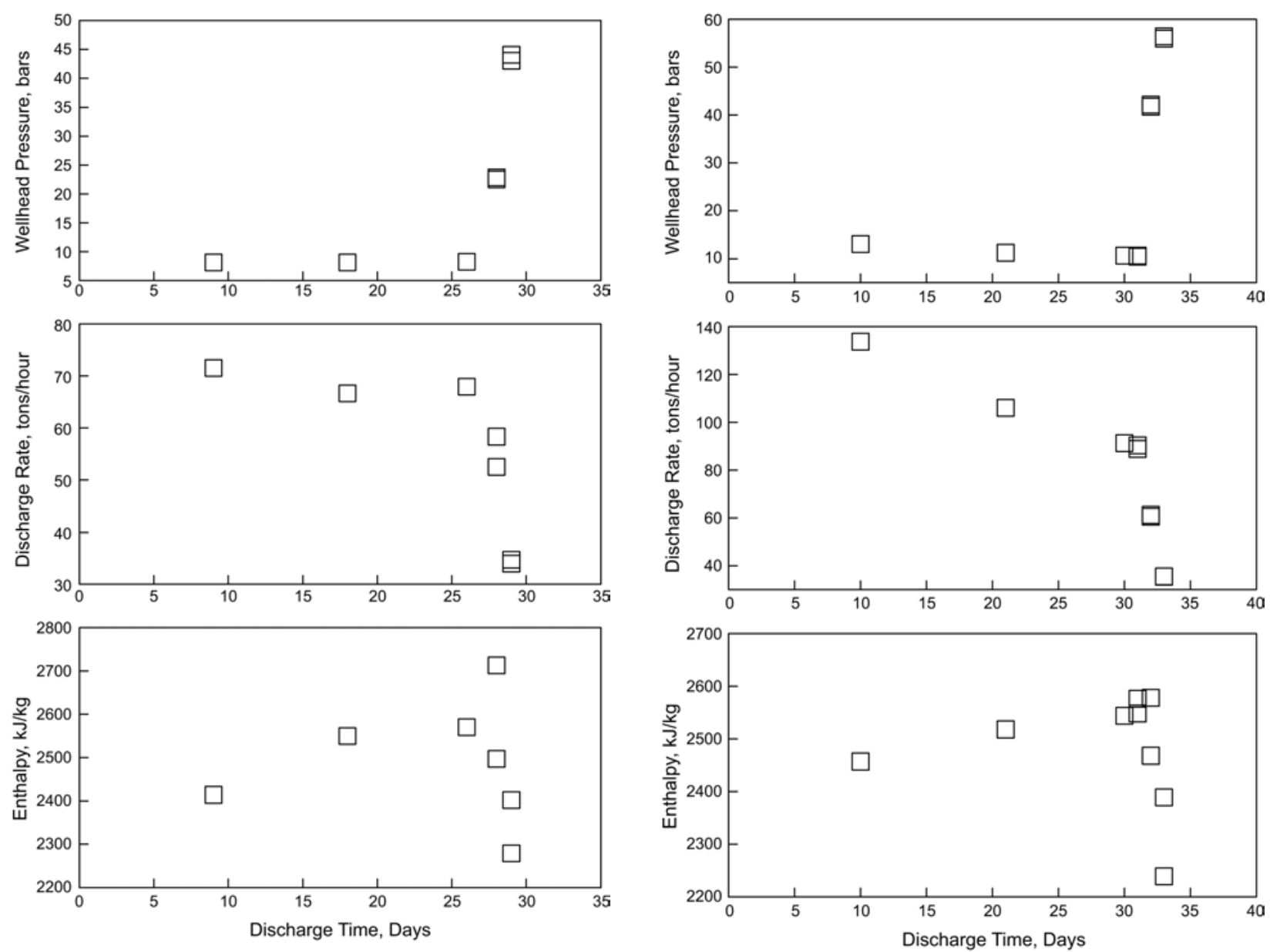

Figure 5.25. Wellhead pressure, discharge rate, and wellhead enthalpy measurements taken during a discharge test of well N-26P from June 26, 1993 to July 25, 1993.

Figure 5.26. Wellhead pressure, discharge rate, and wellhead enthalpy measurements taken during a discharge test of well N-28P from October 26, 1993 to November 28, 1993

\section{Production Well N-28P}

A month-long discharge test of well N-28P was carried out from October 26, 1993 to November 28, 1993. Three downhole surveys were run in the discharging well from November 25, 1993 to November 27, 1993. Prior to the PTS surveys, the discharge rate and wellhead enthalpy were $\sim 90$ tons/hour and $\sim 2550 \mathrm{~kJ} / \mathrm{kg}$, respectively (Figure 5.26 and Table B.26). 


\subsection{Stable Discharge Rate and Wellhead Enthalpy}

A major goal of the present study is to investigate the effect of borehole diameter on the discharge capacity of boreholes producing from two-phase feedzones. When determining the discharge capacity of a borehole, it is implicitly assumed that the discharge rate and wellhead enthalpy are more or less stable. As discussed in Section 5.1, discharge from Okuaizu boreholes is characterized by relatively rapid changes in the mass discharge rate and wellhead enthalpy. Stable or quasistable discharge rates and wellhead enthalpies, as recorded during the various discharge tests, for the Okuaizu boreholes are given in Table 5.1. Prior to December 1987, slim holes OA-4, $\mathrm{N}-1 \mathrm{t}, \mathrm{N}-2 \mathrm{t}, \mathrm{N}-3 \mathrm{t}$ and N-5t, and large-diameter wells N-6T, N-10T , N-14T and N-15T were discharged one at a time. Slim holes N-1t and $\mathrm{N}-3 \mathrm{t}$ produced from liquid feedzones. Discharge from slim holes N-2t and N-5t, and large-diameter wells N-6T, N-10T, N-14T and $\mathrm{N}-15 \mathrm{~T}$ was accompanied by in situ boiling and the production of a moderate amount of excess steam. Unlike other boreholes, slim hole OA4 discharged a high enthalpy fluid; the ratio of steam to water discharge rate was about 3:1. With the initiation of the field-wide discharge test involving wells N-6T, N-10T, N-14T and N-15T and slim hole N-2t in December 1987, a qualitative change occurred in the discharge characteristics of Okuaizu wells. During the 1987-1988 field-wide test, the discharge rates declined and wellhead enthalpies increased rapidly. As an example, the stable discharge rate for N-2t during the 1987-1988 field-wide test was less than $25 \%$ of that observed in the 1985 test. Unlike the earlier test, slim hole $\mathrm{N}-2 \mathrm{t}$ discharged mostly steam during the 1987-1988 test. Wellhead enthalpy for N-6T increased from $1650 \mathrm{~kJ} / \mathrm{kg}$ (April 1987) to $2290 \mathrm{~kJ} / \mathrm{kg}$ in March 1988, and the discharge rate declined by over $25 \%$. Increases in wellhead enthalpy similar to that for N-6T were observed during the 1987-1988 test in wells N-14T and N-15T. By way of contrast, changes in wellhead enthalpy for N-10T were minimal; the discharge rate for $\mathrm{N}-10 \mathrm{~T}$ however declined by more than $50 \%$.

The trends in the discharge behavior of Okuaizu boreholes observed during the 19871988 field-wide test continued at a more moderate pace during the subsequent fieldwide tests in 1988-1989 and 1989-1990. A comparison of March 1988 discharge rates and wellhead enthalpies for wells N-6T, N$10 \mathrm{~T}, \mathrm{~N}-14 \mathrm{~T}$ and N-15T with measurements taken in February 1990 shows relatively small changes. An exception is the wellhead enthalpy for N-15T; unlike the 1987-1988 test, well N-15T was discharging mostly steam in February 1990. For practical purposes, discharge data obtained in March 1989 and later may be used to characterize the discharge performance of large-diameter Okuaizu wells. The stable discharge rates for the 11 production wells range from a low of 39 tons/hour for N-10T to a high of 155 tons/hour for $\mathrm{N}-15 \mathrm{~T}$, and the range for wellhead enthalpies is $1475 \mathrm{~kJ} / \mathrm{kg}(\mathrm{N}-16 \mathrm{~T})$ to $2690 \mathrm{~kJ} / \mathrm{kg}(\mathrm{N}-15 \mathrm{~T})$. The average stable discharge rate for the 11 production wells is $\sim 75$ tons/hour. Excluding well N-15T which has an unusually high productivity index for an Okuaizu borehole, the average discharge rate is $\sim 67$ tons/hour.

With the single exception of slim hole N-2t, none of the other slim holes (OA-4, N-1t, N-3t and $\mathrm{N}-5 \mathrm{t}$ ) were discharged after January 1986. Discharge from slim holes N-1t (June 1985) and N-3t (January 1986) was not accompanied by in situ boiling. Furthermore, wellhead enthalpy data for N-5t (December 1984 test) indicates only a moderate amount of excess steam in the discharge. Thus, the available discharge data from slim holes N-1t, N-3t and $\mathrm{N}-5 \mathrm{t}$ cannot be compared to the discharge data for large diameter Okuaizu wells. Only two slim holes, i.e., OA-4 and N-2t, discharged at 


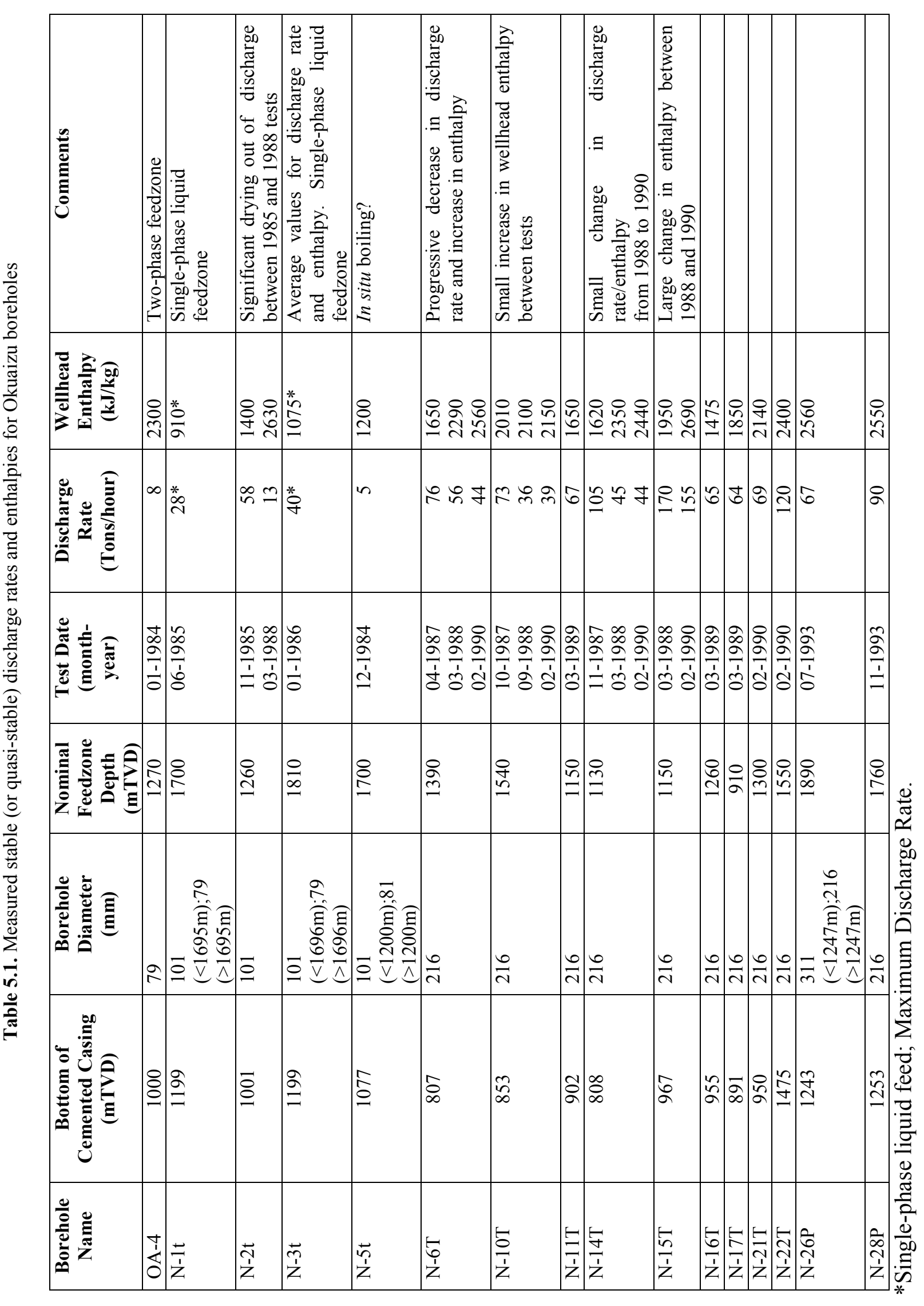


wellhead enthalpies comparable to those for large-diameter wells. Slim hole OA-4 was drilled from a site to the west of the Takiyagawa fault, i.e. from a location outside the main production area. The productivity index for OA-4 (Table 4.1) is smaller by a factor of five or more than the productivity indices for large-diameter production wells at Okuaizu. Garg, et al. (1998) remarked that a productivity index of the order of $0.3 \mathrm{~kg} / \mathrm{s}$-bar is required to obtain economically significant discharge rates from large-diameter wells with two-phase feedzones. Since the productivity index for OA-4 is only $0.035 \mathrm{~kg} / \mathrm{s}-\mathrm{bar}$, it is clear that OA-4 is located in an unproductive area and is not representative of boreholes drilled within the main production area at Okuaizu. Slim hole N-2t, however, lies within the main production area. Furthermore, the single-phase (liquid) productivity index for $\mathrm{N}-2 \mathrm{t}$ is comparable to the single-phase productivity index for large-diameter well N-6T. Unfortunately, both the available downhole PTS surveys were taken in N-2t during the 1985 discharge test by lowering the discharge rate and thus precluding in situ boiling.

Unlike boreholes with liquid feedzones, the "scaled maximum discharge rate" (Pritchett, 1993) cannot be used to predict the discharge characteristics of large-diameter wells with two-phase feedzones based on discharge data from slim holes. Garg, et al. (1998) used a wellbore simulator to investigate the relationship between the discharge capacity of slim holes and large-diameter wells with twophase feedzones. The numerical parameters derived from a fit to the slim hole discharge data were used to predict the discharge behavior of large-diameter wells. As mentioned earlier, no downhole PTS surveys were run in $\mathrm{N}-2 \mathrm{t}$ at the times when the discharge from the borehole was accompanied by in situ boiling. This makes it impractical to simulate the two-phase discharge response of $\mathrm{N}-2 \mathrm{t}$. Therefore, it was decided to simulate the discharge behavior of the large-diameter
Okuaizu wells, and use the resulting model parameters to compute the maximum discharge rate for a slim hole with a completion comparable to that for $\mathrm{N}-2 \mathrm{t}$. Numerical simulations for the various boreholes are presented in Section 5.3.

\subsection{Mathematical Modeling of Fluid Flow in Boreholes with Two-Phase Feedzones}

Mass and energy transport in Okuaizu boreholes was modeled using the wellbore computer simulation program WELBOR (Pritchett, 1985). The WELBOR code treats the steady flow of liquid water and steam up a borehole. The user provides parameters describing the well geometry (inside diameter and angle of deviation with respect to the vertical along the hole length), a stable formation temperature distribution with depth, and an "effective thermal conductivity" as a function of depth representing the effect of conductive heat transfer between the fluid in the wellbore and the surrounding formation. For boreholes with two-phase feedzones considered here, the feedzone fluid state is prescribed by specifying flowing feedpoint pressure (or stable feedpoint pressure and productivity index) and enthalpy.

In WELBOR, the frictional pressure gradient is computed using the Dukler II correlation (Dukler et al., 1964) and a user prescribed roughness factor, $\varepsilon$. For the present application, WELBOR was modified to use the Dukler I correlation (Dukler et al., 1964) for calculating the frictional pressure gradient. (Note that the Dukler II correlation gives a much larger pressure drop than the Dukler I correlation. Numerical experiments have shown that it is necessary to use the Dukler I correlation in order to match the reported discharge rate and enthalpy data for most of the Okuaizu boreholes.) The relative slip between the liquid and gas phases is treated 
using a modified version of the Hughmark liquid holdup correlation (Hughmark, 1962). The slippage rate may vary between the value given by the Hughmark correlation and no slip at all, according to the value of a user specified parameter, $\eta$, which varies between zero (no slip) and unity (Hughmark). For the calculations presented in this subsection, $\eta$ was chosen so as to match the pressure drop along the wellbore.

Most geothermal wells are completed with uncemented slotted (or perforated) liner in the open hole section of the borehole. Based on an examination of downhole pressure profiles in boreholes with two-phase feedzones, Garg, et al. (1998) concluded that the pressure gradient is significantly higher in the slotted/perforated liner section (above the uppermost fluid entry) than in the cemented and cased part of the borehole. As discussed in Section 3, several of the large-diameter Okuaizu wells have multiple fluid entries. The fluid entries often appear as discontinuities in pressure (or temperature) gradient in downhole pressure (temperature) surveys in the discharging well. For the calculations discussed in this subsection, only the section of the borehole above the uppermost entry is considered. To reproduce the observed pressure gradient in the slotted/perforated liner section of the borehole, Garg, et al. (1998) found it necessary (in most cases) to assume (1) a reduced diameter and (2) a non-zero roughness factor for the slotted/perforated section. For the Okuaizu boreholes, the slotted/perforated section was modeled using a non-zero roughness factor. The cased section was, however, assumed to be smooth $(\varepsilon=0)$ for most of the Okuaizu boreholes.

Given the downhole (usually at the uppermost feedzone) values for mass flow, pressure and enthalpy, a wellbore simulator (e.g., WELBOR) can be used to compute the pressure, temperature, and fluid enthalpy distribution along the wellbore and at the wellhead. The principal parameters that may be varied to match the measured conditions along the wellbore and at the wellhead are (1) holdup parameter, $\eta$ and (2) interior roughness factor, $\varepsilon$. In two-phase water/steam flow, pressure and temperature are not independent of each other. For any value of effective thermal conductivity $\mathrm{K}$, the downhole flowing enthalpy may be adjusted to yield the appropriate pressure, and hence temperature, distribution in the wellbore, and flowing wellhead enthalpy. Matching the pressure/temperature distribution in the wellbore does not constrain the flowing feedzone enthalpy and heat loss. Since the flowing feedzone enthalpy is not a measured quantity, it is not possible to determine a unique value for heat loss in the presence of two-phase flow. It was therefore decided to eliminate effective thermal conductivity, $\mathrm{K}$, as a free parameter. For all the calculations described herein, $\mathrm{K}$ was assumed to be 4 $\mathrm{W} / \mathrm{m}-{ }^{\circ} \mathrm{C}$.

As discussed in Section 4, downhole pressure/temperature surveys in the discharging Okuaizu wells were run at two or three discharge rates. In almost all cases, a pressure/temperature survey was first run at the presumably stable discharge rate. The wellhead settings were then changed to run pressure/temperature surveys at discharge rates lower than the stable discharge rate. Because of the short time allowed between changes in wellhead settings and downhole pressure surveys, it appears that the feedzone pressure did not attain a stable value at lower flow rates. This accounts for a reduction in the productivity index along with a lowering of the discharge rate (see e.g., Table 4.1). The downhole pressure/temperatures at lower discharge rates cannot therefore be used to characterize the discharge behavior of the Okuaizu wells. In the following, only the downhole pressure/temperature surveys corresponding to the maximum stable discharge rate will be considered. 
No downhole pressure/temperature surveys are available for well N-21T. The downhole pressure/temperature surveys for the remaining ten (10) production wells were matched using the WELBOR simulator. The model parameters (roughness factor, holdup parameter) derived from fits to downhole data were then used to compute the maximum discharge rate for a slim hole completion similar to that for Okuaizu slim hole $\mathrm{N}-2 \mathrm{t}$ (i.e., $10.2 \mathrm{~cm}$ inside diameter for the cased section, and $10.1 \mathrm{~cm}$ diameter for the slotted/perforated line section). Detailed results of these calculations follow.

\section{Production Well N-6T}

The uppermost fluid entry for Okuaizu well N$6 \mathrm{~T}$ is located at $\sim 990$ mTVD. The stable feedzone temperature and pressure are estimated to be $\sim 280{ }^{\circ} \mathrm{C}$ and 82.6 bars, respectively. The well is completed with a $224 \mathrm{~mm}$ ID casing to a depth of 806.5 mTVD. A $178 \mathrm{~mm}$ OD uncemented liner in a $216 \mathrm{~mm}$ diameter hole is present below $\sim 772 \mathrm{mTVD}$. The following well geometry was assumed for N-6T:

\begin{tabular}{|c|c|c|c|}
\hline $\begin{array}{c}\text { Measured } \\
\text { Depth } \\
\text { (meters) }\end{array}$ & $\begin{array}{c}\text { Vertical } \\
\text { Depth } \\
\text { (meters) }\end{array}$ & $\begin{array}{c}\text { Angle } \\
\text { with } \\
\text { Vertical } \\
\text { (Degrees) }\end{array}$ & $\begin{array}{c}\text { Internal } \\
\text { Diameter } \\
\text { (mm) }\end{array}$ \\
\hline 806.5 & 806.5 & 0.000 & 224 \\
\hline 990.0 & 990.0 & 0.000 & 216 \\
\hline
\end{tabular}

A pressure and temperature survey was run in the discharging well on February 26, 1988. The reported discharge rate and wellhead enthalpy at the time of the latter survey were 61.9 tons/hour $(17.2 \mathrm{~kg} / \mathrm{s})$ and $2240 \mathrm{~kJ} / \mathrm{kg}$, respectively. The measured pressure (Figure 5.27 ) is in good agreement with the saturation pressure corresponding to the local measured temperature, indicating two-phase conditions in the wellbore.

The stable formation temperature was approximated by the following temperature distribution using linear interpolations between tabulated data.

\begin{tabular}{|c|c|}
\hline $\begin{array}{c}\text { Vertical Depth } \\
\text { (meters) }\end{array}$ & $\begin{array}{c}\text { Temperature } \\
\text { (Celsius) }\end{array}$ \\
\hline 0 & 20 \\
\hline 330 & 100 \\
\hline 630 & 200 \\
\hline 990 & 280 \\
\hline
\end{tabular}

The downhole pressure profile was matched using the following values for model parameters:

$$
\begin{aligned}
\text { Discharge Rate } & 17.2 \mathrm{~kg} / \mathrm{s} \\
\text { Flowing Feedzone Pressure }= & 18.83 \mathrm{bars} \\
= & 2270 \mathrm{~kJ} / \mathrm{kg} \\
\text { Feedzone Enthalpy } & 4 \mathrm{~W} / \mathrm{m}-{ }^{\circ} \mathrm{C} \\
\text { Thermal Conductivity, K } & 1.0 \\
\text { Holdup Parameter, } \eta & 0.01 \mathrm{~mm}, \text { for } \\
\text { Roughness Factor, } \varepsilon & \text { depths }<806.5 \\
& \text { meters } \\
= & 0.15 \mathrm{~mm}, \text { for } \\
& \text { depths }>806.5 \\
& \text { meters }
\end{aligned}
$$

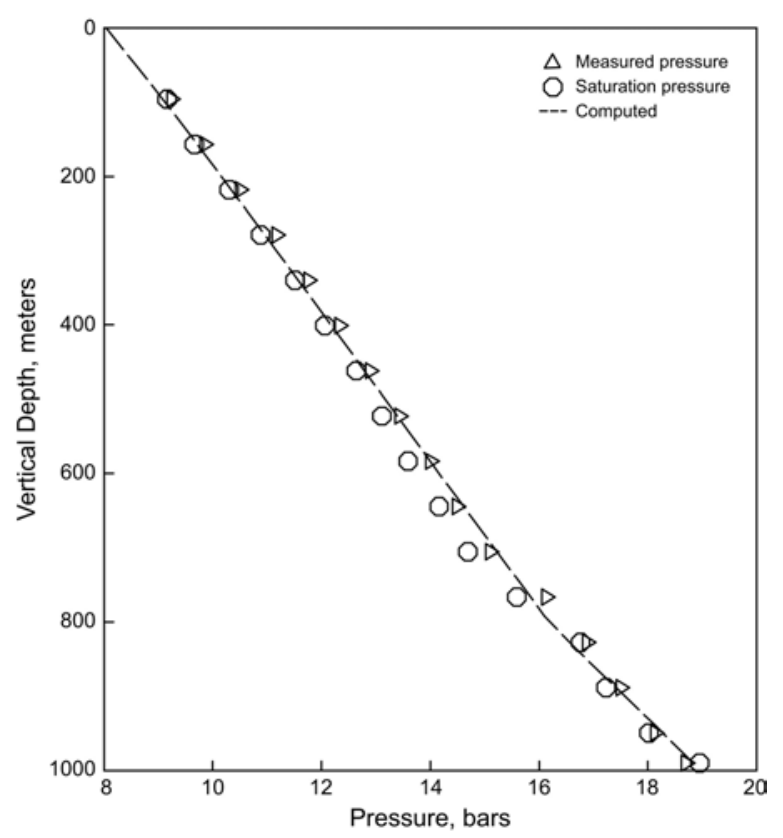

Figure 5.27. Pressure profile $(\Delta)$ recorded in discharging well N-6T on February 26, 1988. The octagon indicates saturation pressure corresponding to local measured temperature. The dashed line is the computed pressure profile. 
The flowing feedzone pressure and discharge rate are measured quantities, and are not model parameters. Also, the effective thermal conductivity was assumed to be a constant. The roughness factor, feedzone enthalpy and holdup parameter were taken to be free parameters and were varied in an iterative process to match the downhole pressure profile and wellhead enthalpy. The computed pressure profile is compared with the measurements in Figure 5.27. The agreement is quite good.

With a discharge rate of $17.2 \mathrm{~kg} / \mathrm{s}$ and a flowing feedzone pressure of 18.83 bars, the productivity index for $\mathrm{N}-6 \mathrm{~T}$ is computed to be:

$$
\begin{aligned}
\text { PI }= & \text { Discharge Rate / (Stable Pressure - } \\
& \text { Flowing Pressure }) \\
= & 17.2 /(82.6-18.83) \\
= & 0.270 \mathrm{~kg} / \mathrm{s}-\text { bar. }
\end{aligned}
$$

The model parameters (feedzone enthalpy, roughness factor, thermal conductivity, productivity index) obtained from a fit to the downhole pressure profile in well N-6T were used to compute the discharge capacity of a slim hole with a completion similar to $\mathrm{N}-2 \mathrm{t}$ (102 mm ID to $806.5 \mathrm{mTVD}$, and $101 \mathrm{~mm}$ ID in the open hole section below). The maximum discharge capacity of the slim hole is computed to be $8.5 \mathrm{~kg} / \mathrm{s}$ (30.6 tons/hour). The wellhead enthalpy corresponding to the maximum discharge rate for the slim hole is $\sim 2174 \mathrm{~kJ} / \mathrm{kg}$.

\section{Production Well N-10T}

The uppermost fluid entry for Okuaizu well $\mathrm{N}-10 \mathrm{~T}$, as deduced from a downhole pressure survey in the discharging well, is located at $\sim 980$ mTVD. The stable feedzone temperature and pressure are estimated to be $\sim 300{ }^{\circ} \mathrm{C}$ and 81.9 bars, respectively. The well is completed with a $224 \mathrm{~mm}$ ID casing to a depth of 853.4 mTVD. A $178 \mathrm{~mm}$ OD uncemented liner in a
$216 \mathrm{~mm}$ diameter hole is present below $\sim 833$ mTVD. The following well geometry was assumed for N-10T:

\begin{tabular}{|l|l|l|l|}
\hline $\begin{array}{c}\text { Measured } \\
\text { Depth } \\
\text { (meters) }\end{array}$ & $\begin{array}{c}\text { Vertical } \\
\text { Depth } \\
\text { (meters) }\end{array}$ & $\begin{array}{c}\text { Angle with } \\
\text { Vertical } \\
\text { (Degrees) }\end{array}$ & $\begin{array}{c}\text { Internal } \\
\text { Diameter } \\
\text { (mm) }\end{array}$ \\
\hline $833.5^{*}$ & $832.7^{*}$ & 2.511 & 224 \\
\hline 981.2 & 980.0 & 4.218 & 159 \\
\hline
\end{tabular}

*top of 178-mm liner.

A pressure and temperature survey was run in the discharging well on September 10, 1988. The reported discharge rate and wellhead enthalpy at the time of the latter survey were 55.6 tons/hour $(15.4 \mathrm{~kg} / \mathrm{s})$ and $2060 \mathrm{~kJ} / \mathrm{kg}$, respectively. The measured pressure (Figure 5.28 ) is more or less in agreement with the saturation pressure corresponding to the local measured temperature, indicating two-phase conditions in the wellbore.

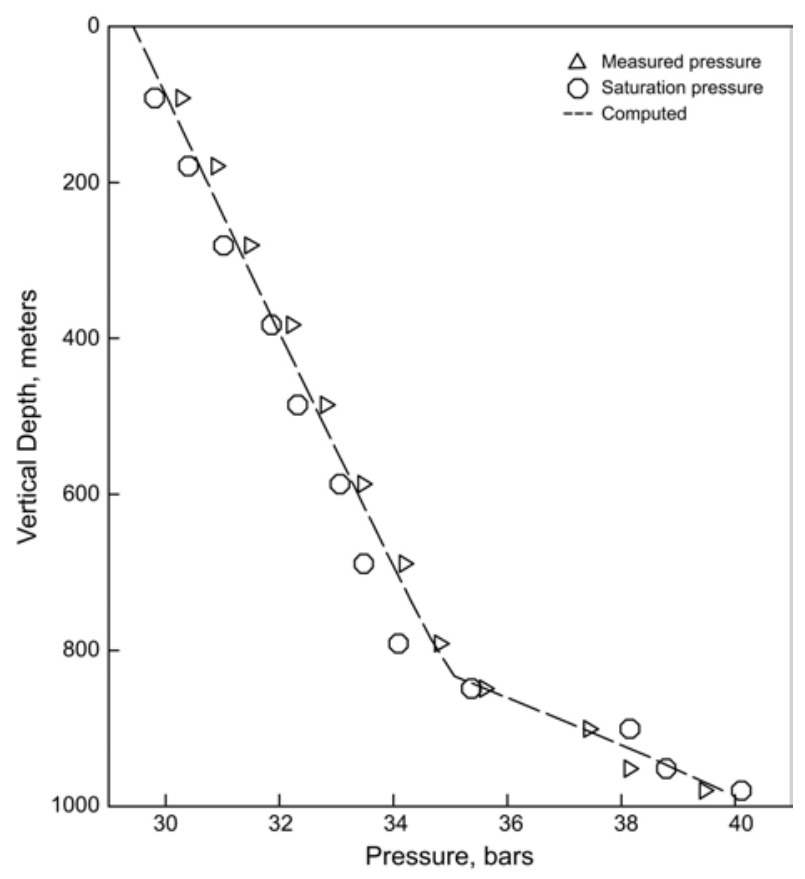

Figure 5.28. Pressure profile $(\Delta)$ recorded in discharging well N-10T on September 10, 1988. The octagon indicates saturation pressure corresponding to local measured temperature. The dashed line is the computed pressure profile. 
The stable formation temperature was approximated by the following temperature distribution using linear interpolations between tabulated data.

\begin{tabular}{|c|c|}
\hline $\begin{array}{c}\text { Vertical Depth } \\
\text { (meters) }\end{array}$ & $\begin{array}{c}\text { Temperature } \\
\text { (Celsius) }\end{array}$ \\
\hline 0 & 25 \\
\hline 325 & 100 \\
\hline 425 & 200 \\
\hline 600 & 280 \\
\hline 980 & 300 \\
\hline
\end{tabular}

The downhole pressure profile was matched using the following values for model parameters:

$\begin{aligned} \text { Discharge Rate } & =15.4 \mathrm{~kg} / \mathrm{s} \\ \text { Flowing Feedzone Pressure }= & 39.78 \mathrm{bars} \\ = & 2090 \mathrm{~kJ} / \mathrm{kg} \\ \text { Feedzone Enthalpy } & 4 \mathrm{~W} / \mathrm{m}^{\circ}{ }^{\circ} \mathrm{C} \\ \text { Thermal Conductivity, K }= & 0.53 \\ \text { Holdup Parameter, } \eta & 0, \text { for depths }< \\ \text { Roughness Factor, } \varepsilon & 832.7 \text { meters } \\ = & 2.2 \mathrm{~mm}, \text { for } \\ & \text { depths }>832.7 \\ & \text { meters }\end{aligned}$

The discharge rate and the flowing feedzone pressure are measured quantities, and are not model parameters. Also, the effective thermal conductivity was assumed to be a constant. The roughness factor, feedzone enthalpy and holdup parameter were taken to be free parameters and were varied in an iterative process to match the downhole pressure profile and wellhead enthalpy. The computed pressure profile is compared with the measurements in Figure 5.28. The agreement is quite good.

With a discharge rate of $15.4 \mathrm{~kg} / \mathrm{s}$ and a flowing feedzone pressure of 39.78 bars, the productivity index for N-10T is computed to be:

$$
\begin{aligned}
\text { PI }= & \text { Discharge Rate / (Stable Pressure - } \\
& \text { Flowing Pressure }) \\
= & 15.4 /(81.9-39.78) \\
= & 0.366 \mathrm{~kg} / \mathrm{s}-\text { bar. }
\end{aligned}
$$

The model parameters (feedzone enthalpy, roughness factor, thermal conductivity, productivity index) obtained from a fit to the downhole pressure profile in well N-10T were used to compute the discharge capacity of a slim hole with a completion similar to $\mathrm{N}-2 \mathrm{t}(102 \mathrm{~mm}$ ID to $853.4 \mathrm{mTVD}$, and $101 \mathrm{~mm}$ ID in the open hole section below). The maximum discharge capacity of the slim hole is computed to be 9.8 $\mathrm{kg} / \mathrm{s}$ (35.3 tons/hour). The wellhead enthalpy corresponding to the maximum discharge rate for the slim hole is $\sim 2041 \mathrm{~kJ} / \mathrm{kg}$.

\section{Production Well N-11T}

The uppermost fluid entry for Okuaizu well N$11 \mathrm{~T}$ is located at $\sim 1150 \mathrm{mTVD}$. The stable feedzone temperature and pressure are estimated to be $\sim 258{ }^{\circ} \mathrm{C}$ and 98.0 bars, respectively. The well is completed with a $224 \mathrm{~mm}$ ID casing to a depth of 902.1 mTVD. A $178 \mathrm{~mm}$ OD uncemented liner in a $216 \mathrm{~mm}$ diameter hole is present below $\sim 892$ mTVD. The following well geometry was assumed for N-11T:

\begin{tabular}{|c|c|c|r|}
\hline $\begin{array}{c}\text { Measured } \\
\text { Depth } \\
\text { (meters) }\end{array}$ & $\begin{array}{c}\text { Vertical } \\
\text { Depth } \\
\text { (meters) }\end{array}$ & $\begin{array}{c}\text { Angle with } \\
\text { Vertical } \\
\text { (Degrees) }\end{array}$ & $\begin{array}{c}\text { Internal } \\
\text { Diameter } \\
\text { (mm) }\end{array}$ \\
\hline 912.1 & 902.1 & 8.492 & 224 \\
\hline 1173.8 & 1150.0 & 18.690 & 216 \\
\hline
\end{tabular}

A pressure and temperature survey was run in the discharging well on March 11, 1989. The reported discharge rate and wellhead enthalpy at the time of the latter survey were 66.1 tons/hour $(18.4 \mathrm{~kg} / \mathrm{s})$ and $1650 \mathrm{~kJ} / \mathrm{kg}$, respectively. The measured pressure (Figure 5.29 ) is in excellent agreement with the saturation pressure corresponding to the local measured temperature, indicating two-phase conditions in the wellbore.

The stable formation temperature was approximated by the following temperature distribution using linear interpolations between tabulated data. 


\begin{tabular}{|c|c|}
\hline $\begin{array}{c}\text { Vertical } \\
\text { Depth } \\
\text { (meters) }\end{array}$ & $\begin{array}{c}\text { Temperature } \\
\text { (Celsius) }\end{array}$ \\
\hline 0 & 20 \\
\hline 320 & 100 \\
\hline 850 & 200 \\
\hline 1050 & 250 \\
\hline 1150 & 258 \\
\hline
\end{tabular}

The downhole pressure profile was matched using the following values for model parameters:

$$
\begin{aligned}
\text { Discharge Rate } & 18.4 \mathrm{~kg} / \mathrm{s} \\
\text { Flowing Feedzone Pressure }= & 16.46 \mathrm{bars} \\
= & 1680 \mathrm{~kJ} / \mathrm{kg} \\
\text { Feedzone Enthalpy } & 4 \mathrm{~W} / \mathrm{m}-{ }^{\circ} \mathrm{C} \\
\text { Thermal Conductivity, K } \mathrm{K}= & 0.30 \\
\text { Holdup Parameter, } \eta & 0, \text { for depths } \\
\text { Roughness Factor, } \varepsilon & <902.1 \text { meters } \\
= & 0.75 \mathrm{~mm}, \text { for } \\
& \text { depths }>902.1 \\
& \text { meters }
\end{aligned}
$$

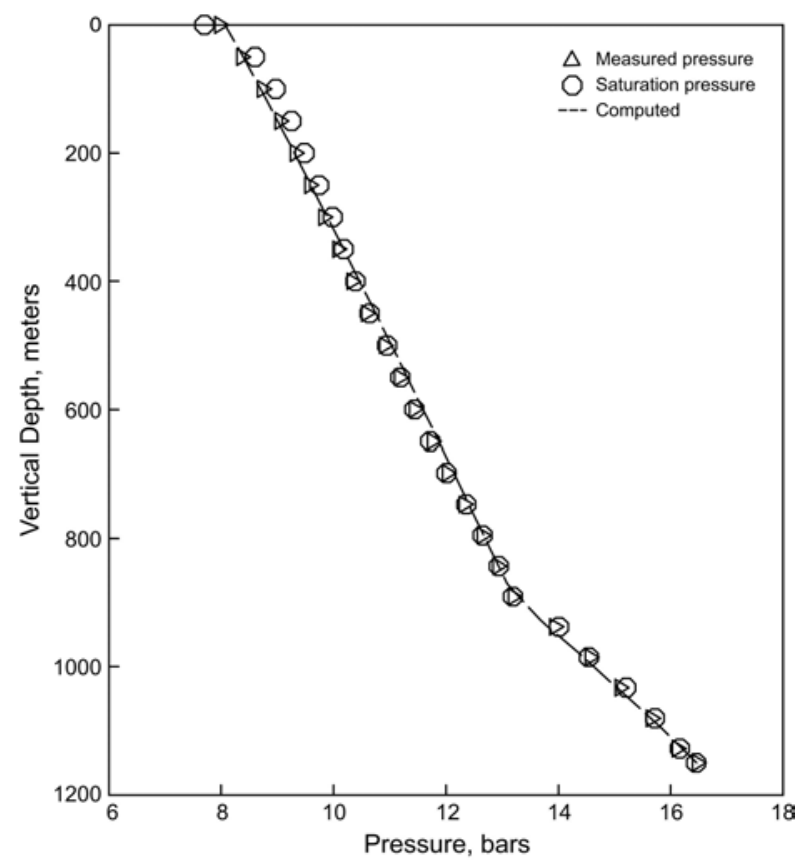

Figure 5.29. Pressure profile $(\Delta)$ recorded in discharging well N-11T on March 11, 1989. The octagon indicates saturation pressure corresponding to local measured temperature. The dashed line is the computed pressure profile.
The flowing feedzone pressure and the discharge rate are measured quantities, and are not model parameters. Also, the effective thermal conductivity was assumed to be a constant. The roughness factor, feedzone enthalpy and holdup parameter were taken to be free parameters and were varied in an iterative process to match the downhole pressure profile and wellhead enthalpy. The computed pressure profile is compared with the measurements in Figure 5.29. The agreement is quite good.

With a discharge rate of $18.4 \mathrm{~kg} / \mathrm{s}$ and a flowing feedzone pressure of 16.46 bars, the productivity index for $\mathrm{N}-11 \mathrm{~T}$ is computed to be:

$$
\begin{aligned}
\text { PI }= & \text { Discharge Rate / (Stable Pressure - } \\
& \text { Flowing Pressure }) \\
= & 18.4 /(98.0-16.46) \\
= & 0.226 \mathrm{~kg} / \mathrm{s}-\mathrm{bar} .
\end{aligned}
$$

The model parameters (feedzone enthalpy, roughness factor, thermal conductivity, productivity index) obtained from a fit to the downhole pressure profile in well $\mathrm{N}-11 \mathrm{~T}$ were used to compute the discharge capacity of a slim hole with a completion similar to $\mathrm{N}-2 \mathrm{t}$ (102 mm ID to $902.1 \mathrm{mTVD}$, and $101 \mathrm{~mm}$ ID in the open hole section below). The maximum discharge capacity of the slim hole is computed to be 10.4 $\mathrm{kg} / \mathrm{s}$ (37.4 tons/hour). The wellhead enthalpy corresponding to the maximum discharge rate for the slim hole is $\sim 1595 \mathrm{~kJ} / \mathrm{kg}$.

\section{Production Well N-14T}

The uppermost fluid entry for Okuaizu well N$14 \mathrm{~T}$ is located at $\sim 1130 \mathrm{mTVD}$. The stable feedzone temperature and pressure are estimated to be $\sim 265{ }^{\circ} \mathrm{C}$ and 100.0 bars, respectively. The well is completed with a $224 \mathrm{~mm}$ ID casing to a depth of 807.9 mTVD. A $178 \mathrm{~mm}$ OD uncemented liner in a $216 \mathrm{~mm}$ diameter hole is present below $\sim 758 \mathrm{mTVD}$. The following well geometry was assumed for N-14T: 


\begin{tabular}{|l|l|l|l|}
\hline $\begin{array}{c}\text { Measured } \\
\text { Depth } \\
\text { (meters) }\end{array}$ & $\begin{array}{c}\text { Vertical } \\
\text { Depth } \\
\text { (meters) }\end{array}$ & $\begin{array}{c}\text { Angle } \\
\text { with } \\
\text { Vertical } \\
\text { (Degrees) }\end{array}$ & $\begin{array}{c}\text { Internal } \\
\text { Diameter } \\
\text { (mm) }\end{array}$ \\
\hline 810.0 & 807.9 & 4.127 & 224 \\
\hline 1136.6 & 1130.0 & 9.522 & 216 \\
\hline
\end{tabular}

A pressure and temperature survey was run in the discharging well on February 21, 1988. The reported discharge rate and wellhead enthalpy at the time of the latter survey were 43.3 tons/hour $(12.0 \mathrm{~kg} / \mathrm{s})$ and $2013 \mathrm{~kJ} / \mathrm{kg}$, respectively. The measured pressure (Figure 5.30) is in good agreement with the saturation pressure corresponding to the local measured temperature, indicating two-phase conditions in the wellbore.

The stable formation temperature was approximated by the following temperature distribution using linear interpolations between tabulated data.

\begin{tabular}{|c|c|}
\hline $\begin{array}{c}\text { Vertical } \\
\text { Depth } \\
\text { (meters) }\end{array}$ & $\begin{array}{c}\text { Temperature } \\
\text { (Celsius) }\end{array}$ \\
\hline 0 & 30 \\
\hline 260 & 100 \\
\hline 660 & 200 \\
\hline 870 & 250 \\
\hline 1130 & 265 \\
\hline
\end{tabular}

The downhole pressure profile was matched using the following values for model parameters:

$\begin{aligned} \text { Discharge Rate } & =12.0 \mathrm{~kg} / \mathrm{s} \\ \text { Flowing Feedzone Pressure }= & 18.65 \mathrm{bars} \\ = & 2040 \mathrm{~kJ} / \mathrm{kg} \\ \text { Feedzone Enthalpy } & 4 \mathrm{~W} / \mathrm{m}-{ }^{\circ} \mathrm{C} \\ \text { Thermal Conductivity, K }= & 0.885 \\ \text { Holdup Parameter, } \eta & 0, \text { for depths }< \\ \text { Roughness Factor, } \varepsilon & 807.9 \text { meters } \\ = & 1.4 \mathrm{~mm}, \text { for } \\ & \text { depths }>807.9 \\ & \text { meters }\end{aligned}$

The discharge rate and flowing feedzone pressure are measured quantities, and are not model parameters. Also, the effective thermal conductivity was assumed to be a constant. The roughness factor, feedzone enthalpy and holdup parameter were taken to be free parameters and were varied in an iterative process to match the downhole pressure profile and wellhead enthalpy. The computed pressure profile is compared with the measurements in Figure 5.30. The agreement is quite good.

With a discharge rate of $12.0 \mathrm{~kg} / \mathrm{s}$ and a flowing feedzone pressure of 18.65 bars, the productivity index for $\mathrm{N}-14 \mathrm{~T}$ is computed to be:

$$
\begin{aligned}
\text { PI }= & \text { Discharge Rate / (Stable Pressure - } \\
& \text { Flowing Pressure }) \\
= & 12.0 /(100.0-18.65) \\
= & 0.148 \mathrm{~kg} / \mathrm{s}-\text { bar. }
\end{aligned}
$$

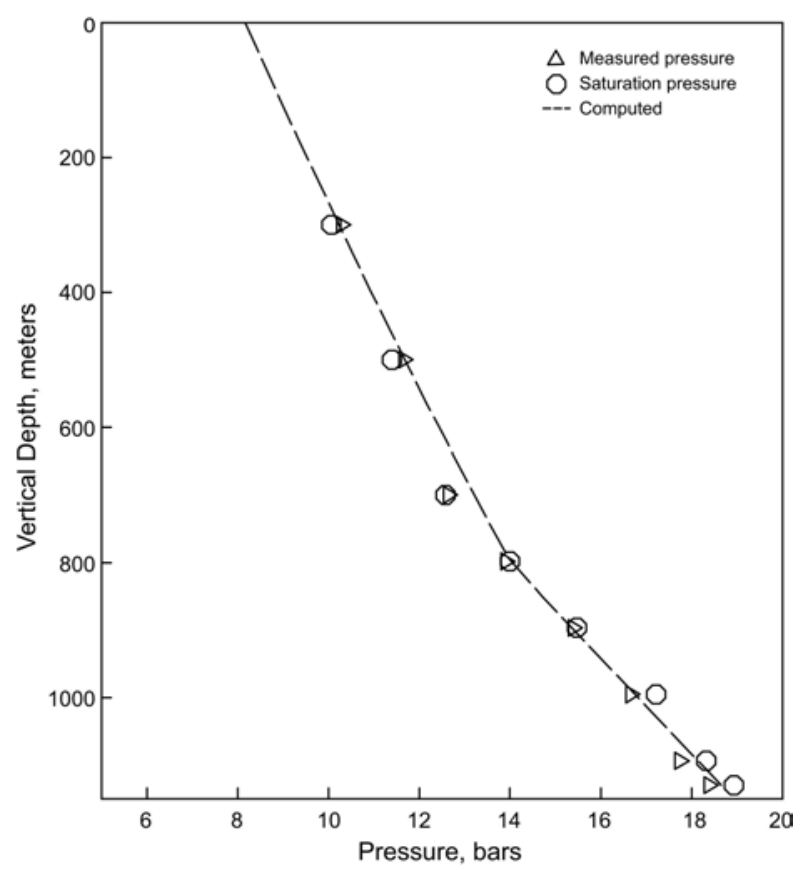

Figure 5.30. Pressure profile $(\Delta)$ recorded in discharging well N-14T on February 21, 1988. The octagon indicates saturation pressure corresponding to local measured temperature. The dashed line is the computed pressure profile.

The model parameters (feedzone enthalpy, roughness factor, thermal conductivity, productivity index) obtained from a fit to the downhole pressure profile in well $\mathrm{N}-14 \mathrm{~T}$ were 
used to compute the discharge capacity of a slim hole with a completion similar to $\mathrm{N}-2 \mathrm{t}$ (102 mm ID to $807.9 \mathrm{mTVD}$, and $101 \mathrm{~mm}$ ID in the open hole section below). The maximum discharge capacity of the slim hole is computed to be $7.2 \mathrm{~kg} / \mathrm{s}$ (25.9 tons/hour). The wellhead enthalpy corresponding to the maximum discharge rate for the slim hole is $\sim 1957 \mathrm{~kJ} / \mathrm{kg}$.

\section{Production Well N-15T}

The uppermost fluid entry for Okuaizu well $\mathrm{N}-15 \mathrm{~T}$, as deduced from a discontinuity in the pressure gradient in the discharging well, is located at $\sim 1280 \mathrm{mTVD}$. The stable feedzone temperature and pressure are estimated to be $\sim 294{ }^{\circ} \mathrm{C}$ and 108.9 bars, respectively. The well is completed with a $224 \mathrm{~mm}$ ID casing to a depth of 967.1 mTVD. A $178 \mathrm{~mm}$ OD uncemented liner in a $216 \mathrm{~mm}$ diameter hole is present below $2921 \mathrm{mTVD}$. The following well geometry was assumed for N-15T:

\begin{tabular}{|l|l|c|c|}
\hline $\begin{array}{c}\text { Measured } \\
\text { Depth } \\
\text { (meters) }\end{array}$ & $\begin{array}{c}\text { Vertical } \\
\text { Depth } \\
\text { (meters) }\end{array}$ & $\begin{array}{c}\text { Angle with } \\
\text { Vertical } \\
\text { (Degrees) }\end{array}$ & $\begin{array}{c}\text { Internal } \\
\text { Diameter } \\
\text { (mm) }\end{array}$ \\
\hline 967.5 & 967.1 & 1.648 & 224 \\
\hline 1282.1 & 1280.0 & 5.959 & 216 \\
\hline
\end{tabular}

A pressure and temperature survey was run in the discharging well on March 2, 1988. The reported discharge rate and wellhead enthalpy at the time of the latter survey were 170 tons/hour $(47.2 \mathrm{~kg} / \mathrm{s})$ and $1900 \mathrm{~kJ} / \mathrm{kg}$, respectively. The measured pressure (Figure 5.31) follows the same trend but is somewhat higher than the saturation pressure corresponding to the local measured temperature. The difference between the saturation and measured pressure is most likely due to an error in gauge calibration.

The stable formation temperature was approximated by the following temperature distribution using linear interpolations between tabulated data.

\begin{tabular}{|c|c|}
\hline $\begin{array}{c}\text { Vertical Depth } \\
\text { (meters) }\end{array}$ & $\begin{array}{c}\text { Temperature } \\
\text { (Celsius) }\end{array}$ \\
\hline 0 & 20 \\
\hline 310 & 100 \\
\hline 690 & 200 \\
\hline 875 & 250 \\
\hline 1280 & 294 \\
\hline
\end{tabular}

The downhole pressure profile was matched using the following values for model parameters:

$\begin{aligned} \text { Discharge Rate } & 47.2 \mathrm{~kg} / \mathrm{s} \\ \text { Flowing Feedzone Pressure }= & 77.66 \mathrm{bars} \\ = & 1934 \mathrm{~kJ} / \mathrm{kg} \\ \text { Feedzone Enthalpy } & 4 \mathrm{~W} / \mathrm{m}-{ }^{\circ} \mathrm{C} \\ \text { Thermal Conductivity, K }= & 0.215 \\ \text { Holdup Parameter, } \eta & 0, \text { for depths }< \\ \text { Roughness Factor, } \varepsilon & 967.1 \text { meters } \\ = & 0.25 \mathrm{~mm}, \text { for } \\ & \text { depths }>967.1 \\ & \text { meters }\end{aligned}$

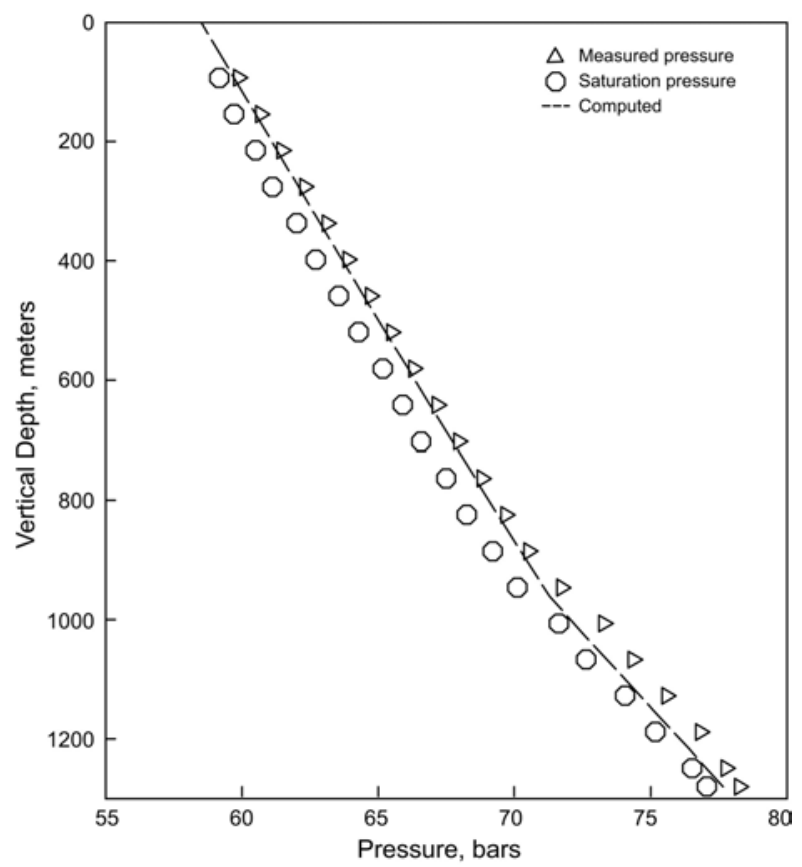

Figure 5.31. Pressure profile $(\Delta)$ recorded in discharging well N-15T on March 2, 1988. The octagon indicates saturation pressure corresponding to local measured temperature. The dashed line is the computed pressure profile. 
The flowing feedzone pressure was obtained by averaging the measured and saturation pressures at $1280 \mathrm{mTVD}$, and is not a model parameter. Also, the effective thermal conductivity was assumed to be a constant. The roughness factor, feedzone enthalpy and holdup parameter were taken to be free parameters and were varied in an iterative process to match the downhole pressure profile and wellhead enthalpy. The computed pressure profile is compared with the measurements in Figure 5.31. The agreement is quite good.

With a discharge rate of $47.2 \mathrm{~kg} / \mathrm{s}$ and a flowing feedzone pressure of 77.66 bars, the productivity index for $\mathrm{N}-15 \mathrm{~T}$ is computed to be:

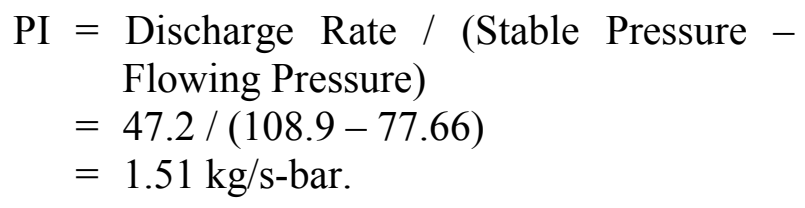

The model parameters (feedzone enthalpy, roughness factor, thermal conductivity, productivity index) obtained from a fit to the downhole pressure profile in well N-15T were used to compute the discharge capacity of a slim hole with a completion similar to $\mathrm{N}-2 \mathrm{t}$ (102 mm ID to $967.1 \mathrm{mTVD}$, and $101 \mathrm{~mm}$ ID in the open hole section below). The maximum discharge capacity of the slim hole is computed to be $18.9 \mathrm{~kg} / \mathrm{s}$ (68.0 tons/hour). The wellhead enthalpy corresponding to the maximum discharge rate for the slim hole is $\sim 1859 \mathrm{~kJ} / \mathrm{kg}$.

\section{Production Well N-16T}

The uppermost fluid entry for Okuaizu well N$16 \mathrm{~T}$ is located at $\sim 1260 \mathrm{mTVD}$. The stable feedzone temperature and pressure are estimated to be $\sim 250{ }^{\circ} \mathrm{C}$ and 104.8 bars, respectively. The well is completed with a $224 \mathrm{~mm}$ ID casing to a depth of 954.8 mTVD. A $178 \mathrm{~mm}$ OD uncemented liner in a $216 \mathrm{~mm}$ diameter hole is present below $\sim 930 \mathrm{mTVD}$. The following well geometry was assumed for N-16T:

\begin{tabular}{|c|c|c|c|}
\hline $\begin{array}{c}\text { Measured } \\
\text { Depth } \\
\text { (meters) }\end{array}$ & $\begin{array}{c}\text { Vertical } \\
\text { Depth } \\
\text { (meters) }\end{array}$ & $\begin{array}{c}\text { Angle with } \\
\text { Vertical } \\
\text { (Degrees) }\end{array}$ & $\begin{array}{c}\text { Internal } \\
\text { Diameter } \\
\text { (mm) }\end{array}$ \\
\hline 964.0 & 954.8 & 7.922 & 224 \\
\hline 1289.2 & 1260.0 & 20.199 & 216 \\
\hline
\end{tabular}

A pressure and temperature survey was run in the discharging well on March 17, 1989. The reported discharge rate and wellhead enthalpy at the time of the latter survey were 65.3 tons/hour $(18.1 \mathrm{~kg} / \mathrm{s})$ and $1475 \mathrm{~kJ} / \mathrm{kg}$, respectively. The measured pressure (Figure 5.32) is in agreement with the saturation pressure corresponding to the local measured temperature, indicating two-phase conditions in the wellbore.

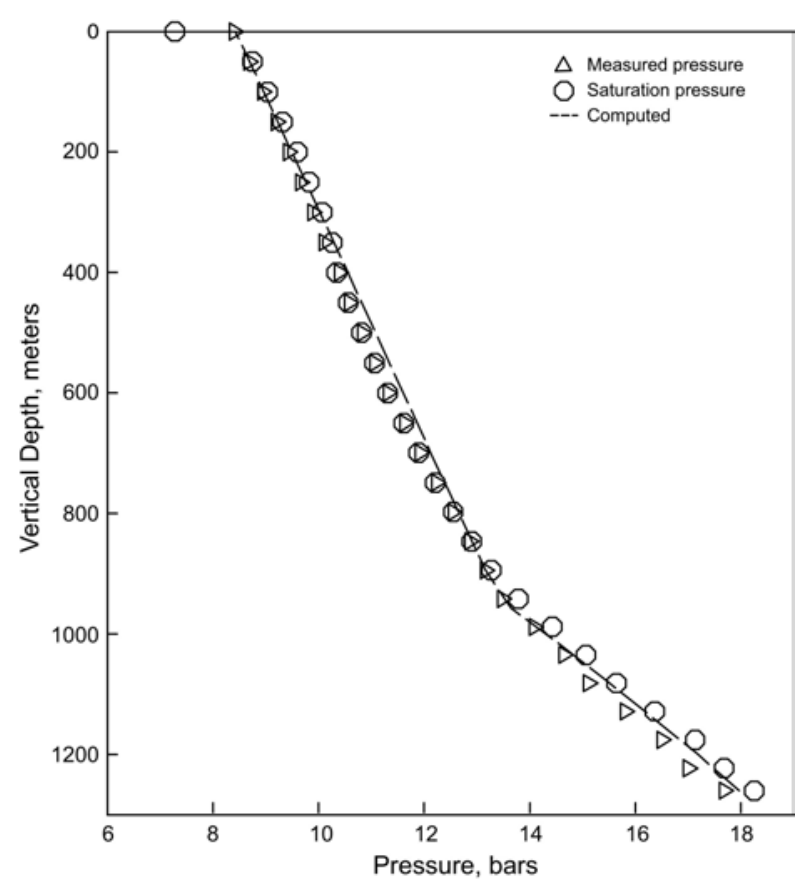

Figure 5.32. Pressure profile $(\Delta)$ recorded in discharging well N-16T on March 17, 1989. The octagon indicates saturation pressure corresponding to local measured temperature. The dashed line is the computed pressure profile.

The stable formation temperature was approximated by the following temperature distribution using linear interpolations between tabulated data. 


\begin{tabular}{|c|c|}
\hline $\begin{array}{c}\text { Vertical Depth } \\
\text { (meters) }\end{array}$ & $\begin{array}{c}\text { Temperature } \\
\text { (Celsius) }\end{array}$ \\
\hline 0 & 30 \\
\hline 280 & 100 \\
\hline 850 & 200 \\
\hline 1260 & 250 \\
\hline
\end{tabular}

The downhole pressure profile was matched using the following values for model parameters:

$\begin{aligned} \text { Discharge Rate } & =18.1 \mathrm{~kg} / \mathrm{s} \\ \text { Flowing Feedzone Pressure }= & 17.96 \mathrm{bars} \\ = & 1505 \mathrm{~kJ} / \mathrm{kg} \\ \text { Feedzone Enthalpy } & 4 \mathrm{~W} / \mathrm{m}-{ }^{\circ} \mathrm{C} \\ \text { Thermal Conductivity, K }= & 0.22 \\ \text { Holdup Parameter, } \eta & 0, \text { for depths }< \\ \text { Roughness Factor, } \varepsilon & 954.8 \text { meters } \\ = & 2.5 \mathrm{~mm}, \text { for } \\ & \text { depths }>954.8 \\ & \text { meters }\end{aligned}$

The flowing feedzone pressure was obtained by averaging the measured and saturation pressures at $1260 \mathrm{mTVD}$, and is not a model parameter. Also, the effective thermal conductivity was assumed to be a constant. The roughness factor, feedzone enthalpy and holdup parameter were taken to be free parameters and were varied in an iterative process to match the downhole pressure profile and wellhead enthalpy. The computed pressure profile is compared with the measurements in Figure 5.32. The agreement is quite good.

With a discharge rate of $18.1 \mathrm{~kg} / \mathrm{s}$ and a flowing feedzone pressure of 17.96 bars, the productivity index for $\mathrm{N}-16 \mathrm{~T}$ is computed to be:

$$
\begin{aligned}
\text { PI }= & \text { Discharge Rate } /(\text { Stable Pressure - } \\
& \text { Flowing Pressure }) \\
= & 18.1 /(104.8-17.96) \\
= & 0.208 \mathrm{~kg} / \mathrm{s}-\text { bar. }
\end{aligned}
$$

The model parameters (feedzone enthalpy, roughness factor, thermal conductivity, productivity index) obtained from a fit to the downhole pressure profile in well N-16T were used to compute the discharge capacity of a slim hole with a completion similar to $\mathrm{N}-2 \mathrm{t}$ (102 mm ID to $954.8 \mathrm{mTVD}$, and $101 \mathrm{~mm}$ ID in the open hole section below). The maximum discharge capacity of the slim hole is computed to be $10.4 \mathrm{~kg} / \mathrm{s}$ (37.4 tons/hour). The wellhead enthalpy corresponding to the maximum discharge rate for the slim hole is $\sim 1423 \mathrm{~kJ} / \mathrm{kg}$.

\section{Production Well N-17T}

The uppermost fluid entry for Okuaizu well N$17 \mathrm{~T}$ is located at $\sim 910 \mathrm{mTVD}$. The stable feedzone temperature and pressure are estimated to be $\sim 255{ }^{\circ} \mathrm{C}$ and 81.0 bars, respectively. The well is completed with a $224 \mathrm{~mm}$ ID casing to a depth of 891.3 mTVD. A $178 \mathrm{~mm}$ OD uncemented liner in a $216 \mathrm{~mm}$ diameter hole is present below $\sim 852 \mathrm{mTVD}$. The following well geometry was assumed for N-15T:

\begin{tabular}{|l|l|l|l|}
\hline $\begin{array}{c}\text { Measured } \\
\text { Depth } \\
\text { (meters) }\end{array}$ & $\begin{array}{c}\text { Vertical } \\
\text { Depth } \\
\text { (meters) }\end{array}$ & $\begin{array}{c}\text { Angle with } \\
\text { Vertical } \\
\text { (Degrees) }\end{array}$ & $\begin{array}{c}\text { Internal } \\
\text { Diameter } \\
\text { (mm) }\end{array}$ \\
\hline $857.2^{*}$ & $851.8^{*}$ & 6.435 & 224 \\
\hline 918.8 & 910.0 & 19.125 & 159 \\
\hline
\end{tabular}

*top of $178 \mathrm{~mm}$ liner.

A pressure and temperature survey was run in the discharging well on March 14, 1989. The reported discharge rate and wellhead enthalpy at the time of the latter survey were 63.5 tons/hour $(17.6 \mathrm{~kg} / \mathrm{s})$ and $1860 \mathrm{~kJ} / \mathrm{kg}$, respectively. The measured pressure (Figure 5.33) follows the same trend but is somewhat higher than the saturation pressure corresponding to the local measured temperature. The difference between the saturation and measured pressure is most likely due to an error in gauge calibration.

The stable formation temperature was approximated by the following temperature distribution using linear interpolations between tabulated data. 


\begin{tabular}{|c|c|}
\hline $\begin{array}{c}\text { Vertical } \\
\text { Depth } \\
\text { (meters) }\end{array}$ & $\begin{array}{c}\text { Temperature } \\
\text { (Celsius) }\end{array}$ \\
\hline 0 & 25 \\
\hline 350 & 100 \\
\hline 820 & 200 \\
\hline 910 & 255 \\
\hline
\end{tabular}

The downhole pressure profile was matched using the following values for model parameters:

$$
\begin{aligned}
\text { Discharge Rate } & =17.6 \mathrm{~kg} / \mathrm{s} \\
\text { Flowing Feedzone Pressure }= & 14.35 \mathrm{bars} \\
= & 1890 \mathrm{~kJ} / \mathrm{kg} \\
\text { Feedzone Enthalpy } & 4 \mathrm{~W} / \mathrm{m}^{\circ}{ }^{\circ} \mathrm{C} \\
\text { Thermal Conductivity, K }= & 0.30 \\
\text { Holdup Parameter, } \eta & 0, \text { for depths }< \\
\text { Roughness Factor, } \varepsilon & 851.8 \text { meters } \\
= & 0.04 \mathrm{~mm}, \text { for } \\
& \text { depths }>851.8 \\
& \text { meters }
\end{aligned}
$$

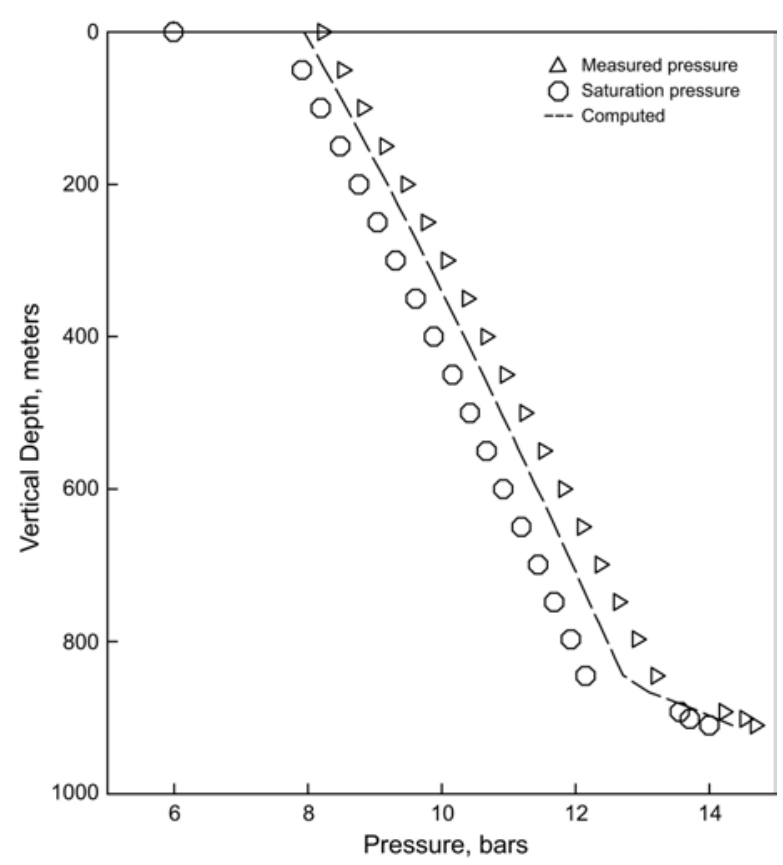

Figure 5.33. Pressure profile $(\Delta)$ recorded in discharging well N-17T on March 14, 1989. The octagon indicates saturation pressure corresponding to local measured temperature. The dashed line is the computed pressure profile.

The flowing feedzone pressure was obtained by averaging the measured and saturation pressures, and is not a model parameter. Also, the effective thermal conductivity was assumed to be a constant. The roughness factor, feedzone enthalpy and holdup parameter were taken to be free parameters and were varied in an iterative process to match the downhole pressure profile and wellhead enthalpy. The computed pressure profile is compared with the measurements in Figure 5.33. The agreement is quite good.

With a discharge rate of $17.6 \mathrm{~kg} / \mathrm{s}$ and a flowing feedzone pressure of 14.35 bars, the productivity index for $\mathrm{N}-17 \mathrm{~T}$ is computed to be:

$$
\begin{aligned}
\text { PI }= & \text { Discharge Rate } /(\text { Stable Pressure - } \\
& \text { Flowing Pressure }) \\
= & 17.6 /(81.0-14.35) \\
= & 0.264 \mathrm{~kg} / \mathrm{s}-\text { bar. }
\end{aligned}
$$

The model parameters (feedzone enthalpy, roughness factor, thermal conductivity, productivity index) obtained from a fit to the downhole pressure profile in well $\mathrm{N}-17 \mathrm{~T}$ were used to compute the discharge capacity of a slim hole with a completion similar to $\mathrm{N}-2 \mathrm{t}$ (102 mm ID to $891.3 \mathrm{mTVD}$, and $101 \mathrm{~mm}$ ID in the open hole section below). The maximum discharge capacity of the slim hole is computed to be $10.5 \mathrm{~kg} / \mathrm{s}$ (37.8 tons/hour). The wellhead enthalpy corresponding to the maximum discharge rate for the slim hole is $\sim 1806 \mathrm{~kJ} / \mathrm{kg}$.

\section{Production Well N-22T}

The uppermost fluid entry for Okuaizu well N$22 \mathrm{~T}$ is located at $\sim 1550 \mathrm{mTVD}$. The stable feedzone temperature and pressure are estimated to be $\sim 285{ }^{\circ} \mathrm{C}$ and 127.7 bars, respectively. The well is completed with a $224 \mathrm{~mm}$ ID casing to a depth of 1475.4 mTVD. A $178 \mathrm{~mm}$ OD uncemented liner in a $216 \mathrm{~mm}$ diameter hole is present below 1432 mTVD. The following well geometry was assumed for N-22T: 


\begin{tabular}{|l|l|l|l|}
\hline $\begin{array}{c}\text { Measured } \\
\text { Depth } \\
\text { (meters) }\end{array}$ & $\begin{array}{c}\text { Vertical } \\
\text { Depth } \\
\text { (meters) }\end{array}$ & $\begin{array}{c}\text { Angle with } \\
\text { Vertical } \\
\text { (Degrees) }\end{array}$ & $\begin{array}{c}\text { Internal } \\
\text { Diameter } \\
\text { (mm) }\end{array}$ \\
\hline $1449.1^{*}$ & $1432.0^{*}$ & 8.811 & 224 \\
\hline 1588.4 & 1550.0 & 32.103 & 159 \\
\hline
\end{tabular}

*top of $178 \mathrm{~mm}$ OD liner.

A pressure and temperature survey was run in the discharging well on February 26, 1990. The reported discharge rate and wellhead enthalpy at the time of the latter survey were 108 tons/hour $(30.0 \mathrm{~kg} / \mathrm{s})$ and $2390 \mathrm{~kJ} / \mathrm{kg}$, respectively. The measured pressure (Figure 5.34) is in agreement the saturation pressure corresponding to the local measured temperature, indicating twophase conditions in the wellbore.

The stable formation temperature was approximated by the following temperature distribution using linear interpolations between tabulated data.

\begin{tabular}{|c|c|}
\hline $\begin{array}{c}\text { Vertical Depth } \\
\text { (meters) }\end{array}$ & $\begin{array}{c}\text { Temperature } \\
\text { (Celsius) }\end{array}$ \\
\hline 0 & 30 \\
\hline 260 & 100 \\
\hline 660 & 200 \\
\hline 870 & 250 \\
\hline 1550 & 285 \\
\hline
\end{tabular}

The downhole pressure profile was matched using the following values for model parameters:

$\begin{aligned} \text { Discharge Rate } & =30.0 \mathrm{~kg} / \mathrm{s} \\ \text { Flowing Feedzone Pressure }= & 37.76 \mathrm{bars} \\ = & 2417 \mathrm{~kJ} / \mathrm{kg} \\ \text { Feedzone Enthalpy } & 4 \mathrm{~W} / \mathrm{m}^{\circ}{ }^{\circ} \mathrm{C} \\ \text { Thermal Conductivity, K } \mathrm{K}= & 0.938 \\ \text { Holdup Parameter, } \eta & 0, \text { for depths }< \\ \text { Roughness Factor, } \varepsilon & 1432 \text { meters } \\ = & 0.06 \mathrm{~mm}, \text { for } \\ & \text { depths }>1432 \\ & \text { meters }\end{aligned}$

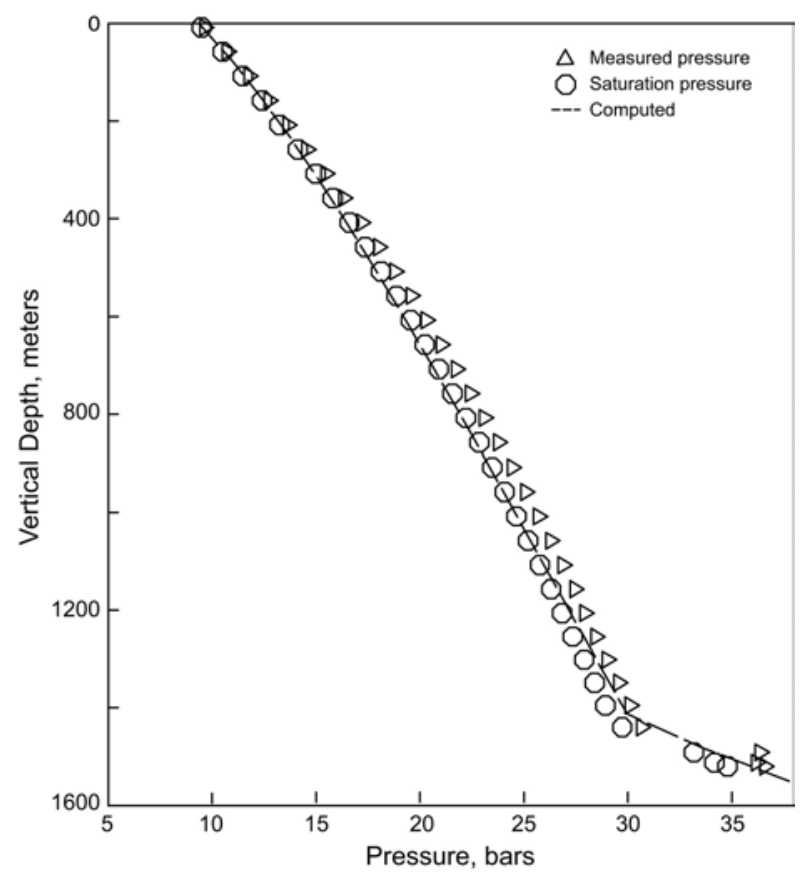

Figure 5.34. Pressure profile $(\Delta)$ recorded in discharging well N-22T February 26, 1990. The octagon indicates saturation pressure corresponding to local measured temperature. The dashed line is the computed pressure profile.

The flowing feedzone pressure was obtained by averaging the measured and saturation pressures at $1550 \mathrm{mTVD}$, and is not a model parameter. Also, the effective thermal conductivity was assumed to be a constant. The roughness factor, feedzone enthalpy and holdup parameter were taken to be free parameters and were varied in an iterative process to match the downhole pressure profile and wellhead enthalpy. The computed pressure profile is compared with the measurements in Figure 5.34. The agreement is quite good.

With a discharge rate of $30.0 \mathrm{~kg} / \mathrm{s}$ and a flowing feedzone pressure of 37.76 bars, the productivity index for $\mathrm{N}-22 \mathrm{~T}$ is computed to be:

$$
\begin{aligned}
\text { PI }= & \text { Discharge Rate } /(\text { Stable Pressure - } \\
& \text { Flowing Pressure }) \\
= & 30.0 /(127.7-37.76) \\
= & 0.334 \mathrm{~kg} / \mathrm{s}-\mathrm{bar} .
\end{aligned}
$$


The model parameters (feedzone enthalpy, roughness factor, thermal conductivity, productivity index) obtained from a fit to the downhole pressure profile in well N-22T were used to compute the discharge capacity of a slim hole with a completion similar to $\mathrm{N}-2 \mathrm{t}$ (102 $\mathrm{mm}$ ID to $1475.4 \mathrm{mTVD}$, and $101 \mathrm{~mm}$ ID in the open hole section below). The maximum discharge capacity of the slim hole is computed to be $13.2 \mathrm{~kg} / \mathrm{s}$ (47.5 tons/hour). The wellhead enthalpy corresponding to the maximum discharge rate for the slim hole is $\sim 2296 \mathrm{~kJ} / \mathrm{kg}$.

\section{Production Well N-26P}

The uppermost fluid entry for Okuaizu well $\mathrm{N}-26 \mathrm{P}$ is located at $\sim 1265 \mathrm{mTVD}$. The stable feedzone pressure is estimated to be 104.0 bars. The well is completed with a $224 \mathrm{~mm}$ ID casing to a depth of 1243 mTVD. A $216 \mathrm{~mm}$ diameter open hole is present below $\sim 1243$ mTVD. The following well geometry was assumed for N-26P:

\begin{tabular}{|c|c|c|c|}
\hline $\begin{array}{c}\text { Measured } \\
\text { Depth } \\
\text { (meters) }\end{array}$ & $\begin{array}{c}\text { Vertical } \\
\text { Depth } \\
\text { (meters) }\end{array}$ & $\begin{array}{c}\text { Angle with } \\
\text { Vertical } \\
\text { (Degrees) }\end{array}$ & $\begin{array}{c}\text { Internal } \\
\text { Diameter } \\
\text { (mm) }\end{array}$ \\
\hline 1300.9 & 1242.6 & 17.218 & 224 \\
\hline 1329.1 & 1265.0 & 37.408 & 216 \\
\hline
\end{tabular}

A pressure and temperature survey was run in the discharging well on July 22, 1993. The reported discharge rate and wellhead enthalpy at the time of the latter survey were 67 tons/hour (18.61 kg/s) and $2560 \mathrm{~kJ} / \mathrm{kg}$, respectively. The measured pressure (Figure 5.35) follows the same trend as the saturation pressure corresponding to the local measured temperature, indicating two-phase conditions in the wellbore. The difference between the measured and saturation pressures is indicative of problems with gauge calibration.

The stable formation temperature was approximated by the following temperature distribution using linear interpolations between tabulated data.

\begin{tabular}{|c|c|}
\hline $\begin{array}{c}\text { Vertical Depth } \\
\text { (meters) }\end{array}$ & $\begin{array}{c}\text { Temperature } \\
\text { (Celsius) }\end{array}$ \\
\hline 0 & 30 \\
\hline 260 & 100 \\
\hline 660 & 200 \\
\hline 870 & 250 \\
\hline 1890 & 285 \\
\hline
\end{tabular}

The downhole pressure profile was matched using the following values for model parameters:

$\begin{array}{ll}\text { Discharge Rate } & =18.61 \mathrm{~kg} / \mathrm{s} \\ \text { Flowing Feedzone Pressure } & =17.03 \mathrm{bars} \\ \text { Feedzone Enthalpy } & =2570 \mathrm{~kJ} / \mathrm{kg} \\ \text { Thermal Conductivity, K } & =4 \mathrm{~W} / \mathrm{m}^{-}{ }^{\circ} \mathrm{C} \\ \text { Holdup Parameter, } \eta & =0.15 \\ \text { Roughness Factor, } \varepsilon & =0, \text { for all depths }\end{array}$

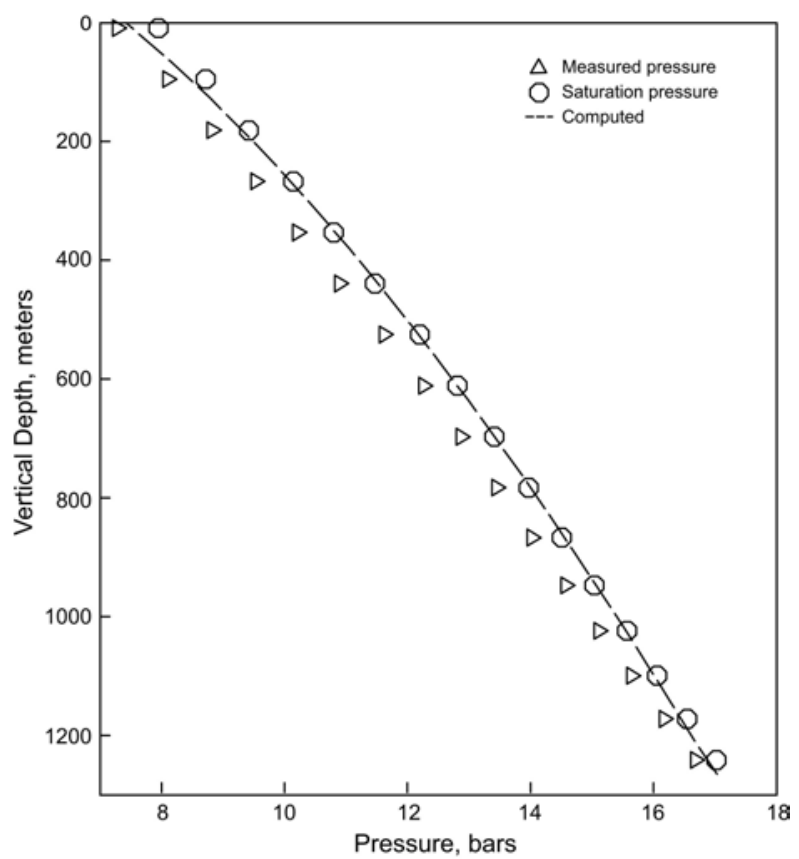

Figure 5.35. Pressure profile $(\Delta)$ recorded in discharging well N-26P on July 22, 1993. The octagon indicates saturation pressure corresponding to local measured temperature. The dashed line is the computed pressure profile.

The flowing feedzone pressure was obtained by averaging the measured and saturation pressures at $1550 \mathrm{mTVD}$, and is not a model 
parameter. Also, the effective thermal conductivity was assumed to be a constant. The roughness factor, feedzone enthalpy and holdup parameter were taken to be free parameters and were varied in an iterative process to match the downhole pressure profile and wellhead enthalpy. The computed pressure profile is compared with the measurements in Figure 5.35. The agreement is quite good.

With a discharge rate of $18.61 \mathrm{~kg} / \mathrm{s}$ and a flowing feedzone pressure of 17.03 bars, the productivity index for $\mathrm{N}-26 \mathrm{P}$ is computed to be:

$$
\begin{aligned}
\text { PI }= & \text { Discharge Rate / (Stable Pressure - } \\
& \text { Flowing Pressure }) \\
= & 18.61 /(104.0-17.03) \\
= & 0.214 \mathrm{~kg} / \mathrm{s}-\text { bar. }
\end{aligned}
$$

The model parameters (feedzone enthalpy, roughness factor, thermal conductivity, productivity index) obtained from a fit to the downhole pressure profile in well N-26P were used to compute the discharge capacity of a slim hole with a completion similar to $\mathrm{N}-2 \mathrm{t}$ (102 mm ID to $1475.4 \mathrm{mTVD}$, and $101 \mathrm{~mm}$ ID in the open hole section below). The maximum discharge capacity of the slim hole is computed to be $9.9 \mathrm{~kg} / \mathrm{s}$ (35.6 tons/hour). The wellhead enthalpy corresponding to the maximum discharge rate for the slim hole is $\sim 2537 \mathrm{~kJ} / \mathrm{kg}$.

\section{Production Well N-28P}

The uppermost fluid entry for Okuaizu well N28P, as deduced from a break in temperature/pressure gradient in the discharging well, is located at $\sim 1300$ mTVD. The stable feedzone temperature and pressure are estimated to be $\sim 300{ }^{\circ} \mathrm{C}$ and 111.4 bars, respectively. The well is completed with a $224 \mathrm{~mm}$ ID casing to a depth of 1253.0 mTVD. A $178 \mathrm{~mm}$ OD uncemented liner in a $216 \mathrm{~mm}$ diameter hole is present below $\sim 1208$ mTVD. The following well geometry was assumed for N-28P:

\begin{tabular}{|c|c|c|c|}
\hline $\begin{array}{c}\text { Measured } \\
\text { Depth } \\
\text { (meters) }\end{array}$ & $\begin{array}{c}\text { Vertical } \\
\text { Depth } \\
\text { (meters) }\end{array}$ & $\begin{array}{c}\text { Angle with } \\
\text { Vertical } \\
\text { (Degrees) }\end{array}$ & $\begin{array}{c}\text { Internal } \\
\text { Diameter } \\
\text { (mm) }\end{array}$ \\
\hline 1300.0 & 1253.0 & 15.454 & 224 \\
\hline 1352.0 & 1300.0 & 25.332 & 216 \\
\hline
\end{tabular}

A pressure and temperature survey was run in the discharging well on November 25, 1993. The reported discharge rate and wellhead enthalpy at the time of the latter survey were 90 tons/hour $(25.0 \mathrm{~kg} / \mathrm{s})$ and $2560 \mathrm{~kJ} / \mathrm{kg}$, respectively. The measured pressure (Figure 5.36) is in agreement with the saturation pressure corresponding to the local measured temperature, indicating two-phase conditions in the wellbore.

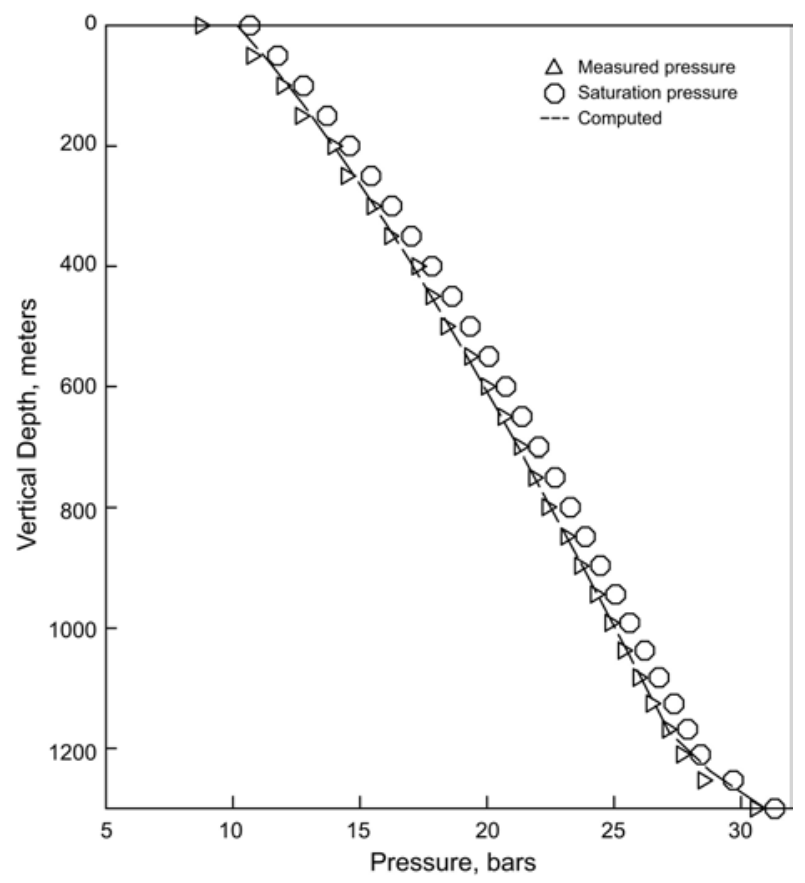

Figure 5.36. Pressure profile $(\Delta)$ recorded in discharging well N-28P on November 25, 1993. The octagon indicates saturation pressure corresponding to local measured temperature. The dashed line is the computed pressure profile.

The stable formation temperature was approximated by the following temperature distribution using linear interpolations between tabulated data. 


\begin{tabular}{|c|c|}
\hline $\begin{array}{l}\text { Vertical Depth } \\
\text { (meters) }\end{array}$ & $\begin{array}{l}\text { Temperature } \\
\text { (Celsius) }\end{array}$ \\
\hline 0 & 25 \\
\hline 425 & 200 \\
\hline 600 & 280 \\
\hline 1300 & 300 \\
\hline
\end{tabular}

The downhole pressure profile was matched using the following values for model parameters:

$\begin{aligned} \text { Discharge Rate }= & 25.0 \mathrm{~kg} / \mathrm{s} \\ \text { Flowing Feedzone Pressure = } & 30.95 \mathrm{bars} \\ = & 2570 \mathrm{~kJ} / \mathrm{kg} \\ \text { Feedzone Enthalpy }= & 4 \mathrm{~W} / \mathrm{m}^{-}{ }^{\circ} \mathrm{C} \\ \text { Thermal Conductivity, K }= & 0.70 \\ \text { Holdup Parameter, } \eta & 0.035 \mathrm{~mm} \text { for } \\ \text { Roughness Factor, } \varepsilon & \text { depths }<1253 \\ & \text { meters } \\ = & 4.2 \mathrm{~mm}, \text { for } \\ & \text { depths }>1253 \\ & \text { meters }\end{aligned}$

The flowing feedzone pressure was obtained by averaging the measured and saturation pressures at $1300 \mathrm{mTVD}$, and is not a model parameter. Also, the effective thermal conductivity was assumed to be a constant. The roughness factor, feedzone enthalpy and holdup parameter were taken to be free parameters and were varied in an iterative process to match the downhole pressure profile and wellhead enthalpy. The computed pressure profile is compared with the measurements in Figure 5.36. The agreement is quite good.

With a discharge rate of $25.0 \mathrm{~kg} / \mathrm{s}$ and a flowing feedzone pressure of 30.95 bars, the productivity index for $\mathrm{N}-28 \mathrm{P}$ is computed to be:

$$
\begin{aligned}
\text { PI }= & \text { Discharge Rate / (Stable Pressure - } \\
& \text { Flowing Pressure }) \\
= & 25.0 /(111.4-30.95) \\
= & 0.311 \mathrm{~kg} / \mathrm{s}-\text { bar. }
\end{aligned}
$$

The model parameters (feedzone enthalpy, roughness factor, thermal conductivity, productivity index) obtained from a fit to the downhole pressure profile in well N-28P were used to compute the discharge capacity of a slim hole with a completion similar to $\mathrm{N}-2 \mathrm{t}$ (102 $\mathrm{mm}$ ID to $1300.0 \mathrm{mTVD}$, and $101 \mathrm{~mm}$ ID in the open hole section below). The maximum discharge capacity of the slim hole is computed to be $9.3 \mathrm{~kg} / \mathrm{s}$ (33.5 tons/hour). The wellhead enthalpy corresponding to the maximum discharge rate for the slim hole is $\sim 2504 \mathrm{~kJ} / \mathrm{kg}$.

\subsection{Borehole Diameter and Discharge Capacity of Two-Phase Wells}

The detailed modeling of downhole pressure/temperature profiles in Okuaizu production wells provides additional support for the conclusions previously derived by Garg, et al. (1998) from analyses of discharge data from two-phase geothermal boreholes in three other Japanese geothermal fields (Kirishima, Oguni and Sumikawa). The important conclusions derived from the present work are summarized in the following paragraphs.

The pressure profile in a discharging twophase borehole can be divided into two parts, i.e., (1) cased hole, and (2) open hole or hole with slotted/perforated liner. In the open hole section, the pressure profile may exhibit one or more discontinuities in pressure gradient; these discontinuities often correspond to fluid entries. The pressure gradient in the slotted liner/open hole section above the uppermost fluid entry is generally significantly greater than that in the cased section of the borehole. The pressure drop in the open hole/slotted liner section of Okuaizu production wells was modeled using a non-zero roughness factor. Most of the Okuaizu production wells discharge high enthalpy fluids. For some of the Okuaizu wells, like the high enthalpy 
Sumikawa borehole SA-1 (Garg, et al., 1998), it was found necessary to assume a reduced diameter for the slotted liner/ open hole section.

In general, the Hughmark slip correlation gives too large a pressure drop in the wellbore. Best fits to the downhole pressure data were obtained by adjusting the value of the holdup parameter so as to reproduce the observed pressure drop in the cased section of the well.

Model parameters derived by matching downhole pressure profiles recorded in Okuaizu production wells were used to compute the productive capacity of a slim hole with a completion similar to N-2t (102 mm ID cased section, and $101 \mathrm{~mm}$ ID open hole section). The predicted discharge rate for the slim hole ranges from a low of 25.9 tons/ hour (based on N-14T) to a high of 68.0 tons/hour (based on N-15T). Borehole N-15T is by far the most productive well at Okuaizu, and its productivity index is about an order of magnitude larger than that for other Okuaizu wells. Excluding the results corresponding to well N-15T, the maximum computed discharge rate for the slim hole is 47.5 tons/hour (based on well N-22T). The computed discharge rates for the slim hole may be compared to the measured discharge rates (58 tons/hour in November 1985 and 13 tons/hour in March 1988) for N-2t. The unusually low discharge rate (13 tons/hour) for $\mathrm{N}-2 \mathrm{t}$ recorded in March 1988 was most likely due to pressure interference between N$2 t$ and nearby wells N-15T, N-6T and N-10T which were also being discharged at the time. In any case, the measured discharge rates for $\mathrm{N}-2 \mathrm{t}$ are consistent with the computed rates for a slim hole based on discharge data from large-diameter wells.

Discharge data from Okuaizu boreholes, like the data from Kirishima two-phase boreholes KE1-6 and KE1-21 (Garg, et al., 1998), suggest that it should be possible to infer the discharge characteristics of large-diameter wells using test data on slim holes. Because of the paucity of good quality data from twophase boreholes, the latter conclusion must be viewed with some caution. Data from a statistically significant number of slim holes and large-diameter wells with two-phase feedzones are required to establish a definite relationship between the borehole diameter and discharge capacity of geothermal boreholes producing from two-phase feedzones. 
Combs, J. and Dunn, J. C. (1992), "Geothermal Exploration and Reservoir Assessment: The Need for a U.S. Department of Energy Slim-Hole Drilling R\&D Program in the 1990s," Geothermal Resources Council Bulletin, Vol. 21, No. 10, pp. 329-337.

Dukler, A. E., Wicks III, M., and Cleveland, R.G. (1964). Frictional pressure drop in two-phase flow - B. An Approach through similarity analysis. A.I.Ch.E. Journal, Vol. 10, pp. 44-51.

Garg, S.K., and Combs, J. (1997), Use of Slim Holes with Liquid Feedzones for Geothermal Reservoir Assessment, Geothermics, vol. 26, no. 2, pp. 153-178.

Garg, S. K., Combs, J., Kodama, M., and Gokou, K. (1998). Analysis of Production/Injection Data from Slim Holes and Large-Diameter Wells at the Kirishima Geothermal Field, Japan. Proceedings Twenty-Third Workshop on Geothermal Reservoir Engineering, 26-28 January. Stanford University, Stanford, California, pp. 64-76.

GeothermEx, Inc. (1987), "Assessment of the Okuaizu Geothermal Field, Fukushima Prefecture, Japan", unpublished report for Mitsui Mining \& Smelting Company and Okuaizu Geothermal Company, Tokyo, Japan.

Hughmark, G.A. (1962). Holdup in gas-liquid flow. Chemical Engineering Progress, Vol. 53, pp. 62-65.

Ishido, T. (1985), "Pressure Transient Tests at the Okuaizu Geothermal Field in Japan," Geothermal Resources Council Transactions, vol. 9, Part II, pp. 521-526.

Kanazawa, Y. and Yoshitome, H. (1996), "Development of the Yanaizu Nishiyama Geothermal Area - From Research to Start of Operation", English translation of an article in Geothermal Energy, vol. 21, pp. 28-35 (in Japanese).

Mizugaki, K. (2000), "Geologic Structure and Volcanic History of the Yanaizu-Nishiyama (Okuaizu) Geothermal Field, Northeast Japan, Geothermics, vol. 29, pp. 233-256.

Nitta, T., Suga, S. and Seo, K. (1988), "Okuaizu Geothermal Field, Tohoku District," in Geothermal Fields and Geothermal Power Plants in Japan,
International Symposium on Geothermal Energy, Kumamoto and Beppu, Japan, pp. 71-76.

Nonokuchi, M. (1988), "Geothermal Development Promotion Survey of Okuaizu Area," Geothermal Resources Council Transactions, vol. 12, p. 263.

Pritchett, J.W. (1985). WELBOR: a computer program for calculating flow in a producing geothermal well. Report No. SSS-R-85-7283, Maxwell Technologies (formerly S-Cubed), San Diego, California.

Pritchett, J. W. (1993). Preliminary Study of Discharge Characteristics of Slim Holes Compared to Production Wells in Liquid-Dominated Geothermal Reservoirs. Proceedings Eighteenth Workshop on Geothermal Reservoir Engineering, 26-28 January. Stanford University, Stanford, California, pp. 181-187.

Sato, M., Sato, T., Okabe, T., Osato, K, and Yokomoto, S. (2000), "Development of Geothermal Database System - The Geochemistry Option," Proceedings, World Geothermal Congress 2000, Kyushu - Tohoku, Japan, pp. 4081-4086.

Seki, Y. (1991), "The Physical and Chemical Structure of the Oku-aizu Geothermal System, Japan," Geochemical Journal, vol. 25, pp. 245-265.

Seki, Y. (2000), "Hydrothermal Alteration in the Sunagohara Formation, Okuaizu Geothermal System, Japan," Proceedings, World Geothermal Congress 2000, Kyushu - Tohoku, Japan, pp. 1719-1724.

Takenouchi, S. (1988), "Fluid Inclusion Study at Okuaizu Geothermal Area," in Exploration and Development of Geothermal Resources, Proceedings International Symposium on Geothermal Energy, Kumamoto and Beppu, Japan, pp. 35-38.

Tosha, T., Ishido, T., Matsushima, N., and Nishi, Y. (2000), "Self-Potential Variation at the YanaizuNishiyama Geothermal Field and Its Interpretation by the Numerical Simulation," Proceedings, World Geothermal Congress 2000, Kyushu - Tohoku, Japan, pp. 1871-1876. 


\section{APPENDIX A \\ DRILLING AND COMPLETION DATA FOR OKUAIZU BOREHOLES}

Well

\section{Contents}

Slim Hole T-1 ….................................................................. A-2

Slim Hole T-2 ….................................................................. A-3

Slim Hole T-3 ......................................................................A-4

Slim Hole T-4 …...................................................................... A-5

Slim Hole T-5 ........................................................................... A-6

Slim Hole T-6 ........................................................................... A-7

Slim Hole OA-1 ....................................................................A-8

Slim Hole OA-2 …....................................................................A-9

Slim Hole OA-3 ........................................................................A-10

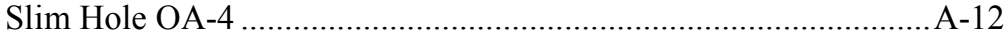

Slim Hole OA-5 ....................................................................A-13

Slim Hole OA-6 .....................................................................

Slim Hole OA-7 ....................................................................A-15

Slim Hole N-1t .............................................................A-17

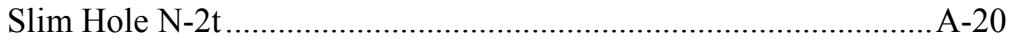

Slim Hole N-3t ............................................................ 22

Slim Hole N-4r.............................................................A-24

Slim Hole N-5t ................................................................A-26

Production Well N-6T ...........................................................

Exploration Well N-7T ...........................................................A-31

Exploration Well N-8T ........................................................A-32

Exploration Well N-9T ........................................................

Production Well N-10T ...........................................................A-35

Production Well N-11T .......................................................A-38

Slim Hole N-12t ....................................................................

Slim Hole N-13t ................................................................A-44

Production Well N-14T .............................................................A-46

Production Well N-15T ..........................................................A-49

Production Well N-16T .......................................................

Production Well N-17T ..........................................................A-55

Slim Hole N-18t .................................................................. A-58

Injection Well N-19R ............................................................

Injection Well N-20R .........................................................A-65

Production Well N-21T ....................................................A-68

Production Well N-22T .......................................................... A-71

Production Well N-23P ..........................................................A-75

Production Well N-24P ...........................................................A-78

Production Well N-25P .........................................................A-82

Production Well N-26P ..........................................................A-85

Production Well N-27P ..........................................................A-89

Production Well N-28P .....................................................A-93

Injection Well N-29R ..................................................... A-96

Production Well N-30P ..............................................................99

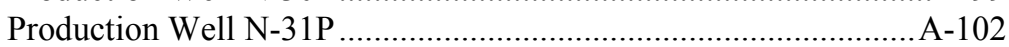




\section{Slim Hole T-1}

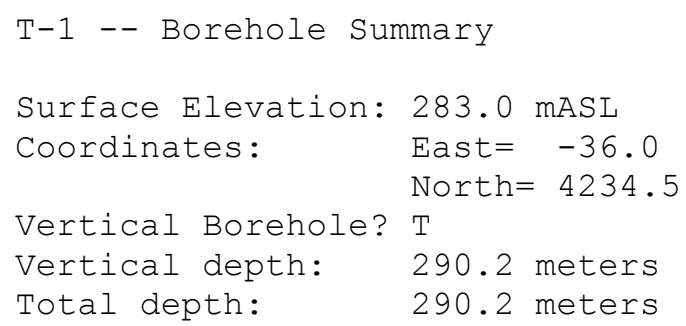




\section{Slim Hole T-2}

T-2 -- Borehole Summary

$\begin{array}{ll}\text { Surface Elevation: } & 483.0 \mathrm{mASL} \\ \text { Coordinates: } & \text { East }=2494.0 \\ & \text { North }=4284.5 \\ \text { Vertical Borehole? } & \text { T } \\ \text { Vertical depth: } & 490.9 \text { meters } \\ \text { Total depth: } & 490.9 \text { meters }\end{array}$

History:

$\begin{array}{lll}\text { Start Time } & \text { End Time } & \text { Status } \\ -1982 / 09 / 05 \text { 00:00:00 } & \text { 1982/10/04 00:00:00 } & \text { Drilling } \\ \text { 1982/10/06 10:00:00 } & & \text { ShutIn } \\ 1982 / 10 / 17 \quad 09: 00: 00 & & \text { ShutIn }\end{array}$

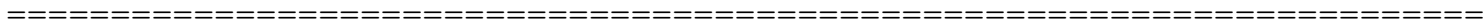
T-2 -- Lost circulation

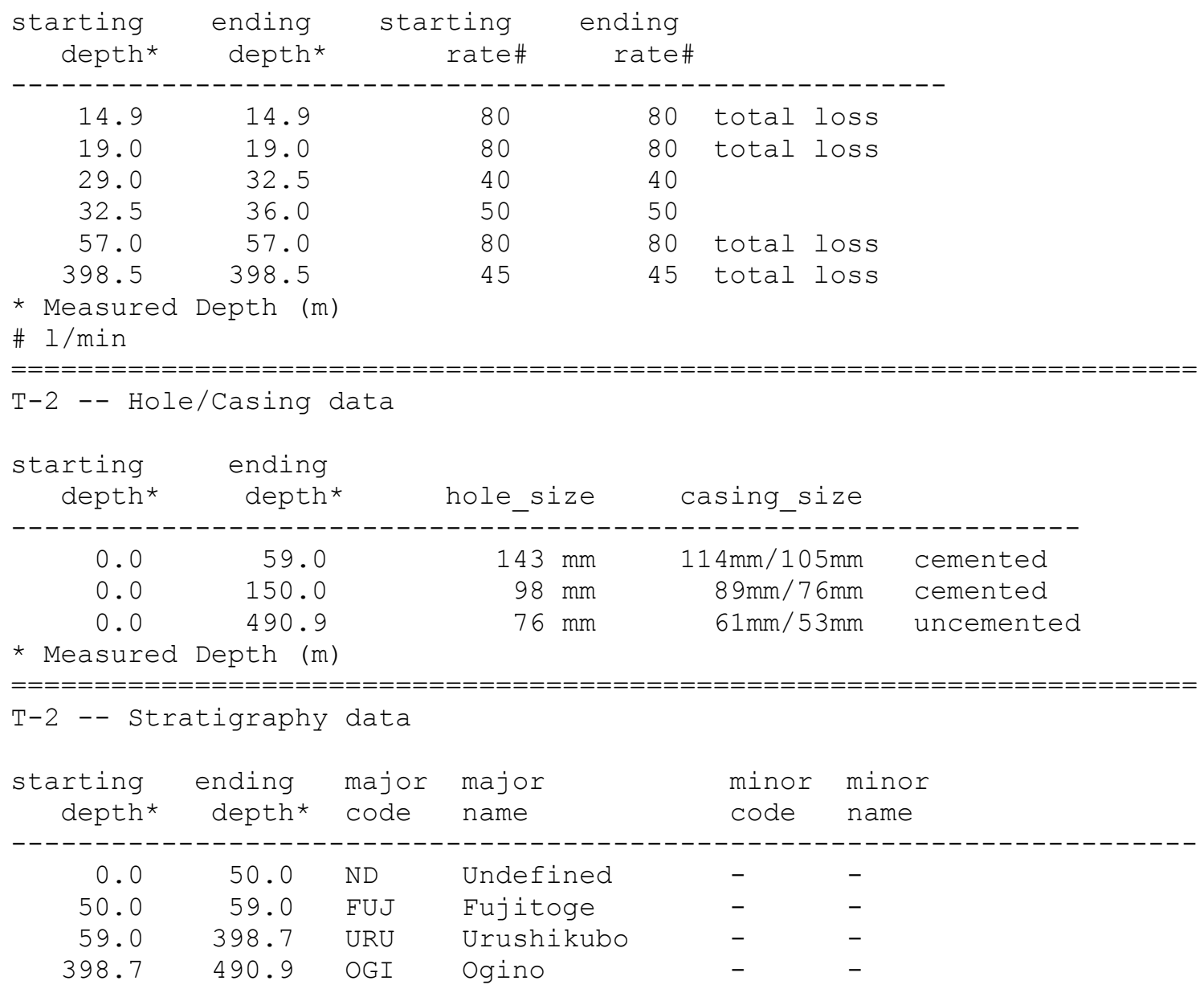

* Measured Depth (m) 


\section{Slim Hole T-3}

T-3 -- Borehole Summary

$\begin{array}{ll}\text { Surface Elevation: } & 380.0 \mathrm{mASL} \\ \text { Coordinates: } & \text { East }=-1861.5 \\ & \text { North }=2885.5 \\ \text { Vertical Borehole? } & \text { T } \\ \text { Vertical depth: } & 380.6 \text { meters } \\ \text { Total depth: } & 380.6 \text { meters }\end{array}$

History:

Start Time End Time Status

1982/08/29 00:00:00 1982/09/13 00:00:00 Drilling

$1982 / 09 / 14$ 10:00:00

ShutIn

$1982 / 09 / 1614: 00: 00$

ShutIn

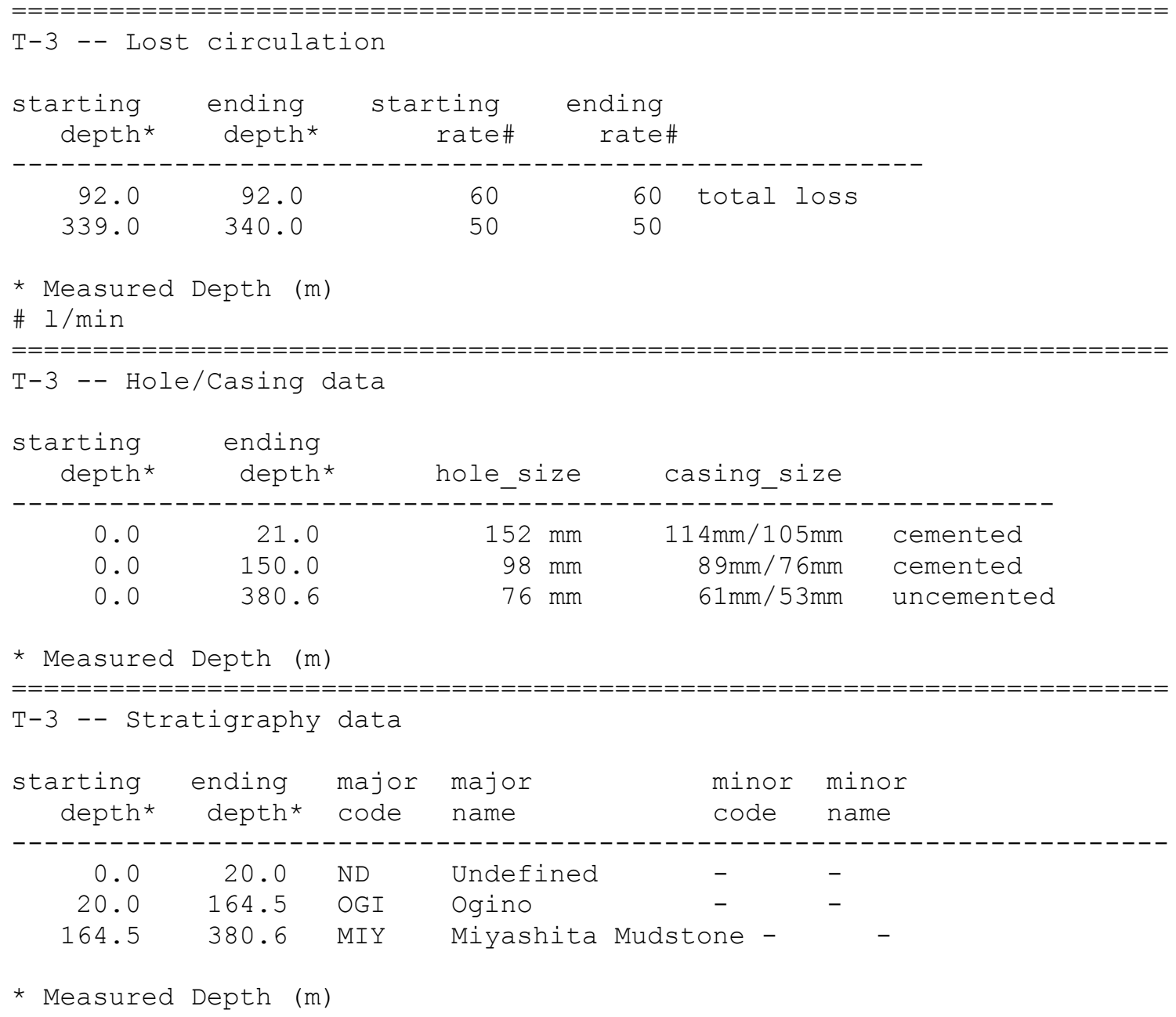




\section{Slim Hole T-4}

T-4 -- Borehole Summary

$\begin{array}{ll}\text { Surface Elevation: } & 457.0 \text { mASL } \\ \text { Coordinates: } & \text { East }=2904.0 \\ & \text { North }=2504.5 \\ \text { Vertical Borehole? } & \text { T } \\ \text { Vertical depth: } & 450.5 \text { meters } \\ \text { Total depth: } & 450.5 \text { meters }\end{array}$

History:

Start Time End Time Status

1982/09/13 00:00:00 1982/10/03 00:00:00 Drilling

$1982 / 10 / 0511: 00: 00$

ShutIn

$1982 / 11 / 0310: 00: 00$

ShutIn

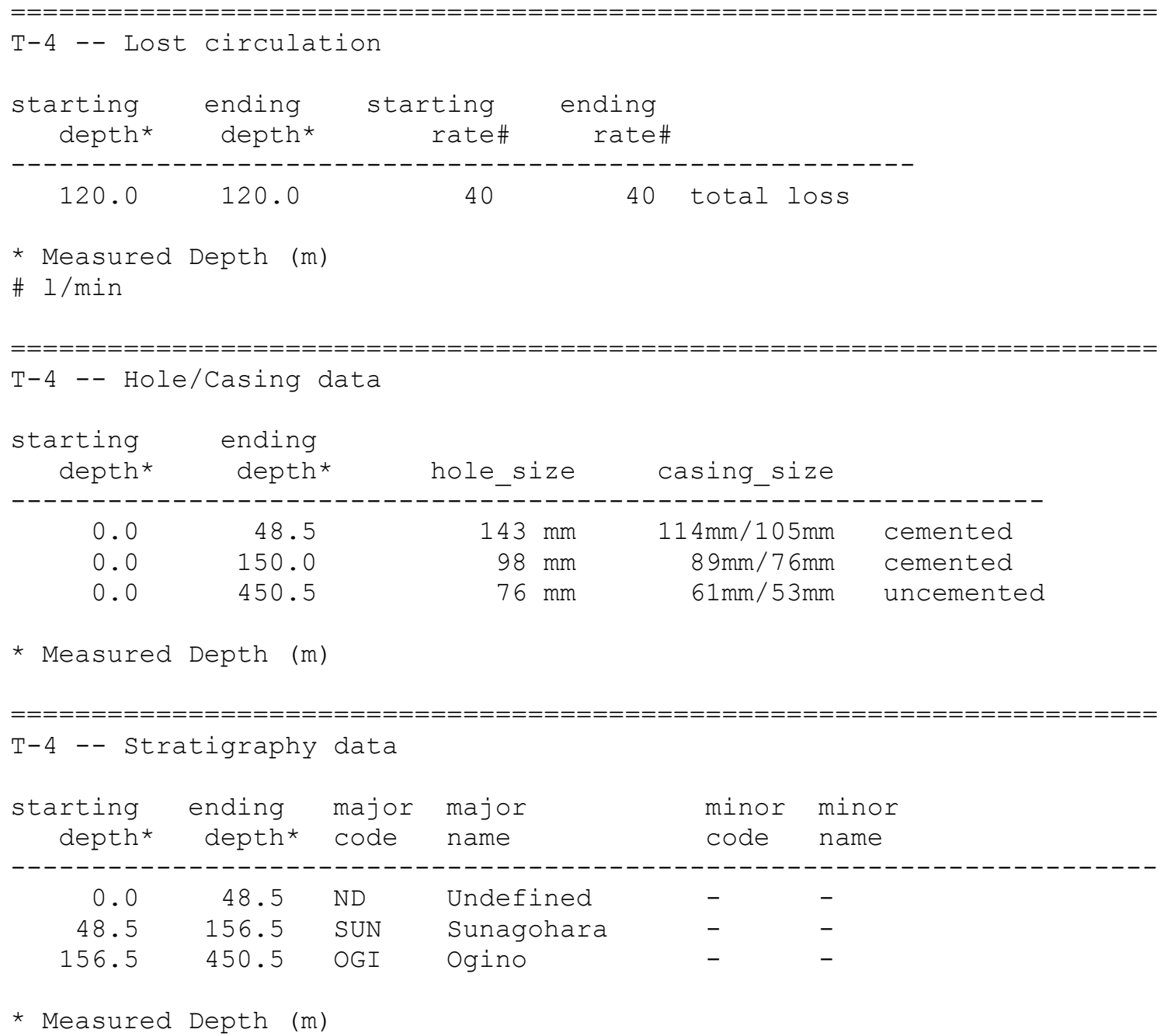




\section{Slim Hole T-5}

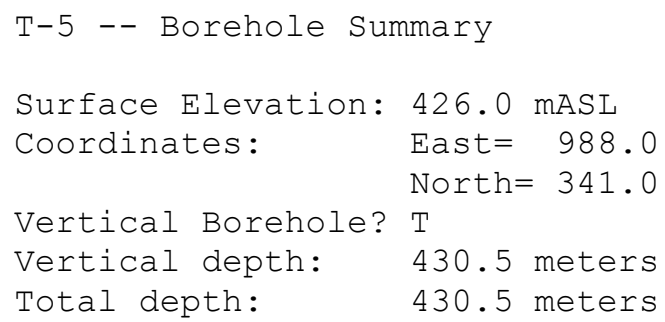




\section{Slim Hole T-6}

T-6 -- Borehole Summary

Surface Elevation: $389.0 \mathrm{mASL}$

Coordinates: $\quad$ East $=-550.0$

Vertical Borehole? T

North $=-1324.5$

Vertical depth: $\quad 361.0$ meters

Total depth: $\quad 361.0$ meters

History:

Start Time End Time Status

1982/10/10 00:00:00 1982/10/28 00:00:00 Drilling

$1982 / 10 / 2914: 00: 00$

ShutIn

$1982 / 11 / 01 \quad 14: 00: 00$

ShutIn

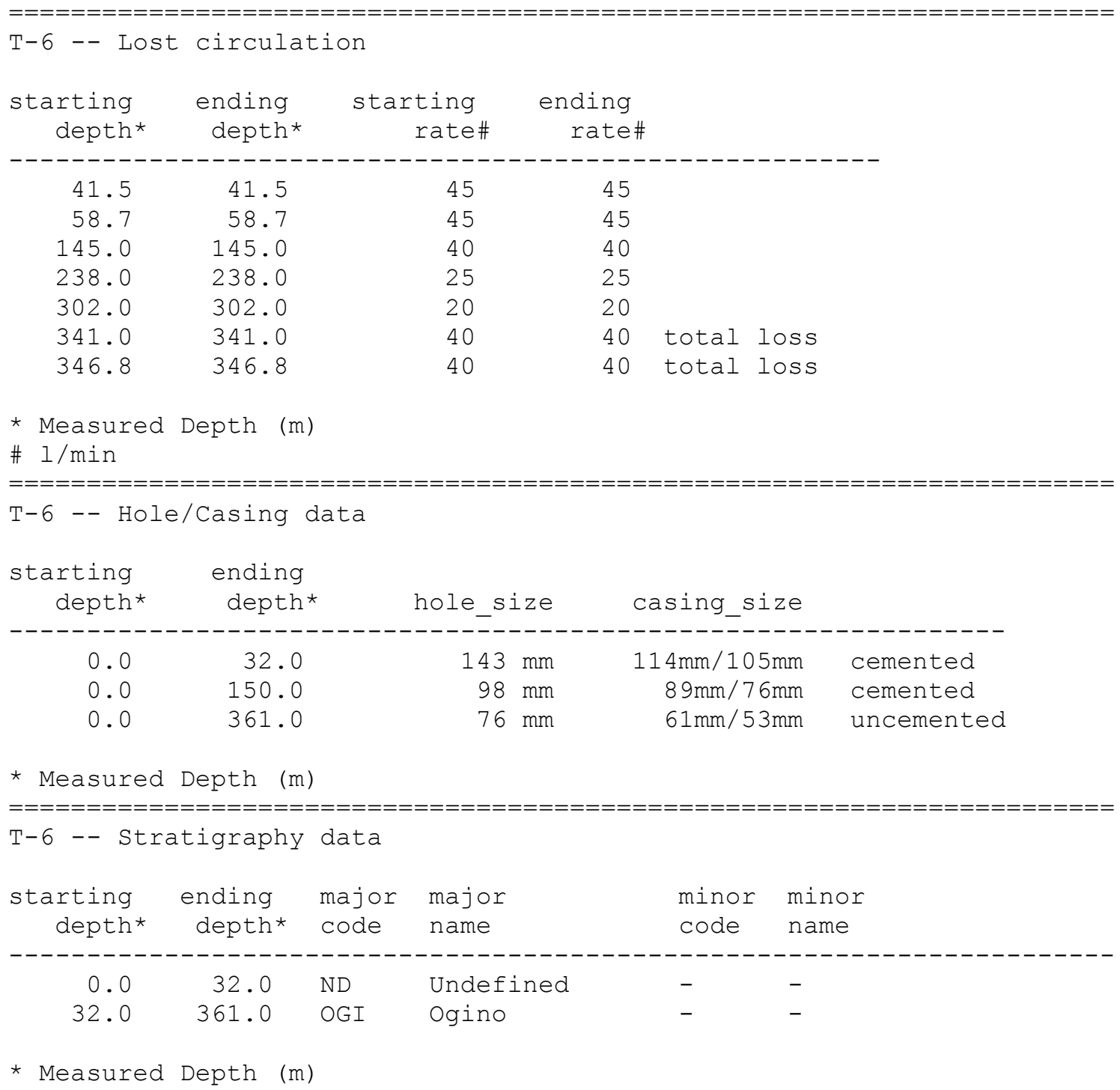




\section{Slim Hole OA-1}

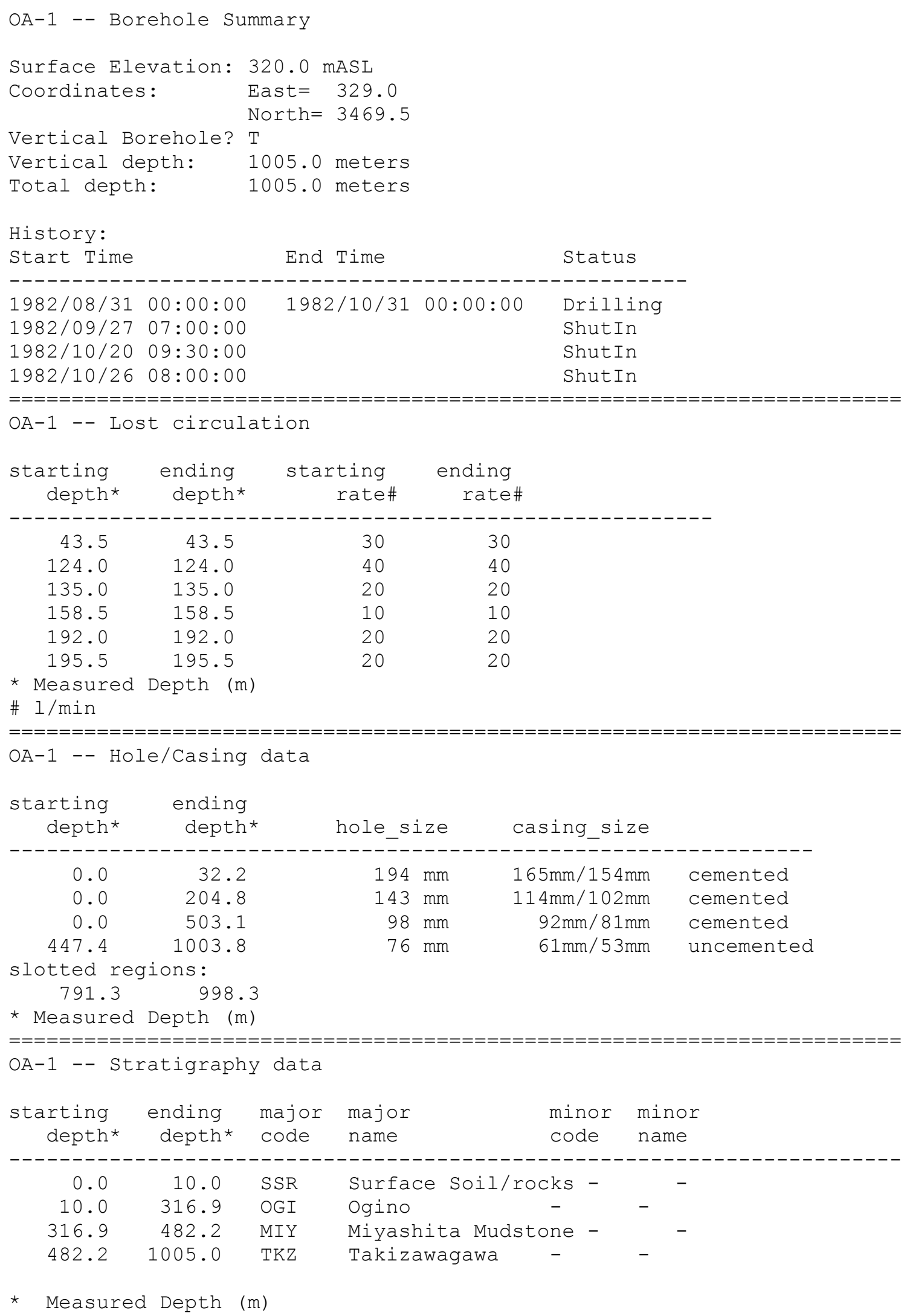


Slim Hole OA-2

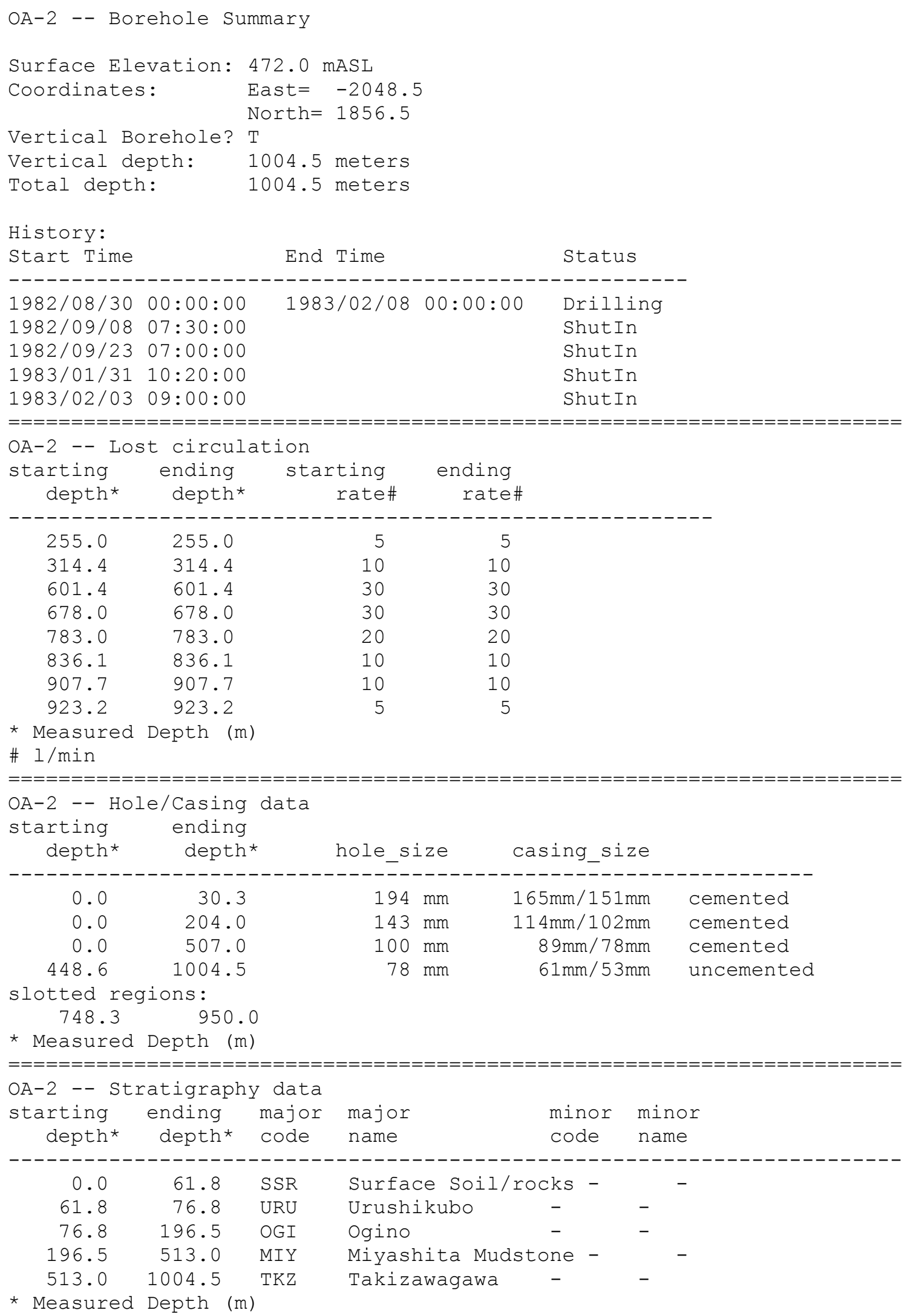




\section{Slim Hole OA-3}

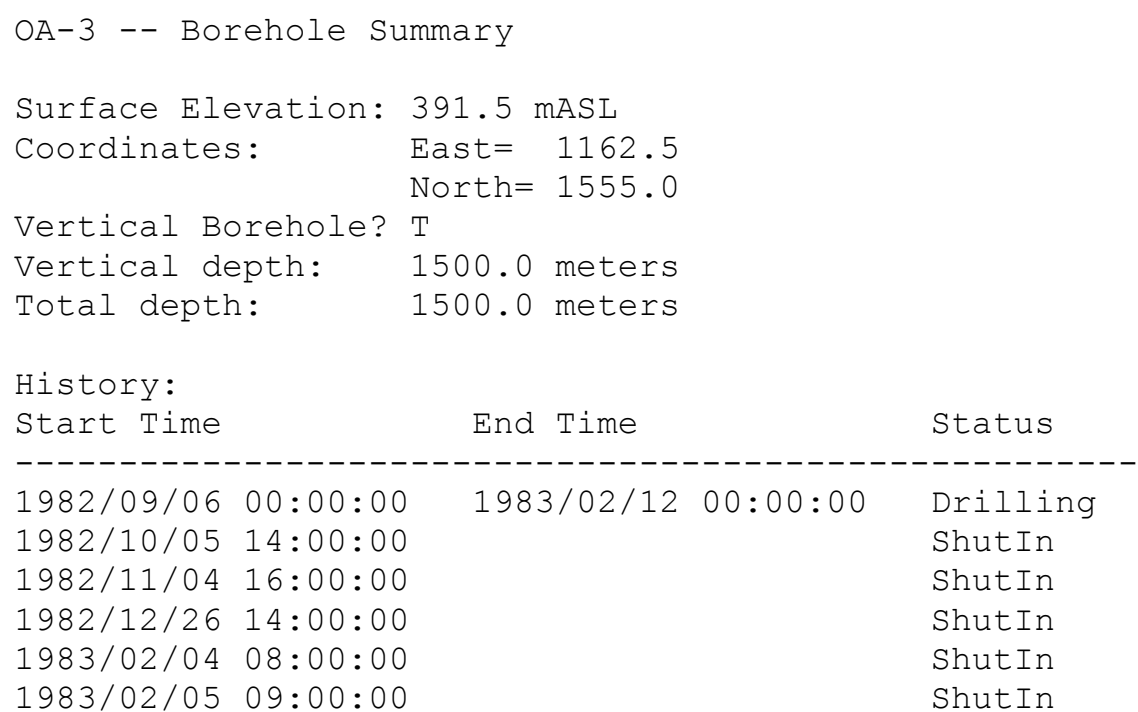

\begin{tabular}{|c|c|c|c|c|}
\hline $\begin{array}{l}\text { starting } \\
\text { depth* }\end{array}$ & $\begin{array}{l}\text { ending } \\
\text { depth* }\end{array}$ & $\begin{array}{l}\text { starting } \\
\text { rate\# }\end{array}$ & $\begin{array}{l}\text { ending } \\
\text { rate\# }\end{array}$ & \\
\hline----------- & --------- & ----------1 & --------- & --------------- \\
\hline 45.0 & 45.0 & 120 & 120 & total loss \\
\hline 62.8 & 62.8 & 60 & 60 & \\
\hline 68.6 & 68.6 & 40 & 40 & \\
\hline 76.8 & 76.8 & 120 & 120 & total loss \\
\hline 83.3 & 83.3 & 90 & 90 & total loss \\
\hline 106.9 & 106.9 & 90 & 90 & total loss \\
\hline 113.0 & 113.0 & 90 & 90 & total loss \\
\hline 131.6 & 131.6 & 90 & 90 & total loss \\
\hline 293.7 & 293.7 & 130 & 130 & total loss \\
\hline 299.5 & 299.5 & 100 & 100 & \\
\hline 529.0 & 529.0 & 120 & 120 & total loss \\
\hline 540.5 & 540.5 & 137 & 137 & total loss \\
\hline 544.5 & 544.5 & 137 & 137 & total loss \\
\hline 553.1 & 553.1 & 274 & 274 & total loss \\
\hline 724.8 & 724.8 & 270 & 270 & total loss \\
\hline 729.3 & 729.3 & 270 & 270 & total loss \\
\hline 734.9 & 734.9 & 270 & 270 & total loss \\
\hline 1232.0 & 1232.0 & 80 & 80 & \\
\hline 1281.8 & 1281.8 & 78 & 78 & \\
\hline 1398.8 & 1398.8 & 130 & 130 & total loss \\
\hline 1401.3 & 1401.3 & 130 & 130 & total loss \\
\hline
\end{tabular}




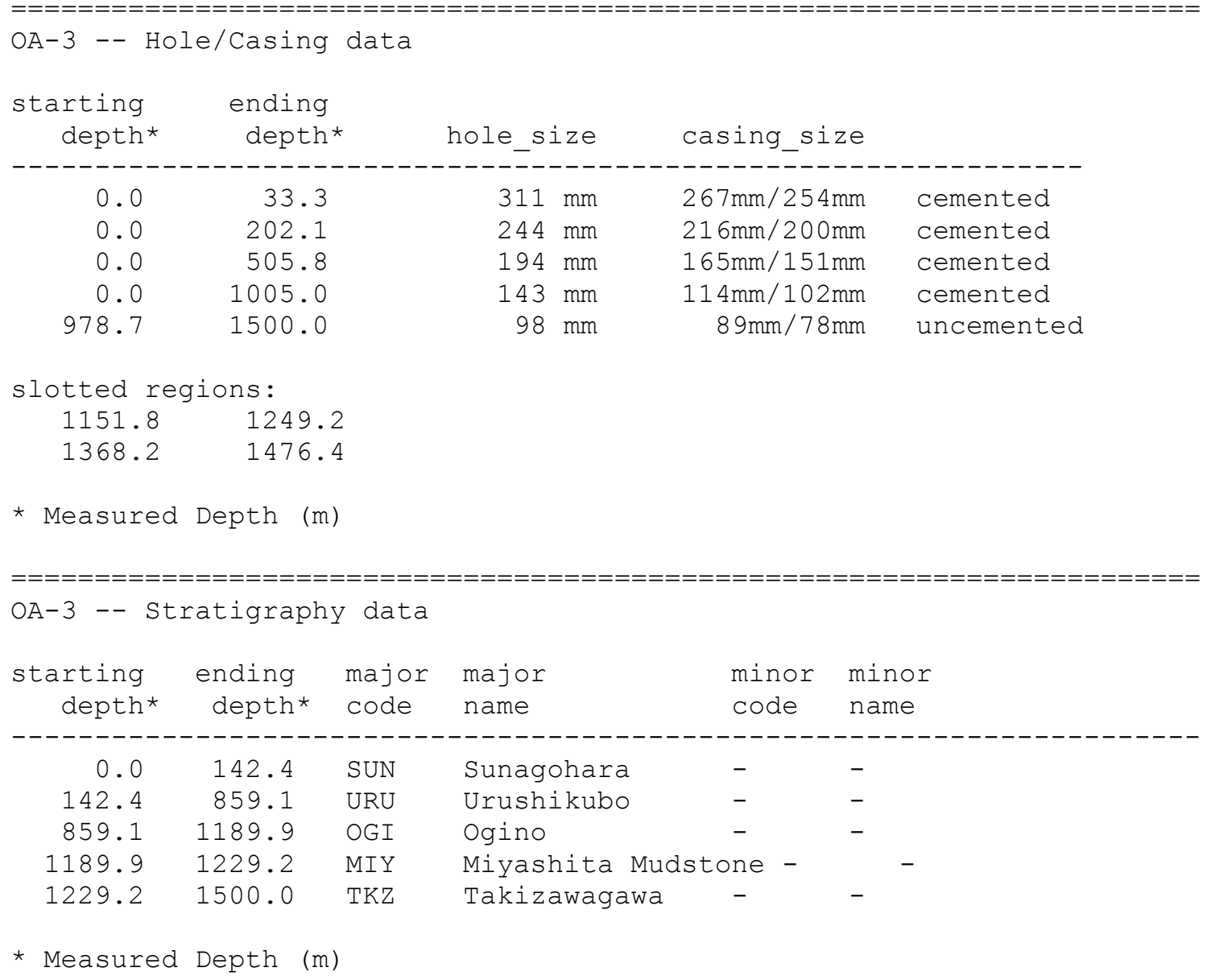




\section{Slim Hole OA-4}

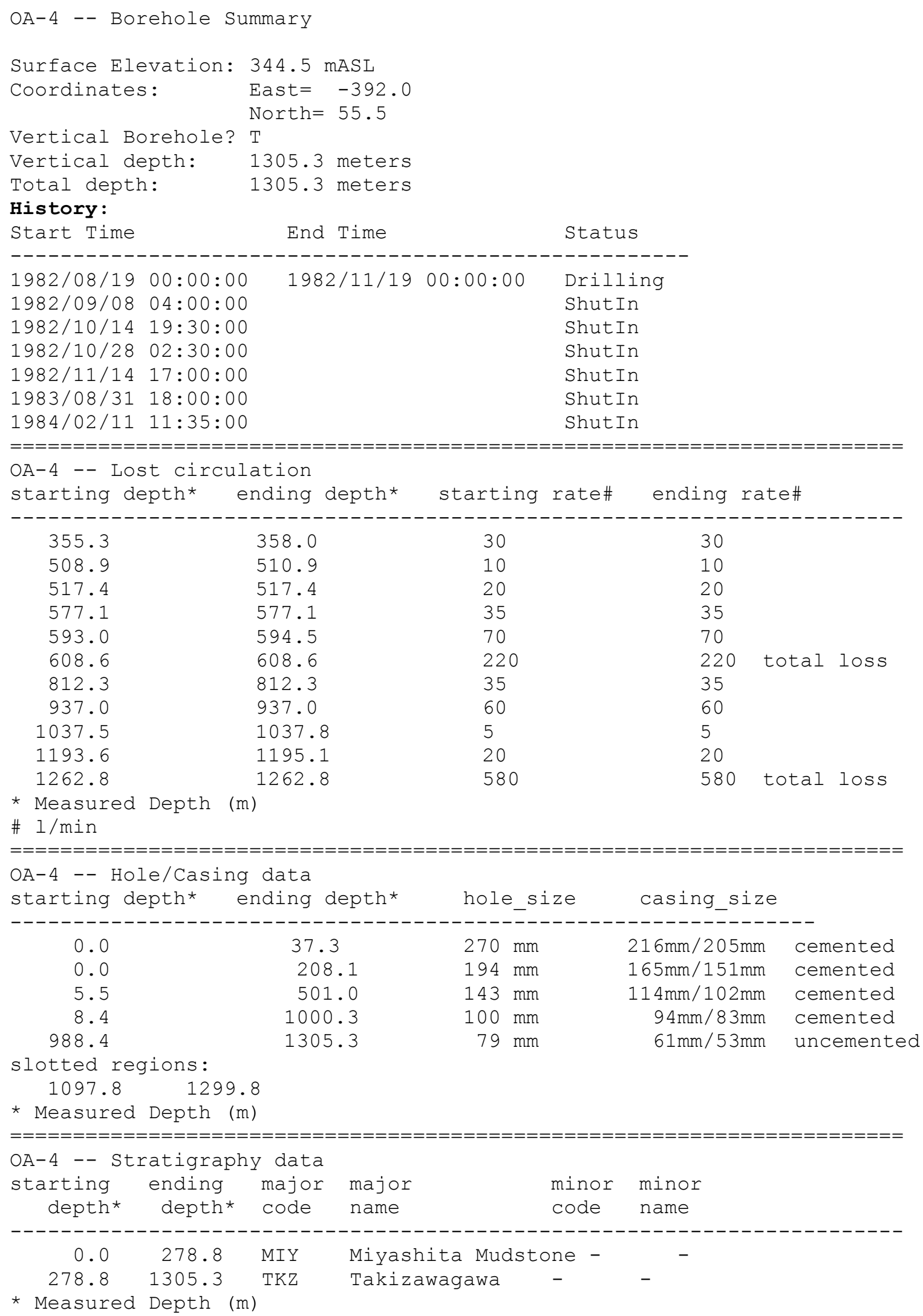




\section{Slim Hole OA-5}

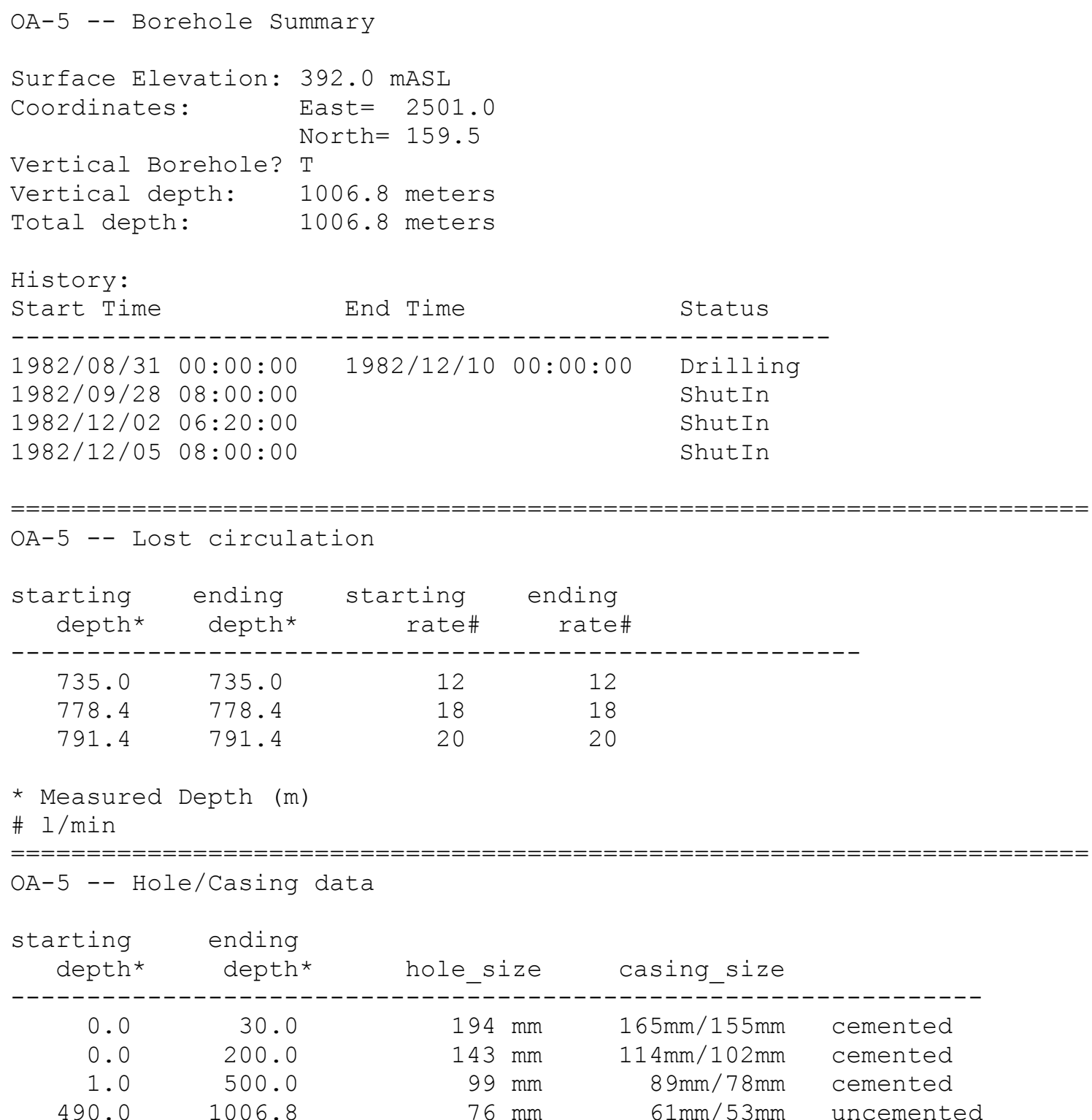

slotted regions:

$$
794.6 \quad 1001.3
$$

* Measured Depth (m)

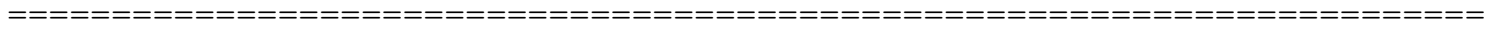
OA-5 -- Stratigraphy data

\begin{tabular}{|c|c|c|c|c|c|}
\hline $\begin{array}{l}\text { starting } \\
\text { depth* }\end{array}$ & $\begin{array}{l}\text { ending } \\
\text { depth* }\end{array}$ & $\begin{array}{l}\text { major } \\
\text { code }\end{array}$ & $\begin{array}{l}\text { major } \\
\text { name }\end{array}$ & $\begin{array}{l}\text { minor } \\
\text { code }\end{array}$ & $\begin{array}{l}\text { minor } \\
\text { name }\end{array}$ \\
\hline - & --- & & -------- & -------- & ------- \\
\hline 0.0 & 200.7 & OGI & Ogino & - & - \\
\hline 200.7 & 204.0 & MIY & Miyashita & Mudstone - & - \\
\hline 204.0 & 1006.8 & TKZ & Takizawaga & al $\quad-$ & - \\
\hline
\end{tabular}

* Measured Depth (m) 


\section{Slim Hole OA-6}

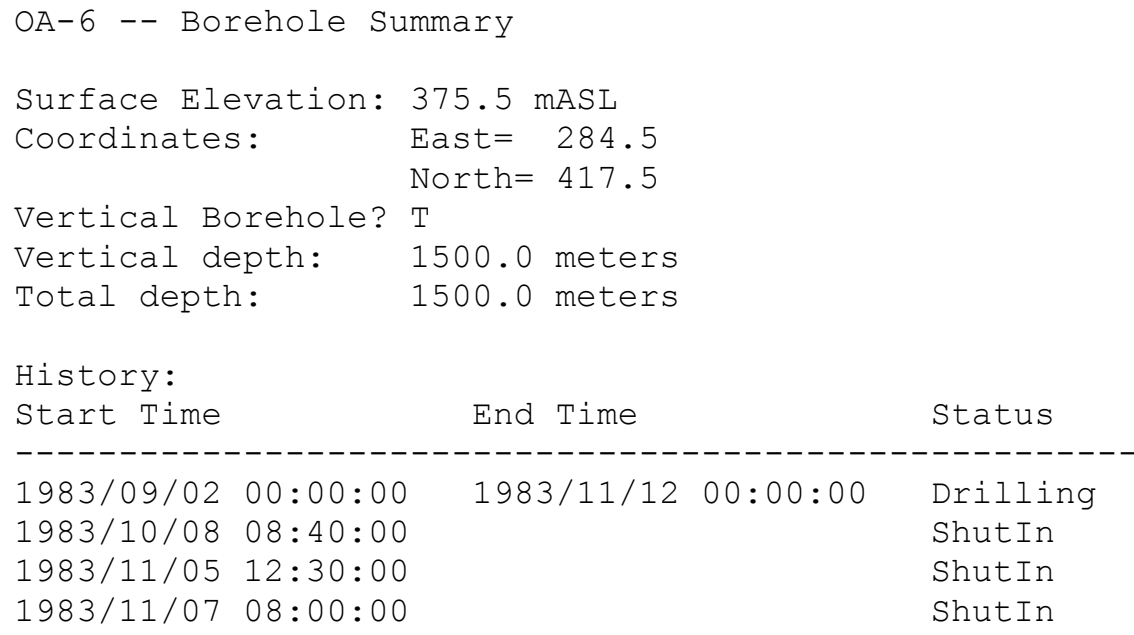

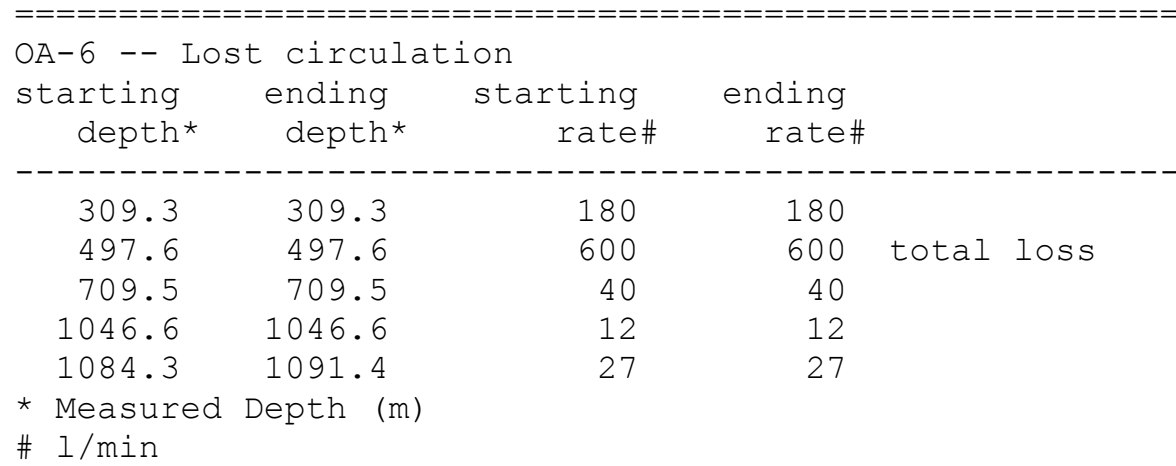

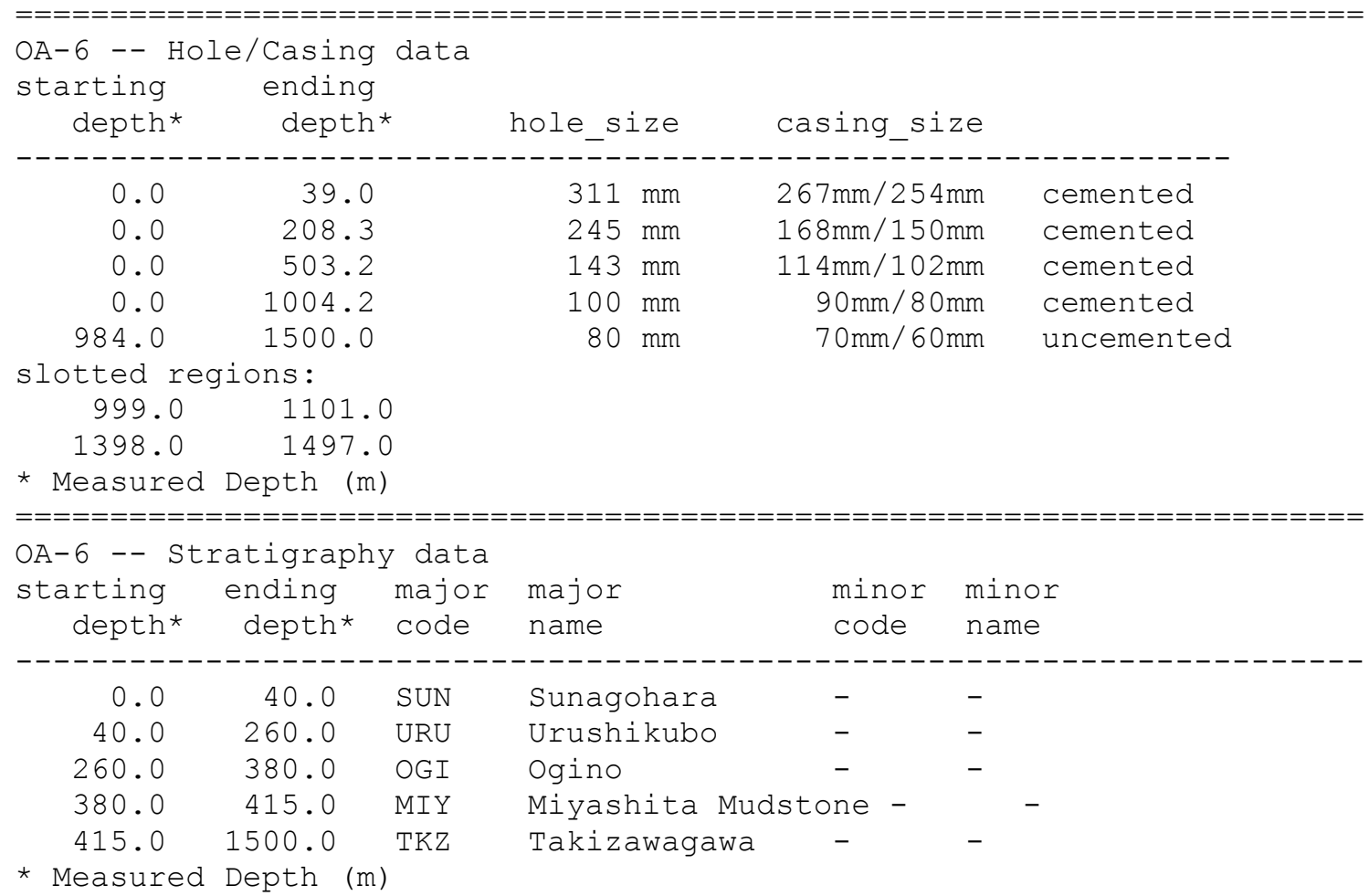


Slim Hole OA-7

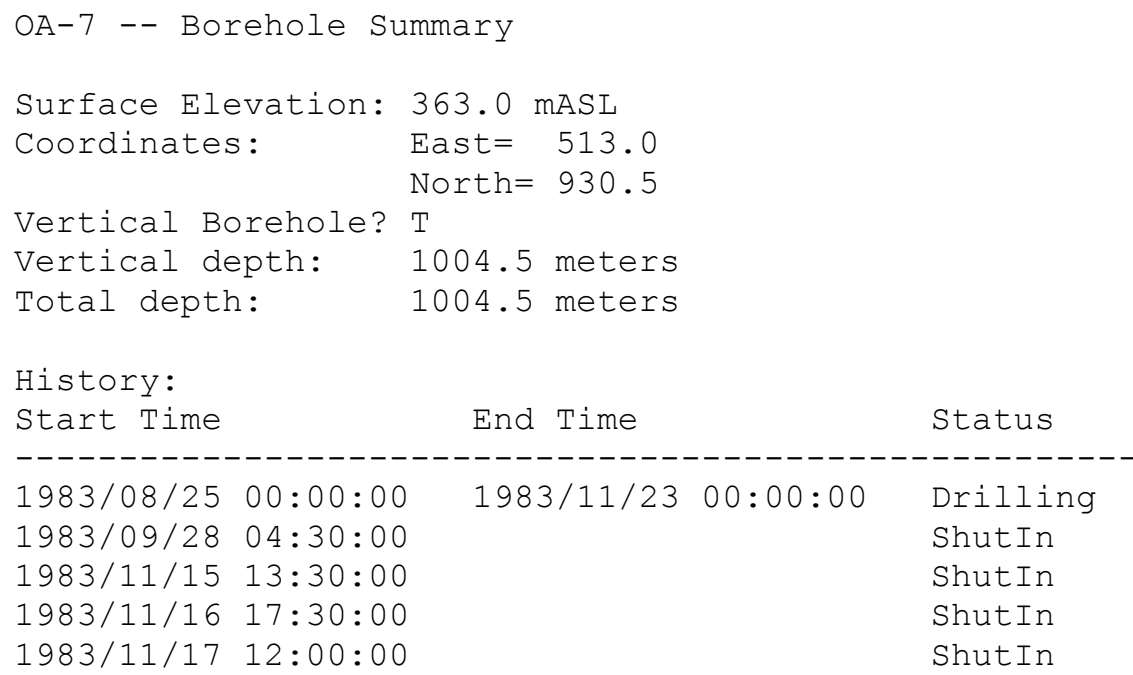

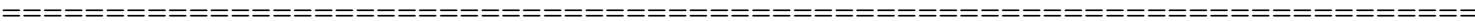
OA-7 -- Lost circulation

starting ending starting ending depth* depth* rate\# rate\#

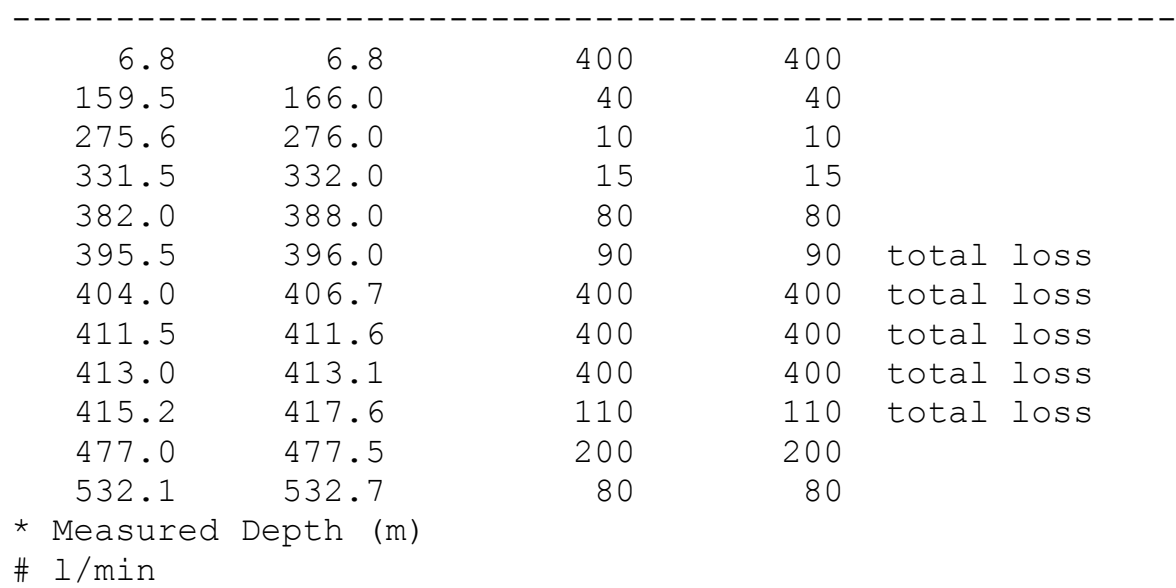

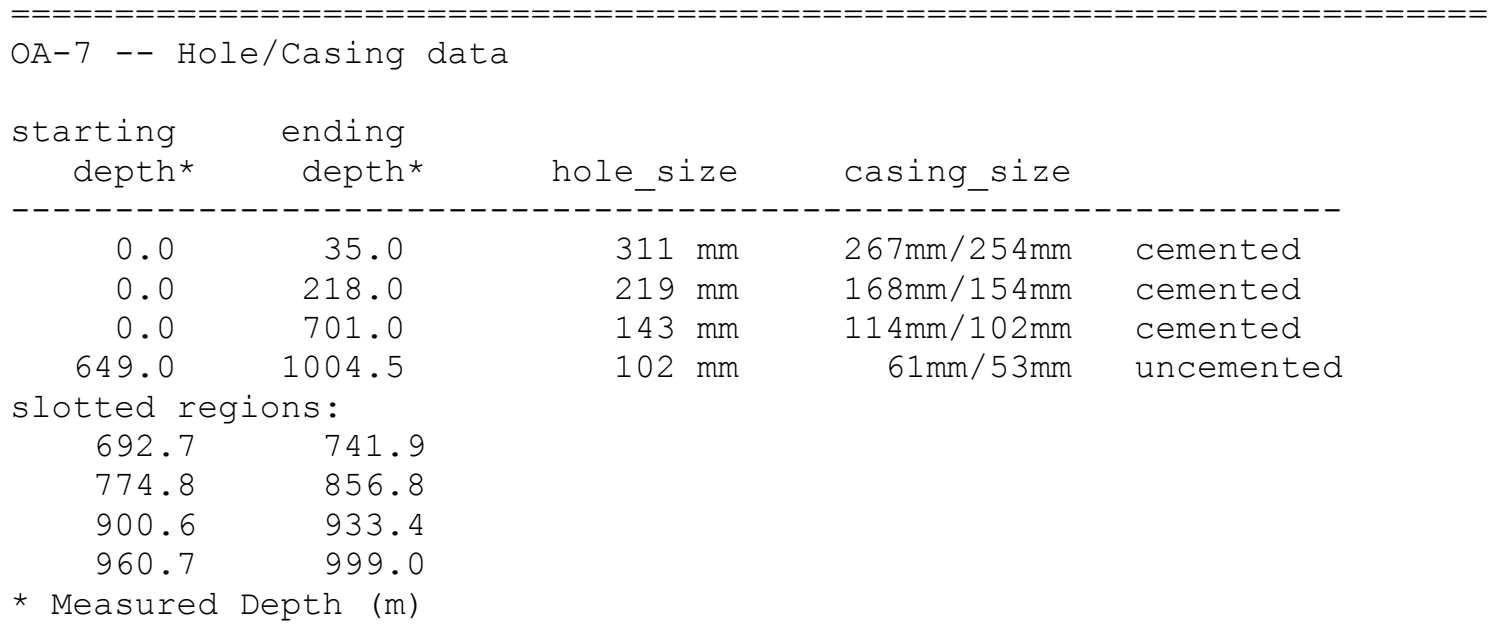




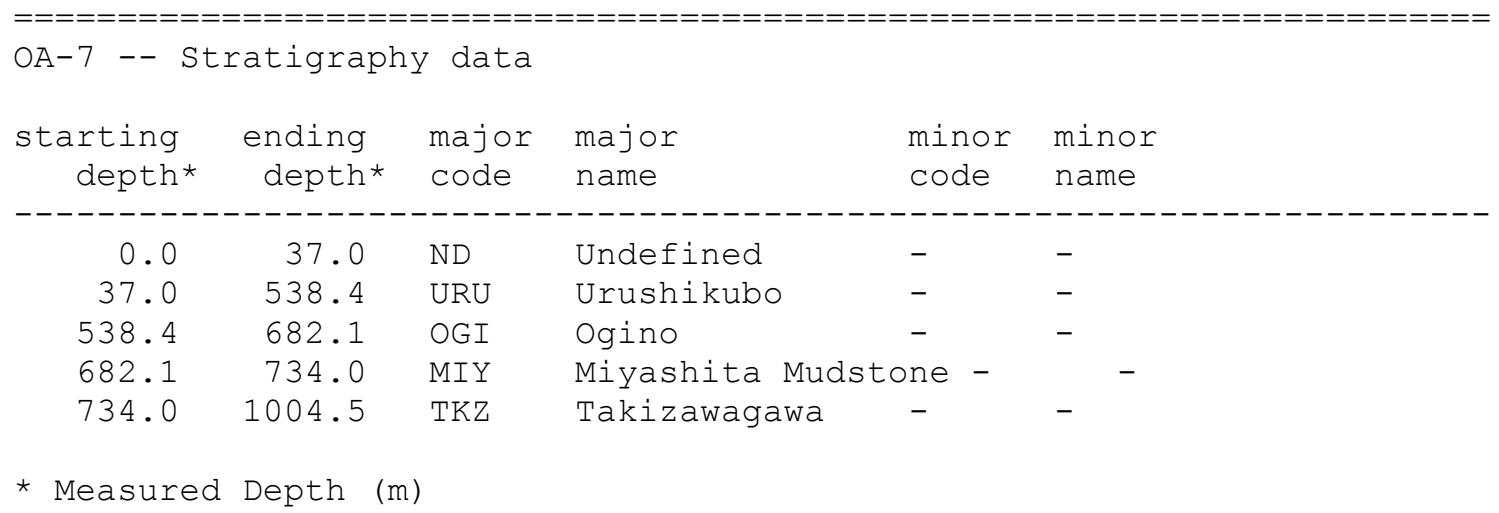




\section{Slim Hole N-1t}

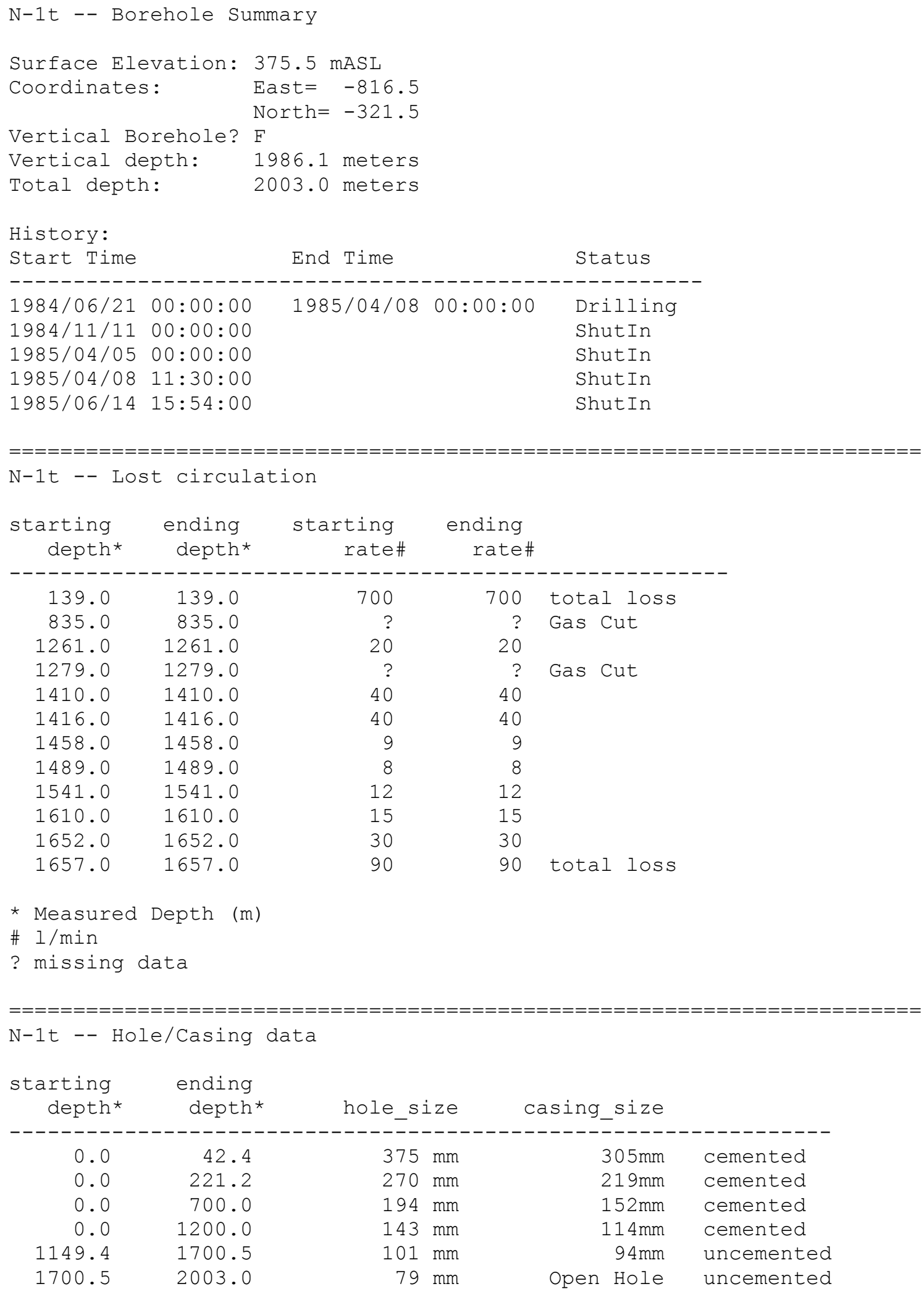




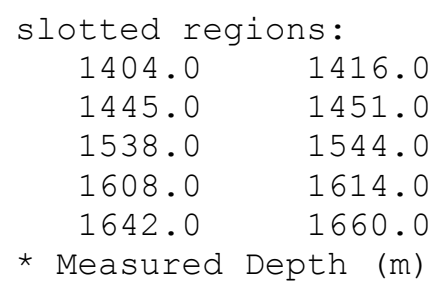

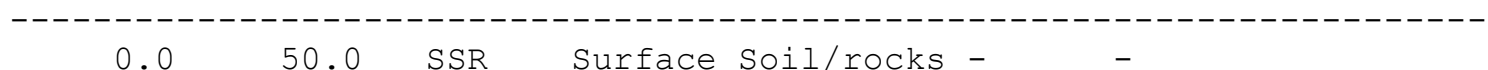

$50.0 \quad 120.0$ URU Urushikubo -

$120.0 \quad 180.0$ OGI Ogino -

180.0 340.0 MIY Miyashita Mudstone - _ -

$340.0 \quad 2003.0 \quad$ TKZ Takizawagawa - _ -

* Measured Depth (m)

\begin{tabular}{|c|c|c|c|}
\hline $\begin{array}{l}\text { N-1t }-- \text { Det } \\
\text { Meas.depth }\end{array}$ & Vert.depth & E_dev. & N_dev. \\
\hline \multicolumn{4}{|c|}{ 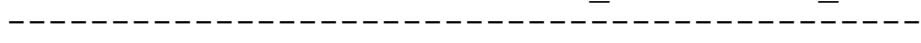 } \\
\hline 0.0 & 0.0 & 0.00 & 0.00 \\
\hline 50.0 & 50.0 & -0.17 & 0.13 \\
\hline 100.0 & 100.0 & -0.45 & 0.45 \\
\hline 150.0 & 150.0 & -0.82 & 0.46 \\
\hline 200.0 & 200.0 & -1.26 & 0.50 \\
\hline 250.0 & 250.0 & -1.75 & 0.73 \\
\hline 300.0 & 300.0 & -2.43 & 1.09 \\
\hline 328.0 & 328.0 & -2.92 & 1.77 \\
\hline 334.5 & 334.5 & -3.07 & 1.97 \\
\hline 340.6 & 340.6 & -3.22 & 2.11 \\
\hline 346.7 & 346.7 & -3.40 & 2.26 \\
\hline 354.0 & 353.9 & -3.65 & 2.46 \\
\hline 360.1 & 360.1 & -3.85 & 2.62 \\
\hline 375.7 & 375.7 & -4.34 & 2.87 \\
\hline 381.8 & 381.7 & -4.56 & 2.93 \\
\hline 388.0 & 387.9 & -4.81 & 2.95 \\
\hline 394.0 & 393.9 & -5.04 & 2.96 \\
\hline 400.0 & 399.9 & -5.28 & 3.01 \\
\hline 406.0 & 405.9 & -5.51 & 3.07 \\
\hline 412.0 & 411.9 & -5.70 & 3.10 \\
\hline 418.0 & 417.9 & -5.89 & 3.11 \\
\hline 436.0 & 435.9 & -6.61 & 3.24 \\
\hline 443.0 & 442.9 & -6.94 & 3.37 \\
\hline 449.0 & 448.9 & -7.23 & 3.54 \\
\hline 455.0 & 454.9 & -7.55 & 3.67 \\
\hline 461.0 & 460.9 & -7.89 & 3.80 \\
\hline 473.0 & 472.8 & -8.50 & 3.72 \\
\hline 479.0 & 478.8 & -8.80 & 3.46 \\
\hline 485.0 & 484.8 & -9.11 & 3.17 \\
\hline 491.0 & 490.8 & -9.39 & 2.88 \\
\hline 497.0 & 496.8 & -9.68 & 2.63 \\
\hline 503.0 & 502.8 & -9.95 & 2.41 \\
\hline 509.0 & 508.8 & -10.20 & 2.18 \\
\hline
\end{tabular}




\begin{tabular}{|c|c|c|c|}
\hline 516.0 & 515.8 & -10.49 & 1.94 \\
\hline 522.0 & 521.7 & -10.74 & 1.75 \\
\hline 527.0 & 526.7 & -10.94 & 1.60 \\
\hline 533.0 & 532.7 & -11.16 & 1.45 \\
\hline 539.0 & 538.7 & -11.35 & 1.27 \\
\hline 546.0 & 545.7 & -11.60 & 1.05 \\
\hline 552.0 & 551.7 & -11.83 & 0.85 \\
\hline 558.0 & 557.7 & -12.04 & 0.66 \\
\hline 564.0 & 563.7 & -12.23 & 0.47 \\
\hline 570.0 & 569.7 & -12.40 & 0.26 \\
\hline 576.0 & 575.7 & -12.56 & 0.08 \\
\hline 582.0 & 581.7 & -12.73 & -0.08 \\
\hline 589.0 & 588.7 & -12.93 & -0.29 \\
\hline 595.0 & 594.7 & -13.11 & -0.48 \\
\hline 601.0 & 600.7 & -13.30 & -0.67 \\
\hline 607.0 & 606.7 & -13.50 & -0.84 \\
\hline 613.0 & 612.7 & -13.70 & -1.00 \\
\hline 619.0 & 618.6 & -13.87 & -1.21 \\
\hline 625.0 & 624.6 & -14.05 & $-1 \cdot 4$ \\
\hline 631.0 & 630.6 & -14.24 & $-1 \cdot 61$ \\
\hline 637.0 & 636.6 & -14.42 & -1.79 \\
\hline 643.0 & 642.6 & -14.59 & $-1 \cdot 9$ \\
\hline 650.0 & 649.6 & -14.75 & -2.14 \\
\hline 656.0 & 655.6 & -14.89 & -2.28 \\
\hline 662.0 & 661.6 & -15.04 & -2.43 \\
\hline 668.0 & 667.6 & -15.18 & -2.57 \\
\hline 674.0 & 673.6 & -15.34 & -2.71 \\
\hline 680.0 & 679.6 & -15.51 & -2.86 \\
\hline 686.0 & 685.6 & -15.70 & -3.0 \\
\hline 695.0 & 694.6 & -16.00 & -3.2 \\
\hline 750.0 & 749.5 & -17.96 & -4.7 \\
\hline 800.0 & 799.5 & -19.83 & -6.21 \\
\hline 850.0 & 849.4 & -21.73 & -7.26 \\
\hline 900.0 & 899.4 & $-23 \cdot 32$ & -7.58 \\
\hline 950.0 & 949.4 & -24.55 & -7.91 \\
\hline 1000.0 & 999.3 & -26.05 & -8.7 \\
\hline 1050.0 & 1049.3 & -27.86 & -9.5 \\
\hline 1100.0 & 1099.3 & -30.06 & -9.98 \\
\hline 1150.0 & 1149.2 & -32.71 & -10.3 \\
\hline 1200.0 & 1199.1 & -35.32 & -10.7 \\
\hline 1250.0 & 1249.1 & -37.83 & -11.2 \\
\hline 1300.0 & 1299.0 & -40.29 & -11.84 \\
\hline 1350.0 & 1348.9 & -42.77 & -12.5 \\
\hline 1400.0 & 1398.8 & -45.31 & -13.33 \\
\hline 1450.0 & 1448.7 & -48.98 & -14.6 \\
\hline 1500.0 & 1498.3 & -54.62 & -17.2 \\
\hline 1550.0 & 1547.7 & -61.47 & -20.8 \\
\hline 1600.0 & 1596.9 & -68.73 & -26.02 \\
\hline 1650.0 & 1645.8 & -76.63 & -32.7 \\
\hline 1700.0 & 1694.3 & -86.79 & -39.0 \\
\hline 1750.0 & 1742.9 & -96.46 & -45.7 \\
\hline 1800.0 & 1791.5 & -104.27 & -54.3 \\
\hline 1850.0 & 1839.9 & -112.71 & -64.0 \\
\hline 1900.0 & 1887.8 & -122.29 & -74.3 \\
\hline 1950.0 & 1935.7 & -132.48 & -84.8 \\
\hline 2000.0 & 1983.2 & -142.99 & -96.1 \\
\hline 2003.0 & 1986.1 & -143.66 & -96.8 \\
\hline
\end{tabular}




\section{Slim Hole N-2t}

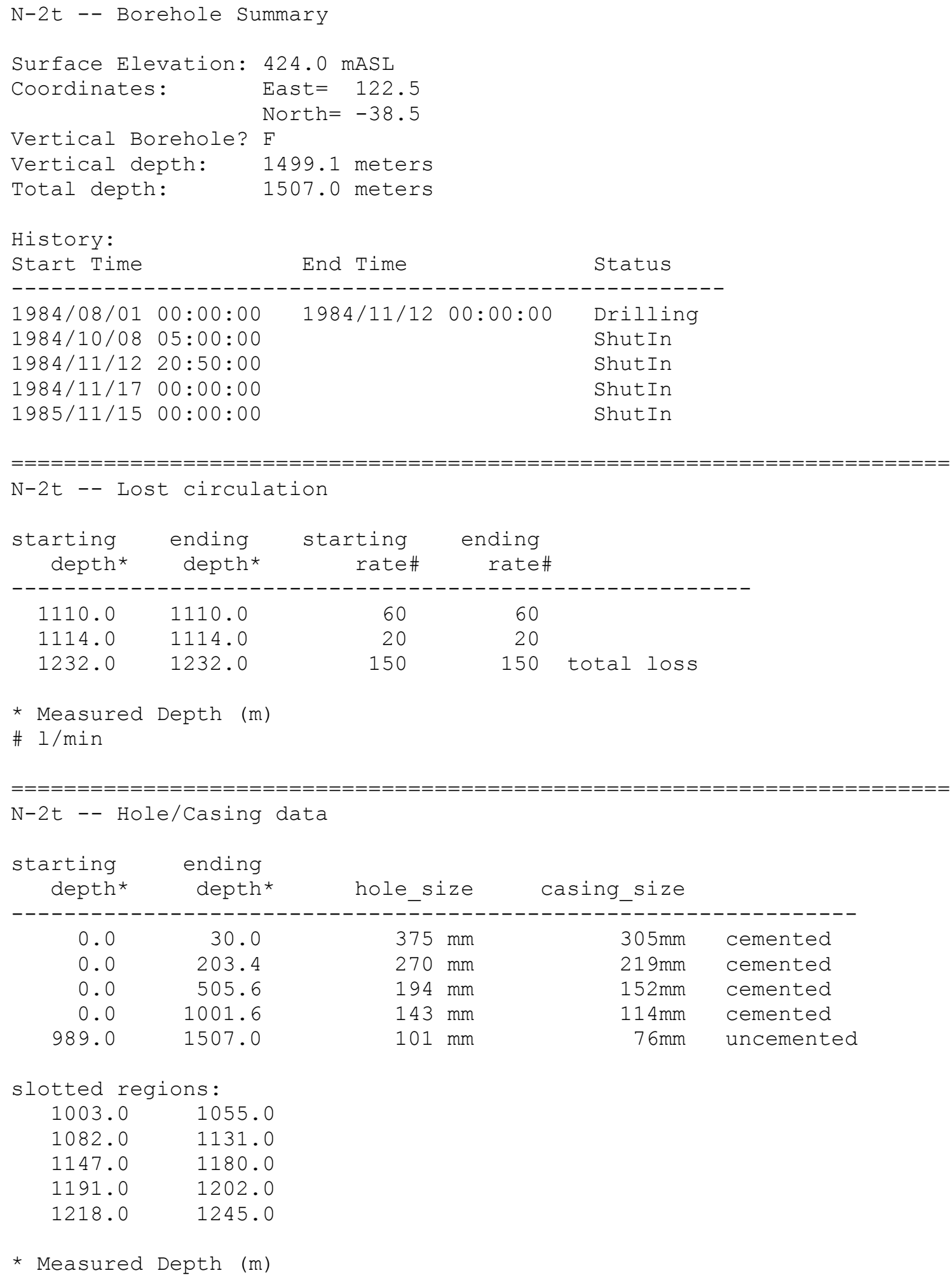


N-2t -- Stratigraphy data

\begin{tabular}{|c|c|c|c|c|c|}
\hline $\begin{array}{l}\text { starting } \\
\text { depth* }\end{array}$ & $\begin{array}{l}\text { ending } \\
\text { depth* }\end{array}$ & $\begin{array}{l}\text { major } \\
\text { code }\end{array}$ & $\begin{array}{l}\text { major } \\
\text { name }\end{array}$ & $\begin{array}{l}\text { minor } \\
\text { code }\end{array}$ & $\begin{array}{l}\text { minor } \\
\text { name }\end{array}$ \\
\hline 0.0 & 20.0 & SSR & Surface Soil & cks - & - \\
\hline 20.0 & 80.0 & SUN & Sunagohara & - & - \\
\hline 80.0 & 160.0 & URU & Urushikubo & - & - \\
\hline 160.0 & 420.0 & OGI & Ogino & - & - \\
\hline 420.0 & 1507.0 & TKZ & Takizawagawa & - & - \\
\hline
\end{tabular}

\begin{tabular}{|c|c|c|c|}
\hline Meas.depth & Vert.depth & E_dev. & $\mathrm{N}_{-}$dev. \\
\hline 0.0 & 0 & O $\cap 0$ & 0.00 \\
\hline 50.0 & 50.0 & -0.05 & -0.21 \\
\hline 100.0 & 100.0 & -0.10 & -0.43 \\
\hline 150.0 & 150.0 & 0.21 & -0.30 \\
\hline 200.0 & 200.0 & 0.49 & -0.03 \\
\hline 250.0 & 250.0 & 0.26 & 0.05 \\
\hline 300.0 & 300.0 & -0.16 & -0.05 \\
\hline 350.0 & 350.0 & -0.36 & -0.18 \\
\hline 400.0 & 400.0 & -0.70 & -0.56 \\
\hline 450.0 & 450.0 & -1.48 & -0.88 \\
\hline 500.0 & 500.0 & -2.34 & -0.99 \\
\hline 550.0 & 550.0 & -3.04 & -1.56 \\
\hline 600.0 & 600.0 & -3.27 & -1.86 \\
\hline 650.0 & 650.0 & -3.26 & $-1 \cdot 32$ \\
\hline 700.0 & 700.0 & -2.99 & -0.59 \\
\hline 750.0 & 749.9 & -2.41 & 0.15 \\
\hline 800.0 & 799.9 & -1.87 & 0.84 \\
\hline 850.0 & 849.9 & -1.43 & 1.55 \\
\hline 900.0 & 899.9 & -0.73 & 2.91 \\
\hline 950.0 & 949.8 & 0.77 & 5.12 \\
\hline 1000.0 & 999.7 & 2.86 & 8.09 \\
\hline 1050.0 & 1049.4 & 5.46 & 12.37 \\
\hline 1100.0 & 1099.2 & 8.95 & 16.45 \\
\hline 1150.0 & 1148.8 & 12.74 & 20.74 \\
\hline 1200.0 & 1198.4 & 16.28 & 26.27 \\
\hline 1250.0 & 1247.8 & 20.71 & 32.48 \\
\hline 1300.0 & 1297.0 & 25.82 & 39.75 \\
\hline 1350.0 & 1346.1 & 30.77 & 47.78 \\
\hline 1400.0 & 1395.1 & 36.10 & 56.41 \\
\hline 1450.0 & 1443.8 & 42.02 & 65.64 \\
\hline 1500.0 & 1492.4 & 47.65 & 76.27 \\
\hline 1507.0 & 1499.1 & 48.37 & 77.90 \\
\hline
\end{tabular}




\section{Slim Hole N-3t}

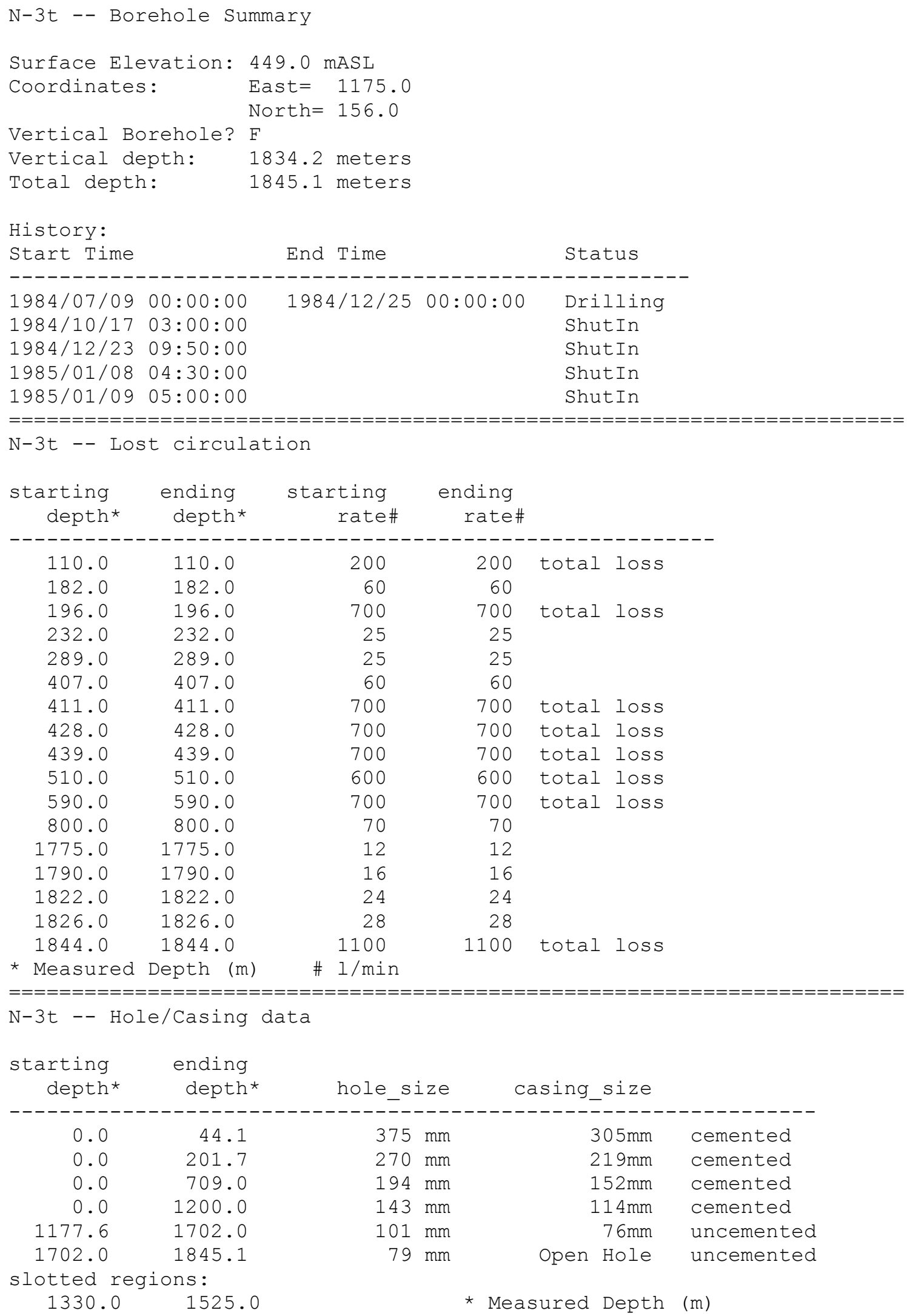


N-3t -- Stratigraphy data

\begin{tabular}{|c|c|c|c|c|c|}
\hline $\begin{array}{l}\text { starting } \\
\text { depth* }\end{array}$ & $\begin{array}{l}\text { ending } \\
\text { depth* }\end{array}$ & $\begin{array}{l}\text { major } \\
\text { code }\end{array}$ & $\begin{array}{l}\text { major } \\
\text { name }\end{array}$ & $\begin{array}{l}\text { minor } \\
\text { code }\end{array}$ & $\begin{array}{l}\text { minor } \\
\text { name }\end{array}$ \\
\hline 0.0 & 40.0 & SSR & Surface Soil/ & cks - & - \\
\hline 40.0 & 60.0 & SUN & Sunagohara & - & - \\
\hline 60.0 & 180.0 & URU & Urushikubo & - & - \\
\hline 180.0 & 500.0 & OGI & Ogino & - & - \\
\hline 500.0 & 1428.2 & TKZ & Takizawagawa & - & - \\
\hline 1428.2 & 1845.1 & $\mathrm{OHI}$ & Ohinokisawa & - & - \\
\hline * Measureo & Depth (m) & & & & \\
\hline
\end{tabular}

\begin{tabular}{|c|c|c|c|}
\hline Meas.depth & Vert.depth & E_dev. & $\mathrm{N}_{-}$dev. \\
\hline 0.0 & 0 & O & 0.00 \\
\hline 50.0 & 50.0 & -011 & 0.31 \\
\hline 100.0 & 100.0 & -0.31 & 0.81 \\
\hline 150.0 & 150.0 & -0.51 & 1.16 \\
\hline 200.0 & 200.0 & -1.16 & 1.05 \\
\hline 250.0 & 250.0 & -2.19 & 0.76 \\
\hline 300.0 & 300.0 & -3.13 & 0.65 \\
\hline 350.0 & 350.0 & -3.97 & 0.45 \\
\hline 400.0 & 400.0 & -4.60 & 0.17 \\
\hline 450.0 & 450.0 & -5.22 & -0.12 \\
\hline 500.0 & 499.9 & -6.04 & -0.11 \\
\hline 550.0 & 549.9 & -6.71 & -0.02 \\
\hline 600.0 & 599.9 & -7.07 & -0.33 \\
\hline 650.0 & 649.9 & -7.52 & -0.81 \\
\hline 700.0 & 699.9 & -8.23 & -1.26 \\
\hline 750.0 & 749.9 & -9.41 & -1.68 \\
\hline 800.0 & 799.9 & -11.53 & -1.71 \\
\hline 850.0 & 849.8 & -14.14 & -1.13 \\
\hline 900.0 & 899.7 & -16.45 & -0.17 \\
\hline 950.0 & 949.7 & -18.10 & 1.08 \\
\hline 1000.0 & 999.7 & -18.94 & 2.68 \\
\hline 1050.0 & 1049.6 & -19.18 & 4.43 \\
\hline 1100.0 & 1099.6 & $-18 \cdot 30$ & 6.31 \\
\hline 1150.0 & 1149.5 & -16.09 & 8.26 \\
\hline 1200.0 & 1199.4 & -13.06 & 9.76 \\
\hline 1250.0 & 1249.2 & -9.21 & 10.66 \\
\hline 1300.0 & 1299.0 & -4.63 & 10.94 \\
\hline 1350.0 & 1348.7 & 0.46 & 10.01 \\
\hline 1400.0 & 1398.4 & 5.20 & 7.33 \\
\hline 1450.0 & 1448.1 & 9.16 & 2.90 \\
\hline 1500.0 & 1497.6 & 12.02 & -3.40 \\
\hline 1550.0 & 1546.9 & 13.65 & $-11 \cdot 26$ \\
\hline 1600.0 & 1596.2 & 13.88 & -19.99 \\
\hline 1650.0 & 1645.3 & 11.51 & -29.14 \\
\hline 1700.0 & 1694.2 & 4.91 & -37.08 \\
\hline 1750.0 & 1742.7 & -5.32 & -43.01 \\
\hline 1800.0 & 1791.0 & -17.54 & -47.61 \\
\hline 1837.0 & 1826.4 & -27.92 & -49.17 \\
\hline 1845.1 & 1834.2 & -30.33 & -49.18 \\
\hline
\end{tabular}




\section{Slim Hole N-4r}

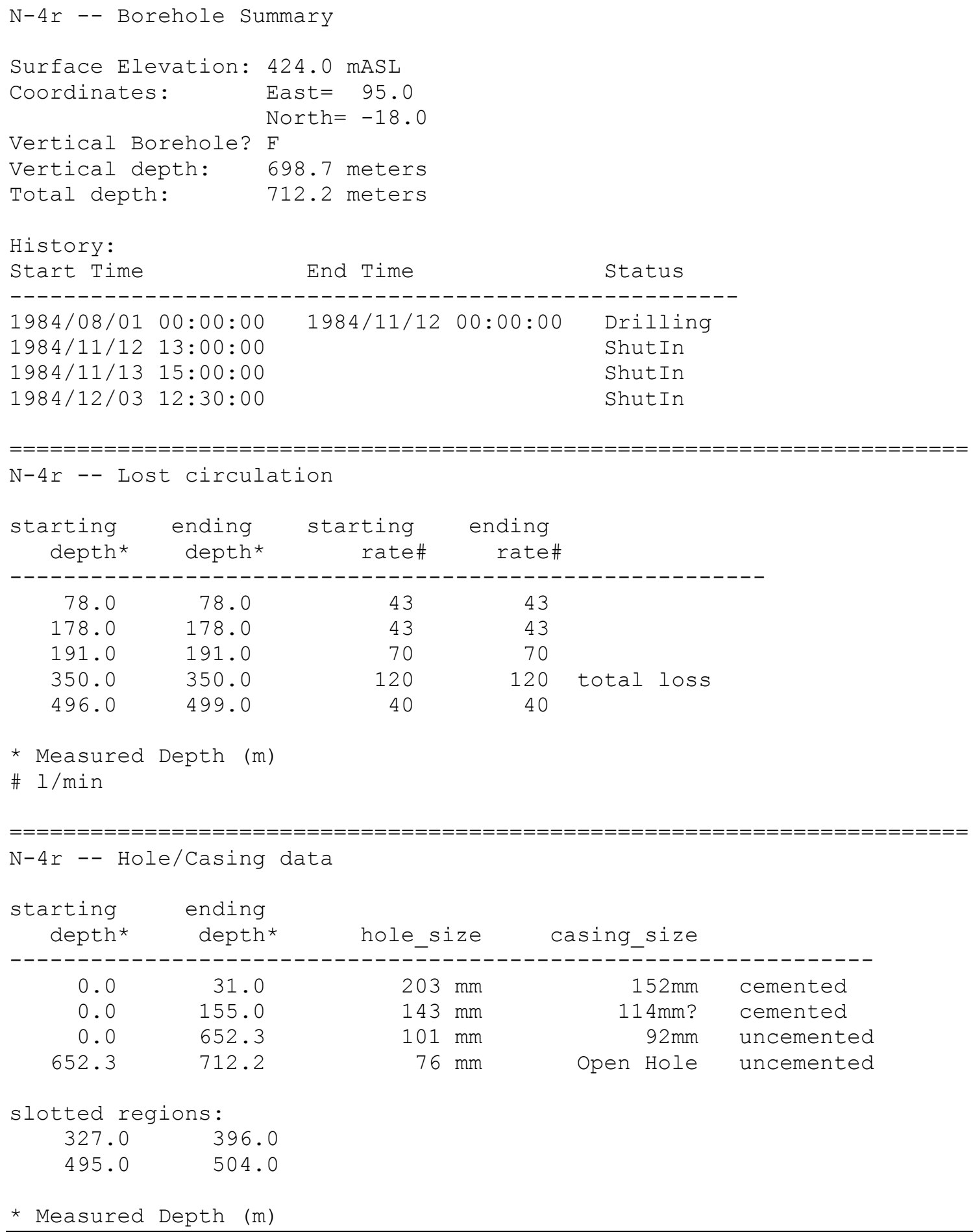


N-4r -- Stratigraphy data

$\begin{array}{ccclll}\begin{array}{c}\text { starting } \\ \text { depth* }\end{array} & \begin{array}{l}\text { ending } \\ \text { depth* }\end{array} & \begin{array}{l}\text { major } \\ \text { code }\end{array} & \begin{array}{l}\text { major } \\ \text { name }\end{array} & \begin{array}{l}\text { minor } \\ \text { code }\end{array} & \begin{array}{l}\text { minor } \\ \text { name }\end{array} \\ \text { 0.0 } & 35.9 & \text { SSR } & \text { Surface Soil/rocks } & - \\ 35.9 & 103.3 & \text { SUN } & \text { Sunagohara } & - & - \\ 103.3 & 245.1 & \text { URU } & \text { Urushikubo } & - & - \\ 245.1 & 563.8 & \text { OGI } & \text { Ogino } & - & - \\ 563.8 & 712.2 & \text { TKZ } & \text { Takizawagawa } & - & - \\ \text { * Measured } & \text { Depth (m) } & & & \end{array}$

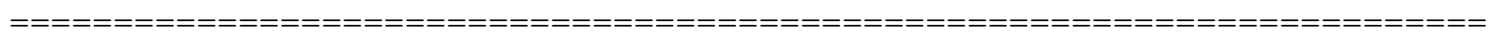
N-4r -- Deviation data $(\mathrm{m})$

$\begin{array}{cccc}\text { Meas.depth } & \text { Vert.depth } & \text { E_dev. } & \text { N_dev. } \\ 0.0 & 0.0 & 0.00 & 0.00 \\ 50.0 & 49.2 & -4.41 & -6.38 \\ 100.0 & 96.9 & -12.66 & -18.74 \\ 150.0 & 145.2 & -19.75 & -29.81 \\ 210.0 & 203.3 & -28.26 & -42.08 \\ 246.0 & 238.1 & -33.58 & -49.23 \\ 259.0 & 250.8 & -35.31 & -51.69 \\ 270.0 & 261.5 & -36.67 & -53.75 \\ 299.0 & 289.8 & -40.12 & -59.03 \\ 330.0 & 320.2 & -43.43 & -64.29 \\ 360.0 & 349.7 & -46.46 & -69.07 \\ 400.0 & 389.0 & -50.50 & -75.07 \\ 450.0 & 438.4 & -55.06 & -81.56 \\ 500.0 & 487.9 & -59.06 & -87.34 \\ 550.0 & 537.4 & -62.65 & -92.79 \\ 600.0 & 587.1 & -65.89 & -97.74 \\ 650.0 & 636.8 & -68.93 & -102.38 \\ 710.0 & 696.5 & -72.17 & -107.39 \\ 712.2 & 698.7 & -72.28 & -107.56\end{array}$




\section{Slim Hole N-5t}

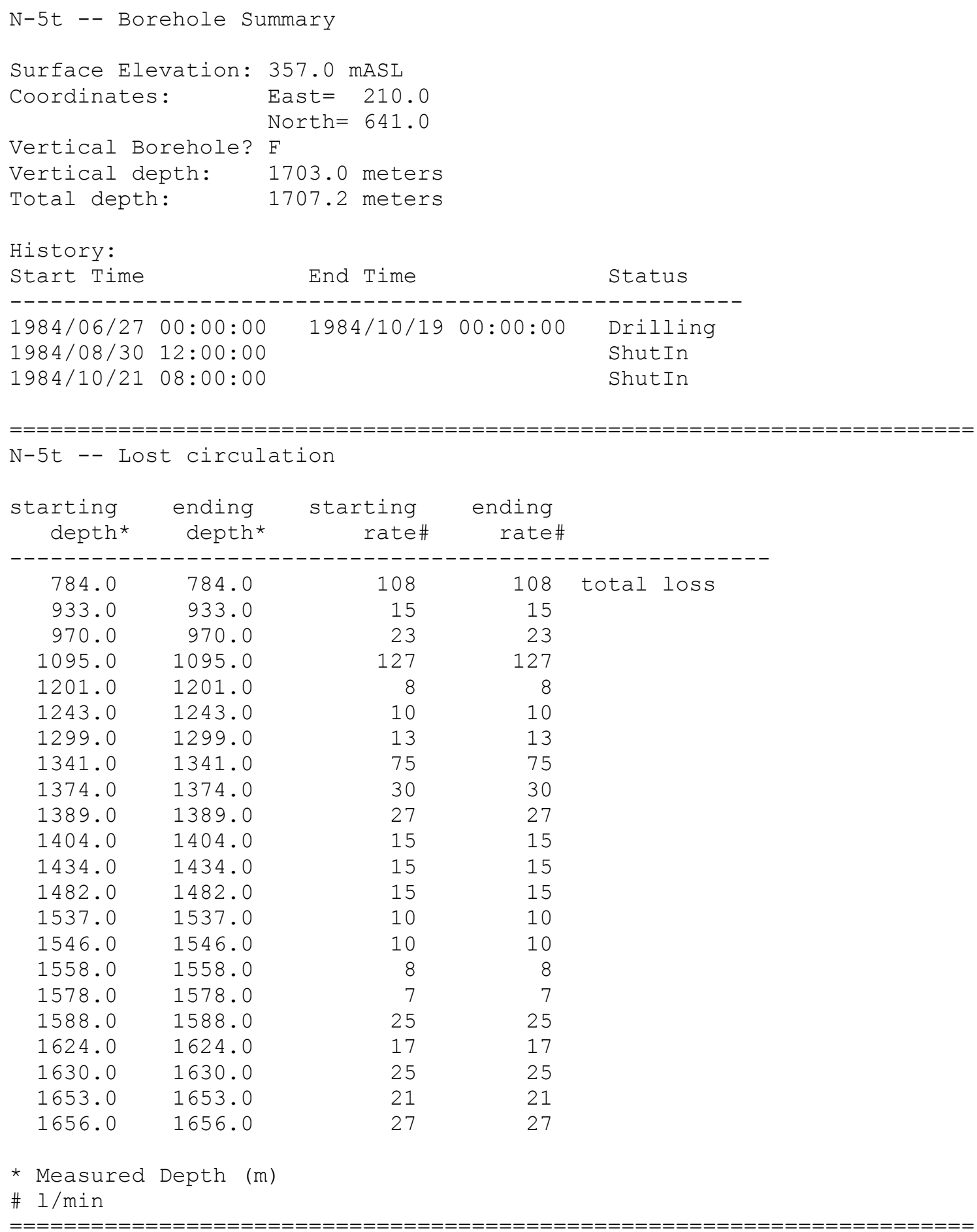




\begin{tabular}{|c|c|c|c|c|}
\hline $\begin{array}{l}\text { starting } \\
\text { depth* }\end{array}$ & $\begin{array}{l}\text { ending } \\
\text { depth* }\end{array}$ & hole_size & casing_size & \\
\hline---------- & --------- & ----------1 & ------------ & ---------- \\
\hline 0.0 & 33.0 & $311 \mathrm{~mm}$ & $254 \mathrm{~mm}$ & cemented \\
\hline 0.0 & 210.0 & $244 \mathrm{~mm}$ & $178 \mathrm{~mm}$ & cemented \\
\hline 0.0 & 703.0 & $159 \mathrm{~mm}$ & $127 \mathrm{~mm}$ & cemented \\
\hline 0.0 & 1077.3 & $101 \mathrm{~mm}$ & $92 \mathrm{~mm}$ & cemented \\
\hline 1077.3 & 1201.0 & $101 \mathrm{~mm}$ & $92 \mathrm{~mm}$ & uncemented \\
\hline 1155.8 & 1707.2 & $81 \mathrm{~mm}$ & $64 \mathrm{~mm}$ & uncemented \\
\hline
\end{tabular}

slotted regions:

$\begin{array}{ll}1292.0 & 1396.0 \\ 1582.0 & 1669.0 \\ 1702.0 & 1707.2\end{array}$

* Measured Depth (m)

\begin{tabular}{|c|c|c|c|c|c|}
\hline $\begin{array}{l}\text { starting } \\
\text { depth* }\end{array}$ & $\begin{array}{l}\text { ending } \\
\text { depth* }\end{array}$ & $\begin{array}{l}\text { major } \\
\text { code }\end{array}$ & $\begin{array}{l}\text { major } \\
\text { name }\end{array}$ & $\begin{array}{l}\text { minor } \\
\text { code }\end{array}$ & $\begin{array}{l}\text { minor } \\
\text { name }\end{array}$ \\
\hline---------- & ------- & ----- & ------------- & ------ & 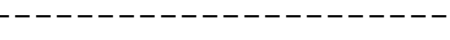 \\
\hline 0.0 & 40.0 & SSR & Surface Soil & cks - & - \\
\hline 40.0 & 120.0 & SUN & Sunagohara & - & - \\
\hline 120.0 & 260.0 & URU & Urushikubo & - & - \\
\hline 260.0 & 460.0 & OGI & Ogino & - & - \\
\hline 460.0 & 1707.2 & TKZ & Takizawagawa & - & - \\
\hline * Measured & \multicolumn{5}{|c|}{ Depth (m) } \\
\hline
\end{tabular}




\begin{tabular}{|c|c|c|c|}
\hline Meas.depth & Vert.depth & E_dev. & $\mathrm{N}$ _dev . \\
\hline & & 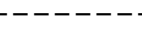 & ------- \\
\hline 0.0 & 0.0 & 0.00 & 0.00 \\
\hline 50.0 & 50.0 & -0.14 & -0.41 \\
\hline 100.0 & 100.0 & -0.51 & -0.46 \\
\hline 150.0 & 150.0 & -0.84 & -0.28 \\
\hline 200.0 & 200.0 & -1.08 & -0.77 \\
\hline 250.0 & 250.0 & -1.26 & -0.74 \\
\hline 300.0 & 300.0 & -1.43 & 0.00 \\
\hline 350.0 & 350.0 & -1.89 & 0.78 \\
\hline 400.0 & 400.0 & -2.55 & 1.50 \\
\hline 450.0 & 450.0 & -2.86 & 1.69 \\
\hline 500.0 & 500.0 & -2.62 & 1.55 \\
\hline 550.0 & 550.0 & -2.73 & 1.57 \\
\hline 600.0 & 600.0 & -3.27 & 1.53 \\
\hline 650.0 & 650.0 & -3.62 & 1.60 \\
\hline 700.0 & 700.0 & -3.97 & 1.71 \\
\hline 750.0 & 749.9 & -2.63 & 2.21 \\
\hline 800.0 & 799.8 & 0.60 & 3.21 \\
\hline 850.0 & 849.7 & 3.83 & 4.30 \\
\hline 900.0 & 899.6 & 6.88 & 5.48 \\
\hline 950.0 & 949.5 & 9.41 & 6.74 \\
\hline 1000.0 & 999.4 & 11.89 & 7.92 \\
\hline 1050.0 & 1049.3 & 14.42 & 9.01 \\
\hline 1100.0 & 1099.3 & 16.61 & 10.08 \\
\hline 1150.0 & 1149.2 & 19.06 & 10.76 \\
\hline 1200.0 & 1199.2 & 19.85 & 9.53 \\
\hline 1250.0 & 1249.1 & 21.06 & 8.38 \\
\hline 1300.0 & 1299.0 & 24.69 & 8.90 \\
\hline 1350.0 & 1348.8 & 28.83 & 9.44 \\
\hline 1400.0 & 1398.7 & 28.52 & 9.31 \\
\hline 1450.0 & 1448.4 & 22.94 & 8.45 \\
\hline 1500.0 & 1498.3 & 23.24 & 8.61 \\
\hline 1550.0 & 1547.8 & 29.84 & 10.21 \\
\hline 1600.0 & 1597.2 & 37.07 & 12.59 \\
\hline 1650.0 & 1646.5 & 44.92 & 15.46 \\
\hline 1700.0 & 1695.9 & 49.69 & 21.48 \\
\hline 1707.2 & 1703.0 & 49.93 & 22.79 \\
\hline
\end{tabular}




\section{Production Well N-6T}

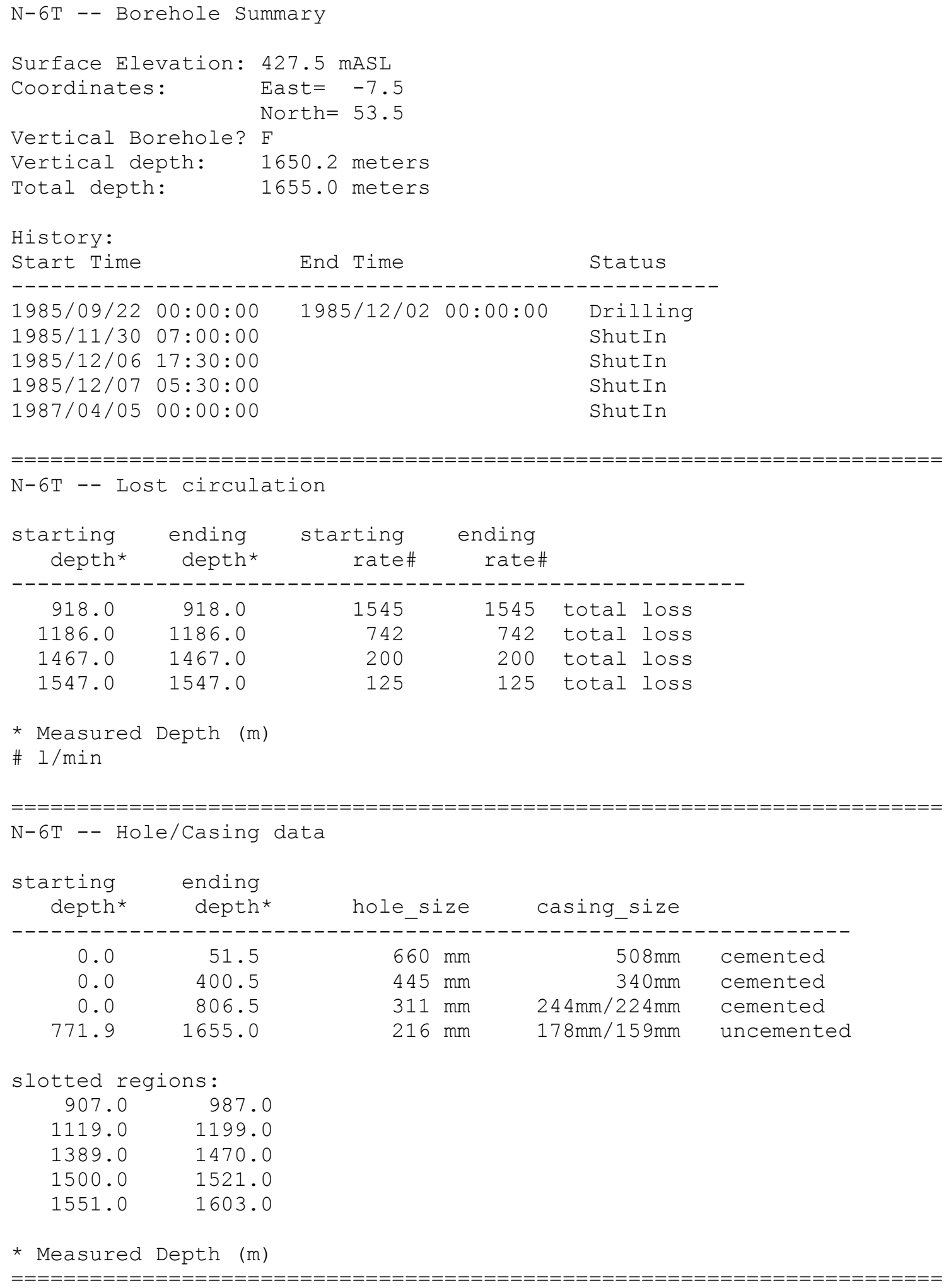


N-6T -- Stratigraphy data

\begin{tabular}{|c|c|c|c|c|c|}
\hline $\begin{array}{l}\text { starting } \\
\text { depth* }\end{array}$ & $\begin{array}{l}\text { ending } \\
\text { depth* }\end{array}$ & $\begin{array}{l}\text { major } \\
\text { code }\end{array}$ & $\begin{array}{l}\text { major } \\
\text { name }\end{array}$ & $\begin{array}{l}\text { minor } \\
\text { code }\end{array}$ & $\begin{array}{l}\text { minor } \\
\text { name }\end{array}$ \\
\hline--------1 & -- & & -------- - - - - & -1 & ----- \\
\hline 0.0 & 60.0 & SSR & Surface Soil/ & $\mathrm{cks}$ & - \\
\hline 60.0 & 260.0 & URU & Urushikubo & - & - \\
\hline 260.0 & 540.0 & OGI & Ogino & - & - \\
\hline 540.0 & 1655.0 & TKZ & Takizawagawa & - & - \\
\hline
\end{tabular}

\begin{tabular}{|c|c|c|c|}
\hline Meas.depth & Vert.depth & E_dev. & N_dev. \\
\hline \multicolumn{4}{|c|}{$----------------------------\bar{L}----------\overline{-}----$} \\
\hline 0.0 & 0.0 & 0.00 & 0.00 \\
\hline 55.0 & 55.0 & -0.09 & -0.13 \\
\hline 100.0 & 100.0 & -0.38 & -0.38 \\
\hline 150.0 & 150.0 & -0.89 & -0.67 \\
\hline 200.0 & 200.0 & -1.35 & -0.88 \\
\hline 250.0 & 250.0 & -1.83 & -1.03 \\
\hline 300.0 & 300.0 & -2.28 & -1.25 \\
\hline 350.0 & 350.0 & -2.57 & -1.56 \\
\hline 400.0 & 400.0 & -2.89 & -1.96 \\
\hline 450.0 & 450.0 & -3.10 & -2.46 \\
\hline 500.0 & 500.0 & -3.31 & -2.97 \\
\hline 550.0 & 550.0 & -3.44 & -3.39 \\
\hline 600.0 & 600.0 & -3.17 & -3.65 \\
\hline 650.0 & 650.0 & -2.72 & -3.52 \\
\hline 700.0 & 700.0 & -2.26 & -3.17 \\
\hline 750.0 & 750.0 & -1.82 & -2.60 \\
\hline 800.0 & 800.0 & -1.56 & -1.78 \\
\hline 850.0 & 850.0 & -1.30 & -0.96 \\
\hline 900.0 & 899.9 & -0.90 & 0.05 \\
\hline 950.0 & 949.9 & -0.41 & 1.45 \\
\hline 1000.0 & 999.9 & 0.59 & 3.25 \\
\hline 1050.0 & 1049.8 & 2.20 & 5.58 \\
\hline 1100.0 & 1099.7 & 4.22 & 8.38 \\
\hline 1150.0 & 1149.5 & 6.66 & 11.59 \\
\hline 1200.0 & 1199.3 & 9.47 & 15.11 \\
\hline 1230.0 & 1229.1 & 10.46 & 18.22 \\
\hline 1250.0 & 1248.9 & 10.44 & 20.95 \\
\hline 1300.0 & 1298.5 & 10.37 & 27.17 \\
\hline 1350.0 & 1348.2 & 11.21 & 33.12 \\
\hline 1400.0 & 1397.8 & 12.66 & 39.33 \\
\hline 1450.0 & 1447.3 & 14.31 & 45.64 \\
\hline 1500.0 & 1496.9 & 16.31 & 51.93 \\
\hline 1550.0 & 1546.4 & 19.17 & 58.49 \\
\hline 1620.0 & 1615.6 & 24.31 & 67.92 \\
\hline 1655.0 & 1650.2 & 27.00 & 72.46 \\
\hline
\end{tabular}




\section{Exploration Well N-7T}

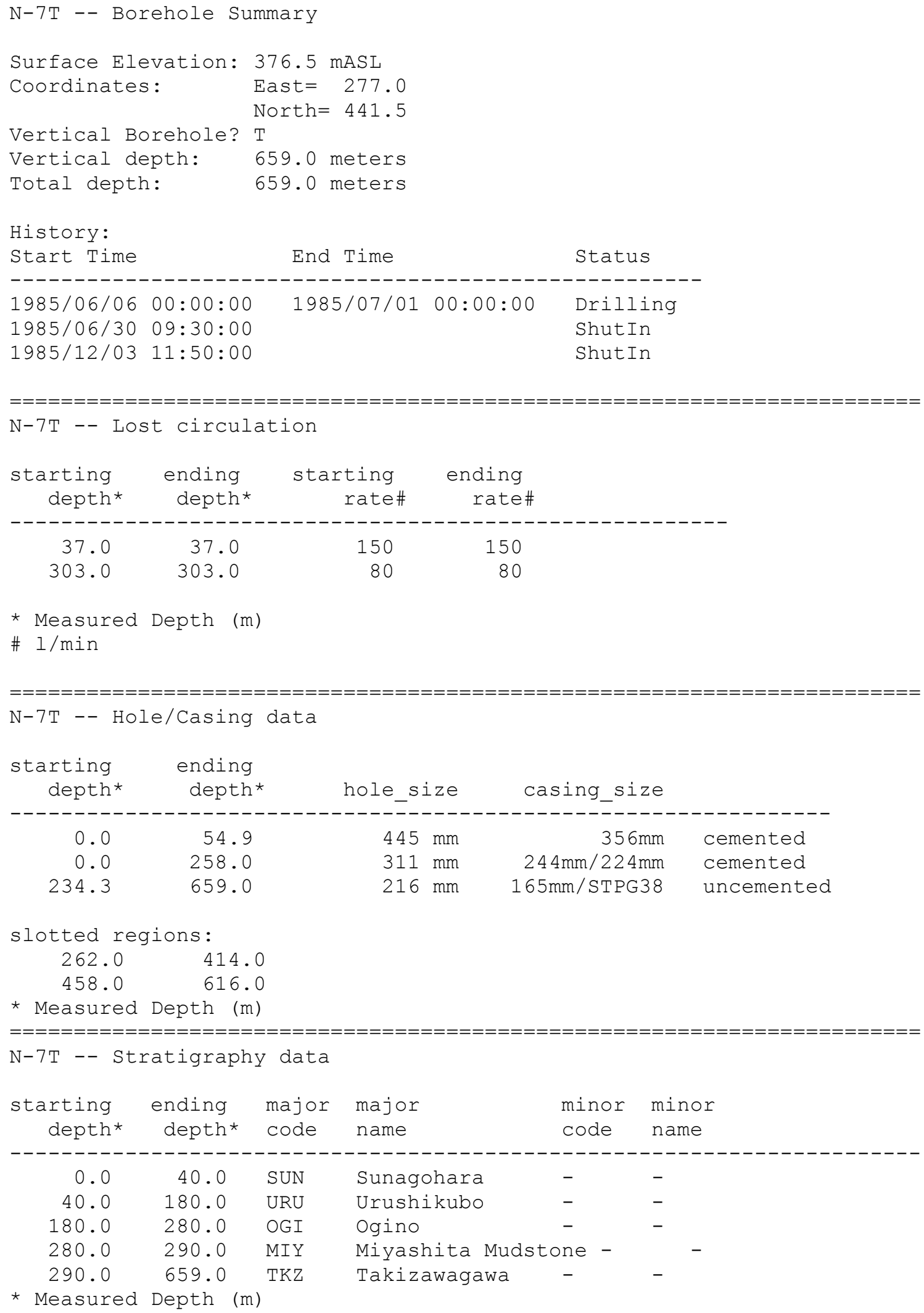




\section{Exploration Well N-8T}

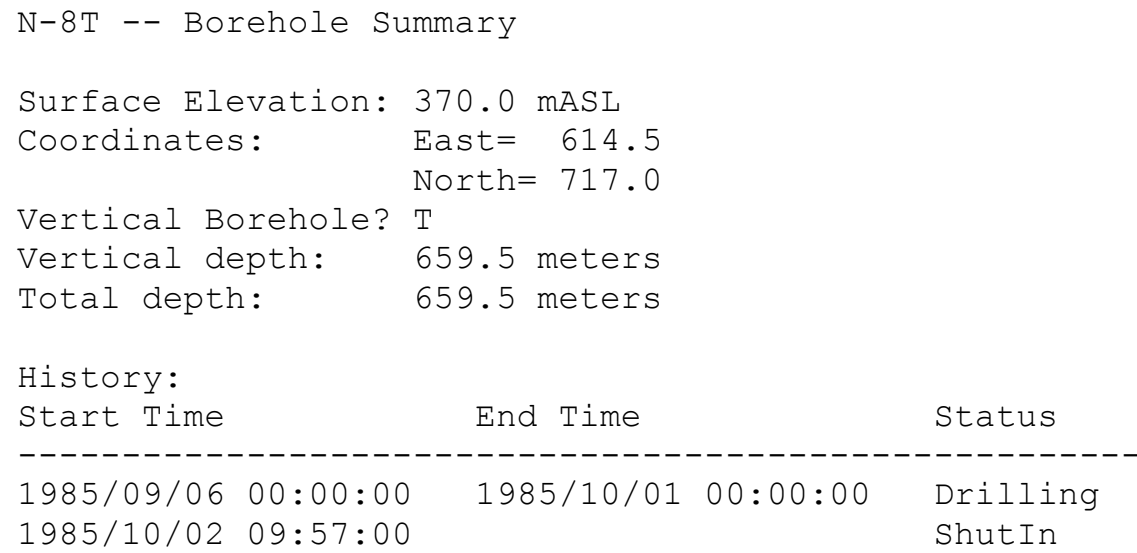

* Measured Depth (m) 


\section{Exploration Well N-9T}

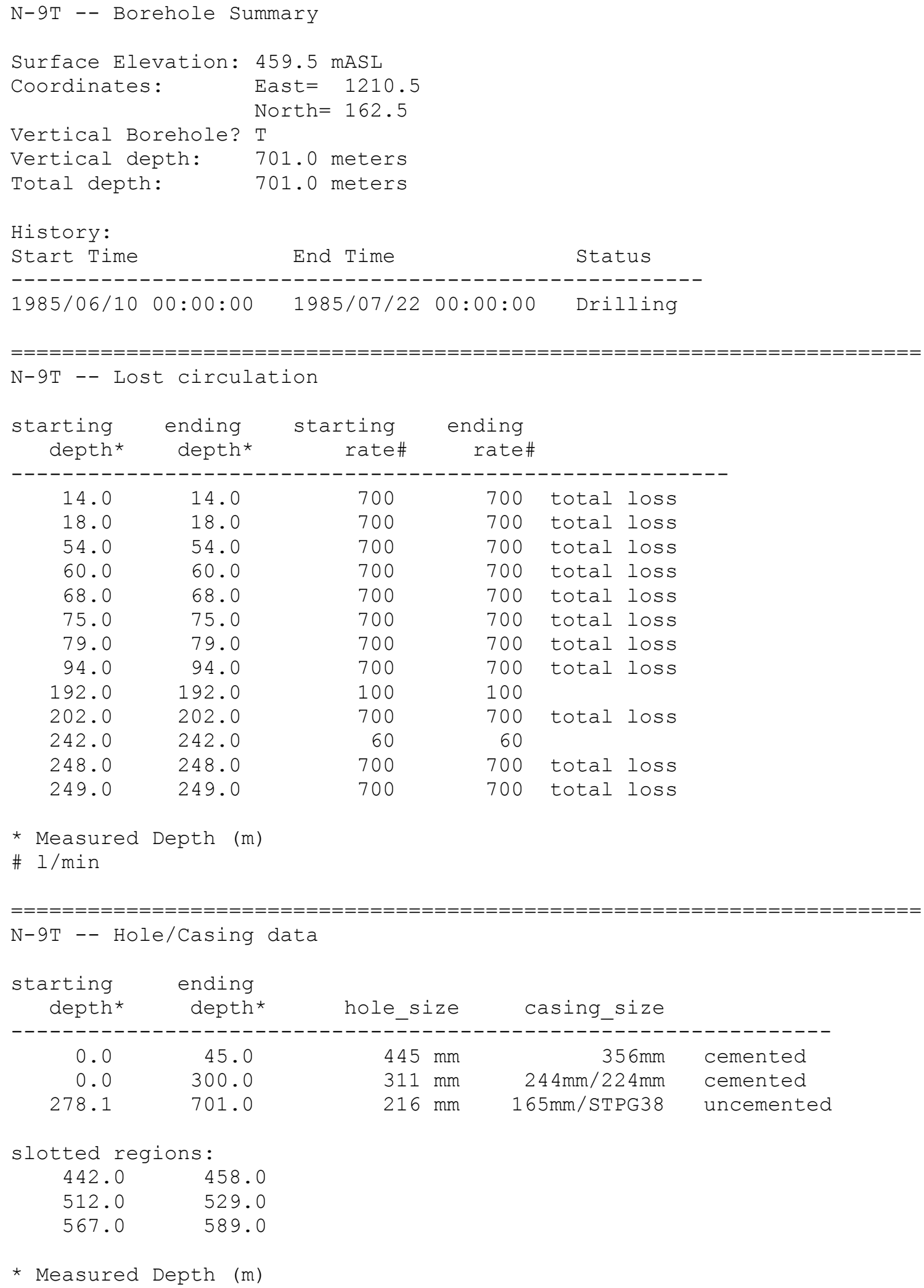




\begin{tabular}{|c|c|c|c|c|c|}
\hline $\begin{array}{l}\text { starting } \\
\text { depth* }\end{array}$ & $\begin{array}{l}\text { ending } \\
\text { depth* }\end{array}$ & $\begin{array}{l}\text { major } \\
\text { code }\end{array}$ & $\begin{array}{l}\text { major } \\
\text { name }\end{array}$ & $\begin{array}{l}\text { minor } \\
\text { code }\end{array}$ & $\begin{array}{l}\text { minor } \\
\text { name }\end{array}$ \\
\hline---------- & --------- & ------- & --------------- & ------- & ------ \\
\hline 0.0 & 80.0 & SUR & Surface Tuffs & - & - \\
\hline 80.0 & 105.0 & URU & Urushikubo & - & - \\
\hline 105.0 & 300.0 & OGI & Ogino & - & - \\
\hline 300.0 & 360.0 & MIY & Miyashita Muds & one - & - \\
\hline 360.0 & 701.0 & TKZ & Takizawagawa & - & - \\
\hline
\end{tabular}

* Measured Depth (m) 


\section{Production Well N-10T}

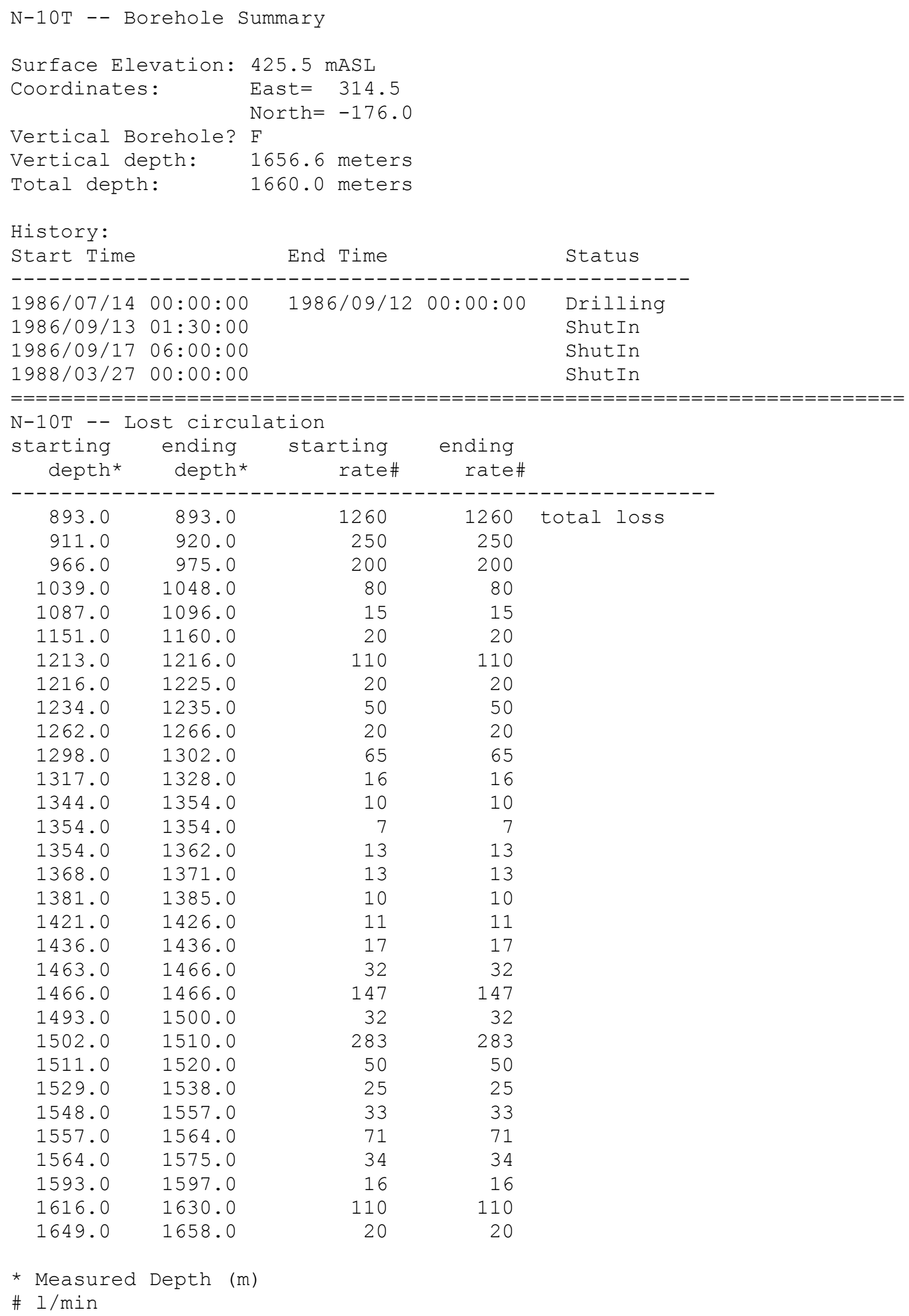




\begin{tabular}{|c|c|c|c|c|}
\hline $\begin{array}{l}\text { starting } \\
\text { depth* }\end{array}$ & $\begin{array}{l}\text { ending } \\
\text { depth* }\end{array}$ & hole_size & casing_size & \\
\hline----------1 & ------- & $----\overline{-}----1$ & ------------ & ---------- \\
\hline 0.0 & 51.1 & $660 \mathrm{~mm}$ & $508 \mathrm{~mm}$ & cemented \\
\hline 0.0 & 407.0 & $445 \mathrm{~mm}$ & $340 \mathrm{~mm}$ & cemented \\
\hline 0.0 & 854.3 & $311 \mathrm{~mm}$ & $244 \mathrm{~mm} / 224 \mathrm{~mm}$ & cemented \\
\hline 833.5 & 1660.0 & $216 \mathrm{~mm}$ & $178 \mathrm{~mm} / 159 \mathrm{~mm}$ & uncemented \\
\hline
\end{tabular}

slotted regions:

$\begin{array}{rr}855.0 & 1033.0 \\ 1063.0 & 1093.0 \\ 1134.0 & 1164.0 \\ 1205.0 & 1225.0 \\ 1255.0 & 1306.0 \\ 1357.0 & 1367.0 \\ 1377.0 & 1387.0 \\ 1487.0 & 1658.0\end{array}$

* Measured Depth (m)

\begin{tabular}{|c|c|c|c|c|c|}
\hline \multicolumn{6}{|c|}{ N-10T -- Stratigraphy data } \\
\hline $\begin{array}{l}\text { starting } \\
\text { depth* }\end{array}$ & $\begin{array}{l}\text { ending } \\
\text { depth* }\end{array}$ & $\begin{array}{l}\text { major } \\
\text { code }\end{array}$ & $\begin{array}{l}\text { major } \\
\text { name }\end{array}$ & $\begin{array}{l}\text { minor } \\
\text { code }\end{array}$ & $\begin{array}{l}\text { minor } \\
\text { name }\end{array}$ \\
\hline \multicolumn{6}{|c|}{-----------------------------------------------------------------------} \\
\hline 0.0 & 20.0 & SSR & Surface Soil & $\mathrm{cks}-$ & - \\
\hline 20.0 & 580.0 & URU & Urushikubo & - & - \\
\hline 580.0 & 680.0 & OGI & Ogino & - & - \\
\hline 680.0 & 720.0 & MIY & Miyashita Muc & one - & - \\
\hline 720.0 & 1660.0 & TKZ & Takizawagawa & - & - \\
\hline * Measured & \multicolumn{5}{|c|}{ Depth (m) } \\
\hline
\end{tabular}


N-10T -- Deviation data (m)

\begin{tabular}{rrrr} 
Meas.depth & Vert.depth & E_dev. & N_dev \\
\hline 0.0 & 0.0 & 0.00 & 0.00 \\
55.0 & 55.0 & -0.10 & -0.31 \\
100.0 & 100.0 & -0.30 & -0.71 \\
150.0 & 150.0 & -0.84 & -1.04 \\
200.0 & 200.0 & -0.53 & -1.05 \\
250.0 & 250.0 & 0.89 & -0.74 \\
300.0 & 299.9 & 2.33 & -0.56 \\
350.0 & 349.9 & 4.12 & -0.30 \\
400.0 & 399.9 & 6.21 & 0.30 \\
450.0 & 449.8 & 8.22 & 1.28 \\
500.0 & 499.8 & 10.27 & 2.53 \\
550.0 & 549.7 & 12.50 & 3.75 \\
600.0 & 599.6 & 14.72 & 5.13 \\
650.0 & 649.5 & 16.96 & 6.46 \\
700.0 & 699.5 & 19.38 & 7.91 \\
750.0 & 749.4 & 22.20 & 9.53 \\
800.0 & 799.3 & 25.21 & 11.15 \\
850.0 & 849.1 & 28.27 & 12.38 \\
900.0 & 899.0 & 31.61 & 13.69 \\
950.0 & 948.9 & 34.93 & 15.32 \\
1000.0 & 998.8 & 37.88 & 16.86 \\
1050.0 & 1048.7 & 40.59 & 18.41 \\
1100.0 & 1098.6 & 43.12 & 19.69 \\
1150.0 & 1148.5 & 45.64 & 20.99 \\
1200.0 & 1198.4 & 48.15 & 22.68 \\
1250.0 & 1248.3 & 50.53 & 24.60 \\
1300.0 & 1298.2 & 53.13 & 26.58 \\
1350.0 & 1348.1 & 56.19 & 28.91 \\
1400.0 & 1397.9 & 59.69 & 31.39 \\
1450.0 & 1447.7 & 63.35 & 33.89 \\
1475.0 & 1472.6 & 65.10 & 35.30 \\
1500.0 & 1497.5 & 66.76 & 36.81 \\
1525.0 & 1522.4 & 68.42 & 38.38 \\
1550.0 & 1547.3 & 70.09 & 40.01 \\
1575.0 & 1572.1 & 71.85 & 41.73 \\
1600.0 & 1597.0 & 73.70 & 43.63 \\
1655.0 & 1651.6 & 77.97 & 48.27 \\
1660.0 & 1656.6 & 78.38 & 48.72
\end{tabular}




\section{Production Well N-11T}

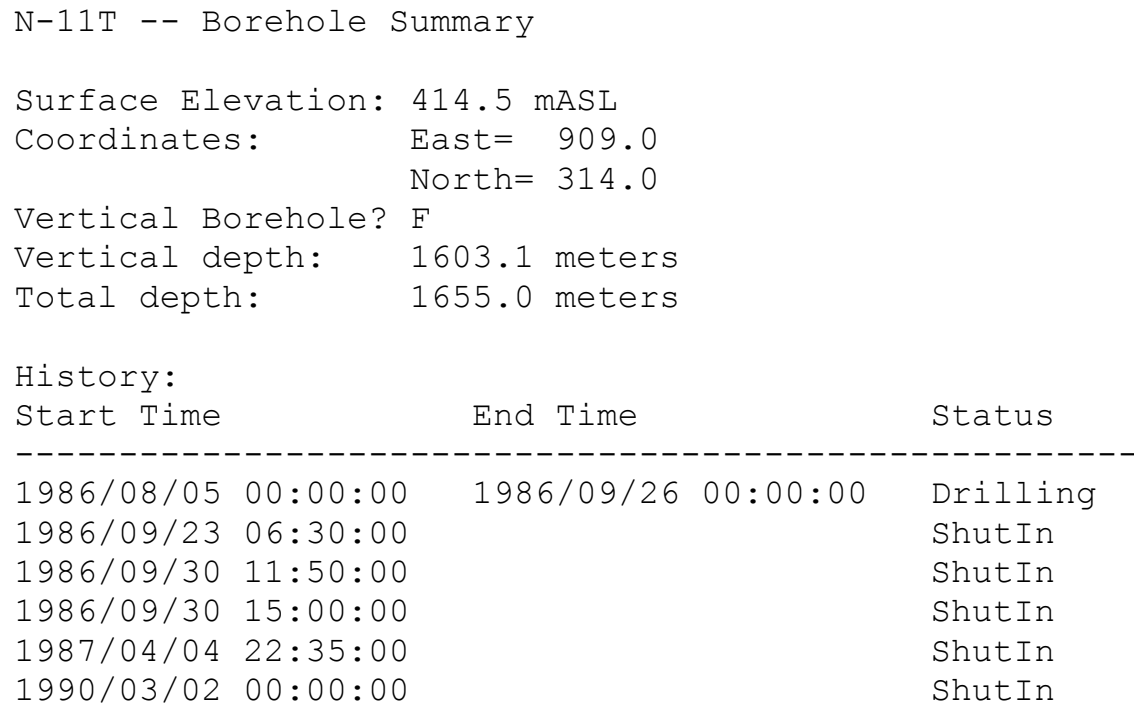

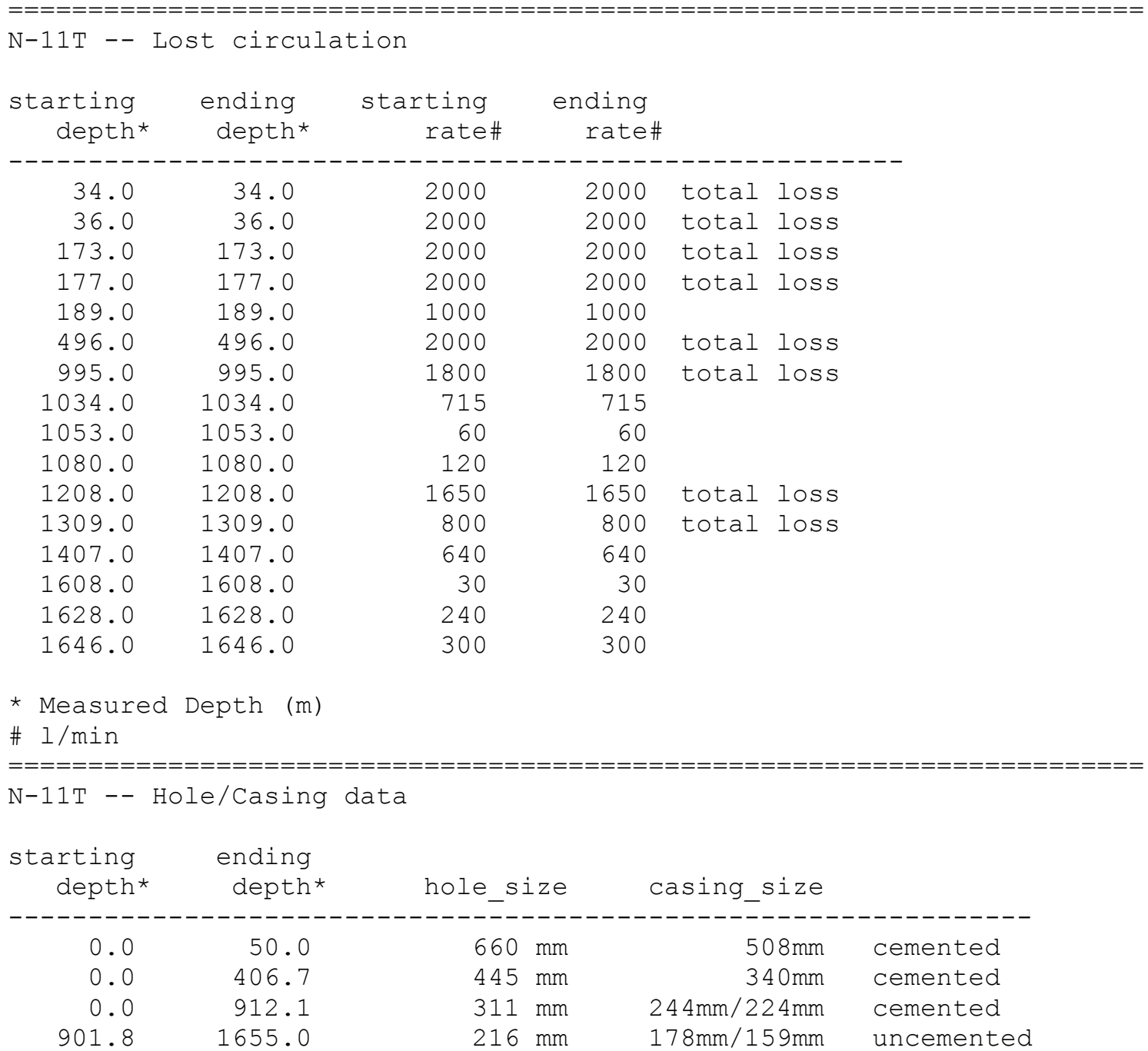




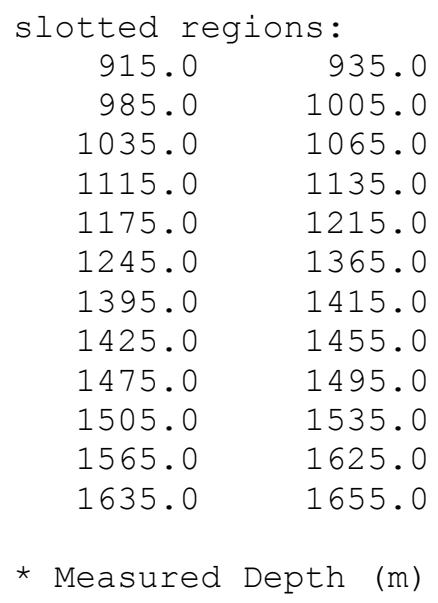




$\begin{array}{rrrr}580.0 & 579.8 & -8.38 & -2.53 \\ 590.0 & 589.8 & -9.37 & -3.23 \\ 600.0 & 599.7 & -10.45 & -3.91 \\ 621.0 & 620.5 & -12.90 & -5.49 \\ 640.0 & 639.3 & -15.27 & -7.18 \\ 660.0 & 659.0 & -17.93 & -9.28 \\ 676.0 & 674.7 & -20.22 & -11.23 \\ 698.0 & 696.2 & -23.66 & -14.15 \\ 715.0 & 712.8 & -26.62 & -16.45 \\ 734.0 & 731.3 & -30.31 & -18.91 \\ 754.0 & 750.7 & -34.49 & -21.45 \\ 773.0 & 769.0 & -38.35 & -24.42 \\ 792.0 & 787.3 & -42.01 & -27.94 \\ 812.0 & 806.6 & -45.96 & -31.66 \\ 831.0 & 824.8 & -49.94 & -35.22 \\ 850.0 & 843.0 & -54.07 & -38.73 \\ 856.0 & 848.8 & -55.40 & -39.84 \\ 865.5 & 857.8 & -57.52 & -41.64 \\ 875.0 & 866.9 & -59.65 & -43.48 \\ 884.5 & 876.0 & -61.86 & -45.35 \\ 894.0 & 885.0 & -64.18 & -47.26 \\ 903.5 & 894.0 & -66.58 & -49.19 \\ 925.0 & 914.3 & -71.84 & -54.00 \\ 944.0 & 932.1 & -76.26 & -58.62 \\ 962.5 & 949.6 & -80.48 & -63.05 \\ 981.5 & 967.6 & -84.72 & -67.49 \\ 1010.5 & 995.1 & -91.02 & -74.09 \\ 1030.0 & 1013.7 & -95.20 & -78.47 \\ 1049.0 & 1031.7 & -99.25 & -82.71 \\ 1068.0 & 1049.8 & -103.35 & -86.73 \\ 1086.0 & 1067.0 & -107.13 & -90.49 \\ 1104.0 & 1084.2 & -110.83 & -94.50 \\ 1133.0 & 1111.6 & -117.09 & -101.41 \\ 1154.0 & 1131.4 & -121.66 & -106.84 \\ 1182.5 & 1158.2 & -127.88 & -114.34 \\ 1230.0 & 1202.7 & -138.60 & -126.81 \\ 1280.0 & 1249.5 & -150.26 & -140.14 \\ 1330.0 & 1296.0 & -162.56 & -153.72 \\ 1380.0 & 1342.2 & -175.66 & -167.67 \\ 1430.0 & 1388.4 & -188.94 & -181.35 \\ 1480.0 & 1435.3 & -200.94 & -193.90 \\ 1530.0 & 1482.8 & -211.94 & -205.24 \\ 1580.0 & 1530.6 & -222.48 & -215.37 \\ 1630.0 & 1578.9 & -231.74 & -224.40 \\ 1655.0 & 1603.1 & -236.00 & -228.70\end{array}$




\section{Slim Hole N-12t}

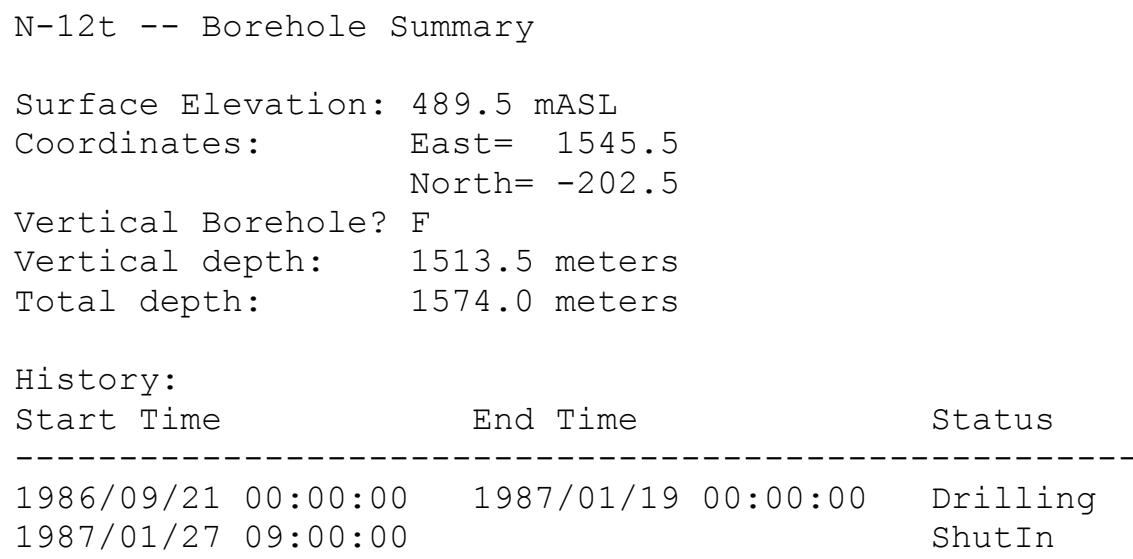

\begin{tabular}{|c|c|c|c|c|}
\hline $\begin{array}{l}\text { starting } \\
\text { depth* }\end{array}$ & $\begin{array}{l}\text { ending } \\
\text { depth* }\end{array}$ & $\begin{array}{l}\text { starting } \\
\text { rate\# }\end{array}$ & $\begin{array}{l}\text { ending } \\
\text { rate\# }\end{array}$ & \\
\hline----------- & --------- & ----------- & --------- & -------------- \\
\hline 81.0 & 81.0 & 700 & 700 & total loss \\
\hline 199.0 & 271.0 & 16 & 26 & \\
\hline 334.0 & 334.0 & 960 & 960 & total loss \\
\hline 529.0 & 529.0 & 50 & 50 & \\
\hline 635.0 & 648.0 & 30 & 70 & \\
\hline 1042.0 & 1042.0 & 85 & 85 & \\
\hline 1054.0 & 1054.0 & 7 & 7 & \\
\hline 1072.0 & 1072.0 & 13 & 13 & \\
\hline 1097.0 & 1097.0 & 7 & 7 & \\
\hline 1109.0 & 1109.0 & 13 & 13 & \\
\hline 1144.0 & 1144.0 & 6 & 6 & \\
\hline 1233.0 & 1233.0 & 7 & 7 & \\
\hline 1256.0 & 1256.0 & 7 & 7 & \\
\hline 1463.0 & 1463.0 & 7 & 7 & \\
\hline 1522.0 & 1522.0 & 13 & 13 & \\
\hline $\begin{array}{l}\text { * Measured } \\
\# 1 / \mathrm{min}\end{array}$ & Depth (m) & & & \\
\hline
\end{tabular}




\begin{tabular}{|c|c|c|c|c|}
\hline $\begin{array}{l}\text { starting } \\
\text { depth* }\end{array}$ & $\begin{array}{l}\text { ending } \\
\text { depth* }\end{array}$ & hole_size & casing_size & \\
\hline---------1 & -------- & ---------1 & ------------1 & ---------- \\
\hline 0.0 & 31.1 & $375 \mathrm{~mm}$ & $305 \mathrm{~mm}$ & cemented \\
\hline 0.0 & 406.7 & $245 \mathrm{~mm}$ & $194 \mathrm{~mm}$ & cemented \\
\hline 0.0 & 952.0 & $159 \mathrm{~mm}$ & $114 \mathrm{~mm} / 102 \mathrm{~mm}$ & cemented \\
\hline 937.8 & 1574.0 & $101 \mathrm{~mm}$ & $94 \mathrm{~mm} / 83 \mathrm{~mm}$ & uncemented \\
\hline
\end{tabular}

slotted regions:

$\begin{array}{rr}955.9 & 1123.9 \\ 1129.9 & 1147.4 \\ 1219.9 & 1237.9 \\ 1243.9 & 1251.9 \\ 1447.9 & 1465.9 \\ 1507.9 & 1525.9\end{array}$

* Measured Depth (m)

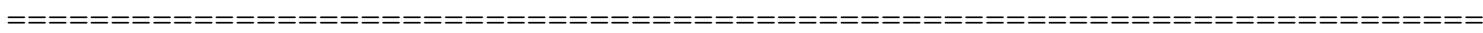
N-12t -- Stratigraphy data

$\begin{array}{ccll}\text { starting } & \text { ending major major } & \text { minor minor } \\ \text { depth* } & \text { depth* code name } & \text { code name }\end{array}$

-----------------------------------------------------------------------

$0.0 \quad 20.0 \quad$ SSR Surface Soil/rocks - _ -

$20.0 \quad 120.0 \quad$ SUN Sunagohara $\quad-$

$120.0 \quad 320.0$ URU Urushikubo -

320.0 680.0 OGI Ogino - -

680.0 720.0 MIY Miyashita Mudstone - -

720.0 1574.0 TKZ Takizawagawa -

* Measured Depth (m)

$==\mathrm{=}=\mathrm{=}=\mathrm{=}=\mathrm{=}=\mathrm{=}=\mathrm{=}=\mathrm{=}=\mathrm{=}=\mathrm{=}=\mathrm{=}=\mathrm{=}=\mathrm{=}=\mathrm{=}=\mathrm{=}=\mathrm{=}=\mathrm{=}=\mathrm{=}=\mathrm{=}=\mathrm{=}=\mathrm{=}=\mathrm{=}=\mathrm{=}=\mathrm{=}=\mathrm{=}=\mathrm{=}=\mathrm{=}$ 


\begin{tabular}{|c|c|c|c|}
\hline Meas.depth & Vert.depth & E_dev. & N_dev. \\
\hline \multicolumn{4}{|c|}{$----------------------------\overline{-}---------------$} \\
\hline 0.0 & 0.0 & 0.00 & 0.00 \\
\hline 50.0 & 50.0 & -0.36 & 0.00 \\
\hline 100.0 & 100.0 & -0.82 & 0.28 \\
\hline 150.0 & 150.0 & -0.67 & 0.82 \\
\hline 200.0 & 200.0 & -0.46 & 1.03 \\
\hline 250.0 & 250.0 & -0.66 & 0.73 \\
\hline 300.0 & 300.0 & -0.79 & 0.70 \\
\hline 350.0 & 350.0 & -0.74 & 0.92 \\
\hline 400.0 & 400.0 & -0.72 & 1.35 \\
\hline 450.0 & 450.0 & -0.70 & 1.64 \\
\hline 500.0 & 500.0 & -0.52 & 1.15 \\
\hline 523.5 & 523.5 & -0.45 & 0.96 \\
\hline 536.8 & 536.8 & -0.50 & 0.85 \\
\hline 542.9 & 542.9 & -0.55 & 0.77 \\
\hline 549.0 & 548.9 & -0.61 & 0.66 \\
\hline 555.0 & 555.0 & -0.68 & 0.52 \\
\hline 561.0 & 561.0 & -0.79 & 0.39 \\
\hline 567.1 & 567.0 & -0.88 & 0.26 \\
\hline 573.2 & 573.1 & -0.99 & 0.09 \\
\hline 585.2 & 585.2 & -1.27 & -0.35 \\
\hline 592.6 & 592.5 & -1.47 & -0.65 \\
\hline 604.3 & 604.3 & -1.77 & -1.16 \\
\hline 616.6 & 616.5 & -2.12 & -1.87 \\
\hline 628.6 & 628.5 & -2.45 & -2.79 \\
\hline 659.5 & 659.2 & -3.36 & -5.45 \\
\hline 695.7 & 695.1 & -6.04 & -9.48 \\
\hline 707.8 & 707.0 & -7.54 & -11.25 \\
\hline 720.0 & 718.9 & -9.20 & -13.19 \\
\hline 732.1 & 730.7 & -10.89 & -15.18 \\
\hline 750.4 & 748.5 & -13.55 & -18.45 \\
\hline 768.0 & 765.6 & -16.17 & -21.91 \\
\hline 780.0 & 777.2 & -17.95 & -24.45 \\
\hline 792.2 & 789.0 & -19.89 & -27.15 \\
\hline 804.5 & 800.7 & -21.87 & -29.91 \\
\hline 816.6 & 812.3 & -23.85 & -32.77 \\
\hline 828.8 & 824.0 & -25.89 & -35.83 \\
\hline 841.1 & 835.6 & -27.94 & -39.03 \\
\hline 865.8 & 859.0 & -32.30 & -45.96 \\
\hline 883.5 & 875.4 & -35.96 & -51.43 \\
\hline 914.0 & 903.1 & -43.38 & -61.77 \\
\hline 944.3 & 930.1 & -51.36 & -72.90 \\
\hline 1000.0 & 979.7 & -65.98 & -93.64 \\
\hline 1050.0 & 1024.8 & -78.60 & -111.24 \\
\hline 1100.0 & 1070.2 & -91.10 & -128.03 \\
\hline 1150.0 & 1115.9 & -102.85 & -144.38 \\
\hline 1200.0 & 1162.0 & -114.02 & -160.24 \\
\hline 1250.0 & 1208.1 & -125.34 & -176.00 \\
\hline 1300.0 & 1254.4 & -136.25 & -191.48 \\
\hline 1350.0 & 1301.0 & -146.42 & -206.47 \\
\hline 1400.0 & 1347.8 & -156.01 & -221.12 \\
\hline 1450.0 & 1394.9 & -165.01 & -235.17 \\
\hline 1500.0 & 1442.4 & -173.35 & -248.43 \\
\hline 1550.0 & 1490.3 & -180.75 & -260.63 \\
\hline 1574.0 & 1513.5 & -184.05 & -266.21 \\
\hline
\end{tabular}




\section{Slim Hole N-13t}

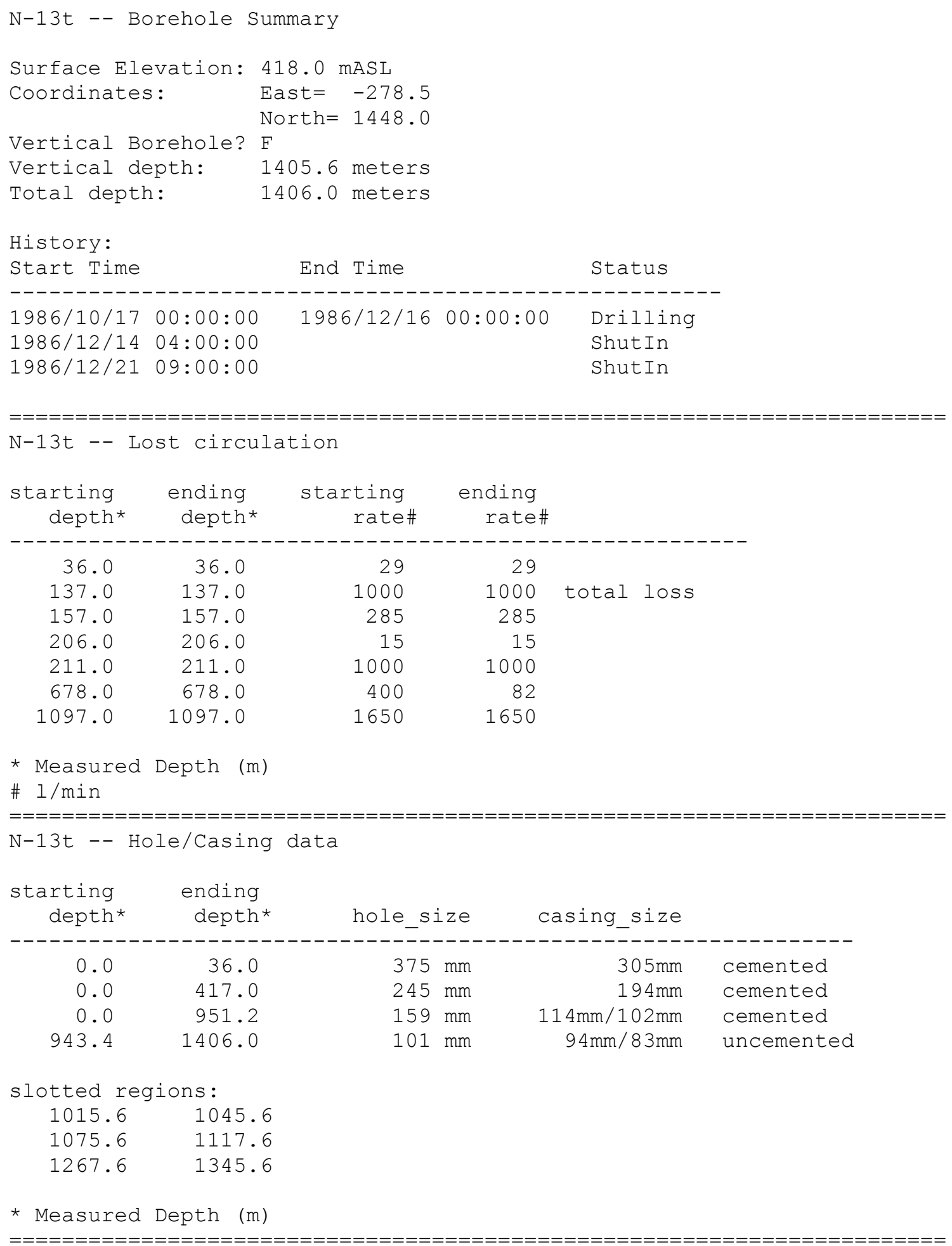


N-13t -- Stratigraphy data

\begin{tabular}{|c|c|c|c|c|c|}
\hline $\begin{array}{l}\text { starting } \\
\text { depth* }\end{array}$ & $\begin{array}{l}\text { ending } \\
\text { depth* }\end{array}$ & $\begin{array}{l}\text { major } \\
\text { code }\end{array}$ & $\begin{array}{l}\text { major } \\
\text { name }\end{array}$ & $\begin{array}{l}\text { minor } \\
\text { code }\end{array}$ & $\begin{array}{l}\text { minor } \\
\text { name }\end{array}$ \\
\hline 0.0 & 20.0 & SUR & Surface Tuffs & - & - \\
\hline 20.0 & 40.0 & SUN & Sunagohara & - & - \\
\hline 40.0 & 580.0 & URU & Urushikubo & - & - \\
\hline 580.0 & 940.0 & OGI & Ogino & - & - \\
\hline 940.0 & 953.0 & MIY & Miyashita Mud & one - & - \\
\hline 953.0 & 1406.0 & TKZ & Takizawagawa & - & - \\
\hline
\end{tabular}

$\begin{array}{rrrr}\text { Meas.depth } & \text { Vert.depth } & \text { E_dev. } & \text { N_dev. } \\ \text { 0.0 } & 0.0 & 0.00 & 0.00 \\ 100.0 & 50.0 & 0.00 & 0.00 \\ 150.0 & 100.0 & 0.00 & 0.00 \\ 200.0 & 150.0 & 0.06 & -0.04 \\ 250.0 & 200.0 & 0.09 & -0.31 \\ 300.0 & 250.0 & -0.08 & -0.86 \\ 350.0 & 300.0 & -0.46 & -1.56 \\ 400.0 & 350.0 & -0.93 & -2.29 \\ 450.0 & 400.0 & -1.44 & -2.75 \\ 500.0 & 450.0 & -1.77 & -3.05 \\ 550.0 & 500.0 & -1.67 & -3.28 \\ 600.0 & 650.0 & -1.46 & -3.31 \\ 650.0 & 650.0 & -1.24 & -3.35 \\ 700.0 & 700.0 & -1.15 & -3.58 \\ 750.0 & 750.0 & -1.49 & -3.47 \\ 762.0 & 762.0 & -2.95 & -3.04 \\ 800.0 & 799.9 & -4.00 & -3.38 \\ 821.5 & 821.4 & -4.56 & -3.45 \\ 839.0 & 838.9 & -5.17 & -3.34 \\ 857.0 & 856.9 & -5.85 & -3.62 \\ 894.0 & 893.9 & -7.20 & -4.40 \\ 912.0 & 911.8 & -8.00 & -4.60 \\ 930.0 & 929.8 & -8.63 & -4.21 \\ 942.0 & 941.8 & -9.05 & -4.02 \\ 975.0 & 974.8 & -10.36 & -4.46 \\ 1003.0 & 1002.8 & -11.28 & -4.89 \\ 1050.0 & 1049.7 & -12.82 & -5.45 \\ 1100.0 & 1099.7 & -14.17 & -5.66 \\ 1150.0 & 1149.7 & -14.98 & -6.00 \\ 1200.0 & 1199.7 & -15.19 & -6.51 \\ 1250.0 & 1249.7 & -14.73 & -6.56 \\ 1300.0 & 1299.7 & -13.66 & -6.55 \\ 1350.0 & 1349.7 & -12.14 & -6.76 \\ 1400.0 & 1399.6 & -10.36 & -7.08 \\ 1406.6 & 1406.2 & -10.11 & -7.14 \\ 1550.0 & 1549.5 & -4.82 & -8.32\end{array}$




\section{Production Well N-14T}

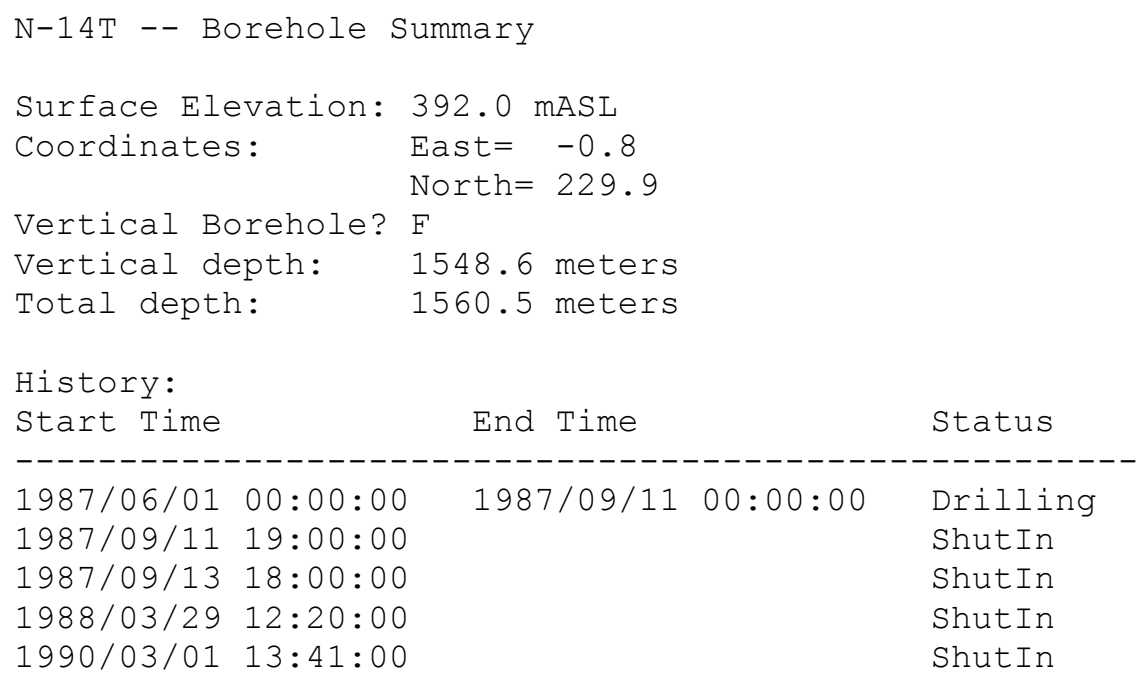

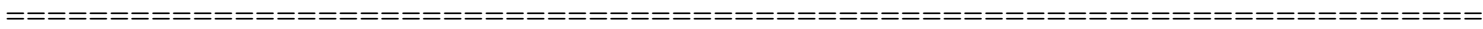
N-14T -- Lost circulation

\begin{tabular}{|c|c|c|c|c|}
\hline $\begin{array}{l}\text { starting } \\
\text { depth* }\end{array}$ & $\begin{array}{l}\text { ending } \\
\text { depth* }\end{array}$ & $\begin{array}{l}\text { starting } \\
\text { rate\# }\end{array}$ & $\begin{array}{l}\text { ending } \\
\text { rate\# }\end{array}$ & \\
\hline----------1 & --------- & ----------- & --------1 & --------------- \\
\hline 494.0 & 494.0 & 820 & 820 & \\
\hline 535.0 & 535.0 & 33 & 33 & \\
\hline 600.0 & 600.0 & 66 & 66 & \\
\hline 818.0 & 818.0 & 33 & 33 & \\
\hline 906.0 & 906.0 & 66 & 66 & \\
\hline 1005.0 & 1005.0 & 27 & 27 & \\
\hline 1072.0 & 1072.0 & 16 & 16 & \\
\hline 1130.0 & 1130.0 & 1230 & 1230 & total loss \\
\hline 1144.0 & 1144.0 & 200 & 200 & \\
\hline 1177.0 & 1177.0 & 234 & 234 & \\
\hline 1222.0 & 1222.0 & 230 & 230 & \\
\hline 1233.0 & 1233.0 & 66 & 66 & \\
\hline 1251.0 & 1251.0 & 262 & 262 & \\
\hline 1262.0 & 1262.0 & 164 & 164 & \\
\hline 1274.0 & 1274.0 & 164 & 164 & \\
\hline 1303.0 & 1303.0 & 164 & 164 & \\
\hline 1343.0 & 1343.0 & 164 & 164 & \\
\hline 1348.0 & 1348.0 & 164 & 164 & \\
\hline 1353.0 & 1353.0 & 276 & 276 & \\
\hline 1435.0 & 1435.0 & 336 & 336 & \\
\hline 1466.0 & 1466.0 & 448 & 448 & \\
\hline 1486.0 & 1486.0 & 561 & 561 & total loss \\
\hline 1520.0 & 1520.0 & 164 & 164 & \\
\hline 1557.0 & 1557.0 & 164 & 164 & \\
\hline $\begin{array}{l}\text { * Measured } \\
\# \text { 1/min }\end{array}$ & Depth (m) & & & \\
\hline
\end{tabular}




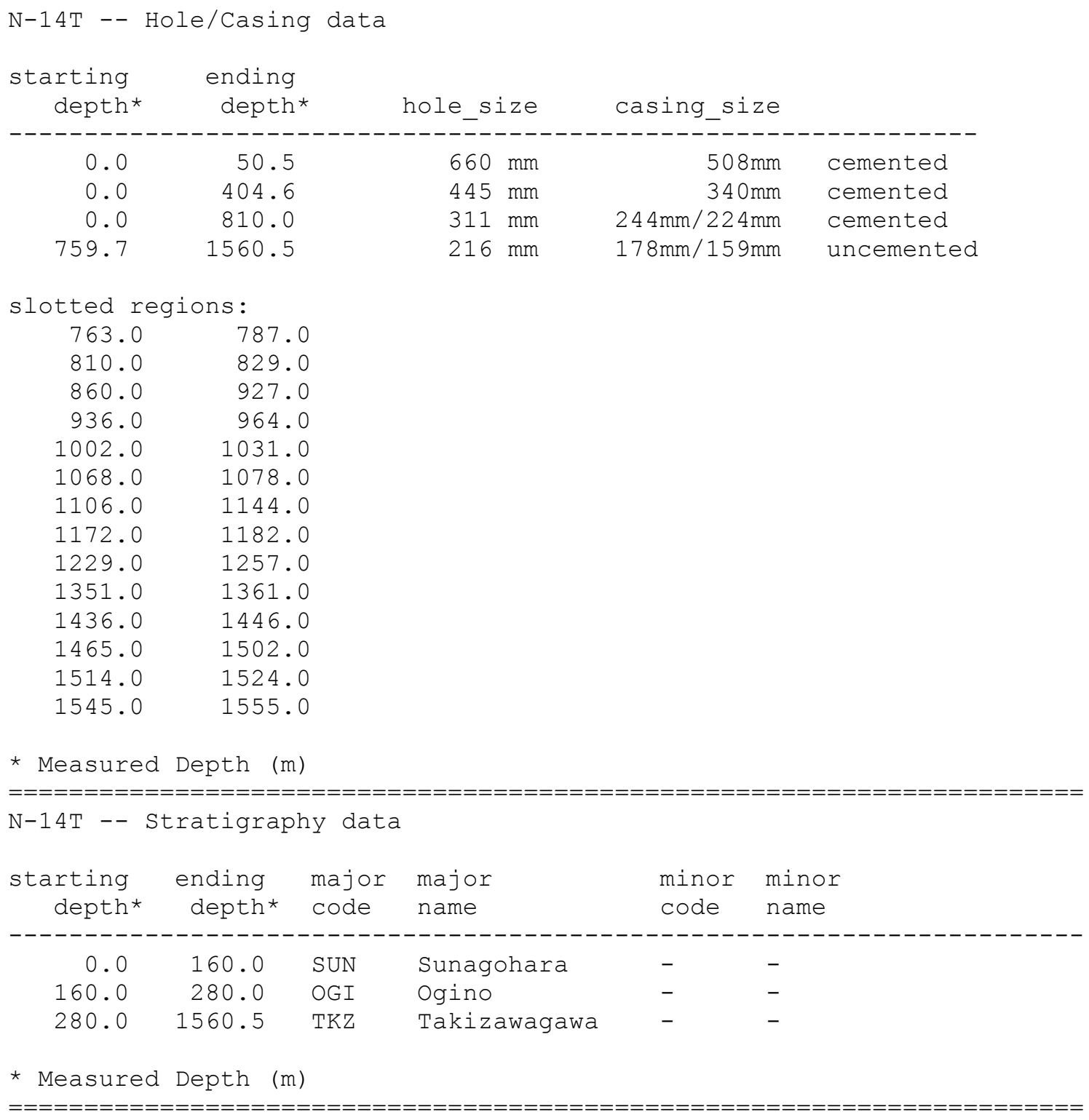

\footnotetext{
$================$
}

N-14T -- Deviation data (m)

Meas.depth Vert.depth E_dev. N_dev.

$\begin{array}{ccc}0.0 & 0.0 & 0.00\end{array}$

$100.0-100.0$

$\begin{array}{llll}150.0 & 150.0 & 0.28 & -0.06\end{array}$

$200.0 \quad 200.0 \quad 0.28 \quad-0.06$

$\begin{array}{llll}250.0 & 250.0 & 0.28 & -0.06\end{array}$

$\begin{array}{llll}300.0 & 300.0 & 0.28 & -0.06\end{array}$

$\begin{array}{llll}350.0 & 350.0 & 0.28 & -0.06\end{array}$

$\begin{array}{llll}400.0 & 400.0 & 0.28 & -0.06\end{array}$

$\begin{array}{llll}450.0 & 450.0 & 0.28 & -0.06\end{array}$

$\begin{array}{llll}500.0 & 500.0 & 0.28 & -0.06\end{array}$

$\begin{array}{llll}550.0 & 550.0 & 0.15 & 0.11\end{array}$ 


$\begin{array}{rrrr}600.0 & 600.0 & -0.06 & 0.72 \\ 610.0 & 610.0 & -0.12 & 0.85 \\ 630.0 & 630.0 & -0.44 & 0.92 \\ 648.0 & 648.0 & -1.32 & 1.01 \\ 657.0 & 656.9 & -2.05 & 0.81 \\ 676.0 & 675.9 & -3.38 & -0.09 \\ 685.0 & 684.8 & -4.18 & -0.73 \\ 695.0 & 694.7 & -5.48 & -1.80 \\ 711.0 & 710.4 & -7.58 & -3.58 \\ 724.0 & 723.2 & -9.26 & -5.09 \\ 747.0 & 745.9 & -12.26 & -7.77 \\ 756.0 & 754.7 & -13.46 & -8.82 \\ 774.0 & 772.4 & -15.84 & -10.92 \\ 810.0 & 807.9 & -20.58 & -15.09 \\ 819.0 & 816.8 & -21.75 & -16.12 \\ 828.0 & 825.6 & -22.91 & -17.14 \\ 855.0 & 852.2 & -26.37 & -20.19 \\ 870.0 & 867.0 & -28.30 & -21.88 \\ 897.0 & 893.6 & -31.78 & -24.84 \\ 923.0 & 919.3 & -35.13 & -27.58 \\ 951.0 & 946.9 & -38.69 & -30.40 \\ 982.0 & 977.5 & -42.71 & -33.35 \\ 1005.0 & 1000.2 & -45.69 & -35.47 \\ 1036.0 & 1030.8 & -49.72 & -38.32 \\ 1063.0 & 1057.4 & -53.32 & -40.88 \\ 1090.0 & 1084.1 & -56.96 & -43.45 \\ 1116.0 & 1109.7 & -60.46 & -45.94 \\ 1143.0 & 1136.3 & -64.20 & -48.49 \\ 1170.0 & 1162.9 & -68.00 & -50.90 \\ 1200.0 & 1192.5 & -72.13 & -53.46 \\ 1242.0 & 1234.0 & -77.84 & -57.07 \\ 1260.0 & 1251.8 & -80.29 & -58.51 \\ 1287.0 & 1278.4 & -84.28 & -60.39 \\ 1311.0 & 1302.1 & -88.03 & -61.64 \\ 1343.0 & 1333.6 & -93.35 & -62.89 \\ 1366.0 & 1356.3 & -97.05 & -63.95 \\ 1384.0 & 1374.1 & -99.47 & -64.92 \\ 1403.0 & 1392.9 & -101.70 & -65.88 \\ 1430.0 & 1419.8 & -104.54 & -67.10 \\ 1448.0 & 1437.6 & -106.48 & -67.94 \\ 1484.0 & 1473.3 & -110.86 & -69.78 \\ 1511.0 & 1500.0 & -114.53 & -71.25 \\ 1538.0 & 1526.7 & -118.64 & -72.86 \\ 1560.0 & 1548.3 & -122.34 & -74.23\end{array}$




\section{Production Well N-15T}

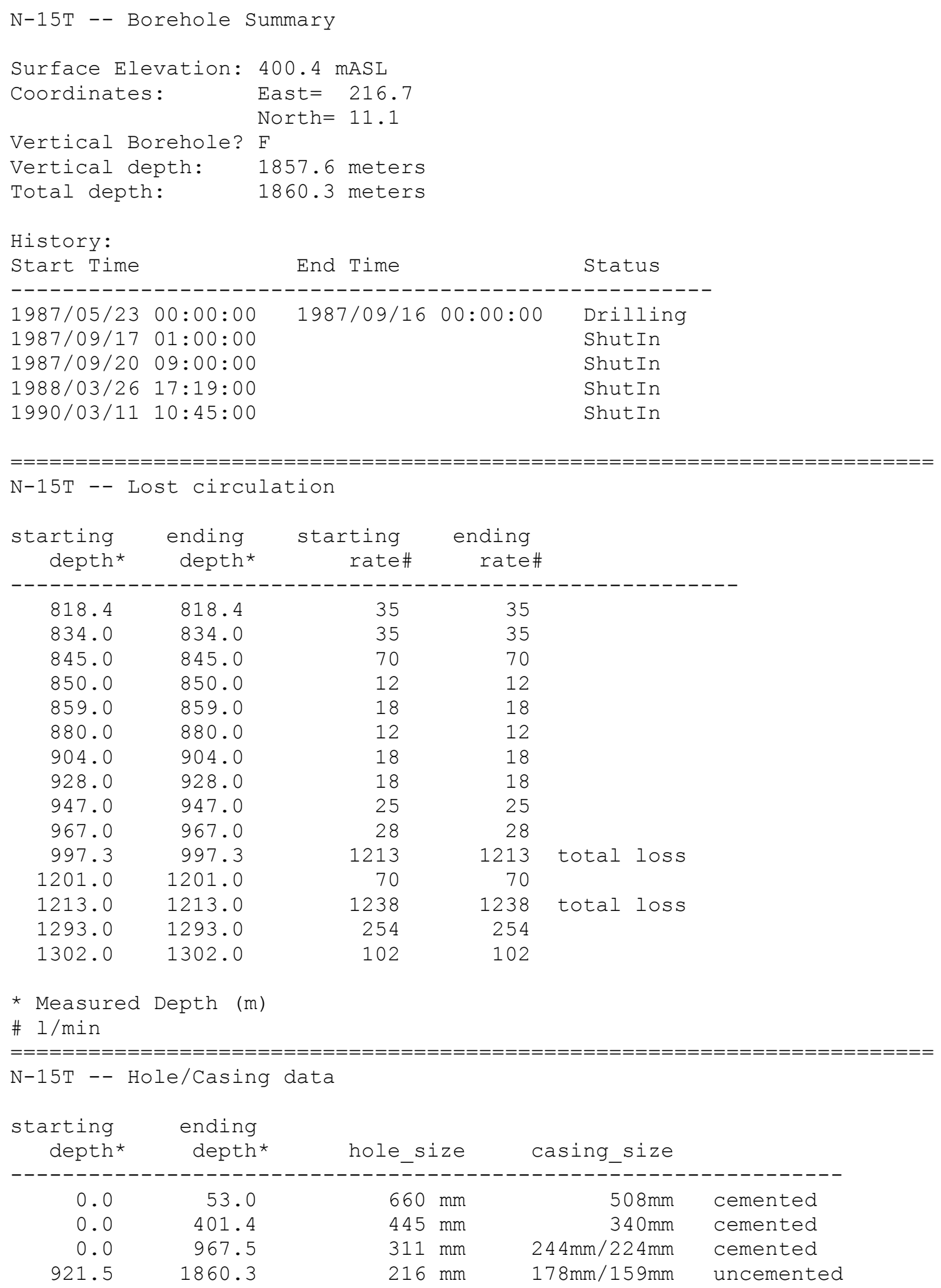




$\begin{array}{rr}\text { slotted regions: } \\ 925.0 & 948.0 \\ 977.0 & 1010.0 \\ 1022.0 & 1031.0 \\ 1041.0 & 1060.0 \\ 1098.0 & 1116.0 \\ 1154.0 & 1221.0 \\ 1258.0 & 1287.0 \\ 1325.0 & 1372.0 \\ 1641.0 & 1651.0 \\ 1682.0 & 1691.0 \\ 1713.0 & 1732.0 \\ 1744.0 & 1762.0 \\ 1772.0 & 1791.0 \\ 1803.0 & 1843.0\end{array}$

* Measured Depth (m)

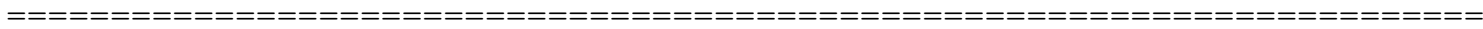
N-15T - Stratigraphy data

\begin{tabular}{|c|c|c|c|c|c|}
\hline $\begin{array}{l}\text { starting } \\
\text { depth* }\end{array}$ & $\begin{array}{l}\text { ending } \\
\text { depth* }\end{array}$ & $\begin{array}{l}\text { major } \\
\text { code }\end{array}$ & $\begin{array}{l}\text { major } \\
\text { name }\end{array}$ & $\begin{array}{l}\text { minor } \\
\text { code }\end{array}$ & $\begin{array}{l}\text { minor } \\
\text { name }\end{array}$ \\
\hline----------- & --------1 & ------ & ------------ & ------- & ------- \\
\hline 0.0 & 200.0 & SUN & Sunagohara & - & - \\
\hline 200.0 & 220.0 & OGI & Ogino & - & - \\
\hline 220.0 & 300.0 & MIY & Miyashita Muc & one - & - \\
\hline 300.0 & 1860.3 & TKZ & Takizawagawa & - & - \\
\hline
\end{tabular}

$\begin{array}{cccc}\text { Meas.depth } & \text { Vert.depth } & \text { E_dev. } & \text { N_dev. } \\ 0.0 & 0.0 & 0.00 & 0.00 \\ 50.0 & 50.0 & 0.00 & 0.00 \\ 100.0 & 100.0 & -0.06 & -0.28 \\ 150.0 & 150.0 & -0.18 & -0.78 \\ 200.0 & 200.0 & -0.29 & -1.28 \\ 250.0 & 250.0 & -0.36 & -1.78 \\ 300.0 & 300.0 & -0.38 & -2.22 \\ 350.0 & 350.0 & -0.35 & -2.57 \\ 400.0 & 400.0 & -0.26 & -2.66 \\ 450.0 & 450.0 & -0.07 & -2.56 \\ 500.0 & 500.0 & 0.29 & -2.23 \\ 550.0 & 550.0 & 0.76 & -1.67 \\ 600.0 & 600.0 & 1.09 & -1.05 \\ 650.0 & 650.0 & 1.32 & -0.45 \\ 700.0 & 700.0 & 1.68 & 0.10 \\ 750.0 & 750.0 & 2.07 & 0.71 \\ 800.0 & 800.0 & 2.76 & 1.45 \\ 850.0 & 849.9 & 3.79 & 2.37 \\ 900.0 & 899.9 & 4.81 & 3.30 \\ 909.0 & 908.9 & 4.90 & 3.38 \\ 927.0 & 926.9 & 4.43 & 3.28 \\ 946.0 & 945.8 & 3.04 & 2.93 \\ 955.0 & 954.8 & 2.05 & 2.65\end{array}$




$\begin{array}{rrrr}964.0 & 963.7 & 0.87 & 2.17 \\ 973.0 & 972.6 & -0.47 & 1.54 \\ 982.0 & 981.4 & -1.90 & 0.88 \\ 993.0 & 992.3 & -3.42 & -0.07 \\ 1012.0 & 1011.1 & -5.45 & -1.84 \\ 1021.0 & 1020.0 & -6.25 & -2.65 \\ 1030.0 & 1029.0 & -6.99 & -3.40 \\ 1039.0 & 1037.9 & -7.69 & -4.13 \\ 1057.0 & 1055.8 & -9.03 & -5.56 \\ 1075.0 & 1073.7 & -10.34 & -6.94 \\ 1093.0 & 1091.6 & -11.62 & -8.28 \\ 1103.0 & 1101.6 & -12.32 & -9.00 \\ 1120.0 & 1118.5 & -13.52 & -10.18 \\ 1138.0 & 1136.4 & -14.79 & -11.42 \\ 1166.0 & 1164.3 & -16.64 & -13.36 \\ 1178.0 & 1176.2 & -17.40 & -14.15 \\ 1201.0 & 1199.1 & -18.88 & -15.44 \\ 1237.0 & 1235.0 & -21.19 & -16.87 \\ 1273.0 & 1270.9 & -23.50 & -17.82 \\ 1302.0 & 1299.9 & -25.15 & -18.62 \\ 1328.0 & 1325.8 & -26.10 & -19.90 \\ 1355.0 & 1352.8 & -26.81 & -21.60 \\ 1381.0 & 1378.7 & -27.48 & -23.21 \\ 1409.0 & 1406.6 & -28.17 & -24.86 \\ 1440.0 & 1437.6 & -28.73 & -26.57 \\ 1475.0 & 1472.5 & -29.05 & -28.32 \\ 1485.0 & 1482.5 & -29.07 & -28.78 \\ 1511.0 & 1508.5 & -29.15 & -29.87 \\ 1538.0 & 1535.5 & -29.05 & -30.78 \\ 1565.0 & 1562.5 & -28.59 & -31.51 \\ 1593.0 & 1590.5 & -28.08 & -32.19 \\ 1620.0 & 1617.4 & -27.50 & -32.83 \\ 1647.0 & 1644.4 & -26.89 & -33.39 \\ 1680.0 & 1677.4 & -26.11 & -34.10 \\ 1707.0 & 1704.4 & -25.42 & -34.74 \\ 1743.0 & 1740.4 & -24.53 & -35.56 \\ 1798.0 & 1795.3 & -23.18 & -36.80 \\ 1830.0 & 1827.3 & -22.33 & -37.52 \\ 1860.0 & 1857.3 & -21.45 & -38.09\end{array}$




\section{Production Well N-16T}

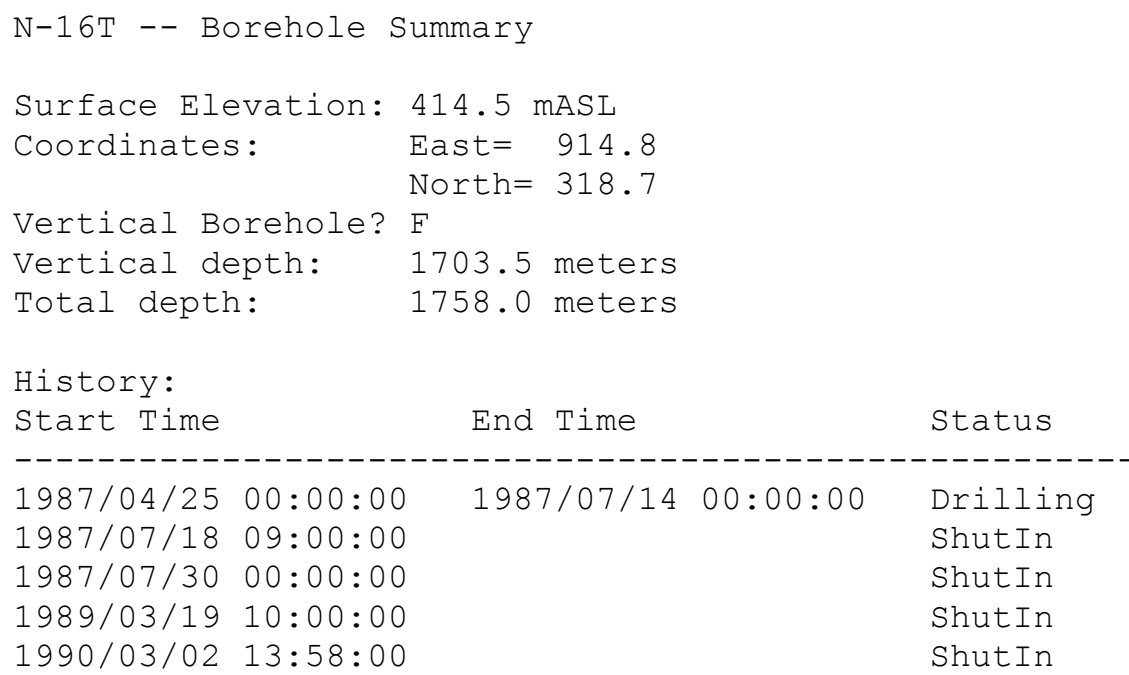

--------------------------------------------------------

$35.0 \quad 35.0 \quad 1950 \quad 1950$ total loss

$\begin{array}{llll}53.2 & 53.2 & 1950 & 1950 \text { total loss }\end{array}$

$66.0 \quad 66.0 \quad 1704 \quad 1704$ total loss

$\begin{array}{llll}175.7 & 175.7 & 460 & 460\end{array}$

$\begin{array}{llll}222.5 & 222.5 & 450 & 450\end{array}$

$\begin{array}{llll}507.0 & 507.0 & 168 & 168\end{array}$

$513.0 \quad 513.0 \quad 132 \quad 132$

$\begin{array}{llll}570.0 & 570.0 & 48 & 48\end{array}$

$\begin{array}{llll}589.0 & 589.0 & 96 & 96\end{array}$

$627.0 \quad 627.0 \quad 48 \quad 48$

$\begin{array}{llll}732.0 & 732.0 & 48 & 48\end{array}$

$\begin{array}{llll}741.0 & 741.0 & 144 & 144\end{array}$

$\begin{array}{llll}779.0 & 779.0 & 48 & 48\end{array}$

$\begin{array}{llll}1072.0 & 1072.0 & 175 & 175\end{array}$

$\begin{array}{llll}1177.0 & 1177.0 & 134 & 134\end{array}$

$\begin{array}{llll}1323.0 & 1323.0 & 302 & 302\end{array}$

$\begin{array}{rrrrr}1405.0 & 1405.0 & 1378 & 1378 & \text { total loss } \\ 1432.0 & 1432.0 & 89 & 89 & \end{array}$

$1619.0 \quad 1619.0 \quad 1596 \quad 1596$ total loss

* Measured Depth (m)

\# $1 / \mathrm{min}$ 


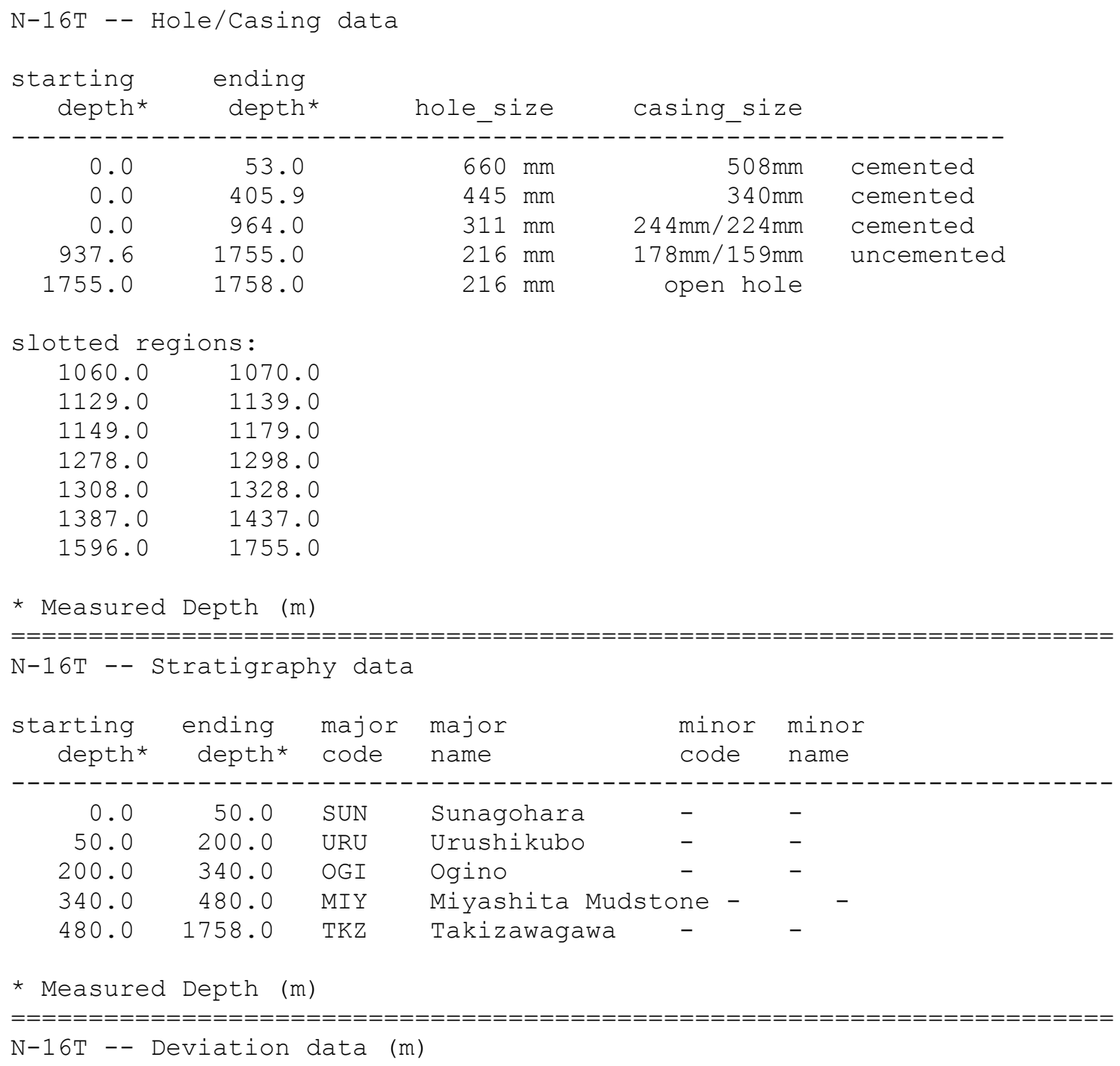




$\begin{array}{rrrr}638.0 & 637.8 & -1.80 & -5.57 \\ 648.0 & 647.8 & -2.66 & -5.98 \\ 657.0 & 656.7 & -3.60 & -6.34 \\ 664.0 & 663.7 & -4.39 & -6.68 \\ 673.0 & 672.6 & -5.51 & -7.09 \\ 683.0 & 682.5 & -6.93 & -7.50 \\ 692.0 & 691.4 & -8.27 & -7.90 \\ 701.0 & 700.3 & -9.56 & -8.41 \\ 711.0 & 710.2 & -11.01 & -8.96 \\ 731.0 & 729.9 & -14.14 & -9.78 \\ 750.0 & 748.6 & -17.41 & -10.65 \\ 760.0 & 758.4 & -19.18 & -11.24 \\ 778.0 & 776.1 & -22.49 & -12.20 \\ 797.0 & 794.7 & -26.36 & -13.01 \\ 805.0 & 802.5 & -28.08 & -13.37 \\ 835.0 & 831.6 & -34.97 & -14.62 \\ 852.0 & 848.1 & -39.17 & -15.31 \\ 873.0 & 868.3 & -44.63 & -16.31 \\ 892.0 & 886.6 & -49.87 & -17.36 \\ 912.0 & 905.7 & -55.75 & -17.79 \\ 954.0 & 945.5 & -69.19 & -18.80 \\ 975.0 & 965.0 & -76.54 & -20.49 \\ 991.0 & 979.9 & -82.29 & -22.17 \\ 1010.0 & 997.5 & -89.12 & -24.18 \\ 1029.0 & 1015.1 & -95.90 & -26.10 \\ 1048.0 & 1032.8 & -102.54 & -27.92 \\ 1095.0 & 1076.8 & -118.67 & -32.04 \\ 1144.0 & 1122.8 & -135.14 & -36.10 \\ 1195.0 & 1170.8 & -151.76 & -39.74 \\ 1252.0 & 1224.8 & -170.02 & -43.07 \\ 1292.0 & 1262.6 & -182.78 & -44.38 \\ 1348.0 & 1315.8 & -200.22 & -46.46 \\ 1385.0 & 1351.0 & -211.44 & -48.91 \\ 1424.0 & 1388.1 & -222.61 & -52.81 \\ 1443.0 & 1406.2 & -227.89 & -55.25 \\ 1472.0 & 1433.7 & -236.28 & -59.23 \\ 1529.0 & 1487.6 & -252.98 & -67.50 \\ 1557.0 & 1514.1 & -260.97 & -71.63 \\ 1577.0 & 1533.0 & -266.51 & -74.73 \\ 1624.0 & 1577.5 & -279.60 & -82.40 \\ 1758.0 & 1614.3 & -291.01 & -88.54 \\ 163.0 & 1632.2 & -296.72 & -91.43 \\ 1682.0 & -312.88 & -99.79 \\ 1703.5 & -320.04 & -103.48\end{array}$




\section{Production Well N-17T}

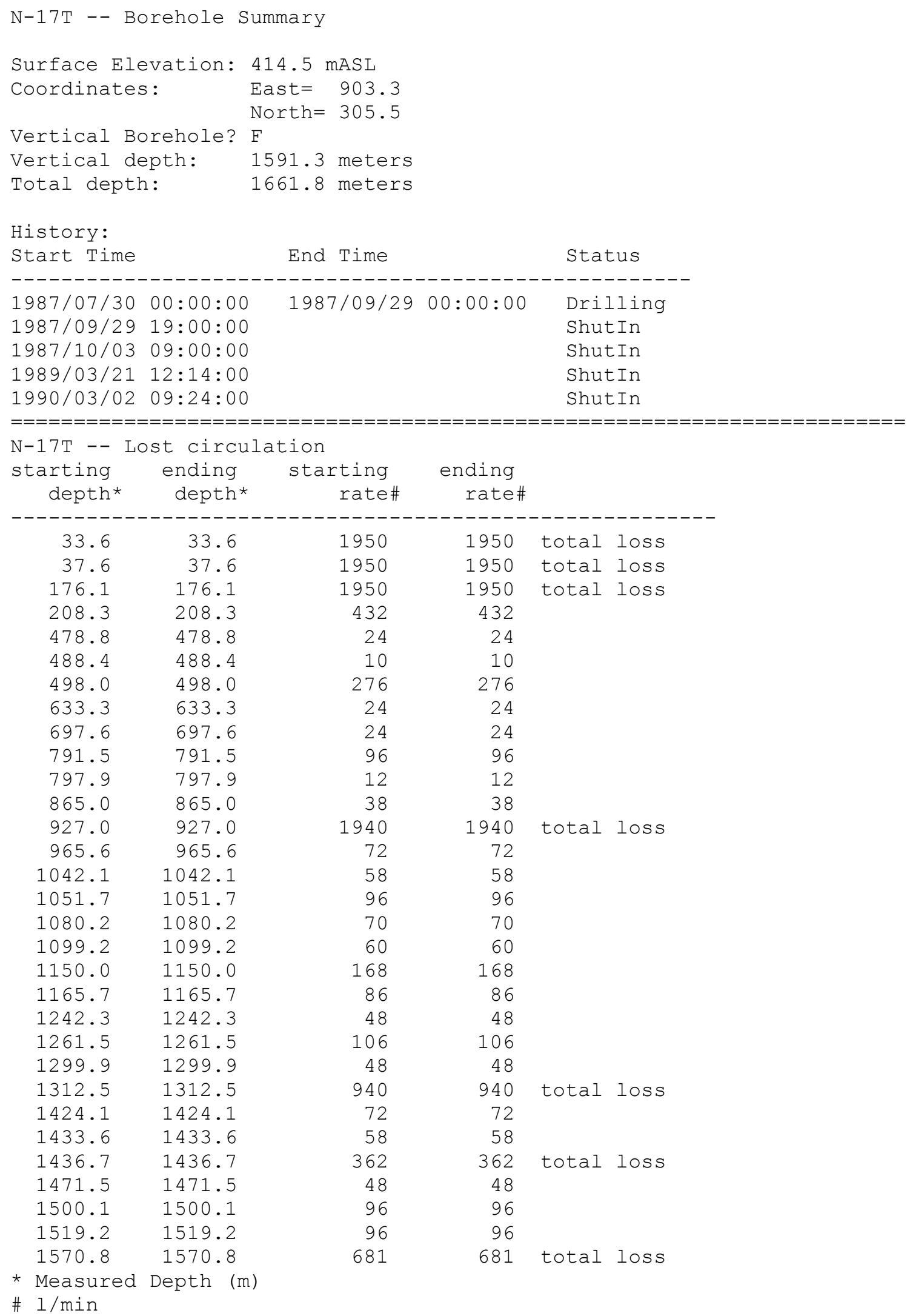




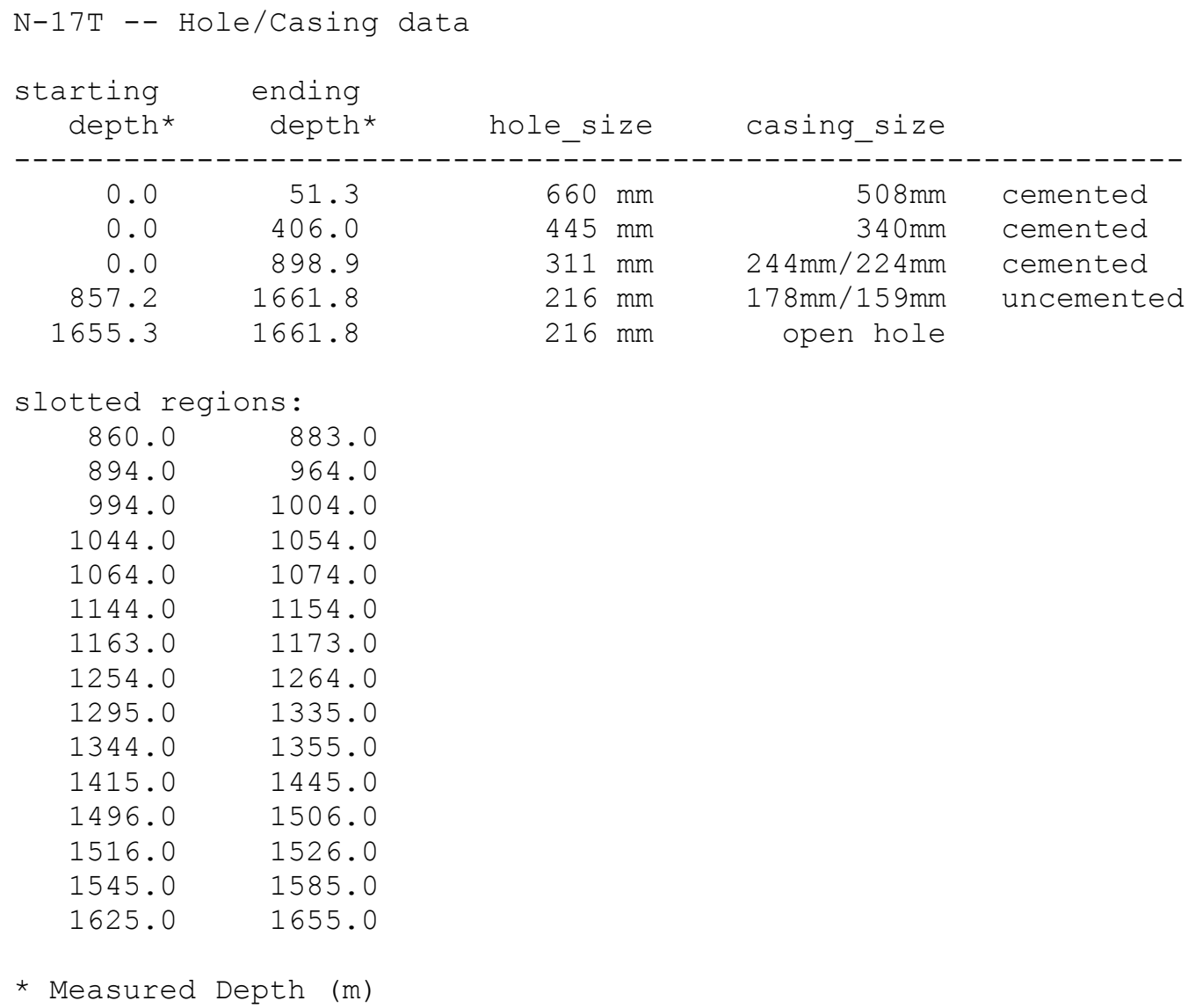


N-17T -- Deviation data (m)

\begin{tabular}{|c|c|c|c|}
\hline Meas.depth & Vert.depth & E_dev. & N_dev \\
\hline 0.0 & 0.0 & 0.00 & 0.00 \\
\hline 50.0 & 50.0 & -0.06 & 0.21 \\
\hline 100.0 & 100.0 & 0.00 & 0.59 \\
\hline 150.0 & 150.0 & 0.28 & 0.92 \\
\hline 200.0 & 200.0 & 0.26 & 1.22 \\
\hline 250.0 & 250.0 & 0.22 & 1.52 \\
\hline 300.0 & 300.0 & 0.53 & 1.83 \\
\hline 350.0 & 350.0 & 0.60 & 2.15 \\
\hline 400.0 & 400.0 & 0.68 & 2.46 \\
\hline 450.0 & 450.0 & 0.87 & 2.58 \\
\hline 500.0 & 500.0 & 0.85 & 2.14 \\
\hline 550.0 & 550.0 & 0.70 & 1.14 \\
\hline 572.0 & 572.0 & 0.69 & 0.32 \\
\hline 593.0 & 592.9 & 0.86 & -0.95 \\
\hline 612.0 & 611.8 & 0.84 & -2.50 \\
\hline 632.0 & 631.8 & 0.74 & -4.50 \\
\hline 651.0 & 650.6 & 0.62 & -6.69 \\
\hline 678.0 & 677.4 & 0.05 & -10.36 \\
\hline 697.0 & 696.1 & -0.31 & $-13 \cdot 31$ \\
\hline 716.0 & 714.9 & -0.57 & -16.46 \\
\hline 745.0 & 743.4 & -0.99 & -21.65 \\
\hline 769.0 & 766.9 & -1.07 & -26.49 \\
\hline 789.0 & 786.4 & -1.05 & -31.05 \\
\hline 810.0 & 806.7 & -1.21 & -36.30 \\
\hline 826.0 & 822.1 & -1.29 & -40.62 \\
\hline 845.0 & 840.3 & -1.41 & -46.23 \\
\hline 864.0 & 858.3 & -1.64 & -52.15 \\
\hline 883.0 & 876.3 & -1.86 & $-58 \cdot 22$ \\
\hline 902.0 & 894.2 & -2.11 & -64.56 \\
\hline 922.0 & 913.0 & -2.55 & -71.44 \\
\hline 937.0 & 927.0 & -2.98 & -76.72 \\
\hline 956.0 & 944.8 & -3.50 & -83.50 \\
\hline 975.0 & 962.5 & -4.03 & -90.29 \\
\hline 994.0 & 980.2 & -4.58 & -97.11 \\
\hline 1013.0 & 997.9 & -5.15 & -104.02 \\
\hline 1055.0 & 1036.9 & -6.28 & -119.60 \\
\hline 1074.0 & 1054.5 & -6.80 & -126.70 \\
\hline 1103.0 & 1081.4 & -7.60 & -137.65 \\
\hline 1151.0 & 1125.7 & -8.78 & -156.11 \\
\hline 1170.0 & 1143.2 & -9.30 & -163.33 \\
\hline 1189.0 & 1160.9 & -9.82 & -170.36 \\
\hline 1210.0 & 1180.4 & -10.44 & -178.05 \\
\hline 1237.0 & 1205.5 & -11.08 & -187.96 \\
\hline 1266.0 & 1232.4 & -11.11 & -198.70 \\
\hline 1290.0 & 1254.7 & -10.98 & -207.79 \\
\hline 1319.0 & 1281.5 & -10.91 & -218.89 \\
\hline 1328.0 & 1289.7 & -10.99 & -222.41 \\
\hline 1371.0 & 1329.1 & -11.95 & -239.76 \\
\hline 1419.0 & 1372.8 & -13.22 & -259.56 \\
\hline 1467.0 & 1416.1 & -14.35 & -280.13 \\
\hline 1515.0 & 1459.3 & -15.33 & -301.09 \\
\hline 1562.0 & 1501.6 & -16.28 & -321.49 \\
\hline 1608.0 & 1543.0 & -17.21 & -341.51 \\
\hline 1650.0 & 1580.8 & -18.07 & -359.90 \\
\hline 1660.0 & 1589.8 & -18.27 & -364.28 \\
\hline
\end{tabular}




\section{Slim Hole N-18t}

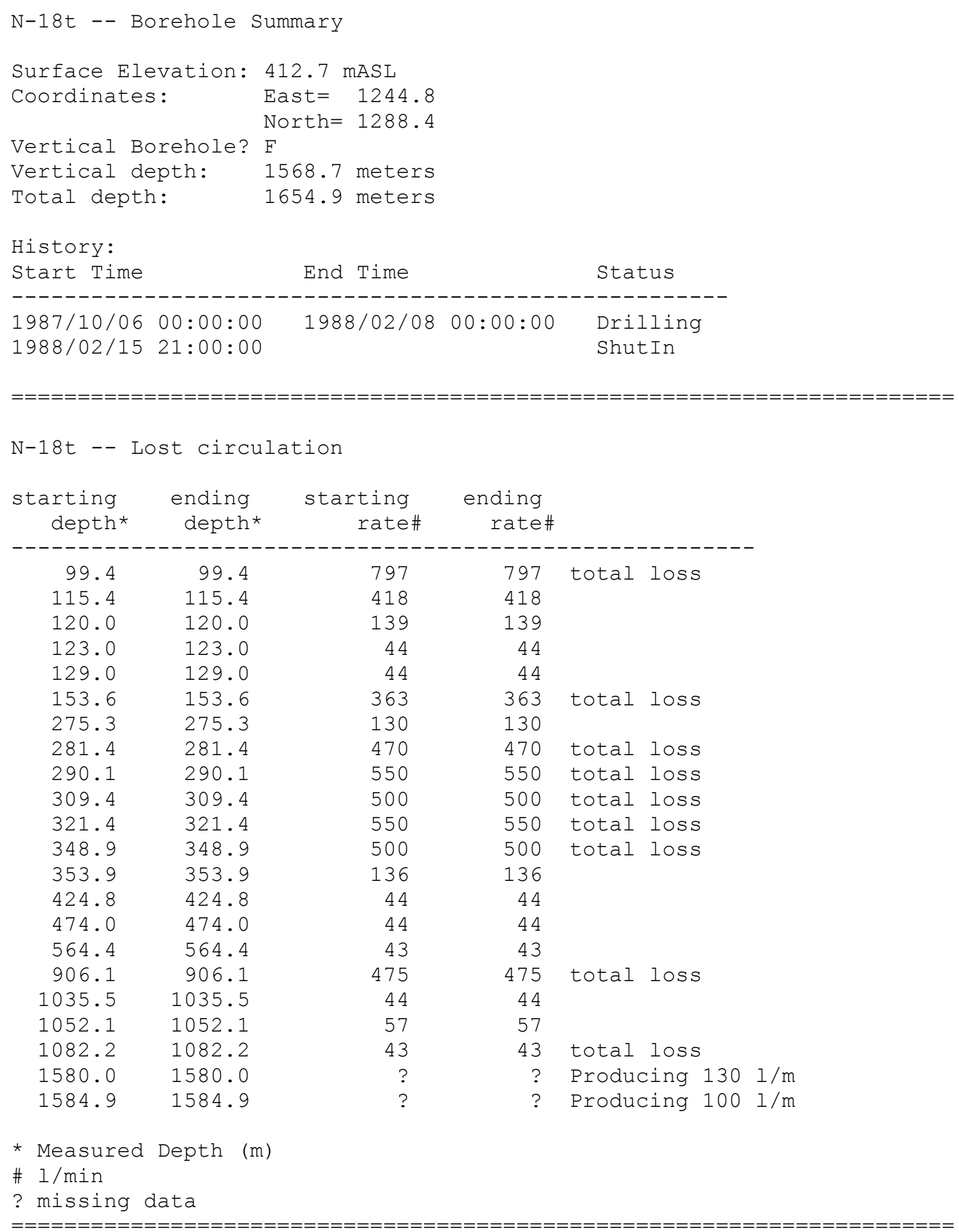




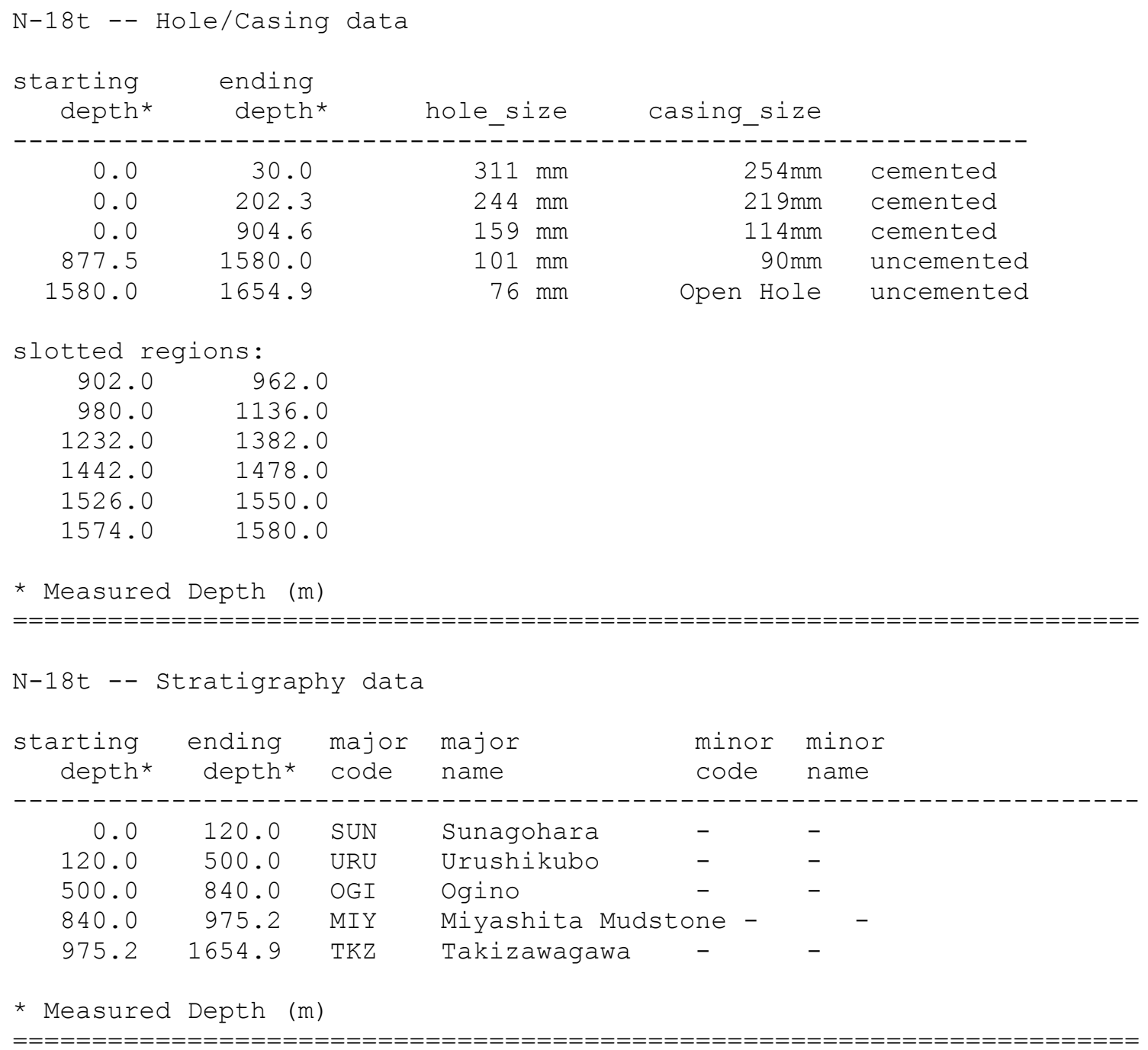


N-18t -- Deviation data (m)

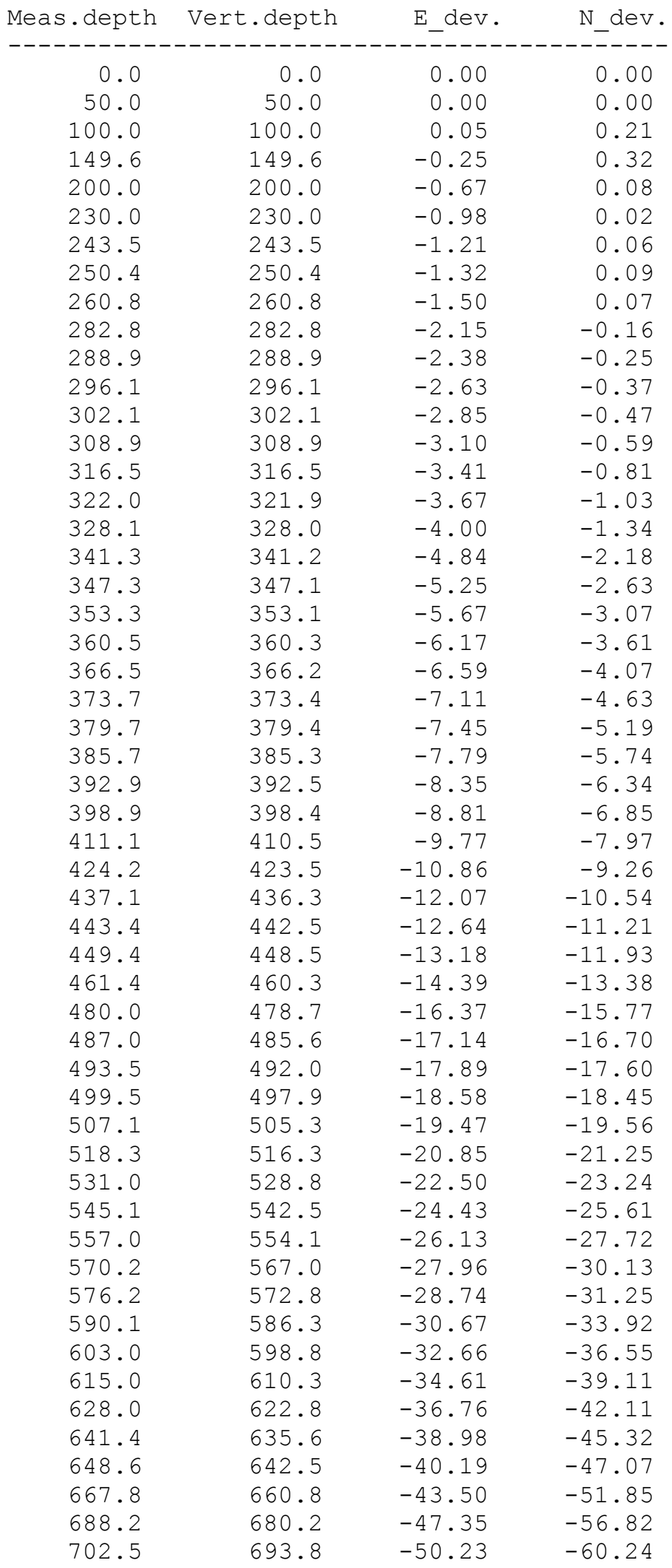




\begin{tabular}{|c|c|c|c|}
\hline 726.5 & 716.5 & -55.25 & -66.17 \\
\hline 733.7 & 723.3 & -56.80 & -68.04 \\
\hline 748.2 & 736.8 & -60.01 & -71.97 \\
\hline 762.6 & 750.3 & -63.31 & -76.02 \\
\hline 767.4 & 754.7 & -64.42 & -77.41 \\
\hline 784.0 & 770.1 & -68.39 & -82.37 \\
\hline 797.5 & 782.4 & -71.79 & -86.61 \\
\hline 809.6 & 793.4 & -75.05 & -90.61 \\
\hline 820.8 & 803.4 & -78.32 & -94.41 \\
\hline 835.4 & 816.3 & -83.16 & -99.28 \\
\hline 840.2 & 820.5 & -84.85 & -100.87 \\
\hline 853.3 & 831.9 & -89.36 & -105.27 \\
\hline 861.3 & 839.0 & -92.09 & -107.94 \\
\hline 874.5 & 850.6 & -96.46 & -112.43 \\
\hline 887.0 & 861.6 & -100.48 & -116.87 \\
\hline 900.2 & 873.0 & -104.76 & -121.85 \\
\hline 928.6 & 897.5 & -113.73 & -133.04 \\
\hline 951.6 & 917.5 & -120.58 & -142.06 \\
\hline 964.1 & 928.5 & -124.20 & -146.88 \\
\hline 993.8 & 954.5 & -132.87 & -158.19 \\
\hline 1025.3 & 982.2 & -142.21 & -170.06 \\
\hline 1058.2 & 1011.3 & -151.69 & -182.20 \\
\hline 1081.4 & 1031.9 & -158.11 & -190.5 \\
\hline 1107.9 & 1055.6 & -165.18 & -200.0 \\
\hline 1136.9 & 1081.8 & -172.29 & -210.3 \\
\hline 1166.9 & 1109.0 & -179.21 & -220.9 \\
\hline 1196.9 & 1136.3 & -185.97 & -231.44 \\
\hline 1220.9 & 1158.1 & -191.33 & -239.7 \\
\hline 1246.8 & 1181.8 & -197.06 & -248.7 \\
\hline 1268.9 & 1202.0 & -201.77 & -256.1 \\
\hline 1294.7 & 1225.8 & -206.98 & -264.6 \\
\hline 1312.6 & 1242.4 & -210.49 & -270.3 \\
\hline 1340.7 & 1268.6 & -215.88 & -279.0 \\
\hline 1374.1 & 1299.9 & -221.92 & -289.0 \\
\hline 1400.7 & 1324.9 & -226.46 & -296.8 \\
\hline 1424.7 & 1347.6 & -230.31 & -303.5 \\
\hline 1448.7 & 1370.5 & -233.99 & -310.0 \\
\hline 1478.7 & 1399.1 & -238.39 & -317.8 \\
\hline 1487.6 & 1407.6 & -239.61 & -320.0 \\
\hline 1526.7 & 1445.3 & -244.62 & -329.2 \\
\hline 1550.7 & 1468.4 & -247.75 & -334.8 \\
\hline 1576.6 & 1493.2 & -251.53 & -341.3 \\
\hline 1601.2 & 1516.7 & -255.17 & -347.4 \\
\hline 1625.5 & 1540.2 & -258.48 & -353.0 \\
\hline 1650.4 & 1564.3 & -261.62 & -358.4 \\
\hline 1655.0 & 1568.7 & -262.17 & -359.3 \\
\hline
\end{tabular}




\section{Injection Well N-19R}

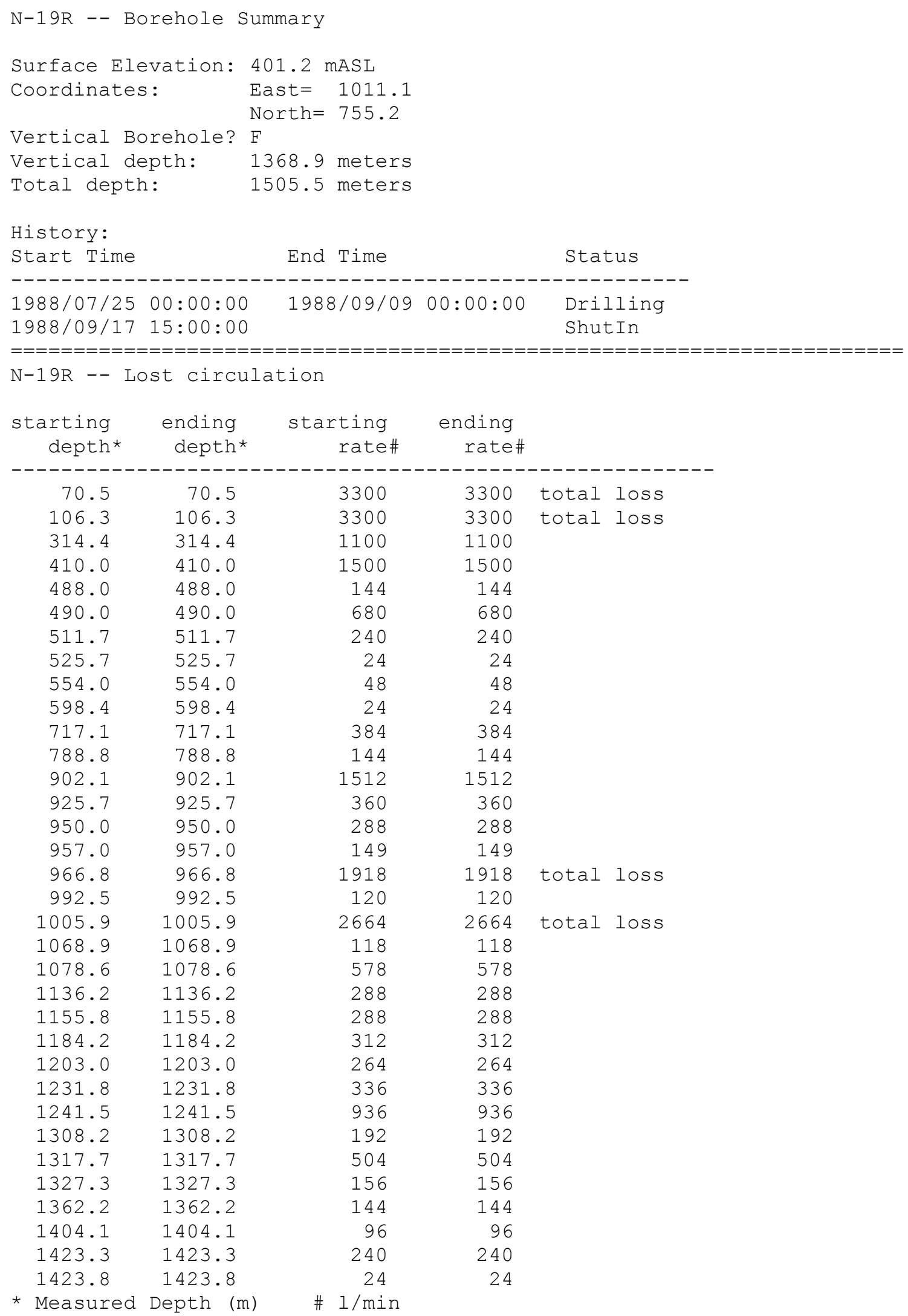




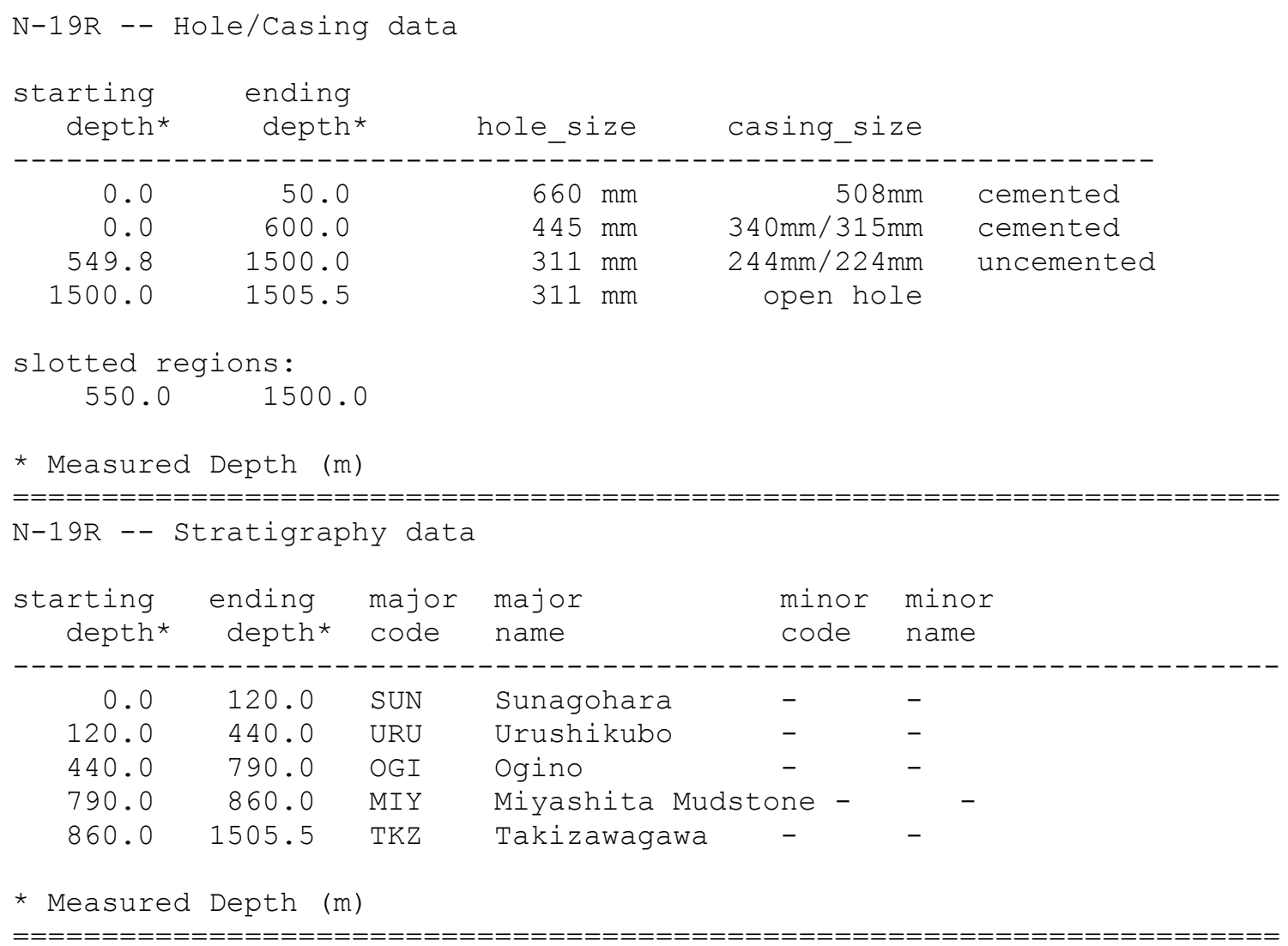


N-19R -- Deviation data (m)

\begin{tabular}{|c|c|c|c|}
\hline Meas.depth & Vert.depth & E_dev. & ${ }_{-}^{N}$ dev $\cdot$ \\
\hline 0.0 & 0.0 & 0.00 & 0.00 \\
\hline 60.0 & 60.0 & 0.26 & -0.01 \\
\hline 100.0 & 100.0 & 0.61 & -0.04 \\
\hline 150.0 & 150.0 & 0.98 & -0.36 \\
\hline 200.0 & 200.0 & 1.28 & -0.94 \\
\hline 250.0 & 250.0 & 1.25 & -1.10 \\
\hline 300.0 & 300.0 & 1.25 & -0.57 \\
\hline 350.0 & 350.0 & 1.29 & 0.25 \\
\hline 400.0 & 400.0 & 1.02 & 0.84 \\
\hline 434.0 & 434.0 & 0.72 & 1.16 \\
\hline 455.0 & 455.0 & 0.57 & 1.65 \\
\hline 473.5 & 473.4 & 0.77 & 2.50 \\
\hline 493.0 & 492.9 & 1.41 & 3.79 \\
\hline 512.0 & 511.8 & 2.18 & 5.61 \\
\hline 531.0 & 530.6 & 3.21 & 8.22 \\
\hline 560.0 & 558.9 & 5.57 & 13.77 \\
\hline 579.0 & 577.3 & 6.91 & 18.31 \\
\hline 607.0 & 604.3 & 9.20 & 25.38 \\
\hline 626.0 & 622.5 & 11.31 & 30.34 \\
\hline 645.0 & 640.6 & 13.69 & 35.61 \\
\hline 664.0 & 658.6 & 16.40 & 41.26 \\
\hline 683.0 & 676.4 & 19.12 & 47.33 \\
\hline 703.0 & 695.0 & 21.90 & 54.16 \\
\hline 721.0 & 711.5 & 24.32 & 60.76 \\
\hline 740.0 & 728.8 & 26.96 & 68.14 \\
\hline 760.0 & 746.8 & 29.91 & 76.40 \\
\hline 779.0 & 763.7 & 33.01 & 84.61 \\
\hline 798.0 & 780.3 & 36.15 & 93.18 \\
\hline 816.0 & 795.9 & 39.13 & 101.75 \\
\hline 835.0 & 812.2 & 42.43 & 110.96 \\
\hline 854.0 & 828.5 & 45.72 & 120.18 \\
\hline 873.0 & 844.7 & 49.01 & 129.39 \\
\hline 882.0 & 852.5 & 50.57 & 133.76 \\
\hline 921.0 & 885.9 & 57.50 & 152.61 \\
\hline 949.0 & 909.9 & 62.47 & 166.15 \\
\hline 978.0 & 934.7 & 67.66 & 180.27 \\
\hline 1006.0 & 958.6 & 72.67 & 193.90 \\
\hline 1035.0 & 983.4 & 77.85 & 208.02 \\
\hline 1074.0 & 1016.6 & 85.10 & 227.23 \\
\hline 1114.0 & 1050.5 & 92.92 & 246.92 \\
\hline 1133.0 & 1066.5 & 96.85 & 256.34 \\
\hline 1142.0 & 1074.0 & 98.76 & 260.90 \\
\hline 1180.0 & 1105.6 & 107.06 & 280.30 \\
\hline 1200.0 & 1122.1 & 111.52 & 290.72 \\
\hline 1237.0 & 1152.3 & 119.75 & 310.42 \\
\hline 1265.0 & 1175.1 & 126.05 & 325.52 \\
\hline 1294.0 & 1198.5 & 132.62 & 341.25 \\
\hline 1323.0 & 1222.0 & 139.19 & 356.98 \\
\hline 1361.0 & 1252.7 & 147.62 & 377.66 \\
\hline 1400.0 & 1284.3 & 155.89 & 399.04 \\
\hline 1438.0 & 1314.9 & 163.64 & 420.13 \\
\hline 1486.0 & 1353.4 & 173.07 & 447.26 \\
\hline 1505.5 & 1368.9 & 176.82 & 458.36 \\
\hline
\end{tabular}




\section{Injection Well N-20R}

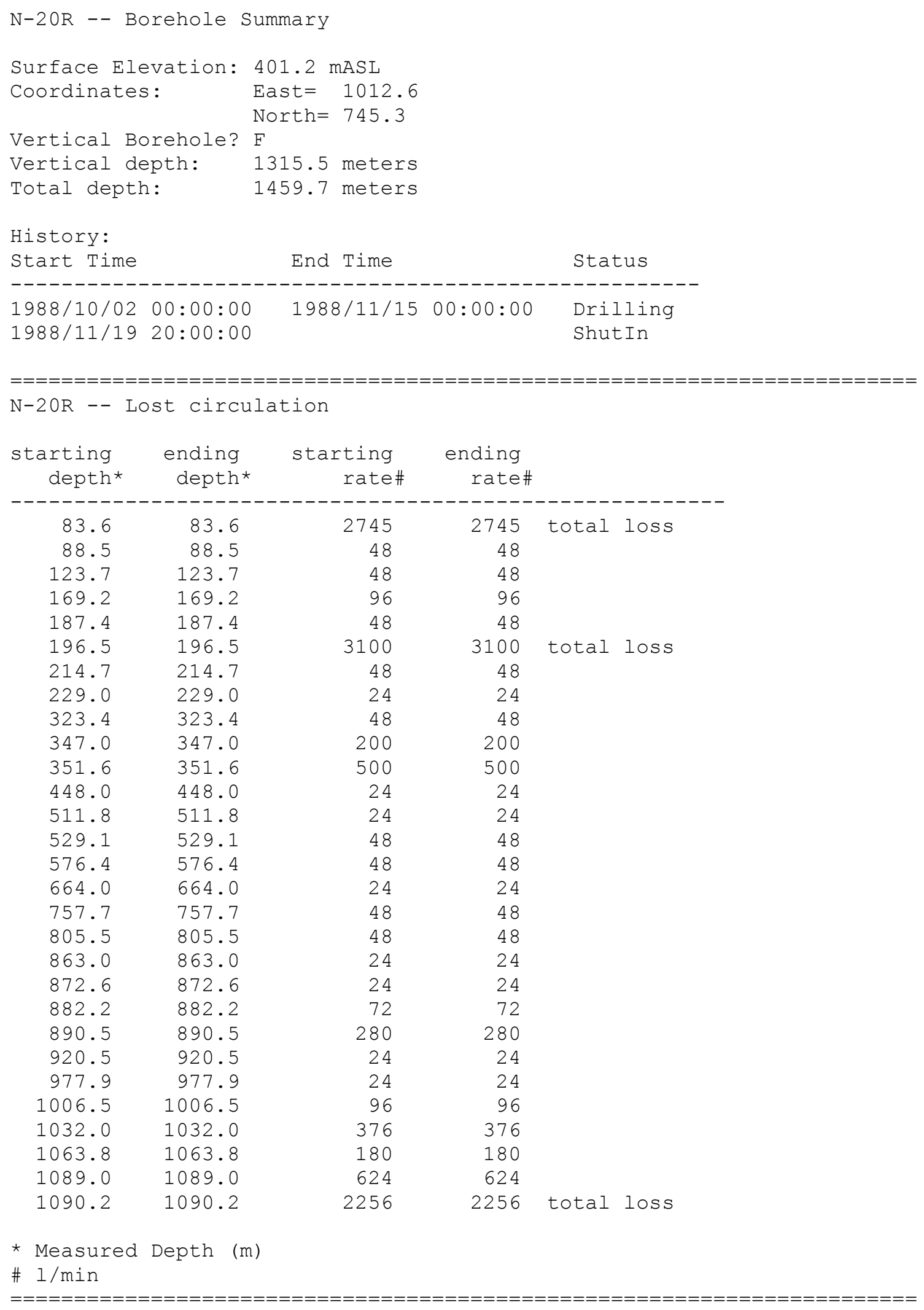




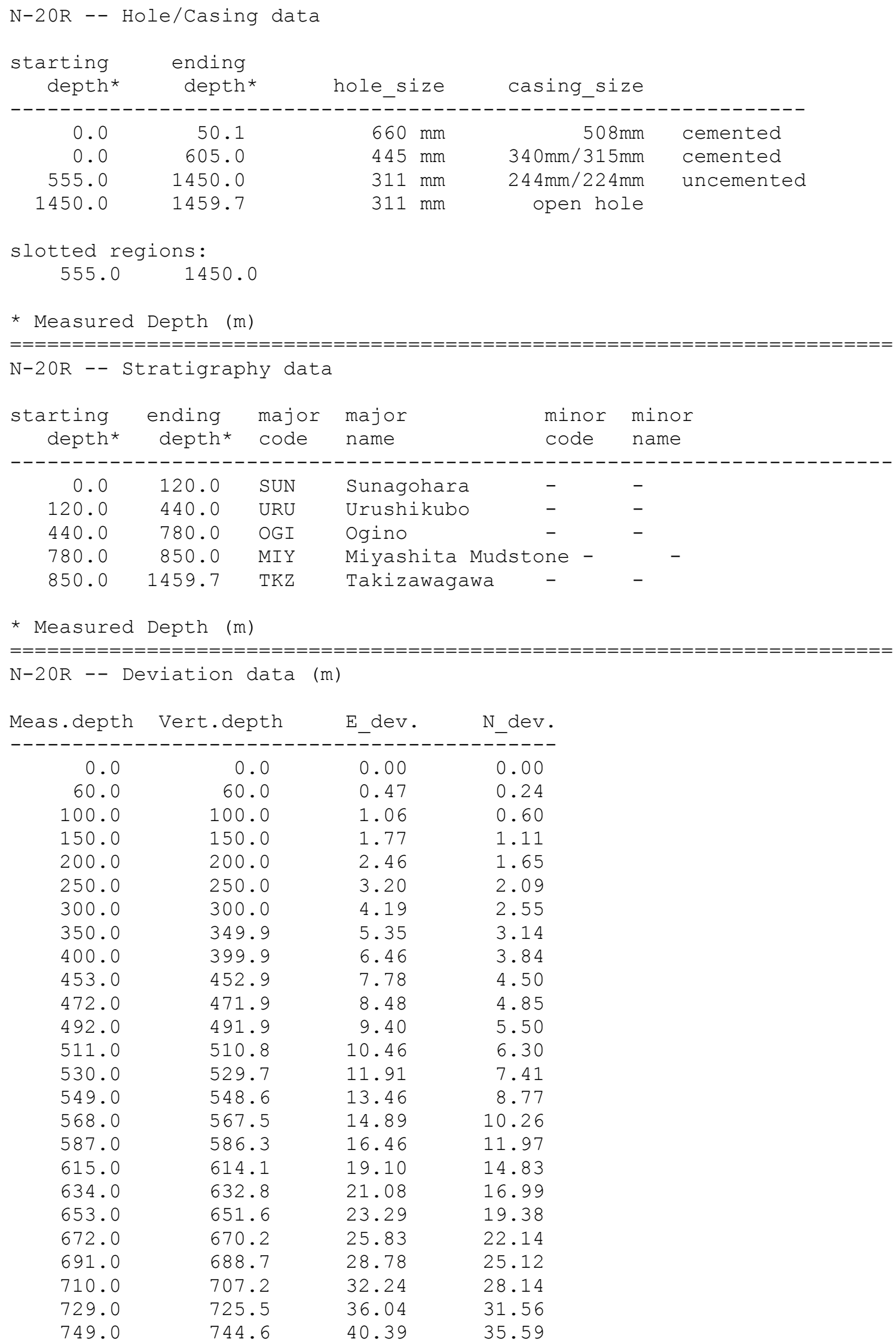




$\begin{array}{rrrr}768.0 & 762.5 & 45.08 & 39.49 \\ 787.0 & 780.4 & 50.24 & 43.57 \\ 806.0 & 798.0 & 55.75 & 48.01 \\ 825.0 & 815.5 & 61.52 & 52.74 \\ 844.0 & 832.8 & 67.53 & 57.66 \\ 863.0 & 850.0 & 73.93 & 62.81 \\ 882.0 & 866.8 & 80.74 & 68.29 \\ 901.0 & 883.5 & 87.88 & 74.05 \\ 920.0 & 899.8 & 95.34 & 80.16 \\ 940.0 & 916.8 & 103.47 & 87.07 \\ 959.0 & 932.5 & 111.52 & 93.90 \\ 977.0 & 947.2 & 119.44 & 100.62 \\ 997.0 & 963.2 & 128.61 & 108.41 \\ 1016.0 & 978.0 & 137.68 & 116.11 \\ 1035.0 & 992.6 & 146.99 & 124.02 \\ 1054.0 & 1007.0 & 156.39 & 132.00 \\ 1073.0 & 1021.4 & 165.85 & 140.03 \\ 1093.0 & 1036.5 & 175.85 & 148.52 \\ 1120.0 & 1056.9 & 189.25 & 160.10 \\ 1147.0 & 1077.3 & 202.66 & 171.69 \\ 1174.0 & 1097.7 & 216.16 & 183.15 \\ 1201.0 & 1118.0 & 229.76 & 194.50 \\ 1228.0 & 1138.4 & 243.46 & 205.72 \\ 1256.0 & 1159.5 & 257.57 & 217.49 \\ 1284.0 & 1180.8 & 271.40 & 229.44 \\ 1312.0 & 1202.0 & 284.94 & 241.57 \\ 1340.0 & 1223.3 & 298.28 & 253.93 \\ 1368.0 & 1244.7 & 311.55 & 266.23 \\ 1396.0 & 1266.2 & 324.85 & 278.35 \\ 1434.0 & 1295.5 & 342.72 & 294.63 \\ 1459.7 & 1315.5 & 354.69 & 305.53\end{array}$




\section{Production Well N-21T}

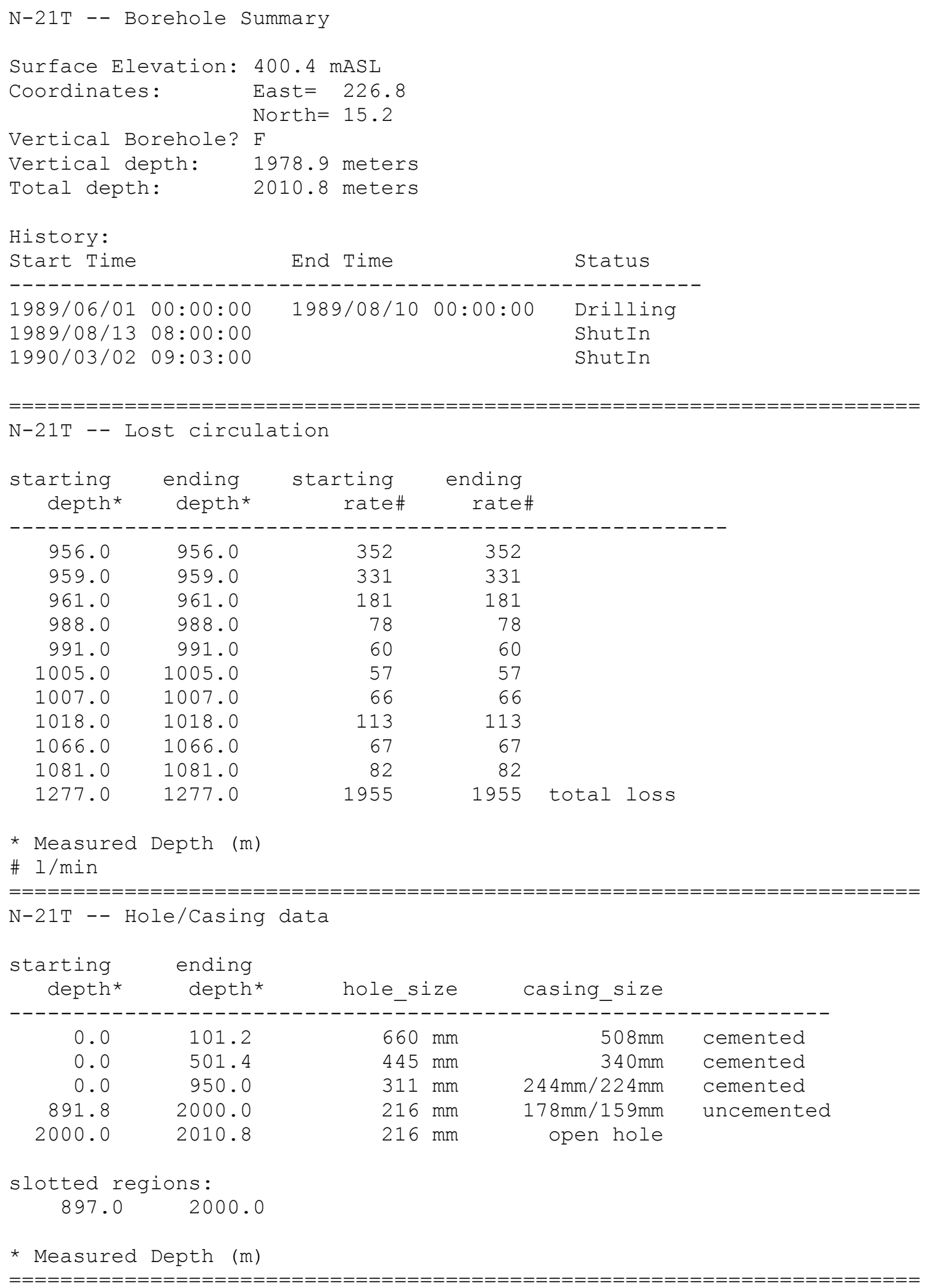


N-21T - - Stratigraphy data

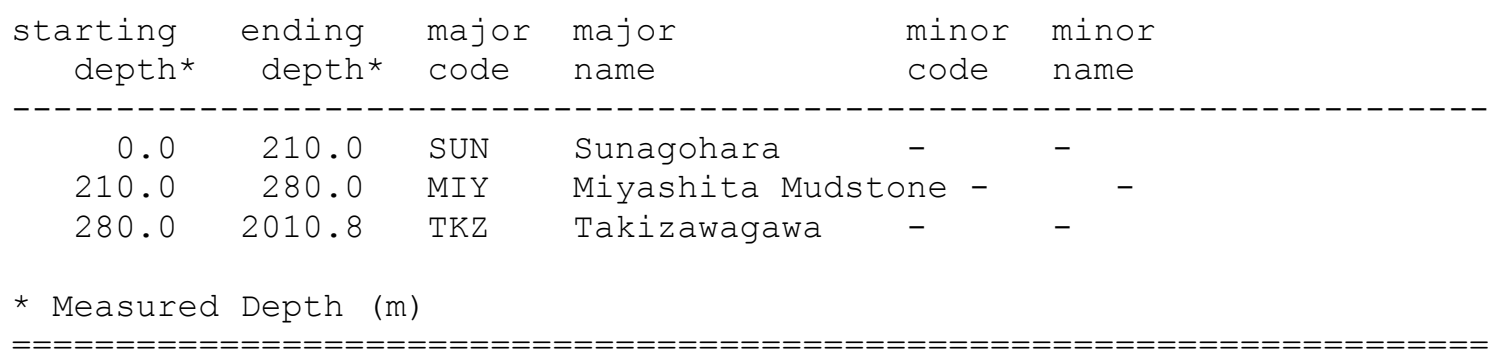

N-21T -- Deviation data (m)

\begin{tabular}{|c|c|c|c|}
\hline Meas.depth & Vert.depth & E_dev. & $\mathrm{N}_{\text {_dev }}$. \\
\hline & & & \\
\hline 0.0 & 0.0 & 0.00 & 0.00 \\
\hline 50.0 & 50.0 & -0.01 & 0.15 \\
\hline 95.0 & 95.0 & -0.02 & 0.34 \\
\hline 150.0 & 150.0 & -0.13 & 0.73 \\
\hline 200.0 & 200.0 & -0.34 & 1.42 \\
\hline 250.0 & 250.0 & -0.46 & 1.91 \\
\hline 300.0 & 300.0 & -0.01 & 2.03 \\
\hline 350.0 & 350.0 & 0.62 & 2.30 \\
\hline 400.0 & 400.0 & 1.02 & 2.73 \\
\hline 450.0 & 450.0 & 1.35 & 3.28 \\
\hline 500.0 & 500.0 & 1.88 & 3.82 \\
\hline 550.0 & 550.0 & 2.66 & 4.22 \\
\hline 600.0 & 600.0 & 3.49 & 4.66 \\
\hline 650.0 & 649.9 & 4.36 & 5.19 \\
\hline 700.0 & 699.9 & 5.23 & 5.71 \\
\hline 750.0 & 749.9 & 5.97 & 6.45 \\
\hline 800.0 & 799.9 & 6.80 & 7.31 \\
\hline 850.0 & 849.9 & 7.94 & 8.20 \\
\hline 900.0 & 899.9 & 9.11 & 9.18 \\
\hline 950.0 & 949.8 & 10.26 & 10.18 \\
\hline 1000.0 & 999.8 & 11.37 & 11.52 \\
\hline 1050.0 & 1049.8 & 12.57 & 13.16 \\
\hline 1100.0 & 1099.7 & 13.95 & 14.94 \\
\hline 1150.0 & 1149.7 & 15.37 & 16.88 \\
\hline 1177.0 & 1176.6 & 16.64 & 17.83 \\
\hline 1213.0 & 1212.5 & 19.43 & 17.89 \\
\hline 1231.0 & 1230.4 & 21.21 & 16.95 \\
\hline 1250.0 & 1249.2 & 23.26 & 15.21 \\
\hline 1270.0 & 1268.9 & 25.40 & 12.93 \\
\hline 1285.0 & 1283.7 & 26.99 & 11.06 \\
\hline 1303.0 & 1301.5 & 28.87 & 8.76 \\
\hline 1321.0 & 1319.2 & 30.81 & 6.44 \\
\hline 1349.0 & 1346.8 & 33.66 & 2.47 \\
\hline 1367.0 & 1364.5 & 35.43 & -0.38 \\
\hline 1388.0 & 1385.1 & 37.72 & -3.78 \\
\hline 1406.0 & 1402.7 & 39.96 & -6.71 \\
\hline 1424.0 & 1420.3 & 42.32 & -9.81 \\
\hline 1441.0 & 1436.8 & 44.41 & -13.00 \\
\hline 1459.0 & 1454.3 & 46.67 & -16.64 \\
\hline 1477.0 & 1471.7 & 49.23 & -20.44 \\
\hline 1495.0 & 1489.0 & 52.22 & -24.36 \\
\hline 1522.0 & 1514.9 & 56.65 & -30.60 \\
\hline
\end{tabular}




$\begin{array}{rrrr}1541.0 & 1533.1 & 59.47 & -35.23 \\ 1559.0 & 1550.4 & 62.23 & -39.59 \\ 1568.0 & 1559.0 & 63.68 & -41.73 \\ 1606.0 & 1595.4 & 68.95 & -51.31 \\ 1631.0 & 1619.3 & 71.32 & -58.29 \\ 1659.0 & 1646.0 & 73.70 & -66.40 \\ 1677.0 & 1663.1 & 75.41 & -71.72 \\ 1695.0 & 1680.2 & 77.29 & -77.06 \\ 1722.0 & 1705.8 & 79.90 & -85.17 \\ 1741.0 & 1723.8 & 81.62 & -90.87 \\ 1769.0 & 1750.5 & 84.08 & -99.00 \\ 1787.0 & 1767.7 & 85.37 & -104.23 \\ 1814.0 & 1793.4 & 87.38 & -112.36 \\ 1844.0 & 1821.8 & 89.72 & -121.50 \\ 1871.0 & 1847.5 & 91.85 & -129.56 \\ 1897.0 & 1872.3 & 94.40 & -137.06 \\ 1924.0 & 1897.9 & 97.59 & -144.81 \\ 1951.0 & 1923.4 & 101.48 & -152.98 \\ 1979.0 & 1949.5 & 106.47 & -161.67 \\ 2000.0 & 1969.0 & 110.78 & -168.35 \\ 2010.8 & 1978.9 & 113.09 & -171.86\end{array}$


Production Well N-22T

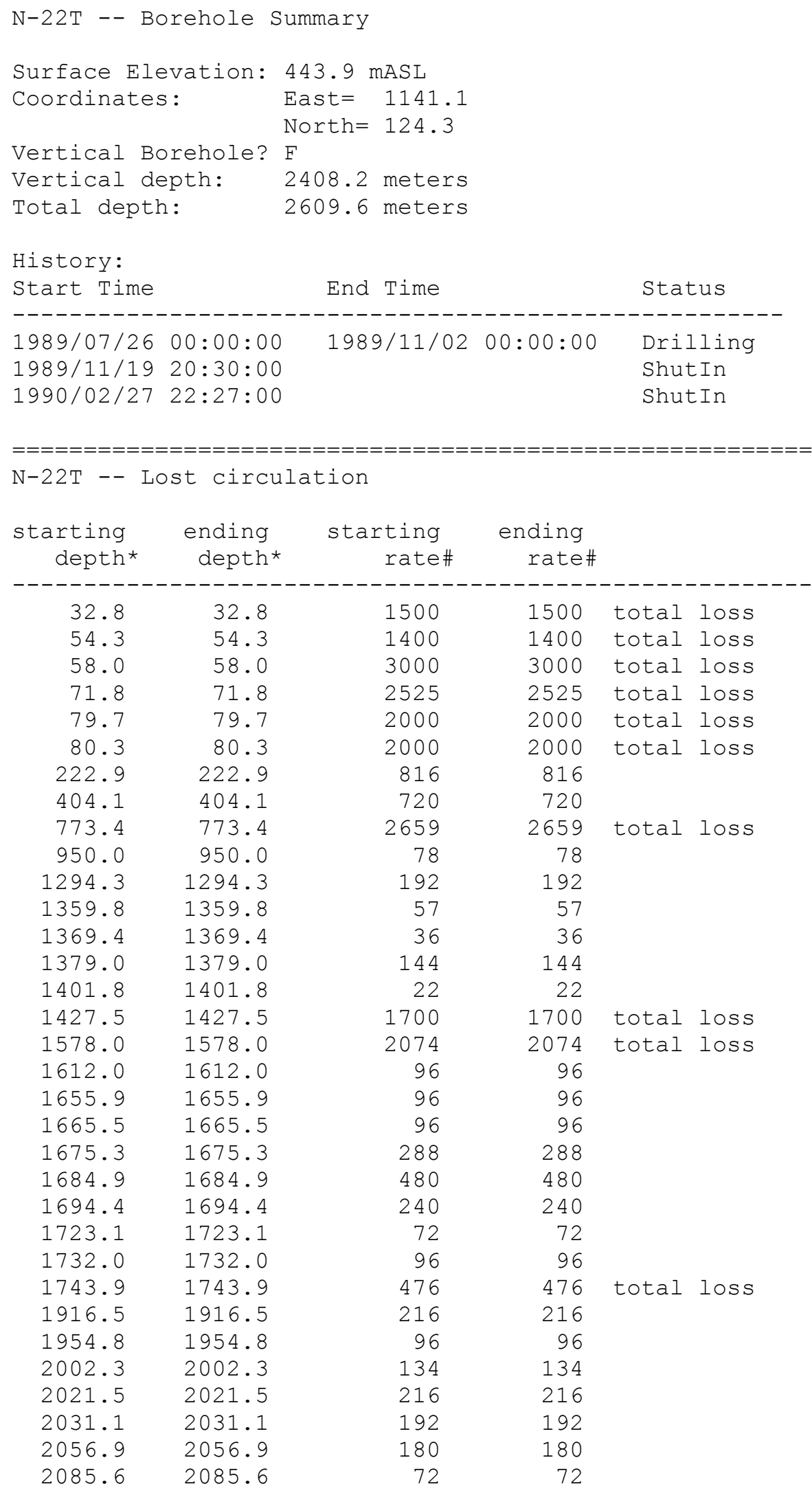




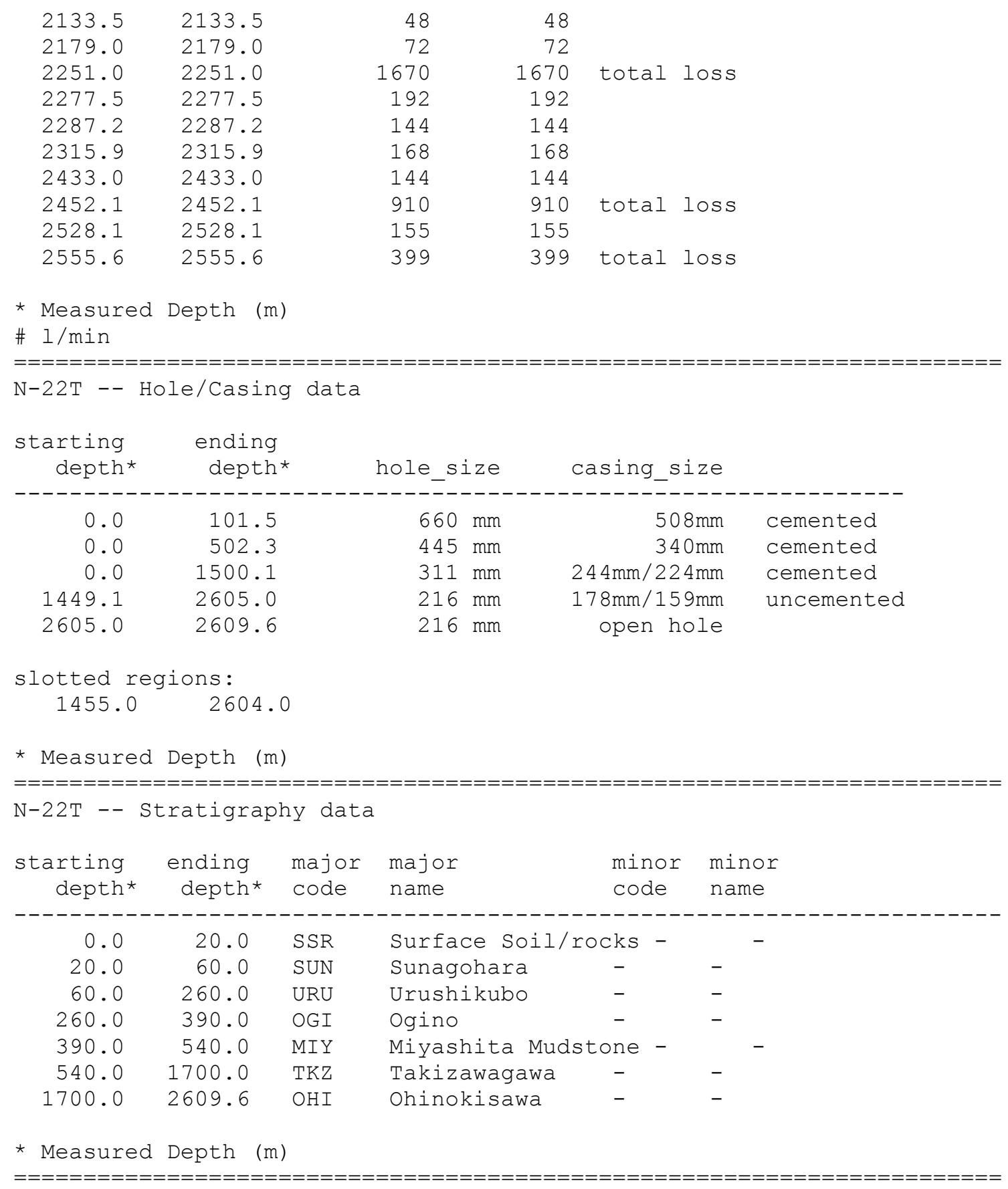


N-22T -- Deviation data (m)

\begin{tabular}{|c|c|c|c|}
\hline Meas.depth & Vert.depth & E_dev. & N_dev. \\
\hline 0.0 & 0.0 & 0 & 0.00 \\
\hline 50.0 & 50.0 & 0.03 & -0.58 \\
\hline 100.0 & 100.0 & -0.15 & -1.85 \\
\hline 150.0 & 150.0 & -0.48 & -2.93 \\
\hline 200.0 & 200.0 & -0.42 & -3.72 \\
\hline 250.0 & 250.0 & -0.55 & -4.12 \\
\hline 300.0 & 300.0 & -1.15 & -4.37 \\
\hline 350.0 & 350.0 & -1.40 & -4.98 \\
\hline 400.0 & 399.9 & -1.20 & -5.35 \\
\hline 450.0 & 449.9 & -1.06 & -5.28 \\
\hline 500.0 & 499.9 & -0.98 & -5.33 \\
\hline 550.0 & 549.9 & -0.55 & -5.33 \\
\hline 600.0 & 599.9 & -0.10 & -4.88 \\
\hline 650.0 & 649.9 & 0.28 & -4.30 \\
\hline 700.0 & 699.9 & 0.55 & -3.92 \\
\hline 750.0 & 749.9 & 0.04 & -3.77 \\
\hline 800.0 & 799.9 & -0.20 & -3.42 \\
\hline 850.0 & 849.9 & -0.24 & -2.67 \\
\hline 900.0 & 899.9 & -0.80 & -1.74 \\
\hline 950.0 & 949.9 & -1.17 & -0.72 \\
\hline 990.0 & 989.9 & -1.46 & 0.16 \\
\hline 1020.0 & 1019.9 & -2.08 & 0.29 \\
\hline 1050.0 & 1049.8 & -3.03 & -0.93 \\
\hline 1070.0 & 1069.8 & -3.76 & $-2 \cdot 38$ \\
\hline 1090.0 & 1089.7 & -4.62 & -4.03 \\
\hline 1110.0 & 1109.6 & -5.49 & -5.95 \\
\hline 1130.0 & 1129.4 & -6.63 & -8.13 \\
\hline 1150.0 & 1149.2 & -8.27 & -10.55 \\
\hline 1170.0 & 1168.9 & -10.07 & -13.70 \\
\hline 1190.0 & 1188.4 & -11.79 & -17.46 \\
\hline 1210.0 & 1207.9 & -13.29 & -21.72 \\
\hline 1240.0 & 1236.9 & -15.87 & -29.03 \\
\hline 1260.0 & 1256.1 & -18.15 & -34.23 \\
\hline 1280.0 & 1275.1 & -20.73 & -39.72 \\
\hline 1310.0 & 1303.5 & -25.39 & -48.39 \\
\hline 1330.0 & 1322.4 & -28.53 & -54.09 \\
\hline 1350.0 & 1341.3 & -31.39 & -59.94 \\
\hline 1370.0 & 1360.1 & -34.19 & -66.18 \\
\hline 1390.0 & 1378.8 & -37.19 & -72.68 \\
\hline 1410.0 & 1397.1 & -40.41 & -79.88 \\
\hline 1420.0 & 1406.2 & -41.97 & -83.81 \\
\hline 1440.0 & 1424.0 & -45.59 & -92.05 \\
\hline 1460.0 & 1441.5 & -49.71 & -100.82 \\
\hline 1480.0 & 1458.6 & -54.07 & $-110 \cdot 32$ \\
\hline 1510.0 & 1483.8 & -60.89 & -125.17 \\
\hline 1537.0 & 1506.4 & -66.79 & -138.63 \\
\hline 1564.0 & 1529.2 & -72.38 & -152.02 \\
\hline 1591.0 & 1552.2 & -77.71 & -165.08 \\
\hline 1618.0 & 1575.4 & -82.92 & -177.87 \\
\hline 1637.0 & 1591.8 & -86.53 & -186.73 \\
\hline 1656.0 & 1608.3 & -90.19 & -195.50 \\
\hline 1675.0 & 1624.6 & -93.91 & -204.42 \\
\hline 1694.0 & 1640.8 & -97.58 & -213.66 \\
\hline
\end{tabular}




$\begin{array}{llll}1713.0 & 1656.8 & -101.28 & -223.23 \\ 1732.0 & 1672.6 & -104.92 & -233.11 \\ 1753.2 & 1690.2 & -109.00 & -244.24 \\ 1762.1 & 1697.6 & -110.81 & -248.90 \\ 1767.5 & 1702.0 & -111.89 & -251.70 \\ 1772.3 & 1706.1 & -112.81 & -254.14 \\ 1789.8 & 1721.2 & -115.90 & -262.33 \\ 1809.2 & 1738.4 & -118.92 & -270.76 \\ 1818.4 & 1746.6 & -120.26 & -274.75 \\ 1837.4 & 1763.4 & -122.94 & -283.17 \\ 1859.5 & 1783.0 & -126.25 & -292.95 \\ 1883.0 & 1803.8 & -130.78 & -302.82 \\ 1896.0 & 1815.3 & -133.56 & -308.14 \\ 1926.7 & 1842.4 & -140.08 & -321.11 \\ 1945.4 & 1858.7 & -144.16 & -329.42 \\ 1964.6 & 1875.2 & -148.28 & -338.29 \\ 1993.4 & 1899.6 & -155.00 & -351.94 \\ 2012.6 & 1915.6 & -159.88 & -361.36 \\ 2031.8 & 1931.3 & -164.92 & -371.17 \\ 2042.0 & 1939.6 & -167.65 & -376.50 \\ 2061.0 & 1955.0 & -172.54 & -386.45 \\ 2087.0 & 1976.3 & -178.85 & -399.89 \\ 2115.5 & 2000.0 & -185.37 & -414.39 \\ 2144.5 & 2024.3 & -192.11 & -428.75 \\ 2173.0 & 2048.3 & -199.00 & -442.47 \\ 2202.0 & 2072.8 & -205.87 & -456.45 \\ 2230.9 & 2097.1 & -212.60 & -470.46 \\ 2259.7 & 2121.6 & -218.94 & -484.24 \\ 2288.0 & 2145.9 & -225.13 & -497.43 \\ 2318.0 & 2171.6 & -232.13 & -511.08 \\ 2338.0 & 2188.8 & -236.88 & -520.14 \\ 2366.0 & 2212.7 & -243.43 & -533.18 \\ 2405.0 & 2245.5 & -252.44 & -552.36 \\ 2443.0 & 2276.8 & -261.42 & -571.92 \\ 2481.0 & 2307.6 & -271.04 & -591.92 \\ 2520.0 & 2338.8 & -283.00 & -612.07 \\ 2558.0 & 2368.6 & -296.87 & -631.01 \\ 2596.0 & 2397.9 & -311.52 & -650.34 \\ 2609.6 & 2408.2 & -316.79 & -657.42\end{array}$




\section{Production Well N-23P}

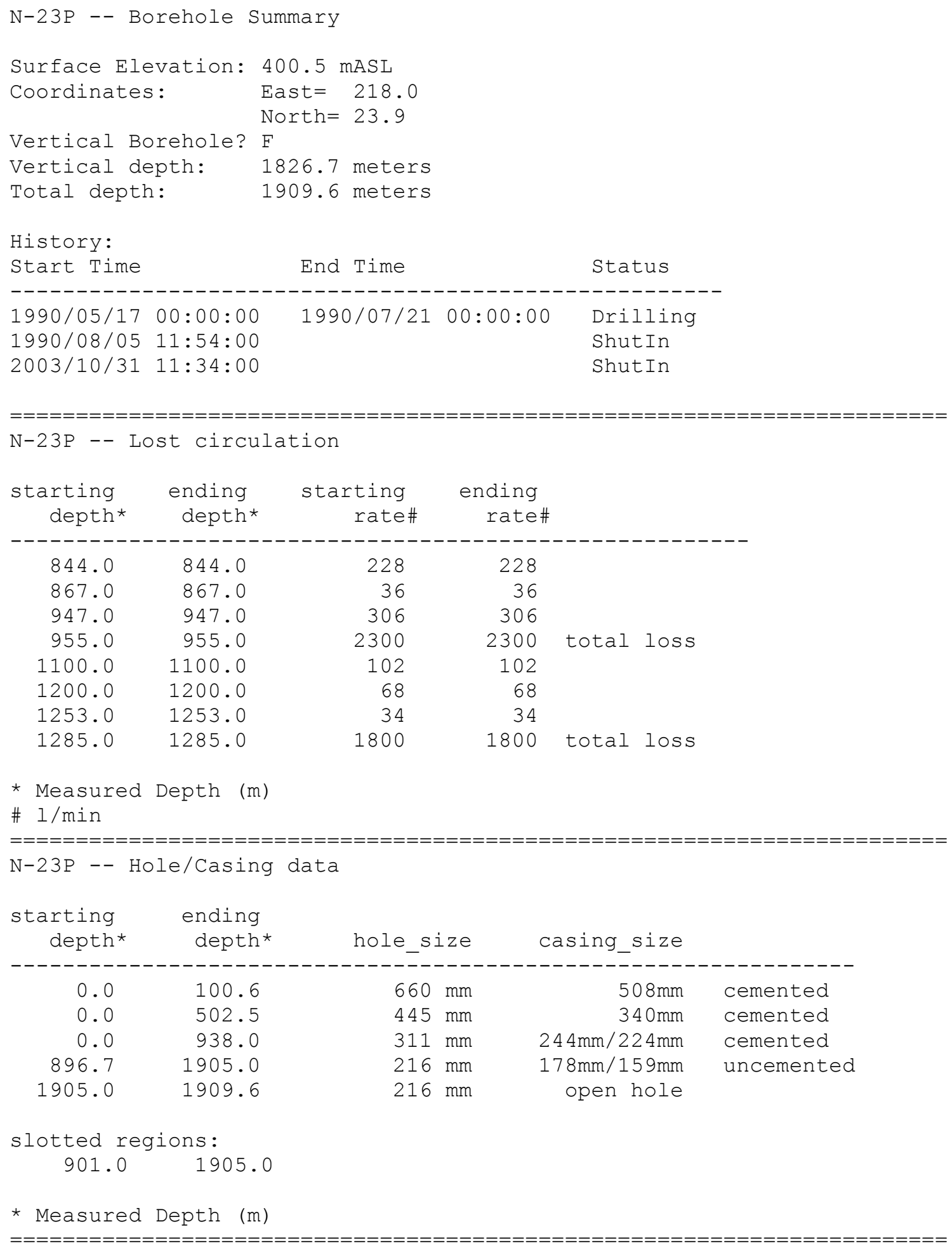


N-23P -- Stratigraphy data

\begin{tabular}{|c|c|c|c|c|c|}
\hline $\begin{array}{l}\text { starting } \\
\text { depth* }\end{array}$ & $\begin{array}{l}\text { ending } \\
\text { depth* }\end{array}$ & $\begin{array}{l}\text { major } \\
\text { code }\end{array}$ & $\begin{array}{l}\text { major } \\
\text { name }\end{array}$ & $\begin{array}{l}\text { minor } \\
\text { code }\end{array}$ & $\begin{array}{l}\text { minor } \\
\text { name }\end{array}$ \\
\hline 0.0 & 220.0 & SUN & Sunagohara & - & - \\
\hline 220.0 & 300.0 & MIY & Miyashita Muc & one - & - \\
\hline 300.0 & 1909.6 & TKZ & Takizawagawa & - & - \\
\hline
\end{tabular}




\begin{tabular}{|c|c|c|c|}
\hline Meas.depth & Vert.depth & E_dev. & $\mathrm{N} \_$dev . \\
\hline----1 & ------- & -------- & ------- \\
\hline 0.0 & 0.0 & 0.00 & 0.00 \\
\hline 50.0 & 50.0 & -0.05 & 0.21 \\
\hline 100.0 & 100.0 & -0.16 & 0.71 \\
\hline 160.0 & 160.0 & -0.49 & 1.40 \\
\hline 200.0 & 200.0 & -0.76 & 1.91 \\
\hline 250.0 & 250.0 & -1.11 & 2.41 \\
\hline 300.0 & 300.0 & -1.25 & 2.91 \\
\hline 350.0 & 350.0 & -1.33 & 3.57 \\
\hline 400.0 & 400.0 & -1.74 & 4.16 \\
\hline 450.0 & 450.0 & -1.80 & 4.86 \\
\hline 500.0 & 500.0 & -1.46 & 5.66 \\
\hline 550.0 & 549.9 & -0.69 & 6.59 \\
\hline 600.0 & 599.9 & 0.41 & 7.54 \\
\hline 650.0 & 649.9 & 1.32 & 8.38 \\
\hline 700.0 & 699.9 & 2.08 & 9.26 \\
\hline 750.0 & 749.9 & 3.08 & 10.30 \\
\hline 800.0 & 799.8 & 4.26 & 11.58 \\
\hline 850.0 & 849.8 & 5.38 & 12.81 \\
\hline 900.0 & 899.8 & 6.61 & 14.04 \\
\hline 950.0 & 949.7 & 8.32 & 15.50 \\
\hline 1000.0 & 999.7 & 10.30 & 17.09 \\
\hline 1050.0 & 1049.6 & 12.20 & 18.67 \\
\hline 1100.0 & 1099.5 & 13.95 & 20.48 \\
\hline 1150.0 & 1149.5 & 13.22 & 22.32 \\
\hline 1174.0 & 1173.4 & 11.53 & 22.66 \\
\hline 1191.0 & 1190.3 & 9.93 & 22.56 \\
\hline 1218.0 & 1217.2 & 6.81 & 22.27 \\
\hline 1245.0 & 1243.9 & 3.04 & 21.85 \\
\hline 1262.0 & 1260.7 & 0.25 & 21.54 \\
\hline 1290.0 & 1288.2 & -4.83 & 21.02 \\
\hline 1310.0 & 1307.8 & -8.86 & 20.83 \\
\hline 1348.0 & 1344.9 & -17.10 & 19.89 \\
\hline 1364.0 & 1360.3 & -21.11 & 18.89 \\
\hline 1390.0 & 1384.9 & -29.21 & 16.83 \\
\hline 1416.0 & 1409.1 & -38.50 & 14.54 \\
\hline 1443.0 & 1433.8 & -49.01 & 11.76 \\
\hline 1470.0 & 1458.1 & -60.42 & 8.74 \\
\hline 1496.0 & 1481.1 & -72.17 & 5.85 \\
\hline 1523.0 & 1504.8 & -84.81 & 2.85 \\
\hline 1550.0 & 1528.3 & -97.79 & 0.02 \\
\hline 1577.0 & 1551.5 & -111.27 & -2.44 \\
\hline 1604.0 & 1574.6 & -125.16 & -4.51 \\
\hline 1631.0 & 1597.5 & -139.41 & -6.39 \\
\hline 1658.0 & 1620.1 & -154.01 & -8.13 \\
\hline 1685.0 & 1642.6 & -168.90 & -9.65 \\
\hline 1712.0 & 1664.8 & -184.14 & -10.94 \\
\hline 1739.0 & 1686.8 & -199.76 & -11.85 \\
\hline 1748.0 & 1694.1 & -205.03 & -12.06 \\
\hline 1777.0 & 1717.6 & -222.03 & -12.76 \\
\hline 1804.0 & 1739.6 & -237.67 & -13.26 \\
\hline 1831.0 & 1761.8 & -253.09 & -13.35 \\
\hline 1858.0 & 1784.0 & -268.44 & -12.90 \\
\hline 1895.0 & 1814.5 & -289.23 & -11.21 \\
\hline 1909.6 & 1826.7 & -297.34 & -10.26 \\
\hline
\end{tabular}




\section{Production Well N-24P}

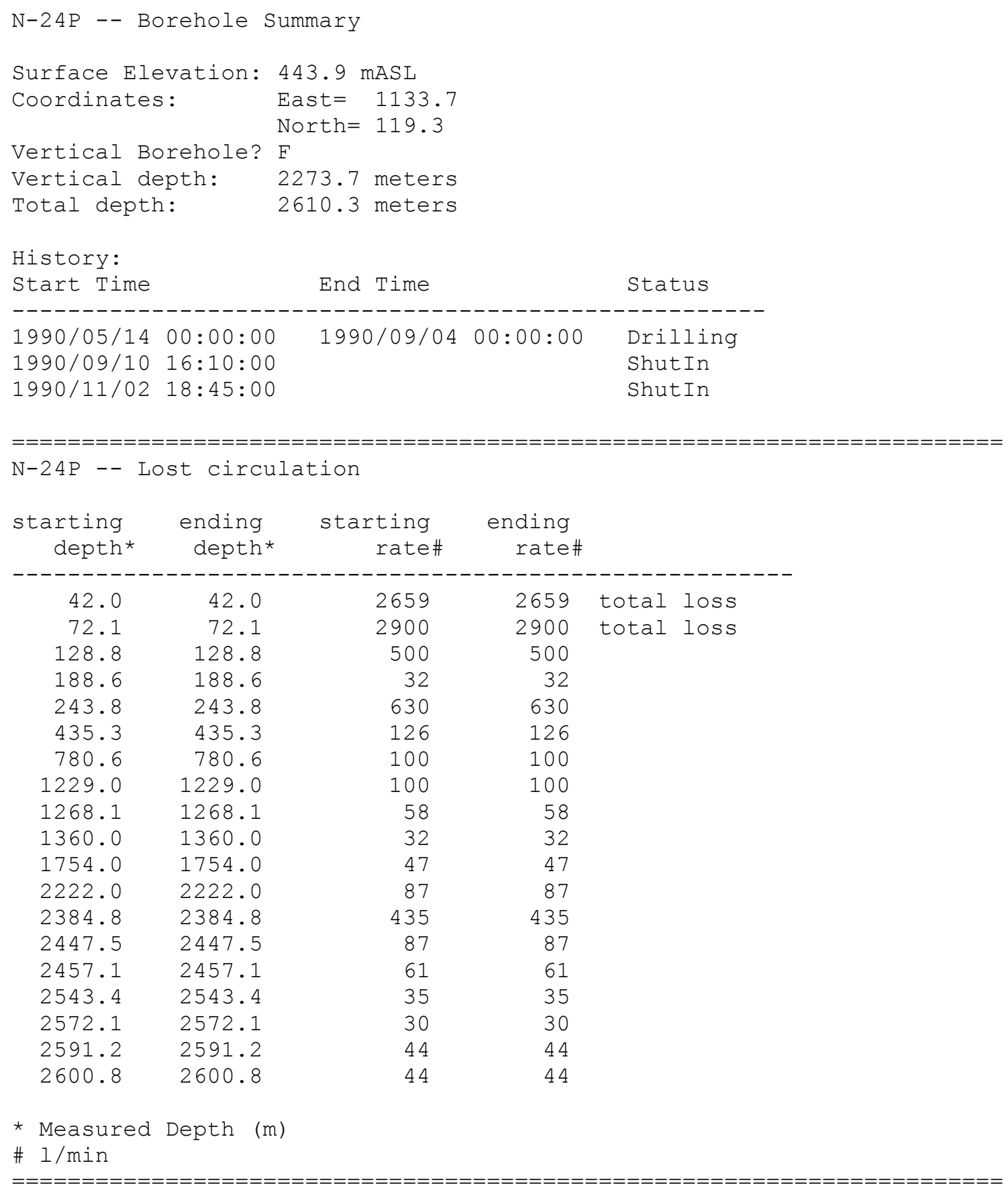




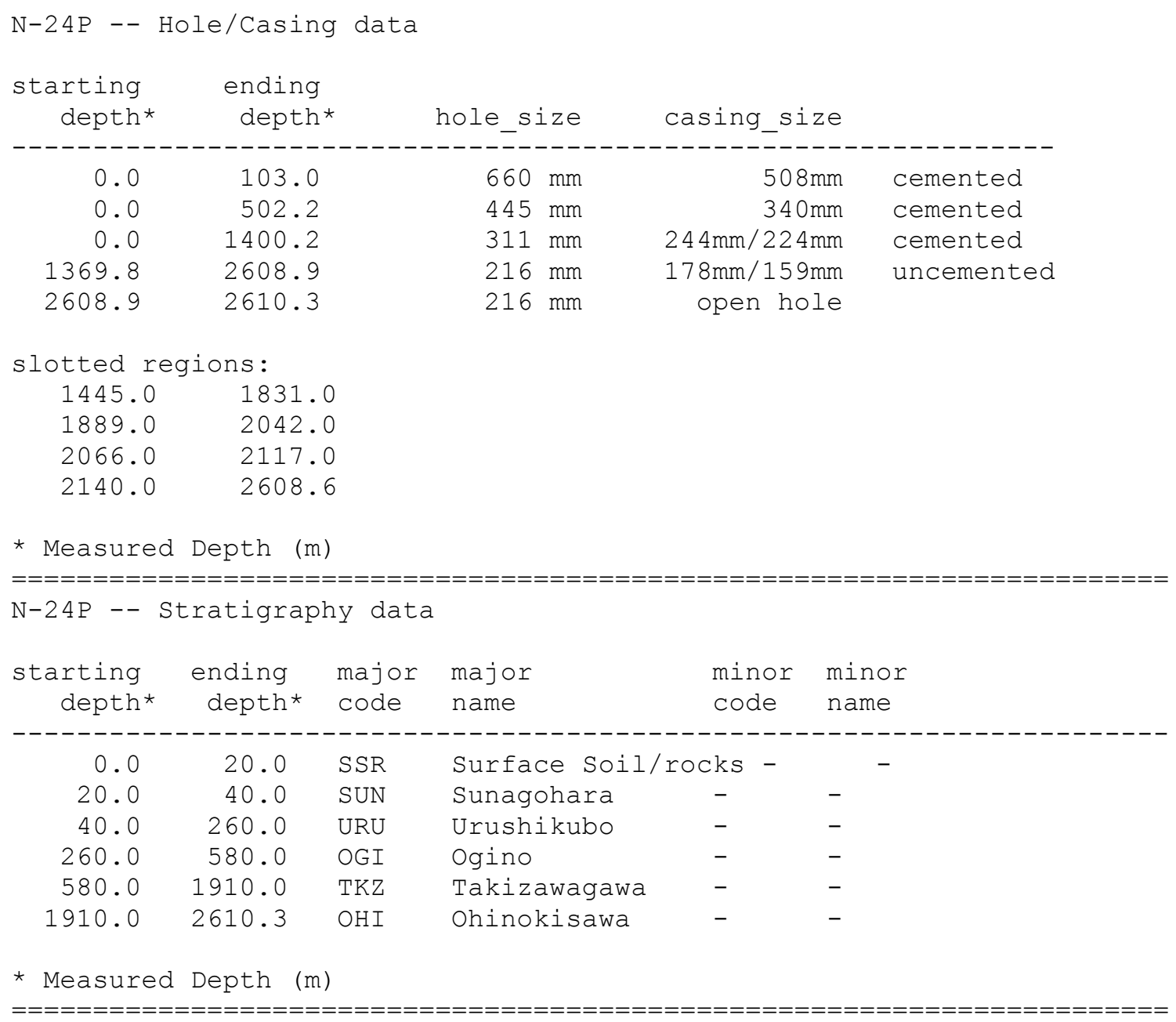


N-24P -- Deviation data (m)

\begin{tabular}{|c|c|c|c|}
\hline Meas.depth & Vert.depth & E_dev. & $\mathrm{N}_{-}$dev . \\
\hline 0.0 & 0.0 & Oم 0 & 000 \\
\hline 50.0 & 50.0 & 0.02 & -0.22 \\
\hline 110.0 & 110.0 & -0.23 & 0.44 \\
\hline 150.0 & 150.0 & -0.59 & 1.35 \\
\hline 200.0 & 200.0 & -0.74 & 2.17 \\
\hline 250.0 & 250.0 & -0.76 & 3.25 \\
\hline 300.0 & 299.9 & -1.10 & 4.73 \\
\hline 350.0 & 349.9 & $-1 \cdot 38$ & 5.78 \\
\hline 400.0 & 399.9 & -1.40 & 6.80 \\
\hline 450.0 & 449.9 & $-1 \cdot 31$ & 8.02 \\
\hline 510.0 & 509.9 & -1.20 & 9.50 \\
\hline 550.0 & 549.8 & -0.82 & 11.06 \\
\hline 600.0 & 599.8 & -0.11 & 13.34 \\
\hline 650.0 & 649.8 & 0.29 & 15.19 \\
\hline 700.0 & 699.7 & 0.47 & 16.55 \\
\hline 750.0 & 749.7 & 0.50 & 17.86 \\
\hline 800.0 & 799.7 & 0.44 & 19.09 \\
\hline 850.0 & 849.7 & -0.13 & 20.21 \\
\hline 900.0 & 899.7 & -1.04 & 21.24 \\
\hline 950.0 & 949.7 & -1.98 & 22.14 \\
\hline 1000.0 & 999.6 & -2.98 & 19.97 \\
\hline 1033.0 & 1032.3 & -4.16 & 15.99 \\
\hline 1050.0 & 1049.1 & -5.05 & 13.33 \\
\hline 1070.0 & 1068.7 & -6.05 & 9.62 \\
\hline 1090.0 & 1088.2 & -7.09 & 5.54 \\
\hline 1110.0 & 1107.7 & -7.92 & 0.98 \\
\hline 1130.0 & 1127.0 & -8.62 & -4.14 \\
\hline 1149.0 & 1145.2 & -9.43 & -9.43 \\
\hline 1169.0 & 1164.3 & -10.24 & -15.52 \\
\hline 1188.0 & 1182.2 & -10.86 & -21.83 \\
\hline 1207.0 & 1199.9 & -11.23 & -28.63 \\
\hline 1235.5 & 1226.3 & -11.54 & -39.30 \\
\hline 1264.5 & 1253.2 & -12.44 & -50.23 \\
\hline 1293.0 & 1279.0 & -14.94 & -61.95 \\
\hline 1312.0 & 1295.8 & -17.44 & -70.56 \\
\hline 1331.0 & 1312.4 & -20.10 & -79.45 \\
\hline 1350.0 & 1328.9 & -22.72 & -88.51 \\
\hline 1370.0 & 1346.1 & -25.29 & -98.33 \\
\hline 1389.0 & 1362.2 & -27.40 & -108.17 \\
\hline 1408.0 & 1378.1 & -29.67 & -118.26 \\
\hline 1427.0 & 1394.1 & -32.20 & -128.29 \\
\hline 1448.0 & 1411.6 & -34.84 & -139.58 \\
\hline 1467.0 & 1427.3 & -36.92 & -150.14 \\
\hline 1486.0 & 1442.7 & -39.06 & -160.96 \\
\hline 1505.5 & 1458.3 & -41.53 & -172.43 \\
\hline 1514.5 & 1465.3 & -42.62 & -177.92 \\
\hline 1533.5 & 1480.1 & -44.52 & -189.73 \\
\hline 1563.0 & 1503.0 & -47.32 & -208.08 \\
\hline 1592.0 & 1525.6 & -50.38 & -226.07 \\
\hline 1619.0 & 1546.6 & -52.93 & -242.77 \\
\hline 1648.0 & 1569.5 & -55.77 & -260.40 \\
\hline 1678.5 & 1593.6 & -59.23 & -278.74 \\
\hline 1707.5 & 1616.3 & -61.62 & -296.62 \\
\hline
\end{tabular}




$\begin{array}{llll}1736.0 & 1638.2 & -63.26 & -314.74 \\ 1756.0 & 1653.3 & -64.79 & -327.81 \\ 1782.5 & 1673.0 & -66.70 & -345.44 \\ 1811.0 & 1694.2 & -68.58 & -364.41 \\ 1840.0 & 1715.8 & -70.66 & -383.61 \\ 1868.5 & 1737.2 & -72.52 & -402.40 \\ 1897.0 & 1758.6 & -74.21 & -421.12 \\ 1926.0 & 1780.5 & -75.93 & -440.06 \\ 1955.0 & 1802.4 & -77.80 & -458.93 \\ 1984.0 & 1824.5 & -79.50 & -477.69 \\ 2012.5 & 1846.1 & -81.16 & -496.12 \\ 2051.8 & 1876.1 & -83.68 & -521.43 \\ 2080.5 & 1897.7 & -85.53 & -540.17 \\ 2109.5 & 1918.9 & -87.49 & -559.85 \\ 2156.0 & 1952.4 & -90.12 & -592.04 \\ 2185.0 & 1973.3 & -91.22 & -612.06 \\ 2213.5 & 1993.9 & -91.97 & -631.76 \\ 2233.0 & 2008.0 & -92.36 & -645.30 \\ 2262.0 & 2028.7 & -93.66 & -665.48 \\ 2290.5 & 2048.9 & -95.30 & -685.60 \\ 2318.5 & 2068.5 & -96.40 & -705.57 \\ 2350.0 & 2090.5 & -97.45 & -728.01 \\ 2379.0 & 2111.0 & -98.58 & -748.51 \\ 2427.0 & 2145.0 & -100.75 & -782.33 \\ 2476.0 & 2179.6 & -103.27 & -816.94 \\ 2533.0 & 2219.7 & -107.63 & -857.24 \\ 2582.0 & 2254.0 & -111.39 & -892.02 \\ 2601.0 & 2267.2 & -112.50 & -905.59 \\ 2610.3 & 2273.7 & -113.04 & -912.22\end{array}$




\section{Production Well N-25P}

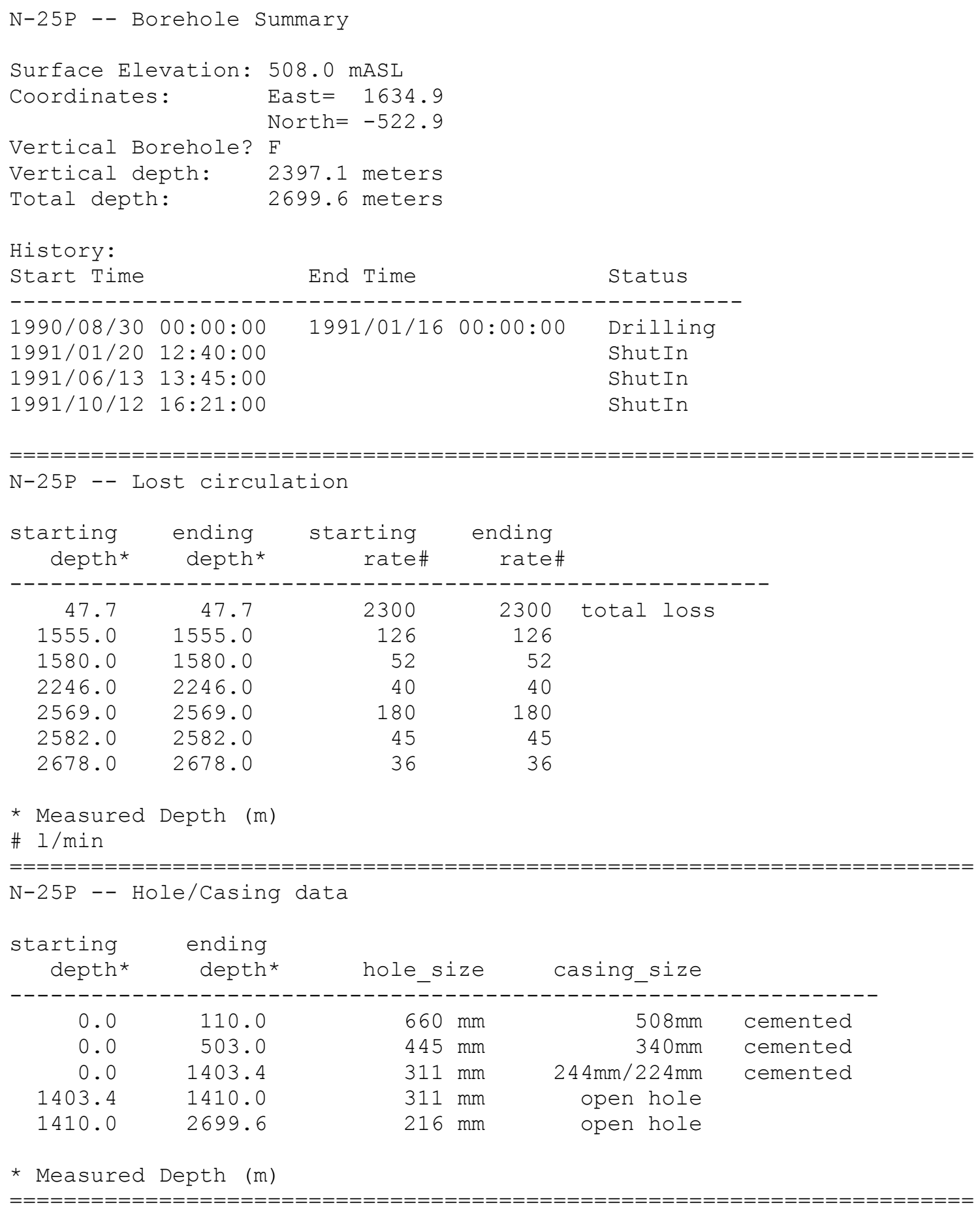


N-25P - - Stratigraphy data

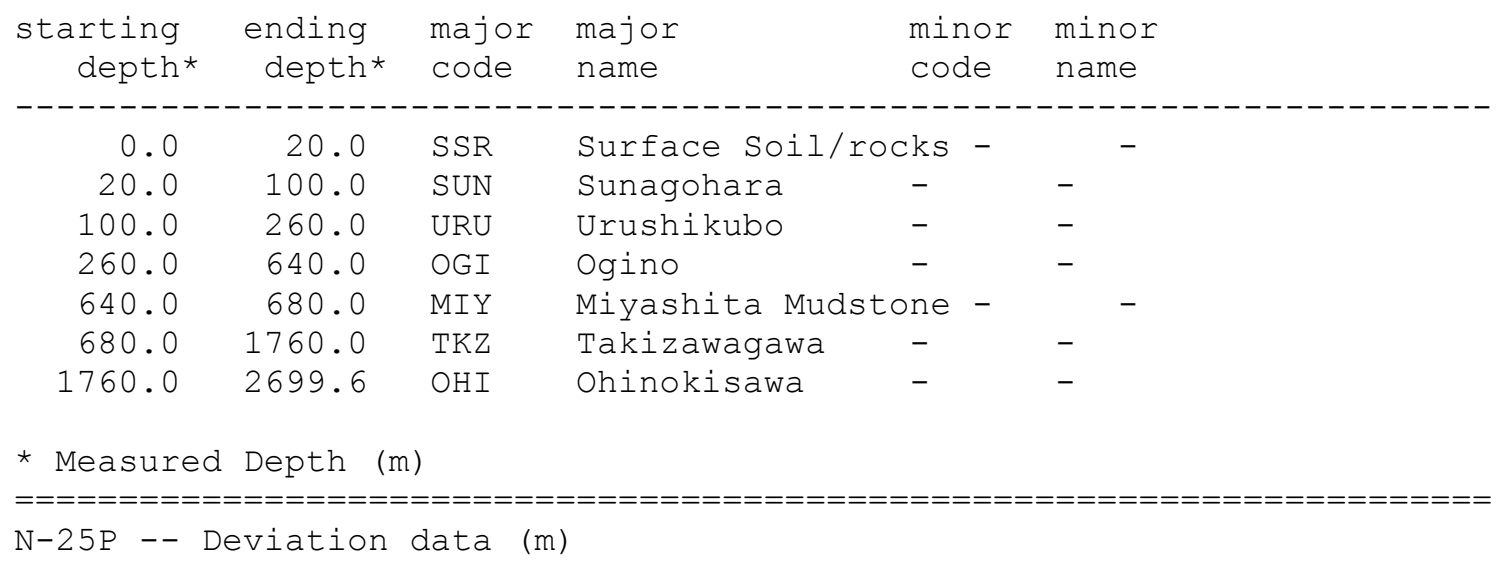

\begin{tabular}{rrrr} 
Meas.depth & Vert.depth & E_dev. & N_dev. \\
\hline 0.0 & 0.0 & 0.00 & 0.00 \\
100.0 & 50.0 & -0.05 & 0.05 \\
150.0 & 100.0 & -0.28 & 0.33 \\
200.0 & 200.0 & -0.56 & 0.67 \\
250.0 & 250.0 & -0.75 & 0.90 \\
300.0 & 300.0 & -0.71 & 0.89 \\
350.0 & 350.0 & -0.53 & 0.62 \\
400.0 & 400.0 & -0.17 & -0.19 \\
450.0 & 450.0 & 0.35 & -1.05 \\
500.0 & 500.0 & 1.06 & -1.97 \\
550.0 & 550.0 & 1.64 & -2.89 \\
600.0 & 599.9 & 2.29 & -3.67 \\
650.0 & 649.9 & 3.15 & -4.33 \\
700.0 & 699.9 & 4.25 & -5.03 \\
750.0 & 749.9 & 5.45 & -5.97 \\
800.0 & 799.9 & 6.52 & -6.95 \\
850.0 & 849.9 & 7.56 & -7.57 \\
900.0 & 899.8 & 8.79 & -8.18 \\
950.0 & 949.8 & 10.10 & -8.76 \\
990.0 & 989.8 & 11.12 & -8.98 \\
1015.0 & 1014.8 & 11.81 & -9.29 \\
1042.0 & 1041.8 & 12.31 & -10.36 \\
1070.0 & 1069.7 & 12.04 & -12.20 \\
1097.0 & 1096.6 & 11.08 & -14.30 \\
1124.0 & 1123.4 & 9.65 & -16.91 \\
1142.0 & 1141.3 & 8.48 & -18.95 \\
1168.0 & 1167.0 & 6.58 & -22.16 \\
1196.0 & 1194.6 & 3.78 & -25.92 \\
1223.0 & 1221.1 & 0.22 & -29.85 \\
1240.0 & 1237.7 & -2.32 & -32.55 \\
1259.0 & 1256.2 & -5.32 & -35.81 \\
1286.0 & 1282.2 & -10.26 & -41.17 \\
1304.0 & 1299.2 & -14.20 & -45.44 \\
1322.0 & 1316.0 & -18.62 & -50.24 \\
1349.0 & 1341.0 & -25.65 & -57.61 \\
1376.0 & 1366.0 & -32.83 & -64.74 \\
1400.0 & 1388.3 & -39.26 & -71.02
\end{tabular}




\begin{tabular}{|c|c|c|c|}
\hline 1425.0 & 1411.4 & -45.96 & -77.57 \\
\hline 1457.0 & 1440.8 & -54.61 & -86.93 \\
\hline 1483.0 & 1464.1 & -61.84 & -95.91 \\
\hline 1500.0 & 1479.0 & -66.79 & -102.44 \\
\hline 1520.0 & 1496.1 & -72.94 & -110.70 \\
\hline 1547.0 & 1518.6 & -81.82 & -122.63 \\
\hline 1565.0 & 1533.3 & -88.05 & -130.99 \\
\hline 1583.0 & 1547.7 & -94.49 & -139.65 \\
\hline 1601.0 & 1561.8 & -101.22 & -148.69 \\
\hline 1620.0 & 1576.2 & -108.60 & -158.60 \\
\hline 1646.0 & 1595.6 & -118.96 & -172.51 \\
\hline 1664.0 & 1608.8 & -126.24 & $-182 \cdot 30$ \\
\hline 1684.0 & 1623.4 & -134.39 & -193.24 \\
\hline 1710.0 & 1642.6 & -145.00 & -207.23 \\
\hline 1728.0 & 1656.1 & -152.29 & -216.68 \\
\hline 1755.0 & 1676.3 & -163.22 & -230.84 \\
\hline 1781.0 & 1695.5 & -174.07 & -244.65 \\
\hline 1790.0 & 1702.0 & -177.92 & -249.45 \\
\hline 1809.0 & 1715.9 & -186.13 & -259.53 \\
\hline 1828.0 & 1729.8 & -194.40 & -269.51 \\
\hline 1854.0 & 1748.9 & -205.73 & -282.93 \\
\hline 1872.0 & 1762.4 & -213.54 & -292.02 \\
\hline 1898.0 & 1781.9 & -224.71 & -305.02 \\
\hline 1917.0 & 1796.2 & -232.90 & -314.56 \\
\hline 1934.0 & 1808.9 & -240.12 & -323.26 \\
\hline 1954.0 & 1824.1 & -248.14 & -333.47 \\
\hline 1962.0 & 1830.3 & -251.23 & -337.46 \\
\hline 1982.0 & 1846.0 & -258.79 & -347.26 \\
\hline 2000.0 & 1860.2 & -265.64 & -355.97 \\
\hline 2027.0 & 1881.2 & -276.33 & -369.10 \\
\hline 2045.0 & 1895.0 & -283.73 & -377.94 \\
\hline 2062.0 & 1908.0 & -290.94 & -386.25 \\
\hline 2080.0 & 1921.7 & -298.75 & -394.87 \\
\hline 2107.0 & 1942.5 & -310.45 & -407.57 \\
\hline 2125.0 & 1956.4 & -318.31 & -415.81 \\
\hline 2143.0 & 1970.5 & -326.23 & -423.82 \\
\hline 2169.0 & 1990.8 & -337.68 & -435.30 \\
\hline 2189.0 & 2006.4 & -346.58 & -444.07 \\
\hline 2216.0 & 2027.3 & -359.03 & -455.81 \\
\hline 2234.0 & 2041.0 & -367.65 & -463.67 \\
\hline 2260.0 & 2060.7 & -380.28 & -474.97 \\
\hline 2278.0 & 2074.5 & -389.01 & -482.65 \\
\hline 2305.0 & 2095.2 & -402.14 & -493.81 \\
\hline 2333.0 & 2116.9 & -415.97 & -504.94 \\
\hline 2359.0 & 2137.0 & -428.98 & -515.04 \\
\hline 2388.0 & 2159.4 & -443.72 & -526.08 \\
\hline 2414.0 & 2179.5 & -457.21 & -535.65 \\
\hline 2442.0 & 2201.1 & -472.03 & -545.58 \\
\hline 2460.0 & 2214.9 & -481.72 & -551.83 \\
\hline 2478.0 & 2228.6 & -491.61 & -558.09 \\
\hline 2514.0 & 2255.6 & -511.92 & -570.45 \\
\hline 2558.0 & 2288.7 & -537.33 & -584.44 \\
\hline 2585.0 & 2309.1 & -553.05 & -592.40 \\
\hline 2612.0 & 2329.7 & -568.78 & -600.02 \\
\hline 2640.0 & 2351.1 & -585.14 & -607.59 \\
\hline 2668.0 & 2372.6 & -601.58 & -614.68 \\
\hline 2699.6 & 2397.1 & -620.29 & -621.99 \\
\hline
\end{tabular}


Production Well N-26P

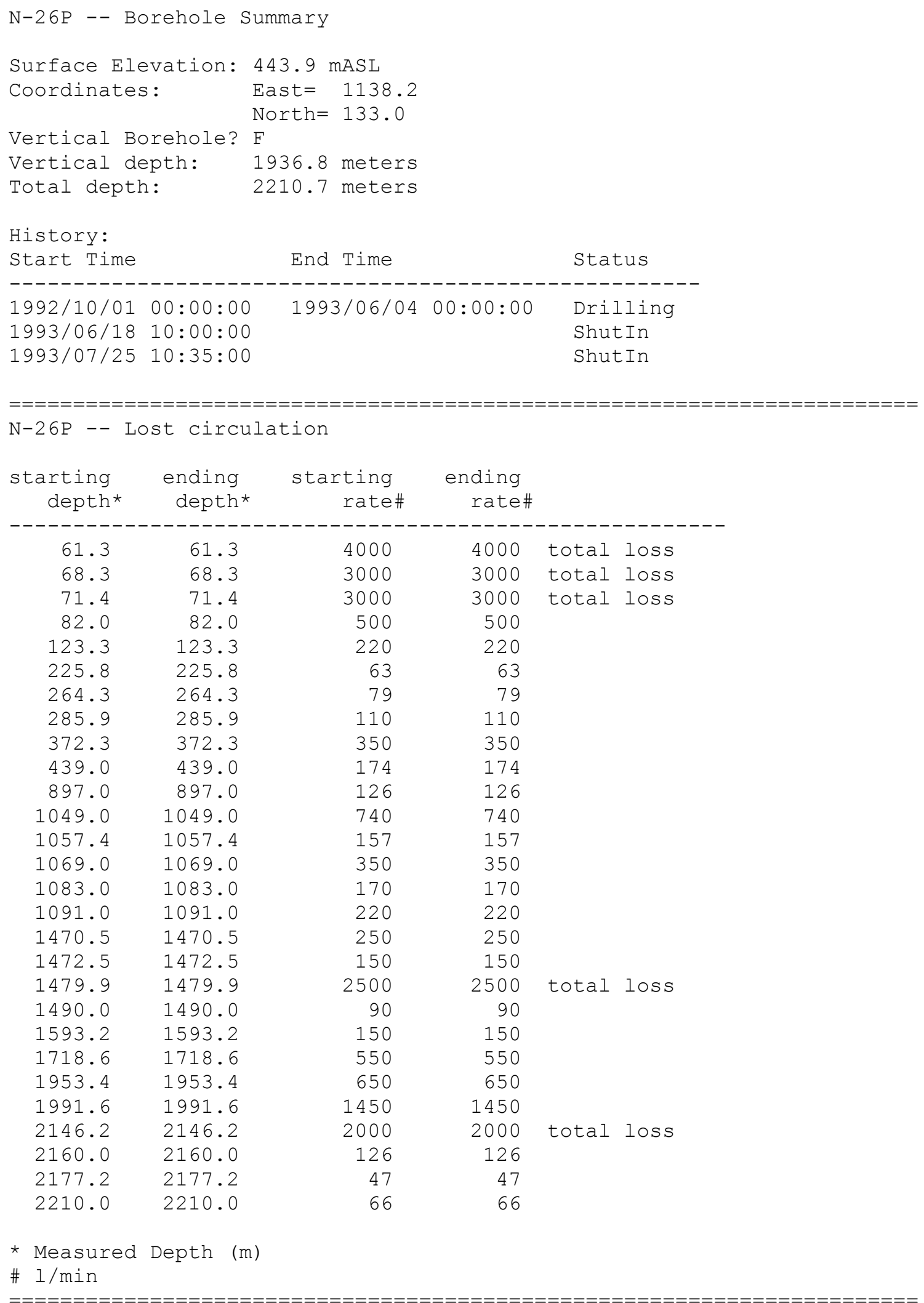




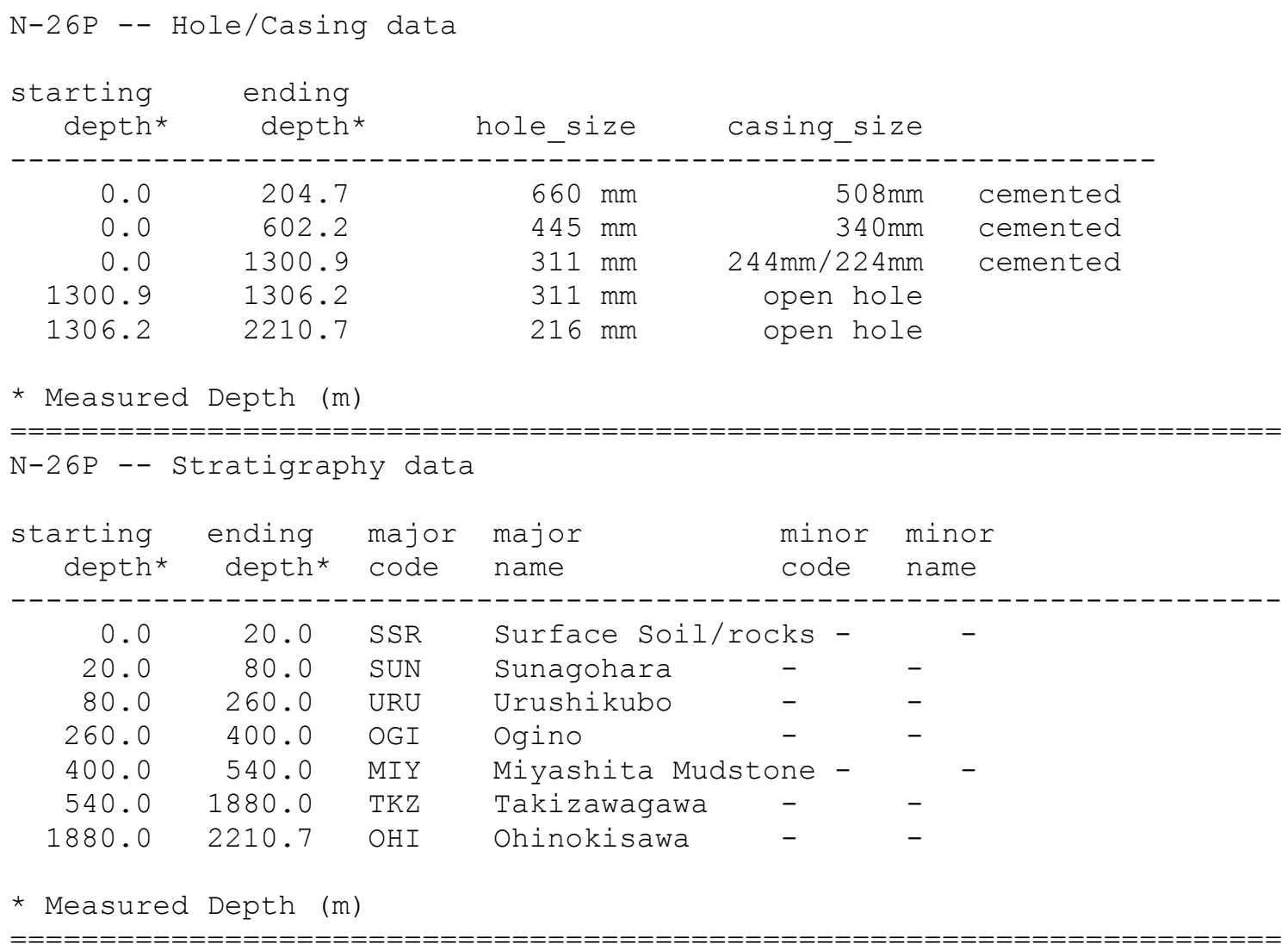


N-26P -- Deviation data (m)

\begin{tabular}{|c|c|c|c|}
\hline Meas.depth & Vert.depth & E_dev. & N_dev. \\
\hline 0.0 & 0.0 & 0 & 0.00 \\
\hline 50.0 & 50.0 & 0.21 & 0.05 \\
\hline 100.0 & 100.0 & 0.43 & 0.09 \\
\hline 150.0 & 150.0 & 0.10 & -0.07 \\
\hline 190.0 & 190.0 & -0.05 & -0.25 \\
\hline 250.0 & 250.0 & -0.12 & 0.43 \\
\hline 300.0 & 300.0 & -0.38 & 1.02 \\
\hline 350.0 & 350.0 & -0.43 & 1.13 \\
\hline 400.0 & 400.0 & -0.26 & 1.27 \\
\hline 450.0 & 450.0 & 0.22 & 1.12 \\
\hline 500.0 & 500.0 & 0.96 & 1.15 \\
\hline 550.0 & 550.0 & 1.87 & 1.29 \\
\hline 587.0 & 587.0 & 2.58 & 1.70 \\
\hline 645.0 & 644.9 & 3.25 & 2.76 \\
\hline 672.0 & 671.9 & 3.21 & 3.09 \\
\hline 690.0 & 689.9 & 3.04 & 3.14 \\
\hline 700.0 & 699.9 & 2.97 & 3.08 \\
\hline 710.0 & 709.9 & 2.89 & 3.01 \\
\hline 720.0 & 719.9 & 2.66 & 2.93 \\
\hline 739.0 & 738.9 & 1.81 & 2.40 \\
\hline 758.0 & 757.8 & 0.57 & 1.30 \\
\hline 777.0 & 776.7 & -0.82 & -0.22 \\
\hline 796.0 & 795.6 & -2.16 & -2.27 \\
\hline 815.0 & 814.3 & -3.70 & -5.03 \\
\hline 834.0 & 832.9 & -5.63 & -8.35 \\
\hline 854.0 & 852.3 & -8.33 & -12.29 \\
\hline 873.0 & 870.6 & $-11 \cdot 34$ & -16.41 \\
\hline 892.0 & 888.7 & -14.72 & -21.02 \\
\hline 911.0 & 906.6 & -18.41 & -26.27 \\
\hline 930.0 & 924.3 & -22.27 & -32.07 \\
\hline 949.0 & 941.7 & -26.40 & -38.39 \\
\hline 968.0 & 958.9 & -30.80 & -45.25 \\
\hline 989.0 & 977.7 & -35.96 & -53.14 \\
\hline 1008.0 & 994.5 & -40.79 & -60.40 \\
\hline 1027.0 & 1011.3 & -45.79 & -67.76 \\
\hline 1047.0 & 1029.0 & -51.02 & -75.62 \\
\hline 1062.0 & 1042.1 & -54.92 & -81.71 \\
\hline 1072.0 & 1050.8 & -57.61 & -85.82 \\
\hline 1094.0 & 1070.1 & -63.75 & -94.54 \\
\hline 1114.0 & 1087.7 & -69.55 & -101.92 \\
\hline 1133.0 & 1104.6 & -75.15 & -108.68 \\
\hline 1143.0 & 1113.4 & -78.14 & -112.29 \\
\hline 1153.0 & 1122.1 & -81.24 & -116.02 \\
\hline 1172.0 & 1138.4 & -87.48 & -123.55 \\
\hline 1191.0 & 1154.2 & -94.22 & -131.68 \\
\hline 1200.0 & 1161.6 & -97.56 & -135.70 \\
\hline 1210.0 & 1169.6 & -101.35 & -140.19 \\
\hline 1220.0 & 1177.7 & -105.22 & -144.62 \\
\hline 1230.0 & 1185.8 & -109.11 & -149.07 \\
\hline 1239.0 & 1193.0 & -112.63 & -153.10 \\
\hline 1248.0 & 1200.3 & -116.15 & -157.12 \\
\hline 1258.0 & 1208.3 & -120.05 & -161.58 \\
\hline 1268.0 & 1216.4 & -124.05 & -166.00 \\
\hline
\end{tabular}




$\begin{array}{llll}1277.0 & 1223.6 & -127.71 & -169.97 \\ 1287.0 & 1231.5 & -131.83 & -174.36 \\ 1297.0 & 1239.5 & -135.99 & -178.72 \\ 1315.0 & 1253.9 & -143.22 & -186.85 \\ 1334.0 & 1268.9 & -150.73 & -195.74 \\ 1353.0 & 1283.7 & -158.46 & -204.74 \\ 1372.0 & 1298.3 & -166.37 & -213.94 \\ 1391.0 & 1312.7 & -174.45 & -223.35 \\ 1410.0 & 1326.9 & -182.60 & -233.00 \\ 1430.0 & 1341.9 & -191.03 & -243.17 \\ 1468.0 & 1370.9 & -206.92 & -262.00 \\ 1486.0 & 1384.7 & -214.33 & -270.78 \\ 1505.0 & 1399.5 & -221.88 & -280.05 \\ 1526.0 & 1415.9 & -230.24 & -290.13 \\ 1545.0 & 1430.7 & -238.11 & -299.13 \\ 1564.0 & 1445.2 & -246.31 & -308.18 \\ 1583.0 & 1459.6 & -254.74 & -317.33 \\ 1602.0 & 1473.8 & -263.01 & -326.79 \\ 1620.0 & 1487.4 & -270.65 & -335.84 \\ 1640.0 & 1502.5 & -279.22 & -345.81 \\ 1659.0 & 1516.8 & -287.32 & -355.24 \\ 1688.0 & 1539.0 & -299.61 & -369.29 \\ 1716.0 & 1560.5 & -311.43 & -382.82 \\ 1745.0 & 1582.8 & -323.68 & -396.83 \\ 1774.0 & 1605.1 & -336.08 & -410.52 \\ 1803.0 & 1627.6 & -348.50 & -423.99 \\ 1831.0 & 1649.3 & -360.55 & -436.84 \\ 1860.0 & 1671.8 & -373.34 & -450.00 \\ 1889.0 & 1694.2 & -386.28 & -463.10 \\ 1917.0 & 1715.9 & -398.76 & -475.72 \\ 1946.0 & 1738.2 & -411.86 & -488.75 \\ 1975.0 & 1760.5 & -425.17 & -501.75 \\ 2004.0 & 1782.6 & -438.67 & -514.71 \\ 2034.0 & 1805.4 & -453.12 & -527.87 \\ 2063.0 & 1827.2 & -467.45 & -540.48 \\ 2092.0 & 1849.0 & -481.94 & -553.00 \\ 2120.0 & 1869.9 & -496.21 & -564.90 \\ 2140.0 & 1884.8 & -506.55 & -573.37 \\ 2168.0 & 1905.6 & -521.19 & -585.16 \\ 2187.0 & 1919.5 & -531.36 & -593.05 \\ 2210.7 & 1936.8 & -544.20 & -602.85\end{array}$


Production Well N-27P

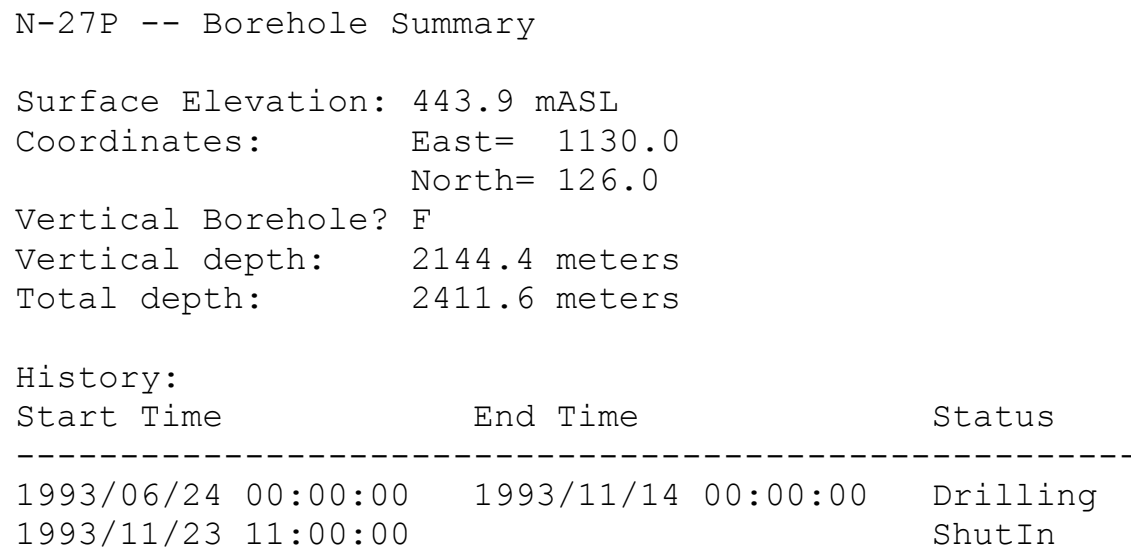

\begin{tabular}{|c|c|c|c|c|}
\hline $\begin{array}{l}\text { starting } \\
\text { depth* }\end{array}$ & $\begin{array}{l}\text { ending } \\
\text { depth* }\end{array}$ & $\begin{array}{l}\text { starting } \\
\text { rate\# }\end{array}$ & $\begin{array}{l}\text { ending } \\
\text { rate\# }\end{array}$ & \\
\hline ---------- & ---------- & ---------- & -------- & ---------------- \\
\hline 50.7 & 50.7 & 500 & 500 & \\
\hline 62.0 & 64.4 & 3000 & 3000 & total loss \\
\hline 68.6 & 68.6 & 2500 & 2500 & \\
\hline 71.0 & 71.0 & 3000 & 3000 & total loss \\
\hline 86.3 & 86.3 & 3300 & 3300 & total loss \\
\hline 716.0 & 716.0 & 50 & 50 & \\
\hline 723.7 & 723.7 & 113 & 113 & \\
\hline 803.0 & 803.0 & 100 & 100 & \\
\hline 823.0 & 823.0 & 220 & 220 & \\
\hline 844.4 & 844.4 & 126 & 126 & \\
\hline 950.0 & 950.0 & 567 & 567 & \\
\hline 962.8 & 962.8 & 63 & 63 & \\
\hline 1130.0 & 1130.0 & 500 & 500 & \\
\hline 1443.0 & 1443.0 & 2500 & 2500 & total loss \\
\hline 2043.0 & 2043.0 & 300 & 300 & \\
\hline 2052.8 & 2052.8 & 200 & 200 & \\
\hline 2102.4 & 2102.4 & 110 & 110 & \\
\hline 2138.1 & 2138.1 & 111 & 111 & \\
\hline 2148.3 & 2148.3 & 1622 & 1622 & total loss \\
\hline 2205.4 & 2205.4 & 158 & 158 & \\
\hline 2266.1 & 2266.1 & 126 & 126 & \\
\hline 2360.0 & 2360.0 & 252 & 252 & \\
\hline 2388.7 & 2388.7 & 1213 & 1213 & total loss \\
\hline $\begin{array}{l}\text { * Measured } \\
\# 1 / \mathrm{min}\end{array}$ & Depth (m) & & & \\
\hline
\end{tabular}




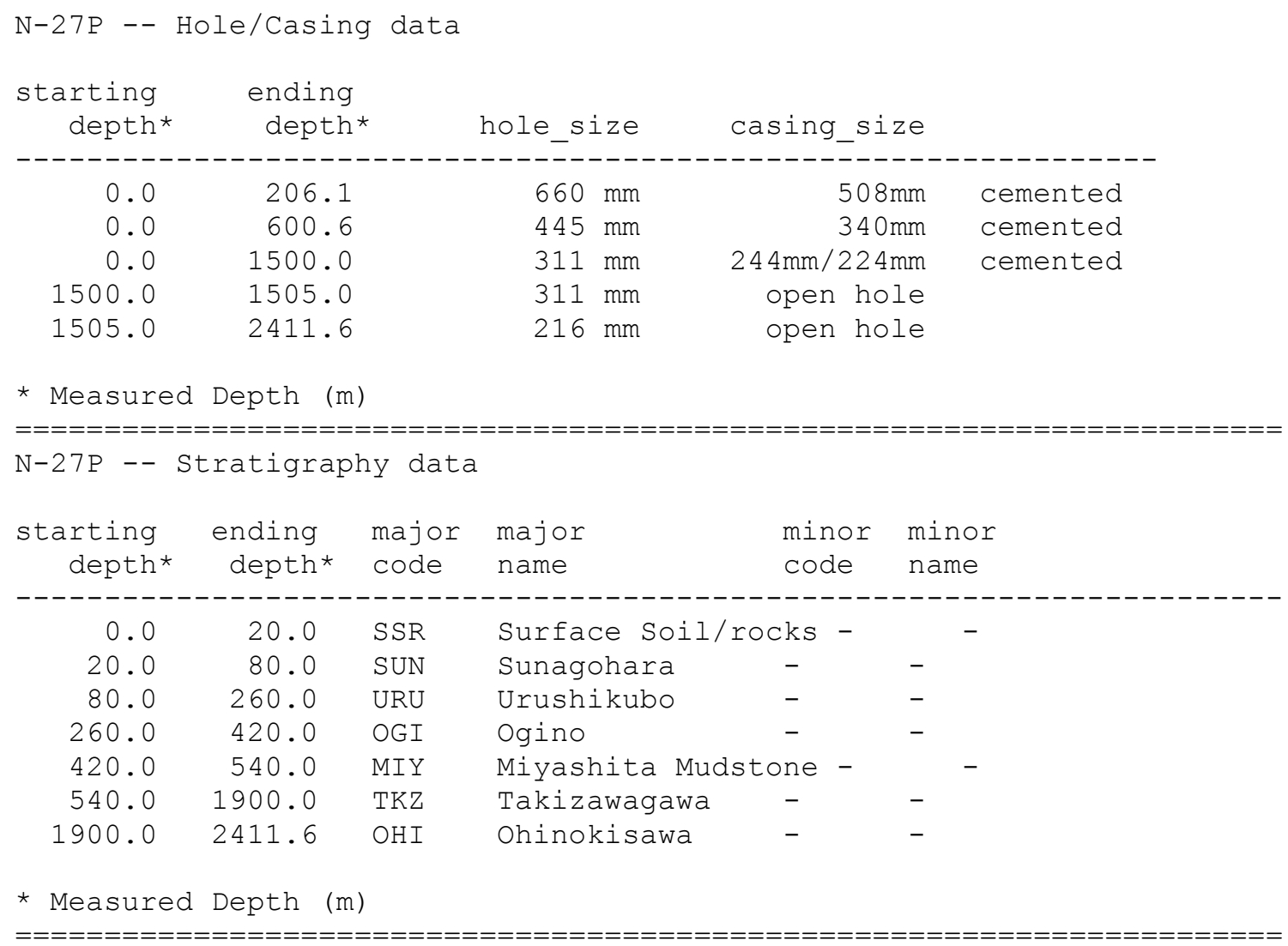


N-27P -- Deviation data (m)

\begin{tabular}{|c|c|c|c|}
\hline Meas.depth & Vert.depth & E_dev. & $\mathrm{N}_{-}$dev . \\
\hline & & & \\
\hline 0.0 & 0.0 & 0.00 & 0.00 \\
\hline 50.0 & 50.0 & -0.29 & 0.01 \\
\hline 100.0 & 100.0 & -0.52 & -0.01 \\
\hline 150.0 & 150.0 & -0.88 & -0.33 \\
\hline 191.0 & 191.0 & -1.58 & -0.47 \\
\hline 250.0 & 250.0 & -2.22 & -0.83 \\
\hline 300.0 & 300.0 & -2.37 & -1.61 \\
\hline 354.0 & 354.0 & -2.61 & -1.77 \\
\hline 400.0 & 400.0 & -2.91 & -1.51 \\
\hline 450.0 & 450.0 & -2.60 & -1.16 \\
\hline 507.0 & 507.0 & -2.11 & -0.85 \\
\hline 546.0 & 546.0 & -1.77 & -0.85 \\
\hline 584.0 & 584.0 & -0.92 & -0.53 \\
\hline 643.0 & 642.9 & 0.34 & 0.19 \\
\hline 663.0 & 662.9 & 0.35 & 0.27 \\
\hline 682.0 & 681.9 & 0.01 & 0.13 \\
\hline 701.0 & 700.9 & -0.91 & -0.42 \\
\hline 720.0 & 719.8 & -2.62 & -1.43 \\
\hline 739.0 & 738.6 & -4.90 & -2.97 \\
\hline 758.0 & 757.3 & -7.83 & -5.00 \\
\hline 778.0 & 776.8 & -11.55 & -7.17 \\
\hline 797.0 & 795.3 & -15.29 & -9.23 \\
\hline 816.0 & 813.7 & -19.34 & -11.45 \\
\hline 835.0 & 832.0 & -23.81 & -13.86 \\
\hline 854.0 & 850.2 & -28.58 & -16.43 \\
\hline 873.0 & 868.3 & -33.87 & -19.04 \\
\hline 893.0 & 887.1 & -39.97 & -22.07 \\
\hline 912.0 & 904.8 & -45.98 & -25.52 \\
\hline 932.0 & 923.3 & -52.37 & -29.73 \\
\hline 950.0 & 939.8 & -58.32 & -33.87 \\
\hline 970.0 & 957.9 & -65.22 & -38.76 \\
\hline 989.0 & 975.0 & -71.95 & -43.54 \\
\hline 1008.0 & 992.0 & -78.87 & -48.44 \\
\hline 1027.0 & 1008.9 & -85.92 & -53.53 \\
\hline 1046.0 & 1025.7 & -93.14 & -58.65 \\
\hline 1067.0 & 1044.2 & -101.41 & -64.30 \\
\hline 1086.0 & 1060.8 & -108.96 & -69.45 \\
\hline 1105.0 & 1077.5 & -116.44 & -74.57 \\
\hline 1115.0 & 1086.3 & -120.37 & -77.20 \\
\hline 1124.0 & 1094.3 & -123.90 & -79.52 \\
\hline 1134.0 & 1103.1 & -127.83 & -82.10 \\
\hline 1144.0 & 1111.9 & -131.77 & -84.65 \\
\hline 1153.0 & 1119.9 & -135.35 & -86.91 \\
\hline 1162.0 & 1127.8 & -138.96 & -89.20 \\
\hline 1181.0 & 1144.6 & -146.46 & -94.03 \\
\hline 1200.0 & 1161.5 & -153.58 & -98.99 \\
\hline 1219.0 & 1178.4 & -160.44 & -104.04 \\
\hline 1238.0 & 1195.5 & -167.26 & -108.96 \\
\hline 1258.0 & 1213.5 & -174.39 & -113.92 \\
\hline 1277.0 & 1230.6 & -181.18 & -118.65 \\
\hline 1300.0 & 1251.3 & -189.36 & -124.45 \\
\hline 1319.0 & 1268.6 & -195.81 & -129.10 \\
\hline 1338.0 & 1285.9 & -202.10 & -133.73 \\
\hline
\end{tabular}




\begin{tabular}{|c|c|c|c|}
\hline 1348.0 & 1295.0 & -205.47 & -136.21 \\
\hline 1367.0 & 1312.1 & -212.10 & -141.13 \\
\hline 1386.0 & 1329.1 & -218.79 & -146.37 \\
\hline 1405.0 & 1345.9 & -225.57 & -151.93 \\
\hline 1425.0 & 1363.4 & -233.07 & -158.08 \\
\hline 1444.0 & 1379.8 & -240.48 & -164.25 \\
\hline 1463.0 & 1395.8 & -248.20 & -170.82 \\
\hline 1482.0 & 1411.6 & -256.35 & -177.61 \\
\hline 1491.0 & 1419.0 & -260.35 & -180.88 \\
\hline 1513.0 & 1436.8 & -270.29 & -189.03 \\
\hline 1532.0 & 1452.2 & -278.95 & -196.13 \\
\hline 1551.0 & 1467.4 & -287.85 & -203.29 \\
\hline 1570.0 & 1482.2 & -297.13 & -210.76 \\
\hline 1580.0 & 1489.8 & -302.13 & -214.86 \\
\hline 1590.0 & 1497.3 & -307.19 & -219.01 \\
\hline 1607.0 & 1510.0 & -315.91 & -226.29 \\
\hline 1626.0 & 1524.0 & -325.68 & -234.58 \\
\hline 1645.0 & 1538.1 & -335.48 & -242.75 \\
\hline 1674.0 & 1559.8 & -350.34 & -254.93 \\
\hline 1702.0 & 1581.1 & -364.50 & -266.33 \\
\hline 1732.0 & 1604.2 & -379.58 & -278.25 \\
\hline 1751.0 & 1618.9 & -389.05 & -285.61 \\
\hline 1770.0 & 1633.7 & -398.47 & -292.80 \\
\hline 1789.0 & 1648.7 & -407.89 & -299.85 \\
\hline 1808.0 & 1663.7 & -417.29 & -306.77 \\
\hline 1827.0 & 1678.7 & -426.63 & -313.64 \\
\hline 1848.0 & 1695.4 & -436.98 & -320.97 \\
\hline 1857.0 & 1702.6 & -441.46 & -324.03 \\
\hline 1867.0 & 1710.6 & -446.47 & -327.39 \\
\hline 1877.0 & 1718.6 & -451.53 & -330.72 \\
\hline 1887.0 & 1726.4 & -456.66 & -334.09 \\
\hline 1896.0 & 1733.5 & -461.33 & -337.11 \\
\hline 1915.0 & 1748.4 & -471.43 & -343.26 \\
\hline 1934.0 & 1763.3 & -481.66 & -349.24 \\
\hline 1963.0 & 1786.1 & -497.18 & -358.14 \\
\hline 1992.0 & 1809.1 & -512.64 & -366.66 \\
\hline 2021.0 & 1832.2 & -528.10 & -374.82 \\
\hline 2049.0 & 1854.7 & -543.02 & -382.37 \\
\hline 2059.0 & 1862.7 & -548.32 & -384.99 \\
\hline 2080.0 & 1879.7 & -559.41 & -390.48 \\
\hline 2091.0 & 1888.6 & -565.29 & -393.32 \\
\hline 2100.0 & 1895.8 & -570.15 & -395.63 \\
\hline 2120.0 & 1911.6 & -581.24 & -400.76 \\
\hline 2130.0 & 1919.4 & -586.96 & -403.34 \\
\hline 2157.0 & 1940.3 & -602.58 & -410.41 \\
\hline 2185.0 & 1961.9 & -618.84 & -417.59 \\
\hline 2214.0 & 1984.5 & -635.68 & -424.34 \\
\hline 2234.0 & 2000.2 & -647.26 & -428.75 \\
\hline 2262.0 & 2022.2 & -663.43 & -434.90 \\
\hline 2282.0 & 2038.0 & -674.95 & -439.17 \\
\hline 2307.0 & 2057.9 & -689.16 & -444.30 \\
\hline 2316.0 & 2065.2 & -694.18 & -446.06 \\
\hline 2355.0 & 2097.2 & -715.87 & -450.67 \\
\hline 2393.0 & 2128.9 & -736.73 & -452.31 \\
\hline
\end{tabular}




\section{Production Well N-28P}

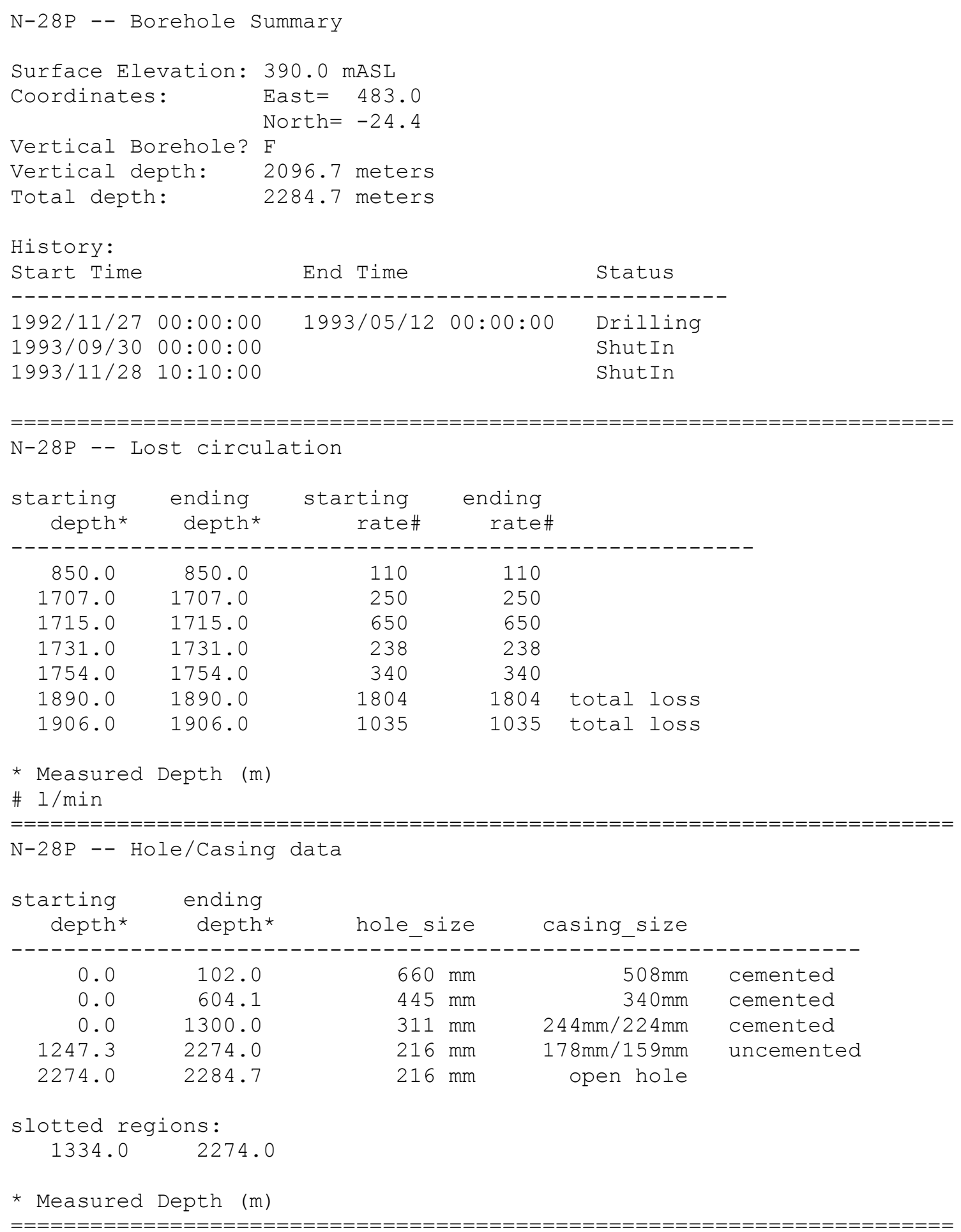




\begin{tabular}{|c|c|c|c|c|c|}
\hline $\begin{array}{l}\text { starting } \\
\text { depth* }\end{array}$ & $\begin{array}{l}\text { ending } \\
\text { depth* }\end{array}$ & $\begin{array}{l}\text { major } \\
\text { code }\end{array}$ & $\begin{array}{l}\text { major } \\
\text { name }\end{array}$ & $\begin{array}{l}\text { minor } \\
\text { code }\end{array}$ & $\begin{array}{l}\text { minor } \\
\text { name }\end{array}$ \\
\hline \multicolumn{6}{|c|}{-----------------------------------------------------------------------} \\
\hline 0.0 & 20.0 & SUR & Surface Tuffs & - & - \\
\hline 20.0 & 80.0 & SUN & Sunagohara & - & - \\
\hline 80.0 & 480.0 & URU & Urushikubo & - & - \\
\hline 480.0 & 620.0 & OGI & Ogino & - & - \\
\hline 620.0 & 680.0 & MIY & Miyashita Muds & one - & - \\
\hline 680.0 & 1680.0 & TKZ & Takizawagawa & - & - \\
\hline 1680.0 & 2284.7 & $\mathrm{OHI}$ & Ohinokisawa & - & - \\
\hline
\end{tabular}

\begin{tabular}{rrrr} 
Meas.depth & Vert.depth & E_dev. & N_dev \\
\hline 0.0 & 0.0 & 0.00 & 0.00 \\
50.0 & 50.0 & 0.14 & 0.17 \\
100.0 & 100.0 & 0.28 & 0.33 \\
150.0 & 150.0 & 0.02 & 0.09 \\
200.0 & 200.0 & -0.42 & -0.72 \\
252.0 & 252.0 & -0.90 & -2.15 \\
300.0 & 300.0 & -1.46 & -3.25 \\
350.0 & 349.9 & -1.99 & -3.74 \\
400.0 & 399.9 & -2.58 & -4.17 \\
450.0 & 449.9 & -3.27 & -4.29 \\
500.0 & 499.9 & -3.96 & -4.07 \\
550.0 & 549.9 & -4.20 & -3.72 \\
600.0 & 599.9 & -4.22 & -3.28 \\
650.0 & 649.9 & -4.12 & -2.93 \\
668.0 & 667.9 & -3.87 & -2.75 \\
678.0 & 677.9 & -3.67 & -2.60 \\
695.0 & 694.9 & -3.34 & -2.10 \\
713.0 & 712.9 & -3.71 & -1.44 \\
745.0 & 744.8 & -6.50 & -1.41 \\
767.0 & 766.6 & -8.98 & -2.31 \\
785.0 & 784.4 & -11.33 & -3.54 \\
803.0 & 802.1 & -14.14 & -5.33 \\
821.0 & 819.7 & -17.19 & -7.46 \\
839.0 & 837.3 & -20.41 & -9.78 \\
858.0 & 855.7 & -23.93 & -12.57 \\
875.0 & 872.2 & -27.23 & -15.33 \\
893.0 & 889.5 & -30.96 & -18.32 \\
911.0 & 906.8 & -34.95 & -21.36 \\
929.0 & 924.0 & -39.09 & -24.52 \\
947.0 & 941.2 & -43.41 & -27.82 \\
965.0 & 958.3 & -47.92 & -31.25 \\
983.0 & 975.3 & -52.65 & -34.87 \\
1001.0 & 992.1 & -57.72 & -38.66 \\
1031.0 & 1019.9 & -66.89 & -45.36 \\
1054.0 & 1040.9 & -74.49 & -50.82 \\
1073.0 & 1058.0 & -81.14 & -55.53 \\
1090.0 & 1073.2 & -87.33 & -60.00 \\
1109.0 & 1090.1 & -94.44 & -65.23
\end{tabular}




$\begin{array}{llll}1127.0 & 1105.8 & -101.47 & -70.31 \\ 1145.0 & 1121.4 & -108.78 & -75.49 \\ 1162.0 & 1136.1 & -115.87 & -80.47 \\ 1181.0 & 1152.2 & -124.16 & -86.11 \\ 1199.0 & 1167.3 & -132.33 & -91.52 \\ 1226.0 & 1189.9 & -144.77 & -99.54 \\ 1236.0 & 1198.3 & -149.31 & -102.42 \\ 1253.0 & 1212.7 & -156.92 & -107.24 \\ 1271.0 & 1228.0 & -164.98 & -112.34 \\ 1287.0 & 1241.6 & -172.15 & -116.87 \\ 1312.0 & 1263.5 & -182.04 & -123.57 \\ 1318.0 & 1269.0 & -184.12 & -124.95 \\ 1342.0 & 1290.9 & -192.37 & -130.27 \\ 1369.0 & 1315.4 & -201.32 & -137.10 \\ 1396.0 & 1339.7 & -210.51 & -144.57 \\ 1423.0 & 1363.6 & -220.36 & -152.43 \\ 1450.0 & 1387.0 & -230.82 & -160.85 \\ 1477.0 & 1410.1 & -241.80 & -169.38 \\ 1495.0 & 1425.5 & -249.32 & -174.96 \\ 1513.0 & 1440.8 & -256.84 & -180.64 \\ 1531.0 & 1456.2 & -264.32 & -186.34 \\ 1567.0 & 1486.9 & -279.27 & -197.75 \\ 1594.0 & 1509.9 & -290.56 & -206.21 \\ 1630.0 & 1540.6 & -305.91 & -217.09 \\ 1654.0 & 1561.1 & -316.26 & -224.16 \\ 1681.0 & 1584.1 & -328.05 & -231.91 \\ 1711.0 & 1609.7 & -341.26 & -240.35 \\ 1747.0 & 1640.3 & -357.19 & -250.34 \\ 1774.0 & 1663.4 & -369.30 & -257.57 \\ 1801.0 & 1686.4 & -381.48 & -264.70 \\ 1828.0 & 1709.4 & -393.72 & -271.71 \\ 1854.0 & 1731.6 & -405.59 & -278.32 \\ 1891.0 & 1763.1 & -422.53 & -287.64 \\ 1916.0 & 1784.4 & -434.12 & -293.76 \\ 1943.0 & 1807.3 & -446.92 & -300.03 \\ 1988.0 & 1845.5 & -468.65 & -309.85 \\ 2024.0 & 1876.0 & -486.23 & -317.26 \\ 2051.0 & 1898.9 & -499.51 & -322.58 \\ 2105.0 & 1944.7 & -526.30 & -332.64 \\ 2134.0 & 1969.3 & -540.82 & -337.66 \\ 2160.0 & 1991.4 & -553.97 & -341.76 \\ 2284.0 & 2015.1 & -568.28 & -345.69 \\ 1214.0 & 2037.1 & -581.78 & -348.88 \\ 1269.0 & 2060.8 & -596.45 & -351.69 \\ 1283.6 & -610.82 & -353.67 \\ 12096.7 & -619.30 & -354.61\end{array}$




\section{Injection Well N-29R}

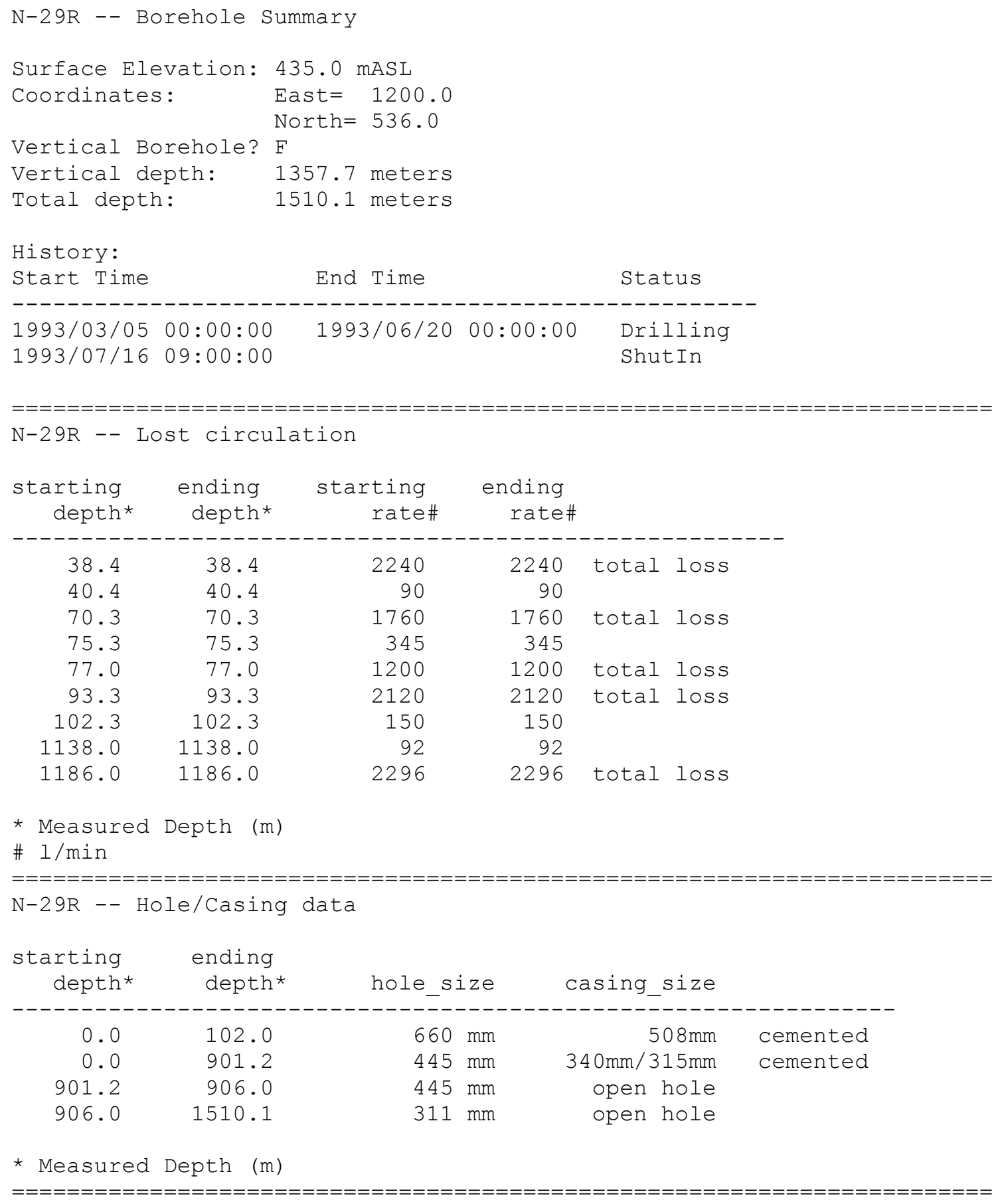


N-29R -- Stratigraphy data

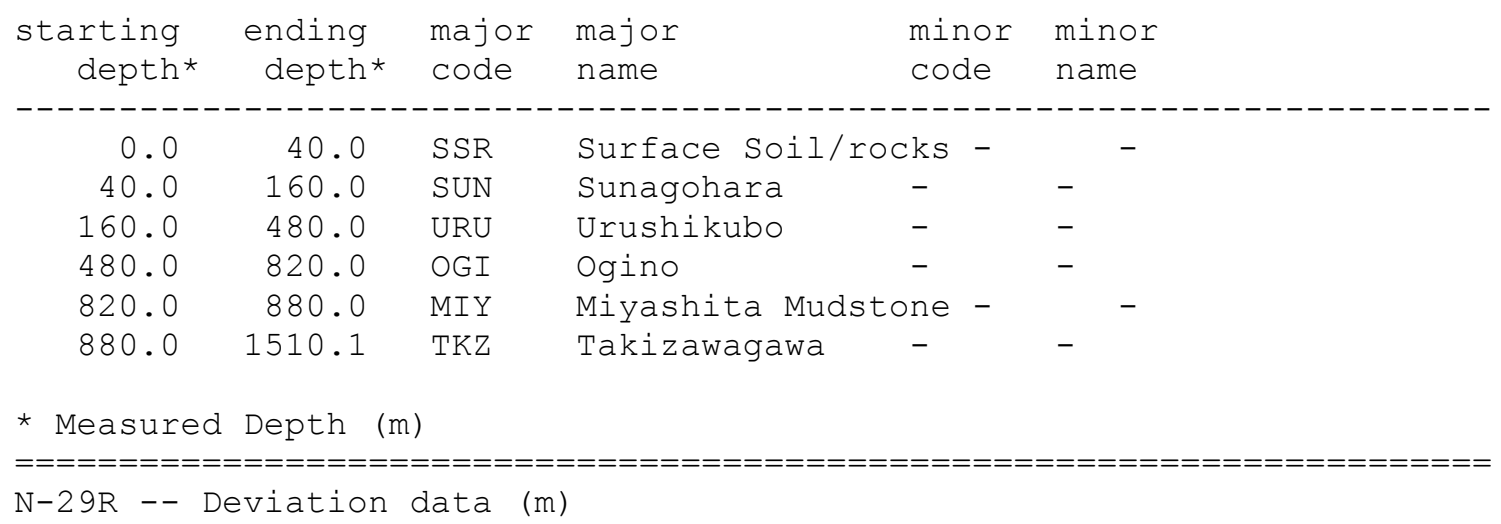

\begin{tabular}{rrrr} 
Meas.depth & Vert.depth & E_dev. & N_dev \\
\hline 0.0 & 0.0 & 0.00 & 0.00 \\
50.0 & 50.0 & -0.05 & 0.06 \\
100.0 & 100.0 & -0.28 & 0.00 \\
150.0 & 150.0 & -0.67 & -0.19 \\
200.0 & 200.0 & -0.51 & -0.31 \\
250.0 & 250.0 & -0.29 & -0.70 \\
300.0 & 300.0 & -0.75 & -1.33 \\
350.0 & 350.0 & -1.12 & -1.58 \\
400.0 & 400.0 & -1.50 & -1.83 \\
450.0 & 450.0 & -1.99 & -2.44 \\
490.0 & 490.0 & -2.47 & -2.68 \\
516.0 & 516.0 & -2.87 & -2.83 \\
535.0 & 535.0 & -3.09 & -3.01 \\
552.0 & 552.0 & -3.35 & -2.91 \\
579.0 & 578.9 & -3.12 & -1.31 \\
606.0 & 605.7 & -1.74 & 1.30 \\
631.0 & 630.5 & 0.21 & 3.63 \\
680.0 & 679.0 & 5.72 & 8.95 \\
696.0 & 694.7 & 7.92 & 10.96 \\
714.0 & 712.3 & 10.55 & 13.40 \\
732.0 & 729.9 & 13.39 & 16.08 \\
750.0 & 747.4 & 16.43 & 18.94 \\
777.0 & 773.3 & 21.76 & 24.07 \\
799.0 & 794.0 & 26.98 & 29.37 \\
823.0 & 816.1 & 33.45 & 36.28 \\
841.0 & 832.3 & 38.85 & 42.03 \\
859.0 & 848.2 & 44.59 & 48.05 \\
877.0 & 864.1 & 50.47 & 54.31 \\
895.0 & 879.7 & 56.47 & 60.83 \\
913.0 & 895.2 & 62.66 & 67.55 \\
925.0 & 905.5 & 66.91 & 72.16 \\
942.0 & 919.8 & 73.16 & 78.82 \\
960.0 & 934.9 & 79.93 & 85.91 \\
978.0 & 949.8 & 86.95 & 93.13 \\
997.0 & 965.3 & 94.63 & 101.04 \\
1014.0 & 979.0 & 101.61 & 108.36 \\
1032.0 & 993.2 & 109.11 & 116.35 \\
1051.0 & 1008.2 & 117.11 & 124.88 \\
1078.0 & 1029.6 & 128.56 & 136.67
\end{tabular}




$\begin{array}{llll}1105.0 & 1051.3 & 139.95 & 147.99 \\ 1131.0 & 1072.2 & 151.01 & 158.80 \\ 1158.0 & 1093.4 & 162.93 & 170.65 \\ 1176.0 & 1106.9 & 171.23 & 179.05 \\ 1205.0 & 1128.5 & 184.87 & 192.85 \\ 1226.0 & 1144.1 & 194.75 & 202.85 \\ 1252.0 & 1163.6 & 207.07 & 214.89 \\ 1281.0 & 1185.8 & 220.62 & 227.68 \\ 1310.0 & 1208.2 & 234.04 & 240.34 \\ 1335.0 & 1227.2 & 245.93 & 251.36 \\ 1362.0 & 1247.4 & 259.03 & 263.50 \\ 1389.0 & 1267.3 & 272.36 & 276.08 \\ 1417.0 & 1287.5 & 286.56 & 289.24 \\ 1444.0 & 1307.2 & 300.17 & 301.64 \\ 1469.0 & 1326.0 & 312.44 & 312.72 \\ 1497.0 & 1347.5 & 325.88 & 324.65 \\ 1510.1 & 1357.7 & 332.09 & 330.11\end{array}$




\section{Production Well N-30P}

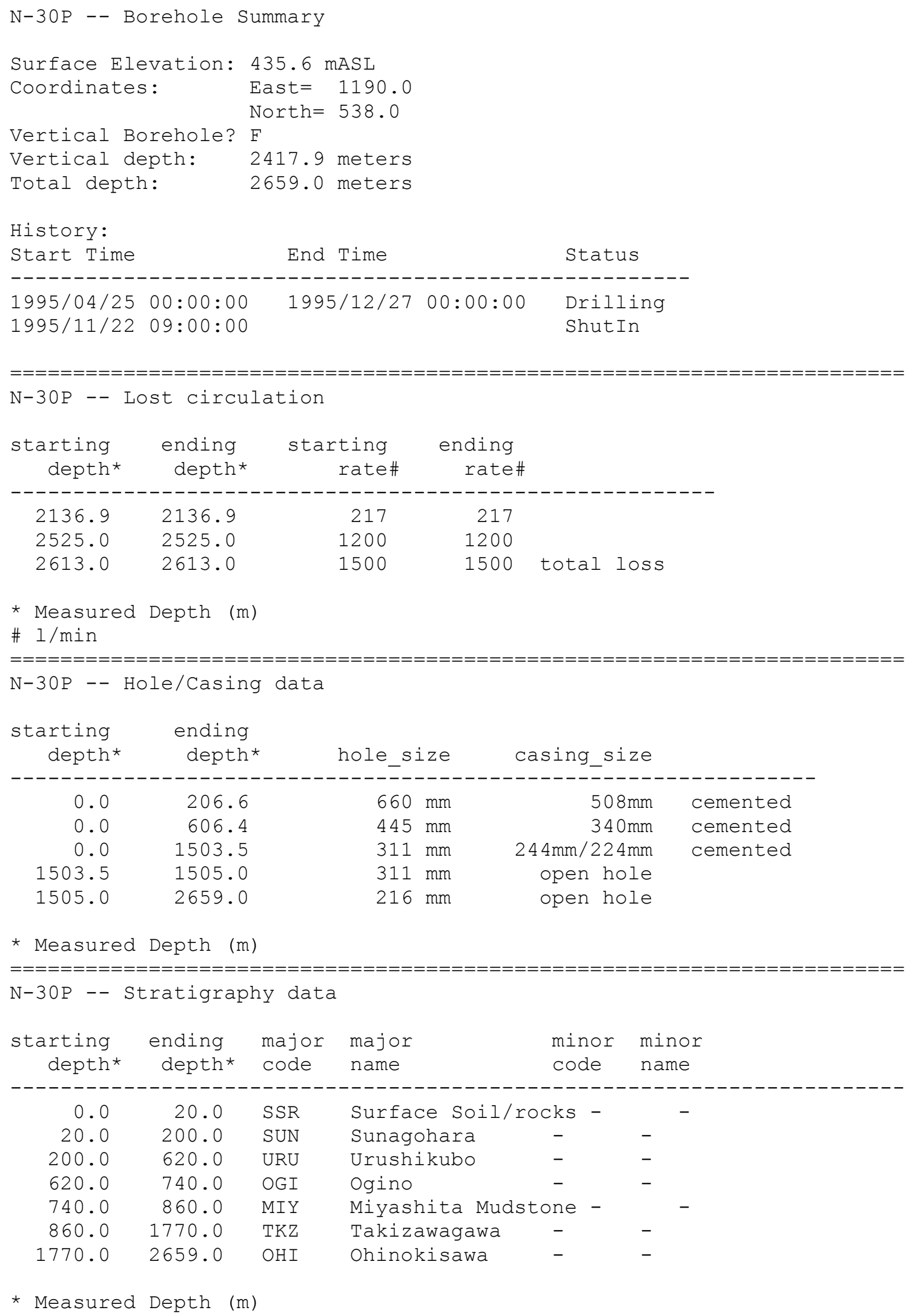


N-30P -- Deviation data (m)

\begin{tabular}{|c|c|c|c|}
\hline Meas.depth & Vert.depth & E_dev. & $\mathrm{N}_{-}$dev . \\
\hline 0.0 & 0.0 & 000 & 0.00 \\
\hline 50.0 & 50.0 & 0.20 & 0.20 \\
\hline 100.0 & 100.0 & 0.70 & 0.10 \\
\hline 150.0 & 150.0 & 0.50 & 0.00 \\
\hline 193.0 & 193.0 & 0.50 & 0.00 \\
\hline 250.0 & 250.0 & 0.80 & -0.30 \\
\hline 300.0 & 300.0 & 1.60 & -1.20 \\
\hline 350.0 & 349.9 & 2.00 & -2.80 \\
\hline 400.0 & 399.9 & 2.50 & -4.50 \\
\hline 450.0 & 449.9 & 2.80 & -5.50 \\
\hline 500.0 & 499.9 & 2.50 & -7.20 \\
\hline 550.0 & 549.8 & 2.50 & -9.50 \\
\hline 600.0 & 599.8 & 2.10 & -11.70 \\
\hline 650.0 & 649.7 & 0.80 & -14.20 \\
\hline 700.0 & 699.6 & -0.20 & -16.60 \\
\hline 750.0 & 749.5 & -1.40 & -18.70 \\
\hline 800.0 & 799.5 & -3.70 & -20.90 \\
\hline 850.0 & 849.3 & -6.30 & -23.00 \\
\hline 900.0 & 899.3 & -8.30 & -25.10 \\
\hline 950.0 & 949.2 & -10.30 & -26.80 \\
\hline 989.0 & 988.1 & -12.00 & -27.50 \\
\hline 1007.0 & 1006.1 & -12.90 & -27.90 \\
\hline 1026.0 & 1025.1 & -13.70 & -28.60 \\
\hline 1045.0 & 1044.0 & -14.20 & -29.90 \\
\hline 1065.0 & 1063.9 & -14.40 & -32.10 \\
\hline 1084.0 & 1082.7 & -14.60 & -34.70 \\
\hline 1103.0 & 1101.5 & -15.10 & -37.40 \\
\hline 1122.0 & 1120.3 & -16.00 & -40.50 \\
\hline 1141.0 & 1138.9 & -16.90 & -44.10 \\
\hline 1160.0 & 1157.5 & -18.10 & -47.90 \\
\hline 1180.0 & 1177.0 & -19.90 & -51.80 \\
\hline 1188.0 & 1184.8 & -20.70 & -53.50 \\
\hline 1199.0 & 1195.4 & -21.80 & -55.90 \\
\hline 1218.0 & 1213.9 & -23.80 & -60.10 \\
\hline 1237.0 & 1232.2 & -25.90 & -64.70 \\
\hline 1256.0 & 1250.3 & -28.30 & -69.80 \\
\hline 1275.0 & 1268.4 & -31.00 & -75.10 \\
\hline 1294.0 & 1286.2 & -33.80 & -80.90 \\
\hline 1313.0 & 1303.9 & -36.70 & -87.30 \\
\hline 1332.0 & 1321.4 & -39.90 & -94.00 \\
\hline 1351.0 & 1338.6 & -43.40 & $-101 \cdot 30$ \\
\hline 1370.0 & 1355.6 & -47.10 & -108.90 \\
\hline 1389.0 & 1372.3 & -51.00 & -117.00 \\
\hline 1408.0 & 1388.8 & -55.30 & -125.50 \\
\hline 1427.0 & 1404.9 & -59.70 & -134.50 \\
\hline 1446.0 & 1420.8 & -64.30 & -143.80 \\
\hline 1467.0 & 1438.3 & -69.50 & -154.30 \\
\hline 1486.0 & 1454.1 & -74.20 & -163.70 \\
\hline 1515.0 & 1478.6 & -81.30 & -177.60 \\
\hline 1534.0 & 1494.6 & -85.80 & -186.60 \\
\hline 1553.0 & 1511.4 & -90.40 & -196.40 \\
\hline 1582.0 & 1534.9 & -96.80 & -210.30 \\
\hline 1611.0 & 1559.1 & -103.60 & -224.70 \\
\hline
\end{tabular}




$\begin{array}{llll}1639.0 & 1582.4 & -110.50 & -238.70 \\ 1665.0 & 1604.0 & -116.60 & -251.80 \\ 1694.0 & 1628.0 & -123.50 & -266.50 \\ 1721.0 & 1650.5 & -129.80 & -280.10 \\ 1748.0 & 1673.2 & -136.10 & -293.30 \\ 1777.0 & 1697.3 & -143.20 & -307.80 \\ 1805.0 & 1720.3 & -149.70 & -322.30 \\ 1833.0 & 1743.1 & -156.70 & -337.10 \\ 1861.0 & 1765.5 & -164.20 & -352.00 \\ 1879.0 & 1779.9 & -168.90 & -361.70 \\ 1908.0 & 1803.3 & -176.40 & -377.10 \\ 1926.0 & 1818.0 & -180.60 & -386.70 \\ 1945.0 & 1833.5 & -185.00 & -396.70 \\ 1964.0 & 1849.2 & -189.70 & -406.40 \\ 1983.0 & 1865.0 & -194.40 & -415.90 \\ 2012.0 & 1889.2 & -201.30 & -430.30 \\ 2040.0 & 1912.4 & -208.00 & -444.30 \\ 2069.0 & 1936.4 & -215.10 & -459.00 \\ 2097.0 & 1959.3 & -222.10 & -473.50 \\ 2125.0 & 1982.1 & -229.10 & -488.30 \\ 2153.0 & 2004.6 & -236.40 & -503.30 \\ 2171.0 & 2018.9 & -241.00 & -513.10 \\ 2199.0 & 2041.1 & -247.80 & -528.70 \\ 2227.0 & 2063.4 & -254.20 & -544.40 \\ 2255.0 & 2085.9 & -260.60 & -559.70 \\ 2283.0 & 2108.8 & -267.50 & -574.50 \\ 2312.0 & 2132.8 & -274.70 & -589.00 \\ 2340.0 & 2156.6 & -280.90 & -602.50 \\ 2368.0 & 2180.4 & -287.00 & -615.80 \\ 2396.0 & 2204.1 & -293.10 & -629.50 \\ 2423.0 & 2226.7 & -298.80 & -643.10 \\ 2450.0 & 2249.2 & -305.00 & -656.60 \\ 2478.0 & 2272.4 & -312.40 & -670.40 \\ 2496.0 & 2287.3 & -317.30 & -679.20 \\ 2506.5 & 2295.9 & -320.00 & -684.50 \\ 2542.0 & 2325.2 & -329.30 & -702.50 \\ 2588.0 & 2362.3 & -340.80 & -727.00 \\ 2641.0 & 2404.0 & -353.64 & -756.83 \\ 2659.0 & 2417.9 & -358.42 & -767.28\end{array}$




\section{Production Well N-31P}

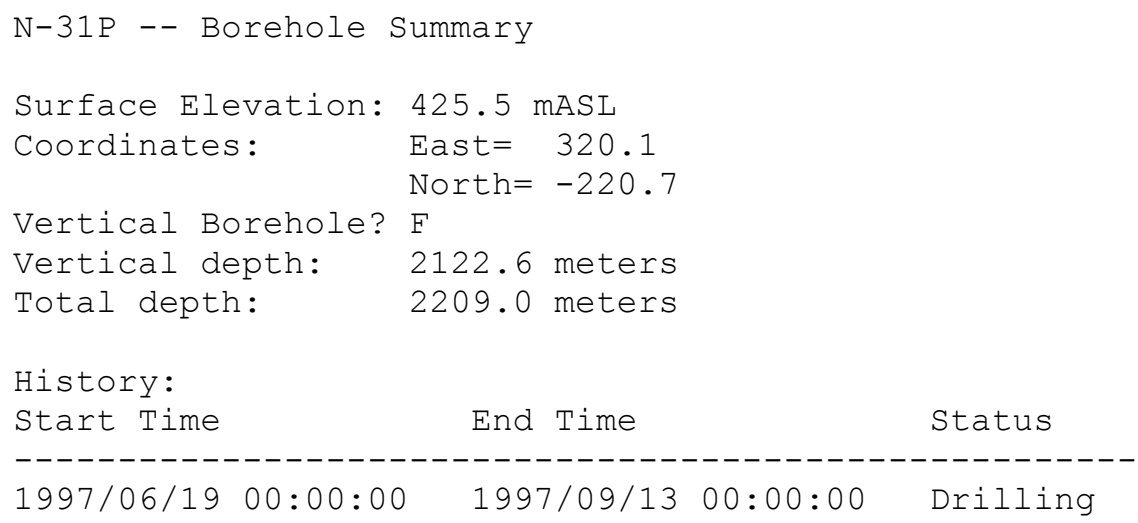

--------------------------------------------------------

$\begin{array}{llll}1280.0 & 1283.0 & 240 & 240\end{array}$

$1435.4 \quad 1435.4 \quad 400 \quad 400$

$\begin{array}{llll}1455.0 & 1455.0 & 470 & 470\end{array}$

$\begin{array}{rrrr}1512.0 & 1512.0 & 690 & 690\end{array}$

$\begin{array}{llll}1527.0 & 1527.0 & 1060 & 1060\end{array}$

$1547.0 \quad 1547.0 \quad 500 \quad 500$

$1570.1 \quad 1570.1$ ?

* Measured Depth (m)

\# $1 / \mathrm{min}$

? missing data

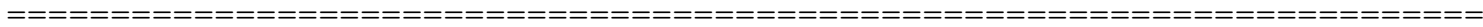
N-31P - - Hole/Casing data

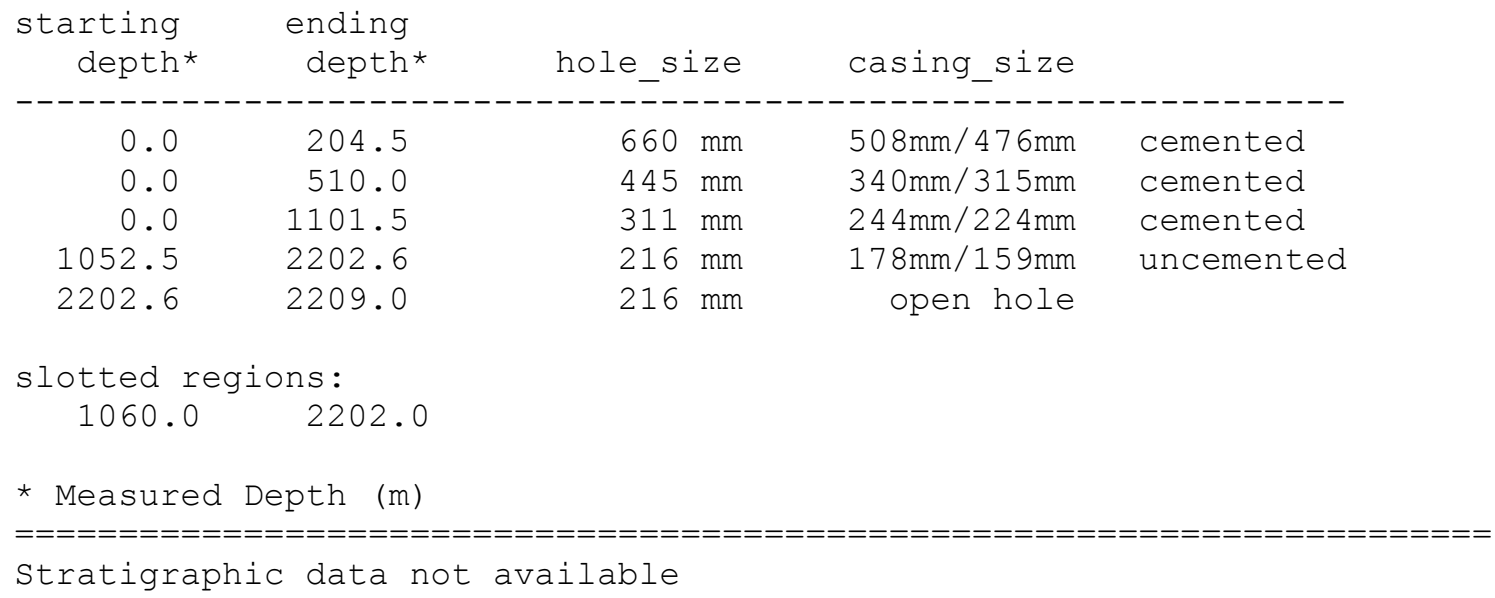


N-31P -- Deviation data (m)

\begin{tabular}{|c|c|c|c|}
\hline Meas.depth & Vert.depth & E_dev. & N_dev. \\
\hline 0.0 & 0.0 & مח 0 & 0.00 \\
\hline 44.0 & 44.0 & -0.23 & 0.09 \\
\hline 97.0 & 97.0 & 0.10 & -0.71 \\
\hline 154.0 & 154.0 & 1.79 & -1.09 \\
\hline 200.0 & 199.9 & 3.38 & -1.59 \\
\hline 250.0 & 249.9 & 5.47 & -1.56 \\
\hline 300.0 & 299.9 & 7.34 & -0.99 \\
\hline 350.0 & 349.8 & 9.01 & -0.28 \\
\hline 400.0 & 399.8 & 11.10 & 0.32 \\
\hline 450.0 & 449.7 & 12.90 & 0.53 \\
\hline 500.0 & 499.7 & 14.68 & 0.89 \\
\hline 550.0 & 549.7 & 16.18 & 1.60 \\
\hline 600.0 & 599.7 & 17.11 & 2.08 \\
\hline 650.0 & 649.6 & 18.24 & 2.49 \\
\hline 700.0 & 699.6 & 19.91 & 3.50 \\
\hline 750.0 & 749.5 & 21.57 & 4.92 \\
\hline 800.0 & 799.5 & 23.35 & 6.18 \\
\hline 819.0 & 818.5 & 24.33 & 6.11 \\
\hline 838.0 & 837.4 & 25.09 & 5.20 \\
\hline 857.0 & 856.4 & 25.77 & 3.81 \\
\hline 875.0 & 874.3 & 26.51 & 2.15 \\
\hline 894.0 & 893.2 & 26.92 & 0.01 \\
\hline 913.0 & 912.0 & 26.61 & -2.25 \\
\hline 931.0 & 929.9 & 25.83 & -4.18 \\
\hline 951.0 & 949.8 & 24.62 & -6.30 \\
\hline 969.0 & 967.6 & 23.25 & -8.44 \\
\hline 989.0 & 987.3 & 21.06 & -11.03 \\
\hline 1008.0 & 1005.9 & 18.49 & -13.63 \\
\hline 1026.0 & 1023.5 & 16.00 & -16.34 \\
\hline 1036.0 & 1033.3 & 14.58 & -17.87 \\
\hline 1041.0 & 1038.2 & 13.87 & -18.63 \\
\hline 1060.0 & 1056.7 & 10.85 & -21.80 \\
\hline 1078.0 & 1074.1 & 7.34 & -25.05 \\
\hline 1098.0 & 1093.2 & 2.93 & -28.79 \\
\hline 1117.0 & 1111.4 & -1.28 & -32.18 \\
\hline 1134.0 & 1127.8 & -4.99 & -35.01 \\
\hline 1155.0 & 1148.0 & -9.55 & -38.37 \\
\hline 1174.0 & 1166.3 & -13.74 & -41.33 \\
\hline 1193.0 & 1184.5 & -18.09 & -44.20 \\
\hline 1212.0 & 1202.9 & -22.36 & -46.90 \\
\hline 1231.0 & 1221.2 & -26.44 & -49.64 \\
\hline 1249.0 & 1238.6 & -30.42 & -52.25 \\
\hline 1268.0 & 1256.9 & -34.62 & -55.01 \\
\hline 1287.0 & 1275.3 & -38.66 & -57.77 \\
\hline 1306.0 & 1293.6 & -42.73 & -60.45 \\
\hline 1315.0 & 1302.3 & -44.67 & -61.61 \\
\hline 1324.0 & 1311.0 & -46.67 & -62.66 \\
\hline 1342.0 & 1328.3 & -51.15 & -65.03 \\
\hline 1361.0 & 1346.3 & -56.47 & -67.96 \\
\hline 1380.0 & 1364.0 & -62.48 & -71.33 \\
\hline 1399.0 & 1381.3 & -69.22 & -75.20 \\
\hline 1418.0 & 1398.2 & -76.71 & -79.67 \\
\hline 1437.0 & 1414.8 & -84.54 & -84.63 \\
\hline
\end{tabular}




$\begin{array}{llrr}1456.0 & 1431.3 & -92.11 & -90.19 \\ 1474.0 & 1447.0 & -98.81 & -96.08 \\ 1494.0 & 1464.2 & -106.26 & -102.88 \\ 1513.0 & 1480.3 & -113.82 & -109.53 \\ 1531.0 & 1495.6 & -120.95 & -115.80 \\ 1560.0 & 1520.7 & -132.13 & -125.29 \\ 1588.0 & 1545.0 & -142.83 & -134.06 \\ 1616.0 & 1569.5 & -153.43 & -142.43 \\ 1636.0 & 1587.2 & -160.79 & -148.26 \\ 1654.0 & 1603.2 & -167.23 & -153.44 \\ 1664.0 & 1612.1 & -170.77 & -156.19 \\ 1683.0 & 1629.1 & -177.43 & -161.36 \\ 1702.0 & 1646.2 & -184.03 & -166.49 \\ 1720.0 & 1662.4 & -190.39 & -171.08 \\ 1730.0 & 1671.4 & -193.92 & -173.49 \\ 1739.0 & 1679.6 & -197.06 & -175.64 \\ 1758.0 & 1696.7 & -203.88 & -180.38 \\ 1777.0 & 1713.7 & -210.75 & -185.17 \\ 1796.0 & 1731.0 & -217.40 & -189.54 \\ 1805.0 & 1739.2 & -220.51 & -191.47 \\ 1824.0 & 1756.6 & -227.15 & -195.35 \\ 1843.0 & 1774.0 & -233.75 & -198.91 \\ 1871.0 & 1799.9 & -243.22 & -203.70 \\ 1900.0 & 1827.0 & -252.72 & -208.30 \\ 1928.0 & 1853.2 & -261.65 & -212.15 \\ 1957.0 & 1880.6 & -270.65 & -215.49 \\ 1985.0 & 1907.2 & -279.03 & -218.35 \\ 2013.0 & 1933.8 & -287.25 & -220.91 \\ 2041.0 & 1960.5 & -295.33 & -223.13 \\ 2069.0 & 1987.3 & -303.14 & -224.83 \\ 2096.0 & 2013.3 & -310.38 & -225.96 \\ 2123.0 & 2039.4 & -317.31 & -226.85 \\ 2209.0 & 2122.6 & -338.91 & -229.63\end{array}$




\section{APPENDIX B \\ DisCHARGE RATE AND ENTHALPY DATA FOR OKUAIZU BOREHOLES}

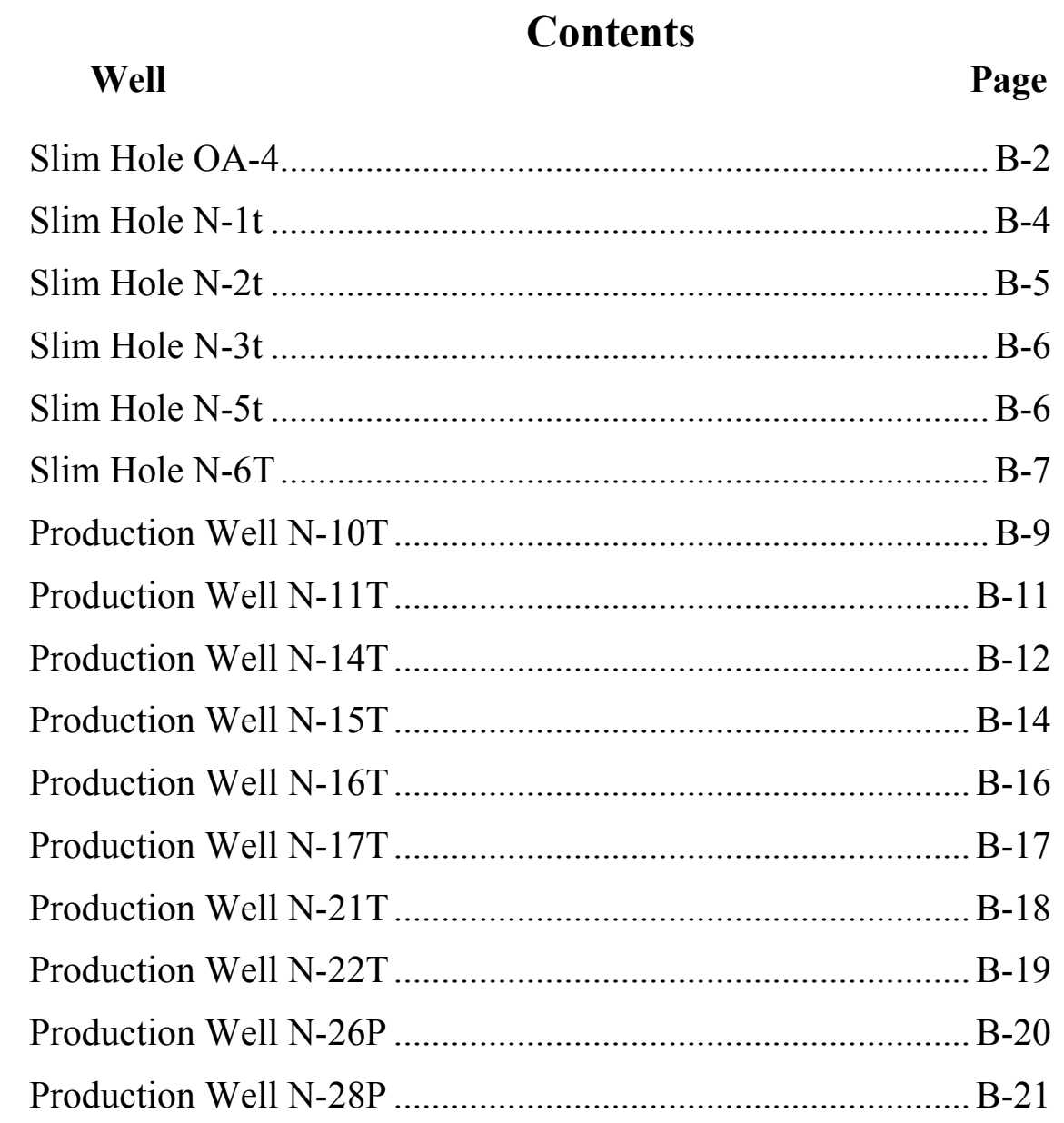




\section{Slim Hole OA-4}

Test Interval: January 10, 1984 - February 11, 1984

Table B.1. Wellhead pressure, steam and hot-water discharge rates, and wellhead discharge enthalpy recorded during a discharge test of slim hole OA-4 from January 10, 1984 to February $11,1984$.

\begin{tabular}{|c|c|c|c|c|c|}
\hline $\begin{array}{l}\text { Date } \\
\& \text { Time } \\
\end{array}$ & $\begin{array}{l}\text { WHP } \\
\text { (bars) }\end{array}$ & $\begin{array}{c}\text { Steam } \\
(\mathrm{T} / \mathrm{HR})\end{array}$ & $\begin{array}{c}\text { Hot-water } \\
(\mathrm{T} / \mathrm{HR})\end{array}$ & $\begin{array}{l}\text { Total } \\
(\mathrm{T} / \mathrm{HR})\end{array}$ & $\begin{array}{l}\text { Enthalpy } \\
(\mathrm{kJ} / \mathrm{kg})\end{array}$ \\
\hline $01-11-84$ & 1.48 & 8.97 & 9.93 & 18.90 & 1522. \\
\hline $01-12-84$ & 1.40 & 8.14 & 7.22 & 15.36 & 1642 . \\
\hline $01-13-84$ & 1.33 & 8.47 & 6.72 & 15.19 & 1699. \\
\hline $01-14-84$ & 1.30 & 8.11 & 5.82 & 13.93 & 1752. \\
\hline $01-15-84$ & 1.28 & 8.01 & 5.41 & 13.42 & 1784. \\
\hline $01-16-84$ & 1.26 & 7.70 & 5.20 & 12.90 & 1784. \\
\hline $01-17-84$ & 1.25 & 7.61 & 5.19 & 12.80 & 1777. \\
\hline $01-18-84$ & 1.23 & 7.31 & 6.01 & 13.32 & 1672 . \\
\hline $01-19-84$ & 1.22 & 7.18 & 4.99 & 12.17 & 1766. \\
\hline $01-20-84$ & 1.21 & 7.24 & 4.59 & 11.83 & 1814. \\
\hline $01-21-84$ & 1.43 & 7.05 & 4.29 & 11.34 & 1848. \\
\hline $01-22-84$ & 1.21 & 6.94 & 5.06 & 12.00 & 1738. \\
\hline $01-22-84$ & 3.98 & 6.41 & 5.35 & 11.76 & 1768. \\
\hline $01-22-84$ & 7.51 & 5.88 & 5.54 & 11.42 & 1769. \\
\hline $01-22-84$ & 11.43 & 5.19 & 5.57 & 10.76 & 1750 . \\
\hline $01-22-84$ & 15.45 & 4.47 & 5.20 & 9.67 & 1748 . \\
\hline $01-22-84$ & 10.75 & 5.35 & 5.45 & 10.80 & 1769 . \\
\hline $01-23-84$ & 6.63 & 6.08 & 4.92 & 11.00 & 1833. \\
\hline $01-23-84$ & 3.88 & 6.47 & 4.53 & 11.00 & 1858. \\
\hline $01-23-84$ & 1.21 & 7.00 & 4.11 & 11.11 & 1854. \\
\hline $01-24-84$ & 1.20 & 6.72 & 4.59 & 11.31 & 1774. \\
\hline $01-25-84$ & 1.20 & 6.17 & 3.40 & 9.57 & 1887. \\
\hline $01-26-84$ & 1.19 & 6.87 & 3.40 & 10.27 & 1940. \\
\hline $01-27-84$ & 1.19 & 6.81 & 2.82 & 9.63 & 2025 . \\
\hline $01-28-84$ & 1.19 & 6.74 & 2.82 & 9.56 & 2020 . \\
\hline $01-29-84$ & 1.19 & 6.75 & 2.19 & 8.94 & 2134 . \\
\hline $01-30-84$ & 1.19 & 6.71 & 1.75 & 8.46 & 2218 . \\
\hline $01-31-84$ & 1.19 & 6.65 & 1.46 & 8.11 & 2279 . \\
\hline $02-01-84$ & 1.19 & 6.56 & 1.21 & 7.77 & 2335 . \\
\hline $02-02-84$ & 1.18 & 6.43 & 2.82 & 9.25 & 1998. \\
\hline $02-03-84$ & 1.17 & 5.70 & 4.76 & 10.46 & 1659 . \\
\hline $02-04-84$ & 1.16 & 6.19 & 5.34 & 11.53 & 1641 . \\
\hline $02-05-84$ & 1.15 & 5.89 & 5.33 & 11.22 & 1615. \\
\hline $02-06-84$ & 1.15 & 5.61 & 5.54 & 11.15 & 1565. \\
\hline $02-07-84$ & 17.61 & 1.89 & 7.40 & 9.29 & 1270 . \\
\hline $02-08-84$ & 5.25 & 5.14 & 6.08 & 11.22 & 1612 . \\
\hline $02-09-84$ & 5.55 & 5.27 & 6.39 & 11.66 & 1605. \\
\hline $02-09-84$ & 1.17 & 5.90 & 5.65 & 11.55 & 1584. \\
\hline $02-10-84$ & 9.18 & 4.19 & 6.86 & 11.05 & 1515. \\
\hline $02-11-84$ & 1.25 & 6.65 & 7.40 & 14.05 & 1505 . \\
\hline
\end{tabular}


Test Interval: January 22-23 \& February 7-10, 1984

Table B.2. Wellhead pressure, steam and hot-water discharge rates, and wellhead discharge enthalpy recorded during a discharge test of slim hole OA-4 on January 22-23, 1984 and February 7-10, 1984.

\begin{tabular}{lrrrrr}
\hline $\begin{array}{l}\text { Date } \\
\text { \& Time }\end{array}$ & $\begin{array}{c}\text { WHP } \\
(\text { bars })\end{array}$ & $\begin{array}{c}\text { Steam } \\
(\mathrm{T} / \mathrm{HR})\end{array}$ & $\begin{array}{r}\text { Hot-wat } \\
(\mathrm{T} / \mathrm{HR})\end{array}$ & $\begin{array}{r}\text { Total } \\
\text { T/HR })\end{array}$ & $\begin{array}{c}\text { Enthalpy } \\
(\mathrm{kJ} / \mathrm{kg})\end{array}$ \\
\hline $01-22-84$ & 1.22 & 6.94 & 5.06 & 12.00 & 1738. \\
$01-22-84$ & 3.95 & 6.42 & 5.34 & 11.76 & 1769. \\
$01-22-84$ & 7.48 & 5.90 & 5.52 & 11.42 & 1772. \\
$01-22-84$ & 11.34 & 5.19 & 5.57 & 10.76 & 1750. \\
$01-22-84$ & 15.43 & 4.48 & 5.19 & 9.67 & 1750. \\
$01-22-84$ & 10.75 & 5.35 & 5.45 & 10.80 & 1769. \\
$01-23-84$ & 6.73 & 6.08 & 4.92 & 11.00 & 1835. \\
$01-23-84$ & 3.88 & 6.47 & 4.53 & 11.00 & 1857. \\
$01-23-84$ & 1.22 & 7.00 & 4.11 & 11.11 & 1854. \\
$02-09-84$ & 1.15 & 5.91 & 5.64 & 11.55 & 1584. \\
$02-09-84$ & 5.52 & 5.28 & 6.38 & 11.66 & 1606. \\
$02-10-84$ & 9.14 & 4.20 & 6.85 & 11.05 & 1517. \\
$02-07-84$ & 17.56 & 1.90 & 7.39 & 9.29 & 1271.
\end{tabular}




\section{Slim Hole N-1t}

Test Interval: June 7-14, 1985

Table B.3. Wellhead pressure, steam and hot-water discharge rates, and wellhead discharge enthalpy recorded during a discharge test of slim hole N-1t from June 7, 1985 to June 14, 1985.

\begin{tabular}{lccccc}
\hline $\begin{array}{l}\text { Date } \\
\text { \& Time }\end{array}$ & $\begin{array}{c}\text { WHP } \\
(\text { bars })\end{array}$ & $\begin{array}{c}\text { Steam } \\
(\mathrm{T} / \mathrm{HR})\end{array}$ & $\begin{array}{c}\text { Hot-water } \\
(\mathrm{T} / \mathrm{HR})\end{array}$ & $\begin{array}{c}\text { Total } \\
(\mathrm{T} / \mathrm{HR})\end{array}$ & $\begin{array}{c}\text { Enthalpy } \\
(\mathrm{kJ} / \mathrm{kg})\end{array}$ \\
\hline $06-07-85$ & 2.23 & 5.18 & 25.22 & 30.40 & 893. \\
$06-10-85$ & 5.67 & 1.88 & 15.22 & 17.10 & 892. \\
$06-12-85$ & 6.16 & 1.37 & 20.03 & 21.40 & 808. \\
$06-14-85$ & 2.04 & 4.96 & 21.84 & 26.80 & 915. \\
$06-10-85$ & 5.67 & 2.00 & 15.30 & 17.30 & 903. \\
$06-11-85$ & 4.49 & 3.10 & 20.00 & 23.10 & 908. \\
$06-09-85$ & 2.14 & 5.00 & 22.10 & 27.10 & 919.
\end{tabular}




\section{Slim Hole N-2t}

Test Interval: August 18, 1985 to November 15, 1985

Table B.4. Wellhead pressure. steam and hot-water discharge rates, and wellhead discharge enthalpy recorded during a discharge test of slim hole N-2t from August 18, 1985 to November $15,1985$.

\begin{tabular}{lccccc}
\hline $\begin{array}{l}\text { Date } \\
\text { \& Time }\end{array}$ & $\begin{array}{c}\text { WHP } \\
(\text { bars })\end{array}$ & $\begin{array}{c}\text { Steam } \\
(\mathrm{T} / \mathrm{HR})\end{array}$ & $\begin{array}{c}\text { Hot-water } \\
(\mathrm{T} / \mathrm{HR})\end{array}$ & $\begin{array}{c}\text { Total } \\
(\mathrm{T} / \mathrm{HR})\end{array}$ & $\begin{array}{c}\text { Enthalpy } \\
(\mathrm{kJ} / \mathrm{kg})\end{array}$ \\
\hline & & & & & \\
$08-18-85$ & 8.81 & 22.46 & 59.34 & 81.80 & 1297. \\
$08-31-85$ & 8.12 & 23.39 & 50.11 & 73.50 & 1375. \\
$09-16-85$ & 7.73 & 21.41 & 44.19 & 65.60 & 1385. \\
$10-16-85$ & 7.73 & 22.37 & 43.13 & 65.50 & 1416. \\
$10-18-85$ & 7.24 & 19.66 & 38.54 & 58.20 & 1400. \\
$11-05-85$ & 7.24 & 21.25 & 38.25 & 59.50 & 1440. \\
$11-08-85$ & 7.04 & 18.49 & 38.61 & 57.10 & 1367. \\
$11-11-85$ & 7.04 & 18.76 & 38.74 & 57.50 & 1372. \\
$11-13-85$ & 42.15 & 4.80 & 36.50 & 41.30 & 1300. \\
& 49.99 & 0.00 & 24.20 & 24.20 & 1155.
\end{tabular}

Test Interval: January 12, 1988-March 28, 1988

Table B.5. Wellhead pressure, steam and hot-water discharge rates, and wellhead discharge enthalpy recorded during a discharge test of slim hole N-2t from January 12, 1988 to March 28, 1988.

\begin{tabular}{lrcccc}
\hline $\begin{array}{l}\text { Date } \\
\text { \& Time }\end{array}$ & $\begin{array}{c}\text { WHP } \\
(\text { bars })\end{array}$ & $\begin{array}{c}\text { Steam } \\
(\mathrm{T} / \mathrm{HR})\end{array}$ & $\begin{array}{c}\text { Hot-water } \\
(\mathrm{T} / \mathrm{HR})\end{array}$ & $\begin{array}{c}\text { Total } \\
(\mathrm{T} / \mathrm{HR})\end{array}$ & $\begin{array}{c}\text { Enthalpy } \\
(\mathrm{kJ} / \mathrm{kg})\end{array}$ \\
\hline $01-20-88$ & 7.53 & 5.80 & 0.20 & 6.00 & 2697. \\
$01-22-88$ & 18.61 & 6.02 & 1.18 & 7.20 & 2485. \\
$02-01-88$ & 23.52 & 8.57 & 1.03 & 9.60 & 2603. \\
$02-01-88$ & 22.63 & 8.24 & 1.06 & 9.30 & 2589. \\
$02-05-88$ & 7.53 & 10.59 & 0.91 & 11.50 & 2605. \\
$02-17-88$ & 7.63 & 11.69 & 0.91 & 12.60 & 2619. \\
$02-29-88$ & 7.53 & 12.19 & 0.81 & 13.00 & 2639. \\
$03-10-88$ & 7.63 & 12.49 & 0.81 & 13.30 & 2642. \\
$03-23-88$ & 7.53 & 12.19 & 0.81 & 13.00 & 2639. \\
$03-24-88$ & 7.53 & 12.19 & 0.91 & 13.10 & 2624. \\
$03-26-88$ & 7.43 & 12.29 & 0.81 & 13.10 & 2639.
\end{tabular}




\section{Slim Hole N-3t}

Test Interval: January 10-18 \& February 21- March 5, 1986

Table B.6. Wellhead pressure, steam and hot-water discharge rates, and wellhead discharge enthalpy recorded during two discharge tests of slim hole N-3t from January 10, 1986 to January 18, 1986 and from February 21, 1986 to March 5, 1986.

\begin{tabular}{|c|c|c|c|c|c|}
\hline $\begin{array}{l}\text { Date } \\
\text { \& Time }\end{array}$ & $\begin{array}{l}\text { WHP } \\
\text { (bars) }\end{array}$ & $\begin{array}{l}\text { Steam } \\
(\mathrm{T} / \mathrm{HR})\end{array}$ & $\begin{array}{c}\text { Hot-water } \\
(\mathrm{T} / \mathrm{HR})\end{array}$ & $\begin{array}{l}\text { Total } \\
(\mathrm{T} / \mathrm{HR})\end{array}$ & $\begin{array}{c}\text { Enthalpy } \\
(\mathrm{kJ} / \mathrm{kg})\end{array}$ \\
\hline $\begin{array}{l}01-10-86 \\
02-27-86\end{array}$ & $\begin{array}{l}6.66 \\
5.78\end{array}$ & $\begin{array}{l}9.71 \\
5.76\end{array}$ & $\begin{array}{l}34.19 \\
30.14\end{array}$ & $\begin{array}{l}43.90 \\
35.90\end{array}$ & $\begin{array}{l}1147 . \\
1000 .\end{array}$ \\
\hline
\end{tabular}

\section{Slim Hole N-5t}

Test Interval: November 27 - December 16, 1984

Table B.7. Stable wellhead pressure, steam and hot-water discharge rates, and wellhead discharge enthalpy recorded during a discharge test of slim hole N-5t from November 27, 1984 to December 16, 1984.

\begin{tabular}{llcccc}
\hline $\begin{array}{l}\text { Date } \\
\text { \& Time }\end{array}$ & $\begin{array}{c}\text { WHP } \\
(\text { bars })\end{array}$ & $\begin{array}{c}\text { Steam } \\
(\mathrm{T} / \mathrm{HR})\end{array}$ & $\begin{array}{c}\text { Hot-water } \\
(\mathrm{T} / \mathrm{HR})\end{array}$ & $\begin{array}{c}\text { Total } \\
(\mathrm{T} / \mathrm{HR})\end{array}$ & $\begin{array}{c}\text { Enthalpy } \\
(\mathrm{kJ} / \mathrm{kg})\end{array}$ \\
\hline N/A & 0.97 & 1.80 & 3.40 & 5.20 & 1196.
\end{tabular}




\section{Slim Hole N-6T}

Test Interval: December 8, 1986 - April 5, 1987

Table B.8. Wellhead pressure, steam and hot-water discharge rates, and wellhead enthalpy recorded during the first long-term discharge test of N-6T from December 8, 1986 to April 5, 1987.

\begin{tabular}{lccccc}
\hline $\begin{array}{l}\text { Date } \\
\text { \& Time }\end{array}$ & $\begin{array}{c}\text { WHP } \\
\text { (bars) }\end{array}$ & $\begin{array}{c}\text { Steam } \\
(\mathrm{T} / \mathrm{HR})\end{array}$ & $\begin{array}{c}\text { Hot-water } \\
(\mathrm{T} / \mathrm{HR})\end{array}$ & $\begin{array}{c}\text { Total } \\
(\mathrm{T} / \mathrm{HR})\end{array}$ & $\begin{array}{c}\text { Enthalpy } \\
(\mathrm{kJ} / \mathrm{kg})\end{array}$ \\
\hline $12-18-86$ & 23.52 & 38.20 & 158.90 & 197.10 & 1307. \\
$12-20-86$ & 21.55 & 38.17 & 156.43 & 194.60 & 1294. \\
$12-20-86$ & 21.26 & 39.22 & 154.98 & 194.20 & 1302. \\
$12-21-86$ & 20.48 & 40.10 & 151.00 & 191.10 & 1310. \\
$12-22-86$ & 19.69 & 38.60 & 150.20 & 188.80 & 1292. \\
$12-23-86$ & 23.71 & 23.80 & 138.50 & 162.30 & 1221. \\
$12-24-86$ & 26.75 & 13.40 & 112.60 & 126.00 & 1173. \\
$12-25-86$ & 26.0 & 12.17 & 112.63 & 124.80 & 1151. \\
$12-26-86$ & 25.38 & 10.30 & 112.80 & 123.10 & 1120. \\
$01-08-87$ & 20.08 & 40.29 & 147.91 & 188.20 & 1314. \\
$01-09-87$ & 12.73 & 56.66 & 120.14 & 176.80 & 1444. \\
$01-20-87$ & 10.37 & 43.21 & 67.59 & 110.80 & 1553. \\
$01-28-87$ & 11.26 & 49.82 & 88.08 & 137.90 & 1507. \\
$01-29-87$ & 9.39 & 48.31 & 79.39 & 127.70 & 1517. \\
$01-30-87$ & 9.20 & 46.26 & 76.74 & 123.00 & 1510. \\
$02-08-87$ & 8.90 & 43.30 & 60.10 & 103.40 & 1592. \\
$02-13-87$ & 8.90 & 42.40 & 62.60 & 105.00 & 1562. \\
$04-04-87$ & 9.69 & 33.26 & 43.44 & 76.70 & 1633. \\
$04-05-87$ & 9.10 & 33.85 & 42.05 & 75.90 & 1650.
\end{tabular}

Test Interval: December 9, 1987 - March 28, 1988

Table B.9. Wellhead pressure, steam and hot-water discharge rates, and wellhead enthalpy recorded during the second long-term discharge test of N-6T from December 9, 1987 to March 28, 1988.

\begin{tabular}{lccccc}
\hline $\begin{array}{l}\text { Date } \\
\text { \& Time }\end{array}$ & $\begin{array}{c}\text { WHP } \\
(\text { bars })\end{array}$ & $\begin{array}{c}\text { Steam } \\
(\mathrm{T} / \mathrm{HR})\end{array}$ & $\begin{array}{c}\text { Hot-water } \\
(\mathrm{T} / \mathrm{HR})\end{array}$ & $\begin{array}{c}\text { Total } \\
(\mathrm{T} / \mathrm{HR})\end{array}$ & $\begin{array}{c}\text { Enthalpy } \\
(\mathrm{kJ} / \mathrm{kg})\end{array}$ \\
\hline $12-16-87$ & 41.66 & 20.88 & 60.52 & 81.40 & 1536. \\
$12-20-87$ & 39.99 & 21.34 & 52.86 & 74.20 & 1580. \\
$12-30-87$ & 37.34 & 23.85 & 40.25 & 64.10 & 1713. \\
$01-08-88$ & 36.46 & 24.65 & 35.25 & 59.90 & 1778. \\
$01-20-88$ & 35.09 & 25.32 & 30.38 & 55.70 & 1847. \\
$01-22-88$ & 39.60 & 25.16 & 28.84 & 54.00 & 1884. \\
$01-30-88$ & 33.62 & 26.16 & 24.54 & 50.70 & 1949. \\
$02-01-88$ & 9.39 & 67.43 & 38.37 & 105.80 & 2041. \\
$02-04-88$ & 8.71 & 55.63 & 87.47 & 143.10 & 1528. \\
$02-17-88$ & 8.31 & 48.74 & 21.36 & 70.10 & 2148. \\
$02-26-88$ & 8.02 & 45.90 & 16.00 & 61.90 & 2240. \\
$02-27-88$ & 17.24 & 38.50 & 15.90 & 54.40 & 2234.
\end{tabular}




$\begin{array}{rrrrrr}02-28-88 & 27.93 & 23.60 & 10.90 & 34.50 & 2230 . \\ 02-29-88 & 8.22 & 48.13 & 15.97 & 64.10 & 2261 . \\ 03-10-88 & 8.02 & 44.20 & 14.00 & 58.20 & 2277 . \\ 03-23-88 & 8.02 & 42.79 & 15.11 & 57.90 & 2235 . \\ 03-24-88 & 8.02 & 42.80 & 13.50 & 56.30 & 2279 . \\ 03-26-88 & 8.02 & 42.92 & 12.98 & 55.90 & 2294 .\end{array}$

Test Interval: November 17, 1989 - March 3, 1990

Table B.10. Wellhead pressure, steam and hot-water discharge rates, and wellhead enthalpy recorded during the third long-term discharge test of N-6T from November 17, 1989 to March 3, 1990.

\begin{tabular}{llcccc}
\hline $\begin{array}{l}\text { Date } \\
\text { \& Time }\end{array}$ & $\begin{array}{l}\text { WHP } \\
(\text { bars })\end{array}$ & $\begin{array}{c}\text { Steam } \\
(\mathrm{T} / \mathrm{HR})\end{array}$ & $\begin{array}{c}\text { Hot-water } \\
(\mathrm{T} / \mathrm{HR})\end{array}$ & $\begin{array}{c}\text { Total } \\
(\mathrm{T} / \mathrm{HR})\end{array}$ & $\begin{array}{c}\text { Enthalpy } \\
(\mathrm{kJ} / \mathrm{kg})\end{array}$ \\
\hline $12-11-89$ & 28.22 & 37.71 & 26.59 & 64.30 & 2054. \\
$12-26-89$ & 22.83 & 38.66 & 26.84 & 65.50 & 2039. \\
$12-28-89$ & 22.44 & 38.89 & 20.01 & 58.90 & 2168. \\
$01-01-90$ & 21.95 & 38.48 & 17.92 & 56.40 & 2207. \\
$01-26-90$ & 16.65 & 39.71 & 9.29 & 49.00 & 2429. \\
$01-26-90$ & 24.50 & 28.74 & 7.76 & 36.50 & 2410. \\
$01-26-90$ & 28.03 & 24.71 & 6.79 & 31.50 & 2412. \\
$01-27-90$ & 19.20 & 37.20 & 7.50 & 44.70 & 2480. \\
$02-21-90$ & 16.45 & 38.08 & 4.72 & 42.80 & 2582. \\
$02-26-90$ & 16.45 & 38.21 & 5.89 & 44.10 & 2537.
\end{tabular}




\section{Production Well N-10T}

Test Interval: September 7, 1987- October 7, 1987

Table B.11. Wellhead pressure, steam and hot-water discharge rates, and wellhead enthalpy recorded during the first long-term discharge test of $\mathrm{N}-10 \mathrm{~T}$ from September 7, 1987 to October 7, 1997.

\begin{tabular}{lrcccc}
\hline $\begin{array}{l}\text { Date } \\
\text { \& Time }\end{array}$ & $\begin{array}{c}\text { WHP } \\
(\text { bars })\end{array}$ & $\begin{array}{c}\text { Steam } \\
(\mathrm{T} / \mathrm{HR})\end{array}$ & $\begin{array}{c}\text { Hot-water } \\
(\mathrm{T} / \mathrm{HR})\end{array}$ & $\begin{array}{c}\text { Total } \\
(\mathrm{T} / \mathrm{HR})\end{array}$ & $\begin{array}{c}\text { Enthalpy } \\
(\mathrm{kJ} / \mathrm{kg})\end{array}$ \\
\hline $09-07-87$ & 39.11 & 64.39 & 97.11 & 161.50 & 1767. \\
$09-09-87$ & 19.10 & 69.74 & 83.16 & 152.90 & 1765. \\
$09-15-87$ & 9.79 & 56.16 & 43.84 & 100.00 & 1892. \\
$09-16-87$ & 9.79 & 55.80 & 42.50 & 98.30 & 1904. \\
$09-26-87$ & 10.77 & 48.30 & 36.10 & 84.40 & 1924. \\
$09-30-87$ & 9.00 & 48.04 & 31.46 & 79.50 & 1970. \\
$10-03-87$ & 9.00 & 45.48 & 27.12 & 72.60 & 2015.
\end{tabular}

Test Interval: December 15, 1987 - March 27, 1988

Table B.12. Wellhead pressure, steam and hot-water discharge rates, and wellhead enthalpy recorded during the second long-term discharge test of N-10T from December 15, 1987 to March 27, 1988.

\begin{tabular}{lccccc}
\hline $\begin{array}{l}\text { Date } \\
\text { \& Time }\end{array}$ & $\begin{array}{l}\text { WHP } \\
(\text { bars })\end{array}$ & $\begin{array}{c}\text { Steam } \\
(\mathrm{T} / \mathrm{HR})\end{array}$ & $\begin{array}{c}\text { Hot-water } \\
(\mathrm{T} / \mathrm{HR})\end{array}$ & $\begin{array}{c}\text { Total } \\
(\mathrm{T} / \mathrm{HR})\end{array}$ & $\begin{array}{c}\text { Enthalpy } \\
(\mathrm{kJ} / \mathrm{kg})\end{array}$ \\
\hline $12-16-87$ & 51.86 & 14.03 & 49.57 & 63.60 & 1525. \\
$12-20-87$ & 46.07 & 15.28 & 33.32 & 48.60 & 1654. \\
$12-30-87$ & 40.97 & 14.35 & 21.25 & 35.60 & 1782. \\
$01-08-88$ & 39.40 & 16.34 & 17.96 & 34.30 & 1901. \\
$01-20-88$ & 36.66 & 17.74 & 15.26 & 33.00 & 1998. \\
$01-22-88$ & 36.26 & 21.57 & 14.23 & 35.80 & 2110. \\
$01-30-88$ & 35.68 & 16.99 & 13.01 & 30.00 & 2045. \\
$02-01-88$ & 9.10 & 49.28 & 26.62 & 75.90 & 2063. \\
$02-04-88$ & 8.71 & 44.84 & 19.66 & 64.50 & 2152. \\
$02-15-88$ & 5.77 & -0.00 & 12.10 & 12.10 & 652. \\
$02-17-88$ & 2.33 & 13.37 & 0.23 & 13.60 & 2677. \\
$02-18-88$ & 2.23 & 13.00 & 6.00 & 19.00 & 2019. \\
$02-19-88$ & 4.20 & 11.40 & 10.80 & 22.20 & 1706. \\
$02-19-88$ & 11.06 & 0.00 & 5.00 & 5.00 & 782. \\
$02-24-88$ & 10.08 & -0.00 & 9.20 & 9.20 & 413. \\
$03-20-88$ & 15.08 & 30.00 & 74.00 & 104.00 & 1407. \\
$03-21-88$ & 11.65 & 29.41 & 56.99 & 86.40 & 1470. \\
$03-24-88$ & 34.50 & 16.15 & 26.55 & 42.70 & 1710. \\
$03-26-88$ & 37.93 & 16.28 & 23.22 & 39.50 & 1785. \\
$03-27-88$ & 40.77 & 15.20 & 8.60 & 23.80 & 2183.
\end{tabular}


Test Interval: August 23, 1988 - October 8, 1988

Table B.13. Wellhead pressure, steam and hot-water discharge rates, and wellhead enthalpy recorded during the third long-term discharge test of N-10T from August 23, 1988 to October 8, 1988.

\begin{tabular}{llcccc}
\hline $\begin{array}{l}\text { Date } \\
\text { \& Time }\end{array}$ & $\begin{array}{l}\text { WHP } \\
(\text { bars })\end{array}$ & $\begin{array}{c}\text { Steam } \\
(\mathrm{T} / \mathrm{HR})\end{array}$ & $\begin{array}{c}\text { Hot-water } \\
(\mathrm{T} / \mathrm{HR})\end{array}$ & $\begin{array}{c}\text { Total } \\
(\mathrm{T} / \mathrm{HR})\end{array}$ & $\begin{array}{c}\text { Enthalpy } \\
(\mathrm{kJ} / \mathrm{kg})\end{array}$ \\
\hline $08-29-88$ & 30.38 & 36.59 & 32.71 & 69.30 & 1958. \\
$09-05-88$ & 30.77 & 31.17 & 26.93 & 58.10 & 1974. \\
$09-10-88$ & 30.97 & 32.50 & 23.10 & 55.60 & 2061. \\
$09-11-88$ & 30.48 & 27.97 & 24.93 & 52.90 & 1959. \\
$09-11-88$ & 30.38 & 28.14 & 23.76 & 51.90 & 1983. \\
$09-22-88$ & 20.67 & 32.18 & 17.42 & 49.60 & 2138. \\
$09-26-88$ & 20.48 & 25.76 & 16.04 & 41.80 & 2076. \\
$09-27-88$ & 20.48 & 23.32 & 12.78 & 36.10 & 2132. \\
$10-04-88$ & 35.58 & 15.15 & 13.85 & 29.00 & 1968.
\end{tabular}

Test Interval: November 26, 1989 - March 3, 1990

Table B.14. Wellhead pressure, steam and hot-water discharge rates, and wellhead enthalpy recorded during the fourth long-term discharge test of N-10T from November 26, 1989 to March 3, 1990.

\begin{tabular}{llcccc}
\hline $\begin{array}{l}\text { Date } \\
\text { \& Time }\end{array}$ & $\begin{array}{l}\text { WHP } \\
(\text { bars })\end{array}$ & $\begin{array}{c}\text { Steam } \\
(\mathrm{T} / \mathrm{HR})\end{array}$ & $\begin{array}{c}\text { Hot-water } \\
(\mathrm{T} / \mathrm{HR})\end{array}$ & $\begin{array}{c}\text { Total } \\
(\mathrm{T} / \mathrm{HR})\end{array}$ & $\begin{array}{c}\text { Enthalpy } \\
(\mathrm{kJ} / \mathrm{kg})\end{array}$ \\
\hline $12-11-89$ & 52.54 & 26.19 & 16.31 & 42.50 & 2169. \\
$12-26-89$ & 48.62 & 22.53 & 15.77 & 38.30 & 2116. \\
$12-28-89$ & 48.42 & 22.27 & 15.53 & 37.80 & 2117. \\
$01-01-90$ & 47.64 & 21.75 & 15.35 & 37.10 & 2110. \\
$01-24-90$ & 37.64 & 28.60 & 16.10 & 44.70 & 2178. \\
$01-24-90$ & 34.60 & 33.25 & 18.75 & 52.00 & 2169. \\
$01-24-90$ & 42.44 & 22.40 & 7.70 & 30.10 & 2366. \\
$01-26-90$ & 32.24 & 31.65 & 16.85 & 48.50 & 2186. \\
$02-22-90$ & 30.97 & 24.85 & 14.95 & 39.80 & 2132. \\
$02-26-90$ & 30.48 & 25.18 & 13.82 & 39.00 & 2169.
\end{tabular}




\section{Production Well N-11T}

Test Interval: December 2, 1988 - March 20, 1989

Table B.15. Wellhead pressure, steam and hot-water discharge rates, and wellhead enthalpy recorded during the first long-term discharge test of $\mathrm{N}-11 \mathrm{~T}$ from December 2, 1988 to March 20, 1989.

\begin{tabular}{lrrrrl}
\hline $\begin{array}{l}\text { Date } \\
\text { \& Time }\end{array}$ & $\begin{array}{r}\text { WHP } \\
(\text { bars })\end{array}$ & $\begin{array}{c}\text { Steam } \\
(\mathrm{T} / \mathrm{HR})\end{array}$ & $\begin{array}{r}\text { Hot-water } \\
(\mathrm{T} / \mathrm{HR})\end{array}$ & $\begin{array}{r}\text { Total } \\
(\mathrm{T} / \mathrm{HR})\end{array}$ & $\begin{array}{c}\text { Enthalpy } \\
(\mathrm{kJ} / \mathrm{kg})\end{array}$ \\
\hline $12-04-88$ & 29.20 & 5.30 & 107.20 & 112.50 & 1086. \\
$12-06-88$ & 29.50 & 5.52 & 102.48 & 108.00 & 1096. \\
$12-16-88$ & 13.12 & 44.13 & 93.87 & 138.00 & 1447. \\
$12-26-88$ & 9.59 & 45.54 & 69.66 & 115.20 & 1554. \\
$01-01-89$ & 9.39 & 43.61 & 62.89 & 106.50 & 1580. \\
$01-08-89$ & 9.10 & 41.27 & 57.03 & 98.30 & 1597. \\
$01-08-89$ & 9.10 & 41.47 & 57.13 & 98.60 & 1599. \\
$01-16-89$ & 9.00 & 39.44 & 51.36 & 90.80 & 1625. \\
$01-23-89$ & 20.28 & 22.47 & 53.73 & 76.20 & 1468. \\
$01-26-89$ & 8.81 & 39.40 & 51.20 & 90.60 & 1624. \\
$02-01-89$ & 8.81 & 37.56 & 50.04 & 87.60 & 1611. \\
$02-04-89$ & 8.71 & 36.60 & 49.20 & 85.80 & 1605. \\
$02-14-89$ & 8.51 & 34.19 & 45.91 & 80.10 & 1603. \\
$02-18-89$ & 8.41 & 34.12 & 45.18 & 79.30 & 1608. \\
$02-24-89$ & 8.41 & 32.12 & 40.98 & 73.10 & 1627. \\
$03-03-89$ & 8.31 & 30.59 & 39.31 & 69.90 & 1622. \\
$03-08-89$ & 8.22 & 30.97 & 36.43 & 67.40 & 1665. \\
$03-11-89$ & 8.22 & 29.86 & 36.74 & 66.60 & 1642. \\
$03-11-89$ & 8.22 & 29.50 & 36.60 & 66.10 & 1638. \\
$03-12-89$ & 11.85 & 21.52 & 36.28 & 57.80 & 1536. \\
$03-12-89$ & 11.85 & 23.20 & 34.40 & 57.60 & 1597. \\
$03-13-89$ & 16.16 & 16.18 & 32.32 & 48.50 & 1506. \\
$03-13-89$ & 16.16 & 18.30 & 29.50 & 47.80 & 1601. \\
$03-17-89$ & 8.22 & 30.47 & 36.83 & 67.30 & 1652.
\end{tabular}




\section{Production Well N-14T}

Test Interval: October 8, 1987 - November 6, 1987

Table B.16. Wellhead pressure, steam and hot-water discharge rates, and wellhead enthalpy recorded during the first long-term discharge test of $\mathrm{N}-14 \mathrm{~T}$ from October 8, 1987 to November 6, 1987.

\begin{tabular}{llrrrr}
\hline $\begin{array}{l}\text { Date } \\
\text { \& Time }\end{array}$ & $\begin{array}{l}\text { WHP } \\
(\text { bars })\end{array}$ & $\begin{array}{c}\text { Steam } \\
(\mathrm{T} / \mathrm{HR})\end{array}$ & $\begin{array}{c}\text { Hot-water } \\
(\mathrm{T} / \mathrm{HR})\end{array}$ & $\begin{array}{r}\text { Total } \\
(\mathrm{T} / \mathrm{HR})\end{array}$ & $\begin{array}{c}\text { Enthalpy } \\
(\mathrm{kJ} / \mathrm{kg})\end{array}$ \\
\hline $10-13-87$ & 18.61 & 31.17 & 134.13 & 165.30 & 1251. \\
$10-15-87$ & 12.53 & 55.79 & 118.91 & 174.70 & 1439. \\
$10-15-87$ & 12.63 & 55.61 & 116.49 & 172.10 & 1448. \\
$10-25-87$ & 10.47 & 48.44 & 75.86 & 124.30 & 1554. \\
$10-27-87$ & 10.37 & 47.35 & 71.85 & 119.20 & 1568. \\
$10-30-87$ & 10.37 & 46.48 & 69.62 & 116.10 & 1574. \\
$11-02-87$ & 9.98 & 44.79 & 59.91 & 104.70 & 1624. \\
$11-05-87$ & 19.10 & 26.70 & 64.00 & 90.70 & 1457.
\end{tabular}

Test Interval: December 12, 1987 - March 29, 1988

Table B.17. Wellhead pressure, steam and hot-water discharge rates, and wellhead enthalpy recorded during the second long-term discharge test of N-14T from December 12, 1987 to March 29, 1988.

\begin{tabular}{|c|c|c|c|c|c|}
\hline $\begin{array}{l}\text { Date } \\
\& \text { Time }\end{array}$ & $\begin{array}{l}\text { WHP } \\
\text { (bars) }\end{array}$ & $\begin{array}{l}\text { Steam } \\
(\mathrm{T} / \mathrm{HR})\end{array}$ & $\begin{array}{l}\text { Hot-wat } \\
(\mathrm{T} / \mathrm{HR})\end{array}$ & $\begin{array}{l}\text { tal } \\
\text { HR) }\end{array}$ & $\begin{array}{l}\text { alpy } \\
\text { g) }\end{array}$ \\
\hline $12-16-87$ & 31.46 & 20.50 & 81.10 & 101.60 & 1381 \\
\hline $12-20-87$ & 25.87 & 33.27 & 50.73 & 84.00 & 1696. \\
\hline $12-30-87$ & 22.73 & 36.19 & 24.81 & 61.00 & 2044 \\
\hline $01-08-88$ & 20.97 & 36.22 & 20.58 & 56.80 & 2119 \\
\hline $01-09-88$ & 20.77 & 35.94 & 17.96 & 53.90 & 2173 \\
\hline $01-20-88$ & 19.59 & 35.97 & 0.63 & 36.60 & 2766 \\
\hline $01-22-88$ & 19.30 & 36.36 & 13.34 & 49.70 & 2289 . \\
\hline $01-30-88$ & 18.51 & 35.88 & 3.72 & 39.60 & 2618. \\
\hline $02-01-88$ & 8.41 & 47.41 & 4.59 & 52.00 & 2591. \\
\hline $02-05-88$ & 8.12 & 45.99 & 0.11 & 46.10 & 2765 . \\
\hline $02-05-88$ & 8.81 & 44.44 & 29.56 & 74.00 & 1960. \\
\hline $02-05-88$ & 8.90 & 43.27 & 27.53 & 70.80 & 1983. \\
\hline $02-17-88$ & 8.31 & 34.19 & 10.81 & 45.00 & 2280 . \\
\hline $02-21-88$ & 8.02 & 27.30 & 16.00 & 43.30 & 2013. \\
\hline $02-22-88$ & 14.69 & 13.40 & 7.00 & 20.40 & 2122 . \\
\hline $02-29-88$ & 8.31 & 37.41 & 15.09 & 52.50 & 2184 . \\
\hline $03-06-88$ & 8.12 & 37.20 & 5.90 & 43.10 & 2490 . \\
\hline $03-07-88$ & 14.00 & 29.10 & 6.00 & 35.10 & 2455 . \\
\hline $03-08-88$ & 11.85 & 33.50 & 5.90 & 39.40 & 2486 . \\
\hline $03-10-88$ & 8.22 & 37.01 & 14.39 & 51.40 & 2198 . \\
\hline $03-14-88$ & 8.22 & 36.79 & 11.41 & 48.20 & 2287. \\
\hline
\end{tabular}




$\begin{array}{rrrrrr}03-20-88 & 8.02 & 36.38 & 5.42 & 41.80 & 2504 . \\ 03-23-88 & 8.12 & 35.87 & 6.53 & 42.40 & 2455 . \\ 03-24-88 & 8.02 & 34.05 & 12.95 & 47.00 & 2205 . \\ 03-26-88 & 8.22 & 36.24 & 7.56 & 43.80 & 2418 .\end{array}$

Test Interval: November 28, 1989 - March 1, 1990

Table B.18. Wellhead pressure, steam and hot-water discharge rates, and wellhead enthalpy recorded during the third long-term discharge test of N-14T from November 28, 1989 to March 1, 1990.

\begin{tabular}{llcrll}
\hline $\begin{array}{l}\text { Date } \\
\text { \& Time }\end{array}$ & $\begin{array}{c}\text { WHP } \\
(\text { bars })\end{array}$ & $\begin{array}{c}\text { Steam } \\
(\mathrm{T} / \mathrm{HR})\end{array}$ & $\begin{array}{c}\text { Hot-water } \\
(\mathrm{T} / \mathrm{HR})\end{array}$ & $\begin{array}{c}\text { Total } \\
(\mathrm{T} / \mathrm{HR})\end{array}$ & $\begin{array}{c}\text { Enthalpy } \\
(\mathrm{kJ} / \mathrm{kg})\end{array}$ \\
\hline $12-11-89$ & 27.83 & 22.46 & 67.14 & 89.60 & 1444. \\
$12-27-89$ & 24.10 & 32.14 & 17.26 & 49.40 & 2156. \\
$12-28-89$ & 22.73 & 32.54 & 19.36 & 51.90 & 2107. \\
$01-01-90$ & 20.67 & 34.48 & 17.12 & 51.60 & 2175. \\
$01-25-90$ & 15.87 & 34.91 & 10.89 & 45.80 & 2333. \\
$01-25-90$ & 18.71 & 28.11 & 10.59 & 38.70 & 2276. \\
$01-25-90$ & 21.06 & 23.08 & 9.02 & 32.10 & 2272. \\
$01-27-90$ & 14.98 & 38.91 & 9.99 & 48.90 & 2394. \\
$02-22-90$ & 12.14 & 36.48 & 8.02 & 44.50 & 2427. \\
$02-26-90$ & 12.04 & 35.93 & 7.47 & 43.40 & 2443.
\end{tabular}




\section{Production Well N-15T}

Test Interval: November 7, 1987 - March 26, 1988

Table B.19. Wellhead pressure, steam and hot-water discharge rates, and wellhead enthalpy recorded during the first long-term discharge test of N-15T from November 7, 1987 to March 26, 1988.

\begin{tabular}{llllll}
\hline $\begin{array}{l}\text { Date } \\
\text { \& Time }\end{array}$ & $\begin{array}{c}\text { WHP } \\
(\text { bars })\end{array}$ & $\begin{array}{c}\text { Steam } \\
(\mathrm{T} / \mathrm{HR})\end{array}$ & $\begin{array}{c}\text { Hot-water } \\
(\mathrm{T} / \mathrm{HR})\end{array}$ & $\begin{array}{c}\text { Total } \\
(\mathrm{T} / \mathrm{HR})\end{array}$ & $\begin{array}{c}\text { Enthalpy } \\
(\mathrm{kJ} / \mathrm{kg})\end{array}$ \\
\hline $11-08-87$ & 62.94 & 20.34 & 169.26 & 189.60 & 1397. \\
$11-15-87$ & 59.90 & 43.28 & 222.32 & 265.60 & 1470. \\
$11-21-87$ & 60.09 & 50.97 & 218.33 & 269.30 & 1512. \\
$11-22-87$ & 59.51 & 52.77 & 216.03 & 268.80 & 1520. \\
$12-01-87$ & 63.62 & 29.43 & 165.97 & 195.40 & 1467. \\
$12-07-87$ & 62.45 & 41.78 & 179.92 & 221.70 & 1520. \\
$12-09-87$ & 63.23 & 42.81 & 170.99 & 213.80 & 1542. \\
$12-09-87$ & 63.33 & 42.58 & 171.72 & 214.30 & 1540. \\
$12-16-87$ & 66.37 & 61.74 & 124.86 & 186.60 & 1754. \\
$12-20-87$ & 66.08 & 63.64 & 105.46 & 169.10 & 1823. \\
$12-30-87$ & 65.68 & 59.90 & 105.50 & 165.40 & 1800. \\
$01-09-88$ & 64.80 & 63.53 & 97.57 & 161.10 & 1847. \\
$01-20-88$ & 63.82 & 70.87 & 93.13 & 164.00 & 1903. \\
$01-22-88$ & 63.13 & 68.43 & 93.87 & 162.30 & 1885. \\
$01-30-88$ & 62.35 & 67.51 & 96.39 & 163.90 & 1868. \\
$02-01-88$ & 62.84 & 67.44 & 91.76 & 159.20 & 1887. \\
$02-04-88$ & 62.94 & 76.34 & 87.46 & 163.80 & 1953. \\
$02-17-88$ & 60.58 & 78.38 & 90.12 & 168.50 & 1946. \\
$02-29-88$ & 59.11 & 76.47 & 92.03 & 168.50 & 1924. \\
$03-02-88$ & 58.62 & 71.60 & 98.40 & 170.00 & 1872. \\
$03-03-88$ & 61.76 & 51.80 & 78.50 & 130.30 & 1843. \\
$03-04-88$ & 62.35 & 47.90 & 69.30 & 117.20 & 1863. \\
$03-10-88$ & 58.23 & 77.63 & 93.57 & 171.20 & 1922. \\
$03-14-88$ & 58.03 & 76.00 & 88.50 & 164.50 & 1935. \\
$03-20-88$ & 58.13 & 66.68 & 86.12 & 152.80 & 1894. \\
$03-23-88$ & 56.86 & 80.16 & 93.14 & 173.30 & 1932. \\
$03-24-88$ & 57.05 & 80.52 & 90.88 & 171.40 & 1944. \\
$03-25-88$ & 57.05 & 80.62 & 88.18 & 168.80 & 1957. \\
$03-26-88$ & 57.05 & 79.59 & 89.91 & 169.50 & 1944. \\
& & & & &
\end{tabular}


Test Interval: November 15, 1989 - March 1, 1990

Table B.20. Wellhead pressure, steam and hot-water discharge ates, and wellhead enthalpy recorded during the second long-term discharge test of N-15T from November 15, 1989 to March 1, 1990.

\begin{tabular}{llrrrl}
\hline $\begin{array}{l}\text { Date } \\
\text { \& Time }\end{array}$ & $\begin{array}{c}\text { WHP } \\
(\text { bars })\end{array}$ & $\begin{array}{c}\text { Steam } \\
(\mathrm{T} / \mathrm{HR})\end{array}$ & $\begin{array}{c}\text { Hot-water } \\
(\mathrm{T} / \mathrm{HR})\end{array}$ & $\begin{array}{c}\text { Total } \\
(\mathrm{T} / \mathrm{HR})\end{array}$ & $\begin{array}{c}\text { Enthalpy } \\
(\mathrm{kJ} / \mathrm{kg})\end{array}$ \\
\hline $12-11-89$ & 49.11 & 135.47 & 71.23 & 206.70 & 2227. \\
$12-26-89$ & 42.83 & 144.26 & 34.74 & 179.00 & 2471. \\
$12-28-89$ & 42.54 & 144.31 & 32.69 & 177.00 & 2486. \\
$01-01-90$ & 41.66 & 143.68 & 26.92 & 170.60 & 2531. \\
$01-19-90$ & 36.85 & 146.39 & 15.11 & 161.50 & 2639. \\
$01-19-90$ & 45.19 & 123.66 & 12.54 & 136.20 & 2643. \\
$01-19-90$ & 52.94 & 91.62 & 12.48 & 104.10 & 2597. \\
$01-26-90$ & 36.56 & 144.95 & 11.05 & 156.00 & 2679. \\
$02-21-90$ & 32.54 & 145.64 & 10.76 & 156.40 & 2681. \\
$02-26-90$ & 32.44 & 144.87 & 8.93 & 153.80 & 2700.
\end{tabular}




\section{Production Well N-16T}

Test Interval: December 1, 1988 - March 19, 1989

Table B.21: Wellhead pressure, steam and hot-water discharge rates, and wellhead enthalpy recorded during the first long-term discharge test of $\mathrm{N}-16 \mathrm{~T}$ from December 1, 1988 to March 19, 1989.

\begin{tabular}{lrrrrl}
\hline $\begin{array}{l}\text { Date } \\
\& \text { Time }\end{array}$ & $\begin{array}{c}\text { WHP } \\
(\text { bars })\end{array}$ & $\begin{array}{c}\text { Steam } \\
(\mathrm{T} / \mathrm{HR})\end{array}$ & $\begin{array}{c}\text { Hot-water } \\
(\mathrm{T} / \mathrm{HR})\end{array}$ & $\begin{array}{c}\text { Total } \\
(\mathrm{T} / \mathrm{HR})\end{array}$ & $\begin{array}{c}\text { Enthalpy } \\
(\mathrm{kJ} / \mathrm{kg})\end{array}$ \\
\hline $12-04-88$ & 28.42 & 7.76 & 121.24 & 129.00 & 1103. \\
$12-06-88$ & 28.52 & 8.20 & 119.10 & 127.30 & 1112. \\
$12-16-88$ & 14.10 & 36.91 & 130.59 & 167.50 & 1263. \\
$12-26-88$ & 10.08 & 36.60 & 107.30 & 143.90 & 1276. \\
$01-01-89$ & 9.59 & 34.70 & 76.00 & 110.70 & 1389. \\
$01-08-89$ & 9.39 & 34.17 & 64.93 & 99.10 & 1449. \\
$01-16-89$ & 9.20 & 32.81 & 64.09 & 96.90 & 1434. \\
$01-22-89$ & 9.10 & 30.96 & 54.84 & 85.80 & 1477. \\
$01-26-89$ & 8.81 & 29.79 & 52.91 & 82.70 & 1472. \\
$02-01-89$ & 8.71 & 28.14 & 50.26 & 78.40 & 1468. \\
$02-04-89$ & 8.71 & 27.15 & 49.05 & 76.20 & 1462. \\
$02-14-89$ & 8.51 & 26.16 & 47.64 & 73.80 & 1455. \\
$02-18-89$ & 8.41 & 25.76 & 44.04 & 69.80 & 1484. \\
$02-24-89$ & 8.41 & 25.38 & 43.72 & 69.10 & 1480. \\
$03-03-89$ & 8.41 & 24.13 & 43.47 & 67.60 & 1459. \\
$03-03-89$ & 8.41 & 24.22 & 43.78 & 68.00 & 1457. \\
$03-08-89$ & 8.31 & 23.52 & 38.38 & 61.90 & 1504. \\
$03-09-89$ & 11.75 & 15.86 & 40.04 & 55.90 & 1359. \\
$03-09-89$ & 11.65 & 17.60 & 38.20 & 55.80 & 1421. \\
$03-10-89$ & 14.40 & 8.50 & 33.40 & 41.90 & 1233. \\
$03-10-89$ & 14.30 & 10.70 & 31.10 & 41.80 & 1335. \\
$03-13-89$ & 8.31 & 23.32 & 36.88 & 60.20 & 1520. \\
$03-17-89$ & 8.41 & 23.93 & 42.17 & 66.10 & 1469. \\
$03-17-89$ & 8.31 & 23.63 & 41.47 & 65.10 & 1469. \\
$03-17-89$ & 8.31 & 24.20 & 41.10 & 65.30 & 1485. \\
& & & & & \\
039 & & & & &
\end{tabular}




\section{Production Well N-17T}

Test Interval: December 4, 1988 - March 21, 1989

Table B.22: Wellhead pressure, steam and hot-water discharge rates, and wellhead enthalpy recorded during the first long-term discharge test of $\mathrm{N}-17 \mathrm{~T}$ from December 4, 1988 to March 21, 1989.

\begin{tabular}{lrrrrl}
\hline $\begin{array}{l}\text { Date } \\
\text { Time }\end{array}$ & $\begin{array}{c}\text { WHP } \\
(\text { bars })\end{array}$ & $\begin{array}{c}\text { Steam } \\
(\mathrm{T} / \mathrm{HR})\end{array}$ & $\begin{array}{c}\text { Hot-water } \\
(\mathrm{T} / \mathrm{HR})\end{array}$ & $\begin{array}{r}\text { Total } \\
(\mathrm{T} / \mathrm{HR})\end{array}$ & $\begin{array}{c}\text { Enthalpy } \\
(\mathrm{kJ} / \mathrm{kg})\end{array}$ \\
\hline $12-04-88$ & 50.68 & 13.69 & 110.51 & 124.20 & 1339. \\
$12-06-89$ & 24.30 & 70.99 & 106.81 & 177.80 & 1693. \\
$12-16-88$ & 14.20 & 50.14 & 66.96 & 117.10 & 1671. \\
$12-26-88$ & 9.49 & 47.45 & 51.95 & 99.40 & 1719. \\
$01-01-89$ & 9.10 & 43.83 & 46.07 & 89.90 & 1734. \\
$01-08-89$ & 8.81 & 40.88 & 39.82 & 80.70 & 1769. \\
$01-16-89$ & 8.61 & 38.91 & 36.39 & 75.30 & 1788. \\
$01-22-89$ & 8.61 & 37.51 & 34.39 & 71.90 & 1798. \\
$01-26-89$ & 8.61 & 37.99 & 33.61 & 71.60 & 1816. \\
$02-01-89$ & 8.51 & 36.96 & 32.54 & 69.50 & 1817. \\
$02-04-89$ & 8.51 & 36.58 & 32.32 & 68.90 & 1815. \\
$02-14-89$ & 8.61 & 37.23 & 36.27 & 73.50 & 1767. \\
$02-18-89$ & 8.61 & 37.09 & 33.71 & 70.80 & 1802. \\
$02-24-89$ & 8.61 & 36.53 & 32.97 & 69.50 & 1806. \\
$03-03-89$ & 8.41 & 34.92 & 30.88 & 65.80 & 1813. \\
$03-03-89$ & 8.51 & 35.97 & 31.03 & 67.00 & 1827. \\
$03-08-89$ & 8.41 & 35.63 & 30.67 & 66.30 & 1827. \\
$03-13-89$ & 8.41 & 35.26 & 29.04 & 64.30 & 1850. \\
$03-14-89$ & 8.41 & 35.17 & 28.93 & 64.10 & 1850. \\
$03-14-89$ & 8.41 & 35.40 & 28.10 & 63.50 & 1868. \\
$03-15-89$ & 11.26 & 30.36 & 28.44 & 58.80 & 1817. \\
$03-15-89$ & 11.16 & 31.60 & 27.30 & 58.90 & 1856. \\
$03-16-89$ & 17.14 & 17.25 & 22.05 & 39.30 & 1717. \\
$03-16-89$ & 17.14 & 19.30 & 20.40 & 39.70 & 1808. \\
$03-20-89$ & 8.51 & 37.32 & 27.28 & 64.60 & 1911. \\
& & & & &
\end{tabular}




\section{Production Well N-21T}

Test Interval: November 24, 1989 - March 2, 1990

Table B.23. Wellhead pressure, steam and hot-water discharge rates, and wellhead enthalpy recorded during a long-term discharge test of N-21T from November 24, 1989 to March 2, 1990.

\begin{tabular}{lrcccc}
\hline $\begin{array}{l}\text { Date } \\
\& \text { Time }\end{array}$ & $\begin{array}{c}\text { WHP } \\
(\text { bars })\end{array}$ & $\begin{array}{c}\text { Steam } \\
(\mathrm{T} / \mathrm{HR})\end{array}$ & $\begin{array}{c}\text { Hot-water } \\
(\mathrm{T} / \mathrm{HR})\end{array}$ & $\begin{array}{c}\text { Total } \\
(\mathrm{T} / \mathrm{HR})\end{array}$ & $\begin{array}{c}\text { Enthalpy } \\
(\mathrm{kJ} / \mathrm{kg})\end{array}$ \\
\hline $12-11-89$ & 28.52 & 27.92 & 44.58 & 72.50 & 1692. \\
$12-26-89$ & 9.30 & 50.98 & 26.02 & 77.00 & 2090. \\
$12-28-89$ & 9.20 & 48.42 & 28.28 & 76.70 & 2027. \\
$01-01-90$ & 9.20 & 48.31 & 28.59 & 76.90 & 2021. \\
$01-23-90$ & 8.41 & 47.64 & 27.06 & 74.70 & 2032. \\
$01-23-90$ & 14.30 & 41.21 & 23.89 & 65.10 & 2073. \\
$01-23-90$ & 23.61 & 28.29 & 24.71 & 53.00 & 1938. \\
$01-26-90$ & 8.51 & 48.31 & 26.79 & 75.10 & 2044. \\
$02-21-90$ & 8.51 & 47.55 & 23.35 & 70.90 & 2100. \\
$02-26-90$ & 8.41 & 48.33 & 19.57 & 67.90 & 2183.
\end{tabular}




\section{Production Well N-22T}

Test Interval: December 1, 1989 - February 27, 1990

Table B.24. Wellhead pressure, steam and hot-water discharge rates, and wellhead enthalpy recorded during a long-term discharge test of $\mathrm{N}-22 \mathrm{~T}$ from December 1, 1989 to February 27, 1990.

\begin{tabular}{lrrrrr}
\hline $\begin{array}{l}\text { Date } \\
\text { \& Time }\end{array}$ & $\begin{array}{c}\text { WHP } \\
\text { (bars })\end{array}$ & $\begin{array}{c}\text { Steam } \\
(\mathrm{T} / \mathrm{HR})\end{array}$ & $\begin{array}{r}\text { Hot-water } \\
(\mathrm{T} / \mathrm{HR})\end{array}$ & $\begin{array}{r}\text { Total } \\
(\mathrm{T} / \mathrm{HR})\end{array}$ & $\begin{array}{c}\text { Enthalpy } \\
(\mathrm{kJ} / \mathrm{kg})\end{array}$ \\
\hline $12-11-89$ & 42.25 & 72.83 & 48.57 & 121.40 & 2121. \\
$12-25-89$ & 15.96 & 60.06 & 32.14 & 92.20 & 2119. \\
$12-27-89$ & 12.83 & 98.26 & 32.64 & 130.90 & 2294. \\
$12-28-89$ & 12.53 & 115.71 & 29.39 & 145.10 & 2385. \\
$01-01-90$ & 11.06 & 91.16 & 30.44 & 121.60 & 2281. \\
$01-18-90$ & 9.59 & 80.95 & 26.35 & 107.30 & 2280. \\
$01-18-90$ & 30.67 & 66.72 & 31.78 & 98.50 & 2226. \\
$01-18-90$ & 50.19 & 54.10 & 25.90 & 80.00 & 2263. \\
$01-27-90$ & 10.28 & 99.42 & 24.58 & 124.00 & 2380. \\
$02-23-90$ & 10.28 & 95.41 & 21.09 & 116.50 & 2415. \\
$02-26-90$ & 9.59 & 83.44 & 21.96 & 105.40 & 2355. \\
$02-26-90$ & 9.88 & 91.40 & 19.30 & 110.70 & 2426. \\
$02-27-90$ & 62.35 & 51.20 & 11.90 & 63.10 & 2489.
\end{tabular}




\section{Production Well N-26P}

Test Interval: June 26, 1993 - July 25, 1993

Table B.25. Wellhead pressure, steam and hot-water discharge rates, and wellhead enthalpy recorded during a long-term discharge test of N-26P from June 26, 1993 to July 25, 1993.

\begin{tabular}{lccccc}
\hline $\begin{array}{l}\text { Date } \\
\text { \& Time }\end{array}$ & $\begin{array}{l}\text { WHP } \\
(\text { bars })\end{array}$ & $\begin{array}{c}\text { Steam } \\
(\mathrm{T} / \mathrm{HR})\end{array}$ & $\begin{array}{c}\text { Hot-water } \\
(\mathrm{T} / \mathrm{HR})\end{array}$ & $\begin{array}{c}\text { Total } \\
(\mathrm{T} / \mathrm{HR})\end{array}$ & $\begin{array}{c}\text { Enthalpy } \\
(\mathrm{kJ} / \mathrm{kg})\end{array}$ \\
\hline $07-04-93$ & 8.12 & 59.07 & 12.43 & 71.50 & 2414. \\
$07-13-93$ & 8.12 & 59.43 & 7.17 & 66.60 & 2550. \\
$07-21-93$ & 8.22 & 61.24 & 6.66 & 67.90 & 2570. \\
$07-23-93$ & 22.83 & 48.77 & 9.53 & 58.30 & 2497. \\
$07-23-93$ & 22.53 & 50.00 & 2.50 & 52.50 & 2713. \\
$07-24-93$ & 43.03 & 24.03 & 10.67 & 34.70 & 2279. \\
$07-24-93$ & 44.11 & 26.00 & 8.00 & 34.00 & 2402.
\end{tabular}




\section{Production Well N-28P}

Test Interval: October 26, 1993 - November 28, 1993

Table B.26. Wellhead pressure, steam and hot-water discharge rates, and wellhead enthalpy recorded during a long-term discharge test of N-28P from October 26, 1993 to November 28, 1993.

\begin{tabular}{llrrrl}
\hline $\begin{array}{l}\text { Date } \\
\text { \& Time }\end{array}$ & $\begin{array}{l}\text { WHP } \\
(\text { bars })\end{array}$ & $\begin{array}{c}\text { Steam } \\
(\mathrm{T} / \mathrm{HR})\end{array}$ & $\begin{array}{r}\text { Hot-water } \\
(\mathrm{T} / \mathrm{HR})\end{array}$ & $\begin{array}{r}\text { Total } \\
(\mathrm{T} / \mathrm{HR})\end{array}$ & $\begin{array}{c}\text { Enthalpy } \\
(\mathrm{kJ} / \mathrm{kg})\end{array}$ \\
\hline $11-04-93$ & 13.07 & 111.22 & 22.38 & 133.60 & 2457. \\
$11-15-93$ & 11.24 & 92.02 & 14.01 & 106.03 & 2518. \\
$11-24-93$ & 10.67 & 80.55 & 10.75 & 91.30 & 2544. \\
$11-25-93$ & 10.66 & 79.82 & 10.48 & 90.30 & 2548. \\
$11-25-93$ & 10.47 & 79.80 & 9.00 & 88.80 & 2576. \\
$11-26-93$ & 41.78 & 49.30 & 11.96 & 61.26 & 2468. \\
$11-26-93$ & 42.15 & 52.60 & 7.90 & 60.50 & 2578. \\
$11-27-93$ & 56.00 & 23.34 & 12.24 & 35.58 & 2239. \\
$11-27-93$ & 56.47 & 26.60 & 8.90 & 35.50 & 2389.
\end{tabular}

